\title{
VALIDATION OF THE COUPLED DISSOLUTION-HYDROGEN EMBRITTLEMENT MECHANISM OF IGSCC IN LOW TEMPERATURE SENSITIZED AA5083-H131
}

A Dissertation Presented to the Faculty of the School of Engineering and Applied Science University of Virginia

\author{
In Partial Fulfillment of the \\ Requirements for the Degree of
}

Doctor of Philosophy in Materials Science and Engineering

\section{By}

Cortney Blue Crane

December, 2013 


\begin{abstract}
APPROVAL SHEET
The dissertation is submitted in partial fulfillment of the requirements for the degree of

Doctor of Philosophy in Materials Science and Engineering

Cortney B. Crane

(Author)
\end{abstract}

This dissertation has been read and approved by the examining Committee:

Richard P. Gangloff
Dissertation Advisor

Robert G. Kelly

Committee Chairmen

John R. Scully

Sean R. Agnew

Anthony P. Reynolds

Patrick E. Hopkins

Accepted for the School of Engineering and Appliad Scienge:

December, 2013 


\begin{abstract}
Non-heat-treatable wrought Al-Mg alloys are commonly used in marine structures that require light weight, moderate strength, weldability, and corrosion resistance. These alloys become susceptible to intergranular corrosion (IGC) and intergranular stress corrosion cracking (IGSCC) when an active $\beta$ phase $\left(\mathrm{Al}_{3} \mathrm{Mg}_{2}\right)$ precipitates on grain boundaries during prolonged thermal exposure. The Degree of Sensitization (DoS) is quantified using the standard nitric acid mass loss test. Coupled dissolution of $\beta$ and $\mathrm{H}$ embrittlement is the hypothesized mechanism of IGSCC in sensitized Al-Mg. The primary objectives of this research are to characterize the interactive crack tip electrochemical and mechanical factors that govern IGSCC in Al-Mg alloy 5083-H131, and particularly to test this hypothesized mechanism. Research is focused on low temperature, long time sensitization with discrete grain boundary $\beta$ precipitation. High resolution subcritical crack growth experiments established a critical DoS of about $10 \mathrm{mg} / \mathrm{cm}^{2}$ for IGSCC susceptibility in 5083-H131 stressed at near open circuit potential in neutral $\mathrm{NaCl}$. Below this DoS, the alloy is essentially immune to IGSCC, while above this sensitization, crack growth rates increase as a unique function of DoS for several time-temperature conditions. This threshold is likely due to an acidic crack tip chemistry established by the dissolution of a critical volume of $\beta$, in combination with an increase in local stress for increased $\mathrm{H}$ concentration ahead of the crack tip due to $\beta$ presence. As $\beta$ volume increases and spacing decreases, these factors continue to increase crack growth rates. Crack growth measurements and elastic-plastic Jintegral analysis establish that this alloy is susceptible to $\mathrm{H}$ embrittlement in the absence of $\beta$ phase, provided that an acidic chemistry is artificially generated in the crack tip, as an analog to $\beta$ dissolution. The role of $\beta$ is verified using polarization to either promote or preclude $\beta$ dissolution. Anodic polarization significantly enhances crack growth, while cathodic polarization suppresses IGSCC because both $\beta$ and matrix dissolution are limited. Results demonstrate the strong benefit of modest cathodic polarization as a means to control IGSCC. The role of $\mathrm{H}$ is separated from $\beta$ dissolution through hydrogen precharging of tensile specimens stressed in the absence of a $\beta$-dissolving crack tip electrolyte. Results demonstrate that, though $\beta$ is not essential for hydrogen environment embrittlement, $\beta$ presence promotes $\mathrm{H}$ damage. The coupled dissolution $\mathrm{H}$-embrittlement mechanism for IGSCC in 5083-H131 is validated by demonstrating that: a) $\beta$ distribution controls crack tip chemistry and $\mathrm{H}$ localization at the fracture process zone, b) crack tip electrochemistry provides the $\mathrm{H}$ production and uptake for grain boundary decohesion, and c) H-diffusion, rate-limited embrittlement is the dominant mechanism for crack growth between $\beta$. Unexpectedly rapid IGSCC rates can be explained based on enhanced $\mathrm{H}$ diffusion in this ligament as trapping impedance is reduced. The comprehensive, highresolution characterization of corrosion and cracking phenomena generated in this research is essential for component prediction modeling, specifically with crack growth parallel to the rolling/forging plane.
\end{abstract}




\section{EXECUTIVE SUMMARY}

Non-heat treatable wrought Al-Mg alloys are used in marine structures that require lightweight, moderate strength, weldability, and corrosion resistance. These alloys become susceptible, or sensitized, to intergranular corrosion (IGC) and intergranular stress corrosion cracking (IGSCC) when an active $\beta$ phase $\left(\mathrm{Al}_{3} \mathrm{Mg}_{2}\right)$ precipitates on grain boundaries during prolonged thermal exposure. The hypothesized mechanism of IGSCC in sensitized 5083-H131 is coupled grain boundary $\beta$ dissolution and $\mathrm{H}$ embrittlement. Though literature supports this mechanism, the interactive roles of each element have not been confirmed. Extensive systematically obtained IGSCC growth rate data are required; focusing on the pertinent low temperature, long time sensitization with discrete grain boundary $\beta$ precipitation. The objectives of this dissertation are to characterize the interactive electrochemical and mechanical factors that govern IGSCC in the Al-Mg alloy 5083-H131, and particularly to validate this mechanism. This dissertation is structured into three chapters that focus on each aspect of the mechanism. The first chapter (Chapter 2) characterizes IGSCC as a function of sensitization, and identifies the role of $\beta$ size, spacing, and morphology. The second chapter (Chapter 3) focuses on the electrochemical and chemical impact of the environment on IGSCC using polarization and crack tip chemistry control. The final chapter (Chapter 4) focuses on the role of $\mathrm{H}$ in the absence of a $\beta$ dissolving crack tip electrolyte. Rapid cracking kinetics are justified by a $\mathrm{H}$ diffusion limited crack growth rate model.

In Chapter 2, the sensitization dependence of IGSCC is probed using slow-rate loading of fatigue precracked specimens in full immersion $0.6 \mathrm{M} \mathrm{NaCl}$ polarized to near OCP 
$\left(-0.800 \mathrm{~V}_{\mathrm{SCE}}\right)$ in the Al-Mg alloy $5083-\mathrm{H} 131$ across a range of low temperature sensitizations $\left(60^{\circ} \mathrm{C}\right.$ to $\left.100^{\circ} \mathrm{C}\right)$. The crack is restricted to the plane parallel to the grain boundary surfaces (typical of rolled plate) to provide an intrinsic measure of IGSCC, which is not significantly impacted by intergranular crack path tortuosity. The degree of sensitization (DoS) is quantified by the standard nitric acid mass loss test (NAMLT). Severe IGSCC in 5083-H131 begins at a critical DoS of about $10 \mathrm{mg} / \mathrm{cm}^{2}$, as indicated by a significant increase in Stage II crack growth rate and a decrease in threshold stress intensity below the fracture toughness. Above $10 \mathrm{mg} / \mathrm{cm}^{2}$, Stage II crack growth rates continue to increase, and the threshold stress intensity continues to decrease, both as a unique function of increasing DoS for several time-temperature conditions. The critical DoS for IGSCC susceptibility $\left(10 \mathrm{mg} / \mathrm{cm}^{2}\right)$ likely corresponds to the combination of a critical volume of grain boundary $\beta$ necessary for development of an acidic crack tip chemistry, an enhancement of local stress by constraint between $\beta$ particles for increased local $\mathrm{H}$ damage, and the possibility of more rapid $\mathrm{H}$ diffusivity ahead of the crack tip due to a reduction in local $\mathrm{H}$ trap sites. Above this critical DoS, IGSCC susceptibility continues to increase with rising DoS, due to secondary effects: a) increased grain boundary $\beta$ volume produces a more aggressive crack tip chemistry by dissolution, $b$ ) inter- $\beta$ ligament-size decrease enhances local constraint and boundary $\mathrm{H}$ embrittlement. High resolution kinetics, analyzed with $\mathrm{J}$ integral analysis, established crack growth rates in air on the order of $1 \mathrm{~nm} / \mathrm{s}$ for stress intensities above $15 \mathrm{MPa} \sqrt{ }$ m. Low rates could be attributed to low humidity HEAC, creep, or plasticity. The first two-dimensional IGC growth measurements from a fatigue precrack prior to IGSCC at low stress intensities correlate with measured 
and modeled (unstressed) IGC rates, suggesting that stress does not influence these measured fatigue crack corrosion rates.

In Chapter 3, subcritical cracking experiments investigate the role of crack tip chemistry in IGSCC. The role of $\beta$ is verified using polarization to either promote or preclude $\beta$ dissolution in sensitized 5083-H131. Results indicate that: a) $\alpha$ dissolution is essential for rapid crack growth rates, b) $\beta$ dissolution alone can cause sluggish IGSCC, and c) cathodic polarization provides a practical approach to improve IGSCC resistance. Grain boundary $\beta$ dissolution is the critical trigger for $\alpha$ dissolution that promotes $\mathrm{Mg}^{2+}$ and $\mathrm{Al}^{3+}$ hydrolytic acidification, which in turn leads to high crack tip $\mathrm{H}$ production, uptake, and then $\mathrm{H}$ embrittlement. The crack/fissure tip environment is electrochemically predicted using dissolution rates measured during subcritical cracking experiments at low stress intensities. Results indicate that rapid crack growth rates generally correlate with a high magnitude of crack tip overpotential for $\mathrm{H}$ production. Relatively rapid crack growth rates are measured in $\beta$-free as-received $5083-\mathrm{H} 131$ when a high overpotential for $\mathrm{H}$ production is artificially established at the crack tip as an analog to $\beta$ dissolution, with either an acidic simulated crack tip solution or anodically polarized $\mathrm{NaCl}$. Environmentmicrostructure conditions that may not supply significant $\mathrm{H}$ to the FPZ (as estimated by the overpotential for $\mathrm{H}$ production at the crack tip) have considerably lower crack growth rates. These conditions include: a) unsensitized 5083-H131 $\left(3 \mathrm{mg} / \mathrm{cm}^{2}\right)$ in near neutral $\mathrm{NaCl}$ at near open circuit potential, b) unsensitized $5083-\mathrm{H} 131\left(3 \mathrm{mg} / \mathrm{cm}^{2}\right)$ in alkaline $\mathrm{NaOH}$ with high cathodic polarization, and c) sensitized 5083-H131 (22 mg/cm $\left.{ }^{2}\right)$ in near neutral $\mathrm{NaCl}$ with high cathodic polarization. Using measured crack growth rates and the hydrogen diffusion-limited crack growth rate model, the $\mathrm{H}$ concentration expected at the 
fracture process zone increases exponentially with the predicted, environment sensitive overpotential for each environment-microstructure experiment. This $\mathrm{H}$ concentration may also be influenced by crack tip $\mathrm{pH}$ and $\mathrm{Mg}^{3+}$ concentration.

Chapter 4 furthers understanding of the interactive role of $\beta$ and $\mathrm{H}$ in impacting rates of IGSCC. Both sensitized and unsensitized 5083-H131 are intrinsically embrittled in the absence of a $\beta$ dissolving electrolyte following electrochemical charging with $\mathrm{H}$. Results demonstrate that, though $\beta$ is not necessary for embrittlement, $\beta$ presence promotes $H$ embrittlement. This $\mathrm{H}$ charging technique may also provide a successful way to characterize $\beta$ using SEM. The challenge lies in identifying the nm-sized grain boundary particles. Critically, chapter 4 demonstrates that the unexpectedly rapid IGSCC rates can be explained based on rapid $\mathrm{H}$ diffusion in inter- $\beta$ ligaments, which is accelerated due to the filling or elimination of otherwise reversible $\mathrm{H}$ traps. Electrochemical and mechanical contributions cannot independently promote this rapid crack growth rate.

The contributions of this $\mathrm{PhD}$ research are as follows. Results validate the dissolution$\mathrm{H}$ embrittlement IGSCC mechanism for IGSCC, by showing a) $\beta$ distribution controls crack tip chemistry and $\mathrm{H}$ localization at the FPZ, b) crack tip electrochemistry provides the $\mathrm{H}$ production and uptake for grain boundary decohesion, and c) $\mathrm{H}$ diffusion rate-limited embrittlement is the dominant mechanism for growth between $\beta$. The high resolution subcritical crack growth experiments used to validate this mechanism not only provide the first ever IGC measurement from an occluded crack, but also generate a comprehensive crack growth rate data set on IGSCC kinetics for Al-Mg alloys to date. Corrosion and cracking kinetics of this type are essential for component prediction modeling, specifically when the crack is parallel to the rolling/forging plane. 


\section{ACKNOWLEDGEMENTS}

This research was supported financially by the Office of Naval Research with Dr. Airan Perez as the Scientific Officer. The majority of the fractographic analysis reported in this dissertation was conducted at the Naval Research Laboratory, with Dr. Ronald Holtz as program mentor under the National Research Enterprise Internship Program administered by the American Society for Engineering Education. This support is greatly appreciated. I'd also like to thank Francine Bovard at the Alcoa Technical Center for providing the 5083-H131 plate.

This project would not have been possible without the help of many important people. I would like to start by thanking my advisor, Richard Gangloff. His support, guidance, knowledge, and patience have helped me grow as a scientist, writer and researcher. I especially would like to thank him for helping me stray from vague language, by forcing me to think logically and write with precision. I greatly appreciate his help in focusing my path forward.

I'd like to thank my dissertation committee for their consideration and patience during many helpful discussions: Professors Robert Kelly and John Scully have helped to shape the electrochemical aspects of this research. Their knowledge and support is greatly appreciated. I'd like to thank Sean Agnew, Anthony Reynolds, and Patrick Hopkins for their assistance and input in this dissertation work. Their advice and guidance is highly valued and appreciated.

I would like to thank everyone one in the fracture group for their support, friendship, and help in the lab. I'd like to thank Dr. Jen Warner for her friendship, support and advice. 
I'd like to thank Professor James Burns, Greg Pioszak, Amber Lass, Justin Dolph, and Ryan Donahue for all their help in the lab and out. I'm also very happy that I had a chance to meet and work with the newest members of the group: Jenny Jones, Thad Waterman, and Noelle Co. I wish you the best of luck!

I would also like to acknowledge the members of the Center for Electrochemical Science and Engineering. Mary Lyn Lim conducted all of the NAMLT measurements used in this Dissertation, and selflessly helped me with many other aspects of this project. Dr. Elissa Bumiller's support while at UVA and at NRL is greatly appreciated. And thank you to everyone else who so graciously helped me around the Wilsdorf labs.

Graduate school would not have been possible without the support of my family, Mom, Dad, Tara, Doug, Bryce, Cam, Tom, PopPop and Joan, and countless friends within and outside the department. I'd like to thank all of you for your support through graduate school and throughout my life. 


\section{TABLE OF CONTENTS}

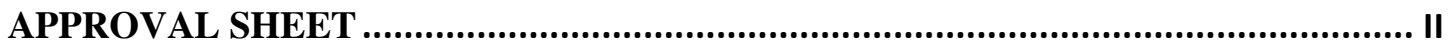

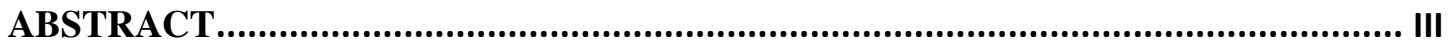

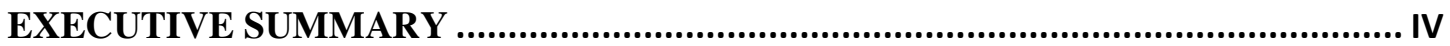

ACKNOWLEDGEMENTS ................................................................................... VII

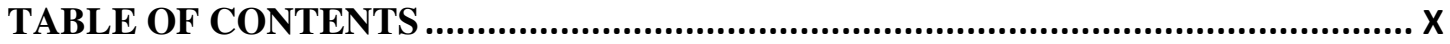

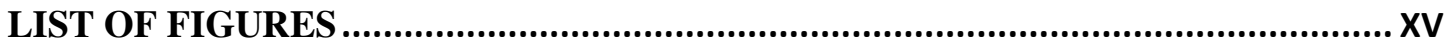

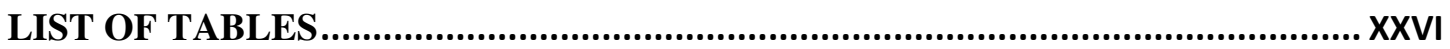

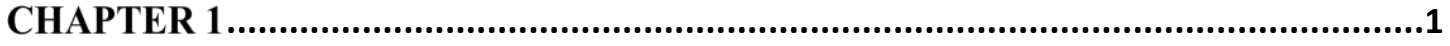

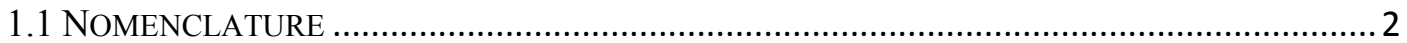

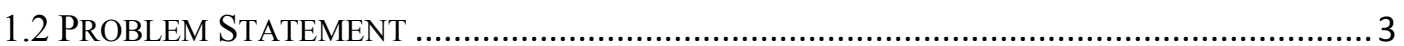

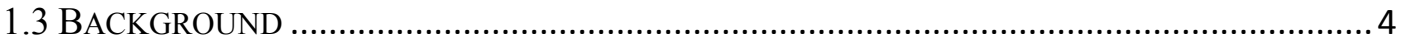

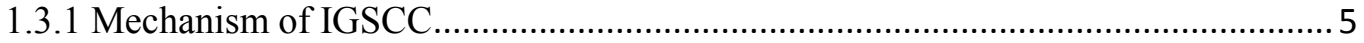

1.3.2 The role of DoS on IGSCC in the literature .......................................................... 10

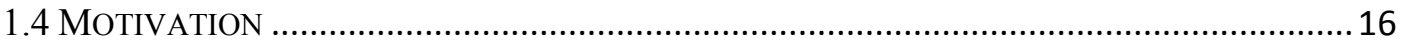

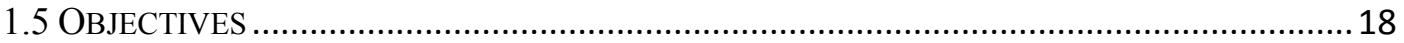

1.5.1 Chapter 2: Effect of low temperature sensitization on IGSCC of 5083-H131 ......19

1.5.2 Chapter 3: Crack tip chemistry control of IGSCC in 5083-H131 ........................20

1.5.3 Chapter 4: Dissolution and H diffusion control of IGSCC in 5083-H131 ............20 


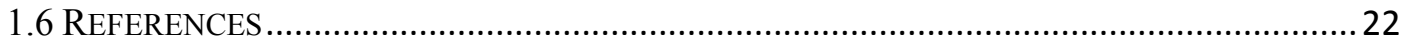

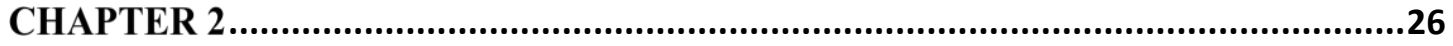

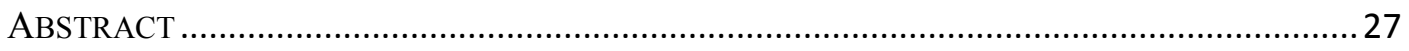

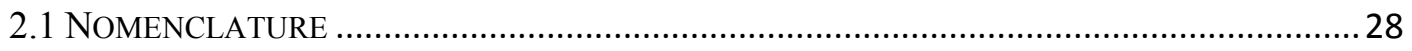

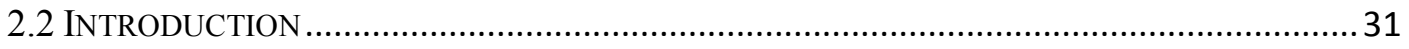

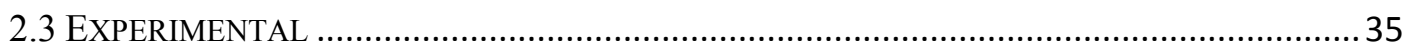

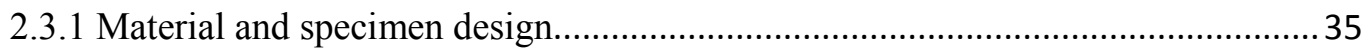

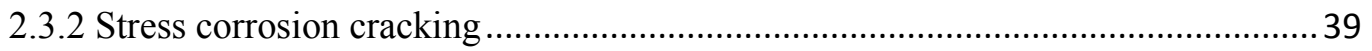

2.3.3 Crack length measurement by dcPD .......................................................... 41

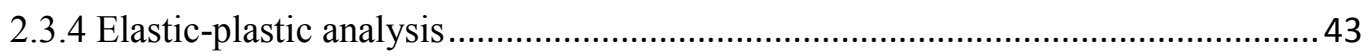

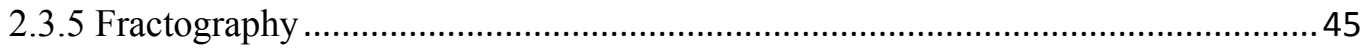

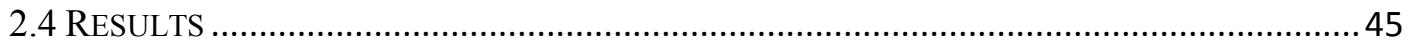

2.4.1 Crack growth detection resolution ........................................................... 45

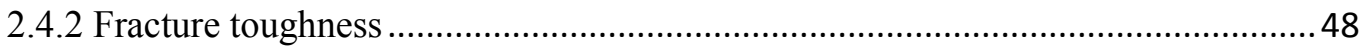

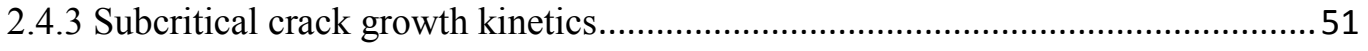

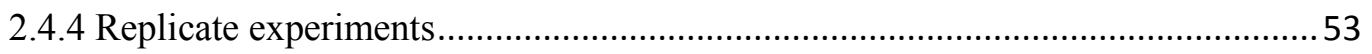

2.4.5 Intergranular corrosion dependence on DoS …............................................... 55

2.4.6 Intergranular SCC dependence on DoS ....................................................... 58

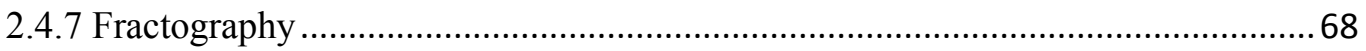

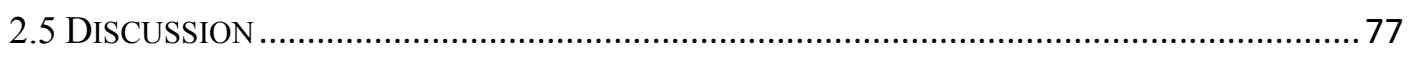

2.5.1 Fracture toughness as a function of DoS ..................................................... 78

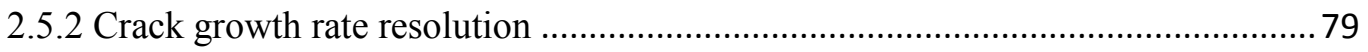

2.5.3 Mechanism of IGSCC in sensitized Al-Mg alloys ........................................... 81 
2.5.4 Literature on IGSCC kinetics for sensitized Al-Mg alloys...................................8 84

2.5.5 Sensitization dependence of IGSCC in 5083-H131 ............................................95

2.5.6 Sensitization dependence of intergranular corrosion .......................................... 121

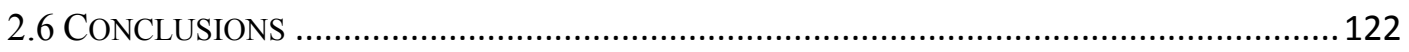

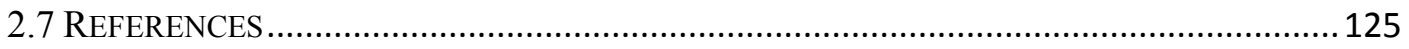

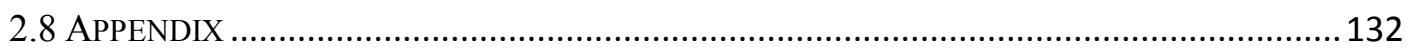

2.8.1 Cation concentrations due to $\beta$ dissolution in the stress corrosion crack..............132

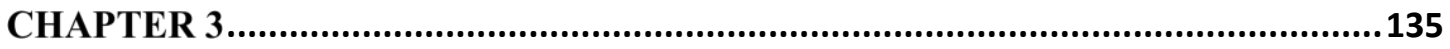

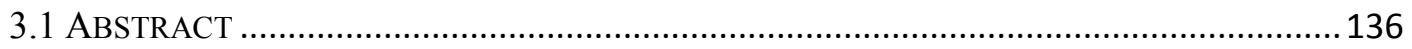

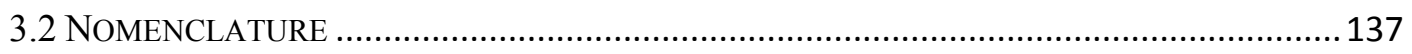

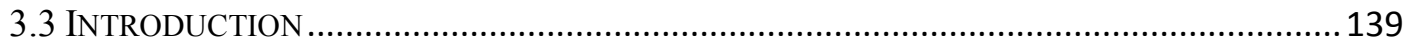

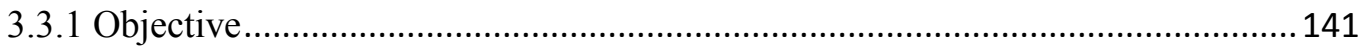

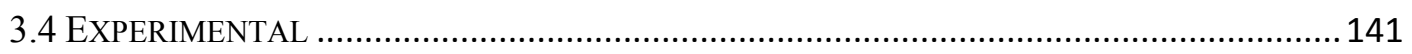

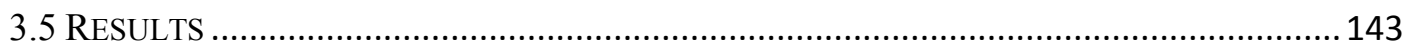

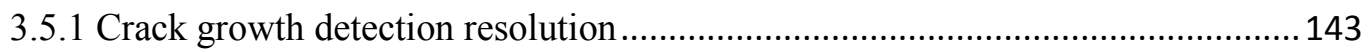

3.5.2 Effect of applied polarization of sensitized 5083-H131 .................................. 146

3.5.3 Effect of solution composition for unsensitized 5083-H131 ............................. 151

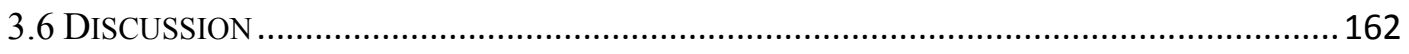

3.6.1 Crack growth rate resolution and water vapor HEAC ...................................... 162

3.6.2 Fissure tip electrochemistry as a function of potential and solution.....................165

3.6.3 Fracture process zone hydrogen embrittlement controlled IGSCC ....................188

3.6.4 Intergranular SCC as a function of applied potential in sensitized 5083 ............. 193

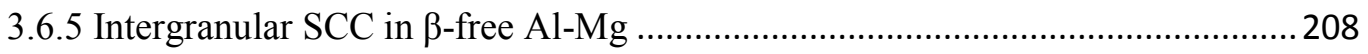




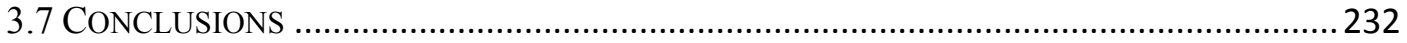

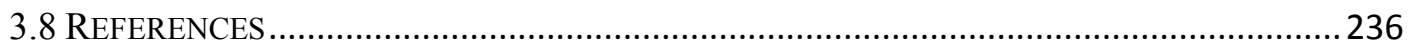

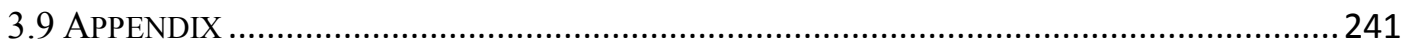

3.9.1 Formulation of Ohmic drop predictions ....................................................... 241

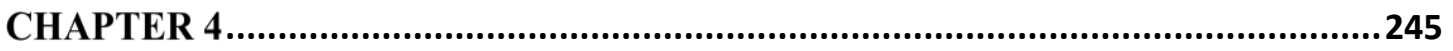

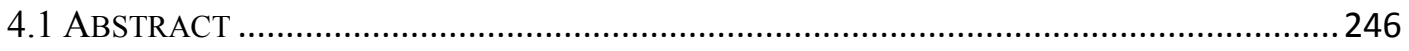

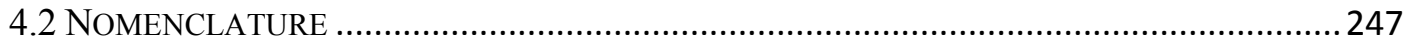

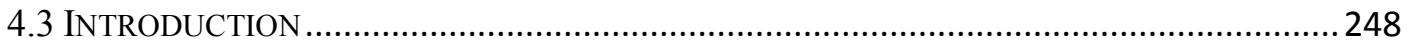

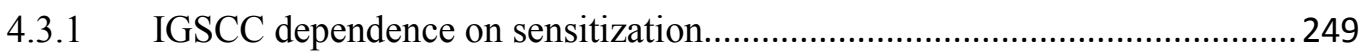

4.3.2 Crack tip electrochemical control of IGSCC in Al-Mg ................................251

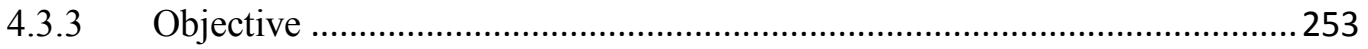

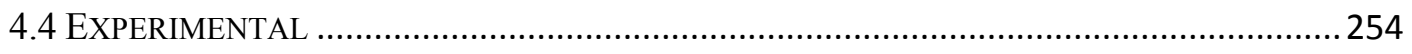

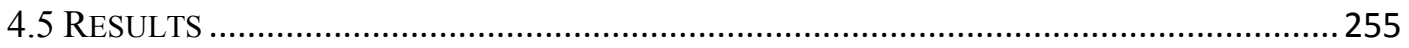

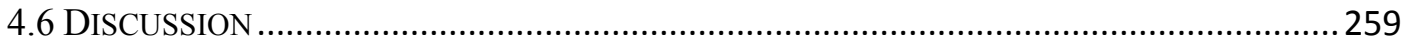

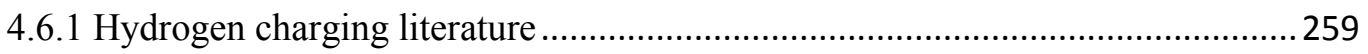

4.6.2 Embrittlement by H charging in $5083-\mathrm{H} 131$................................................. 260

4.6.3 Fractography indicating intergranular failure in 5083-H131 ............................261

4.6.4 Hydrogen diffusion controlled HEAC and IGSCC ….......................................263

4.6.5 Hydrogen diffusion controlled crack growth rates in 5083-H131 .......................267

4.6.6 Mechanism confirmation with other Al alloys .................................................2. 276

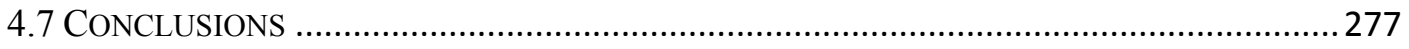

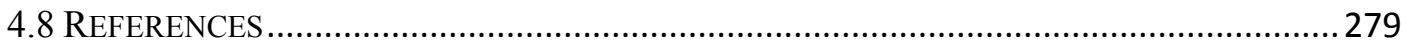




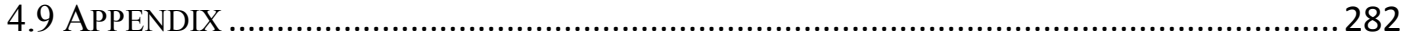

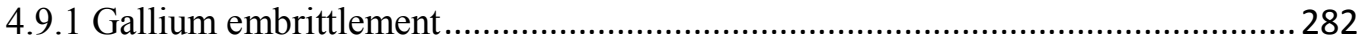

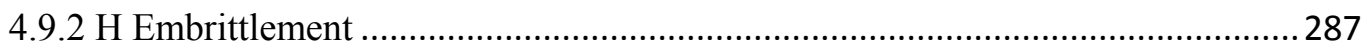

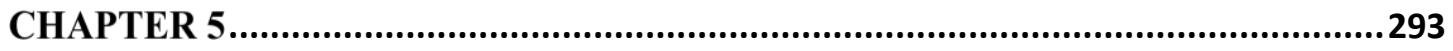

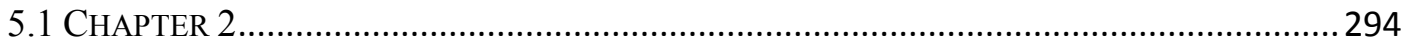

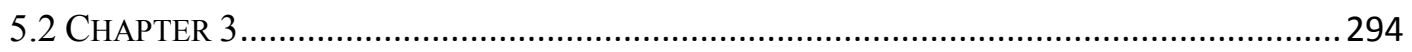

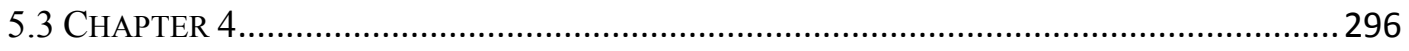




\section{LIST OF FIGURES}

Figure 1.1 The hypothesized interaction of grain boundary $\beta$ dissolution, along the corroding crack tip front, leading to $H$ production and uptake that localizes at $\beta$ matrix interfaces and $\beta$-free $\alpha$ boundary ligaments within the fracture process zone along an Al grain boundary surface.

Figure 1.2 Crack growth rates as a function of stress intensity for 5083 (S-L) exposed to $\mathrm{NaCl}$ by dropwise addition, under constant crack mouth opening displacement, at various sensitizations [9]..... 12

Figure 1.3 The threshold stress intensity as a function of DoS (NAMLT) for 5083-H131 (S-L) fully immersed in chromate inhibited $\mathrm{NaCl}$ during rising-step loading [11].

Figure 1.4 A somewhat schematic map of $\beta$ morphology as a function of aging time and temperature. The $\beta$ morphology was identified with TEM of SHT 5083-H131 sensitized at $100^{\circ} \mathrm{C}$ and non-SHT $5083-\mathrm{H} 131$ sensitized at $70^{\circ} \mathrm{C}$ and $175^{\circ} \mathrm{C}$ by Holtz et al. [10,34,51]. This is the same lot of 5083-H131 as studied in the present work. 14

Figure 1.5 The distribution of $\beta$ coverage along grain boundaries in SHT 5083-H131 sensitized for varying times at $100^{\circ} \mathrm{C}$, reported by Lim et al. [14]. The grains were revealed with a Barker's Etch and optical imaging, while grain boundaries were deeply etched in phosphorous acid and examined for $\beta$ coverage by SEM. This is the same lot of 5083-H131 as studied in the present work................................ 15

Figure 1.6 The (a) equivalent diameter and (b) nearest neighbor distance of grain boundary $\beta$ in SHT 5083-H131 exposed by Ga attack and observed with SEM imaging as a function of sensitization time at $100^{\circ} \mathrm{C}$ by Birbilis et al. [28]. 17

Figure 2.1 Optical images of the microstructures at the center of a $5.7 \mathrm{~cm}$ thick 5083 $\mathrm{H} 131$ plate sensitized at $100^{\circ} \mathrm{C}$ for $30 \mathrm{~d}\left(50 \mathrm{mg} / \mathrm{cm}^{2}\right)$ [37]. The LS surface is shown at higher magnification.

Figure 2.2 Nitric acid mass loss per ASTM G67 versus sensitization time for solution heat treated (small points) and as-received (large points) 5083-H131 plate for the timetemperature conditions examined for IGSCC susceptibility $[6,21,44]$. 38

Figure 2.3 The S-L orientated SENT specimen used in stress corrosion crack growth experiments. All measurements are in $\mathrm{mm}$, and specimen length and width are parallel to the plate $\mathrm{S}$ and $\mathrm{L}$ directions, respectively. 40 
Figure 2.4 Crack extension versus time for three SENT 5083-H131 specimens sensitized at $100^{\circ} \mathrm{C}$ for $175 \mathrm{~h}\left(22 \mathrm{mg} / \mathrm{cm}^{2}\right)$, then stressed to low $\mathrm{K}$ in moist air (bottom), to high $\mathrm{K}$ in moist air (middle) or immersed in $0.6 \mathrm{M} \mathrm{NaCl}$ polarized to $-0.800 \mathrm{~V}_{\mathrm{SCE}}$ while loaded to low K (top). The linear regression lines for the growth measured in $\mathrm{NaCl}$ represent the steady state growth rates observed after short incubation periods. 46

Figure 2.5 Crack growth rates measured in moist laboratory air for specimens of various sensitizations and loading rates. 47

Figure 2.6 Direct current potential difference $(\mathrm{V})$ and displacement $(\delta)$ for as-received $5083-\mathrm{H} 131$ (S-L) loaded in moist air at $0.30 \mathrm{MPa} \sqrt{\mathrm{m}} / \mathrm{h}$ illustrating the method used to determine initiation fracture toughness $\left(\mathrm{K}_{\mathrm{JIC}}\right)[49]$. 49

Figure 2.7 The elastic $\mathrm{K}$ dependence of subcritical crack growth rate for sensitized 5083$\mathrm{H} 131$ (S-L, $100^{\circ} \mathrm{C}$ for $175 \mathrm{~h}$, DoS of $22 \mathrm{mg} / \mathrm{cm}^{2}$ ) stressed with the constant then rising displacement protocol while immersed in $0.6 \mathrm{M} \mathrm{NaCl}$ solution at $-0.800 \mathrm{~V}_{\mathrm{SCE}}$. The solid lines represent exponential regression fits for each regime of crack growth. The grey region represents the resolution of dcPD measurement. 52

Figure 2.8 Subcritical crack growth rate versus K for seven replicate SCC experiments with the S-L orientation of 5083-H131, sensitized for $175 \mathrm{~h}$ at $100^{\circ} \mathrm{C}\left(22 \mathrm{mg} / \mathrm{cm}^{2}\right)$ and exposed to the fixed-to-slow rising displacement protocol during immersion in $0.6 \mathrm{M} \mathrm{NaCl}$ solution polarized to $-0.800 \mathrm{~V}_{\mathrm{SCE}}$. The grey box represents the resolution limit of the dcPD measurement............................................................. 54

Figure 2.9 Sensitization time dependence of IGC growth rate measured during the low-K hold with 5083-H131 immersed in $0.6 \mathrm{M} \mathrm{NaCl}$ solution at fixed potential of $-0.800 \mathrm{~V}_{\mathrm{SCE}}$. All rates were calculated while the specimen was held between 2.0 MPa $\sqrt{\mathrm{m}}$ and 5.0 $\mathrm{MPa} \sqrt{\mathrm{m}}$. Solid lines represent estimated trends. Unstressed IGC rates for sensitizations at $80^{\circ} \mathrm{C}$ (with SHT, x) and $100^{\circ} \mathrm{C}$ (non-SHT, *) were measured by Lim et al. [6,44]. 56

Figure 2.10 Nitric acid mass loss based DoS dependence of IGC growth rate measured during the constant $\mathrm{K}$ hold at $2.0 \mathrm{MPa} \sqrt{\mathrm{m}}$ to $5.0 \mathrm{MPa} \sqrt{\mathrm{m}}$ for $5083-\mathrm{H} 131$ immersed in $0.6 \mathrm{M} \mathrm{NaCl}$ solution at fixed potential of $-0.800 \mathrm{~V}_{\mathrm{SCE}}$. Unstressed IGC rates for sensitizations at $80^{\circ} \mathrm{C}$ (with SHT, $\mathbf{x}$ ) and $100^{\circ} \mathrm{C}$ (non-SHT, *) were measured by Lim et al. [6,44]. Simulated IGC penetration rates calculated from fissurechemistry considerations by Bumiller and Kelly are shown with dashed lines $[17,18]$. 58

Figure 2.11 Crack length versus time for $5083-\mathrm{H} 131$ sensitized at $60^{\circ} \mathrm{C}$ for $30 \mathrm{~d}, 60 \mathrm{~d}$ and $90 \mathrm{~d}$ loaded at a constant than rising displacement in $0.6 \mathrm{M} \mathrm{NaCl}$ at $-0.800 \mathrm{~V}_{\mathrm{SCE}}$. 
Figure 2.12 The K dependence of subcritical crack growth for as-received and sensitized $\left(60^{\circ} \mathrm{C}\right.$ for various times) $5083-\mathrm{H} 131$ (S-L) stressed with the constant then rising displacement protocol while immersed in $0.6 \mathrm{M} \mathrm{NaCl}$ solution at $-0.800 \mathrm{~V}_{\mathrm{SCE}}$. Both as-received and low DoS $\left(9 \mathrm{mg} / \mathrm{cm}^{2}\right)$ specimens were analyzed with elastic-plastic analysis. The kinetics measured for an as-received specimen loaded in air are plotted for reference with the grey box representing crack growth rates within this limit. 61

Figure 2.13 Sensitization time dependence of $\mathrm{K}_{\mathrm{TH}}$ for IGSCC in 5083-H131 immersed in $0.6 \mathrm{M} \mathrm{NaCl}$ solution at fixed potential of $-0.800 \mathrm{~V}_{\mathrm{SCE}}$. Elastic-plastic $\mathrm{K}_{\mathrm{JIC}}$ toughness is plotted as $\Delta$ for as-received, $\mathrm{O}$ for $\left(100^{\circ} \mathrm{C} 175 \mathrm{~h}\right)$, and $\square$ for $\left(80^{\circ} \mathrm{C}\right.$ $45 \mathrm{~d})$ specimens, with a grey band showing the range of $\mathrm{K}_{\text {JIC }}$. Elastic-plastic analysis was used for IGSCC specimens exhibiting $\mathrm{K}_{\mathrm{TH}}$ greater than $14 \mathrm{MPa} \sqrt{\mathrm{m}}$. Solid lines are regression fits, and dashed lines are estimated trends.

Figure 2.14 Nitric acid mass loss based DoS dependence of $\mathrm{K}_{\mathrm{TH}}$ for IGSCC in 5083-H131 immersed in $0.6 \mathrm{M} \mathrm{NaCl}$ solution at fixed potential of $-0.800 \mathrm{~V}_{\mathrm{SCE}}$. Elastic-plastic $\mathrm{K}_{\mathrm{JIC}}$ toughness (S-L) is plotted as $\boldsymbol{\Delta}$ for as-received, $\mathrm{O}$ for $\left(100^{\circ} \mathrm{C} 175 \mathrm{~h}\right.$, $\left.22 \mathrm{mg} / \mathrm{cm}^{2}\right)$, and $\square$ for $\left(80^{\circ} \mathrm{C} 45 \mathrm{~d}, 45 \mathrm{mg} / \mathrm{cm}^{2}\right)$ specimens, with a grey band showing the range of $\mathrm{K}_{\mathrm{JIC}}$. Elastic-plastic analysis was used for specimens exhibiting $\mathrm{K}_{\mathrm{TH}}$ greater than $14 \mathrm{MPa} \sqrt{\mathrm{m}}$. The dark dashed line for $\mathrm{K}_{\mathrm{TH}}$ vs. DoS greater than $10 \mathrm{mg} / \mathrm{cm}^{2}$ is based on linear regression $\left(\mathrm{R}^{2}=0.74\right)$. The light dashed line represents the predicted trend line through resistant microstructures. 64

Figure 2.15 Sensitization time dependence of IGSCC growth rate at $\mathrm{K}_{\text {elastic }}$ of $15 \mathrm{MPa} \sqrt{\mathrm{m}}$ for $5083-\mathrm{H} 131$ immersed in $0.6 \mathrm{M} \mathrm{NaCl}$ solution at $-0.800 \mathrm{~V}_{\mathrm{SCE}}$. Solid lines are estimated trends. Open data points represent da/dt where $\mathrm{K}_{J}$ of $15 \mathrm{MPa} \sqrt{\mathrm{m}}_{\mathrm{m}}$ is in Stage I or earlier. Arrows indicate experiments where acquisition rate was not fast enough to record IGSCC past $10 \mathrm{MPa} \sqrt{\mathrm{m}}_{\mathrm{m}}$; actual growth rates are likely higher...

Figure 2.16 The $\mathrm{K}$ dependence of subcritical crack growth for replicate experiments with sensitized $\left(100^{\circ} \mathrm{C}\right.$ for $30 \mathrm{~d}$ with $50 \mathrm{mg} / \mathrm{cm}^{2}$, and $45 \mathrm{~d}$ with $\left.59 \mathrm{mg} / \mathrm{cm}^{2}\right) 5083-\mathrm{H} 131$ (S-L) stressed with the constant then rising displacement protocol while immersed in $0.6 \mathrm{M} \mathrm{NaCl}$ solution at $-0.800 \mathrm{~V}_{\mathrm{SCE}}$ (the experiment noted "hold only" fractured before rising displacement was applied). 67

Figure 2.17 Nitric acid mass loss based DoS dependence of Stage II crack growth rates at $\mathrm{K}$ of $15 \mathrm{MPa} \sqrt{ } \mathrm{m}$ for $5083-\mathrm{H} 131$ immersed in $0.6 \mathrm{M} \mathrm{NaCl}$ solution at $-0.800 \mathrm{~V}_{\mathrm{SCE}}$. The dark dashed line indicates $\mathrm{da} / \mathrm{dt}_{\mathrm{K} 15}$ vs. DoS linear regression $\left(\mathrm{R}^{2}=0.30\right)$ for DoS greater than $10 \mathrm{mg} / \mathrm{cm}^{2}$. The light dashed line is the predicted trend line through the resistant microstructures. Open data points represent da/dt where $\mathrm{K}_{\mathrm{J}}$ of $15 \mathrm{MPa} \sqrt{\mathrm{m}}$ is in Stage I or before. Arrows indicate experiments where acquisition rate was not fast enough to record IGSCC past $10 \mathrm{MPa} \sqrt{\mathrm{m}}$, therefore actual growth rates are likely higher. 68 
Figure 2.18 SEM fractographs of as-received 5083-H131 (S-L) loaded in air (A-C) and $0.6 \mathrm{M} \mathrm{NaCl}$ polarized to $-0.800 \mathrm{~V}_{\mathrm{SCE}}(\mathrm{D}-\mathrm{F})$. Shaded regions in $\mathrm{D}$ and $\mathrm{E}$ are shown in detail in Fig. 2.19. 71

Figure 2.19 (A) and (B) detail the shaded regions in Figures 2.18(D and E), respectively, showing environmental crack extension in as-received 5083-H131 (S-L) polarized to $-0.800 \mathrm{~V}_{\mathrm{SCE}}$ in $0.6 \mathrm{M} \mathrm{NaCl}$. The arrow in (B) shows microvoid nucleating particles. 72

Figure 2.20 Optical image (left) of the IGSCC fracture surface of 5083-H131 (S-L) sensitized for $175 \mathrm{~h}$ at $100^{\circ} \mathrm{C}\left(22 \mathrm{mg} / \mathrm{cm}^{2}\right)$ and loaded in $0.6 \mathrm{M} \mathrm{NaCl}$ solution at $-0.800 \mathrm{~V}_{\mathrm{SCE}}$, with SEM fractographs portraying specific regions of the surface. Labels on the optical image refer to dcPD measured crack length for each stage of IGSCC in Fig. 2.7. 73

Figure 2.21 SEM fractographs representing (S-L) fracture surfaces of (A-B) low sensitized $\left(30 \mathrm{~d}, 60^{\circ} \mathrm{C}, 9 \mathrm{mg} / \mathrm{cm}^{2}\right)$ and $(\mathrm{C}-\mathrm{D})$ highly sensitized $\left(30 \mathrm{~d}, 100^{\circ} \mathrm{C}\right.$, $50 \mathrm{mg} / \mathrm{cm}^{2}$ ) $5083-\mathrm{H} 131$ immersed in $0.6 \mathrm{M} \mathrm{NaCl}$ at $-0.800 \mathrm{~V}_{\mathrm{SCE}}$. Intergranular

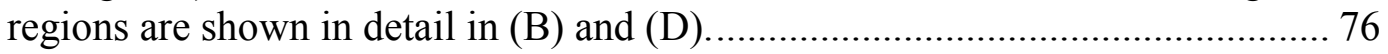

Figure 2.22 The interactive role of grain boundary $\beta$ dissolution along the corroding crack tip front for $\mathrm{H}$ production, and $\mathrm{H}$ uptake to $\beta$-matrix interfaces and $\beta$-free ligaments at the fracture process zone along an $\mathrm{Al}$ grain boundary surface. 82

Figure 2.23 Sensitization time dependence of IGSCC growth rate at $\mathrm{K}$ of $15 \mathrm{MPa} \sqrt{\mathrm{m}}$ in 5083-H131. Crack growth rates measured while fully immersed in $0.6 \mathrm{M} \mathrm{NaCl}$ solution at fixed potential of $-0.800 \mathrm{~V}_{\mathrm{SCE}}$ are represented by solid points (Fig. 2.15). The grey band represents the upper bound resolution limit of the dcPD measurement technique. Stage II crack growth rates plotted as $(\mathrm{O}, \Delta$, and $\triangleleft)$ represent (S-L) $5083-\mathrm{H} 321$ sensitized at $100^{\circ} \mathrm{C}, 120^{\circ} \mathrm{C}$ and $175^{\circ} \mathrm{C}$, respectively, and exposed to $\mathrm{NaCl}$ by dropwise addition by Bovard [1]. Stage II crack growth rates at $25 \mathrm{MPa} \sqrt{\mathrm{m}}$ plotted as (x) represent recrystallized (T-L) 5083-H321 sensitized at $175^{\circ} \mathrm{C}$ and loaded in full immersion $0.6 \mathrm{M} \mathrm{NaCl}$ by Jones et al. [12]. 86

Figure 2.24 Nitric acid mass loss based DoS dependence of IGSCC growth rate at K of $15 \mathrm{MPa} \sqrt{\mathrm{m}}$ for $5083-\mathrm{H} 131$. Crack growth rates measured while fully immersed in $0.6 \mathrm{M} \mathrm{NaCl}$ solution at fixed potential of $-0.800 \mathrm{~V}_{\mathrm{SCE}}$ are represented by solid points (Fig. 2.16). Stage II crack growth rates plotted as $(\mathrm{O}, \Delta$, and $\triangleleft)$ are for (S-L) specimens sensitized at $100^{\circ} \mathrm{C}, 120^{\circ} \mathrm{C}$ and $175^{\circ} \mathrm{C}$, respectively, and exposed to $\mathrm{NaCl}$ by dropwise addition by Bovard [1]. 88 
Figure 2.25 Sensitization time dependence of $\mathrm{K}_{\mathrm{TH}}$ for IGSCC in 5083-H131 (S-L). Thresholds measured while fully immersed in $0.6 \mathrm{M} \mathrm{NaCl}$ solution at fixed potential of $-0.800 \mathrm{~V}_{\mathrm{SCE}}$ are represented by solid points (Fig. 2.13). Elastic-plastic $\mathrm{K}_{\mathrm{JIC}}$ toughness is plotted as $(\boldsymbol{\Delta})$ for as-received, $(\boldsymbol{O})$ for $\left(100^{\circ} \mathrm{C} 175 \mathrm{~h}\right)$ and $(\boldsymbol{\square})$ for $\left(80^{\circ} \mathrm{C} 45 \mathrm{~d}\right) 5083-\mathrm{H} 131$ (S-L), with a grey band showing the range of $\mathrm{K}_{\mathrm{JIC}}$. Solid lines are regression fits and dashed lines are estimated trends. Thresholds represented by open points were measured on the same plate of 5083-H131 by Holtz et al. with a rising-step load procedure in chromate inhibited $\mathrm{NaCl}$ [34]. The white dashed line provides the estimated trend for these data.

Figure 2.26 Nitric acid mass loss based DoS dependence of $\mathrm{K}_{\mathrm{TH}}$ for IGSCC in 5083-H131 (S-L). Thresholds measured while fully immersed in $0.6 \mathrm{M} \mathrm{NaCl}$ solution at fixed potential of $-0.800 \mathrm{~V}_{\mathrm{SCE}}$ are represented by solid points (Fig. 2.14). Elastic-plastic $\mathrm{K}_{\mathrm{JIC}}$ toughness is plotted as $(\boldsymbol{\Delta})$ for as-received $\left(3 \mathrm{mg} / \mathrm{cm}^{2}\right),(\boldsymbol{O})$ for $\left(22 \mathrm{mg} / \mathrm{cm}^{2}\right)$ and ( $\mathbf{a})$ for $\left(45 \mathrm{mg} / \mathrm{cm}^{2}\right)$ specimens, with a grey band showing the range of $\mathrm{K}_{\mathrm{JIC}}$. Solid lines are regression fits; dashed lines are estimated trends. Thresholds represented by open points were measured on the same 5083-H131 plate used in this study by Holtz et al. with a rising-step load procedure in chromate inhibited $\mathrm{NaCl}$ [34]. The white dashed line provides the estimated trend for these data. ... 93

Figure 2.27 Thickness and continuity of $\beta$ along grain boundaries of 5083-H131 with sensitization at $40^{\circ} \mathrm{C}$ to $70^{\circ} \mathrm{C}$ measured with SEM analysis following diluted phosphoric acid etching by Zhu et al. [82]. 100

Figure 2.28 The distribution of $\beta$ along grain boundaries in SHT 5083-H131 (from a plate of the same heat used in this study) sensitized at $100^{\circ} \mathrm{C}$ by Lim et al. [6]. The grains were revealed with Barker's Etch and optical imaging, while the attack sites were exposed by a phosphorous etch and imaged by SEM [6]. 101

Figure 2.29 A map of $\beta$ morphology as a function of aging time and temperature. Morphology was studied with TEM on SHT 5083-H131 sensitized at $100^{\circ} \mathrm{C}$ and non-SHT $5083-\mathrm{H} 131$ sensitized at $70^{\circ} \mathrm{C}$ and $175^{\circ} \mathrm{C}$ by Holtz et al. $[3,75,83]$. The 5083-H131 plate was from the same heat used in this study. The symbols and arrows indicate IGSCC susceptibility (in $0.6 \mathrm{M} \mathrm{NaCl}$ at $-0.800 \mathrm{~V}_{\mathrm{SCE}}$ in the S-L orientation) for 5083-H131 sensitized for times in excess of the open point at (o) $100^{\circ} \mathrm{C},(\Delta) 80^{\circ} \mathrm{C}$ and $(\diamond) 60^{\circ} \mathrm{C}$ 103

Figure 2.30 The (a) equivalent diameter and (b) nearest neighbor spacing of grain boundary $\beta$ in SHT 5083-H131 exposed by Ga attack and observed with SEM imaging as a function of sensitization time using a plate of the same heat as the present study by Birbilis et al. [5] ................................................................ 105

Figure 2.31 Crack geometry used in cation concentration calculation....................... 134

Figure 3.1 Crack extension versus time for three SENT 5083-H131 specimens sensitized at $100^{\circ} \mathrm{C}$ for $175 \mathrm{~h}\left(22 \mathrm{mg} / \mathrm{cm}^{2}\right)$, then stressed to low $\mathrm{K}$ in moist air (bottom), to high $\mathrm{K}$ in moist air (middle) or immersed in $0.6 \mathrm{M} \mathrm{NaCl}$ polarized to $-0.800 \mathrm{~V}_{\mathrm{SCE}}$ while loaded to low K (top). 144 
Figure 3.2 The crack growth rate measured in moist air for 5083-H131 (S-L) with different sensitization and loading rates. 145

Figure 3.3 Crack extension versus time for 5083-H131 (S-L) sensitized at $100^{\circ} \mathrm{C}$ for $175 \mathrm{~h}$ $\left(22 \mathrm{mg} / \mathrm{cm}^{2}\right)$, immersed in $0.6 \mathrm{M} \mathrm{NaCl}$ and held at $4 \mathrm{MPa} \sqrt{\mathrm{m}}$, then loaded at $0.25 \mathrm{MPa} \sqrt{\mathrm{m}} / \mathrm{h}$ to $6 \mathrm{MPa} \sqrt{\mathrm{m}}$ for various constant-applied potentials. As-received 5083-H131 (S-L, $3 \mathrm{mg} / \mathrm{cm}^{2}$ ) loaded to $4 \mathrm{MPa} \sqrt{\mathrm{m}}$ in air $(\mathrm{O})$ for $20 \mathrm{~h}$ is shown for reference......

Figure 3.4 Rates of fatigue crack IGC on: a) logarithmic and b) linear scales for sensitized $5083-\mathrm{H} 131$ (S-L, $22 \mathrm{mg} / \mathrm{cm}^{2}$ ) during a hold at $4 \mathrm{MPa} \sqrt{\mathrm{m}}$. The range of $\mathrm{pH}$-sensitive breakdown potentials for $\alpha$ is shown with the thin vertical lines, and the range of $\mathrm{pH}$-sensitive $\beta$ breakdown potentials is shown by the thick vertical dashed lines. 148

Figure 3.5 The stress intensity dependence of da/dt for sensitized $\left(100^{\circ} \mathrm{C}\right.$ for $175 \mathrm{~h}$, $22 \mathrm{mg} / \mathrm{cm}^{2}$ ) 5083-H131 (S-L) stressed with the constant then rising displacement protocol while immersed in $0.6 \mathrm{M} \mathrm{NaCl}$ solution with different constant applied potentials. Specimens polarized between $-1.300 \mathrm{~V}_{\mathrm{SCE}}$ and $-0.900 \mathrm{~V}_{\mathrm{SCE}}$ and in air were analyzed with elastic-plastic analysis. Sensitized $5083-\mathrm{H} 131\left(22 \mathrm{mg} / \mathrm{cm}^{2}\right)$, loaded with the same protocol in air is plotted for reference. The grey box represents growth rate resolution from Fig. 3.2. 150

Figure 3.6 The crack growth rate of sensitized (DoS $\left.22 \mathrm{mg} / \mathrm{cm}^{2}\right)$ 5083-H131 (S-L) at constant $\mathrm{K}$ of $15 \mathrm{MPa} \sqrt{\mathrm{m}}$ plotted as a function of applied potential. The range of $\mathrm{pH}$-sensitive breakdown potentials for $\alpha$ is shown with the thin vertical lines, and the range of $\mathrm{pH}$-sensitive $\beta$ breakdown potentials is shown by the dashed vertical lines. The resolution limit of the dcPD measurement is shown with grey boxes (lower for $22 \mathrm{mg} / \mathrm{cm}^{2}$ in air and upper for as-received in air at $\mathrm{K}=15 \mathrm{MPa} \sqrt{\mathrm{m}}$ ). 151

Figure 3.7 Crack extension versus time for as-received 5083-H131 SENT (S-L, $3 \mathrm{mg} / \mathrm{cm}^{2}$ ) specimens fully immersed in $\mathrm{NaOH}(\Delta), \mathrm{NaCl}(\diamond)$, and $\mathrm{AlCl}_{3} / \mathrm{MgCl}_{2}$ solutions $(\square)$; held at $4 \mathrm{MPa} \sqrt{\mathrm{m}}$ for $10 \mathrm{~h}$, then loaded at $0.25 \mathrm{MPa} \sqrt{\mathrm{m}} / \mathrm{h}$ to $6 \mathrm{MPa} \sqrt{\mathrm{m}}$. As-received 5083-H131 (S-L, $3 \mathrm{mg} / \mathrm{cm}^{2}$ ) loaded to $4 \mathrm{MPa} \sqrt{\mathrm{m}}$ in air ( $)$ for $20 \mathrm{~h}$ is shown for reference. 153

Figure 3.8 Rates of fatigue crack IGC for 5083-H131 (S-L) as-received and sensitized microstructures in various environments, stressed at constant $\mathrm{K}$ of $4 \mathrm{MPa} \sqrt{\mathrm{m}}$. The bar at $-0.800 \mathrm{~V}_{\mathrm{SCE}}$ represents maximum and minimum rates measured in replicate experiments. The $\mathrm{NaOH}$ specimen at $-1.370 \mathrm{~V}_{\mathrm{SCE}}$ remained at OCP (with no applied potential). The range of environmental sensitive breakdown potentials of both $\alpha$ and $\beta$ are shown with vertical dashed lines. The dcPD resolution limit is $4 \times 10^{-3} \mathrm{~nm} / \mathrm{s}$ for static loading at $\mathrm{K}$ of $4 \mathrm{MPa} \sqrt{\mathrm{m}}$. 154 
Figure 3.9 The $\mathrm{K}_{\mathrm{J}}$ dependence of $\mathrm{da} / \mathrm{dt}$ for as-received $\left(3 \mathrm{mg} / \mathrm{cm}^{2}\right) 5083-\mathrm{H} 131$ (S-L) stressed with the constant then rising displacement protocol while immersed in $\mathrm{NaOH}(\Delta), \mathrm{NaCl}(\diamond)$, and $\mathrm{AlCl}_{3} / \mathrm{MgCl}_{2}$ solutions $(\square)$. All experiments were analyzed with elastic-plastic $\mathrm{K}_{\mathrm{J}}$, with the exception of the specimens immersed in $\mathrm{AlCl}_{3} / \mathrm{MgCl}_{2}$ and polarized to $-0.730 \mathrm{VSCE}$ in $\mathrm{NaCl}$. As-received 5083-H131 $\left(3 \mathrm{mg} / \mathrm{cm}^{2}\right)$ loaded with the same protocol in air is plotted for reference. The grey box represents growth rate resolution from Fig. 3.2 …..................................... 156

Figure 3.10 Rates of IGSCC for 5083-H131 (S-L) as-received and sensitized microstructures in various environments, stressed at constant $\mathrm{dK} / \mathrm{dt}$ of $0.25 \mathrm{MPa} \sqrt{\mathrm{m}} / \mathrm{h}$. The $\mathrm{pH}$ sensitive range of environmental sensitive breakdown potentials of both $\alpha$ and $\beta$ are shown with vertical dashed lines. The resolution at $\mathrm{K}$ of $15 \mathrm{MPa} \sqrt{\mathrm{m}}$ is shown by the grey box. 157

Figure 3.11 SEM fractographs of corrosion product covered/damaged regions in unsensitized 5083-H131 after $2.1 \mathrm{~mm}$ of crack extension during loading in acidic $\mathrm{AlCl}_{3} / \mathrm{MgCl}_{2}$ at $-1.000 \mathrm{~V}_{\text {SCE}}$. The resulting corrosion damage at the shaded rectangle in (a) is enlarged in (b). Crack growth is down in the L direction, with T in the horizontal direction. 158

Figure 3.12 SEM fractographs of corrosion covered regions in unsensitized 5083-H131 loaded in alkaline $\mathrm{NaOH}$ at OCP. The resulting corrosion damage at the shaded rectangle in (a) is enlarged in (b). Crack growth is down in the L direction, with T in the horizontal direction. 159

Figure 3.13 Fractographs of possible IGSCC regions in unsensitized 5083-H131 loaded in neutral $\mathrm{NaCl}$ at a) $-0.730 \mathrm{~V}_{\mathrm{SCE}}$ and b) $-0.800 \mathrm{~V}_{\mathrm{SCE}}$. Crack growth is down in the $\mathrm{L}$ direction, with $\mathrm{T}$ in the horizontal dirction 161

Figure 3.14 Potentiodynamic scans of $\alpha$ in $0.6 \mathrm{M} \mathrm{NaCl}(\mathrm{pH} 6)$, and $\beta$ in $0.6 \mathrm{M} \mathrm{NaCl}$ ( $\mathrm{pH}$ 8.6) [15], and $\alpha$ and $\beta$ in $80 \%$ saturated $\mathrm{Al}-4 \% \mathrm{Mg}$ acidic solution $(\mathrm{pH}-0.12)[17,18]$. The range of $\mathrm{pH}$-sensitive breakdown potential for each phase is shown with a horizontal bar.

Figure 3.15 The average pit stability product calculated for artificial pits in $25 \mu \mathrm{m}$ and $127 \mu \mathrm{m}$ diameter $\mathrm{Al}$ wires after $200 \mathrm{~s}$ at the given applied potential [47]. 172

Figure 3.16 Three orientations of the occluded fissure (crack) used to calculate Ohmic drop adapted from Stewart [53]. 174

Figure 3.17 Predicted fatigue crack tip corrosion fissure potential at $\mathrm{K}=5 \mathrm{MPa} \sqrt{\mathrm{m}}$ as a function of applied potential for sensitized 5083-H131 (S-L, $\left.22 \mathrm{mg} / \mathrm{cm}^{2}\right)$ and the three orientations represented in Fig. 3.16. The black line is the applied potential equal to crack tip potential. The dashed line represents the lower bound of the fissure tip potential (OCP of $\alpha$ in simulated crack tip solution $[17,18]$ ). 177 
Figure 3.18 The fatigue crack tip corrosion growth rate at $5 \mathrm{MPa} \sqrt{\mathrm{m}}$ in sensitized $\left(22 \mathrm{mg} / \mathrm{cm}^{2}\right) 5083-\mathrm{H} 131(\mathrm{~S}-\mathrm{L})$ in $\mathrm{NaCl}$ plotted as a function of applied potential. Arrows represent the Ohmic (IR) drop predicted in the crack tip for the three orientations represented in Fig. 3.16. The $\mathrm{pH}$ sensitive breakdown potentials of $\beta$ and $\alpha$ are shown with dashed lines $[17,18]$. The black dashed line represents the lower limit for fissure tip potential (OCP of $\alpha$ in simulated crack tip

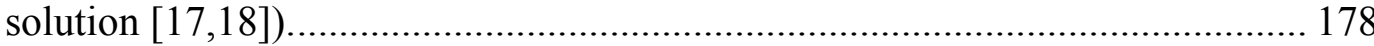

Figure 3.19 Reported potential dependent $\mathrm{pH}$ from literature used to estimate crack tip $\mathrm{pH}$ in this study over the potential range $-1.000 \mathrm{~V}_{\mathrm{SCE}}$ to $-0.730 \mathrm{~V}_{\mathrm{SCE}}$ [22]. The right axis provides the crack growth rate measured in this study as a function of applied potential for reference. 179

Figure 3.20 The $\mathrm{pH}$ measured in $2 \mathrm{M} \mathrm{AlCl}_{3}$ as a function of $\mathrm{MgCl}_{2}$ addition [28]..... 180

Figure 3.21 $\mathrm{C}_{\mathrm{H}-\mathrm{Diff}}$ as a function of $\eta_{\mathrm{H}}$ for a: a) $\mathrm{Ni}$ alloy (Monel K-500) in $\mathrm{NaCl}$ at $\mathrm{pH} 7$ showing variability in $\mathrm{C}_{\mathrm{H} \text {-Diff }}$ measurement by various techniques [58], and b) an ultra high strength martensitic steel AerMet 100 immersed in borate buffered chloride-free electrolyte, showing how $\mathrm{H}$ solubility differs with $\mathrm{pH}$ [52]. 191

Figure 3.22 Flow chart demonstrating how applied potential-dependent crack tip chemistry influences crack growth rate. 192

Figure 3.23 Predicted crack tip potential at $\mathrm{K}=15 \mathrm{MPa} \sqrt{\mathrm{m}}$ as a function of applied potential for sensitized 5083-H131 (S-L, $\left.22 \mathrm{mg} / \mathrm{cm}^{2}\right)$. The black line is the applied potential equal to the tip potential. The dashed line represents the lower bound of the crack tip potential (OCP of $\alpha$ in simulated crack tip solution $[17,18]$ ). 197

Figure 3.24 The crack growth rate at $15 \mathrm{MPa} \sqrt{\mathrm{m}}$ in sensitized5083-H131 (S-L, $\left.22 \mathrm{mg} / \mathrm{cm}^{2}\right)$ in $\mathrm{NaCl}$ as a function of polarization. Arrows represent the Ohmic drop predicted at the crack tip for three orientations illustrated in Fig. 3.16. The $\mathrm{pH}$ sensitive breakdown potentials of $\beta$ and $\alpha$ are shown with dashed lines [17,18]. The vertical black dashed line represents the lower limit for crack tip potential (OCP of $\alpha$ in simulated crack tip solution [17,18]). The resolution limit for the dcPD measurement technique is shown with the grey box 200

Figure 3.25 The da/dt 15 for sensitized (S-L) $5083-\mathrm{H} 131\left(22 \mathrm{mg} / \mathrm{cm}^{2}\right)$ as a function of predicted crack tip $\mathrm{pH}$. 202

Figure 3.26 Crack tip potential as a function of crack tip $\mathrm{pH}$, showing the predicted overpotential for $\mathrm{H}$ production at the crack tip of sensitized 5083-H131 $\left(22 \mathrm{mg} / \mathrm{cm}^{2}\right)$ stressed in $\mathrm{NaCl}$ at three applied potentials. The lower dashed line is parallel to the $\mathrm{pH}$ dependent reversible potential for water and proton reduction and is drawn for reference. Applied potential, crack tip overpotential, and crack growth rate from Fig. 3.24 are given for each experiment. 203

Figure 3.27 The da/ $/ \mathrm{dt}_{\mathrm{K} 15}$ for sensitized $5083-\mathrm{H} 131\left(\mathrm{~S}-\mathrm{L}, 22 \mathrm{mg} / \mathrm{cm}^{2}\right.$ ) as a function of predicted overpotential for $\mathrm{H}$ production for the three crack tip orientations illustrated in Fig. 3.16. 205 
Figure 3.28 Crack tip potential as a function of crack tip pH (Tables 3.6-3.9), showing the predicted overpotential for $\mathrm{H}$ production in a crack tip of 5083-H131 at three different microstructure-environment combinations. The lower dashed line is parallel to the $\mathrm{pH}$ dependent reversible potential for water and proton reduction and is drawn for reference. Applied potential, bulk solution, DoS and measured crack growth rate from Fig. 3.10 are listed for each experiment

213

Figure 3.29 Stage II crack growth rate plotted as a function of trap sensitive H diffusivity. The solid trend line and filled symbols $(\bullet[61,68])$ represent maximum $\mathrm{da}^{-} \mathrm{dt}_{\mathrm{II}}$ reported for $\mathrm{H}$ diffusion controlled HEAC in high strength alloys. All other data represent da/dt 15 in 5083-H131 (S-L): (a) the 2 grey rectangles are sensitized (from $10 \mathrm{mg} / \mathrm{cm}^{2}$ to $49 \mathrm{mg} / \mathrm{cm}^{2}$ ) in $0.6 \mathrm{M} \mathrm{NaCl}$ polarized to $-0.800 \mathrm{~V} \mathrm{SCE}$, (b) (O) are sensitized $\left(22 \mathrm{mg} / \mathrm{cm}^{2}\right)$ in $0.6 \mathrm{M} \mathrm{NaCl}$ at given applied potentials, $(\dot{\sim})$ ) as-received $\left(3 \mathrm{mg} / \mathrm{cm}^{2}\right)$ in $\mathrm{AlCl}_{3} / \mathrm{MgCl}_{2}$ at $-1.000 \mathrm{~V}_{\mathrm{SCE}},(\square)$ as-received $\left(3 \mathrm{mg} / \mathrm{cm}^{2}\right)$ in $\mathrm{NaCl}$ at $-0.730 \mathrm{~V}_{\mathrm{SCE}},(\Delta)$ as-received $\left(3 \mathrm{mg} / \mathrm{cm}^{2}\right)$ in $\mathrm{NaCl}$ at $-0.800 \mathrm{~V}_{\mathrm{SCE}}$ and $(\nabla)$ asreceived in $\mathrm{NaOH}$ at both OCP and $-1.800 \mathrm{~V}_{\text {SCE }}$. 219

Figure 3.30 The (A) linear and (B) logarithmic relationship between $\mathrm{C}_{\mathrm{H \sigma}} / \mathrm{C}_{\mathrm{H}-\text { crit }}$ (calculated from measured crack growth rates using Eqn. 3.2 with $D_{H-E F F}$ of $10^{-10} \mathrm{~cm}^{2} / \mathrm{s}$ and XCRIT of $0.9 \mu \mathrm{m})$ for as-received $5083-\mathrm{H} 131\left(3 \mathrm{mg} / \mathrm{cm}^{2}\right)$ as a function of electrochemically predicted crack tip $\eta_{\mathrm{H}}$ at $\mathrm{K}$ of $15 \mathrm{MPa} \sqrt{\mathrm{m}}$. 224

Figure 3.31 The (A) linear and (B) logarithmic relationship between $\mathrm{C}_{\mathrm{H \sigma}} / \mathrm{C}_{\mathrm{H}-\text { crit }}$ (calculated from measured crack growth rates using Eqn. 3.2 with $D_{\mathrm{H}-\mathrm{EFF}}$ of $10^{-7} \mathrm{~cm}^{2} / \mathrm{s}$ and XCRIT of $0.9 \mu \mathrm{m})$ for sensitized $5083-\mathrm{H} 131\left(22 \mathrm{mg} / \mathrm{cm}^{2}\right)$ as a function of electrochemically predicted $\eta_{\mathrm{H}}$ at $\mathrm{K}$ of $15 \mathrm{MPa} \sqrt{\mathrm{m}}$. 225

Figure 3.32 The (A) linear and (B) logarithmic relationship between the $\mathrm{C}_{\mathrm{H \sigma}} / \mathrm{C}_{\mathrm{H}-\text { crit }}$ (calculated from measured crack growth rates using Eqn. 3.2 with $\mathrm{D}_{\mathrm{H}-\mathrm{EFF}}$ of $10^{-8} \mathrm{~cm}^{2} / \mathrm{s}$ and $\mathrm{x}_{\text {CRIT }}$ of $\left.0.9 \mu \mathrm{m}\right)$ for sensitized $5083-\mathrm{H} 131\left(22 \mathrm{mg} / \mathrm{cm}^{2}\right)$ as a function of electrochemically predicted $\eta_{\mathrm{H}}$ at $\mathrm{K}$ of $15 \mathrm{MPa} \sqrt{\mathrm{m}}_{\mathrm{m}}$ 226

Figure 4.1 Stage II crack growth rate (at an elastic stress intensity, K, of $15 \mathrm{MPa} \sqrt{\mathrm{m}}$ ) as a function of DoS from ASTM International Standard G67-04 for Al-Mg alloy 5083$\mathrm{H} 131$ stressed in $0.6 \mathrm{M} \mathrm{NaCl}$ polarized to $-0.800 \mathrm{~V}_{\mathrm{SCE}}$ which is near the open-circuit potential (OCP). The Mode I crack was stressed in the plate-thickness (S) direction and grew in the plate rolling $(\mathrm{L})$ direction. 250

Figure 4.2 Rates of IGSCC for as-received and sensitized microstructures of 5083-H131 (S-L) stressed in various environments at constant $\mathrm{dK} / \mathrm{dt}$ of $0.25 \mathrm{MPa} \sqrt{\mathrm{m}} / \mathrm{h}$. The ranges of $\mathrm{pH}$ sensitive breakdown potentials of both $\alpha$ and $\beta$ are shown with vertical dashed lines. The crack growth rate resolution at $\mathrm{K}$ of $15 \mathrm{MPa} \sqrt{\mathrm{m}}$ is shown by the grey box. 
Figure 4.3 Net-section stress versus grip displacement during loading of double notched specimens in moist air at $0.00045 \mathrm{~mm} / \mathrm{min}(23 \mathrm{MPa} / \mathrm{h}$ to $29 \mathrm{MPa} / \mathrm{h})$ for $\mathrm{H}$ precharged S-L oriented 5083-H131 at different sensitization conditions. ........ 256

Figure 4.4 Scanning electron fractograph of 5083-H131 sensitized at $100^{\circ} \mathrm{C}$ for $175 \mathrm{~h}$ $\left(22 \mathrm{mg} / \mathrm{cm}^{2}\right)$ and $\mathrm{H}$ charged for $16 \mathrm{~d}$ prior to slow-rate loading in moist air. .... 257

Figure 4.5 Scanning electron fractographs of 5083-H131 sensitized at $100^{\circ} \mathrm{C}$ for $175 \mathrm{~h}$ and $\mathrm{H}$ charged for $16 \mathrm{~d}$ prior to slow-rate loading in moist air illustrating particles on the grain surface. The boxed area in Fig. 4.4 is detailed in (a), the area noted in (a) is detailed in (b). 258

Figure 4.6: Maximum da/dt $\mathrm{dI}_{\text {II }}$ reported for $\mathrm{H}$ diffusion controlled $\mathrm{HEAC}$ in high strength alloys ( [30], $\boldsymbol{\Delta}$ [33]). Trend line is plotted with the discontinuous model (Eqn. 4.1) and the continuous model (Eqn. 4.6), defining $\mathrm{x}_{\text {CRIT }}$ as $0.9 \mu \mathrm{m}$ and $0.2 \mu \mathrm{m}$, respectively. 264

Figure 4.7: Stage II crack growth rate as a function of trap sensitive effective H diffusivity. The solid trend line and filled symbols $(\bullet[30], \boldsymbol{\Delta}[33])$ represent maximum da/dt reported for $\mathrm{H}$ diffusion controlled HEAC in high strength alloys. Open symbols are for 5083-H131 (S-L): (એ) as-received in $\mathrm{AlCl}_{3} / \mathrm{MgCl}_{2}$ at $-1.000 \mathrm{~V}_{\mathrm{SCE}}$ (Fig. 4.2), ( $\square)$ as-received in $\mathrm{NaCl}$ at $-0.730 \mathrm{~V}_{\mathrm{SCE}}$ (Fig. 4.2), ( $\left.\nabla\right)$ sensitized $\left(10 \mathrm{mg} / \mathrm{cm}^{2}\right)$ in $\mathrm{NaCl}$ at $-0.800 \mathrm{~V}_{\mathrm{SCE}}$ (Fig. 4.1), (O) as-received in $\mathrm{NaCl}$ at $-0.800 \mathrm{~V}$ SCE (Fig. 4.1). The light grey rectangle at $D_{\text {H-EFF }}$ of $10^{-10} \mathrm{~cm}^{2} / \mathrm{s}$ shows the range of $\mathrm{da} / \mathrm{dt}_{\text {II }}$ for sensitized 5083 from Fig. 4.1 269

Figure 4.8 Modification of Fig. 4.7, demonstrating that a decrease in $\mathrm{x}_{\text {CRIT }}$ cannot explain the high crack growth rates in sensitized 5083-H131, though an increase in $\mathrm{D}_{\mathrm{H}-\mathrm{EFF}}$ can do so. 271

Figure 4.9 SEM fractographs of grain boundaries (LT surface) of unsensitized 5083-H131 (3 $\mathrm{mg} / \mathrm{cm}^{2}$ ) separated with Ga: (a) shows boundaries covered with Ga contamination, and (b) shows a relatively clean grain surface with some Ga debris. 283

Figure 4.10 Grain boundary surfaces (LT surface) of 5083-H131 separated with Ga attack: (a) unsensitized $\left(3 \mathrm{mg} / \mathrm{cm}^{2}\right)$, and (b) sensitized at $60^{\circ} \mathrm{C}$ for $30 \mathrm{~d}\left(23 \mathrm{mg} / \mathrm{cm}^{2}\right) . .285$

Figure 4.11 Grain boundary surfaces of 5083-H131 separated with Ga attack following sensitization at: (a) $100^{\circ} \mathrm{C}$ for $7 \mathrm{~d}\left(22 \mathrm{mg} / \mathrm{cm}^{2}\right)$, and (b) $100^{\circ} \mathrm{C}$ for $30 \mathrm{~d}\left(50 \mathrm{mg} / \mathrm{cm}^{2}\right)$. 286

Figure 4.12 Fracture surface of $\mathrm{H}$ charged as-received 5083-H131 $\left(3 \mathrm{mg} / \mathrm{cm}^{2}\right) \ldots \ldots \ldots .288$

Figure 4.13 Fracture surface of $\mathrm{H}$ charged $5083-\mathrm{H} 131$, sensitized at $100^{\circ} \mathrm{C}$ for $175 \mathrm{~h}$ $\left(22 \mathrm{mg} / \mathrm{cm}^{2}\right)$. 288

Figure 4.14 Fracture surface of $\mathrm{H}$ charged sensitized $5083-\mathrm{H} 131100^{\circ} \mathrm{C}$ for $175 \mathrm{~h}$ $\left(22 \mathrm{mg} / \mathrm{cm}^{2}\right)$. 289 
Figure 4.15 Fracture surface of $\mathrm{H}$ charged $5083-\mathrm{H} 131$ sensitized at $100^{\circ} \mathrm{C}$ for $30 \mathrm{~d}$ $\left(50 \mathrm{mg} / \mathrm{cm}^{2}\right)$. Intergranular features are surrounded by ductile features in (a), and evidence of several particles is provided in (b). ................................................ 291

Figure 4.16 Fracture surface of $\mathrm{H}$ charged $5083-\mathrm{H} 131$ sensitized at $100^{\circ} \mathrm{C}$ for $30 \mathrm{~d}$

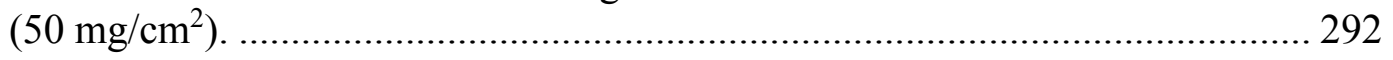

Figure 4.17 Fracture initiation in $\mathrm{H}$ charged $5083-\mathrm{H} 131$ sensitized at $60^{\circ} \mathrm{C}$ for $90 \mathrm{~d}$ $\left(23 \mathrm{mg} / \mathrm{cm}^{2}\right)$. 


\section{LIST OF TABLES}

Table 2.1 Chemical composition of 5083-H131 in wt. pct. [36] ................................. 36

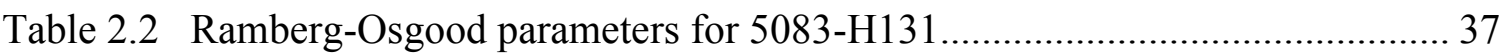

Table 2.3 Sensitivity analysis of the effect of plasticity on fracture toughness of asreceived $5083-\mathrm{H} 131$ loaded at $0.30 \mathrm{MPa} \sqrt{\mathrm{m}} / \mathrm{h}$ in moist air. Stress intensity equations are from Tada et al. [46] 50

Table 2.4 Estimated cation concentrations for dissolution of occluded IGSCC crack $\beta$ at $\mathrm{K}$ of $15 \mathrm{MPa} \sqrt{\mathrm{m}}$. 109

Table 2.5 DoS dependent values used to calculate cation concentration. .................... 133

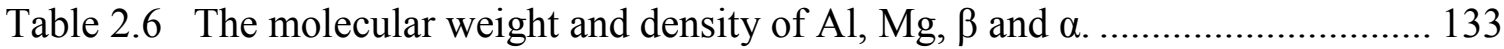

Table 3.1 Chemical composition of 5083-H131 in wt. pct. [27] ............................... 142

Table 3.2 Breakdown potentials of $\beta$ and $\alpha$ phase in neutral and acidic environments from Fig. 3.14. 167

Table 3.3 Predicted bold surface [17,18] and measured fatigue crack (K of $5 \mathrm{MPa} \sqrt{\mathrm{m}}$ ) IGC growth rates for sensitized $\left(22 \mathrm{mg} / \mathrm{cm}^{2}\right)$ 5083-H131 in $0.6 \mathrm{M} \mathrm{NaCl}$......... 168

Table 3.4 Predicted $\mathrm{pH}$ and potential at the fatigue crack-IGC fissure tip in sensitized $\left(22 \mathrm{mg} / \mathrm{cm}^{2}\right) 5083-\mathrm{H} 131$ in $0.6 \mathrm{M} \mathrm{NaCl}$ at $\mathrm{K}$ of $5 \mathrm{MPa} \sqrt{\mathrm{m}}$ for the three orientations represented in Fig. 3.16. 176

Table 3.5 Measured and modeled IGC rates in unsensitized 5083-H131.................. 184

Table 3.6 The predicted fissure $\mathrm{pH}$ and tip potentials for unsensitized 5083-H131 at $\mathrm{K}$ of $5 \mathrm{MPa} \sqrt{\mathrm{m}}$ with the three orientations provided in Fig. 3.16. 185

Table 3.7 Predicted crack tip $\mathrm{pH}$ and potential during IGSCC in sensitized 5083-H131 $\left(22 \mathrm{mg} / \mathrm{cm}^{2}\right)$ in $0.6 \mathrm{M} \mathrm{NaCl}$ at $\mathrm{K}$ of $15 \mathrm{MPa} \sqrt{\mathrm{m}}$ for three different orientations (Fig. 3.16) 196

Table 3.8 Predicted potential at the IGSCC tip in unsensitized 5083-H131 $\left(3 \mathrm{mg} / \mathrm{cm}^{2}\right)$ at $\mathrm{K}$ of $15 \mathrm{MPa} \sqrt{\mathrm{m}}$ for the three orientations illustrated in Fig. 3.16. 211

Table 3.9 Predicted $\mathrm{pH}$ and $\eta_{\mathrm{H}}$ at the IGSCC tip in unsensitized 5083-H131 $\left(3 \mathrm{mg} / \mathrm{cm}^{2}\right)$ at K of 15 MPam for the three orientations illustrated in Fig. 3.16.................. 211

Table 3.10 Crack growth rate in 5083-H131 (S-L), measured for various environments, and corresponding $\mathrm{C}_{\mathrm{H \sigma}} / \mathrm{C}_{\mathrm{H} \text {-crit }}$ predicted by Eqn. 3.2 and assuming $\mathrm{x}_{\mathrm{CRIT}}=0.9 \mu \mathrm{m}$.

Table 3.11 Diffusion distances and slot height used to calculate the Ohmic difference due to the active tip and passive wall for $5083-\mathrm{H} 131$ sensitized at $10 \mathrm{mg} / \mathrm{cm}^{2}$ and $22 \mathrm{mg} / \mathrm{cm}^{2}$. 242

Table 3.12 Values used to calculate the height of the slot for IGC and IGSCC crack tips. 
CHAPTER 1

INTRODUCTION 


\subsection{NOMENCLATURE}

$\alpha-\mathrm{Al}-4 \% \mathrm{Mg}$ (wt. pct.) solid solution matrix phase

$\beta-\mathrm{Al}_{3} \mathrm{Mg}_{2}$ intergranular precipitate in $\mathrm{Al}-\mathrm{Mg}$ alloys

$\mathrm{C}_{\mathrm{H} \sigma}$ - concentration of $\mathrm{H}$ in the FPZ

$\mathrm{da} / \mathrm{dt}_{\text {II }}$ - Stage II crack growth rate

$\mathrm{D}_{\mathrm{H}-\mathrm{EFF}}$ - trap-sensitive diffusivity of $\mathrm{H}$

DoS - degree of sensitization quantified by NAMLT

FPZ - fracture process zone

$\mathrm{H}$ - atomic hydrogen

HEAC - hydrogen environment assisted cracking

$\eta_{\mathrm{H}}-$ overpotential for $\mathrm{H}$ production by proton or water reduction

IGC -intergranular corrosion

IGSCC - intergranular stress corrosion cracking

$\mathrm{K}$ - linear elastic stress intensity

$\mathrm{K}_{\mathrm{TH}}$ - threshold stress intensity

$\mathrm{L}$ - longitudinal (plate rolling) direction

L-T - crack orientation, loading in L and crack growth in $\mathrm{T}$ directions

NAMLT - nitric acid mass loss test per ASTM G67

OCP - open circuit potential

$\mathrm{S}$ - short-transverse direction (plate thickness)

SENT - single edge notched tensile specimen

SEM - scanning electron microscopy

SHT - solution heat-treated

$\mathrm{S}-\mathrm{L}$ - crack orientation, loading in S and crack growth in L directions

$\mathrm{T}-$ transverse direction (plate width)

TEM - transmission electron microscopy

$\mathrm{T}-\mathrm{L}$ - crack orientation, loading in $\mathrm{T}$ and crack growth in $\mathrm{L}$ directions

$\mathrm{x}_{\text {CRIT }}$ - critical distance ahead of the crack tip where $\mathrm{H}$ damage nucleates 


\subsection{PROBLEM STATEMENT}

The characteristic high strength-to-weight ratio, general corrosion resistance and weldability makes a typical Al-Mg alloy an ideal light-weight candidate to replace steel in marine applications. The vulnerability of this alloy becomes apparent during extended exposure to service environments, when the alloy is rendered susceptible to intergranular corrosion (IGC) and intergranular stress corrosion cracking (IGSCC). Since these damage processes are detrimental to the structural integrity of components, many studies have focused on understanding the corrosion and cracking response of $\mathrm{Al}-\mathrm{Mg}$ alloys exposed to chloride environments [1-26]. Though significant advancements have been made, the challenge remains to develop a scientific and engineering understanding of the mechanisms driving IGSCC in Al-Mg alloys, specifically during long term and low temperature service exposure, in an effort to mitigate damage and advance life prediction models.

The overall objective of this research is to establish quantitative, high resolution cracking kinetics, and then to further understanding of the interactive electrochemical and mechanical mechanisms involved in IGSCC in the Al-Mg alloy 5083-H131. Significant advancements have been made to understand the electrochemical elements and kinetics of IGC in 5083-H131 [13-20]. This knowledge will be incorporated into an IGSCC framework. Literature has also identified damage mechanisms of IGSCC in Al-Mg alloys $[2,7-9,11,12]$, but work is by no means complete. Currently, the lack of mechanistic understanding of IGSCC in Al-Mg alloys limits the ability to predict crack growth in marine structures. This knowledge is necessary, not only for mitigation strategies in alloys currently employed in marine environments, but also for the development of Al-Mg alloys that are resistant to hydrogen embrittlement. 
This dissertation consists of three tasks that achieve the aforementioned research objective. The background of IGSCC in Al-Mg alloys, is provided below, followed by a review of the motivation and corresponding objective for each task.

\subsection{BACKGROUND}

Aluminum-magnesium alloys derive their strength from both cold work, and solid solution strengthening from $\mathrm{Mg}$; however, alloys containing more than 3 wt. pct. $\mathrm{Mg}$ readily precipitate an anodically active $\mathrm{Mg}$ rich $\beta$ phase $\left(\mathrm{Al}_{3} \mathrm{Mg}_{2}\right)$ along the solid solution $\mathrm{Al}-4 \% \mathrm{Mg}(\alpha)$ grain boundaries. Precipitation of $\beta$ can occur during alloy fabrication or in service during long term exposure to low temperatures in the range of $50^{\circ} \mathrm{C}$ to $175^{\circ} \mathrm{C}[1]$. The $\beta$ phase preferentially corrodes, providing an easy path for IGC and IGSCC [1]. As the volume fraction of $\beta$ increases on grain boundaries, so does the degree of sensitization (DoS) to IGC and IGSCC. The DoS is often quantified using a nitric acid mass loss test (NAMLT) based on ASTM G67 [27]. Since nitric acid selectively corrodes $\beta$, the mass loss test indicates the amount of $\beta$ dissolved as well as the separation loss of $\alpha$ grains. The increase in connectivity and coverage of grain boundary $\beta$ promotes increasingly severe mass loss and DoS [27].

For low temperature exposure (lower than $100^{\circ} \mathrm{C}$ ), $\beta$ forms as discrete grain boundary particles rather than an interconnected morphology reported for high temperature exposures $[14,19,20,28,29]$. The majority of published corrosion and stress corrosion cracking investigations on $\mathrm{Al}-\mathrm{Mg}$ alloys have focused on high temperature laboratory sensitizations (short times above $150^{\circ} \mathrm{C}$ ) $[2,4,6,7,9,12,18,26]$. Susceptibility of IGSCC in Al-Mg alloys likely depends, not only on the presence of $\beta$, but especially on the form and distribution of this phase along grain boundaries produced by specific sensitization time 
and temperature. When a connected morphology is present on the crack tip, IGSCC can propagate continuously, and presumably very rapidly along grain boundary surfaces. Whereas with discrete $\beta$ precipitation, the mechanism of crack growth between $\beta$ is more complicated. The sensitization time and temperature controlled size, spacing and morphology of $\beta$ may contribute to alternative IGSCC mechanisms [9,26]; specifically, by enhancing: 1) $\beta$ dissolution and the crack tip chemistry, 2) hydrogen embrittlement of the grain boundary region between discrete $\beta$ particles, or 3 ) the interaction of both. Investigations on the impact of $\beta$ morphologies produced at low temperatures where grain boundary coverage is mainly discontinuous are lacking, as recently reviewed by Scamans [26].

\subsubsection{Mechanism of IGSCC}

Though many studies have contributed to understanding the mechanism for IGSCC in 5xxx, the interactive roles of $\beta$ and $\mathrm{H}$ embrittlement are still debatable. There are three major theories: 1) anodic dissolution of grain boundary $\beta, 2$ ) hydrogen embrittlement of $\alpha$ $\alpha$ and $\alpha-\beta$ interfaces, and 3) depletion of $\mathrm{Mg}$ at the grain boundaries causing fracture related to highly localized plastic deformation.

\subsubsection{Anodic dissolution of $\beta$}

Highly localized anodic dissolution was proposed to cause IGSCC in three steps: 1) dissolution produces small, localized fissures along boundaries creating stress concentration points, 2) when tensile stress is high enough, cracks advance by ductile fracture, 3) the advancing crack exposes new material which undergoes significant dissolution [8]. 
Significant advancements established the electrochemical roles of $\beta$ and matrix $(\alpha)$ dissolution in both penetration and surface spreading of IGC [13-16]. Specifically, IGC penetration was characterized over a range of DoS, polarizations, and orientations [14]. These results were used to validate an electrochemically based IGC rate prediction model, which included the effects of DoS and potential $[15,16]$. The combination of these studies provides important input into understanding the governing electrochemistry changes within a growing-occluded IGSCC. The crack tip chemistry developed during IGC likely contributes to the IGSCC tip chemistry. Corrosion growth rates were modeled using dissolution rates of $\alpha$ and $\beta[15,16]$. When $\beta$ does not completely cover the grain boundaries, IGC is rate limited by the slow dissolution rate of $\alpha[15,16]$. Results suggest that a near saturated, highly acidic, crack tip chemistry is required to promote $\alpha$ dissolution and IGC, which likely contributes to IGSCC $[15,16]$. This aggressive chemistry is highly dependent on the grain boundary coverage of $\beta$; without a critical coverage, the chemistry will be neither established nor sustained $[15,16]$. These studies also illustrated that even rapid dissolution of $\beta$ is not fast enough to sustain crack growth rates measured in highly sensitized $5083[9,15,16]$. Another mechanism must interact with $\beta$ dissolution to establish the rapid crack growth rates characteristic of IGSCC.

\subsubsection{Hydrogen embrittlement}

The literature suggests that $\mathrm{H}$ plays a role in the cracking mechanism during IGSCC in Al-Mg alloys [2-6,22,30]. Several mechanisms of $\mathrm{H}$ embrittlement have been put forth for a variety of $\mathrm{Fe}, \mathrm{Ni}$, Ti and Al-based alloys [31-33]. Three mechanisms potentially relevant to $\alpha$ boundary cracking in Al-Mg alloys include: 1) $\mathrm{H}$ enhanced decohesion [2-6,22,30],

2) $\mathrm{Mg}$ segregation enhancing $\mathrm{H}$ uptake $[2,5,7,18,22,29,34-38]$, and 3) brittle hydride 
formation [2,39]. Additionally, H may impact dislocation dynamics, leading to slip localization and crack growth [31].

\subsection{Hydrogen enhanced decohesion}

Following the decohesion mechanism, grain boundary cracking occurs when the resolved local tensile stress just exceeds the intrinsic grain boundary bonding strength, which is reduced by an amount proportional to the local atomic hydrogen concentration $\left(\mathrm{C}_{\mathrm{H \sigma}}\right)[32,33]$. Figure 1.1 demonstrates this process. A high $\mathrm{H}$ concentration is developed in the crack tip electrolyte [40,41]. Hypothetically, in 5083-H131, dissolution of $\beta$ produces $\mathrm{Mg}^{2+}$ for hydrolysis, or furthers dissolution of $\alpha[15,16]$, both of which lead to significant $\mathrm{H}$ production and uptake $[22,30]$. Once absorbed, atomic $\mathrm{H}$ will accumulate at trap sites along the grain boundary, which may include $\beta$ - $\alpha$ interfaces, or at the $\alpha$ ligament between $\beta$ where the local stress may be enhanced by brittle particle constraint $[42,43]$. When a sufficient concentration of $\mathrm{H}$ diffuses to the fracture process zone, the combination of the crack tip hydrostatic stress, microstructure-scale tensile stress, and a localized $\mathrm{H}$ concentration promote $\mathrm{H}$ embrittlement of the grain boundary [32].

The effect of $\beta$ precipitates on local stress state, local hydrogen trapping, and $\mathrm{C}_{\mathrm{H \sigma}}$ are controversial in the reported literature. Danielson suggested that $\mathrm{H}$ does not trap at $\beta$ based on the lack of a characteristic time delay in current transient data measured from a standard permeation experiment [44]. Scamans et al. found that $\mathrm{H}$ permeates equally rapidly through 5083-H115 regardless of whether it is cold-rolled or sensitized at $150^{\circ} \mathrm{C}$ for $7 \mathrm{~d}$, suggesting limited $\beta$ trapping influence [35]. This is consistent with the trap affected $H$ diffusivity (DH-EFF) measured by Ai et al. in pure $\mathrm{Al}$ and 5083-H131, which demonstrated that $\mathrm{D}_{\mathrm{H}-\mathrm{EFF}}$ is independent of specimen orientation and DoS $[45,46]$. In contrast, Scully et al. reviewed 
several publications that indicated $\mathrm{H}$ trapping at particles in aluminum alloys, especially those which produce elastic tensile stress fields in the surrounding matrix [47], which $\beta$ does [29].

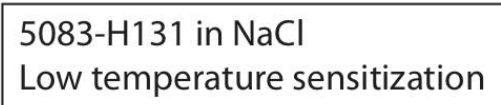

Crack Tip

$\mathrm{pH} \sim 2.0-3.0$
Loading Direction

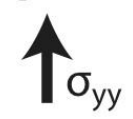

Anodic Dissolution: $\quad \quad \mathrm{Al}_{->} \mathrm{Al}^{3+}+3 \mathrm{e}^{-}$ Hydrolysis: $\quad \mathrm{Al}^{3+}+\mathrm{H}_{2} \mathrm{O}->\mathrm{H}^{+}+\mathrm{AlOH}^{3+}$

Cathodic Reactions: $\mathrm{H}_{2} \mathrm{O}+\mathrm{e}^{-}->\mathrm{OH}^{-}+\mathrm{H}$

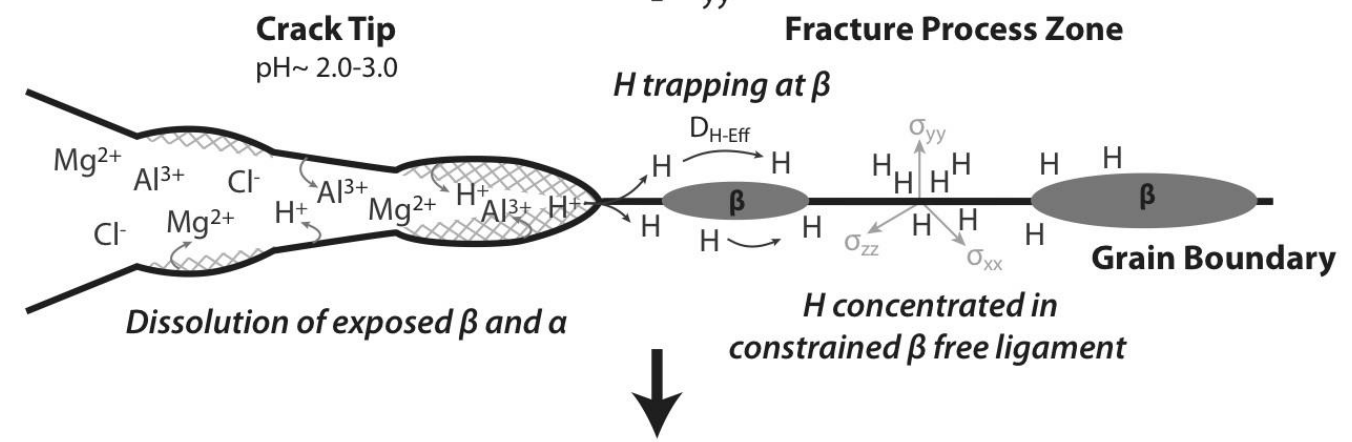

Figure 1.1 The hypothesized interaction of grain boundary $\beta$ dissolution, along the corroding crack tip front, leading to $\mathrm{H}$ production and uptake that localizes at $\beta$-matrix interfaces and $\beta$-free $\alpha$ boundary ligaments within the fracture process zone along an $\mathrm{Al}$ grain boundary surface.

\subsection{Magnesium segregation enhancing $\mathrm{H}$ uptake}

The Mg segregation mechanism was established to explain IGSCC in Al-Mg despite very small $\beta$ coverage; studies focused on distinguishing between the roles of segregated $\mathrm{Mg}$ and $\beta$ dissolution [2,22]. Dissolution of $\beta$-free $\mathrm{Mg}$-enriched grain boundaries in unsensitized specimens and/or between grain boundary $\beta$ may also occur; however, the role of $\mathrm{Mg}$ segregation is not conclusive [2,5,7,18,22,29,34-38]. Scamans et al. observed an increase in $\mathrm{Mg}$ at grain boundaries, often between $\beta$, following heat treatments at $150^{\circ} \mathrm{C}$ in high $\mathrm{Mg}$ containing binary Al-Mg alloys [35]. Magnesium segregation was thought to 
enhance $\mathrm{H}$ entry into the microstructure, though without $\mathrm{H}-\beta$ interaction the microstructure always resisted cracking [35]. Baer used Auger Electron Spectroscopy and Transmission Electron Microscopy (TEM) to show that only $\beta$ coverage, not Mg segregation, influenced cracking in Al-Mg [22]. This was later supported by Jones who showed that segregated $\mathrm{Mg}$ did not affect IGSCC [2]. Grain boundary Mg segregation was not observed in recent TEM studies of the 5083-H131 plate used in this study [29,34], and therefore is not considered as a mechanism in this work.

\subsection{Hydride formation}

Though $\beta$ is expected to catalyze IGSCC; local stress, $\mathrm{Mg}$ segregation, and $\mathrm{H}$ concentration may promote brittle $\mathrm{Mg}$ hydride formation between $\beta$ particles, which could cause grain boundary weakening [2,39]. The concurrent action of $\mathrm{H}$ and $\mathrm{Mg}$ in degrading grain boundary bonding cohesion is equally plausible. Literature continues to debate the relative importance of these two damage mechanisms [2,39]. The rapid degradation of hydrides by electron beam exposure, and a stress-sensitive solvus for hydride precipitation, complicate direct electron microscopy observation, though indirect calorimetric studies provide strong evidence for the formation of $\mathrm{Mg}$ hydrides in Al-Mg alloys [39]. Evidence of an aluminum hydride was also reported in 5083 using X-ray diffraction following $\mathrm{H}$ charging [48]. In contrast, XRD on bulk synthesized $\beta$ suggested that $\beta$ hydriding did not occur during exposure to $\mathrm{NaOH}$ [45]. A similar analysis was conducted for a range of sensitizations of 5083-H131 (of the same plate used in this study), where Al hydriding was not detected [45]. Based on these results, and paralleling interpretations of $\mathrm{H}$ embrittlement in other Al alloy systems [33,47], the influence of Al hydrides will not be considered in this work. 
Overall, understanding from the hydrogen embrittlement perspective must be merged with the direct role of $\beta$ presence and occluded crack dissolution in IGSCC propagation. Ultimately, understanding from the $\beta$-sensitive hydrogen embrittlement perspective must be merged with the direct role of $\beta$ presence and dissolution in IGSCC propagation.

\subsubsection{The role of DoS on IGSCC in the literature}

Several studies established the role of DoS through IGSCC experiments, while others characterized $\beta$ through TEM, etching-scanning electron microscopy and boundaryseparation embrittlement techniques. The combination of these results strongly indicates that $\beta$ is critical to IGSCC.

\subsubsection{Sensitization dependence in IGSCC}

Recent work focused on the role of $\beta$ in IGSCC, with fracture experiments on Al-Mg over a range of DoS levels $[2,7-9,11,12,18,19,24,49]$. Though a strong role of sensitization was established, the majority of these studies characterized IGSCC through slow strain rate tensile experiments with smooth-polished specimens, which do not separate the kinetic effects of IGC, IGSCC initiation, and IGSCC propagation [7,18,19,24,49]. Research on IGSCC propagation in the presence of a sharp pre-existing crack identified a critical DoS for severe IGSCC by quantifying SCC properties $[2,9,11]$ : the stress intensity where IGSCC initiates $\left(\mathrm{K}_{\mathrm{TH}}\right)$, and the stress intensity independent Stage II SCC growth rate (da/dt $\mathrm{dI}_{\text {II }}$. Results of this sort are critical to advance mechanistic and life prediction models.

Jones reported da/dt $/$ in recrystallized 5083-H321 and compared crack growth rates in $\mathrm{NaCl}$ for specimens sensitized at $175^{\circ} \mathrm{C}$ for $1 \mathrm{~h}$ and $100 \mathrm{~h}$ [2]. Rates increased more than 5-times in the highly sensitized condition. Though the role of sensitization was established, the very high applied stress intensity factor $(\mathrm{K})$ and limited levels of sensitization (at high 
temperature) confined the kinetics and basic interpretations used to inform mechanistic modeling that ultimately impact marine service failures.

Bovard measured da/dtII in semi-recrystallized $5083-\mathrm{H} 321$ as a function of both sensitization and precrack orientation [9]. A significant influence of DoS on IGSCC growth in 5083 exposed to $\mathrm{NaCl}$ by dropwise addition was measured for a precrack parallel to the rolling plane (growth in the $\mathrm{L}$ direction) and loaded in the short direction (S) for the S-L orientation case. Results are reproduced in Fig. 1.2. Crack growth rates increased 3 orders of magnitude to as high as $11,300 \mathrm{~nm} / \mathrm{s}$ with both increasing sensitization time and increasing temperature $\left(100^{\circ} \mathrm{C}\right.$ to $\left.175^{\circ} \mathrm{C}\right)$. Although the crucial role of sensitization was established, a critical DoS dependence versus a critical sensitization temperature dependence was not established. At relatively high DoS $\left(32 \mathrm{mg} / \mathrm{cm}^{2}\right.$ and $\left.44 \mathrm{mg} / \mathrm{cm}^{2}\right)$ a severe effect of crack orientation was demonstrated. Specimens resisted IGSCC for the L$\mathrm{T}$ case (loading in $\mathrm{L}$ and crack growth in the transverse ( $\mathrm{T}$ ) direction), while specimens failed rapidly in the S-L orientation. These results established that S-L is the most IGSCC susceptible orientation owing to an essentially in-plane crack path along elongated grains.

A final study demonstrated the low temperature sensitization dependence of $\mathrm{K}_{\mathrm{TH}}$ in the highly susceptible S-L orientation of the same lot of 5083-H131 used in the present study; results are reproduced in Fig. 1.3 [11]. Holtz used rising step loading applied to a fatigue precracked specimen fully immersed in chromate doped $\mathrm{NaCl}$ to determine $\mathrm{K}_{\mathrm{TH}}$ [11]. The threshold stress intensity decreased from $20 \mathrm{MPa} \sqrt{\mathrm{m}}$ to $2 \mathrm{MPa} \sqrt{\mathrm{m}}$ with increasing DoS near $30 \mathrm{mg} / \mathrm{cm}^{2}$, indicating a critical DoS for several sensitization temperatures [11]. The majority of the thresholds reported were measured with 5083-H131 sensitized at relatively high temperatures $\left(100^{\circ} \mathrm{C}\right.$ and $\left.175^{\circ} \mathrm{C}\right)$; the results for sensitization at $70^{\circ} \mathrm{C}$ are limited [11]. 
The incorporation of a chromate inhibitor complicates the fundamental interpretation of the results, though a critical DoS indicates that $\beta$ controls IGSCC susceptibility [11]. These data are discussed in detail in Chapter 2.

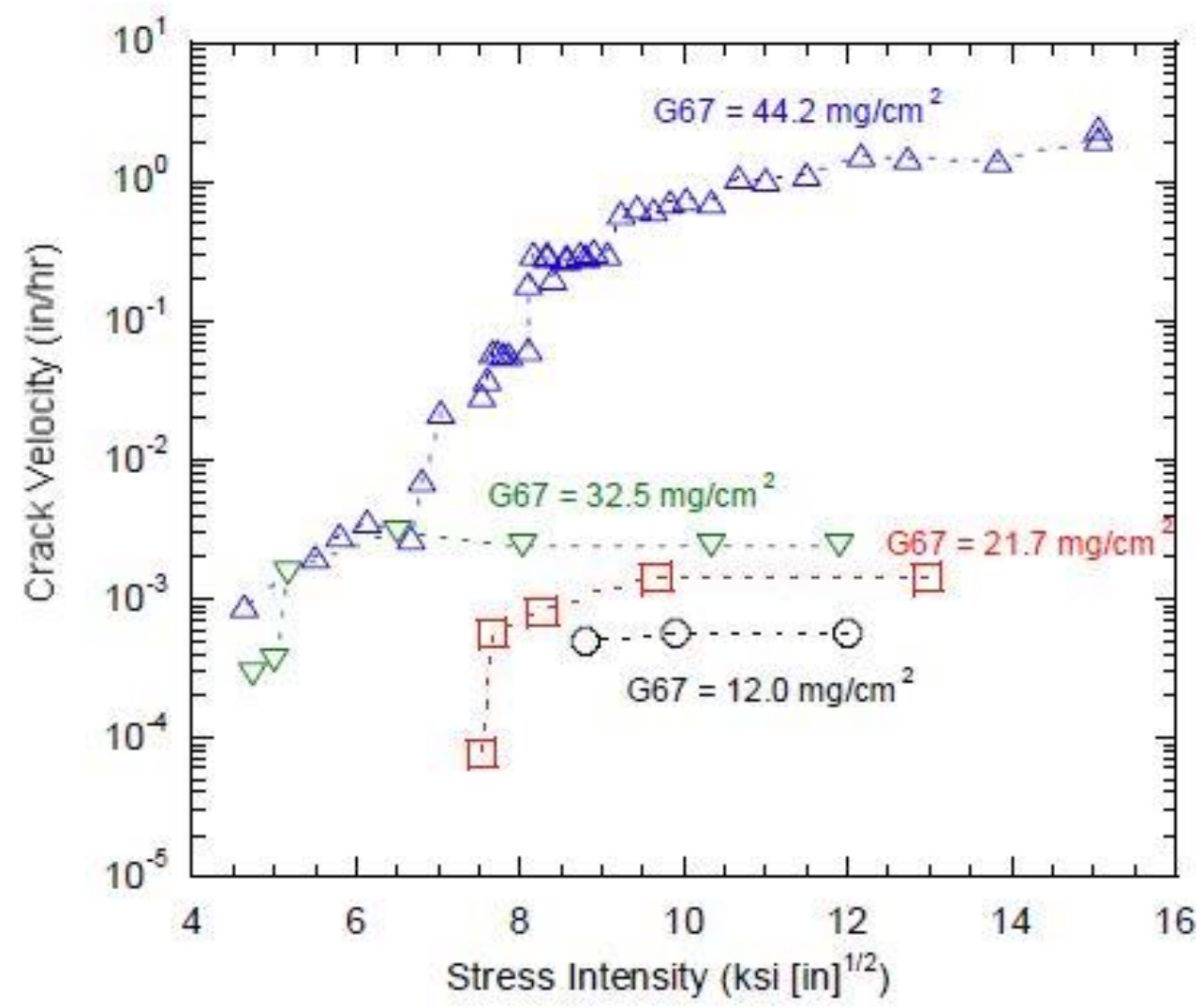

Figure 1.2 Crack growth rates as a function of stress intensity for 5083 (S-L) exposed to $\mathrm{NaCl}$ by dropwise addition, under constant crack mouth opening displacement, at various sensitizations [9]. 


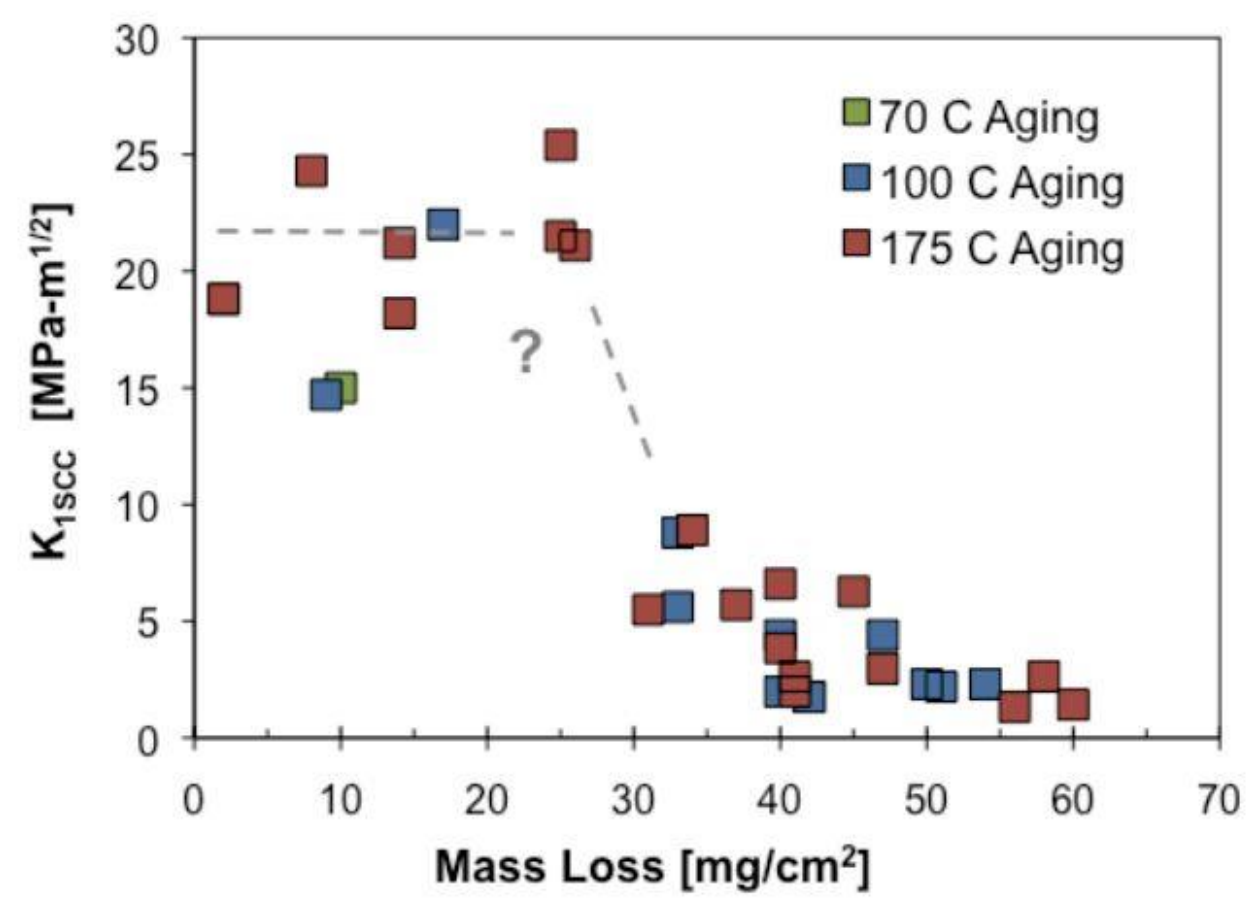

Figure 1.3 The threshold stress intensity as a function of DoS (NAMLT) for 5083$\mathrm{H} 131$ (S-L) fully immersed in chromate inhibited $\mathrm{NaCl}$ during rising-step loading [11].

\subsubsection{Characterization of $\beta$}

Several studies have characterized the distribution, morphology, and size of $\beta$ precipitates on grain boundaries of Al-Mg alloys, as a function of DoS in an effort to understand why a critical DoS is established in IGC and IGSCC. The morphology of $\beta$ indicates the connectivity or coverage of $\beta$ on the grain boundaries, and will contribute to the continuity of rapid $\beta$ dissolution and IGC. The spacing of $\beta$ is critical in that $\alpha$ dissolution between $\beta$ is rate controlling for IGC, and may compromise pit stability. The volume of $\beta$ is essential in providing a high $\mathrm{Mg}^{2+}$ concentration for hydrolysis at the fissure tip. Characterization results to date are somewhat contradictory $[28,29,50]$. These factors must be integrated with a model of crack tip damage, which governs IGSCC. 
The $\beta$ morphology on grain boundaries of 5083-H131 as a function of sensitization was investigated with TEM in several parallel studies [10,34,51]. The morphology of $\beta$ in 5083 was observed after solution heat treatment $\left(\mathrm{SHT}, 275^{\circ} \mathrm{C}\right.$ for $10 \mathrm{~h}$ ) followed by sensitization over a range of times at $70^{\circ} \mathrm{C}, 100^{\circ} \mathrm{C}$ and $175^{\circ} \mathrm{C}[10,34,51]$. Results suggested that discrete $\beta$ precipitated at short times and low temperatures, a connected "ribbon" morphology began to precipitate at mid-range times and temperatures, and a continuous- $\beta$ film formed at long times and high temperatures [10,34,51]. A map of these results is shown in Fig. $1.4[10,34,51]$. Given that TEM can only examine a limited number of specimens and areas of the microstructure, the time boundaries are approximate.

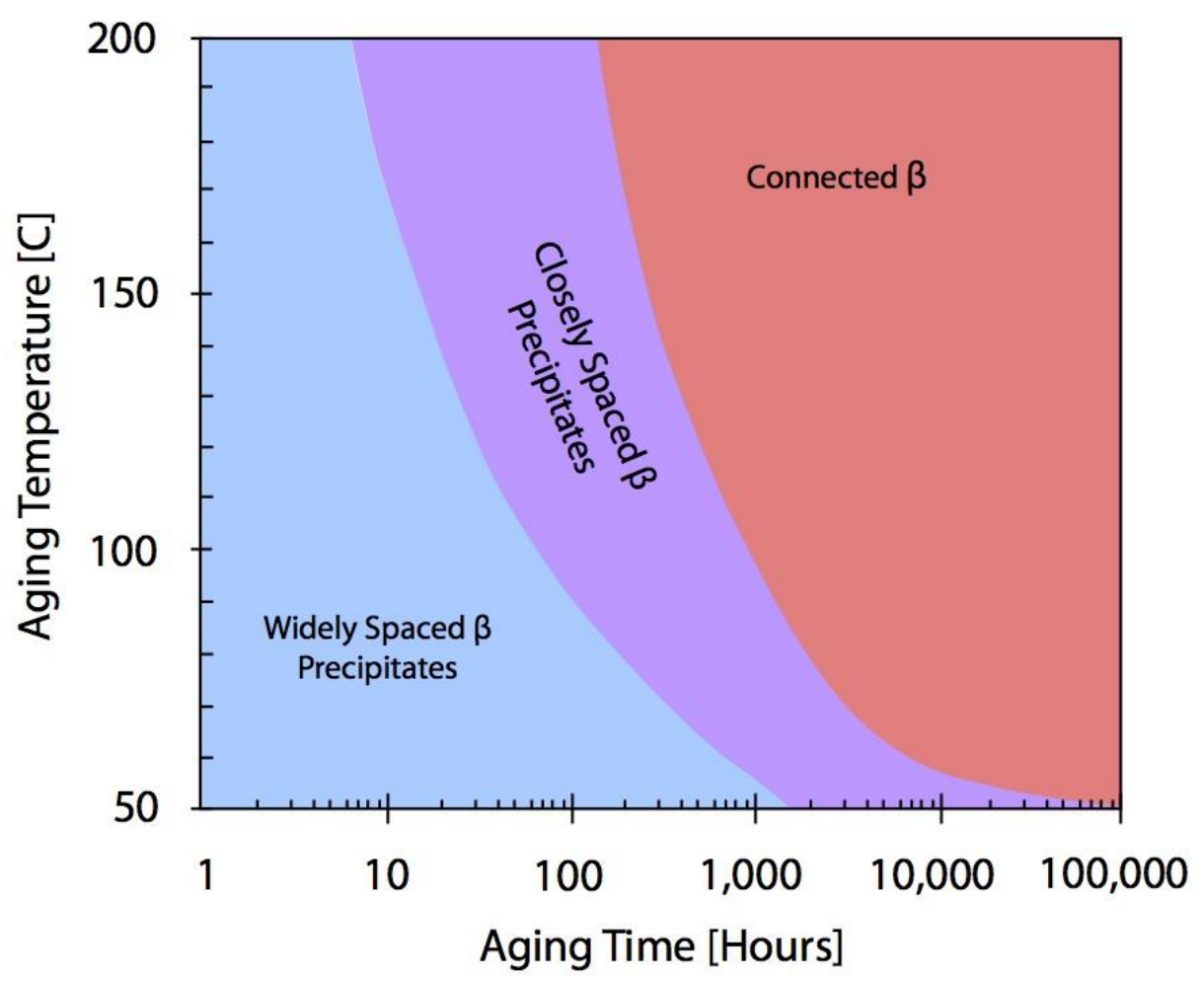

Figure 1.4 A somewhat schematic map of $\beta$ morphology as a function of aging time and temperature. The $\beta$ morphology was identified with TEM of SHT 5083-H131 sensitized at $100^{\circ} \mathrm{C}$ and non-SHT $5083-\mathrm{H} 131$ sensitized at $70^{\circ} \mathrm{C}$ and $175^{\circ} \mathrm{C}$ by Holtz et al. [10,34,51]. This is the same lot of 5083-H131 as studied in the present work. 
Scanning electron microscopy (SEM) analysis of etched $\alpha$ grain boundaries provides a valuable method to establish a quantitative distribution of $\beta$ coverage in $\mathrm{Al}-\mathrm{Mg}$ alloys $[14,19,52-54]$. Most recently, $\beta$ coverage was measured as a function of total length of grain boundaries for $5083-\mathrm{H} 131$ sensitized at $100^{\circ} \mathrm{C}$ [14]. This is the lot of $5083-\mathrm{H} 131$ plate used in the present research. Results, reproduced in Fig. 1.5 [14], demonstrate that the number of $\beta$-free grain boundaries decreases linearly with increasing sensitization. Both, the number of high coverage grains (greater than $70 \%$ coverage per grain boundary) and low coverage grains (less than $70 \%$ coverage per grain boundary), increase by about the same dependence on DoS for the relatively wide range of sensitization studied.

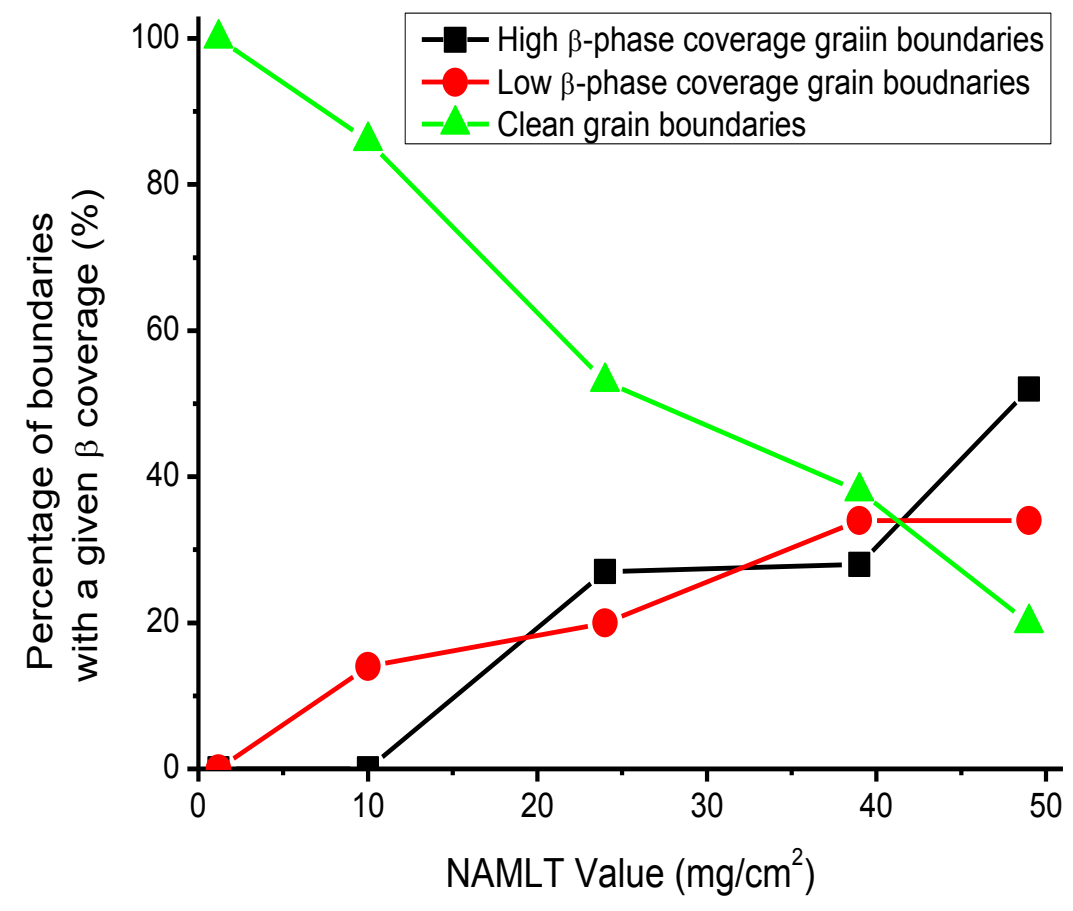

Figure 1.5 The distribution of $\beta$ coverage along grain boundaries in SHT 5083-H131 sensitized for varying times at $100^{\circ} \mathrm{C}$, reported by Lim et al. [14]. The grains were revealed with a Barker's Etch and optical imaging, while grain boundaries were deeply etched in phosphorous acid and examined for $\beta$ coverage by SEM. This is the same lot of 5083-H131 as studied in the present work. 
Finally, a three dimensional technique to characterize $\beta$ coverage on grain boundaries was developed using Ga metal embrittlement of Al grain boundaries. Grain boundaries of 5083-H131 (same lot as that used in the present study) were exposed with Ga attack to allow $\beta$ size and spacing observation with SEM. Results, reproduced in Fig. 1.6, demonstrate that the size of the $\beta$ precipitates increases with increasing sensitization at $100^{\circ} \mathrm{C}$, but the spacing remains relatively the same. Most importantly, a continuous $\beta$ morphology was not observed even at the highest sensitization studied.

\subsection{MOTIVATION}

While the combination of cracking and characterization studies is consistent with the anodic dissolution and hydrogen environment assisted crack (HEAC) growth mechanism, the independent roles of $\beta$ and $H$ were not confirmed. Grain boundary $\beta$ could contribute to crack growth by: (a) anodic dissolution, (b) H production, (c) providing a location for $\mathrm{H}$ trapping, and (d) local stress concentration.

The extent and distribution of $\beta$ dissolution at the electrolyte-crack tip surface interface, associated $\mathrm{H}$ production and uptake, local crack tip stress state, $\mathrm{H}$ trapping, and FPZ embrittlement could each change with the extent of sensitization, and therefore are essential features to characterize and understand in order to validate the electrochemical-mechanistic model of IGSCC in Al-Mg alloys. High-resolution and systematically obtained IGSCC growth rate data (specifically, da/dt $(\mathrm{K})$, da/dt $\mathrm{dI}$, and $\mathrm{K}_{\mathrm{TH}}$ ) pertinent to low temperature sensitization are required to identify interacting mechanisms. 

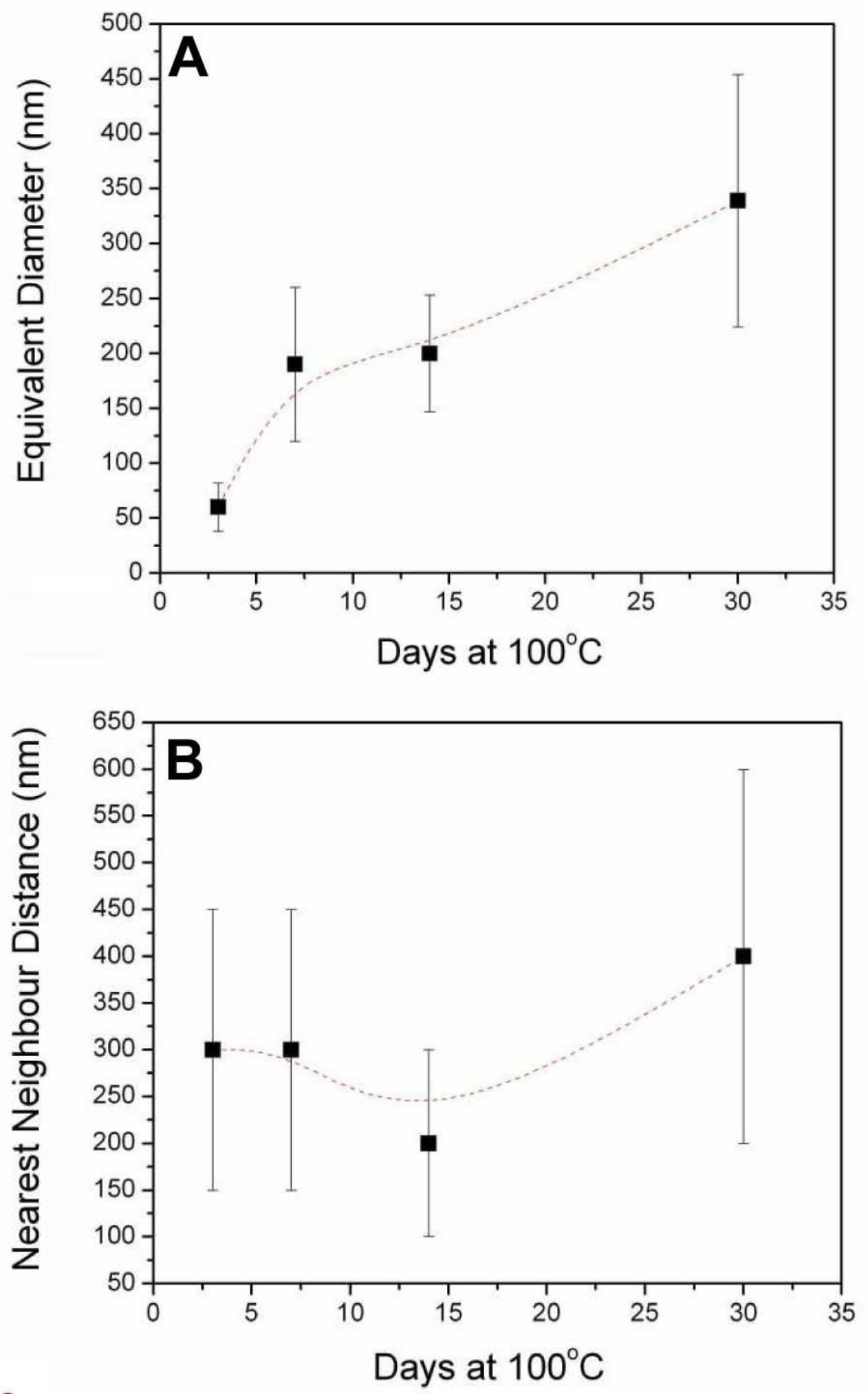

Figure 1.6 The (a) equivalent diameter and (b) nearest neighbor distance of grain boundary $\beta$ in SHT 5083-H131 exposed by Ga attack and observed with SEM imaging as a function of sensitization time at $100^{\circ} \mathrm{C}$ by Birbilis et al. [28]. 
These uncertainties are addressed through several tasks. First, quantification of sensitization dependent crack growth kinetics, in combination with $\beta$ characterization from the literature, can establish a basis for understanding the critical role of $\beta$, specifically the size, shape, or morphology required for IGSCC susceptibility. Next, electrochemical control of the occluded crack tip environment, through polarization and solution control, can distinguish the specific roles of $\beta$ dissolution and $\mathrm{H}$ embrittlement in both $\beta$-free and sensitized microstructures. These elements, crack tip electrochemistry and $\mathrm{H}$ embrittlement, can be quantitatively integrated with an existing H-diffusion based model of IGSCC kinetics. Finally, $\mathrm{H}$ charging can demonstrate the role of $\mathrm{H}$ embrittlement in the absence of electrochemical $\beta$ dissolution. This work focuses on accomplishing each of these tasks and is enabled by associated studies of IGC $[13-17,55], \quad \beta$ microstructure [11,14,20,28,29,50,53], and $\mathrm{H}$ interactions [45-47]. Most of these associated studies were on the same plate of 5083-H131 used in the present study.

\subsection{OBJECTIVES}

The objective of this research is to further understanding of the interactive electrochemical and mechanical mechanisms involved in IGSCC in the commercial Al-Mg alloy 5083-H131. Experimental results that provide high resolution and quantitative IGSCC evolution in controlled environments establish the foundation for such mechanistic understanding. Moreover, such quantitative data provide the basis for fracture mechanics modeling of the What-If impact of proposed methods to mitigate IGSCC in model component structure.

This dissertation responds to three objectives, each of which is addressed in a selfcontained chapter. The final chapter combines the conclusions from all chapters. The 
background and justification for each objective are summarized below. The S-L crack orientation is implemented to focus on the effect of crack tip electrochemical and $\mathrm{H}$ contributions to IGSCC, separate from the important and complicating effect of crack path tortuosity. The S-L orientation provides a lower bound on IGSCC resistance, which is useful in testing the benefits of potential mitigation strategies. Moreover, in terms of a fracture mechanics framework, S-L data provide a relevant starting point for engineering predictions of component IGSCC, which may involve either Mode I or mixed mode cracking depending on stress state and alloy microstructure [9]. This aspect of the IGSCC problem is not explicitly considered in the present work, but the results will none-the-less be relevant.

\subsubsection{Chapter 2: Effect of low temperature sensitization on IGSCC of 5083-H131}

The objectives of Chapter 2 are to experimentally quantify the effect of low temperature sensitization $\left(60^{\circ} \mathrm{C}\right.$ to $\left.100^{\circ} \mathrm{C}\right)$ on the kinetics of subcritical IGSCC propagation in an Al$\mathrm{Mg}$ alloy. High-resolution subcritical cracking experiments are optimized to generate IGSCC kinetics as a function of sensitization. Results incorporate characterization of $\beta$ from the literature, to establish understanding of the role of sensitization on IGSCC as a function of $\beta$ size, spacing, and morphology.

This work points to three fundamental questions:

- Does sensitization temperature impact IGSCC, apart from a single DoS dependence across multiple temperatures?

- Why is IGSCC dependent on grain boundary $\beta$ coverage embodied in DoS?

- Do results validate the hypothesized interaction of $\beta$ dissolution and crack tip $H$ embrittlement? 
This chapter is an expansion of two papers co-authored by R.P. Gangloff: a published conference proceeding [56], and a paper that is in preparation for publication.

\subsubsection{Chapter 3: Crack tip chemistry control of IGSCC in 5083-H131}

The objective of Chapter 3 is to test the proposed $\beta$ dissolution $-\mathrm{H}$ embrittlement mechanism of IGSCC by manipulation of crack tip chemistry and electrochemistry. First, the possibility of crack growth between $\beta$-free grain boundary ligaments is probed with subcritical cracking experiments that expose unsensitized Al-Mg alloys with minimal grain boundary $\beta$ to near neutral $\mathrm{NaCl}$, simulated-acidic crack tip solution, and alkaline $\mathrm{NaOH}$ producing various levels of crack tip H. Second, the role of $\beta$ dissolution was investigated with IGSCC susceptible sensitized 5083-H131 in near-neutral $\mathrm{NaCl}$ using applied polarization to promote or preclude $\beta$ and $\alpha$ breakdown.

This work answers two fundamental questions:

- Is $\beta$ dissolution required for H production and uptake?

- Can IGSCC susceptibility in sensitized 5083-H131 be eliminated with polarization?

This chapter is an expansion of two papers: a published conference proceeding with co-author R.P. Gangloff [57], and a paper that is in preparation for publication with coauthors R.P. Gangloff and R.G. Kelly.

\subsubsection{Chapter 4: Dissolution and H diffusion control of IGSCC in 5083-H131}

The objective of this chapter is to explain how the kinetics of $\beta$ dissolution, $\mathrm{H}$ uptake, and $\mathrm{H}$ diffusion in the crack tip FPZ can sustain the very fast crack growth rates measured in Chapter 2 and Chapter 3. Contributions of enhanced crack tip H concentration from $\beta$ dissolution, and the characteristics of $\mathrm{H}$ diffusion in the context of the size of crack tip FPZ 
mechanics and intra- $\beta$ ligament size, are considered in the context $\mathrm{H}$ diffusion limited Stage II crack propagation. Hydrogen charging experiments illustrate the role of sensitization on $\mathrm{H}$ embrittlement decoupled from $\beta$ dissolution, and provides a grain boundary surface for $\beta$ precipitate characterization. Two questions are put fourth:

- How are very high rates of Stage II crack growth rate sustained in sensitized Al$M g$, specifically in the context of the validated interactive $\beta$ dissolution and crack tip H embrittlement mechanism?

- How does $H$ interact with grain boundary microstructure at and between $\beta$, and how does this interaction control IGSCC kinetics through the HEAC mechanism?

This chapter is an expansion of a paper that is in press with co-author R.P. Gangloff [58]. 


\subsection{REFERENCES}

1. E.H. Dix, Jr., A. Anderson, and M.B. Shumaker: Corrosion, 1959, vol. 15, pp. 55-62.

2. R.H. Jones, D.R. Baer, M.S Danielson, and J.S. Vetrano: Metall. Mater. Trans. A, 2001, vol. 32, pp. 1699-1711.

3. R.H. Jones and M.J. Danielson: "Role of Hydrogen in Stress Corrosion Cracking of Low-Strength Al-Mg Alloys," in Corrosion 2003 Conference, NACE, Houston, TX, 2003, p. 03513.

4. R.H. Jones, J.S. Vetrano, and C.F. Windisch: Corrosion, 2004, vol. 60, pp. 1144-54.

5. R.H. Jones: JOM, 2003, vol. 55, pp. 42-46.

6. J.R. Pickens, J.R. Gordon, and J.A.S. Green: Metall. Mater. Trans. A, 1983, vol. 14, pp. 925-30.

7. J.L. Searles, P.I. Gouma, and R.G. Buchheit: Metall. Mater. Trans. A, 2001, vol. 32, pp. 2859-67.

8. J.L. Searles: "The Electrochemical Characteristics of $\mathrm{Al}_{3} \mathrm{Mg}_{2}$ and Stress Corrosion Cracking of AA5083 (Al-4.5Mg-1.0Mn)," PhD Dissertation, The Ohio State University, Columbus, OH, 2000.

9. F.S. Bovard: "Sensitization and Environmental Cracking of 5xxx Aluminum Marine Sheet and Plate Alloys," in Corrosion Marine Saltwater Environment II, D. A. Shifler, T. Tsuru, P.M. Natishan, and S. Ito, eds., ECS, Pennington, NJ, 2005, pp. 232-43.

10. R.L. Holtz, P.S. Pao, R.A. Bayles, and T.M. Longazel: "Corrosion Fatigue of A1 5083H131 Sensitized at 70, 100, and 175C and Relation to Microstructure and Degree of Sensitization," in Department of Defense 2011 Corrosion Conference, CorrDefense, NACE, Houston, TX, 2011.

11. R.L. Holtz, P.S. Pao, R.A. Bayles, T. Longazel, and R. Goswami: "Corrosion Fatigue and Stress Corrosion Cracking of Sensitized Al-Mg Structural Alloys," in Symposium on Structural Materials for Aerospace and Defense, MS\&T, Columbus, OH, 2011.

12. J. Gao and D.J. Quesnel: Metall. Mater. Trans. A, 2010, vol. 42, pp. 356-64.

13. S. Jain, M.L.C. Lim, J.L. Hudson, and J.R. Scully: Corros. Sci., 2012, vol. 59, pp. 13647.

14. M.L. Lim, R.G. Kelly, and J.R. Scully: Corrosion, 2013, vol. 69, pp. 35-47.

15. E. Bumiller: "Intergranular Corrosion in AA5XXX Aluminum Alloys with Discontinuous Precipitation at the Grain Boundaries," PhD Dissertation, University of Virginia, Charlottesville, VA, 2011.

16. E. Bumiller and R.G. Kelly: "Intergranular Corrosion in AA5xxx: A Case for Continuous Attack with a Discontinuous Active Path," in Department of Defense 2011 Corrosion Conference, CorrDefense, NACE International, Houston, TX, 2011.

17. D. Mizuno and R.G. Kelly: Corrosion, 2013, vol. 69, pp. 580-92. 
18. Y. Yuan: "Localized Corrosion and Stress Corrosion Cracking of AluminumMagnesium Alloys," PhD Dissertation, University of Birmingham, Birmingham, England, 2005.

19. A.J. Davenport, Y. Yuan, R. Ambat, B.J. Connolly, M. Strangwood, A. Afseth, and G.M. Scamans: Mater. Sci. Forum, 2010, vol. 519-521, pp. 641-46.

20. Y. Zhu, D.A. Cullen, S. Kar, M.L. Free, and L.F. Allard: Metall. Mater. Trans. A, 2012, vol. 43, pp. 4933-39.

21. I.N.A. Oguocha, O.J. Adigun, and S. Yannacopoulos: J. Mater. Sci., 2008, vol. 43, pp. 4208-14.

22. D.R. Baer, C.F. Windisch, M.H. Engelhard, M.J. Danielson, R.H. Jones, and J.S. Vetrano: J. Vac. Sci. Technol. A, 2000, vol. 18, pp. 131-36.

23. M.-S Han: Met. Mater. Int., 2008, vol. 14, pp. 203-11.

24. T. Takemoto and I. Okamoto: Trans. JWRI, 1984, vol. 13, p. 113-21.

25. M. Elboujdaini, M.T. Shehata, and E. Ghali: Microstruct. Sci., 1997, vol. 25, pp. 4149.

26. G. Scamans: "Low Temperature Sensitisation of AA5xxx Alloys," Report IR07-197, Oxon, UK, 2008.

27. ASTM Standard G67, 2004, "Standard Test Method for Determining the Susceptibility to Intergranular Corrosion of 5xxx Series Aluminum Alloys by Mass Loss After Exposure to Nitric Acid (NAMLT Test)," ASTM International, West Conshohocken, PA, 2004, DOI: 10.1520/G0067-04, www.astm.org.

28. N. Birbilis, M.L.C. Lim, A.K. Gupta, C.H.J. Davies, S.P. Lynch, R.G. Kelly, and J.R. Scully: Corrosion, 2013, vol. 69, pp. 396-402.

29. R. Goswami and R.L. Holtz: Metall. Mater. Trans. A, 2013, vol. 44, pp. 1279-89.

30. D. Tanguy, B. Bayle, R. Dif, and Th. Magnin: Corros. Sci., 2002, vol. 44, pp. 116375.

31. S.P. Lynch: "Metallographic and Fractographic Techniques for Characterizing and Understanding Hydrogen-Assisted Cracking of Metals," in Gaseous Hydrogen Embrittlement Metals in Energy Technologies, R.P. Gangloff and B.P. Somerday, eds., Woodhead Publishing Ltd., Cambridge, UK, 2012, pp. 274-339.

32. R.A. Oriani: Corrosion, 1987, vol. 43, pp. 390-97.

33. R.P. Gangloff: "Hydrogen Assisted Cracking of High Strength Alloys," in Comprehensive Structural Integrity, I. Milne, R.O. Ritchie, B. Karihaloo, J. Scott, and P. Petit, eds., Elsevier Science, New York, NY, 2003, pp. 31-101.R.

34. Goswami, G. Spanos, P.S. Pao, and R.L. Holtz: Metall. Mater. Trans. A, 2011, vol. 42, pp. 348-55.

35. G.M. Scamans, N.J.H. Holroyd, and C.D.S. Tuck: Corros. Sci., 1987, vol. 27, pp. 32947. 
36. H. Yukawa, Y. Murata, M. Morinaga, Y. Takahashi, and H. Yoshida: Acta Metall. Mater., 1995, vol. 43, pp. 681-88.

37. P. Doig and J.W. Edington: Proc. R. Soc. Lond. A.,1974, vol. 339, pp. 37-47.

38. L. Tan and T.R. Allen: Corros. Sci., 2010, vol. 52, pp. 548-54.

39. C.D.S. Tuck: "Evidence for the Formation of Magnesium Hydride on the Grain Boundaries of Al-Mg and Al-Zn-Mg Alloys During Their Exposure to Water Vapor," in Hydrogen Effects in Metals: Proceedings of the Third International Conference on Effect of Hydrogen on Behavior of Materials, I.M. Bernstein, and A.W. Thompson, eds., AIME, Warrendale, PA, 1983, pp. 503-11.

40. J. Ai, H.M. Ha, R.P. Gangloff, and J.R. Scully: Acta Mater., 2013, vol. 61, pp. 318699.

41. B. Kehler: "Modeling and Experiments to Explain the Potential Dependency of an UHSS to Hydrogen Environment Assisted Cracking," PhD Dissertation, University of Virginia, Charlottesville, VA, 2008.

42. B.P. Somerday and R.P. Gangloff: Metall. Mater. Trans. A, 1994, vol. 25, pp. 147179.

43. D.J. Lloyd: Acta Metall. Mater., 1991, vol. 39, pp. 59-71.

44. M.J. Danielson: Corros. Sci., 2002, vol. 44, pp. 829-40.

45. J. Ai, M.L. Lim, and J.R. Scully: Corrosion, 2013, DOI: http://dx.doi.org/10.5006/0987.

46. J. Ai and J.R. Scully: Corrosion, 2013, vol. 69, pp. 752-67.

47. J.R. Scully, G.A. Young, Jr., and S. Smith: "Hydrogen Embrittlement and Hydrogen Environment Embrittlement in Al Alloys," in Gaseous Hydrogen Embrittlement Metals in Energy Technologies, R.P. Gangloff and B.P. Somerday, eds., Woodhead Publishing Ltd., Cambridge, UK, 2012, pp. 707-68.

48. C.N. Panagopoulos, A.S. El-Amoush, and K.G. Georgarakis: J. Alloys Compd., 2005, vol. 392, pp. 159-64.

49. E.C. Cormack: "The Effect of Sensitization on the Stress Corrosion Cracking of Aluminum Alloy 5456," MS Thesis, Naval Postgraduate School, Monterey, CA, 2012.

50. R. Goswami, G. Spanos, P.S. Pao, and R.L. Holtz: Mater. Sci. Eng. A, 2010, vol. 527, pp. 1089-95.

51. R.L. Holtz, P.S. Pao, R.A. Bayles, T.M. Longazel, and R. Goswami: Metall. Mater. Trans. A, 2011, vol. 43, pp. 2839-49.

52. Y.-K Yang and T.R. Allen: Metall. Mater. Trans. A, 2013, DOI: 10.1016/j.corsci.2009.10.013.

53. L. Chen, D.E. Brown, X.Wang, and R.G Kelly: "Integrated Effects of Grain Boundary Characteristics on the Behavior of Intergranular Corrosion in 5xxx Alloys," in Department of Defense 2011 Corrosion Conference, NACE International, Houston, TX, 2011. 
54. L. Chen: "Image Fusion and an Outlier Detection Framework for Hierachical Modeling with Application to Corrosion Prediction," PhD Disseration, University of Virginia, Charlottesville, VA, 2013.

55. S. Jain: "Microstructural-Scale Model for Surface Spreading of Intergranular Corrosion in Sensitized Stainless Steels and Al-Mg (AA5XXX) Alloys," PhD Dissertation, University of Virginia, Charlottesville, VA, 2011.

56. C.B. Crane and R.P. Gangloff: "Stress Corrosion Cracking of Low Temperature Sensitized AA5083," in Department of Defense 2011 Corrosion Conference, NACE International, Houston, TX, 2011.

57. C.B. Crane and R.P. Gangloff: "The Effect of Applied Polarization on Stress Corrosion Cracking in Sensitized AA5083," in Department of Defense Corrosion Conference 2013, CorrDefense, NACE International, 2013.

58. C.B. Crane and R.P. Gangloff: "Dissolution and Hydrogen Diffusion Control of IGSCC in Sensitized Al-Mg Alloys," in Hydrogen Effects on Materials, B.P. Somerday and P. Sofronis, eds., ASME, New York, NY, In-Press, 2013. 


\section{CHAPTER 2}

THE EFFECT OF LOW TEMPERATURE SENSITIZATION

ON IGSCC OF 5083-H131 


\section{ABSTRACT}

The sensitization dependence of IGSCC in 5083-H131 is probed in the context of the hypothesized mechanism of coupled matrix- $\beta$ dissolution and crack tip $\mathrm{H}$ embrittlement. High resolution cracking kinetics, utilizing $\mathrm{J}$ integral and limited SEM fractographic analysis, are characterized as a systematic function of sensitization, specifically produced at low temperatures $\left(60^{\circ} \mathrm{C}\right.$ to $\left.100^{\circ} \mathrm{C}\right)$. Cracking becomes severe at relatively low degrees of sensitization (DoS), near $10 \mathrm{mg} / \mathrm{cm}^{2}$, as characterized by standard nitric acid mass loss. The threshold stress intensity $\left(\mathrm{K}_{\mathrm{TH}}\right)$ falls and subcritical crack growth rate $\left(\mathrm{da} / \mathrm{dt}_{\mathrm{II}}\right)$ rises, both as a unique function of increasing DoS in the mass loss range of $10 \mathrm{mg} / \mathrm{cm}^{2}$ to $50 \mathrm{mg} / \mathrm{cm}^{2}$. Intergranular SCC susceptibility at $10 \mathrm{mg} / \mathrm{cm}^{2}$ correlates with the onset of either a critical volume fraction of grain boundary $\beta$ coverage, or a critical level of discontinuous- $\beta$ spacing, as reported in the literature. A critical volume of $\beta$ may promote the crack tip chemistry for $\mathrm{H}$ production and uptake by dissolution, and a critical $\beta$ spacing likely favors local stress elevation or may contribute to an increase in the local $\mathrm{H}$ diffusivity ahead of the crack tip. Crack growth rates continue to increase with sensitization higher than $10 \mathrm{mg} / \mathrm{cm}^{2}$, likely due to secondary effects of $\mathrm{H}$ interaction with increasing $\beta$ volume fraction and decreasing inter- $\beta$ ligament size. Sensitization dependent IGC is measured at the fatigue crack prior to IGSCC, indicating a new method of measuring IGC. The hypothesized mechanism and IGSCC characterization database provide a means to manage stress corrosion damage in service by establishing the role of $\beta$ and a threshold sensitization level for IGSCC susceptibility. 


\subsection{NOMENCLATURE}

$a$ - crack length

$\mathrm{a}_{\mathrm{o}}$ - fatigue precrack length

$\alpha-\mathrm{Al}-4 \% \mathrm{Mg}$ (wt. pct.) solid solution matrix phase

$\alpha$-dimensionless constant in Ramberg-Osgood equation

$\mathrm{B}$ - specimen thickness

$\mathrm{b}$ - uncracked ligament of SENT specimen

$b$ - length of constrained-deformable Al between elastic particles

$\beta-\mathrm{Al}_{3} \mathrm{Mg}_{2}$ intergranular precipitate in $\mathrm{Al}-\mathrm{Mg}$ alloys

$\beta$ - non-dimensional material constant for limit load calculation

$\mathrm{C}_{\mathrm{GB} \sigma}$ - stress enhanced concentration of $\mathrm{H}$ at the grain boundary

$\mathrm{C}_{\mathrm{H} \text {-crit }}$ - critical concentration of $\mathrm{H}$ at the FPZ necessary to nucleate damage

$\mathrm{C}_{\mathrm{H} \sigma}$ - concentration of $\mathrm{H}$ in the FPZ

$\mathrm{C}_{\mathrm{i}}$ - fitting parameter for regression of each IGSCC region (e.g. IGC, I, II)

$\mathrm{C}_{\mathrm{L} \sigma}$ - stress enhanced concentration of $\mathrm{H}$ in the lattice

CMOD - crack mouth opening displacement

CT - compact tension

CTOD - crack tip opening displacement

$\mathrm{D}_{\mathrm{H}-\mathrm{EFF}}$ - trap-sensitive diffusivity of $\mathrm{H}$

DoS - degree of sensitization quantified by NAMLT

$\mathrm{d}$ - depth of the localized corrosion site

$\mathrm{da} / \mathrm{dt}$ - crack growth rate

$\mathrm{da} / \mathrm{dt}_{\mathrm{II}}$ - Stage II crack growth rate

$\mathrm{da} / \mathrm{dt}_{\mathrm{K} 15}$ - crack growth rate at $\mathrm{K}=15 \mathrm{MPa} \sqrt{\mathrm{m}}$

$\mathrm{da} / \mathrm{dt}_{\mathrm{IGC}}$ - rate of fatigue crack extension due to IGC

dcPD - direct current potential difference

$\mathrm{dK} / \mathrm{dt}$ - loading rate

$\delta$ - unit-less local stress enhancement due to constraint between elastic particles

$\mathrm{E}$ - elastic modulus

EDX - energy dispersive X-ray spectroscopy

$\mathrm{E}_{\mathrm{GB}}$ - grain boundary $\mathrm{H}$ trap binding energy

$\epsilon-$ true strain

$\epsilon_{\mathrm{o}}-\sigma_{\mathrm{o}} / \mathrm{E}$

$\mathrm{FPZ}$ - fracture process zone

$\gamma$ - cohesive strength weighting factor $(\mathrm{MPa} /$ atom fraction $\mathrm{H}$ )

$\mathrm{H}$ - atomic hydrogen

HEAC - hydrogen environment assisted cracking

$h$ - height of constraining particles

$\mathrm{h}_{\mathrm{I}}-$ elastic-plastic parameter that is a function of $\mathrm{a} / \mathrm{W}$, stress state, and $\mathrm{n}$

$\eta_{\mathrm{H}}-$ overpotential for $\mathrm{H}$ production by proton or water reduction

IGC - intergranular corrosion

IGSCC - intergranular stress corrosion cracking

$\mathrm{i}$ - dissolution current density at the localized corrosion site

$\mathrm{J}_{\text {elastic }}$ - linear elastic component of $\mathrm{J}_{\text {tot }}$

$\mathrm{J}_{\text {plastic }}$ - elastic-plastic component of $\mathrm{J}_{\text {tot }}$ 
$\mathrm{J}_{\text {tot }}-\mathrm{J}$ integral

$\mathrm{K}$ - linear elastic stress intensity

$\mathrm{K}_{\text {elastic }}$ - linear elastic stress intensity with plastic zone correction

$\mathrm{K}_{\mathrm{IC}}$ - plane strain fracture toughness

$\mathrm{K}_{\mathrm{J}}$ - elastic-plastic stress intensity

$\mathrm{K}_{\text {IIC }}$ - elastic-plastic fracture toughness

$K_{\max }$ - constant maximum stress intensity during fatigue cracking

$K_{\min }-$ constant minimum stress intensity during fatigue cracking

$\mathrm{K}_{\mathrm{TH}}$ - threshold stress intensity

$\mathrm{L}$ - longitudinal (plate rolling) direction

$\mathrm{L}-\mathrm{T}$ - crack orientation, loading in $\mathrm{L}$ and crack growth in $\mathrm{T}$ directions

$\mathrm{m}$ - cohesive strength scaling factor

NAMLT - nitric acid mass loss test per ASTM G67

$\mathrm{n}$ - strain hardening exponent

$n_{i}-$ fitting parameter for regression of each IGSCC region (e.g. IGC, I, II)

$\mathrm{OCP}$ - open circuit potential

$\mathrm{P}$ - remote applied tensile load

$\mathrm{P}_{\mathrm{o}}$ - limit load

$\mathrm{P} \epsilon-$ plane strain

$\mathrm{P} \sigma-$ plane stress

$\mathrm{R}$ - ideal gas constant

$\mathrm{R}^{2}$ - coefficient of determination for regression

$\mathrm{RH}$ - relative humidity

$\mathrm{r}_{\mathrm{PZ}}$ - radius of the plastic zone

$\mathrm{S}$ - short-transverse direction (plate thickness)

SCE - saturated calomel electrode

SENT - single edge notched tensile specimen

SEM - scanning electron microscopy

SGP - strain gradient plasticity

SHT - solution heat-treatment

$\mathrm{S}-\mathrm{L}$ - crack orientation, loading in $\mathrm{S}$ and crack growth in $\mathrm{L}$ directions

$\sigma-$ standard deviation

$\sigma^{*}-\mathrm{H}$-free grain boundary cohesive strength

$\sigma_{\mathrm{f}}-$ failure strength

$\sigma_{\mathrm{H}}-$ position dependent crack tip hydrostatic tension

$\sigma_{\text {local }}$-maximum local tensile stress midway between two constraining particles

$\sigma_{0}-$ Ramberg-Osgood reference stress, defined as true $0.2 \%$-offset yield strength

$\sigma_{\text {UTS }}$ - ultimate tensile strength

$\sigma_{\mathrm{YS}}-0.2 \%$-offset yield strength

$\sigma_{\mathrm{YS}-\mathrm{c}}-0.2 \%$-offset yield strength in compression

$\mathrm{T}-$ transverse direction (plate width)

$\mathrm{T}$ - temperature

TEM - transmission electron microscopy

$\mathrm{T}-\mathrm{L}$ - crack orientation, loading in $\mathrm{T}$ and crack growth in $\mathrm{L}$ directions

$t$ - time

$\mathrm{V}-$ potential difference 
$\mathrm{V}_{\mathrm{H}}$ - partial molar volume of $\mathrm{H}$ in $\mathrm{Al}$

$\mathrm{V}_{\mathrm{ai}}$ - dcPD measurement that corresponds to the initial crack extension

$\mathrm{V}_{\mathrm{i}}-\mathrm{dcPD}$ measurement that corresponds to the initiation of stable ductile tearing

$\mathrm{V}_{\mathrm{o}}$ - initial dcPD measurement corresponding to $\mathrm{a}_{\mathrm{o}}$

$v-$ Poisson's ratio

W - specimen width

$\mathrm{X}_{\text {CRIT }}$ - critical distance ahead of the crack tip where $\mathrm{H}$ damage nucleates 


\subsection{INTRODUCTION}

The non-heat treatable wrought Al-Mg alloy is used on modern ship structures that require light weight, moderate strength, formability, weldability, and general corrosion resistance during exposure to sea environments [1]. When the solid solution strengthening Mg content exceeds about 3 wt. pct., the alloy may become "sensitized" to intergranular corrosion (IGC) or intergranular stress corrosion cracking (IGSCC) [2]. The degree of sensitization (DoS) is controlled by the size, spacing, and morphology of the grain boundary $\beta$ phase $\left(\mathrm{Al}_{3} \mathrm{Mg}_{2}\right)[3-8]$. Precipitation of $\beta$ can occur during manufacturing or in service during extended thermal exposure $[2,8,9]$. In chloride solution, preferential dissolution of reactive $\beta$ plays a dominant role in IGC and IGSCC $[2,6,7,10-20]$. As such, the DoS is a critically important variable, which is conveniently characterized by an electrochemical mass loss measurement [6,21]. The grain shape and size are critical variables that impact cracking kinetics by dictating the intergranular path for corrosion or stress corrosion cracking $[1,6]$.

The often proposed mechanism for IGSCC in sensitized Al-Mg, specifically 5083H131 centers on grain boundary $\beta$ dissolution coupled with boundary embrittlement by atomic hydrogen $(\mathrm{H})$ [10-12,22-25]. For example, both as-received and sensitized 5083$\mathrm{H} 131$, are intrinsically embrittled by $\mathrm{H}$ following electrochemical charging with $\mathrm{H}$, even in the absence of $\beta$ dissolution, as discussed in Chapter $4[26,27]$. The role of $\beta$ dissolution was established with electrochemical studies of occluded IGC fissures in 5083-H131 exposed to chloride solutions, as discussed in Chapter $3[6,17,18]$. Results suggest a sequence of events for IGSCC by HEAC. Specifically, dissolution of $\beta$ triggers further dissolution of the Al-Mg solid solution matrix $(\alpha)[17,18]$, which leads to significant $\mathrm{H}$ 
production and uptake $[22,23]$. Once absorbed, $\mathrm{H}$ will diffuse to the fracture process zone and may localize near the undissolved grain boundary $\beta$, either at the matrix- $\beta$ interface or the hydrostatic stress field between discrete $\beta$, resulting in grain boundary decohesion [28]. Without grain boundary $\beta$, crack acidification in bulk neutral $\mathrm{NaCl}$ near OCP is insignificant; however, severe cathodic polarization was reported to increase IGSCC susceptibility in unsensitized 5083 [29]. It follows that the interaction of DoS and electrochemical potential is critical to IGSCC susceptibility [12].

The DoS and more fundamentally grain boundary $\beta$ size and spacing, along with grain size and shape relative to the stress axis, are critical metallurgical variables which impact the interaction of localized $\beta$ dissolution and $\mathrm{H}$ embrittlement that governs IGSCC in Al$\mathrm{Mg}$ alloys. Most investigations of IGSCC of Al-Mg alloys focused on high temperature exposure (above $150^{\circ} \mathrm{C}$ ), where severe sensitization occurs in relatively short times and results in a nearly continuous $\beta$ morphology along grain boundaries $[10-16,30,31]$. This $\beta$ morphology provides a near-continuous active path for severe IGSCC. Sensitization at lower temperatures and very long times typical of service $[2,20,32]$, causes discrete $\beta$ precipitation with a spacing on the order of several hundred nm [5]. With discrete $\beta$, dissolution alone will not generate IGSCC between particles; in principle the mechanism for IGSCC between active $\beta$ precipitates can be provided by HEAC [10-12]. Anodic dissolution of $\beta$-free $\mathrm{Mg}$-enriched grain boundaries may also occur; however, neither the presence nor the role of segregated $\mathrm{Mg}$ in activating $\mathrm{Al}$ corrosion has been conclusively established $[3,8,10,13,20,22,33]$.

The intergranular nature of IGSCC reinforces the importance of grain size and shape, and loading mode for cracking kinetics. Intergranular growth on elongated grains, 
specifically loaded in the S-L orientation (loading in the short-transverse, S, direction with crack growth in the rolling direction, L), maintains a simple mode I crack path, while intergranular growth in large isotropic grains (greater than $50 \mu \mathrm{m}$ in diameter) of the same loading orientation is tortuous. The literature established that the S-L orientation in an anisotropic grain structure is the most susceptible orientation for IGSCC [1].

While the dissolution-based HEAC mechanism is reasonable, and IGSCC susceptibility of Al-Mg sensitized at low temperatures is technologically important, pertinent crack growth rate data are lacking. Intergranular SCC susceptibility generally increases with increasing DoS produced at temperatures as low as $100^{\circ} \mathrm{C}$ for several commercial Al-Mg alloys stressed in $\mathrm{NaCl}$ solution $[1,11,12,14,16,34]$. However, the majority of such studies focused on sensitization temperatures above $150^{\circ} \mathrm{C}$, which either: (a) did not employ high resolution monitoring and fracture mechanics analysis of subcritical crack growth kinetics, or (b) did not separate the roles of grain boundary $\beta$ size/connectivity and grain size/shape relative to the stress axis. Growth rates for IGSCC driven by drop-wise exposure of 5083 (S-L) increased with increasing DoS (at sensitization temperatures of $100^{\circ} \mathrm{C}$ to $175^{\circ} \mathrm{C}$ ) [1]. Though valuable, these data are insufficient due to the small range of sensitization studied, and the complicated crack tip environment developed during dropwise addition limits mechanistic interpretation. Sensitization dependent crack growth rates were also reported for rolled and recrystallized 5083 (T-L) fully immersed in pure $\mathrm{NaCl}[11,12]$. Results were restricted to a very high sensitization temperature $\left(175^{\circ} \mathrm{C}\right)$, very high stress intensity $(\mathrm{K})$ levels, and did not isolate the effect of $\beta$ from grain structure-crack path $[11,12]$. A third study reported the sensitization dependence for IGSCC thresholds of 5083 (S-L) stressed under rising-step-load while 
immersed in chromate-inhibited $\mathrm{NaCl}$ solution with sensitization at temperatures as low as $70^{\circ} \mathrm{C}$ [34]. The crack electrochemistry is unique to inhibited full immersion, and is not directly relevant to typical marine environments. Crack tip passivation from chromate likely dominates crack electrochemistry, and should impact the kinetics of IGSCC in a way that is not relevant to further electrochemically-informed mechanistic interpretations of IGSCC (discussed in Chapter 3).

The distinct environmental, experimental, crack orientation/grain structure, and temper/sensitization temperature differences involved in each of these studies complicate IGSCC rate comparisons, as evidenced by the large variability in reported Stage II growth rates even for the same sensitization condition $[1,12,16,20,35]$. Reported crack growth rates are not sufficient to validate the proposed mechanism for IGSCC and associated crack chemistry modeling [24], or to enable engineering decisions regarding fitness-for-mission. Lacking are systematic investigations of the DoS dependence of IGSCC kinetics including association with $\beta$ size, spacing, and morphology characteristic of low sensitization temperatures where $\beta$ coverage is discrete on average and likely absent on some grain boundaries $[5,6,8]$.

The objectives of this research are to experimentally quantify the effect of low temperature sensitization on the kinetics of subcritical IGSCC propagation in an Al-Mg alloy, and to understand the crack tip damage mechanism. Fatigue precracked specimens are sensitized for various times at $60^{\circ} \mathrm{C}$ to $100^{\circ} \mathrm{C}$ and stressed at a slow-rising displacement rate in aqueous chloride solution at constant potential. Crack growth is continually measured with a high-resolution electrical potential technique and correlated with stress intensity factor $(\mathrm{K})$ from linear elastic and elastic-plastic analyses. Quantitative stress- 
enhanced IGC rates, threshold stress intensity $\left(\mathrm{K}_{\mathrm{TH}}\right)$ and crack growth rate $(\mathrm{da} / \mathrm{dt})$ measurements are reported as a function of DoS. These data are supplemented by fractographic analysis, which is limited by crack wake corrosion. Results are interpreted to understand the cracking mechanism, where grain boundary $\beta\left(\mathrm{Al}_{2} \mathrm{Mg}_{3}\right)$ precipitate characteristics and crack electrochemistry dominate, as well as to inform micromechanicalchemical modeling of IGSCC-HEAC threshold and growth rate properties. Experiments center on the highly susceptible S-L crack orientation in an anisotropic grain structure to isolate the effect of grain boundary $\beta$ from IGSCC path tortuosity for mechanistic interpretation. Such data provide a relevant starting point for engineering predictions of component IGSCC, which may involve either Mode I or mixed mode cracking depending on stress state and alloy microstructure [1].

\subsection{EXPERIMENTAL}

\subsubsection{Material and specimen design}

Investigation focused on a $5.7 \mathrm{~cm}$ thick plate of $5083-\mathrm{H} 131$ with the heat-specific chemical composition given in Table 2.1 [36]. The largely unrecrystallized microstructure at the relevant mid-thickness region of the as-received plate is illustrated in Fig. 2.1 [37]. Optical images were prepared with a phosphoric acid etch $\left(90 \mathrm{~s}\right.$ at $\left.55^{\circ} \mathrm{C}\right)$ of $5083-\mathrm{H} 131$ sensitized for $30 \mathrm{~d}$ at $100^{\circ} \mathrm{C}$. The etch attacks grain boundaries whether or not $\beta$ is present. The large dark features are likely constituent particles that fell out after the surrounding matrix was etched. The smaller black features within the grains are possibly small dispersoids or an etching artifact. Critically, the grain structure is highly anisotropic; the average grain size (determined with ASTM E112 [38]) at the plate center is about $200 \mu \mathrm{m}$ in $\mathrm{L}, 100 \mu \mathrm{m}$ in $\mathrm{T}$, and $30 \mu \mathrm{m}$ in $\mathrm{S}$. 
Table 2.1 Chemical composition of 5083-H131 in wt. pct. [36].

\begin{tabular}{lllllllllllll}
\hline$M g$ & $M n$ & $F e$ & $S i$ & $C r$ & $Z n$ & $T i$ & $G a$ & $P b$ & $N i$ & $C u$ & $N a$ & $A l$ \\
\hline 4.4 & 0.7 & 0.22 & 0.1 & 0.08 & 0.02 & 0.02 & 0.01 & 0.001 & 0.004 & 0.05 & 0.0001 & Bal. \\
\hline
\end{tabular}

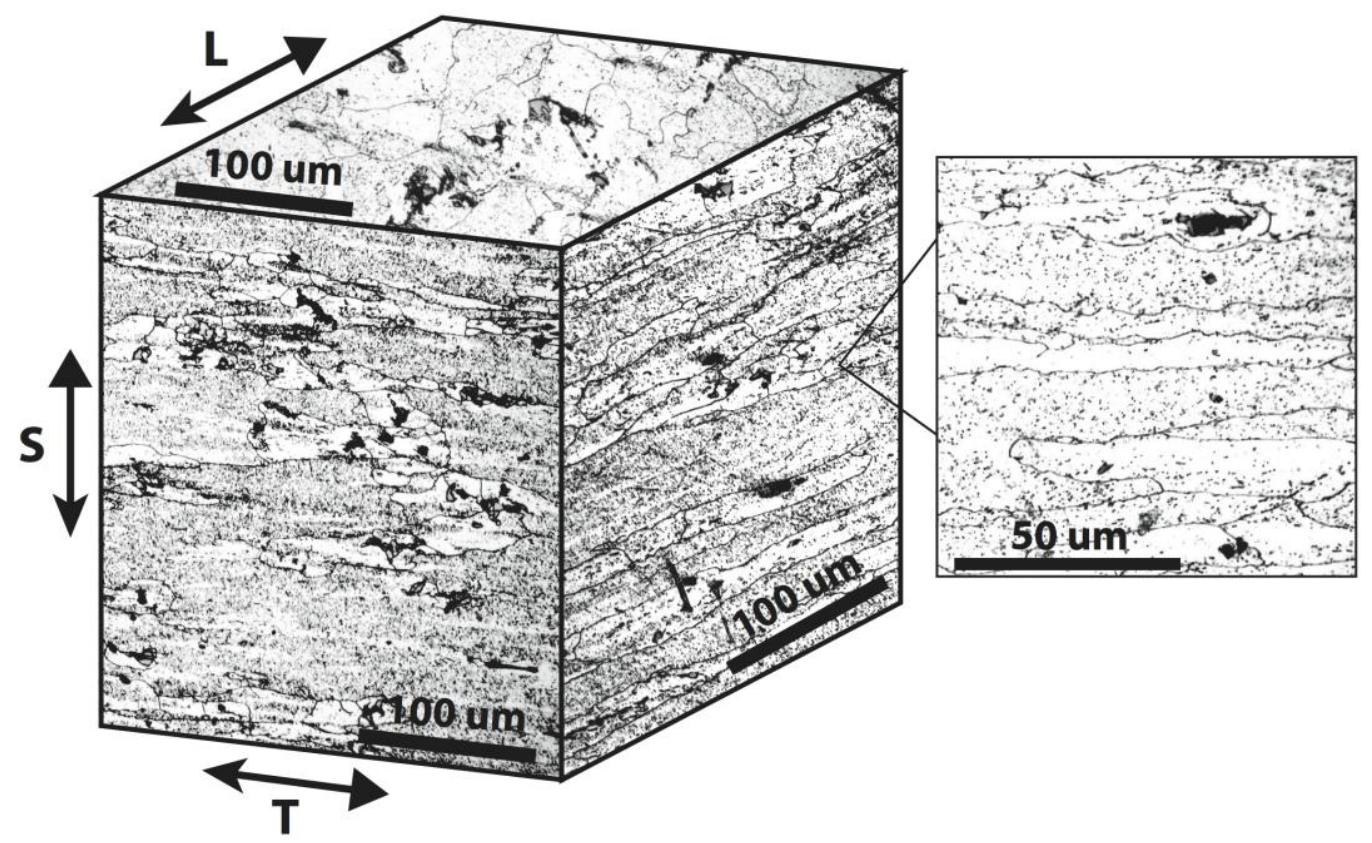

Figure 2.1 Optical images of the microstructures at the center of a $5.7 \mathrm{~cm}$ thick 5083$\mathrm{H} 131$ plate sensitized at $100^{\circ} \mathrm{C}$ for $30 \mathrm{~d}\left(50 \mathrm{mg} / \mathrm{cm}^{2}\right)$ [37]. The LS surface is shown at higher magnification.

Tensile yield strength and ultimate tensile strength, $335 \mathrm{MPa}\left(\sigma_{\mathrm{YS}}\right)$ and $353 \mathrm{MPa}\left(\sigma_{\mathrm{UTS}}\right)$ respectively, were reported in the $\mathrm{L}$ direction for the heat used in this study [36]. This measured $\sigma_{\mathrm{YS}}$ is at the upper bound of literature results for 5083-H131 (L, $175 \mathrm{MPa}$ to $337 \mathrm{MPa}$ ) [15,16,39-42], perhaps due to variability in degree of recrystallization, soluble $\mathrm{Mg}$ concentration, or resolution of yielding in a work hardening alloy. Compression testing on as-received and sensitized $\left(100^{\circ} \mathrm{C}\right.$ for $\left.175 \mathrm{~h}\right) 5083-\mathrm{H} 131$ yielded a $0.2 \%$ offset yield strength $\left(\sigma_{Y S-c}\right)$ of $259 \mathrm{MPa}$ and $264 \mathrm{MPa}$, respectively, and an elastic modulus (E) of 
70.3 $\mathrm{GPa}$ and $70.6 \mathrm{GPa}$, respectively. Flow curves measured by tensile $[40,41]$ and compression loading were fit to the Ramberg-Osgood equation [43]:

$$
\frac{\epsilon}{\epsilon_{o}}=\frac{\sigma}{\sigma_{o}}+\alpha\left(\frac{\sigma}{\sigma_{o}}\right)^{n}
$$

where $\sigma_{\mathrm{o}}$ is arbitrarily set as the true $0.2 \%$ offset yield strength, $\epsilon$ is strain, $\epsilon_{\mathrm{o}}$ is $\sigma_{\mathrm{o}} / \mathrm{E}, \mathrm{n}$ is the strain hardening exponent, and $\alpha$ is a dimensionless constant; $\mathrm{n}$ and $\alpha$ are determined from regression analysis. Ramberg-Osgood parameters were also estimated using the true yield and ultimate tensile strengths measured by Alcoa [36], as well as the true yield strength measured by Tucker et al. [40,41], and true ultimate tensile strength measured by Alcoa [36]. These parameters are compiled in Table 2.2.

Table 2.2 Ramberg-Osgood parameters for 5083-H131.

\begin{tabular}{|c|c|c|c|}
\hline Source & $\sigma_{0}(\mathrm{MPa})$ & $\boldsymbol{\alpha}$ & $\mathbf{n}$ \\
\hline Tensile, Tucker $(0.001 / s)[40,41]$ & 267 & 0.63 & 15.7 \\
\hline Compression, As-received & 259 & 0.52 & 11.6 \\
\hline Compression, Sensitized $\left(22 \mathrm{mg} / \mathrm{cm}^{2}\right)$ & 263 & 0.49 & 12.1 \\
\hline Alcoa $\sigma y s$ and $\sigma$ UTS $^{+}[36]$ & 337 & 1.40 & 16.3 \\
\hline Tucker $\sigma_{Y S}$ and Alcoa $\sigma_{U_{T S}}{ }^{+}[36,40,41]$ & 267 & 1.57 & 7.6 \\
\hline
\end{tabular}

Blanks from the as-received $5.7 \mathrm{~cm}$ thick plate were sensitized at $60^{\circ} \mathrm{C}, 80^{\circ} \mathrm{C}$, and $100^{\circ} \mathrm{C}$ for times ranging from $3 \mathrm{~d}$ to $120 \mathrm{~d}$. Susceptibility to IGC was quantitatively characterized in a parallel study by nitric acid mass loss testing (NAMLT) in accordance with ASTM International Standard G67 [6,21,44]. Nitric acid preferentially attacks grain boundary $\beta$ without significant dissolution of the Al-Mg solid solution matrix, therefore mass loss is attributed to IGC and grain fallout [1,21,45]. Data in Fig. 2.2 show that 


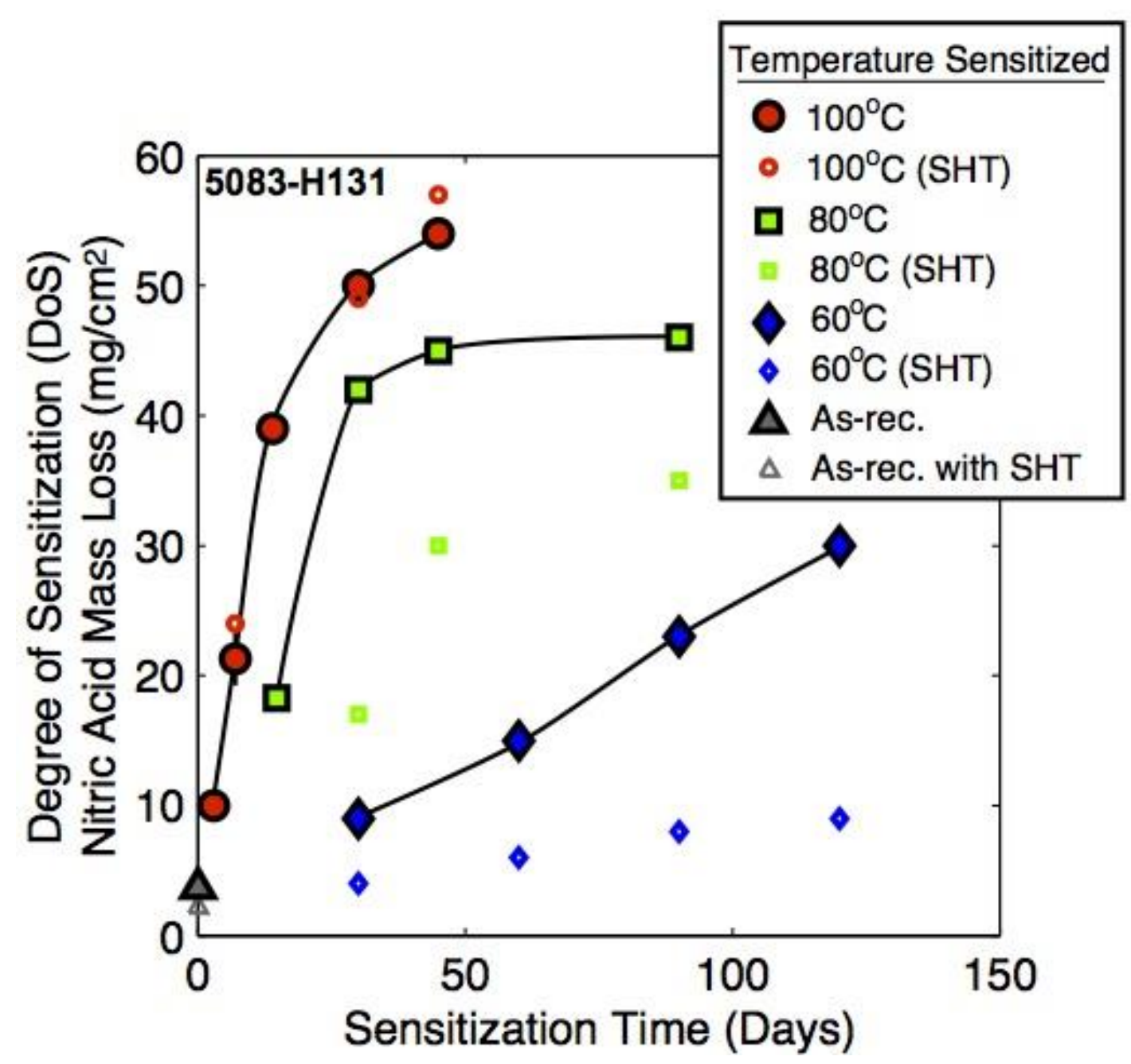

Figure 2.2 Nitric acid mass loss per ASTM G67 versus sensitization time for solution heat treated (small points) and as-received (large points) 5083-H131 plate for the timetemperature conditions examined for IGSCC susceptibility $[6,21,44]$.

NAMLT, or DoS, increases monotonically with increasing sensitization time and temperature for both the as-received plate specimens and select specimens that were solution heat treated $\left(\mathrm{SHT}, 275^{\circ} \mathrm{C} \text { for } 10 \mathrm{~h}\right)^{1}$. This additional SHT reduced NAMLT

1 ASTM G67 reports variability among six laboratories with the standard deviation $(\sigma)$ from each laboratory ranging from $5.5 \mathrm{mg} / \mathrm{cm}^{2}$ to $6.6 \mathrm{mg} / \mathrm{cm}^{2}$ for susceptible material (greater than $30 \mathrm{mg} / \mathrm{cm}^{2}$ ) [21]. In order to assure the measurements reported in Fig. 2.2 were within this variability, 14 replicate NAMLT measurements were made on the plate used in the present study, sensitized at $100^{\circ} \mathrm{C}$ for $7 \mathrm{~d}$ (without SHT). The mean DoS value was $21.5 \mathrm{mg} / \mathrm{cm}^{2}+/-2.0 \mathrm{mg} / \mathrm{cm}^{2}(+/-1 \sigma)$ [44]. 
relative to the as-received plate specimens with the same sensitization times at $60^{\circ} \mathrm{C}$ and $80^{\circ} \mathrm{C}$. All IGSCC results in this study were obtained from the as-received plate without additional SHT before sensitization. The SHT-based data in Fig. 2.2 are provided to indicate the impact of this heat treatment which is sometimes used in the literature $[6,8]$.

\subsubsection{Stress corrosion cracking}

Single edge notch tensile (SENT) specimens for fracture mechanics IGSCC testing were machined with specimen thickness (B) of $6.62 \mathrm{~mm}$, width (W) of $17.33 \mathrm{~mm}$, notch depth of $1.52 \mathrm{~mm}$ and notch-mouth opening of $0.38 \mathrm{~mm}$, shown in Fig. 2.3. The electrical discharge machined notch located IGSCC at the plate mid-plane. All specimens were fatigue precracked in moist air to a notch plus crack depth that ranged from $2.75 \mathrm{~mm}$ to $4.00 \mathrm{~mm}$ depending on specimen requirements. The fatigue crack was initiated with constant maximum stress intensity $\left(K_{\max }\right)$ of $6.5 \mathrm{MPa} \vee \mathrm{m}$, followed by decreasing $K_{\max }$ to 3.5 $\mathrm{MPa} \sqrt{\mathrm{m}}$ until the desired crack length was established. The loading frequency was $10 \mathrm{~Hz}$ and stress ratio $\left(K_{\min } / K_{\max }\right)$ was 0.10 . A $185 \mathrm{~mL}$ Plexiglas cell housed the SENT specimen under full immersion in aerated $0.6 \mathrm{M} \mathrm{NaCl}$ circulated at $30 \mathrm{~mL} / \mathrm{min}$ from a $2 \mathrm{~L}$ reservoir at ambient temperature. The $\mathrm{pH}$ of the bulk unbuffered solution was confirmed to be within $6.3 \pm 0.5$ units before and after each experiment. The round ends of the SENT specimen were O-ring sealed through the cell and attached to stainless steel grips outside of the solution to avoid galvanic coupling. A servo-electric feedback-controlled tensile machine was operated in grip displacement control provided by a single screw electromechanical actuator. Clevis-based gripping provided the free rotation necessary for the SENT elastic stress intensity $(\mathrm{K})$ solution [46]: 


$$
K=\left(\frac{P}{B W}\right) \sqrt{\pi a}\left[\sqrt{\left(\frac{2 W}{\pi a}\right) \tan \left(\frac{\pi a}{2 W}\right)} \frac{0.752+2.02\left(\frac{a}{W}\right)+0.37\left(1-\sin \left(\frac{\pi a}{2 W}\right)\right)^{3}}{\cos \left(\frac{\pi a}{2 W}\right)}\right]
$$

where $\mathrm{P}$ is the remote-applied tensile load and $a$ is crack length.

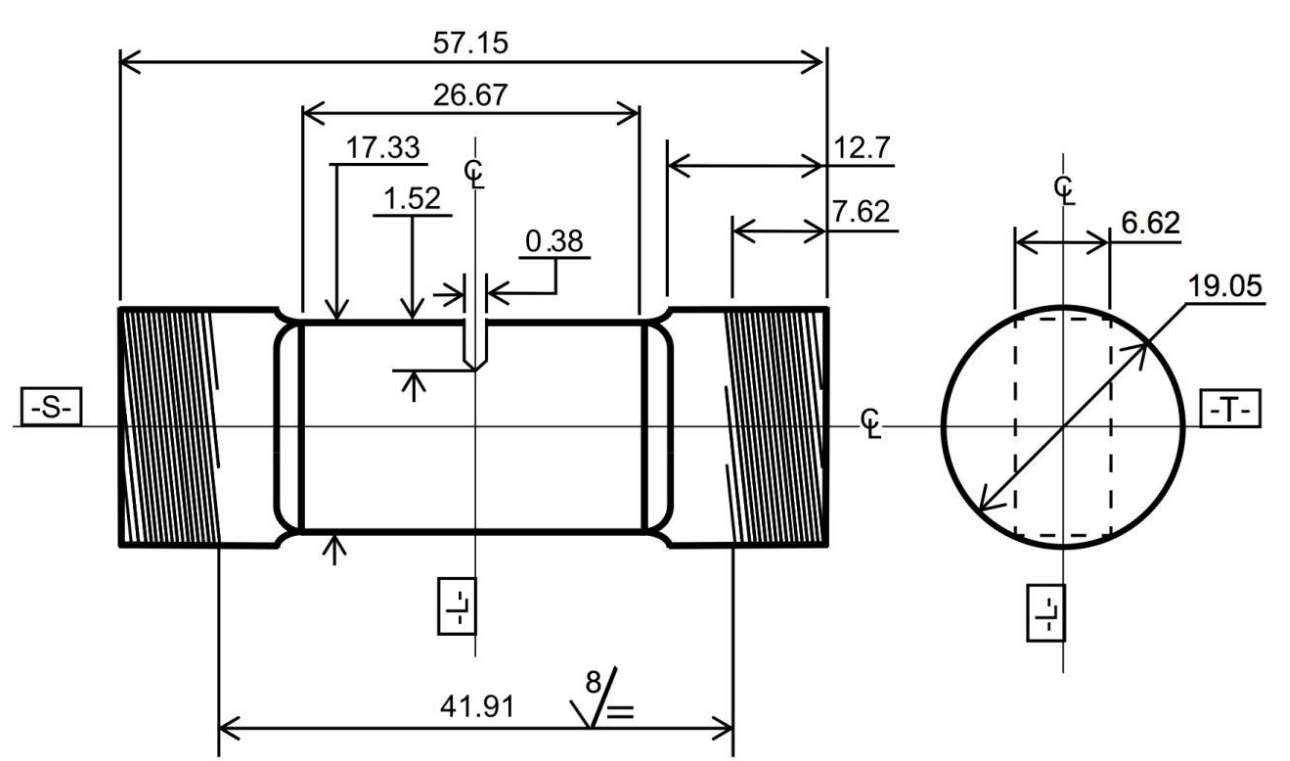

Figure 2.3 The S-L orientated SENT specimen used in stress corrosion crack growth experiments. All measurements are in $\mathrm{mm}$, and specimen length and width are parallel to the plate $\mathrm{S}$ and $\mathrm{L}$ directions, respectively.

Subcritical crack growth experiments were conducted at constant electrochemical potential of $-0.800 \mathrm{~V}$ versus saturated calomel electrode (SCE). This potential was within the range of the open circuit potential (OCP) of 5083 in $0.6 \mathrm{M} \mathrm{NaCl}$ (about $-0.750 \mathrm{~V}_{\mathrm{SCE}}$ after 1-2 $\mathrm{h}$ immersion, falling to $-0.900 \mathrm{~V}_{\mathrm{SCE}}$ with further corrosion [47]), but well above the $\beta$ breakdown potential in simulated crack tip solution (-1.015 $\mathrm{V}_{\mathrm{SCE}}$ [17]). Polarization was provided by a potentiostat electrically isolated from earth ground and attached to the working electrode (specimen), which was grounded through the mechanical test machine. The fatigue cracked specimen was preloaded to a $\mathrm{K}$ of $0.4 \mathrm{MPa} \sqrt{\mathrm{m}}$, fully immersed in $\mathrm{NaCl}$ 
at $-0.800 \mathrm{~V}_{\mathrm{SCE}}$, and stabilized for $1 \mathrm{~h}$. The specimen was then loaded under grip displacement control to $4 \mathrm{MPa} \sqrt{\mathrm{m}}$ at a displacement rate of $0.1 \mathrm{~mm} / \mathrm{min}$ and held at constant load for $10 \mathrm{~h}$. Immediately following this hold period, the specimen was loaded at a rate $(\mathrm{dK} / \mathrm{dt})$ of $0.25 \mathrm{MPa} \sqrt{\mathrm{m}} / \mathrm{h}$ until final fracture. The grip displacement rate was constant at $1.6 \times 10^{-4} \mathrm{~mm} / \mathrm{min}$ and $\mathrm{dK} / \mathrm{dt}$ was constant to the point of crack-growth initiation, than increased with crack extension. Specimen load, actuator displacement, time, crack length, and potentiostat-applied current were recorded with the data acquisition system.

\subsubsection{Crack length measurement by dcPD}

Crack length was monitored using a computer-automated direct current potential difference $(\mathrm{dcPD})$ method [48-51]. Copper wires $(0.13 \mathrm{~mm}$ diameter) were spot welded to the specimen, $1.15 \mathrm{~mm}+/-0.2 \mathrm{~mm}$ above and below the notch centerline and contacting across the specimen thickness. These wires measured the potential difference (V) across the notch and crack in conjunction with a $10.000 \mathrm{~A}$ to $12.000 \mathrm{~A}( \pm 0.0004 \mathrm{~A})$ constantcurrent source and a 20,000 gain direct-current amplifier. The potential, starting in the range of $35 \mu \mathrm{V}$ to $45 \mu \mathrm{V}$, was converted to crack length using Johnson's equation [52]. The potential measured after a 30 min stabilization during the initial load hold ( $\mathrm{K}$ between $2 \mathrm{MPa} \sqrt{\mathrm{m}}$ and $4 \mathrm{MPa} \sqrt{\mathrm{m}}$ ), defined the calibration constant, $\mathrm{V}_{\mathrm{o}}$, which corresponded to the fatigue precrack length, $a_{0}$, confirmed by scanning electron microscopy (SEM) at the conclusion of the experiment.

Several enhancements were implemented to maximize resolution and minimize long term variation in crack length from dcPD. Spurious thermoelectric potentials were eliminated by reversing the polarity of current flow [50]. Voltages were block averaged, 
where 56 voltage readings were acquired in $1 / 60^{\text {th }}$ of a second to cancel alternating current noise. This was repeated 20 times, then the current was reversed and the whole process was repeated. This total of 2240 voltage readings was averaged to constitute one recorded voltage. Voltage measurements were not affected by electrochemical polarization, and vice versa, because conflicting ground levels were avoided.

Reference probes, a second set of copper wires, were spot welded across the specimen thickness at $13.15 \mathrm{~mm} \pm 0.25 \mathrm{~mm}$ above and below the notch mouth to eliminate false crack growth due to current supply variation, global corrosion, and resistivity changes due to temperature and strain variation [50]. To affect correction at a given load, active voltage change from $V_{o}$ was normalized by the corresponding change in normalized-reference voltage [50]. Though measured far from the crack plane, reference potential increased mildly with increasing crack size, limiting reference probe correction only to formation and initial growth of the IGSCC crack up to a depth of about $4.0 \mathrm{~mm}$. Crack growth rate was calculated at a given time ( $t$ ) with a second-order polynomial fit to $a$ vs. $t$ over $t \pm 3$ or $t \pm 10$ data points, depending on the number of crack length points acquired. The slope of the tangent at the midpoint is the crack growth rate (da/dt). This process was repeated to determine da/dt at every recorded value of $a$ and associated $\mathrm{K}$.

Initial fatigue crack and final average SCC lengths were measured with the SEM (nine measurements across the crack front) for several specimens with both well-behaved and irregular crack fronts. These averages agreed within $5 \%$ of the final crack lengths calculated from dcPD. This agreement validates the quality of the dcPD measurement procedure and demonstrates a lack of crack wake electrical shorting that can degrade the accuracy of crack length measurements, particularly for IGSCC. Given this small 
difference, crack lengths measured by dcPD were not corrected based on post-test actual crack lengths.

\subsubsection{Elastic-plastic analysis}

The majority of IGSCC da/dt values were accurately described with linear-elastic stress intensity (Kelastic) for the SENT specimen (Eqn. 2.2) [46]. The contribution of plasticity was established for DoS conditions resistant to IGSCC and specimens cracked in air. An elastic-plastic analysis was performed using the $\mathrm{J}$ integral, $\mathrm{J}_{\mathrm{tot}}[43,53]$. The $\mathrm{J}_{\text {tot }}$ is composed of the sum of elastic ( $\left.\mathrm{J}_{\text {elastic }}\right)$ and plastic $\left(\mathrm{J}_{\text {plastic }}\right)$ components. The stress intensity $\left(\mathrm{K}_{\mathrm{J}}\right)$, computed to include the effect of plasticity, is:

$$
K_{J}=\left(J_{t o t} E^{\prime}\right)^{1 / 2}
$$

where the effect of global stress state is given by $\mathrm{E}^{\prime}=\mathrm{E}$ for plane stress $(\mathrm{P} \sigma)$ and $\mathrm{E} /\left(1-v^{2}\right)$ for plane strain $(\mathrm{P} \epsilon)$ with $v$ as Poisson's ratio. The elastic component of $\mathrm{J}_{\text {tot }}$ is given by:

$$
J_{\text {elastic }}=\frac{K_{\text {elastic }}^{2}}{E^{\prime}}
$$

When considering the effect of crack tip plasticity on $\mathrm{K}_{\text {elastic, }}$ it is customary to increase the physically measured crack length by the radius of the plastic zone, $\mathrm{rPZ}_{\mathrm{PZ}}$ [43]. The $\mathrm{r}_{\mathrm{PZ}}$ approximation depends on stress state, where plane strain $\mathrm{r}_{\mathrm{PZ}}$ is given by $(1 /(6 \pi))\left(\mathrm{K}_{\text {elastic }} / \sigma_{\mathrm{YS}}\right)^{2}$, and plane stress is given by $(1 /(2 \pi))\left(\mathrm{K}_{\text {elastic }} / \sigma_{\mathrm{YS}}\right)^{2}$. The effective crack length, $a+\mathrm{r}_{\mathrm{PZ}}$, was used to define $\mathrm{K}_{\text {elastic }}$ in the elastic-plastic analysis (the effective crack length is not used in linear elastic analysis).

Plastic $J_{\text {plastic }}$ can be determined from the area defined by load vs. load line or crack mouth displacement for the SENT specimen with unloading compliance calculated from dcPD crack length following developments in fracture toughness and R-curve 
characterizations $[49,54,55]$. Such displacements, however, were not measured during the current study. Rather $J_{\text {plastic }}$ was computed by an analytical approach $[43,53]$. For a rotating SENT specimen, the plastic $\mathrm{J}$ component is given by:

$$
J_{\text {plastic }}=\alpha \epsilon_{o} \sigma_{o} \frac{b a}{W} h_{1}\left(\frac{a}{W}, n\right)\left(\frac{P}{P_{o}}\right)^{n+1}
$$

where $\alpha, \sigma_{0}, \epsilon_{\mathrm{o}}$ and $\mathrm{n}$ are constants from Eqn. 2.1 and $\mathrm{b}$ is $(\mathrm{W}-a)$ [43,53]. The $\mathrm{h}_{1}$ parameter is a function of $a / \mathrm{W}$, stress state, and $\mathrm{n}$; a fourth-order polynomial was fit to the relevant $h_{1}$ vs. a/W from tabulated values $[43,53]$. The limit load, $P_{o}$, defines the full spread of plasticity though the net-cross section ahead of the crack tip and is calculated by:

$$
P_{o}=\beta\left(\sqrt{1+\left(\frac{a}{b}\right)^{2}-\frac{a}{b}}-\frac{a}{b}\right) B b \sigma_{o}
$$

where $\beta$ is 1.0 for $\mathrm{P} \sigma$ or 1.455 for $\mathrm{P} \epsilon$.

The precise stress state for cracking of the SENT specimen in the present study is uncertain, but reasonably bound by either a $\mathrm{P} \epsilon$ formulation or the average of $\mathrm{P} \epsilon$ and $\mathrm{P} \sigma$ dependent terms. Three-dimensional finite element analysis (FEA) of the SENT specimen of 5083-H131 confirmed the accuracy of this elastic-plastic analysis [56]. The refined crack tip mesh consisted of collapsed 20 node brick elements. Four contour values of $\mathrm{K}_{\mathrm{J}}$ were calculated and converged, confirming path independence of the method. The analysis was done along the crack front with $\mathrm{J}$ values dropping at either surface; values reported were taken from the mid-plane of the crack front. The Tucker and Alcoa flow parameters (Table 2.2) were used to define the flow rule for this non-linear analysis. 


\subsubsection{Fractography}

After IGSCC, several SENT specimens were fractured by tensile overload in laboratory air, ultrasonically cleaned in acetone and methanol, and then preserved under vacuum until SEM was performed. Fracture surfaces were characterized using a cold field emission electron source operated at $10 \mathrm{kV}$ to $15 \mathrm{kV}$ and a working distance between $7 \mathrm{~mm}$ and $15 \mathrm{~mm}$. In all images the crack grows from top to bottom in the $\mathrm{L}$ direction.

\subsection{RESULTS}

\subsubsection{Crack growth detection resolution}

Experiments were conducted in moist air to establish the minimum dcPD crack growth rate resolved during low $\mathrm{K}$ hold and slow rate rising $\mathrm{K}$ loading. Results are presented in Figs. 2.4 and 2.5, and provide a baseline for assessment of IGSCC in $\mathrm{NaCl}$ solution. Even with reference probe correction, time dependent dcPD signal change produced apparent crack extension at all $\mathrm{K}$ levels. An average signal change, related to an equivalent crack size change of $-0.001 \mathrm{~nm} / \mathrm{s}$, was measured when a small static $\mathrm{K}(4 \mathrm{MPa} \sqrt{\mathrm{m}})$ was applied over $20 \mathrm{~h}$, as shown by the bottom data set in Fig. 2.4 for sensitized $5083-\mathrm{H} 131\left(100^{\circ} \mathrm{C}\right.$ for $175 \mathrm{~h}, 22 \mathrm{mg} / \mathrm{cm}^{2}$ ), and replicated for an as-received 5083-H131 SENT specimen (not shown). Over the initial $5 \mathrm{~h}$ for both experiments, the average apparent growth rate was up to $+0.004 \mathrm{~nm} / \mathrm{s}$, which is used as the resolution of the dcPD measurement technique for measuring crack growth at quasi-static $\mathrm{K}$ below $5 \mathrm{MPa} \sqrt{\mathrm{m}}$. Growth measured above this limit is considered to be real precrack extension, as illustrated in Fig. 2.4 for sensitized 5083-H131 stressed at low $\mathrm{K}(4 \mathrm{MPa} \sqrt{ } \mathrm{m}$ to $6 \mathrm{MPa} \sqrt{\mathrm{m}})$ in $\mathrm{NaCl}$.

The false dcPD signal rise (even with linear reference probe correction) escalated with actively rising K, as evidenced in Figs. 2.4 and 2.5. Figure 2.4 shows acceleration in da/dt, 
to as high as about $0.4 \mathrm{~nm} / \mathrm{s}$, as $\mathrm{K}$ rose from the static level at $6.8 \mathrm{MPa} \sqrt{\mathrm{m}}$ to as high as 12.4 MPa $\sqrt{\mathrm{m}}$ at $\mathrm{dK} / \mathrm{dt}$ of $0.28 \mathrm{MPa} \sqrt{\mathrm{m}} / \mathrm{h}$. Figure 2.5 quantifies this behavior for sensitized $5083-\mathrm{H} 131\left(100^{\circ} \mathrm{C}\right.$ for $\left.175 \mathrm{~h}, 22 \mathrm{mg} / \mathrm{cm}^{2}\right)$, as well as for as-received and sensitized $\left(80^{\circ} \mathrm{C}\right.$ for $\left.45 \mathrm{~d} ; 45 \mathrm{mg} / \mathrm{cm}^{2}\right)$ microstructures, each loaded in moist air. The as-received and $22 \mathrm{mg} / \mathrm{cm}^{2}$ sensitized specimens were loaded to failure at a dK/dt between $0.28 \mathrm{MPa} \sqrt{ } / \mathrm{h}$ and-0.30 MPa $\sqrt{\mathrm{m}} / \mathrm{h}$ starting at a $\mathrm{K}$ of $6.8 \mathrm{MPa} \sqrt{\mathrm{m}}$. At $7 \mathrm{MPa} \sqrt{\mathrm{m}}$, the as-received specimen exhibited a dcPD signal indicating growth at $0.7 \mathrm{~nm} / \mathrm{s}$, which increased to $1.3 \mathrm{~nm} / \mathrm{s}$ at

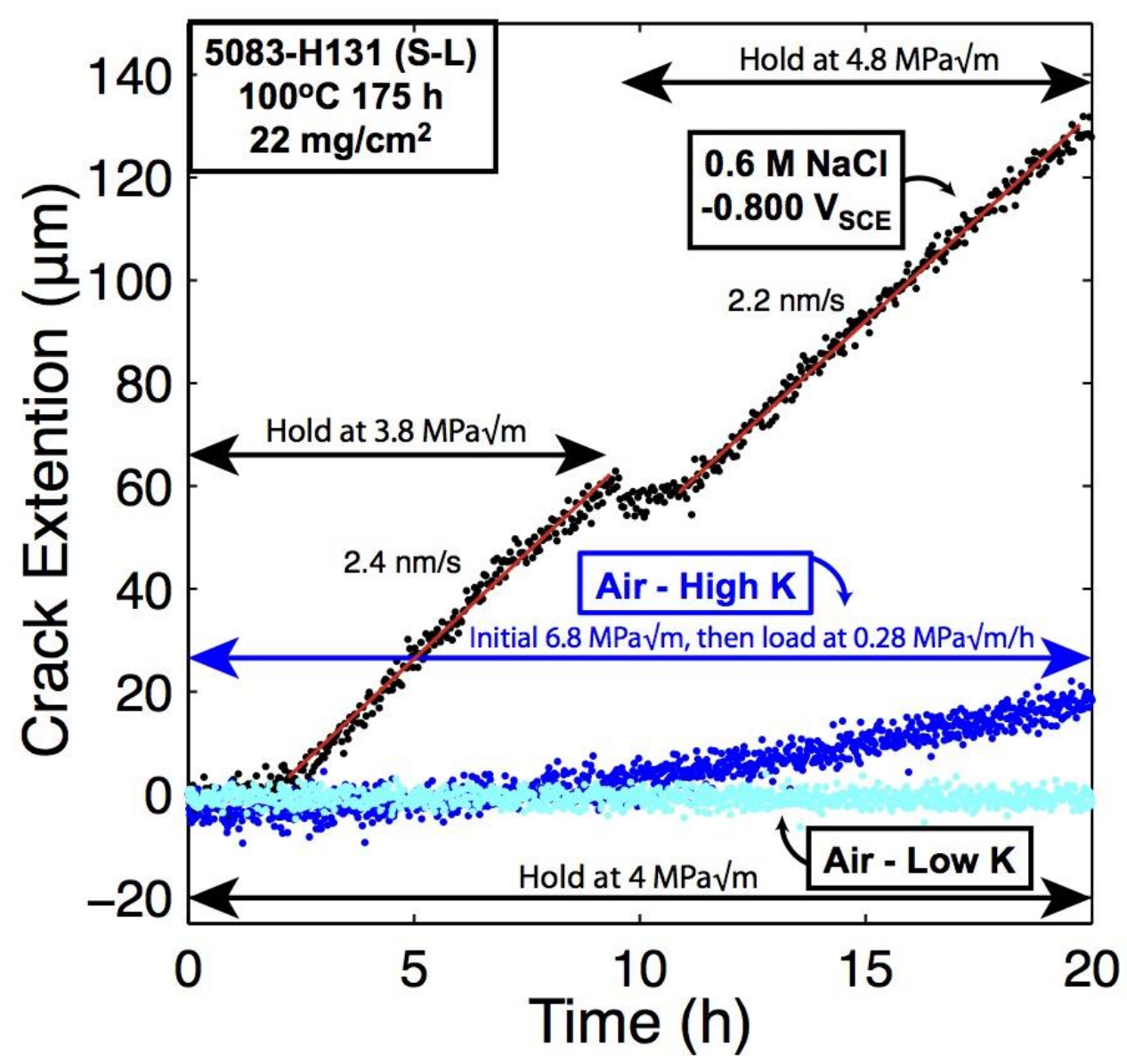

Figure 2.4 Crack extension versus time for three SENT 5083-H131 specimens sensitized at $100^{\circ} \mathrm{C}$ for $175 \mathrm{~h}\left(22 \mathrm{mg} / \mathrm{cm}^{2}\right)$, then stressed to low $\mathrm{K}$ in moist air (bottom), to high $\mathrm{K}$ in moist air (middle) or immersed in $0.6 \mathrm{M} \mathrm{NaCl}$ polarized to $-0.800 \mathrm{~V}_{\mathrm{SCE}}$ while loaded to low $\mathrm{K}$ (top). The linear regression lines for the growth measured in $\mathrm{NaCl}$ represent the steady state growth rates observed after short incubation periods. 


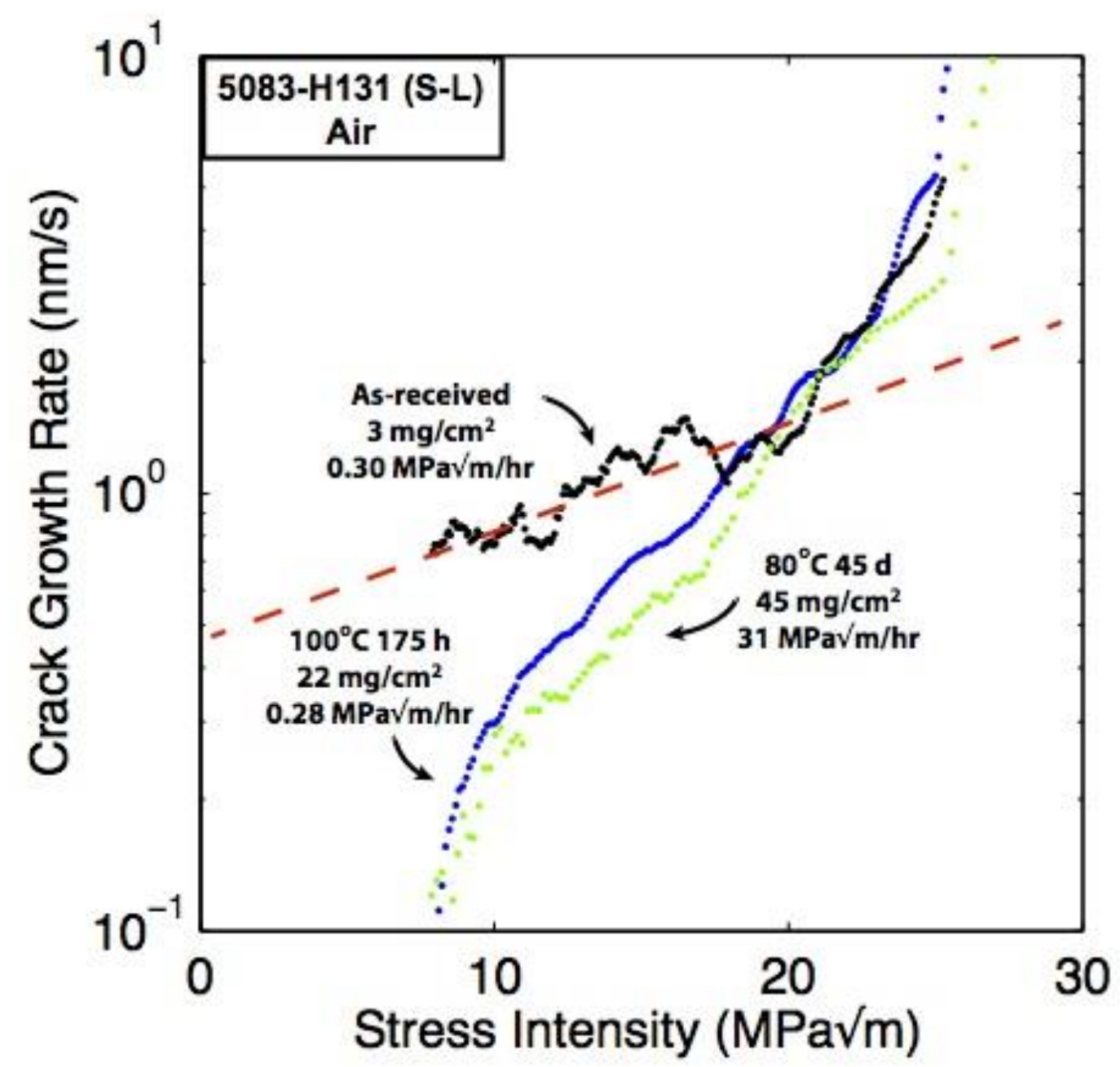

Figure 2.5 Crack growth rates measured in moist laboratory air for specimens of various sensitizations and loading rates.

$20 \mathrm{MPa} \sqrt{\mathrm{m}}$, and higher at the elastic-plastic fracture toughness (KIIC) and above (K $\mathrm{K}_{\text {IIC }}$ for as-received 5083-H131 is $21.7 \mathrm{MPa} \vee \mathrm{m}$, defined in the Section 2.5.1). The sensitized experiment yielded somewhat similar results: the average false da/dt rose from $0.11 \mathrm{~nm} / \mathrm{to}$ $2.6 \mathrm{~nm} / \mathrm{s}$ for $\mathrm{K}$ between $6 \mathrm{MPa} \sqrt{\mathrm{m}}$ and $20 \mathrm{MPa} \sqrt{\mathrm{m}}$, and even higher for $\mathrm{K}_{\mathrm{J}}$ at and above

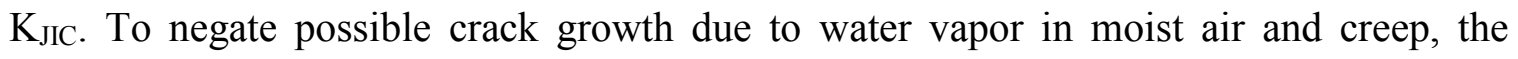
specimen sensitized at $80^{\circ} \mathrm{C}$ was loaded at a very rapid rate of $31 \mathrm{MPa} \sqrt{\mathrm{m}} / \mathrm{h}$. Apparent da/dt are comparable to those shown for as-received and $22 \mathrm{mg} / \mathrm{cm}^{2}$, once da/dt was reduced 
100-times for proper comparison to slow loading rate data. Specifically, the values of loading-rate normalized da/dt are plotted in Fig. 2.5 , and rose from $0.1 \mathrm{~nm} / \mathrm{s}$ at $8 \mathrm{MPa} \sqrt{\mathrm{m}}$ to $2.2 \mathrm{~nm} / \mathrm{s}$ at $20 \mathrm{MPa} \sqrt{\mathrm{m}}$, and continued to rise past $\mathrm{K}_{\mathrm{JIC}}$. The conservative da/dt resolution limit for interpreting IGSCC experiments is set by the fastest rates measured in air for K less than $\mathrm{K}_{\mathrm{JIC}}$, as represented by the dashed line in Fig. 2.5. The physical factors that establish the resolution limit suggested by the data in Fig. 2.5 are considered in Section 2.5.2.

\subsubsection{Fracture toughness}

Fracture toughness experiments conducted with SENT specimens were stressed in moist air at a constant-slow displacement rate producing an average $\mathrm{dK} / \mathrm{dt}$ prior to cracking of $0.29 \mathrm{MPa} \sqrt{\mathrm{m}} / \mathrm{h}$. Stable crack growth initiation was defined by the first change in slope of the linearized dcPD signal (V) vs. load-line displacement ( $\delta$ ) curve (Fig. 2.6) [49]. A least squares regression was fit to determine a baseline $\mathrm{V}-\delta$ between $0.5 \delta$ ' and $0.95 \delta$ ', where $\delta$ ' is the estimated point where $\mathrm{V}-\delta$ changes slope. The crack growth region is determined from a least squares regression fit between $1.05 \delta$ ' and $1.3 \delta$ '. The intersection of the baseline and the crack growth regression lines represents the potential at the initial crack extension $\left(\mathrm{V}_{\mathrm{ai}}\right)$ which replaces $\mathrm{V}_{\mathrm{o}}$ in Johnson's equation [52], and is associated with the fatigue crack depth $\left(a_{0}\right)$. The intersection of a $0.2 \mu \mathrm{V}$ offset (upper horizontal dashed line in Fig. 2.6) and the crack growth regression line $\left(\mathrm{V}_{\mathrm{i}}\right)$ operationally defines the initiation of stable ductile tearing $\left(\mathrm{K}_{\mathrm{JIC}}\right)$. This technique is only used to determine the initiation of stable ductile tearing in air. The critical $\mathrm{K}$ for this fracture initiation was determined by both elastic $\mathrm{K}_{\mathrm{IC}}$ and elastic-plastic $\mathrm{K}_{\mathrm{JIC}}$ analyses. 


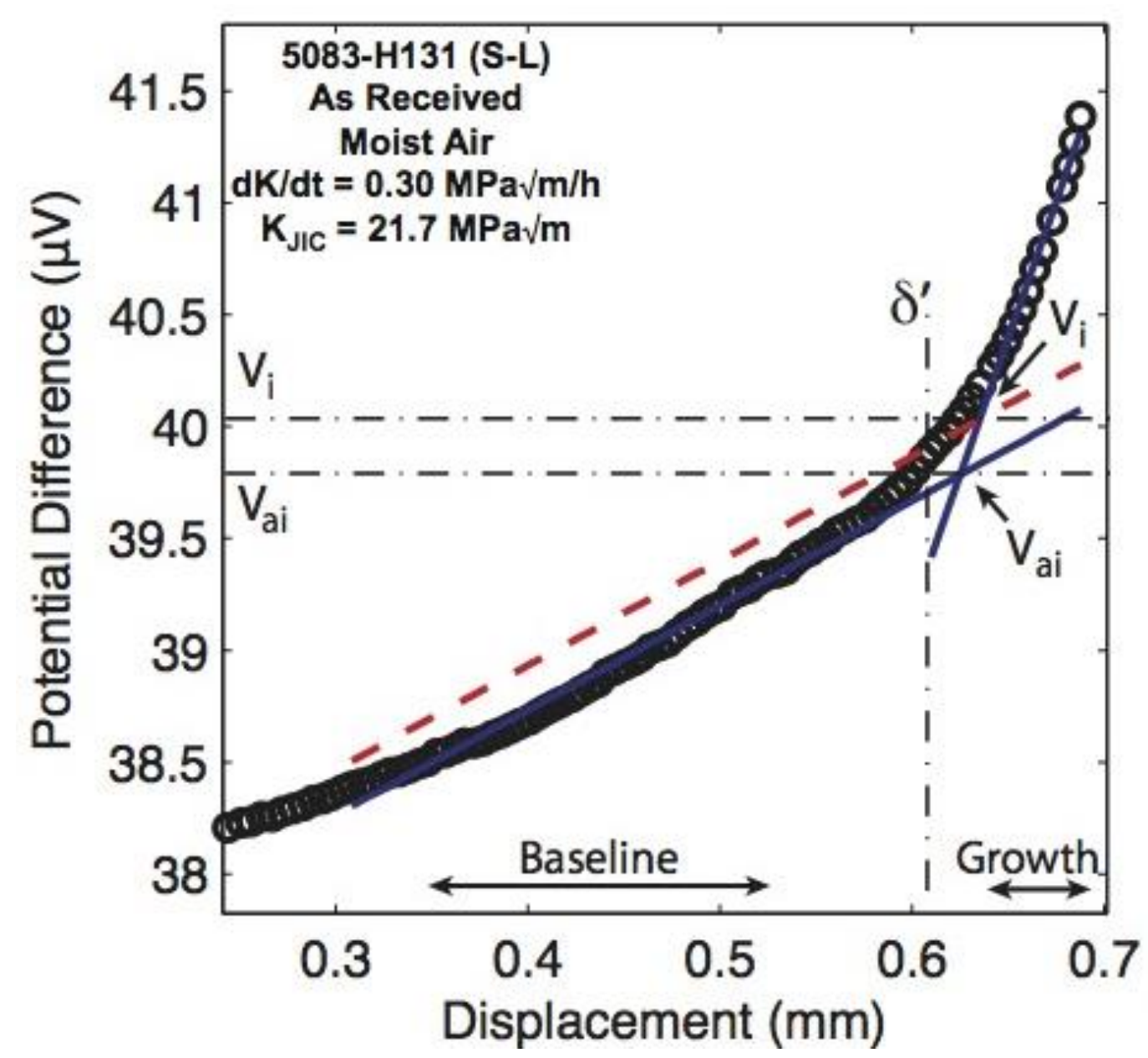

Figure 2.6 Direct current potential difference $(\mathrm{V})$ and displacement $(\delta)$ for as-received $5083-\mathrm{H} 131$ (S-L) loaded in moist air at $0.30 \mathrm{MPa} \sqrt{\mathrm{m}} / \mathrm{h}$ illustrating the method used to determine initiation fracture toughness $\left(\mathrm{K}_{\mathrm{JIC}}\right)$ [49].

The importance of the plasticity correction for stress intensity, and impact of variations in the input terms used to compute $\mathrm{K}_{\mathrm{JIC}}$ for the data in Fig. 2.6, were tested by a sensitivity analysis for as-received 5083-H131 (S-L) SENT specimens; results are shown in Table 2.3. The $\mathrm{K}_{\mathrm{JIC}}$, calculated by 3-dimensional FEA with either the Tucker or the Alcoa RambergOsgood parameters (Table 2.2), is $21.5 \mathrm{MPa} \sqrt{\mathrm{m}}$ at the initiation of stable ductile tearing [56]. Linear elastic $\mathrm{K}_{\mathrm{IC}}(19.2 \mathrm{MPa} \sqrt{\mathrm{m}}$ from Eqn. 2.2) is $13 \%$ smaller than this FEA value, demonstrating the requirement for elastic-plastic analysis. The deterministic 
$\mathrm{J}$ integral analysis (Eqns. 2.3-2.5) yielded $\mathrm{K}_{\mathrm{JIC}}$ values between $19.2 \mathrm{MPa} \sqrt{\mathrm{m}}$ and 19.7 MPa $\sqrt{\mathrm{m}}$, without a plastic zone correction to $\mathrm{K}_{\text {elastic }}$ and depending on the flow rule and stress state assumption (Table 2.3). The plastic zone correction increased this range of $\mathrm{K}_{\text {IIC }}$ to between $20.8 \mathrm{MPa} \sqrt{\mathrm{m}}$ and $22.3 \mathrm{MPa} \sqrt{\mathrm{m}}$, essentially equaling the results of the more rigorous FEA analysis. The calculated $\mathrm{K}_{\text {JIC }}(21.7 \mathrm{MPa} \sqrt{\mathrm{m}})$ closest to the FEA value (21.5 MPa $\sqrt{ }$ ) was based on averaged $\mathrm{P} \epsilon$ and $\mathrm{P} \sigma$ with a plastic zone correction to $\mathrm{K}_{\text {elastic }}$ and the flow rule defined by Tucker et al. [40,41] (Table 2.2). This combination was used to calculate elastic-plastic $\mathrm{K}_{\mathrm{J}}$ with Eqns. 2.3-2.6 for all IGSCC resistant microstructures. This result validates the use of the analytical J-integral solution for the freely rotating SENT specimen, as captured in Eqns. 2.3-2.5, and relevant to future use of this specimen in environmental cracking experiments.

Table 2.3 Sensitivity analysis of the effect of plasticity on fracture toughness of asreceived 5083-H131 loaded at $0.30 \mathrm{MPa} \sqrt{\mathrm{m}} / \mathrm{h}$ in moist air. Stress intensity equations are from Tada et al. [46]

\begin{tabular}{|c|c|c|c|c|}
\hline \multicolumn{2}{|c|}{$\begin{array}{l}\text { Critical Stress Intensity } \\
(\mathbf{M P a} \sqrt{ } \mathbf{m})\end{array}$} & $\begin{array}{l}\text { Tucker } \\
\text { } \boldsymbol{\sigma}_{\text {YS }} / \boldsymbol{\sigma}_{\text {UTS }}[40,41]\end{array}$ & $\begin{array}{l}\text { Tucker } \boldsymbol{\sigma} \text { YS/Alcoa } \\
\text { 花s } \\
{[36,40,41]}\end{array}$ & $\begin{array}{l}\text { Alcoa } \\
\sigma_{\text {YS }} / \sigma_{\text {UTS }}[36]\end{array}$ \\
\hline \multicolumn{2}{|c|}{$\begin{array}{l}\text { Finite element } \mathrm{K}_{\text {IIC }}[56] \\
\mathrm{E}^{\prime}=\mathrm{E} /\left(1-v^{2}\right)\end{array}$} & 21.5 & -- & 21.5 \\
\hline \multicolumn{2}{|c|}{ Linear elastic $\mathrm{K}_{\mathrm{IC}}$} & 19.2 & 19.2 & 19.2 \\
\hline \multirow{2}{*}{$\begin{array}{l}\text { Elastic-plastic } \\
\mathrm{K}_{\text {JIC }}\end{array}$} & $\mathrm{P} \epsilon$ & 19.2 & 19.4 & 19.2 \\
\hline & $\begin{array}{l}\text { Avg. P } \epsilon \\
\text { and } \mathrm{P} \sigma \\
\end{array}$ & 19.2 & 19.7 & 19.2 \\
\hline \multirow{2}{*}{$\begin{array}{l}\text { Elastic-plastic } \\
\text { KJIC with PZ }_{\text {correction }}\end{array}$} & $\mathrm{P \epsilon}$ & 20.4 & 20.7 & 19.9 \\
\hline & $\begin{array}{l}\text { Avg. P } \epsilon \\
\text { and Po }\end{array}$ & 21.7 & 22.3 & 20.8 \\
\hline
\end{tabular}


From this analysis, $\mathrm{K}_{\mathrm{JIC}}$ is taken to be $21.7 \mathrm{MPa} \sqrt{\mathrm{m}}$ (S-L) for as-received $5083-\mathrm{H} 131$ stressed slowly $(0.28 \mathrm{MPa} \sqrt{\mathrm{m}} / \mathrm{h})$ at room temperature in moist air. While the effect of DoS on $\mathrm{K}$ was not examined systematically, $\mathrm{K}_{\mathrm{IIC}}$ increased to $23.2 \mathrm{MPa} \sqrt{\mathrm{m}}$ following sensitization at $100^{\circ} \mathrm{C}$ for $175 \mathrm{~h}\left(22 \mathrm{mg} / \mathrm{cm}^{2}\right)$ and loading at $0.28 \mathrm{MPa} \sqrt{\mathrm{m}} / \mathrm{h}$, and to 27.5 MPa $\sqrt{\mathrm{m}}$ following sensitization at $80^{\circ} \mathrm{C}$ for $45 \mathrm{~d}\left(45 \mathrm{mg} / \mathrm{cm}^{2}\right)$ and loading at 31.0 MPa $\sqrt{\mathrm{m}} / \mathrm{h}$.

\subsubsection{Subcritical crack growth kinetics}

The S-L crack orientation of 5083-H131 is susceptible to severe IGSCC in $0.6 \mathrm{M} \mathrm{NaCl}$ when polarized to $-0.800 \mathrm{~V}_{\mathrm{SCE}}$ and after sensitization at $60^{\circ} \mathrm{C}, 80^{\circ} \mathrm{C}$, and $100^{\circ} \mathrm{C}$. Measured crack growth rates exhibit typical SCC characteristics when plotted vs. applied elastic K, but are preceded by atypical crack extension at low K levels. An example is presented in Fig. 2.7 for a specimen sensitized at $100^{\circ} \mathrm{C}$ for $175 \mathrm{~h}\left(22 \mathrm{mg} / \mathrm{cm}^{2}\right)$ then stressed in chloride solution. Slow-stable crack extension is observed at the beginning of the experiment during two load hold periods at $\mathrm{K}$ of $3.8 \mathrm{MPa} \sqrt{\mathrm{m}}$ and $4.8 \mathrm{MPa} \vee \mathrm{m}$. The measured $a-t$ during this stage of the experiment is shown in Fig. 2.4 (top). After a resolvable incubation period of $3.2 \mathrm{~h}$, slow crack growth occurred at a constant rate (da/dt $/ \mathrm{IGC})$ of $2.4 \mathrm{~nm} / \mathrm{s}$ until the load was increased to $4.8 \mathrm{MPa} \sqrt{\mathrm{m}}$ at displacement rate of $0.1 \mathrm{~mm} / \mathrm{min}$. Another short incubation $(2.3 \mathrm{~h})$ was observed after this load increase and followed by a constant growth rate of $2.2 \mathrm{~nm} / \mathrm{s}$. This low crack growth rate at fixed load $(\mathrm{K})$ is real based on the comparison with crack extension for the same sensitization loaded at low $\mathrm{K}$ in moist air (Fig. 2.4, bottom). Following the load holds, Fig. 2.7 shows that crack extension continued with slow-rising $\mathrm{K}(0.25 \mathrm{MPa} \vee \mathrm{m} / \mathrm{h})$ starting at $5 \mathrm{MPa} \sqrt{\mathrm{m}}$, with da/dt $/ \mathrm{IGC}$ of $1 \mathrm{~nm} / \mathrm{s}$ and rising to $5 \mathrm{~nm} / \mathrm{s}$ with increasing $\mathrm{K}$ approaching 10.5 MPa $\sqrt{\mathrm{m}}$. Both the environment-sensitive crack growth and 
rate increases are real compared to the da/dt resolution limit represented by the grey area in Fig. 2.7 and defined by dcPD measurement in air. Published IGSCC studies have not resolved this initial growth stage at low $\mathrm{K}$ and slow loading rate $[1,11,12,16,34]$. The growth in this regime suggests IGC within the occluded fatigue precrack, with possible stress assistance from rising $\mathrm{K}$.

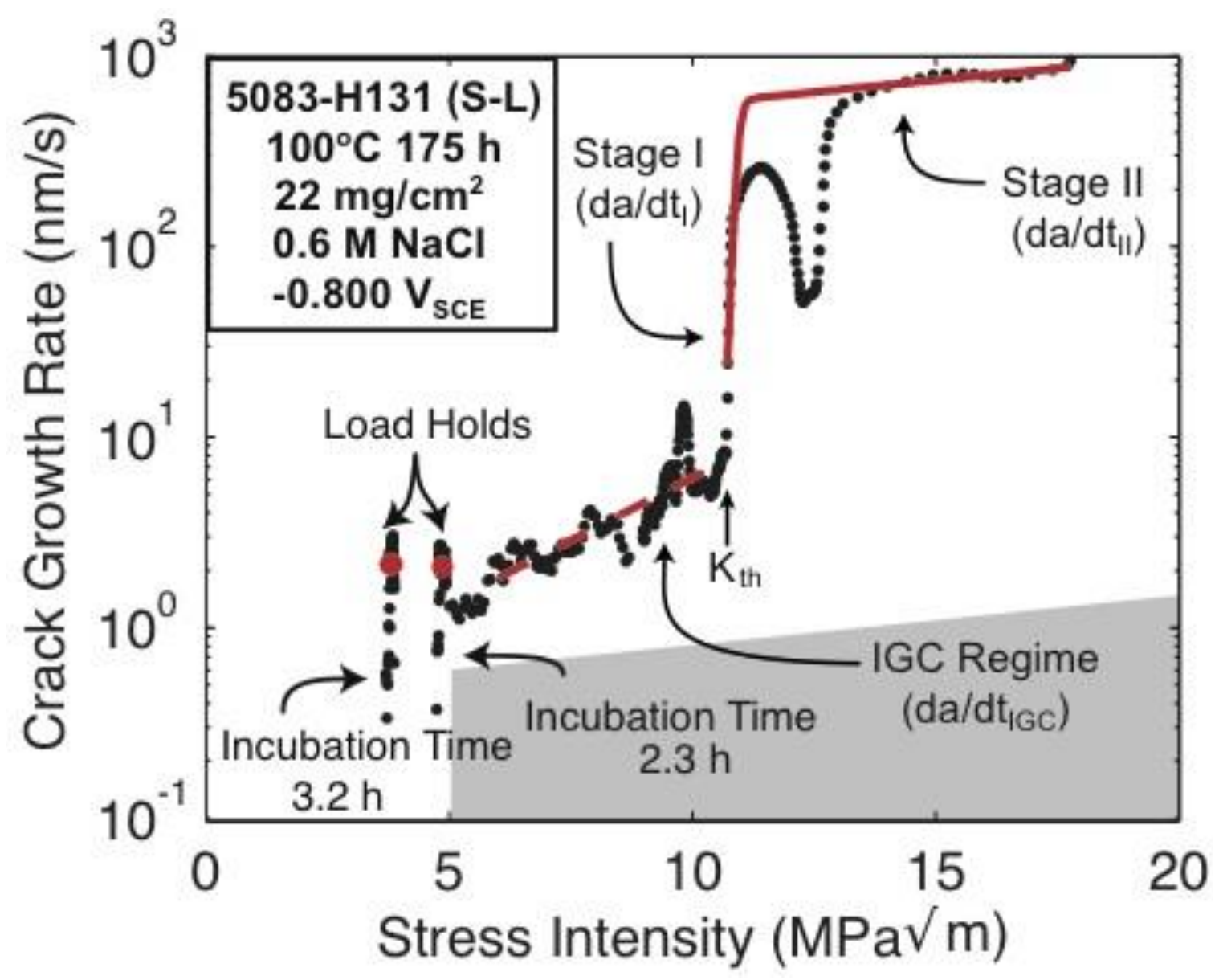

Figure 2.7 The elastic $\mathrm{K}$ dependence of subcritical crack growth rate for sensitized $5083-\mathrm{H} 131$ (S-L, $100^{\circ} \mathrm{C}$ for $175 \mathrm{~h}, \mathrm{DoS}$ of $22 \mathrm{mg} / \mathrm{cm}^{2}$ ) stressed with the constant then rising displacement protocol while immersed in $0.6 \mathrm{M} \mathrm{NaCl}$ solution at $-0.800 \mathrm{~V}_{\text {SCE. }}$. The solid lines represent exponential regression fits for each regime of crack growth. The grey region represents the resolution of dcPD measurement. 
Crack growth rate increases sharply as $\mathrm{K}$ increases, suggesting an apparent threshold stress intensity $\left(\mathrm{K}_{\mathrm{TH}}\right)$ for the onset of classic Stage I SCC. This threshold at $10.7 \mathrm{MPa} \sqrt{\mathrm{m}}$ in Fig. 2.7 is followed by a decrease in da/dt at $\mathrm{K}$ of $11.5 \mathrm{MPa} \sqrt{\mathrm{m}}$, then increase at 12.7 $\mathrm{MPa} \sqrt{\mathrm{m}}$. Such crack growth deceleration and acceleration was reproducible in replicate experiments. This transient behavior has not been reported for SCC in sensitized Al-Mg alloys $[1,11,12,16,34]$. There is uncertainty in $\mathrm{K}_{\mathrm{TH}}$ if the crack accelerates then decelerates before a resolvable Stage I behavior is sustained; all $\mathrm{K}_{\mathrm{TH}}$ defined in this study represent the initial rapid acceleration into Stage $\mathrm{I}$. The measured $\mathrm{K}_{\mathrm{TH}}$ for this sensitized specimen is much less than $\mathrm{K}_{\mathrm{JIC}}$ of $21.7 \mathrm{MPa} \sqrt{\mathrm{m}}$ to $27.5 \mathrm{MPa} \sqrt{\mathrm{m}}$ in unsensitized and sensitized specimens, establishing the occurrence of subcritical stress corrosion cracking in 5083-H131 at this DoS level. Following Stage I, crack growth reaches a maximum da/dt, which is weakly dependent on increasing $\mathrm{K}$. This region is referred to as Stage II SCC. Linear regression of $\log (\mathrm{da} / \mathrm{dt})$ vs. linear K was applied to each stage in Fig. 2.7 according to:

$$
\left(\frac{d a}{d t}\right)_{i}=C_{i} 10^{\left(n_{i} K\right)}
$$

where $C_{i}$ and $n_{i}$ are fitting parameters and $i$ represents the region (IGC, I and II). Data associated with each region were subjectively chosen, and the growth rate decelerations in Stages I and II were not included.

\subsubsection{Replicate experiments}

To establish variability in IGSCC kinetics for probabilistic assessment of component cracking life [57], multiple experiments were performed on sensitized 5083-H131 (175 h at $100^{\circ} \mathrm{C}, 22 \mathrm{mg} / \mathrm{cm}^{2}$ ) stressed in $0.6 \mathrm{M} \mathrm{NaCl}$ at $-0.800 \mathrm{~V}_{\mathrm{SCE}}$. Each experiment was 
conducted with the same loading protocol. Elastic stress intensity analysis and the regression fits of the crack growth kinetics for seven replicate tests are shown in Fig. 2.8. These results show significant variation in the IGSCC parameters for a single sensitization condition, even though the experiments were designed to minimize sources of $\mathrm{K}_{\mathrm{TH}}$ and $\mathrm{da} / \mathrm{dt}$ variability with high-resolution crack growth monitoring. The S-L crack orientation was also used to minimize the effect of grain size/shape and resulting intergranular crack path tortuosity.

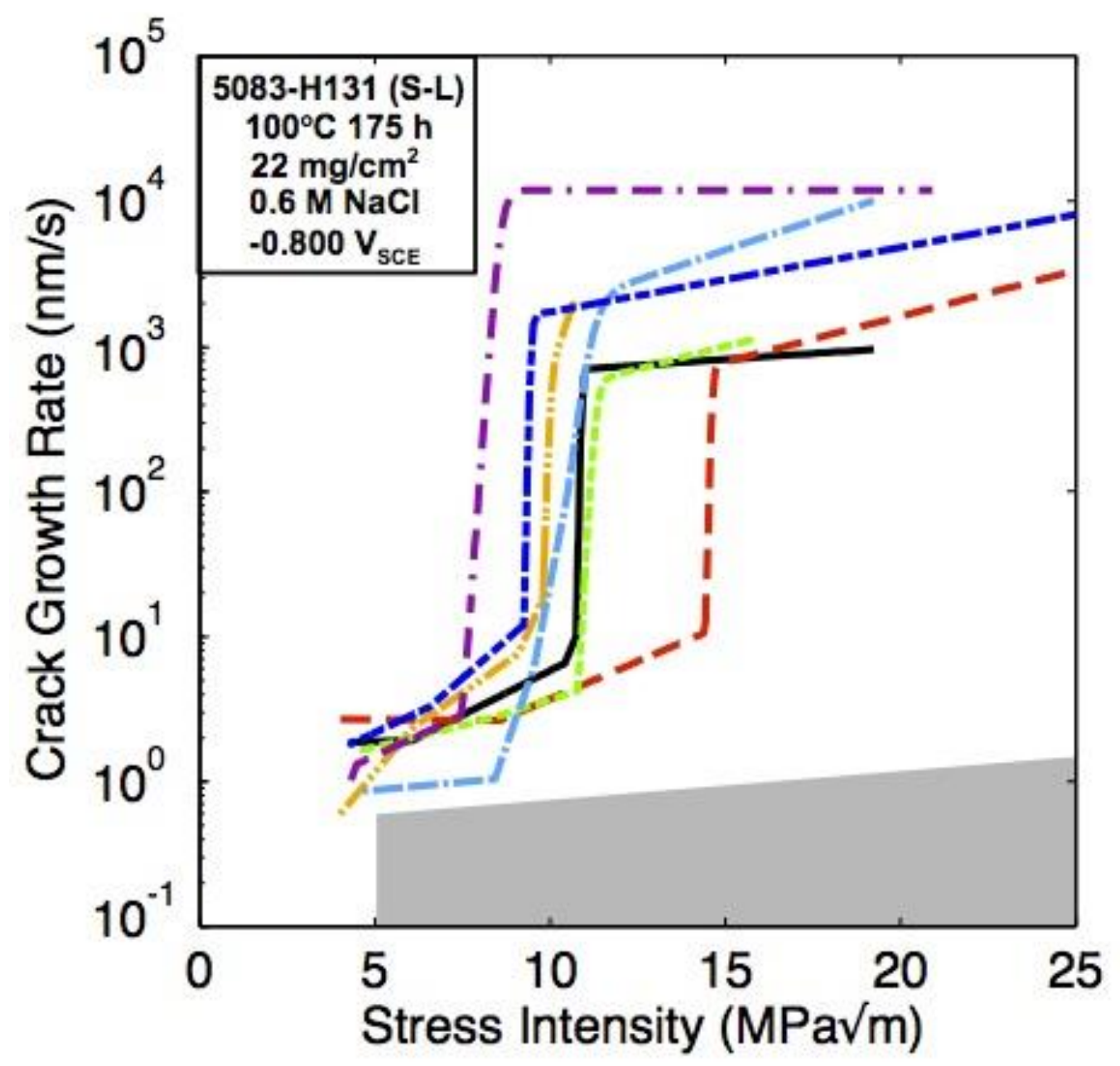

Figure 2.8 Subcritical crack growth rate versus K for seven replicate SCC experiments with the S-L orientation of $5083-\mathrm{H} 131$, sensitized for $175 \mathrm{~h}$ at $100^{\circ} \mathrm{C}\left(22 \mathrm{mg} / \mathrm{cm}^{2}\right)$ and exposed to the fixed-to-slow rising displacement protocol during immersion in $0.6 \mathrm{M}$ $\mathrm{NaCl}$ solution polarized to $-0.800 \mathrm{~V}_{\mathrm{SCE}}$. The grey box represents the resolution limit of the dcPD measurement. 
Variability is observed in all three regimes of crack extension. Significant changes in $\mathrm{da} / \mathrm{dt}_{\mathrm{IGC}}$ (between $0.8 \mathrm{~nm} / \mathrm{s}$ and $2.6 \mathrm{~nm} / \mathrm{s}$ during the hold period, and between $1 \mathrm{~nm} / \mathrm{s}$ and $9 \mathrm{~nm} / \mathrm{s}$ during initial-rising $\mathrm{K}), \mathrm{K}_{\mathrm{TH}}(8 \mathrm{MPa} \sqrt{\mathrm{m}}$ to $14 \mathrm{MPa} \sqrt{\mathrm{m}}$, with the majority of values between $9 \mathrm{MPa} \sqrt{\mathrm{m}}$ and $11 \mathrm{MPa} \sqrt{\mathrm{m}}$ ), and $\mathrm{da} / \mathrm{dt}_{\text {II }}$ (up to an order of magnitude between $10^{3} \mathrm{~nm} / \mathrm{s}$ and $10^{4} \mathrm{~nm} / \mathrm{s}$ ) are not attributable to any errant or variable condition in these replicate experiments. Rather, variability is likely derived from distributions of $\beta$ size, spacing and morphology, interacting with distributions of grain size and grain shape. Intergranular $\beta$ coverage has a large effect on crack tip chemistry, $H$ uptake, and crack tip damage evolution as considered in Section 2.5.5.3.

\subsubsection{Intergranular corrosion dependence on DoS}

Intergranular corrosion growth rate, measured during the low $\mathrm{K}$ hold period in $\mathrm{NaCl}$ solution $\left(-0.800 \mathrm{~V}_{\mathrm{SCE}}\right)$ is plotted as a function of sensitization time in Fig. 2.9 for $60^{\circ} \mathrm{C}$, $80^{\circ} \mathrm{C}$, and $100^{\circ} \mathrm{C}$. Unstressed IGC penetration rate data from metallographic cross sectioning of $5083-\mathrm{H} 131$, sensitized at $100^{\circ} \mathrm{C}\left(*\right.$, non-SHT) and $80^{\circ} \mathrm{C}(\mathrm{x}$, with SHT) are also presented in Fig. 2.9 [6]. The T-S face was boldly exposed to $0.6 \mathrm{M} \mathrm{NaCl}$ and polarized to $-0.730 \mathrm{~V}_{\mathrm{SCE}}$, causing initiation and penetration in the L-direction, which is consistent with SENT crack orientation. The dcPD recorded fatigue crack tip IGC growth rate for asreceived 5083-H131 stressed at constant load in $\mathrm{NaCl}$ solution $(0.03 \mathrm{~nm} / \mathrm{s})$ is only marginally faster than growth measured in moist air at low $\mathrm{K}(0.004 \mathrm{~nm} / \mathrm{s})$ and is therefore not represented in Fig. 2.9. The IGC rate increases with sensitization time at $100^{\circ} \mathrm{C}$ for up to $50 \mathrm{~d}$. The variability in IGC da/dt for the $100^{\circ} \mathrm{C} 175 \mathrm{~h}$ sensitization is consistent with the rapid rise in susceptibility in the early stage of sensitization. Rates of IGC for $80^{\circ} \mathrm{C}$ and 
$60^{\circ} \mathrm{C}$ sensitizations are finite, but relatively low and essentially constant for up to $90 \mathrm{~d}$ and $120 \mathrm{~d}$, respectively.

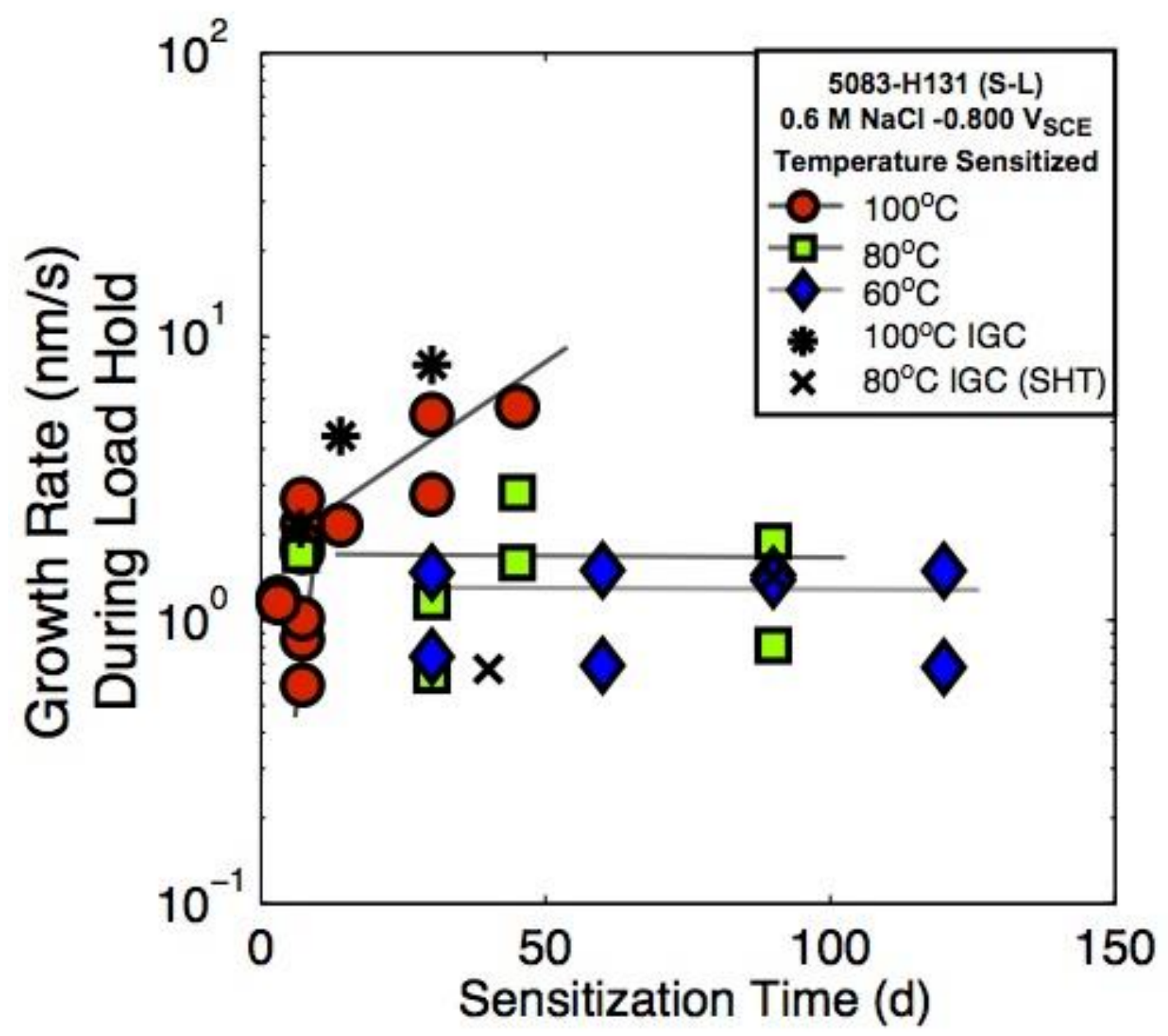

Figure 2.9 Sensitization time dependence of IGC growth rate measured during the low-K hold with $5083-\mathrm{H} 131$ immersed in $0.6 \mathrm{M} \mathrm{NaCl}$ solution at fixed potential of $-0.800 \mathrm{~V}_{\text {SCE. }}$. All rates were calculated while the specimen was held between 2.0 MPa $\sqrt{\mathrm{m}}$ and $5.0 \mathrm{MPa} \sqrt{\mathrm{m}}$. Solid lines represent estimated trends. Unstressed IGC rates for sensitizations at $80^{\circ} \mathrm{C}$ (with SHT, $\mathbf{x}$ ) and $100^{\circ} \mathrm{C}$ (non-SHT, *) were measured by Lim et al. $[6,44]$.

The IGC growth rate data in Fig. 2.9 are replotted in Fig. 2.10 as a function of DoS measured with NAMLT. Overall, this standardized DoS measurement provides a single 
parameter that reasonably collapses the effects of three different sensitization temperatures to a single time dependence. The variability of the $100^{\circ} \mathrm{C}-175 \mathrm{~h}$ sensitization, no longer correlates with a steep increase in growth rate; rather, it represents the variability in growth rate, which is likely for all temperatures and sensitizations. Fatigue precrack IGC occurs at about $1.5 \mathrm{~nm} / \mathrm{s}$ for the relatively low DoS of $9 \mathrm{mg} / \mathrm{cm}^{2}$ to $10 \mathrm{mg} / \mathrm{cm}^{2}$ compared to the very low rate $(0.03 \mathrm{~nm} / \mathrm{s})$ typical of as-received $5083-\mathrm{H} 131$ with DoS of $3 \mathrm{mg} / \mathrm{cm}^{2}$ (not shown). The da/dt IGC increases mildly at best with rising mass loss for NAMLT values less than about $40 \mathrm{mg} / \mathrm{cm}^{2}$ (slope: $0.021 \pm 0.036(\mathrm{~nm} / \mathrm{s}) /\left(\mathrm{mg} / \mathrm{cm}^{2}\right), 95 \%$ confidence interval). For NAMLT values above $40 \mathrm{mg} / \mathrm{cm}^{2}$, da/dt IGC rises more sharply with increasing DoS.

A strong agreement is observed between the values of the DoS dependent fatigue crack tip and bold surface IGC rates in Fig. 2.10. The dashed lines surrounding the measured IGC rates in Fig. 2.10 are model-predicted (stress free) IGC penetration rates for high purity $\mathrm{Al}-\mathrm{Mg}$ exposed in $\mathrm{NaCl}$ at $-0.800 \mathrm{~V}_{\mathrm{SCE}}$ and plotted as a function of grain boundary $\beta$ coverage $[17,18]$. The upper and lower trends are based on a local-fissure chemistry, which is either fully saturated or $80 \%$ saturated in the cations from $\alpha$ and $\beta$ dissolution. The majority of experimental fatigue precrack IGC growth rates lie within these bounds. Thus, the models of Bumiller and Kelly can be considered as good estimates of the upper and lower bound predictions. 


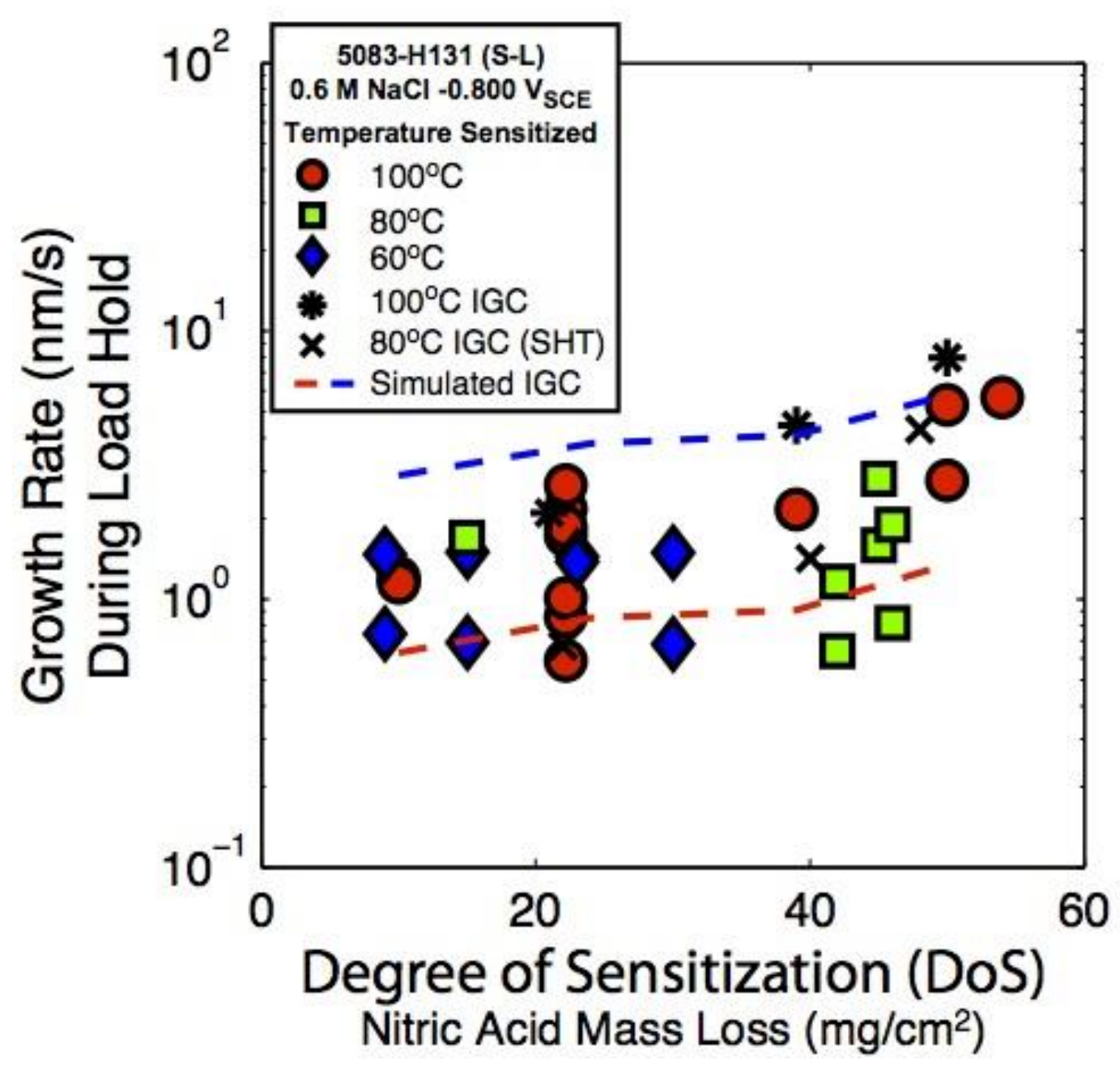

Figure 2.10 Nitric acid mass loss based DoS dependence of IGC growth rate measured during the constant $\mathrm{K}$ hold at $2.0 \mathrm{MPa} \sqrt{\mathrm{m}}$ to $5.0 \mathrm{MPa} \sqrt{\mathrm{m}}$ for $5083-\mathrm{H} 131$ immersed in $0.6 \mathrm{M} \mathrm{NaCl}$ solution at fixed potential of $-0.800 \mathrm{~V}_{\mathrm{SCE}}$. Unstressed IGC rates for sensitizations at $80^{\circ} \mathrm{C}$ (with SHT, $\mathbf{x}$ ) and $100^{\circ} \mathrm{C}$ (non-SHT, *) were measured by Lim et al. [6,44]. Simulated IGC penetration rates calculated from fissure-chemistry considerations by Bumiller and Kelly are shown with dashed lines $[17,18]$.

\subsubsection{Intergranular SCC dependence on DoS}

The cracking behavior of 5083-H131 sensitized at $60^{\circ} \mathrm{C}$ for 3 exposure times is shown in Fig. 2.11. For each experiment, crack growth is measured at constant load (4 MPa $\sqrt{\mathrm{m}}$ ) over the first $10 \mathrm{~h}$, than loaded at a constant $\mathrm{K}$ rate $(0.25 \mathrm{MPa} \vee \mathrm{m} / \mathrm{h})$ until final fracture in 
$0.6 \mathrm{M} \mathrm{NaCl}$ polarized to $-0.800 \mathrm{~V}_{\mathrm{SCE}}$. Crack growth does not accelerate over the first $60 \mathrm{~h}$ for $5083-\mathrm{H} 131$ sensitized at $60^{\circ} \mathrm{C}$ for $30 \mathrm{~d}\left(9 \mathrm{mg} / \mathrm{cm}^{2}\right)$. For sensitizations between $23 \mathrm{mg} / \mathrm{cm}^{2}$ and $30 \mathrm{mg} / \mathrm{cm}^{2}$ crack growth accelerates within $25 \mathrm{~h}$ to $35 \mathrm{~h}$.

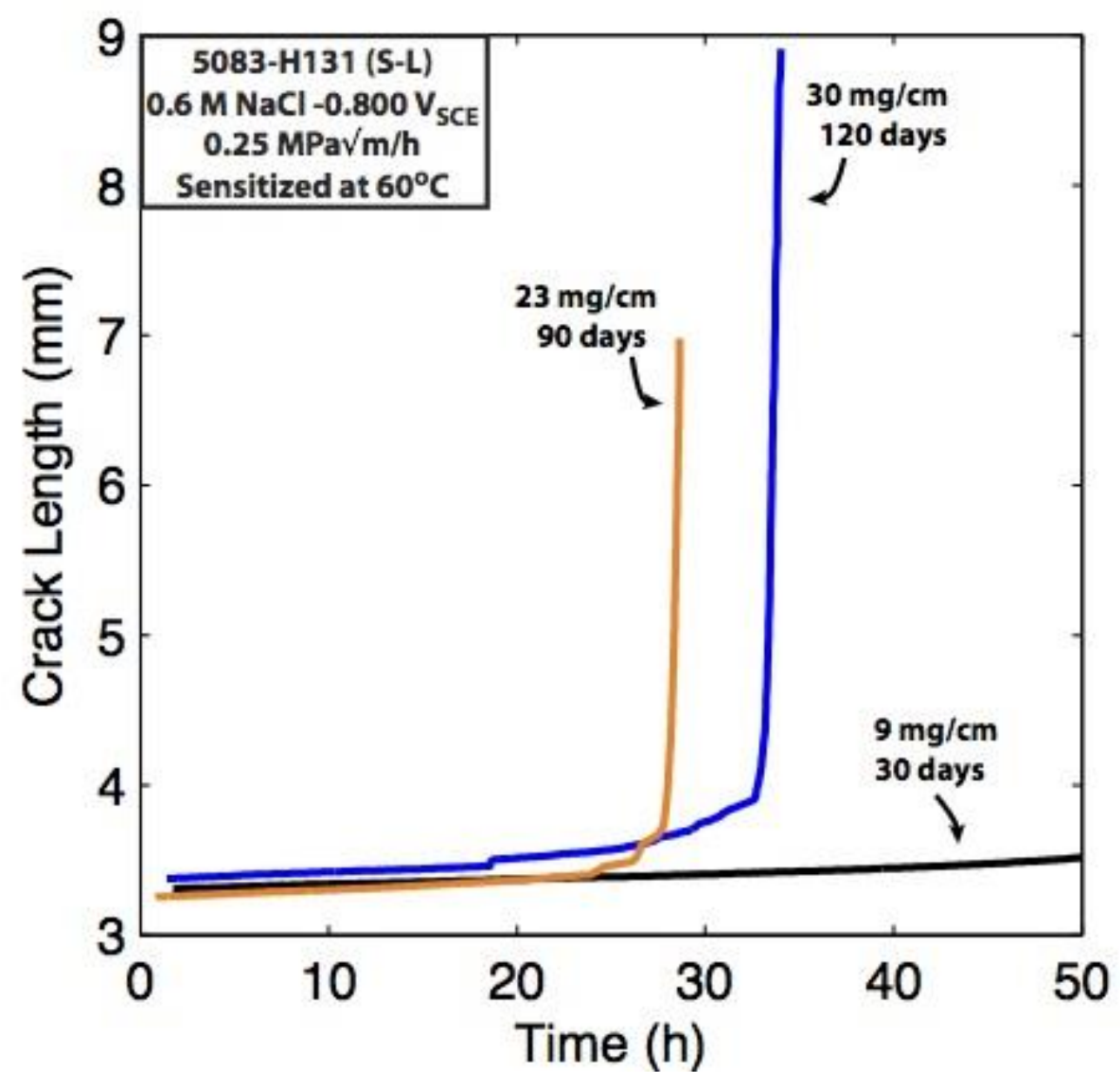

Figure 2.11 Crack length versus time for $5083-\mathrm{H} 131$ sensitized at $60^{\circ} \mathrm{C}$ for $30 \mathrm{~d}, 60 \mathrm{~d}$ and $90 \mathrm{~d}$ loaded at a constant than rising displacement in $0.6 \mathrm{M} \mathrm{NaCl}$ at $-0.800 \mathrm{~V}_{\text {SCE}}$.

The crack growth rate as a function of $\mathrm{K}$ for each sensitization of $5083-\mathrm{H} 131$ at $60^{\circ} \mathrm{C}$ (see Fig. 2.11) is plotted in Fig. 2.12, with results from as-received 5083-H131 (DoS of $3 \mathrm{mg} / \mathrm{cm}^{2}$ ) loaded in the same environment with the same K-protocol. As-received 5083H131 loaded in $0.6 \mathrm{M} \mathrm{NaCl}$ polarized to $-0.800 \mathrm{~V}_{\mathrm{SCE}}$ resists IGSCC, but does not appear 
to be immune to environmental cracking. Crack extension rates in $\mathrm{NaCl}$ follow da/dt measured for an as-received specimen in air (light grey points and grey resolution limit box) until $\mathrm{K}_{\mathrm{JIC}}$ of $21.7 \mathrm{MPa} \sqrt{\mathrm{m}}_{\mathrm{m}}$. For higher $\mathrm{K}_{\mathrm{J}}$, crack extension in $\mathrm{NaCl}$ likely includes a strong contribution from stable-ductile tearing; however, IGSCC is also evidenced. Specifically, the rising displacement was held constant at $\mathrm{K}$ of $36 \mathrm{MPa} \sqrt{\mathrm{m}}_{\text {( }} \star$ in Fig. 2.12) and crack growth continued at a decreasing rate with over $0.15 \mathrm{~mm}$ of crack extension based on dcPD analysis. This growth at constant displacement is likely IGSCC rather than stable ductile tearing since the latter will not occur at fixed or falling $\mathrm{K}$, provided creep is minimal. The declining but finite da/dt above the resolution limit at high quasi-static $\mathrm{K}$ demonstrates IGSCC growth is possible and likely occurred with rising displacement above a $\mathrm{K}_{\mathrm{J}}$ of about $22 \mathrm{MPa} \sqrt{\mathrm{m}}_{\mathrm{m}}$ for resistant microstructures of 5083.

Increasing low temperature DoS of $5083-\mathrm{H} 131$ at $60^{\circ} \mathrm{C}$ for $30 \mathrm{~d}, 60 \mathrm{~d}$, and $120 \mathrm{~d}(\mathrm{DoS}$ values of $9 \mathrm{mg} / \mathrm{cm}^{2}, 15 \mathrm{mg} / \mathrm{cm}^{2}$, and $30 \mathrm{mg} / \mathrm{cm}^{2}$, respectively) systematically increases susceptibility to IGSCC as shown in Fig. 2.12. The elastic-plastic $\mathrm{K}_{\mathrm{J}}$ was used for the IGSCC resistant $30 \mathrm{~d}$ sensitization; elastic $\mathrm{K}$ was used for more severely sensitized specimens. With sensitization at $60^{\circ} \mathrm{C}$ for $30 \mathrm{~d}\left(9 \mathrm{mg} / \mathrm{cm}^{2}\right)$ IGC initiated at about $1 \mathrm{~nm} / \mathrm{s}$ and reached $2.5 \mathrm{~nm} / \mathrm{s}$ with slow rising $\mathrm{K}$, followed by a more rapid Stage I type of subcritical crack growth defining $\mathrm{K}_{\mathrm{TH}}$ of $18.5 \mathrm{MPa} \vee_{\mathrm{m}}$. The close proximity of $\mathrm{K}_{\mathrm{TH}}$ to $\mathrm{K}_{\mathrm{JIC}}$ (as-received 21.7 MPa $\sqrt{\mathrm{m}}$ ) confirms IGSCC resistance. It is unclear if this mildly sensitized condition exhibits Stage II SCC since the experiment was terminated at near $\mathrm{K}_{\text {JIC. }}$ Clear IGSCC behavior is observed for specimens sensitized for $60 \mathrm{~d}$ and $120 \mathrm{~d}$ : low $\mathrm{K}_{\mathrm{TH}}$ (at 11.8 $\mathrm{MPa} \sqrt{\mathrm{m}}$ and 9.2 $\mathrm{MPa} \sqrt{\mathrm{m}}$, respectively) and Stage II with da/dt $/$ close to $1700 \mathrm{~nm} / \mathrm{s}$ 
for both sensitizations. Without question, IGSCC can be promoted by prolonged sensitization at $60^{\circ} \mathrm{C}$.

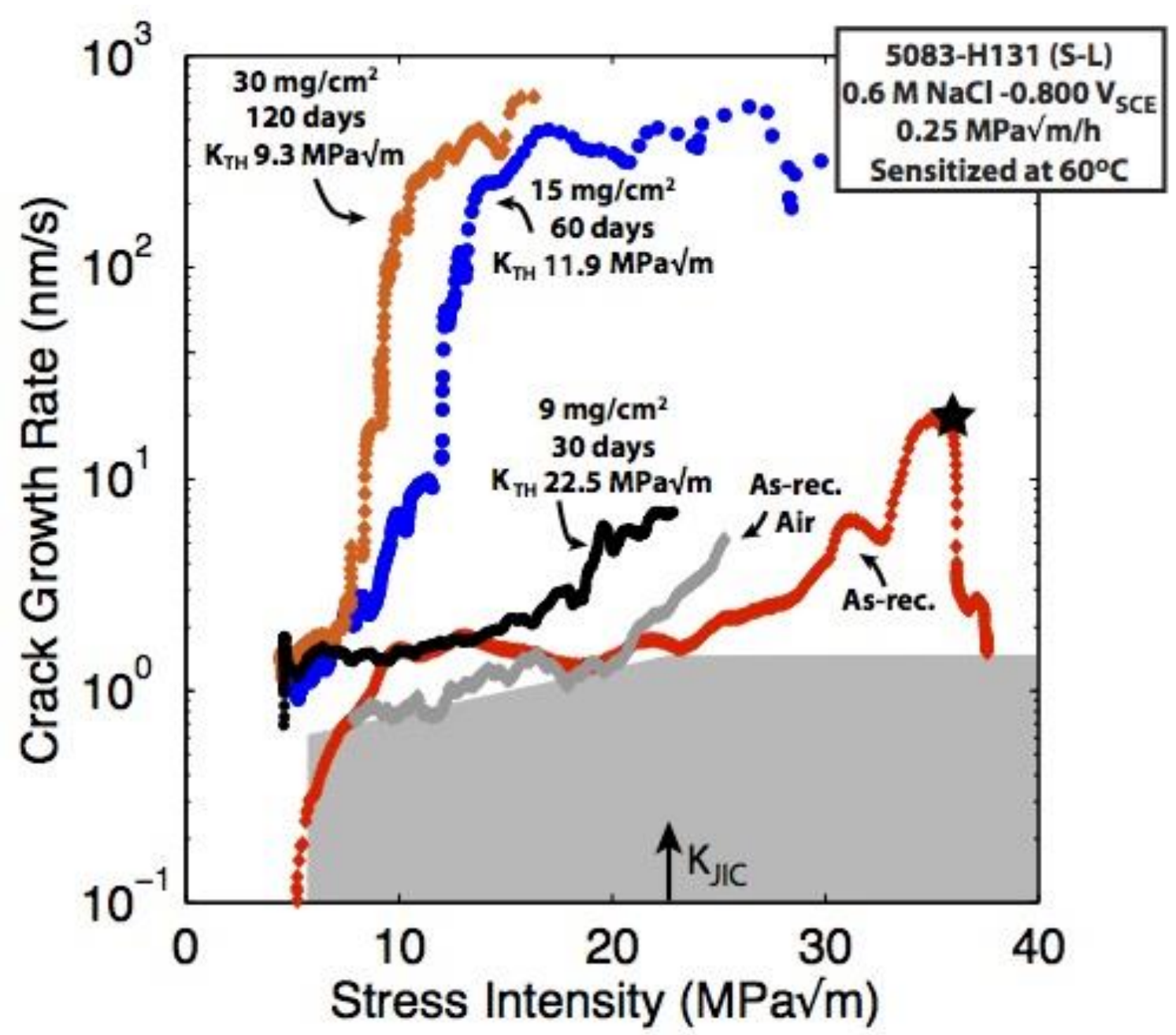

Figure 2.12 The K dependence of subcritical crack growth for as-received and sensitized $\left(60^{\circ} \mathrm{C}\right.$ for various times) $5083-\mathrm{H} 131$ (S-L) stressed with the constant then rising displacement protocol while immersed in $0.6 \mathrm{M} \mathrm{NaCl}$ solution at $-0.800 \mathrm{~V}_{\mathrm{SCE}}$. Both asreceived and low $\operatorname{DoS}\left(9 \mathrm{mg} / \mathrm{cm}^{2}\right)$ specimens were analyzed with elastic-plastic analysis. The kinetics measured for an as-received specimen loaded in air are plotted for reference with the grey box representing crack growth rates within this limit.

Intergranular SCC of 5083-H131 is affected systematically by sensitization time and temperature for the conditions represented in Fig. 2.2 (without additional SHT). The 
relationship between $\mathrm{K}_{\mathrm{TH}}$ and sensitization time (Fig. 2.13) resembles a step function for each sensitization temperature. Elastic-plastic fracture toughness for moist air, $\mathrm{K}_{\mathrm{JIC}}$, is plotted as open symbols for as-received $(\Delta)$ and sensitized $\left(\mathrm{O}, 100^{\circ} \mathrm{C}\right.$ for $175 \mathrm{~h}$ and $\square, 80^{\circ} \mathrm{C}$ for 45 d) $5083-\mathrm{H} 131$ in the S-L orientation. The grey band represents the likely range of fracture toughness over sensitization time. Elastic-plastic $\mathrm{K}_{\mathrm{TH}}$ for as-received and $60^{\circ} \mathrm{C}$ sensitized (30 d) specimens are within the grey band describing $\mathrm{K}_{\mathrm{JIC}}$, illustrating high resistance to IGSCC. All other $\mathrm{K}_{\mathrm{TH}}$ (including those with very short sensitization times) are lower than the $\mathrm{K}_{\mathrm{JIC}}$ range, demonstrating increasing IGSCC susceptibility with sensitization. For each sensitization temperature, $\mathrm{K}_{\mathrm{TH}}$ falls rapidly until a critical sensitization time, where a transition occurs and $\mathrm{K}_{\mathrm{TH}}$ reduction is much slower with increasing time. The critical sensitization exposure times are $7 \mathrm{~d}, 14 \mathrm{~d}$, and $30 \mathrm{~d}$ for $100^{\circ} \mathrm{C}$, $80^{\circ} \mathrm{C}$, and $60^{\circ} \mathrm{C}$, respectively.

A unique relationship is established when $\mathrm{K}_{\mathrm{TH}}$ is plotted as a function of DoS for all sensitization times and temperatures (Fig. 2.14). Three regions are identified in this plot: (a) the resistant microstructures where $\mathrm{K}_{\mathrm{TH}}$ is within the $\mathrm{K}_{\mathrm{JIC}}$ region, (b) the highly susceptible microstructures where $\mathrm{K}_{\mathrm{TH}}$ is less than $15 \mathrm{MPa} \sqrt{\mathrm{m}}$, and (c) the transition between these two regions. The intersection of the resistant trend line and the transition trend line identifies a critical DoS near $10 \mathrm{mg} / \mathrm{cm}^{2}$; with sensitization higher than $10 \mathrm{mg} / \mathrm{cm}^{2}, \mathrm{~K}_{\mathrm{TH}}$ decreases rapidly from $\mathrm{K}_{\mathrm{JIC}}$, illustrating the onset of IGSCC susceptibility for modest but finite sensitization. While there is no fundamental basis for a unique $\mathrm{K}_{\mathrm{TH}}$ vs. mass loss relationship, an engineering correlation is suggested by the linear regression analysis of $\mathrm{K}_{\mathrm{TH}}$ values for DoS greater than $10 \mathrm{mg} / \mathrm{cm}^{2}$ shown in Fig. 2.14: $\mathrm{K}_{\mathrm{TH}}=-0.23(\mathrm{DoS})+16.4$ with $\mathrm{K}_{\mathrm{TH}}$ as $\mathrm{MPa} \sqrt{\mathrm{m}}$ and DoS from NAMLT as $\mathrm{mg} / \mathrm{cm}^{2}$ 
$\left(\mathrm{R}^{2}=0.74\right)$. This result suggests that both the IGC/grain fallout that governs mass loss and IGSCC damage at $\mathrm{K}_{\mathrm{TH}}$ are controlled by increased grain boundary $\beta$ coverage.

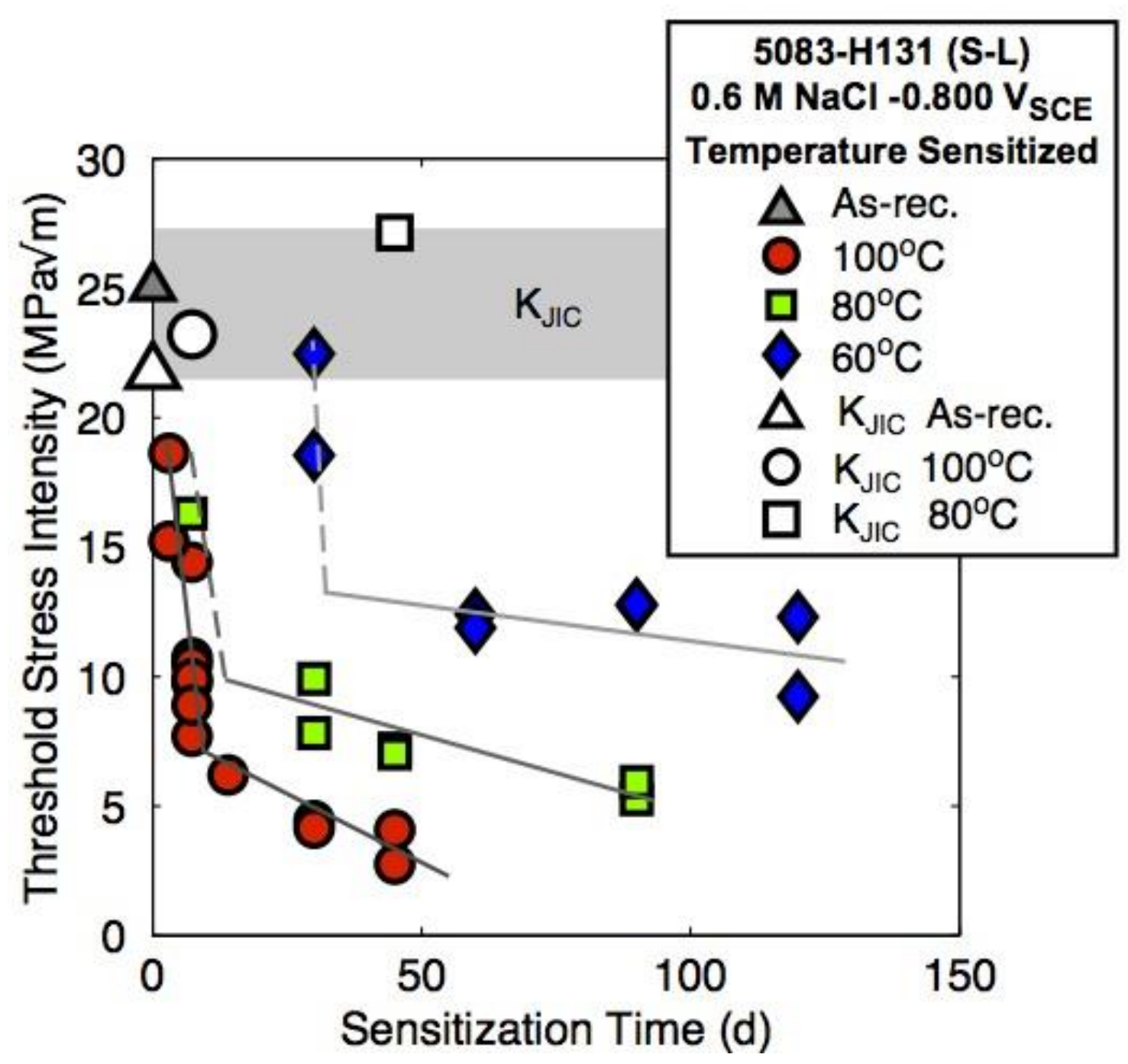

Figure 2.13 Sensitization time dependence of $\mathrm{K}_{\mathrm{TH}}$ for IGSCC in 5083-H131 immersed in $0.6 \mathrm{M} \mathrm{NaCl}$ solution at fixed potential of $-0.800 \mathrm{~V}$ SCE. Elastic-plastic $\mathrm{K}_{\text {JIC }}$ toughness is plotted as $\Delta$ for as-received, $\mathrm{O}$ for $\left(100^{\circ} \mathrm{C} 175 \mathrm{~h}\right)$, and $\square$ for $\left(80^{\circ} \mathrm{C} 45 \mathrm{~d}\right)$ specimens, with a grey band showing the range of $\mathrm{K}_{\text {IIC. }}$. Elastic-plastic analysis was used for IGSCC specimens exhibiting $\mathrm{K}_{\mathrm{TH}}$ greater than $14 \mathrm{MPa} \sqrt{\mathrm{m}}$. Solid lines are regression fits, and dashed lines are estimated trends. 


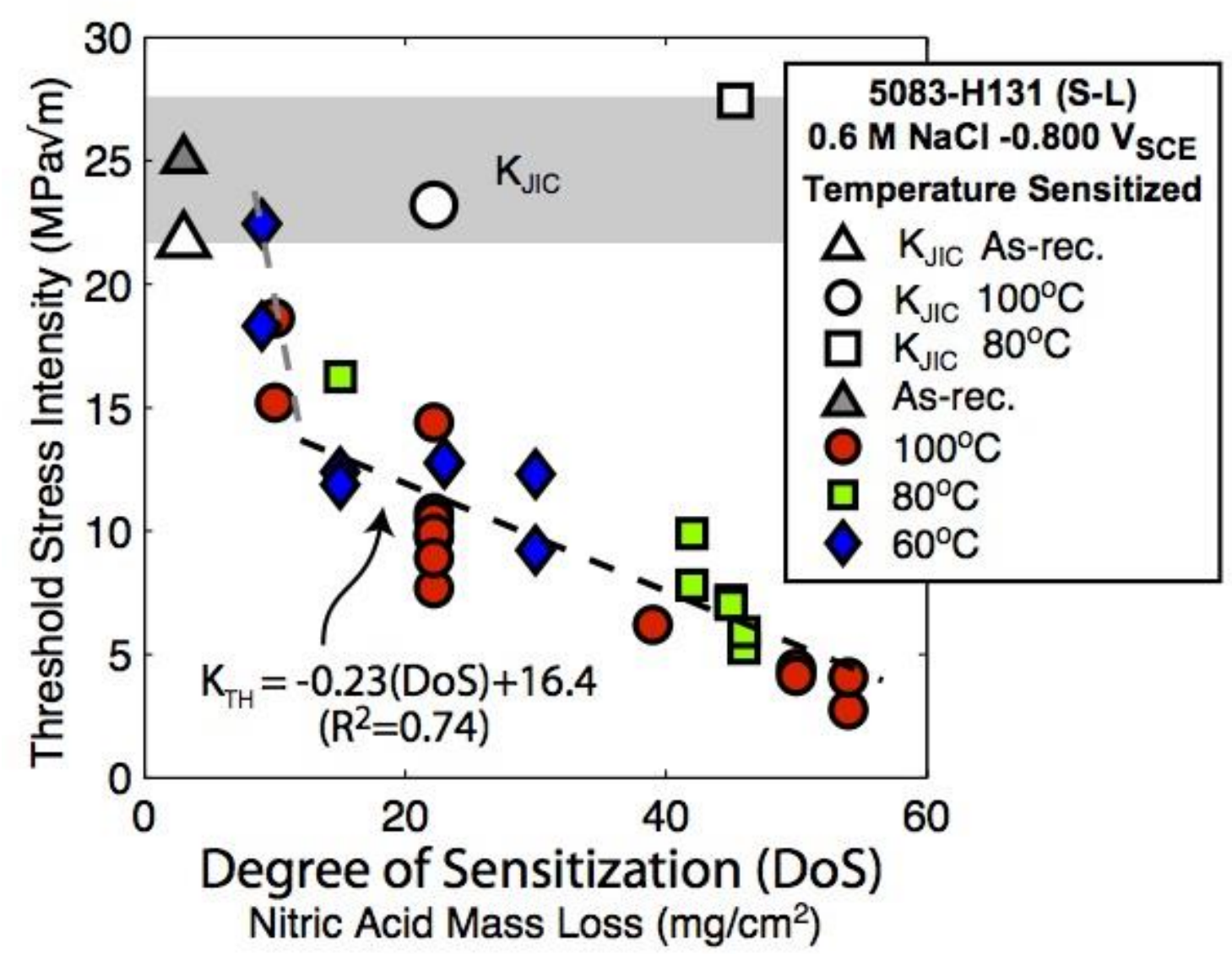

Figure 2.14 Nitric acid mass loss based DoS dependence of $\mathrm{K}_{\text {TH }}$ for IGSCC in 5083$\mathrm{H} 131$ immersed in $0.6 \mathrm{M} \mathrm{NaCl}$ solution at fixed potential of $-0.800 \mathrm{~V}_{\text {SCE }}$. Elastic-plastic $\mathrm{K}_{\mathrm{JIC}}$ toughness (S-L) is plotted as $\Delta$ for as-received, $\mathrm{O}$ for $\left(100^{\circ} \mathrm{C} 175 \mathrm{~h}, 22 \mathrm{mg} / \mathrm{cm}^{2}\right)$, and $\square$ for $\left(80^{\circ} \mathrm{C} 45 \mathrm{~d}, 45 \mathrm{mg} / \mathrm{cm}^{2}\right)$ specimens, with a grey band showing the range of

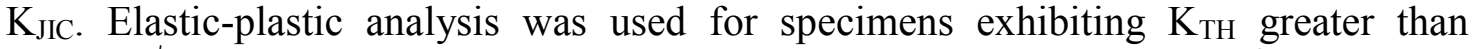
$14 \mathrm{MPa} \sqrt{\mathrm{m}}$. The dark dashed line for $\mathrm{K}_{\mathrm{TH}}$ vs. DoS greater than $10 \mathrm{mg} / \mathrm{cm}^{2}$ is based on linear regression $\left(\mathrm{R}^{2}=0.74\right)$. The light dashed line represents the predicted trend line through resistant microstructures.

Considering IGSCC, most Stage II crack growth rates depend somewhat on K (66\% of $\mathrm{da} / \mathrm{dt}_{\mathrm{II}}$ depend on $\mathrm{K}$ for sensitizations above $10 \mathrm{mg} / \mathrm{cm}^{2}$ and irregular Stage II behavior convoluted the $\mathrm{K}$ dependence for lower sensitizations). For this reason, the crack growth rate (da/dt 15$)$ at a $\mathrm{K}$ of $15 \mathrm{MPa} \sqrt{\mathrm{m}}$ was used to quantify susceptibility to IGSCC. This $\mathrm{K}$ was chosen because it is lower than $\mathrm{K}_{\mathrm{JIC}}(21.7 \mathrm{MPa} \sqrt{\mathrm{m}}$ to $27.5 \mathrm{MPa} \sqrt{\mathrm{m}})$ and within Stage II 
for most IGSCC experiments. The sensitization time dependence of da/dt $\mathrm{K}_{15}$ (Fig. 2.15) for $5083-\mathrm{H} 131$ sensitized for varying times at $60^{\circ} \mathrm{C}, 80^{\circ} \mathrm{C}$, and $100^{\circ} \mathrm{C}$ resembles a step function for each temperature. The critical times for the onset of severe IGSCC susceptibility are $5 \mathrm{~d}, 10 \mathrm{~d}$, and $30 \mathrm{~d}$ for $100^{\circ} \mathrm{C}, 80^{\circ} \mathrm{C}$, and $60^{\circ} \mathrm{C}$ respectively. The open symbols $(\diamond, \square$, and $\mathrm{O})$ for short-term sensitization at $60^{\circ} \mathrm{C}, 80^{\circ} \mathrm{C}$ and $100^{\circ} \mathrm{C}$, respectively, distinguish specimens where the $\mathrm{da} / \mathrm{dt}_{\mathrm{K} 15}$ occurred within Stage I or before, while all filled points describe Stage II crack growth rates. Crack growth rates for two severely sensitized specimens (DoS of $50 \mathrm{mg} / \mathrm{cm}^{2}$ and $59 \mathrm{mg} / \mathrm{cm}^{2}$, corresponding to exposure times of $30 \mathrm{~d}$ and $45 \mathrm{~d}$ at $100^{\circ} \mathrm{C}$ ) exceeded the dcPD acquisition rate and were not recorded past $\mathrm{K}$ of $10 \mathrm{MPa} \sqrt{\mathrm{m}}$. The crack growth rate as a function of $\mathrm{K}$ is plotted in Fig. 2.16 for each of these highly sensitized 5083-H131 specimens. Severe cracking began within the first $3 \mathrm{~h}$ during the $2 \mathrm{MPa} \sqrt{\mathrm{m}}$ hold for sensitized 5083 -H131 with $59 \mathrm{mg} / \mathrm{cm}^{2}\left(100^{\circ} \mathrm{C}\right.$ for $\left.45 \mathrm{~d}\right)$. The $\mathrm{K}_{\mathrm{TH}}$ was near $3 \mathrm{MPa} \sqrt{\mathrm{m}}$, and the rapid increase in crack growth rate caused a rapid drop in load, which led to a small decrease in $\mathrm{K}$ at the end of the experiment (during the load hold in this experiment the displacement is held constant, therefore, the load drops during cracking). A similar trend was observed for the three other experiments in Fig. 2.16, though the $\mathrm{K}_{\mathrm{TH}}$ for each increased to near $4 \mathrm{MPa} \sqrt{\mathrm{m}}$. An extrapolation of the $\mathrm{da} / \mathrm{dt}$ at $\mathrm{K}=15 \mathrm{MPa} \sqrt{\mathrm{m}}$ was not made due to the absence of a clear Stage II region for all but one experiment; The second highly sensitized 5083-H131 (59 mg/cm $\left.{ }^{2}\right)$ specimen initiated a Stage II region, though evidence of acceleration and deceleration complicated extrapolation of this crack growth rate to higher K. The values reported in Fig. 2.15 are the maximum crack growth rates recorded, and rates at $\mathrm{K}$ of $15 \mathrm{MPa} \sqrt{\mathrm{m}}$ are likely higher than plotted. 


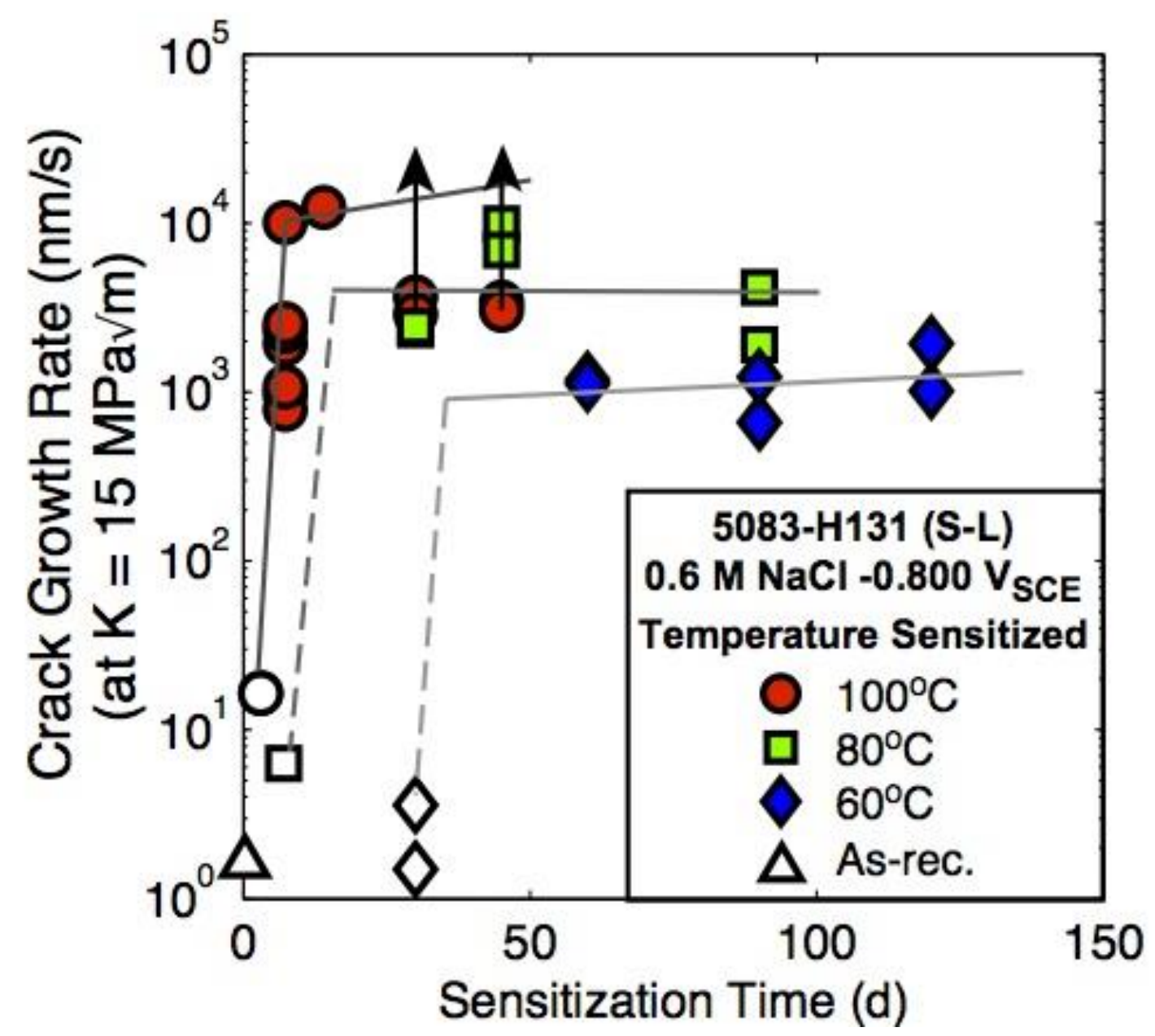

Figure 2.15 Sensitization time dependence of IGSCC growth rate at $\mathrm{K}_{\text {elastic }}$ of $15 \mathrm{MPa} \sqrt{\mathrm{m}}$ for $5083-\mathrm{H} 131$ immersed in $0.6 \mathrm{M} \mathrm{NaCl}$ solution at $-0.800 \mathrm{~V}_{\text {SCE. }}$. Solid lines are estimated trends. Open data points represent da/dt where $\mathrm{K}_{\mathrm{J}}$ of $15 \mathrm{MPa}{ }_{\mathrm{m}}$ is in Stage I or earlier. Arrows indicate experiments where acquisition rate was not fast enough to record IGSCC past $10 \mathrm{MPa} \sqrt{\mathrm{m}}$; actual growth rates are likely higher.

A single dependence on mass loss is observed when $\mathrm{da} / \mathrm{dt}_{\mathrm{K} 15}$ is plotted against DoS in Fig. 2.17, as demonstrated for DoS-dependent $\mathrm{K}_{\mathrm{TH}}$ in Fig. 2.14. A similar critical DoS value of $10 \mathrm{mg} / \mathrm{cm}^{2}$ is identified by the intersection of the transition trend line and the resistant crack growth rates, which are on the order measured by as-received 5083-H131 in $\mathrm{NaCl}(\Delta)$. A semi-logarithmic regression fit for highly susceptible microstructures with 
DoS values above $10 \mathrm{mg} / \mathrm{cm}^{2}$ yielded: dadt $15=298^{*} 10^{(0.024 * \text { DoS })}$, with $\mathrm{da} / \mathrm{dt}_{\mathrm{K} 15} \mathrm{as} \mathrm{nm} / \mathrm{s}$ and DoS as $\mathrm{mg} / \mathrm{cm}^{2}\left(\mathrm{R}^{2}=0.27\right)$. Though variability is significant, the correlation suggests that $\beta$ coverage measured by DoS controls IGSCC and grain fall out kinetics.

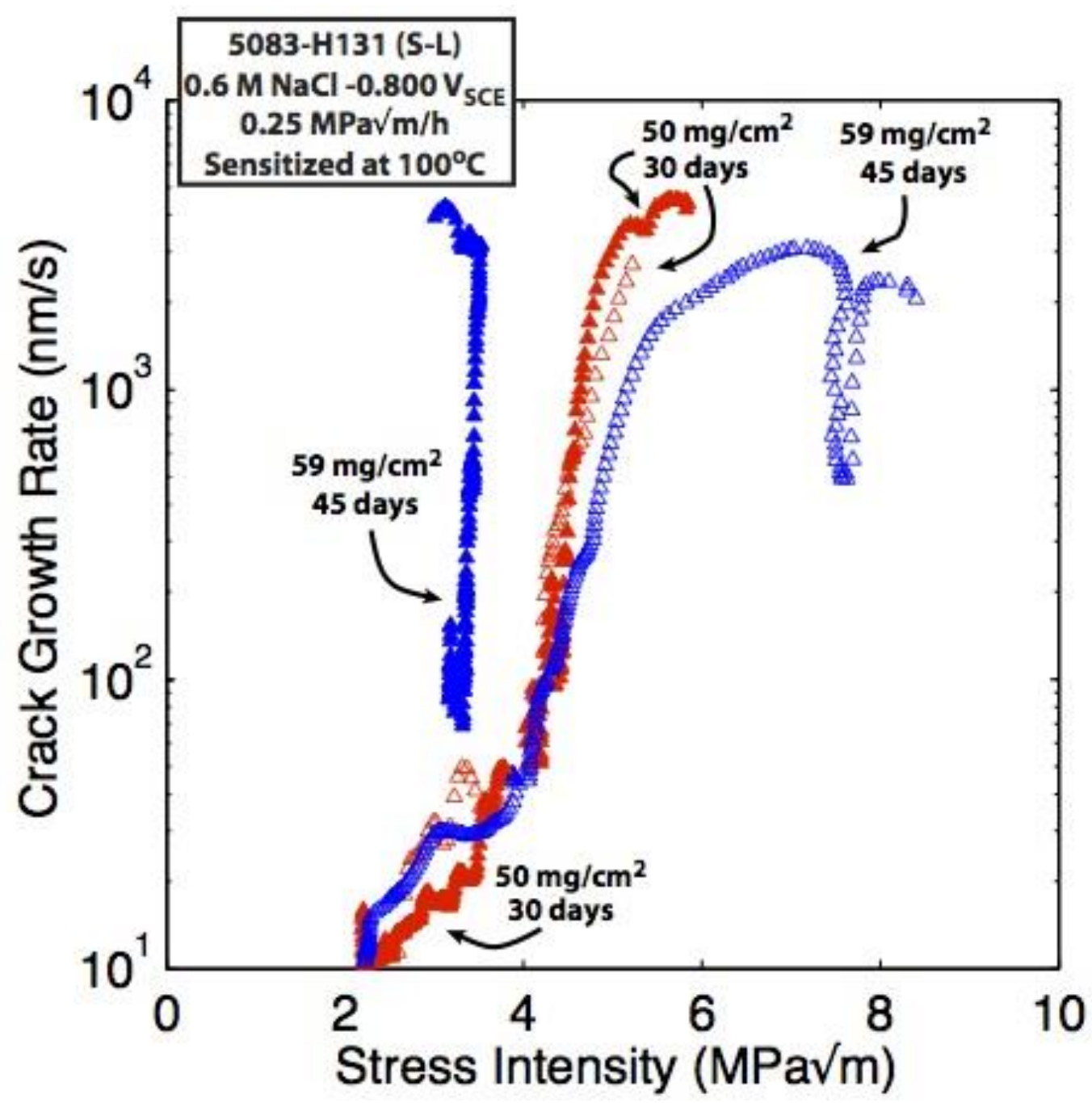

Figure 2.16 The $\mathrm{K}$ dependence of subcritical crack growth for replicate experiments with sensitized $\left(100^{\circ} \mathrm{C}\right.$ for $30 \mathrm{~d}$ with $50 \mathrm{mg} / \mathrm{cm}^{2}$, and $45 \mathrm{~d}$ with $\left.59 \mathrm{mg} / \mathrm{cm}^{2}\right) 5083-\mathrm{H} 131$ (S-L) stressed with the constant then rising displacement protocol while immersed in $0.6 \mathrm{M} \mathrm{NaCl}$ solution at $-0.800 \mathrm{~V}_{\mathrm{SCE}}$ (the experiment noted "hold only" fractured before rising displacement was applied). 


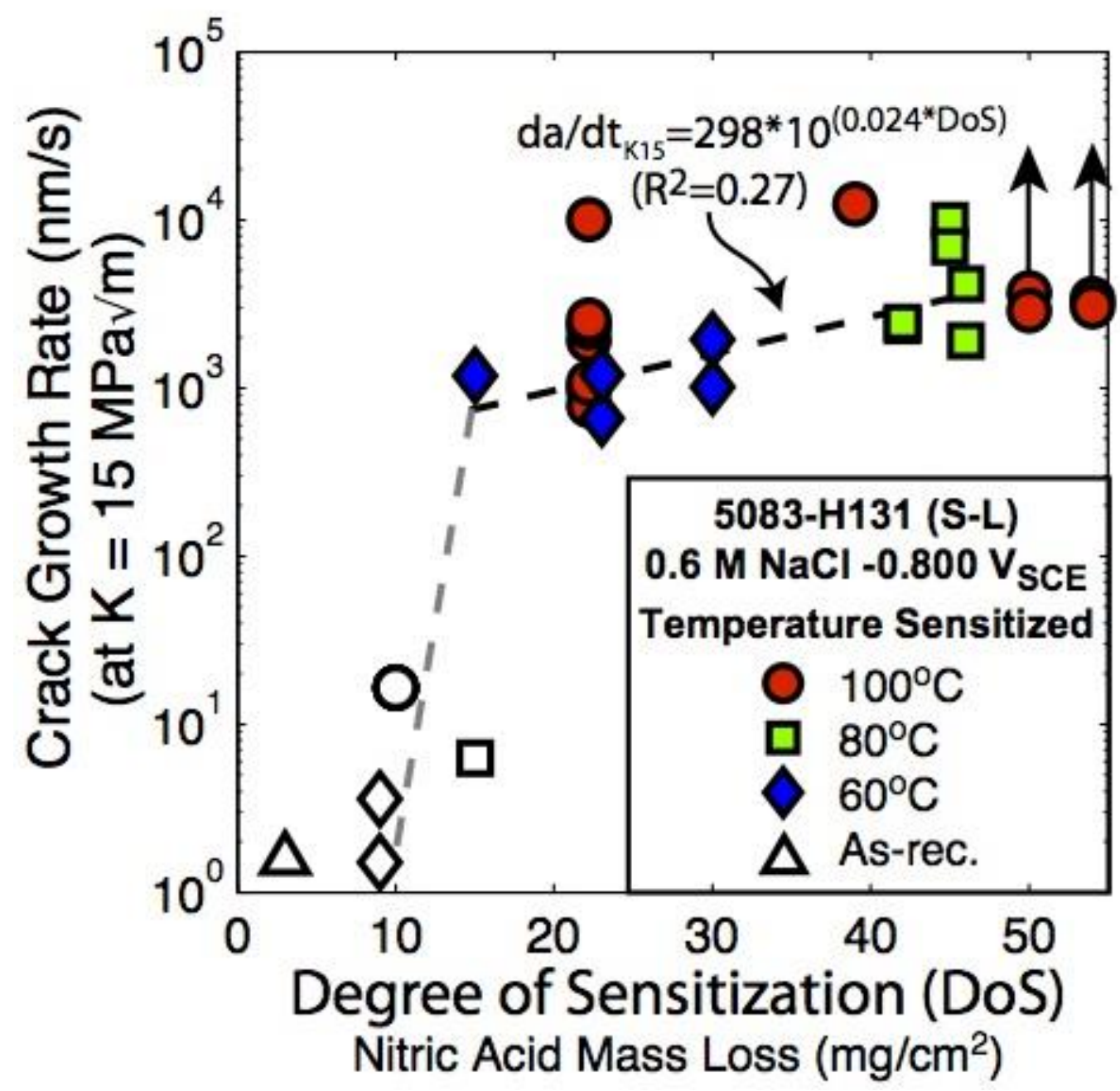

Figure 2.17 Nitric acid mass loss based DoS dependence of Stage II crack growth rates at $\mathrm{K}$ of $15 \mathrm{MPa} \sqrt{\mathrm{m}}$ for $5083-\mathrm{H} 131$ immersed in $0.6 \mathrm{M} \mathrm{NaCl}$ solution at $-0.800 \mathrm{~V}_{\mathrm{SCE}}$. The dark dashed line indicates $\mathrm{da} / \mathrm{dt}_{\mathrm{K} 15}$ vs. DoS linear regression $\left(\mathrm{R}^{2}=0.30\right)$ for DoS greater than $10 \mathrm{mg} / \mathrm{cm}^{2}$. The light dashed line is the predicted trend line through the resistant microstructures. Open data points represent da/dt where $\mathrm{K}_{\mathrm{J}}$ of $15 \mathrm{MPa} \sqrt{\mathrm{m}}$ is in Stage I or before. Arrows indicate experiments where acquisition rate was not fast enough to record IGSCC past $10 \mathrm{MPa} \sqrt{\mathrm{m}}$, therefore actual growth rates are likely higher.

\subsubsection{Fractography}

The S-L oriented fracture surface of as-received 5083-H131 cracked in moist air is characterized by ductile microvoid-based damage (Fig. 2.18(A-C)). Immediately following the fatigue precrack microvoids are apparent and vary in size with respective initiating- 
particle size. Large rectangular constituent particles $(\sim 10 \mu \mathrm{m})$, identified as Al,Mn,Fe rich by Goswami et al. [8,9], initiate larger voids $(\sim 20 \mu \mathrm{m})$, as shown with the arrow in Fig. 2.18B. Smaller voids ( $3 \mu \mathrm{m}$ to $5 \mu \mathrm{m}$ ) form from smaller rod shaped ( $80 \mathrm{~nm}$ to $1000 \mathrm{~nm}$ ) or spherical (50 $\mathrm{nm}$ to $100 \mathrm{~nm}$ ) particles and are more regularly spaced (Fig. 2.18C). These particles are too small to characterize with SEM-EDS, but are likely Al-Mn,Cr,Fe-based intragranular and intergranular dispersoids $[3,8,9]$. Smaller voids form void-sheets between larger voids (not shown), which is well documented for precipitation hardened Al alloys [58]. Fracture surfaces from as-received and sensitized $\left(100^{\circ} \mathrm{C}\right.$ for $\left.175 \mathrm{~h}\right) \mathrm{SENT}$ specimens cracked in air showed no variation in microvoid characteristics, which contrasts increasing $\mathrm{K}_{\mathrm{JIC}}$ with DoS in Fig. 2.14. Fractography suggests that grain boundary $\beta$ does not play a role in microvoid fracture. There is no fractographic evidence for a unique role of high angle grain boundaries in ductile fracture for this S-L orientation.

Evidence for IGSCC growth in highly resistant low DoS (3 mg/ $\mathrm{cm}^{2}$, as-received) 5083 $\mathrm{H} 131$ loaded in $0.6 \mathrm{M} \mathrm{NaCl}$ at $-0.800 \mathrm{~V}_{\mathrm{SCE}}$ is shown in Fig. 2.18(D-F). This specimen remained in $\mathrm{NaCl}$ at $\mathrm{OCP}$ for several hours following final fracture, causing corrosion damage on the majority of the fracture surface and rendering some IGSCC features unidentifiable. From dcPD measurement of this experiment (Fig. 2.12) environmentassisted crack growth likely initiated at a $\mathrm{K}_{\mathrm{J}}$ between $25 \mathrm{MPa} \sqrt{\mathrm{m}}$ and $30 \mathrm{MPa} \sqrt{\mathrm{m}}$ and continued for about $0.40 \mathrm{~mm}$ of growth to $a / \mathrm{W}$ of 0.27 and $\mathrm{K}_{\mathrm{J}}$ of $36 \mathrm{MPa} \sqrt{\mathrm{m}}$. Displacement was held constant at this point $(\star)$ and time-dependent crack growth continued at a declining rate causing $0.15 \mathrm{~mm}$ of further crack extension to $a / \mathrm{W}$ of 0.28 . The majority of the crack surface ahead of the fatigue crack (to $a / \mathrm{W}$ of 0.28 ) consisted of isolated, relatively flat regions between $0.1 \mathrm{~mm}$ and $0.2 \mathrm{~mm}$ long (about the size of grains (Fig. 2.1)) 
surrounded by ductile regions (Fig. 2.18(D,E)). These features suggest that discrete regions of IGSCC caused crack extension that was resolved by dcPD measurement. The flat, likely IGSCC, regions are decorated with either holes or cathodic particles with the surrounding matrix dissolved (arrows in Fig. 2.18E). Particles in Fig. 2.18(E,F) are likely Mn-rich dispersoids, rather than $\beta$, since they: (a) were not dissolved during chloride exposure, and (b) are present in as-received material where there should be very little $\beta$ present $[3,8,9]$.

Figure 2.19 details the shaded regions in Fig. 2.18(D,E). The shallow dimples in the IG region (Fig. 2.19A) could either be: (a) an artifact of grain face $\alpha$ dissolution during IGSCC at $-0.800 \mathrm{~V}_{\mathrm{SCE}}$, (b) $\alpha$ dissolution during post-test OCP measurement and specimen removal, or (c) remains of matrix corrosion and fallout of small cathodic particles of the type identified by Goswami et al. $[3,8,9]$. The holes are likely not due to $\beta$ dissolution, as $\beta$ precipitation is negligible in as-received microstructures. Figure 2.19B compares the IG and ductile region in detail. The IG crack growth is distinct from ductile rupture, because it lacks microvoids with initiating particles at the base (arrow). The proportion of ductile features significantly increased as $\mathrm{K}_{\mathrm{J}}$ increased with crack growth and there is no evidence of the rising-to-fixed displacement transition ( $\star$ in Fig. 2.12) on the fracture surface, nor is there expected to be. Following unstable fracture, only ductile features were identified: microvoids (about $5 \mu \mathrm{m}$ ) with initiating particles $(\sim 1 \mu \mathrm{m})$ in Fig. $2.18 \mathrm{~F}$ that are similar in size to Mn-rich dispersoids seen in Fig. 2.18C. 


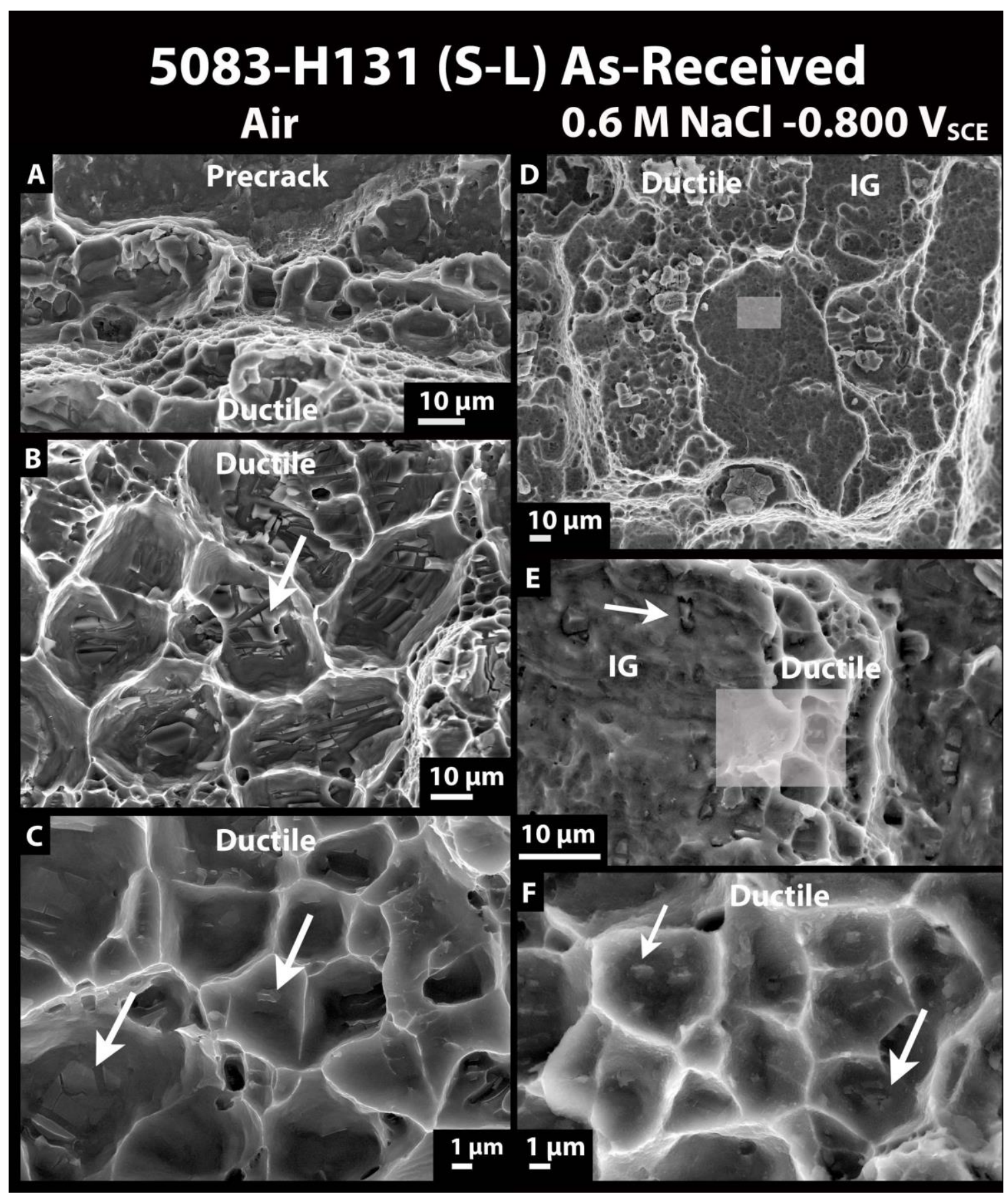

Figure 2.18 SEM fractographs of as-received 5083-H131 (S-L) loaded in air (A-C) and $0.6 \mathrm{M} \mathrm{NaCl}$ polarized to $-0.800 \mathrm{~V}_{\mathrm{SCE}}(\mathrm{D}-\mathrm{F})$. Shaded regions in $\mathrm{D}$ and $\mathrm{E}$ are shown in detail in Fig. 2.19. 


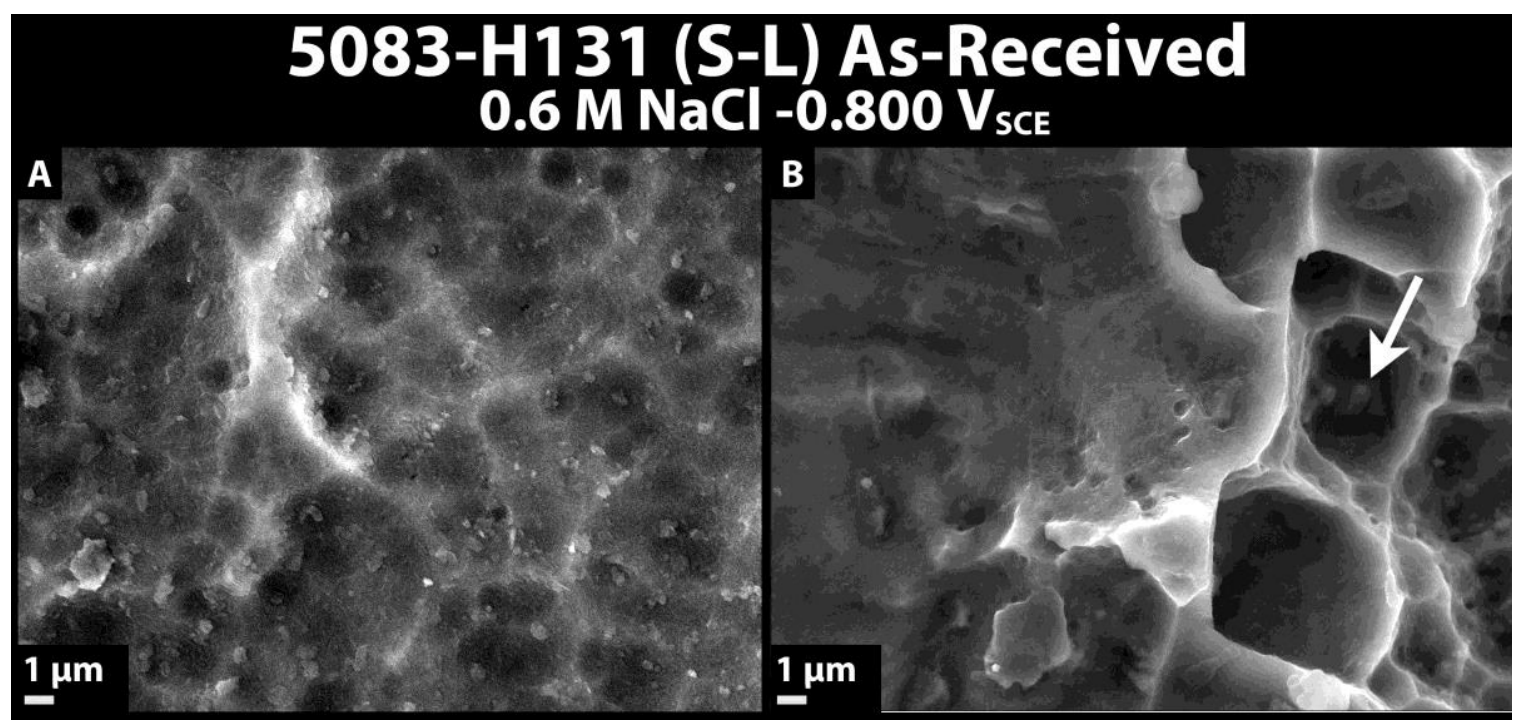

Figure 2.19 (A) and (B) detail the shaded regions in Figures 2.18(D and E), respectively, showing environmental crack extension in as-received 5083-H131 (S-L) polarized to $-0.800 \mathrm{~V}_{\mathrm{SCE}}$ in $0.6 \mathrm{M} \mathrm{NaCl}$. The arrow in (B) shows microvoid nucleating particles.

Typical IGSCC surface features are characterized in Fig. 2.20 for 5083-H131 (S-L) sensitized for $175 \mathrm{~h}$ at $100^{\circ} \mathrm{C}\left(22 \mathrm{mg} / \mathrm{cm}^{2}\right)$ and stressed in $0.6 \mathrm{M} \mathrm{NaCl}$ solution at $-0.800 \mathrm{~V}_{\mathrm{SCE}}$. This fracture surface remained in solution for less than $10 \mathrm{~min}$ after final fracture; limited corrosion damage occurred after fracture, though all $\beta$ was likely dissolved. A full-SENT thickness optical image of the irregular IGSCC path, shown on the left, is labeled with points corresponding to regions identified in the SEM images on the right. The final measured dcPD crack length, $9.5 \mathrm{~mm}$, indicates the average crack extension across the crack front and is consistent with the SEM measured average crack length associated with the unique crack shape. The macroscopic image shows preferentialsubcritical crack growth proximate to the bold surfaces, as represented by the final crack shape and discussed in Section 3.6.4.4. Most sensitized specimens (with DoS between $22 \mathrm{mg} / \mathrm{cm}^{2}$ and $48 \mathrm{mg} / \mathrm{cm}^{2}$ ) had irregular crack fronts similar to Fig. 2.20. The fractographs on the left distinguish three regions observed on the fracture surface in Fig. 2.20: 
(A) fatigue precrack, (B) intergranular growth, (C) final ductile rupture. The fractographs on the right show high magnification of typical features from Fig. 2.7: (D) the first load hold (K of 3.8 MPa $\sqrt{m}),(E) K_{T H}(10.7 \mathrm{MPa} \sqrt{m})$ and (F) Stage II IGSCC (15 MPa $\left.\sqrt{m}\right)$. The first hold is marked with a grey line (D) at the top of the optical image at $4.8 \mathrm{~mm}$ from the notch tip. Increased da/dt began at $\mathrm{K}_{\mathrm{TH}}$ at $5.1 \mathrm{~mm}$, represented with the first dashed line (E). Crack growth rate plateaued during Stage II at $710 \mathrm{~nm} / \mathrm{s}$, with an average crack depth of $7.0 \mathrm{~mm}$ and $\mathrm{K}$ of $15 \mathrm{MPa} \sqrt{\mathrm{m}}(\mathrm{F})$. Evidence of the Stage I-Stage II transition was not observed in the fracture surface morphology, nor was it expected.

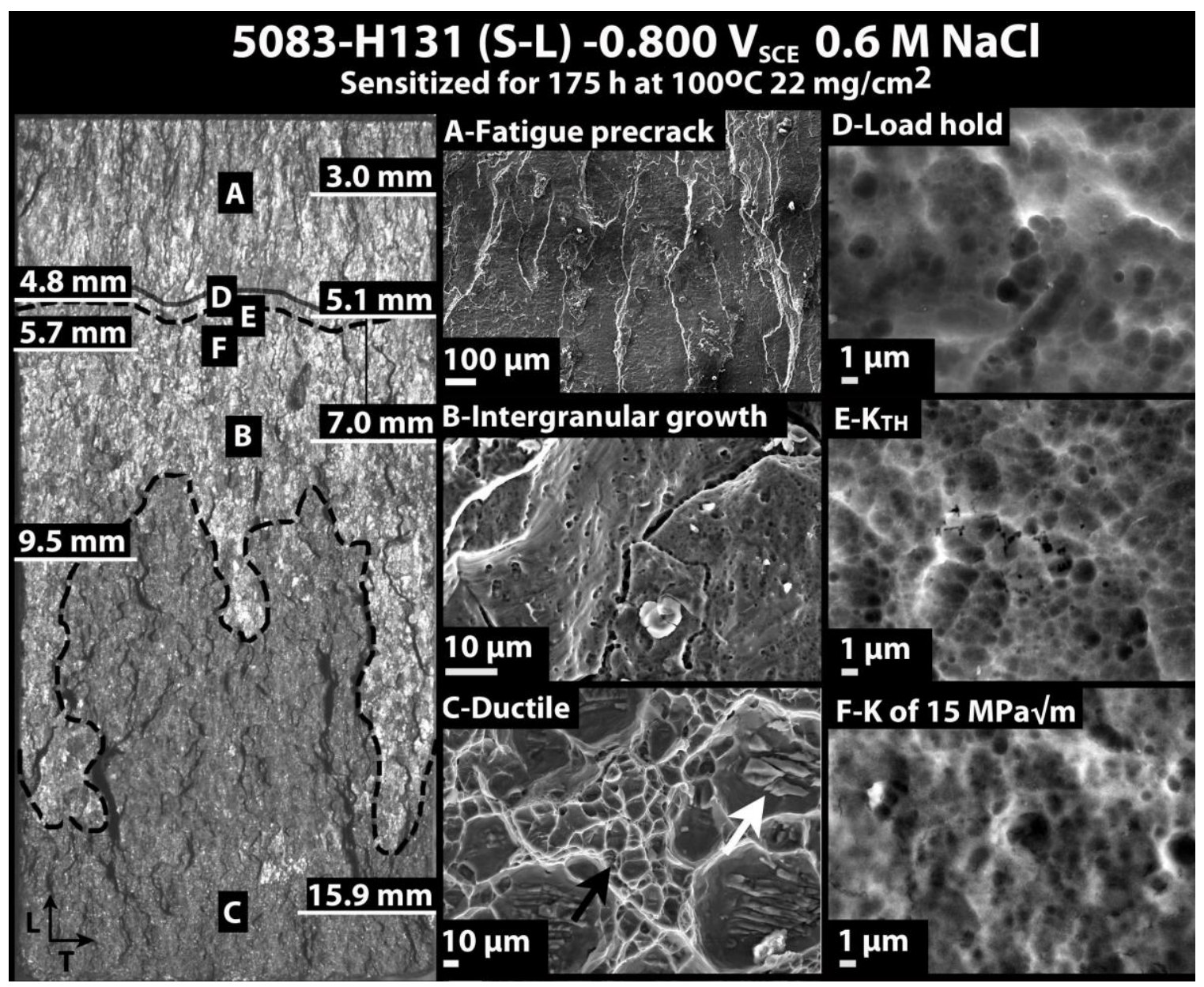

Figure 2.20 Optical image (left) of the IGSCC fracture surface of 5083-H131 (S-L) sensitized for $175 \mathrm{~h}$ at $100^{\circ} \mathrm{C}\left(22 \mathrm{mg} / \mathrm{cm}^{2}\right)$ and loaded in $0.6 \mathrm{M} \mathrm{NaCl}$ solution at $-0.800 \mathrm{~V}_{\mathrm{SCE}}$, with SEM fractographs portraying specific regions of the surface. Labels on the optical image refer to dcPD measured crack length for each stage of IGSCC in Fig. 2.7. 
Figure 2.20(A-C) distinguishes the three fracture modes during the constant displacement rate subcritical cracking experiment (dcPD results in Fig. 2.7). The midsection of the fatigue precrack in air (A), produced with $K_{\max }$ of $6.5 \mathrm{MPa} \sqrt{\mathrm{m}}$ and $K_{\min } / K_{\max }$ of 0.1 , is characterized by a relatively flat transgranular surface. The surface is decorated with shallow dimples representative of matrix and cathodic particle dissolution, as $\beta$ precipitation is not expected along this transgranular fatigue crack surface. The intergranular region (B) shows relatively flat grain boundary fracture interrupted by various shallow dimples, with significant out-of-plane attack that resembles trenching. The out of plane dimples along grain boundaries are likely representative of small-localized corrosion regions, possibly triggered by $\beta$ dissolution. The final fracture surface $(C)$ is exclusively ductile, consisting of particle-containing microvoids. Both large (white arrow) and small (black arrow) voids are evident, with respective large constituent and small dispersoid initiating particles at the base of the voids, similar to that seen in Fig. 2.18(A-C).

Figure 2.20(D-F) shows similar features at high magnification for both IGC and IGSCC of 5083-H131 at different growth rates and K. Growth during IGC (D) is characterized by evenly distributed dimples, without initiating particles present. This region was exposed to solution for the longest time; therefore, the low volume of shallow dimples could be due to uniform corrosion damage. These dimples, however, are deeper than those in as-received specimens (Fig. 2.19A), suggesting an origin from $\beta$ dissolution on sensitized grain boundaries. Considering IGSCC with increasing $\mathrm{K}$ above $\mathrm{K}_{\mathrm{TH}}$, similar intergranular features are observed during Stage I and II growth Fig. 2.20(E,F). These intergranular surfaces have three aspects in common: (a) relatively flat regions about the size of an LT grain in Fig. 2.1, separated by short out-of-plane grain boundary cracking in the $\mathrm{S}$ direction, 
(b) each relatively smooth grain boundary fracture surface (LT) is decorated with shallow dimples, likely caused by localized matrix and/or particle dissolution, and (c) no evidence of microvoid dimples with initiation particles. Examples of the closely spaced dimples are evident during the initiation of IGSCC at $\mathrm{K}_{\mathrm{TH}}(\mathrm{E})$, and during Stage II growth (F). In these images, the dimple spacing is on the order of $1-2 \mu \mathrm{m}$, which is larger than reported $\beta$ spacing of about $300 \mathrm{~nm}$ for this alloy and sensitization condition [63]. If $\beta$ dissolution is the source of these dimples, the larger size and spacing shown in Fig. 2.20(E,F) suggests extensive corrosion of the matrix and/or limited SEM resolution of the corroded surface.

To analyze the effect of sensitization on IGSCC, Fig. 2.21 compares IGSCC fracture surfaces at $\mathrm{K}_{\mathrm{TH}}$ for low sensitized ((A,B): $30 \mathrm{~d}$ at $\left.60^{\circ} \mathrm{C}, 9 \mathrm{mg} / \mathrm{cm}^{2}\right)$ and highly sensitized ((C,D): $30 \mathrm{~d}$ at $\left.100^{\circ} \mathrm{C}, 50 \mathrm{mg} / \mathrm{cm}^{2}\right)$ 5083-H131. The low-sensitized specimen remained in solution at OCP for $3 \mathrm{~h}$ after final fracture, while the higher sensitized specimen was removed from solution immediately after fracture. For the resistant case in (A,B), IGSCC damage is intermixed with ductile rupture at $\mathrm{K}_{\mathrm{TH}}\left(18.5 \mathrm{MPa} \sqrt{\mathrm{m}}_{\mathrm{m}}\right.$ after $200 \mu \mathrm{m}$ of IGC-crack extension, Fig. 2.12). Ductile regions in Fig. 2.21A contain microvoids initiating from large constituent particles similar to those seen during cracking in air (Fig. 2.18B). A discrete relatively flat region (B) resembles intergranular cracking seen in Fig. 2.20A, with shallow dimples and some particles that were likely affected by post-test corrosion damage. Arrows in Fig. 2.21B highlight smaller cathodic particles (likely Mn-rich dispersoids) with dissolution of the surrounding matrix (anodic particles would have been dissolved completely). An abrupt transition occurred, from mixed-discrete IGSCC and ductile regions to a majority of ductile regions, after $0.8 \mathrm{~mm}$ of growth and at $\mathrm{K}$ of $23.3 \mathrm{MPa} \sqrt{\mathrm{m}}$ (not shown). 


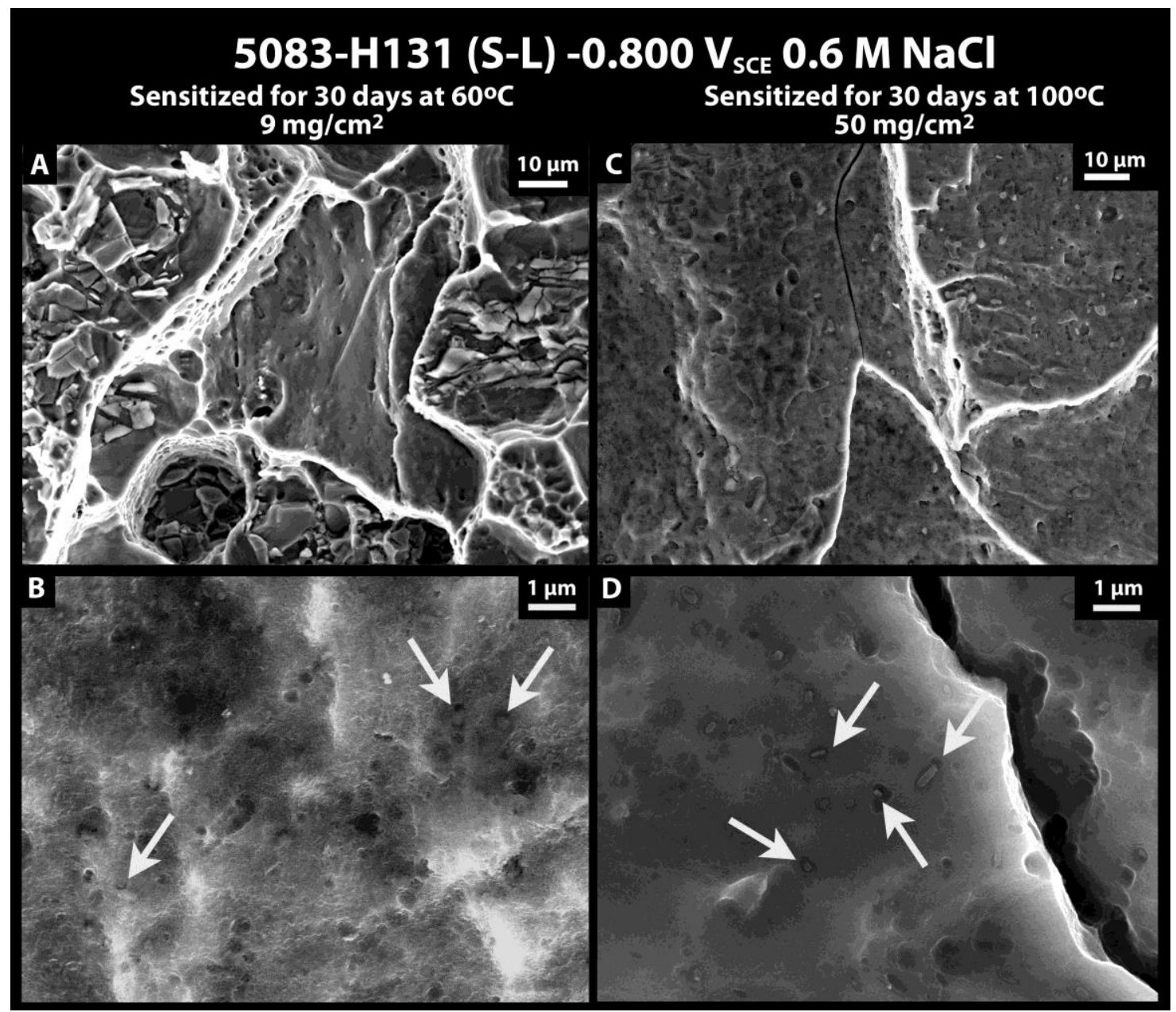

Figure 2.21 SEM fractographs representing (S-L) fracture surfaces of (A-B) low sensitized $\left(30 \mathrm{~d}, 60^{\circ} \mathrm{C}, 9 \mathrm{mg} / \mathrm{cm}^{2}\right)$ and $(C-D)$ highly sensitized $\left(30 \mathrm{~d}, 100^{\circ} \mathrm{C}, 50 \mathrm{mg} / \mathrm{cm}^{2}\right)$ $5083-\mathrm{H} 131$ immersed in $0.6 \mathrm{M} \mathrm{NaCl}$ at $-0.800 \mathrm{~V}_{\mathrm{SCE}}$. Intergranular regions are shown in detail in (B) and (D).

The fracture surface (Fig. 2.21(C,D)) of the highly sensitized specimen at $\mathrm{K}_{\mathrm{TH}}$ is exclusively IGSCC, as shown in (C) and detailed in (D). This IGSCC surface has the three aspects also observed in Fig. 2.20(B,D-F): (a) flat (LT) grain sized regions separated by out-of-plane grain boundary cracking in the S direction, (b) the smooth grain boundary (LT) fracture surface is decorated with dimples, caused by localized matrix dissolution surrounding particles (shown with arrows), and (c) no evidence of microvoid dimples with initiating particles. 


\subsection{DISCUSSION}

Subcritical cracking properties, including IGC growth rate (da/dt IGC), threshold stress intensity $\left(\mathrm{K}_{\mathrm{TH}}\right)$, and Stage II crack growth rate $\left(\mathrm{da} / \mathrm{dt}_{\mathrm{II}}\right)$, were determined from high resolution kinetics of the sort shown in Fig. 2.7 for the susceptible S-L orientation of 5083H131 fully immersed in $0.6 \mathrm{M} \mathrm{NaCl}$ and polarized to $-0.800 \mathrm{~V}_{\text {SCE }}$. These IGC and IGSCC properties were correlated with sensitization temperature $\left(60^{\circ} \mathrm{C}, 80^{\circ} \mathrm{C}\right.$, and $\left.100^{\circ} \mathrm{C}\right)$ and exposure time ( $3 \mathrm{~d}$ to $120 \mathrm{~d}$ ), as well as with DoS measured by nitric acid mass loss testing (ASTM G67 [21]) for engineering consideration. Intergranular corrosion growth rate increases, $\mathrm{K}_{\mathrm{TH}}$ decreases, and da/dt $\mathrm{dI}_{\mathrm{II}}$ increases with increasing sensitization exposure in the range of $60^{\circ} \mathrm{C}$ to $100^{\circ} \mathrm{C}$ (see Figs. 2.9-2.10, 2.13-2.15, and 2.17). Four points are notable: (1) the experimental approach provides the first reported measurement of IGC extension ahead of an occluded fatigue crack tip stressed at low $\mathrm{K}$ and can be compared to measured rates without stress, (2) substantial IGSCC was produced in microstructures sensitized at $60^{\circ} \mathrm{C}$, which is the lowest temperature investigated to date with regard to quantitative resistance to IGSCC, (3) crack growth rates measured in 5083-H131 sensitized to high DoS at $80^{\circ} \mathrm{C}$ and $100^{\circ} \mathrm{C}$ align with crack growth rates measured in $5083-\mathrm{H} 321$ sensitized to high DoS at $175^{\circ} \mathrm{C}[1]$, indicating that cracking kinetics may not be sensitive to sensitization temperature, and (4) a critical DoS level of $10 \mathrm{mg} / \mathrm{cm}^{2}$ must be exceeded for substantial IGSCC susceptibility, independent of the time-temperature sensitization condition. This critical sensitization demonstrates the requirement for intergranular $\beta$ in IGSCC, and helps develop the proposed mechanism for IGSCC based on coupled $\alpha-\beta$ dissolution and $\mathrm{H}$ embrittlement. The roles of sensitization in controlling fracture toughness, IGSCC and IGC 
are considered in the following sections, with a focus on developing the dissolution- $\mathrm{H}$ embrittlement mechanism for IGSCC in Al-Mg alloys.

\subsubsection{Fracture toughness as a function of DoS}

Elastic-plastic fracture toughness (S-L), $21.7 \mathrm{MPa} \sqrt{\mathrm{m}}$ measured for as-received $\left(3 \mathrm{mg} / \mathrm{cm}^{2}\right)$ 5083-H131, is consistent with reported fracture toughness of $18.6 \mathrm{MPa} \sqrt{\mathrm{m}}$ for 5083-H131 (S-L) [39]. Higher values were reported for solution heat treated (SHT) and cold rolled 5083-H131 [59]; though these values are suspect due to the minimal difference in T-L (29.3 MPa $\sqrt{m}), \mathrm{L}-\mathrm{T}(28.3 \mathrm{MPa} \sqrt{\mathrm{m}})$, and S-L (33.3 MPa $\sqrt{\mathrm{m}})$ crack orientations. Data for a range of precipitation hardened Al alloys suggest that the S-L toughness is about twothirds of typical values reported for L-T and T-L orientations owing to anisotropic grain structure $[49,60]$. On this basis, the $\mathrm{S}-\mathrm{L}$ values of $\mathrm{K}_{\mathrm{JIC}}$ reported in this study are reasonable and validate the elastic-plastic J-integral analysis method.

While limited, fracture toughness results suggest that $\mathrm{K}_{\text {IIC }}$ increases (from $21.7 \mathrm{MPa} \sqrt{\mathrm{m}}_{\mathrm{m}}$ to $27.5 \mathrm{MPa} \sqrt{\mathrm{m}}$ ) with increasing DoS (from $3 \mathrm{mg} / \mathrm{cm}^{2}$ to $50 \mathrm{mg} / \mathrm{cm}^{2}$ ), as shown in Fig. 2.14. Sensitization dependent fracture toughness was also reported for 5083-H116 (S-L), characterized with the chevron notch method [15]. Fracture toughness for an unsensitized specimen increased from $36 \mathrm{MPa} \sqrt{\mathrm{m}}$ to $50 \mathrm{MPa} \sqrt{\mathrm{m}}$ with increasing sensitization exposure time up to $200 \mathrm{~h}$ at $175^{\circ} \mathrm{C}\left(\mathrm{DoS}\right.$ of $\left.60 \mathrm{mg} / \mathrm{cm}^{2}\right)$ [15]. For exposures between $200 \mathrm{~h}$ and $60 \mathrm{~d}$ at $175^{\circ} \mathrm{C}, \mathrm{K}_{\mathrm{IC}}$ varied randomly in the range of $43 \mathrm{MPa} \sqrt{\mathrm{m}}$ to $55 \mathrm{MPa} \sqrt{\mathrm{m}}$ [15]. Toughness measured by the chevron notched method is likely elevated compared to the initiation toughness technique described in Fig. 2.6 owing to R-curve, crack length detection, and plasticity effects $[43,61]$. Moreover, the yield strength of the H116 temper of 5083 $(188 \mathrm{MPa}[15,16])$ is lower than that of 5083-H131 (335 MPa [36]). The important point 
is that air fracture toughness is not degraded due to sensitization and the associated presence of very high levels of grain boundary $\beta$ precipitation.

\subsubsection{Crack growth rate resolution}

The fracture toughness experiments conducted in moist air provide insight regarding the factors that govern the da/dt resolution limit suggested by the data in Fig. 2.5. This lowlevel da/dt, at $\mathrm{K}$ below $\mathrm{K}_{\mathrm{JIC}}$ and in the absence of IGSCC, is attributed to contributions from three sources: (1) water vapor HEAC, (2) low temperature creep crack growth, and (3) plasticity from rising $\mathrm{K}$ loading. Creep crack growth and water vapor HEAC were reasonably eliminated for sensitized $5083-\mathrm{H} 131\left(80^{\circ} \mathrm{C}\right.$ for 45 d) loaded rapidly (30 $\mathrm{MPa} \sqrt{\mathrm{m}} / \mathrm{h}$ ) in air; due to rapid loading, only time-independent crack tip plasticity is considered in this experiment. A dominant role of electrical resistivity/resistance increase due to crack tip plastic deformation and increasing dislocation density is indicated by the increased voltage measurement with K. Specifically, this measured da/dt vs. K response is comparable to dcPD results reported for an ultra-high strength martensitic steel $\left(\sigma_{\mathrm{YS}}=\right.$ 1,700 MPa) stressed in an environment where HEAC was not evidenced by SEM and room temperature creep is not expected $[57,62]$. Assuming that false da/dt is proportional to crack tip plastic strain given by $\mathrm{K}^{2} / \sigma_{\mathrm{YSE}}$, these extensive steel results suggest that the plasticity-based false da/dt for 5083 should rise from $1.1 \mathrm{~nm} / \mathrm{s}$ to $1.8 \mathrm{~nm} / \mathrm{s}$ as K rises from $10 \mathrm{MPa} \sqrt{\mathrm{m}}$ to $20 \mathrm{MPa} \sqrt{\mathrm{m}}$. The measured values in Fig. 2.5 for this fast rate experiment are $0.3 \mathrm{~nm} / \mathrm{s}$ to $1.4 \mathrm{~nm} / \mathrm{s}$ at these $\mathrm{K}$ levels. Considering that the precise dependence of the false $\mathrm{da} / \mathrm{dt}$ on crack tip plasticity is unknown, it is reasonable to conclude that time-independent crack tip plasticity and blunting geometry change are capable of producing increased dcPD which translates to a false da/dt at the levels shown by the fast-rate da/dt data in Fig. 2.5. 
Two moist air experiments were conducted at slow-loading rate to assess the extent to which water vapor HEAC and creep crack growth contribute to the da/dt reported in Fig. 2.5. Creep occurs in Al-Mg alloys when stressed at $20^{\circ} \mathrm{C}$ [63]; however, creep crack growth rates were not reported. Very slow growth rates of $0.05 \mathrm{~nm} / \mathrm{s}$ were measured in recrystallized $5083-\mathrm{H} 321$ (S-L) stressed at $23^{\circ} \mathrm{C}$ and a high $\mathrm{K}$ of $25 \mathrm{MPa} \sqrt{\mathrm{m}}$ while cathodically polarized $\left(-1.4 \mathrm{~V}_{\mathrm{SCE}}\right)$ in $\mathrm{NaCl}$ solution [12]. Since IGSCC is essentially precluded at this cathodic potential [12], these rates provide an approximate upper bound for creep crack growth, which is well below the false da/dt ( $\sim 2 \mathrm{~nm} / \mathrm{s}$, Fig. 2.5$)$ created by crack tip plasticity at this $\mathrm{K}$ level. Lee et al. used a micromechanics model to estimate the rate of creep crack growth in 5083 (about $0.1 \mathrm{~nm} / \mathrm{s}$ for high $\mathrm{K}$ ) [24]. This model has not been validated for aluminum alloys. The specific mechanism and model of cavity growth $[24,64]$ used by Lee et al. were not specified, and the input parameters were largely selected for 5083 to enforce a fit with the experimental da/dt values from the cathodic polarization experiments $[12,24]$. Collectively, these results suggest a very small role of creep crack growth during loading in air of 5083.

The somewhat higher da/dt values measured during slow loading of as-received and sensitized 5083-H131 in air are attributed to experimental variability and water vapor HEAC. Limited literature data suggest that da/dt $\mathrm{II}$ is $1.3 \mathrm{~nm} / \mathrm{s}$ for $5456-\mathrm{H} 321(\mathrm{~S}-\mathrm{L})$ stressed at $\mathrm{K}$ of $28 \mathrm{MPa} \sqrt{\mathrm{m}}$ in $100 \%$ relative humidity $(\mathrm{RH})$ at $25^{\circ} \mathrm{C}$ [65]. More extensive data for 7075-T651 (S-L) show that da/dt $\mathrm{dI}_{\mathrm{II}}$ is $5 \mathrm{~nm} / \mathrm{s}$ for $100 \% \mathrm{RH}$ and $\mathrm{K}$ above $12 \mathrm{MPa} \sqrt{\mathrm{m}}$ (with $\mathrm{K}_{\mathrm{TH}}$ of $8 \mathrm{MPa} \sqrt{\mathrm{m}}$ ) [65-68]. This rate declines to $2 \mathrm{~nm} / \mathrm{s}$ for $40 \% \mathrm{RH}$ typical of a laboratory environment [65-67]. Assuming this same water vapor pressure dependence for Al-Mg, 
the range of $\mathrm{da} / \mathrm{dt}_{\mathrm{II}}$ possible for water vapor driven HEAC in $5083-\mathrm{H} 131$ at high $\mathrm{K}$ is $\sim 0.5 \mathrm{~nm} / \mathrm{s}$ to $1.3 \mathrm{~nm} / \mathrm{s}$.

This analysis shows that plasticity-based false da/dt is well represented by the fastloading da/dt data in Fig. 2.5. The increases in da/dt, above this inherent resolution limit, are likely due to water vapor HEAC, which could progress at $0.5 \mathrm{~nm} / \mathrm{s}$ to $1.3 \mathrm{~nm} / \mathrm{s}$ independent of $\mathrm{K}$ above a threshold of order $10 \mathrm{MPa} \sqrt{\mathrm{m}}$. The difference in da/dt vs. K for the slow $\mathrm{dK} / \mathrm{dt}$ experiments with as-received and sensitized 5083-H131 (S-L) is not understood, and appears to reflect the variability inherent in this complex dcPD measurement of very slow growth rates. These results provide the foundation for characterization of the effect of sensitization on IGSCC kinetics; rates represented by the dashed line Fig. 2.5 are used as the $\mathrm{K}$ dependent crack growth rate resolution limit for detection of IGSCC.

\subsubsection{Mechanism of IGSCC in sensitized Al-Mg alloys}

The proposed mechanism for IGSCC in low temperature sensitized Al-Mg, originally proposed by Jones et al., centers on grain boundary $\beta$ dissolution coupled with boundary embrittlement by atomic hydrogen $(\mathrm{H})$ as schematically represented in Fig. 2.22 for discontinuously distributed $\beta$ [12]. Such $\beta$ may influence the crack growth rate according to the three numbered regions in Fig. 2.22. First, the critical-necessary role of the occluded crack chemistry follows from electrochemical studies of IGC in Al-Mg alloys exposed in chloride solutions near the open circuit potential (OCP) $[6,17,18]$. Specifically, dissolution of $\beta$ occurs at potentials above $-1.015 \mathrm{~V}_{\mathrm{SCE}}$ to $-0.960 \mathrm{~V}_{\mathrm{SCE}}$ and triggers further dissolution of the Al-Mg solid solution matrix leading to near-saturation of crack tip $\mathrm{Al}^{3+}$ and $\mathrm{Mg}^{2+}$ (labeled (1) in Fig. 2.22) [17,18]. Hydrolysis of these cations produces a highly acidic crack 
tip solution $[22,23]$, for significant $\mathrm{H}$ production and uptake. An acidic crack tip is critical for IGSCC propagation. This hypothesis is amplified and confirmed by crack growth rate experiments and detailed crack electrochemistry considerations in Chapter 3.

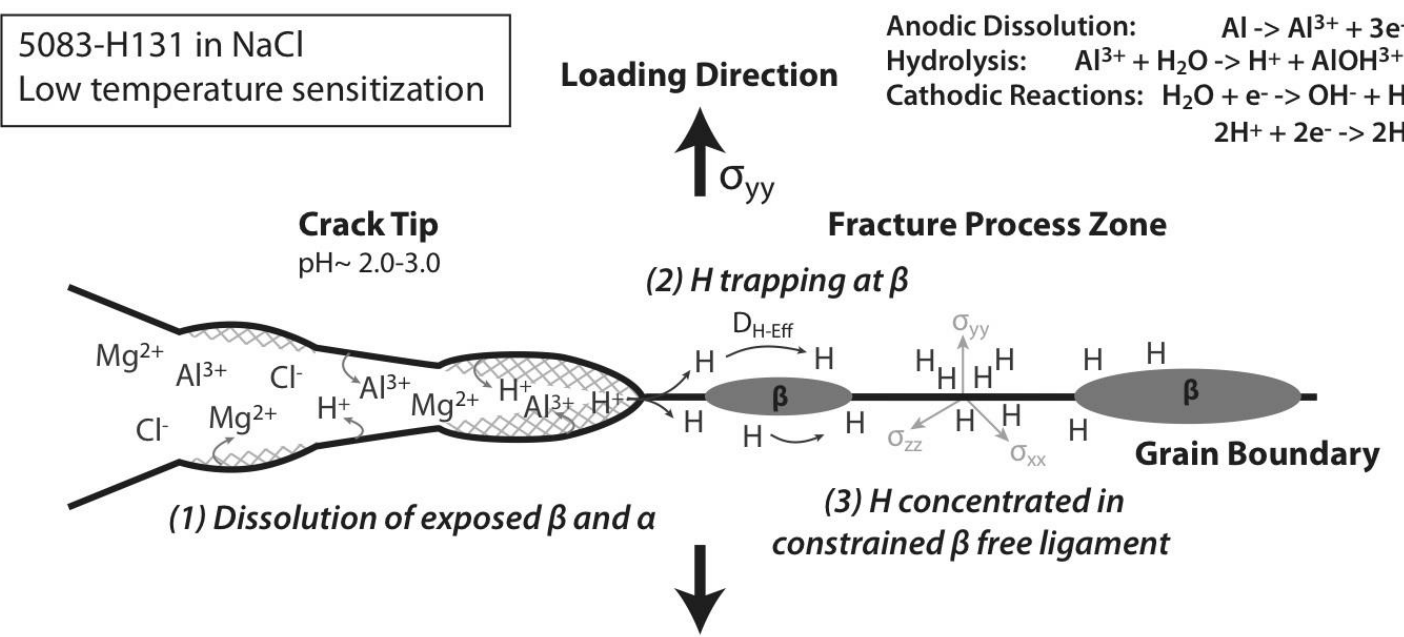

Figure 2.22 The interactive role of grain boundary $\beta$ dissolution along the corroding crack tip front for $\mathrm{H}$ production, and $\mathrm{H}$ uptake to $\beta$-matrix interfaces and $\beta$-free ligaments at the fracture process zone along an Al grain boundary surface.

Beta may also influence where $\mathrm{H}$ concentrates ahead of the crack tip. Specifically, after permeation into the crack tip fracture process zone (FPZ), H likely localizes at $\beta$ (not contacting the electrolyte) by trapping at either the matrix- $\beta$ interface (labeled (2) in Fig. 2.22) or the hydrostatic stress field between $\beta$ (labeled (3) in Fig. 2.22). The local tensile stress ahead of the crack tip, which is central to boundary decohesion, could be elevated by a stress concentration at the non-deformable $\beta$ and within the $\alpha$ ligament by constraint associated with $\beta$ [69]. The combination of increased hydrostatic/tensile stress and high $\mathrm{H}$ concentration at the FPZ results in grain boundary decohesion [28]. This will be discussed in Section 2.5.5.3. 
Explanation of the important effect of DoS on da/dt vs. K for IGSCC in 5083 should follow from the mechanism represented in Fig. 2.22. The threshold, $\mathrm{K}_{\mathrm{TH}}$, represents the FPZ equilibrium where crack tip tensile stress, perhaps $\beta$-microstructure enhanced, just exceeds the cohesive strength of atomic bonding across an $\alpha-\alpha$ grain boundary. This strength is lowered by local $\mathrm{H}$ that accumulates in response to the crack tip stress [70]. The transition to a relatively $\mathrm{K}$-independent Stage II growth is a result of $\mathrm{H}$ diffusion rate limitation in the FPZ [70,71]. The Stage II crack growth rate, following the scenario in Fig. 2.22, is given by [70]:

$$
\left(\frac{d a}{d t}\right)_{I I}=\frac{4 D_{H-E F F}}{x_{c r i t}}\left[\operatorname{erf}^{-1}\left(1-\frac{C_{H-c r i t}}{C_{H \sigma}}\right)\right]^{2}
$$

where $\mathrm{D}_{\mathrm{H}-\mathrm{EFF}}$ is the trap sensitive diffusivity of $\mathrm{H}, \mathrm{C}_{\mathrm{H}-\text { crit }}$ is the critical $\mathrm{H}$ concentration required for local intergranular decohesion, dependent on local tensile stress and thus microstructure-scale plasticity, $\mathrm{x}_{\mathrm{CRIT}}$ is the critical distance ahead of the crack tip where $\mathrm{H}$ cracking nucleates, and $\mathrm{C}_{\mathrm{H} \sigma}$ is the local stress enhanced $\mathrm{H}$ concentration at $\mathrm{x}_{\mathrm{CRIT}}$ associated with crack tip surface $H$ solubility, the overpotential for $H$ production $\left(\eta_{H}\right)$, and the H-trap binding energy for the intergranular crack path.

This growth rate model, and particularly the coefficient of 4 , is based on the assumption that crack tip advance is discontinuous, occurring over a distance equal to $\mathrm{x}_{\mathrm{CRIT}}$ [70,71]. It follows that da/dt in Eqn. 2.8 is the ratio of this distance ( $\mathrm{x}_{\mathrm{CRIT}}$ ) to the time required for trap sensitive $\mathrm{H}$ diffusion to supply a stress enhanced $\mathrm{H}$ concentration $\left(\mathrm{C}_{\mathrm{H \sigma}}\right)$ equal to $\mathrm{C}_{\mathrm{H}-\text { crit }}$ at the damage location set by $\mathrm{x}_{\mathrm{CR}}$ IT. In this formulation, the crack tip stress field, perhaps interacting with a microstructural distance such as $\beta$ nearest-neighbor spacing and/or

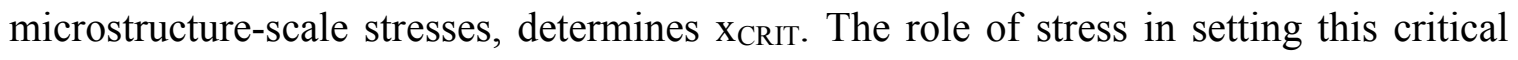
distance is likely dominant. 
Literature reports of the fastest-measured da/dtII for a wide range of high strength alloys and H-producing environments, interpreted in terms of Eqn. 2.8, established an $\mathrm{x}_{\mathrm{CRIT}}$ of $0.9 \mu \mathrm{m}$ for the near-upper bound case where the inverse error function term is 1.0 [71]. A DoS independent $D_{\text {H-EFF }}$ was reported as $10^{-10} \mathrm{~cm}^{2} / \mathrm{s}\left(25^{\circ} \mathrm{C}\right)$ for the specific plate of 5083H131 under study [72]. This value of $\mathrm{D}_{\mathrm{H}-\mathrm{EFF}}$ provides an important starting point for consideration of da/dt II through Eqn. 2.8; however, the interaction of H and FPZ trap sites complicates this analysis $[72,73]$ as considered in detail in Chapter 4. Both $\mathrm{H}$ concentration-based terms and $\mathrm{x}_{\mathrm{CRIT}}$ in Eqn. 2.8 are likely influenced by $\beta$ size and spacing, as governed by sensitization time and temperature. The DoS dependence of IGSCC in 5083-H131 is investigated using this model in the following sections.

\subsubsection{Literature on IGSCC kinetics for sensitized AI-Mg alloys}

Intergranular SCC properties were reported for Al-Mg alloys with a variety of sensitization treatments exclusively produced by exposure at temperatures above $70^{\circ} \mathrm{C}[1,7,11,12,14,16,34,35]$. Threshold stress intensities were as low as $1 \mathrm{MPa} \sqrt{\mathrm{m}}$ and rates of environment-assisted growth spanned the range from $0.1 \mathrm{~nm} / \mathrm{s}$ to as high as $13,000 \mathrm{~nm} / \mathrm{s}$, depending on specific test conditions. The present results are consistent with literature results which show that $\mathrm{K}_{\mathrm{TH}}$ falls to $2 \mathrm{MPa} \sqrt{\mathrm{m}}$ and da/dtII rises to $10,000 \mathrm{~nm} / \mathrm{s}$ or higher with increasing sensitization time for temperatures between $60^{\circ} \mathrm{C}$ and $100^{\circ} \mathrm{C}$. Quantitative comparisons between literature data and the current results are complicated by differences in critical variables including degree of recrystallization and temper, dropwise vs. full immersion environmental exposure, electrochemical potential, static or falling vs. actively rising $\mathrm{K}$, and precision of the crack length monitoring method employed. Moreover, variations in material heat and NAMLT measurement procedure likely caused 
differences in the DoS values used to correlate da/dtII and $\mathrm{K}_{\mathrm{TH}}$. None-the-less, comparisons with these studies help further understanding of IGSCC in 5083, specifically by demonstrating how experimental and environmental differences affect the role of $\beta$ in IGSCC and, more specifically, the critical sensitization for the onset of severe IGSCC.

Intergranular SCC growth rates were measured using dcPD for 5083-H321, sensitized at three DoS levels and stressed under full immersion in $0.6 \mathrm{M} \mathrm{NaCl}$ at OCP [12]. A thick plate $(2.54 \mathrm{~cm})$ was initially solution heat treated $(\mathrm{SHT})$, rolled and fully recrystallized, then machined into compact tension (CT) specimens in the T-L orientation with the crack growth direction parallel to the plate rolling direction [12]. These CT specimens were sensitized for $1 \mathrm{~h}, 10 \mathrm{~h}$, and $100 \mathrm{~h}$ at $175^{\circ} \mathrm{C}$ [12]. Crack growth rates at $25 \mathrm{MPa} \sqrt{\mathrm{m}}$ increased slowly with sensitization at $1 \mathrm{~h}$ and $10 \mathrm{~h}(0.1 \mathrm{~nm} / \mathrm{s}$ and $0.25 \mathrm{~nm} / \mathrm{s}$ respectively), then increased to $0.56 \mathrm{~nm} / \mathrm{s}$ for the highest sensitization $\left(100 \mathrm{~h}\right.$ for $175^{\circ} \mathrm{C}$, (x) in Fig. 2.23) [12]. This high sensitization produced a significant coverage of discrete $\beta$ on boundaries studied by TEM, though DoS quantification by NAMLT was not reported [12]. Consistent with the present results, crack growth rates increased with sensitization exposure time. However, these reported crack growth rates are unexpectedly much slower than rates in the present study (Fig. 2.23); intergranular crack growth in the T-L orientation should not be significantly tortuous along isotropic recrystallized grains (sized on the order of $10 \mu \mathrm{m}$ to $25 \mu \mathrm{m}$ ), and growth rates should be rapid at the high $\mathrm{K}$ of $25 \mathrm{MPa} \sqrt{\mathrm{m}}$. The cause of these slow rates is not understood. Results identify a role of $\beta$ in IGSCC using the combination of: (a) sensitization time dependent IGSCC rates, and (b) corresponding grain boundary $\beta$ coverage analyzed with TEM [12]. Unfortunately, the narrow range of sensitization 
conditions limited investigation of the influence of $\beta$ size, spacing, and morphology; a quantitative correlation was not reported.

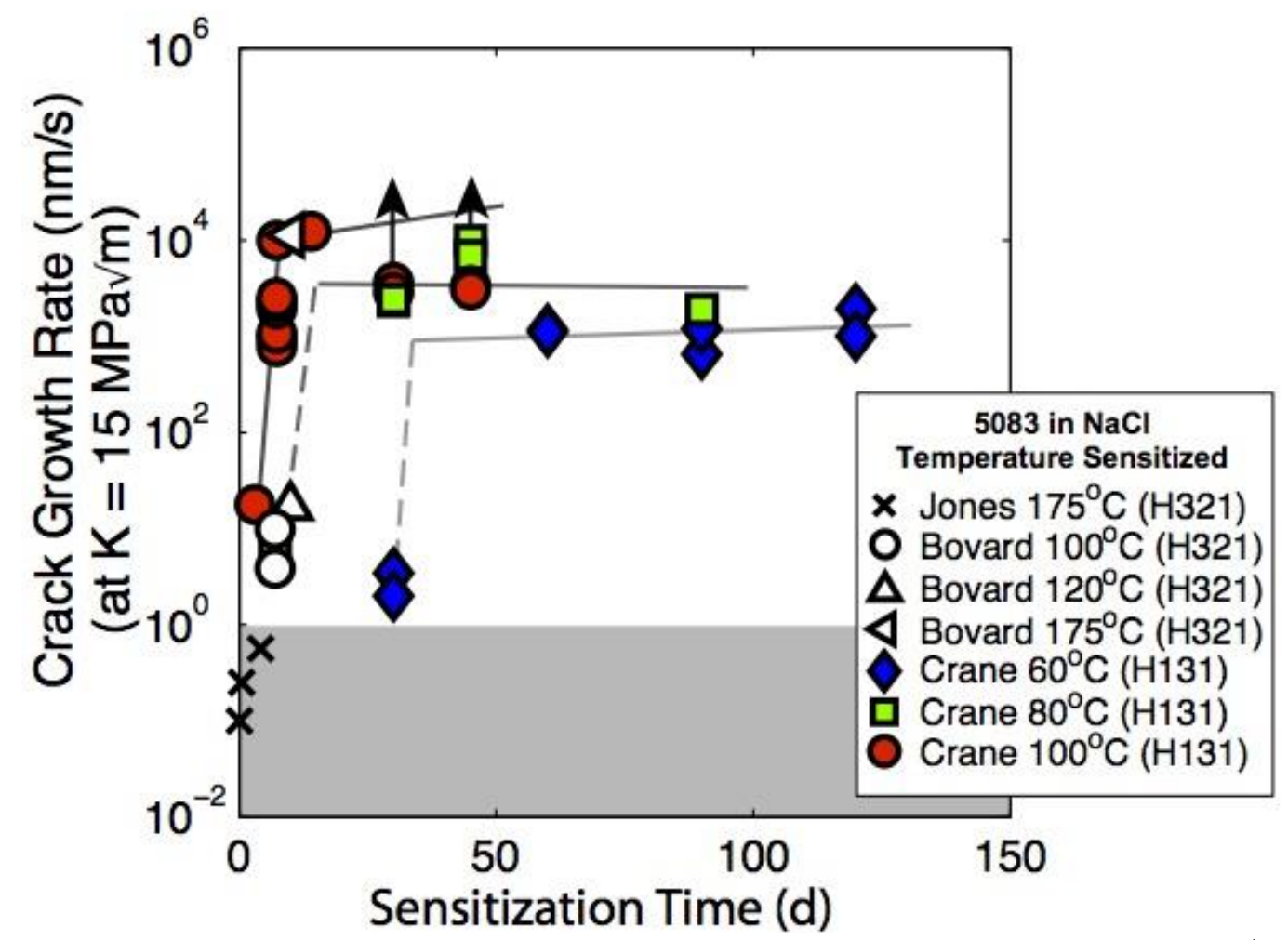

Figure 2.23 Sensitization time dependence of IGSCC growth rate at K of $15 \mathrm{MPa} \sqrt{\mathrm{m}}$ in 5083-H131. Crack growth rates measured while fully immersed in $0.6 \mathrm{M} \mathrm{NaCl}$ solution at fixed potential of $-0.800 \mathrm{~V}_{\mathrm{SCE}}$ are represented by solid points (Fig. 2.15). The grey band represents the upper bound resolution limit of the dcPD measurement technique. Stage II crack growth rates plotted as $(\mathrm{O}, \Delta$, and $\triangleleft)$ represent (S-L) 5083-H321 sensitized at $100^{\circ} \mathrm{C}, 120^{\circ} \mathrm{C}$ and $175^{\circ} \mathrm{C}$, respectively, and exposed to $\mathrm{NaCl}$ by dropwise addition by Bovard [1]. Stage II crack growth rates at $25 \mathrm{MPa} \vee \mathrm{m}$ plotted as (x) represent recrystallized (T-L) $5083-\mathrm{H} 321$ sensitized at $175^{\circ} \mathrm{C}$ and loaded in full immersion $0.6 \mathrm{M} \mathrm{NaCl}$ by Jones et al. [12].

Two separate studies used a large range of sensitization conditions to establish a critical DoS for IGSCC susceptibility in 5083 in the S-L orientation; one demarked by a severe increase in Stage II IGSCC growth rate with sensitization (Figs. 2.23 and 2.24) [1], and the other with a severe drop in $\mathrm{K}_{\mathrm{TH}}$ with sensitization (Figs. 2.25 and 2.26) [34]. Both data sets are compared with results from the present study. 
Crack growth rates were measured in sensitized 5083-H321 (S-L) during dropwise addition of $\mathrm{NaCl}$ [1]. Fatigue cracked cantilever beam specimens machined from a $2.54 \mathrm{~mm}$ thick plate were sensitized at $100^{\circ} \mathrm{C}$ and $120^{\circ} \mathrm{C}$ for low $\mathrm{DoS}$ and at $175^{\circ} \mathrm{C}$ for high sensitizations. Crack growth rates increased three orders of magnitude $(18 \mathrm{~nm} / \mathrm{s}$ to $11,300 \mathrm{~nm} / \mathrm{s}$ ) between sensitization levels of $32 \mathrm{mg} / \mathrm{cm}^{2}$ and $44 \mathrm{mg} / \mathrm{cm}^{2}$ (Fig. 2.24) [1]. This jump occurred between specimens sensitized at $120^{\circ} \mathrm{C}$ for $10 \mathrm{~d}$ and $175^{\circ} \mathrm{C}$ for $10 \mathrm{~d}$; therefore, these results do not confirm a critical DoS dependence over a critical temperature dependence [1].

While both this study and the present study, examined S-L oriented specimens taken from a thick semi-recrystallized plate of 5083, quantitative comparisons are limited due to: (a) possible $\beta$ morphology differences owing to differences in sensitization temperatures $\left(100^{\circ} \mathrm{C}\right.$ and less vs. $\left.175^{\circ} \mathrm{C}\right)$, and (b) differences in crack tip chemistry due to experimental exposure (full immersion vs. dropwise addition). Inherent variability in the DoS measurement (ASTM G67 [21]) further complicates comparison because, although the critical DoS level for dropwise addition (between $32 \mathrm{mg} / \mathrm{cm}^{2}$ and $44 \mathrm{mg} / \mathrm{cm}^{2}$ ) is much higher than the present study $\left(10 \mathrm{mg} / \mathrm{cm}^{2}\right.$, Fig. 2.24), reported DoS measurements for 5083 H321 specimens are consistently lower than those measured at similar times and temperatures in the present study on 5083-H131. The fact remains that for similar time and temperature sensitizations, dropwise exposure is not as aggressive with regards to IGSCC for low sensitizations, though growth rates are similar for highly sensitized specimens (at different temperatures). This comparison suggests that high temperature sensitization does not cause a difference in IGSCC growth rates for 5083 at the same DoS level. 


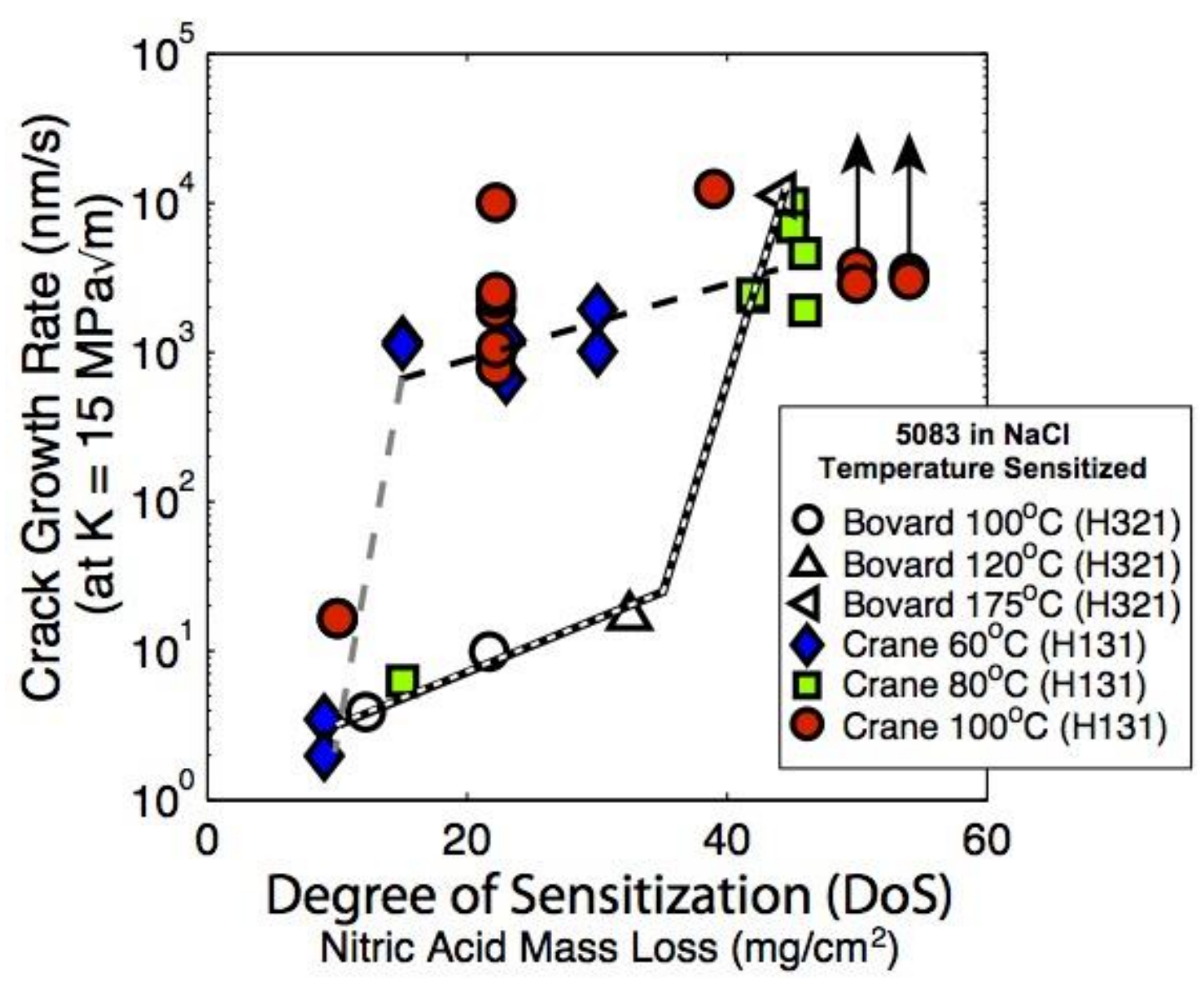

Figure 2.24 Nitric acid mass loss based DoS dependence of IGSCC growth rate at K of $15 \mathrm{MPa} \sqrt{\mathrm{m}}$ for $5083-\mathrm{H} 131$. Crack growth rates measured while fully immersed in $0.6 \mathrm{M} \mathrm{NaCl}$ solution at fixed potential of $-0.800 \mathrm{~V}_{\mathrm{SCE}}$ are represented by solid points (Fig. 2.16). Stage II crack growth rates plotted as (O, $\Delta$, and $\triangleleft)$ are for (S-L) specimens sensitized at $100^{\circ} \mathrm{C}, 120^{\circ} \mathrm{C}$ and $175^{\circ} \mathrm{C}$, respectively, and exposed to $\mathrm{NaCl}$ by dropwise addition by Bovard [1].

The chemistry developed in the crack tip is different in dropwise addition compared to full immersion owing to different separations of anodes and the cathodes. During dropwise addition, cathodic and anodic reactions are restricted to the crack volume where solution is present. An electrochemical connection between the crack tip and bold surface does not exist. In full immersion, the crack tip is connected with the bold surface; anodic reactions occur at the crack tip, while cathodic reactions occur both at the flanks and on the bold 
surface such that a net anodic current flows out of the crack mouth [24]. The location of these reactions significantly changes crack tip chemistry, and $\eta_{\mathrm{H}}$ for $\mathrm{H}$ production and uptake at the crack tip. For example, with dropwise addition the crack solution will tend to become more alkaline due to the local cathodic reactions producing $\mathrm{OH}^{-}$. The crack tip will not acidify, even mildly, with initial passive $\alpha$ dissolution. Higher sensitization for a significant volume of $\beta$ dissolution will be critical to trigger acidification and $\mathrm{H}$ production.

At DoS between $10 \mathrm{mg} / \mathrm{cm}^{2}$ and $32 \mathrm{mg} / \mathrm{cm}^{2} \mathrm{HEAC}$ is retarded with dropwise addition relative to full immersion. Both the lack of acidic crack tip, and the fixed concentration of crack tip $\mathrm{Cl}^{-}$, may limit $\mathrm{H}$ uptake in dropwise addition at low sensitizations. Without ion migration from the bulk environment, the crack tip $\mathrm{Cl}^{-}$concentration will not increase to levels seen in acidic crack tips during full immersion experiments. The breakdown potential of both $\beta$ and 5083 increases with a decrease in $\mathrm{Cl}^{-}$concentration, resulting in an decrease in dissolution rate $[37,74]$. The crack tip potential expected during crack growth in $5083-\mathrm{H} 321\left(22 \mathrm{mg} / \mathrm{cm}^{2}\right)$ during dropwise addition of $\mathrm{NaCl}$ can be predicted by comparing crack growth rates with those of $5083-\mathrm{H} 131$ sensitized to $22 \mathrm{mg} / \mathrm{cm}^{2}$ during full immersion on $\mathrm{NaCl}$ at given applied potentials (Chapter 3). Stage II da/dt at $22 \mathrm{mg} / \mathrm{cm}^{2}$ for dropwise addition is $10 \mathrm{~nm} / \mathrm{s}$ for 5083-H321, da/dt $\mathrm{II}$ of 5083-H131 during full immersion at applied potentials between $-0.960 \mathrm{~V}_{\mathrm{SCE}}$ and $-0.870 \mathrm{~V}_{\mathrm{SCE}}$ is near $10 \mathrm{~nm} / \mathrm{s}$; therefore the potential $(\mathrm{OCP})$ at the crack tip during dropwise addition may be between $-0.960 \mathrm{~V}_{\mathrm{SCE}}$ and $-0.870 \mathrm{~V}_{\mathrm{SCE}}$. The combination of low $\beta$ volume fraction at low sensitizations and lower crack tip potential during dropwise addition (compared to $-0.800 \mathrm{~V}_{\mathrm{SCE}}$ for the present fullimmersion experiments) likely limits acidification and $\alpha$ dissolution for significant crack tip $\mathrm{H}$ production, uptake and rapid crack growth. 
The severe increase in crack growth rate at $30 \mathrm{mg} / \mathrm{cm}^{2}$ during dropwise exposure may be due to a critical volume of $\beta$ that triggers crack tip acidification. The combination of $\alpha$ and $\beta$ dissolution at high sensitization likely saturates the crack tip leading to a maximum overpotential for $\mathrm{H}$ production $\left(\eta_{\mathrm{H}}\right)$ in both full immersion and dropwise environments, which would explain the similar rapid da/dt $/$ in both environments at DoS greater than $40 \mathrm{mg} / \mathrm{cm}^{2}\left(10^{4} \mathrm{~nm} / \mathrm{s}\right.$ in Fig. 2.24). This explanation is developed in Chapter 3.

A critical DoS was also reported for SCC thresholds of 5083-H131 measured by a rising step loading procedure with fatigue cracked samples (S-L) fully immersed in $\mathrm{NaCl}$ with a chromate inhibitor (Fig. 2.25) [34]. Specimens from a $2.54 \mathrm{~mm}$ thick plate were sensitized for a full range of times at three different temperatures, $70^{\circ} \mathrm{C}, 100^{\circ} \mathrm{C}$, and $175^{\circ} \mathrm{C}$. Cracking thresholds were constant, though highly variable with increasing sensitization until a severe drop in threshold occurred after a DoS of $30 \mathrm{mg} / \mathrm{cm}^{2}$ (Fig. 2.25), which correlates with sensitization produced by a $50 \mathrm{~d}$ exposure at $70^{\circ} \mathrm{C}$, or by $3 \mathrm{~d}$ at $100^{\circ} \mathrm{C}$, or by $1.25 \mathrm{~d}$ at $175^{\circ} \mathrm{C}[34,75]$. The critical DoS level for IGSCC susceptibility measured by the step load procedure is much higher than the critical DoS reported with SENT specimens, though the thresholds measured in both experiments are similar for highly resistant microstructures (near $20 \mathrm{MPa} \sqrt{\mathrm{m}}$ for DoS less than $10 \mathrm{mg} / \mathrm{cm}^{2}$ ) and highly susceptible microstructures (at and below $5 \mathrm{MPa} \vee \mathrm{m}$ for DoS greater than $30 \mathrm{mg} / \mathrm{cm}^{2}$ ).

The increased resistance in the step loading procedure between DoS of $10 \mathrm{mg} / \mathrm{cm}^{2}$ and $30 \mathrm{mg} / \mathrm{cm}^{2}$ is likely due to the combination of: (a) a limited generation of a critical acidic crack tip chemistry due to presence of chromate in the occluded crack, and (b) the risingstep loading format. The Cr-bearing passive film that forms on $\alpha$ at the crack tip 


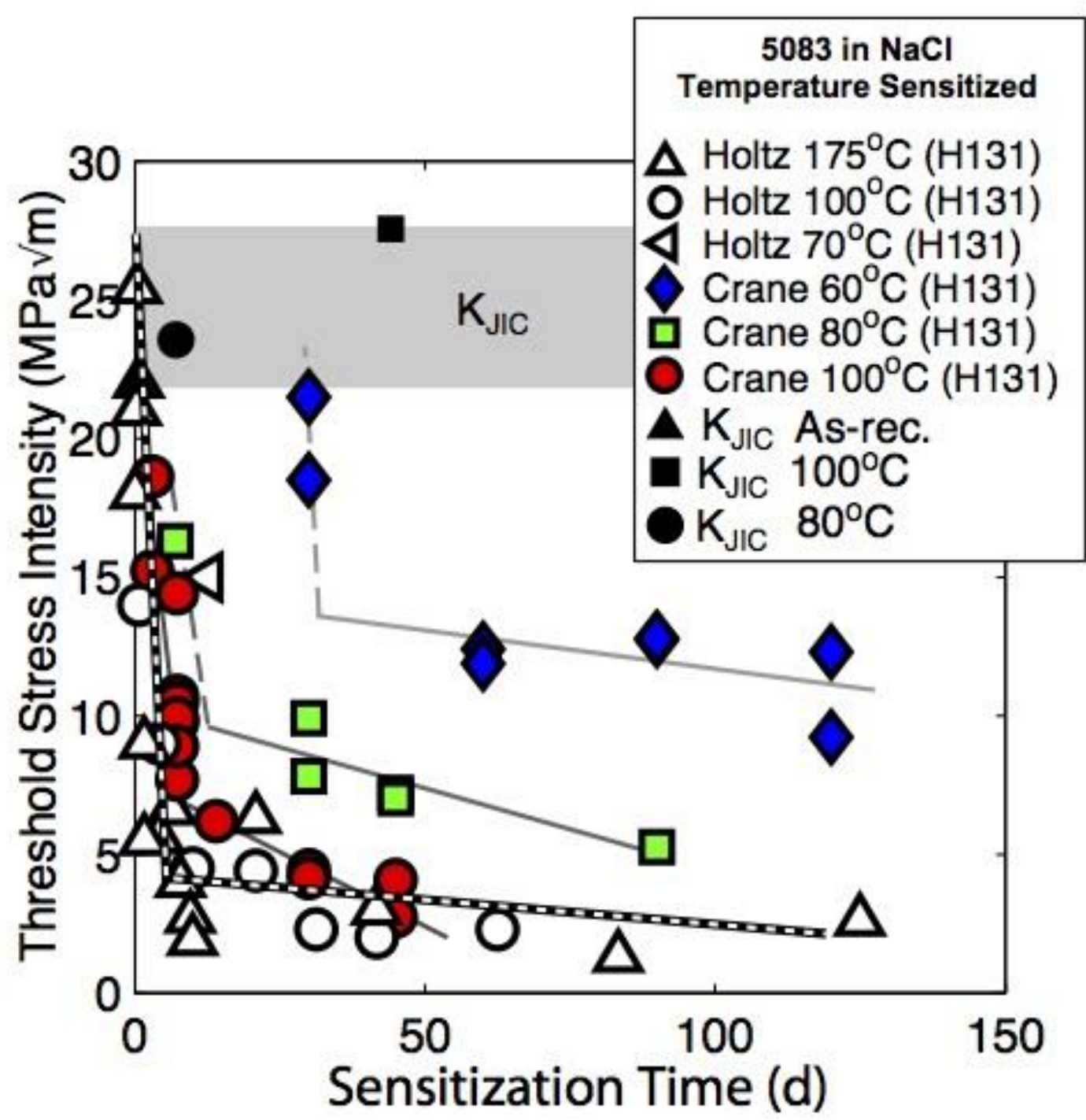

Figure 2.25 Sensitization time dependence of $\mathrm{K}_{\mathrm{TH}}$ for IGSCC in 5083-H131 (S-L). Thresholds measured while fully immersed in $0.6 \mathrm{M} \mathrm{NaCl}$ solution at fixed potential of $-0.800 \mathrm{~V}_{\text {SCE }}$ are represented by solid points (Fig. 2.13). Elastic-plastic $\mathrm{K}_{\text {JIC }}$ toughness is plotted as $(\boldsymbol{\Delta})$ for as-received, $(\bullet)$ for $\left(100^{\circ} \mathrm{C} 175 \mathrm{~h}\right)$ and $(\boldsymbol{\bullet})$ for $\left(80^{\circ} \mathrm{C} 45 \mathrm{~d}\right) 5083-$ H131 (S-L), with a grey band showing the range of $\mathrm{K}_{\text {JIC. }}$ Solid lines are regression fits and dashed lines are estimated trends. Thresholds represented by open points were measured on the same plate of 5083-H131 by Holtz et al. with a rising-step load procedure in chromate inhibited $\mathrm{NaCl}$ [34]. The white dashed line provides the estimated trend for these data. 
surface in the presence of a chromate inhibitor is more resistant to $\mathrm{Cl}^{-}$attack than the inherent $\mathrm{Al}$ passive film, $\mathrm{Al}_{2} \mathrm{O}_{3}$ [76]. The chromate inhibitor, however, does not passivate the Mg-rich $\beta$ phase as shown with potentiodynamic scans of $\beta$ in chromate environments [11]. In fact, the inhibitor increases the galvanic driving force for $\beta$ dissolution in the presence of $\alpha$ by increasing the OCP of $\alpha$ [11]. Even with accelerated $\beta$ dissolution, development of an acidic crack tip chemistry may be stifled due to limited $\alpha$ dissolution. At low sensitization where $\beta$ coverage is low, matrix dissolution is critical to sustain a high cation concentration for hydrolysis and a high $\mathrm{H}$ overpotential $\left(\eta_{\mathrm{H}}\right)$ for HEAC (Chapter 3). At sensitizations between $10 \mathrm{mg} / \mathrm{cm}^{2}$ and $30 \mathrm{mg} / \mathrm{cm}^{2}$ in chromate inhibited solution, the volume of $\beta$ is likely not sufficient to sustain the concentration of $\mathrm{H}$ for IGSCC. In contrast, for sensitizations greater than $30 \mathrm{mg} / \mathrm{cm}^{2}$, where a high volume of $\beta$ covers grain boundaries, $\beta$ dissolution at the crack tip may trigger the acidic environment required to destabilize the Cr-bearing passive film for significant $\alpha$ dissolution. When dissolution produces a maximum $\eta_{\mathrm{H}}$, similar-low IGSCC thresholds are expected and were measured for highly sensitized 5083-H131 in the two different environments (Fig. 2.26). These results are consistent with a separate study: IGSCC crack growth rates for recrystallized and highly sensitized $5083-\mathrm{H} 321\left(100 \mathrm{~h}\right.$ at $\left.175^{\circ} \mathrm{C}\right)$ in a chromate doped $\mathrm{NaCl}$ solution were 6 times faster than in $\mathrm{NaCl}$ alone [11]. In contrast, crack growth rates in low sensitized $5083-\mathrm{H} 321\left(1 \mathrm{~h}\right.$ at $\left.175^{\circ} \mathrm{C}\right)$ in chromate solution were an order of magnitude lower than in $\mathrm{NaCl}[11]$. 


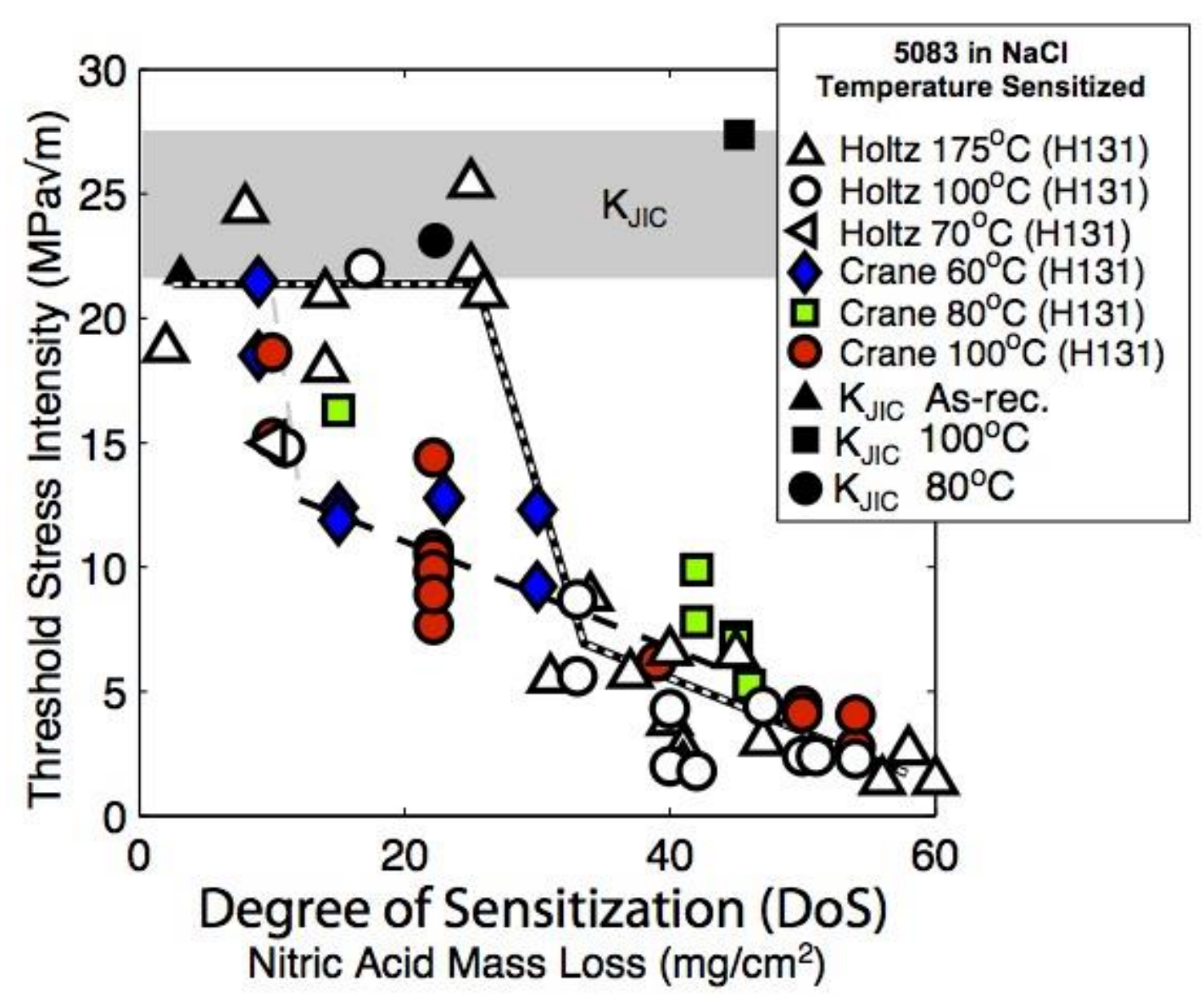

Figure 2.26 Nitric acid mass loss based DoS dependence of $\mathrm{K}_{\text {TH }}$ for IGSCC in 5083H131 (S-L). Thresholds measured while fully immersed in $0.6 \mathrm{M} \mathrm{NaCl}$ solution at fixed potential of $-0.800 \mathrm{~V}_{\mathrm{SCE}}$ are represented by solid points (Fig. 2.14). Elastic-plastic $\mathrm{K}_{\mathrm{IIC}}$ toughness is plotted as ( $\mathbf{\Lambda})$ for as-received $\left(3 \mathrm{mg} / \mathrm{cm}^{2}\right),(\bullet)$ for $\left(22 \mathrm{mg} / \mathrm{cm}^{2}\right)$ and $(\boldsymbol{\bullet})$ for $\left(45 \mathrm{mg} / \mathrm{cm}^{2}\right)$ specimens, with a grey band showing the range of $\mathrm{K}_{\text {IIC. }}$. Solid lines are regression fits; dashed lines are estimated trends. Thresholds represented by open points were measured on the same 5083-H131 plate used in this study by Holtz et al. with a rising-step load procedure in chromate inhibited $\mathrm{NaCl}$ [34]. The white dashed line provides the estimated trend for these data.

Rising-step loading influences the IGSCC susceptibility of 5083 by producing a different strain rate profile at the crack tip compared to that developed during constant rate rising displacement loading. At sensitizations below $30 \mathrm{mg} / \mathrm{cm}^{2}$ during the initial loading step, a rapid strain rate will likely exceed the rupture strain of the passive film, therefore exposing a bare crack tip. In the presence of chromate inhibitor this ruptured film should 
repassivate rapidly to restrict significant crack tip dissolution and limit the amount of $\mathrm{H}$ absorption [76-78]. During the hold period following the rapid step, only limited dissolution would progress in the crack tip passivated by chromate. Hydrogen production and uptake is likely eliminated during this period. The volume of $\beta$ dissolution in the chromate environment is likely not sufficient to produce the acidic chemistry required for H production, uptake, and HEAC. At this DoS (between $10 \mathrm{mg} / \mathrm{cm}^{2}$ and $30 \mathrm{mg} / \mathrm{cm}^{2}$ in the present study), the chromate-free environment likely promotes film destabilization, and the continuous loading likely enhances $\mathrm{H}$ localization ahead of the crack tip for more rapid cracking. Above $30 \mathrm{mg} / \mathrm{cm}^{2}$, a highly acidic crack tip chemistry is likely established by $\beta$ and $\alpha$ dissolution, which would destabilize the passive film in both environments; therefore the loading format may not affect IGSCC at high sensitizations. This would explain why thresholds are low and similar in both experiments at high DoS (Fig. 2.26). This comparison suggests that high temperature sensitization does not cause a difference in IGSCC threshold stress intensities for 5083 at the same DoS level.

Collectively these three studies confirm that in 5083: (a) above a critical $10 \mathrm{mg} / \mathrm{cm}^{2}$, $\mathrm{da} / \mathrm{dt}_{\mathrm{II}}$ increases and $\mathrm{K}_{\mathrm{TH}}$ decreases with DoS, (b) with low to mid-range sensitization $\left(10 \mathrm{mg} / \mathrm{cm}^{2}\right.$ to $\left.30 \mathrm{mg} / \mathrm{cm}^{2}\right)$, IGSCC depends on environmental variables, loading mode, and cracking orientation, and (c) in chloride environments at high DoS (above $30 \mathrm{mg} / \mathrm{cm}^{2}$ ) the maximum $\mathrm{da} / \mathrm{dt}_{\mathrm{II}}$ is near $10,000 \mathrm{~nm} / \mathrm{s}$ and the minimum $\mathrm{K}_{\mathrm{TH}}$ is about $2 \mathrm{MPa} \sqrt{\mathrm{m}}$, these cracking kinetics are consistent for sensitization temperatures up to $175^{\circ} \mathrm{C}$. The literature suggests that $\beta$ volume fraction likely influences the critical DoS for HEAC, however the role of $\mathrm{H}$ on $\mathrm{HEAC}$ and the interaction of $\mathrm{H}$ and $\beta$ during $\mathrm{HEAC}$ in terms of spacing and morphology were not investigated [1,34]. 


\subsubsection{Sensitization dependence of IGSCC in 5083-H131}

Experimental results presented in Figs. 2.24 and 2.26 establish that 5083-H131 (S-L) resists IGSCC (but is not immune) in $\mathrm{NaCl}$ at near OCP for DoS below about $10 \mathrm{mg} / \mathrm{cm}^{2}$, as produced by sensitization at $100^{\circ} \mathrm{C}, 80^{\circ} \mathrm{C}$, and $60^{\circ} \mathrm{C}$. At this DoS, $\mathrm{K}_{\mathrm{TH}}$ falls and da/dt $\mathrm{dI}_{\mathrm{II}}$ raises both in a near-step-function dependence. With further sensitization to $60 \mathrm{mg} / \mathrm{cm}^{2}$, IGSCC susceptibility depends modestly on a unique function of DoS, where $\mathrm{K}_{\mathrm{TH}}$ decreases and $\mathrm{da} / \mathrm{dt}_{\mathrm{II}}$ accelerates to as high as $10^{4} \mathrm{~nm} / \mathrm{s}$ or faster. These results correlate with the literature including IGSCC in 5083 with high temperature sensitization (up to $\left.175^{\circ} \mathrm{C}\right)[1,12,34]$. This correlation illustrates that the temperature of sensitization does not have a significant effect on IGSCC for 5083 with similar mass loss measurements. It is possible to interpolate IGSCC properties for 5083 sensitized at temperatures between $60^{\circ} \mathrm{C}$ to $100^{\circ} \mathrm{C}$ (and possibly lower) from IGSCC data from 5083 sensitized at higher temperatures, as long as the DoS is known and comparable.

Three important questions are associated with the results in Figs. 2.24 and 2.26 and were not addressed in literature:

(1) Is grain boundary $\beta$ precipitation an absolute requisite for IGSCC by HEAC?

(2) Why is a threshold-critical amount of $\beta$ precipitation required to trigger severe IGSCC in 5083-H131 (specifically at $10 \mathrm{mg} / \mathrm{cm}^{2}$ )?

(3) Why are the subsequent IGSCC kinetics only modestly dependent on further increases in $\beta$ volume fraction following the threshold amount of $\beta$ ?

The answers to these questions are considered based on the mechanistic framework shown in Fig. 2.22 coupled with literature reports on the DoS dependencies of the size, spacing, and morphology of discrete grain boundary $\beta$ precipitates. The present study 
focuses on the S-L orientation of 5083-H131. Given the anisotropic grain structure, this orientation and da/dt vs. $\mathrm{K}$ data provide an ideal basis to separate the important effects of intergranular crack path tortuosity and grain boundary- $\beta$ microstructure.

\subsubsection{Intergranular SCC-HEAC in 5083-H131 without $\beta$}

Intergranular SCC susceptibility in sensitized 5083-H131 could be controlled by $\beta$ in four ways: 1) $\beta$ dissolution triggers crack acidification necessary for HEAC, 2) nondeformable $\beta$ precipitates cause a local stress concentration and/or a local constraint at the inter- $\beta$ ligaments, 3) $\beta$ precipitates provide $H$ trapping locations at the grain boundary, 4) inter- $\beta$ ligament size possibly controls rapid local $\mathrm{H}$ diffusion at dislocation free crack tip. These issues or considered in this and the following chapters: Chapter 3 demonstrates the critical importance of crack acidification, which is summarized below; Chapter 4 demonstrates that the presence of $\beta$ enhances $H$ embrittlement in the absence of a $\beta$ dissolving crack tip electrolyte either by increasing local stress concentration and constraint, or by providing $\mathrm{H}$ trap sites; Chapter 4 also suggests the importance of $\beta$ spacing in regards to dislocation structure in enhancing local crack tip $\mathrm{H}$ diffusion in the ligaments between $\beta$.

Without a highly acidic crack tip environment, 5083-H131 at any DoS level is highly resistant to IGSCC. Specifically, as-received 5083-H131 (S-L) was immune to IGSCC at $-0.800 \mathrm{~V}_{\mathrm{SCE}}$ in $\mathrm{NaCl}$ until very high $\mathrm{K}$, as demonstrated by measured growth kinetics (Fig. 2.12). Chapter 3 demonstrates that unsensitized, $\beta$-free 5083-H131 resists IGSCC in neutral $\mathrm{NaCl}$ near OCP because, in the absence of $\beta$ dissolution, the critical crack tip solution chemistry is not sustained for $\alpha$ dissolution and hydrolysis; $\mathrm{pH}$ will not fall to the level established by $\beta$ dissolution, which results in a lower concentration of $\mathrm{H}$ available for 
uptake into the FPZ. Fractographic analysis (Fig. 2.18(D-F)) confirmed resistance, but not immunity, as a small number of isolated grain-sized areas along the crack front, likely representative of IGSCC, were surrounded by ductile microvoid fracture. At these isolated locations, the critical combination of tensile stress and FPZ $\mathrm{H}$ concentration was likely established for intergranular cracking. The literature suggested that $\beta$ precipitates preferentially on grain boundaries due to misorientation angle, specifically at low sensitizations [79]. It is possible that as-received 5083-H131 had a small volume of $\beta$ precipitation on specific grains boundaries, which induced $\mathrm{H}$ embrittlement preferentially in these isolated regions. In regions where the critical $\mathrm{H}$ concentration is not achieved for $\mathrm{H}$ embrittlement, ductile fracture occurred independent of dissolution and hydrogen embrittlement.

The critical importance of $\beta$ as a trigger for crack acidification leading to IGSCC is indicated with experiments in Chapter 3. These results are presented here to demonstrate the critical importance of crack acidification in HEAC, and the associated role of $\beta$ (when present). Without sensitization and with minimal grain boundary $\beta, 5083-\mathrm{H} 131$ (S-L: $3 \mathrm{mg} / \mathrm{cm}^{2}$ ) was embrittled when stressed in highly acidic (simulated) crack tip solution. Cracking initiated at a low $\mathrm{K}_{\mathrm{TH}}\left(5 \mathrm{MPa} \sqrt{\mathrm{m}}_{\mathrm{m}}\right)$ and da/dt levels were 50 to 200 times faster than the very low values measured for stressing in near neutral $\mathrm{NaCl}$ at $-0.800 \mathrm{~V}_{\mathrm{SCE}}$. Crack growth was also promoted in as-received 5083-H131 when anodically polarized $\left(-0.730 \mathrm{~V}_{\mathrm{SCE}}\right)$ in near neutral $0.6 \mathrm{M} \mathrm{NaCl}$. At this applied potential, the crack tip potential in the occluded crack tip remained above the breakdown potential of $\alpha$ in the acidic environment expected in the crack tip $\left(-0.870 \mathrm{~V}_{\mathrm{SCE}}[17,18]\right)$; therefore, significant dissolution of $\alpha$ was promoted leading to an acidic crack tip and a high $\eta_{H}$ for HEAC of $\beta$ - 
free 5083-H131. For near-neutral $\mathrm{NaCl}$ solution, $\beta$ is necessary to produce crack acidification, yet $\mathrm{H}$ embrittlement is possible in the absence of $\beta$ as long as an acidic chemistry is developed in the crack tip. As developed in Chapters 3 and 4, the measured rates of IGSCC in $\beta$-free 5083-H131 are well aligned with the broad alloy correlation represented by Eqn. 2.8, using DH-EFF of $10^{-8} \mathrm{~cm}^{2} / \mathrm{s}$. This result supports the conclusion that essentially $\beta$-free $5083-\mathrm{H} 131$ is susceptible to severe HEAC if an acidified crack environment is developed.

\subsubsection{Characterization of $\beta$ as a function of DoS}

Present IGSCC results show that a significant increase in susceptibility occurs in the low DoS range $\left(10 \mathrm{mg} / \mathrm{cm}^{2}\right.$ to $\left.12 \mathrm{mg} / \mathrm{cm}^{2}\right)$, likely due to a significant change in $\beta$ volume fraction size, or spacing. With further sensitization above this range, $\mathrm{da} / \mathrm{dt}_{\text {II }}$ continues to increase and $\mathrm{K}_{\mathrm{TH}}$ falls, suggesting that a continuous $\beta$ change also occurs at higher sensitizations. Several studies have characterized the distribution, morphology, and size of $\beta$ precipitates on grain boundaries as a function of DoS; though, the reported size and continuity of $\beta$ is somewhat contradictory $[5,8,9]$.

The thickness and "continuity" of $\beta$ along grain boundaries was reported in several studies with etching techniques $[4,6,7,79-82]$. The continuity is defined as the volume fraction of etched grain boundaries, where the etching is assumed to be due solely to $\beta$ presence. Recently, the $\beta$ thickness of 5083-H131 (same plate used in the present study) following long term (1-5 months) sensitization at constant temperatures from $40^{\circ} \mathrm{C}$ to $70^{\circ} \mathrm{C}$ was measured with SEM analysis following diluted phosphoric acid etching [82]. The etched trenches were assumed to represent the continuity and thickness of the dissolved $\beta$ phase. Both continuity and thickness of the trenches increased continuously with time of 
exposure at low temperatures, as reproduced in Fig. 2.27 [82]. This increase in grain boundary $\beta$ coverage likely influences the increase in $\mathrm{da} / \mathrm{dt}_{\mathrm{II}}$ with rising sensitization; the basis for the step dependence at low DoS is not clarified (Figs. 2.24 and 2.26).

A similar analysis determined the $\beta$ phase coverage relative to the total length of grain boundaries for SHT and sensitized 5083-H131 for the same plate used in the present study [6]. Barker's etch and optical imaging was used to reveal grains [6]. The same location was then etched using phosphorous acid etch and SEM imaging to reveal the corresponding attack sites [6]. Most attacked regions occurred on grain boundaries revealed with the Barker's etch. These regions were suggested to be dissolution of either discrete $\beta$ precipitates, or $\beta$ precipitates that grew close enough to appear connected in two dimensions [6]. Results are reproduced in Fig. 2.28 [6]. Etching attack was not observed on any grain boundary in the solution heat treated unsensitized condition [6]. When sensitized to $10 \mathrm{mg} / \mathrm{cm}^{2}\left(3 \mathrm{~d}\right.$ at $\left.100^{\circ} \mathrm{C}\right), 14 \%$ of the grain boundaries were etched [6]. Each of those etched grain boundaries was covered with less than $70 \% \beta$. High coverage of grain boundaries (greater than $70 \%$ coverage per grain boundary) were only observed for sensitization levels higher than $10 \mathrm{mg} / \mathrm{cm}^{2}$ [6]. The initiation of low $\beta$ coverage at $10 \mathrm{mg} / \mathrm{cm}^{2}$ correlates with the critical DoS level for IGSCC susceptibility in the present study. This microstructure may provide the $\beta$ distribution necessary for IGSCC susceptibility at low DoS by activating all 3 regions in Fig. 2.22: (1) an acidic crack tip chemistry, (2) $\mathrm{H}$ trapping at $\beta$, and (3) local stress and constraint between $\beta$. An increase in high coverage boundaries at higher DoS may influence the continuous increase in $\mathrm{da} / \mathrm{dt}_{\mathrm{II}}$ with increasing sensitization above the initial IGSCC susceptibility, and will be discussed in Section 2.5.5.3. 

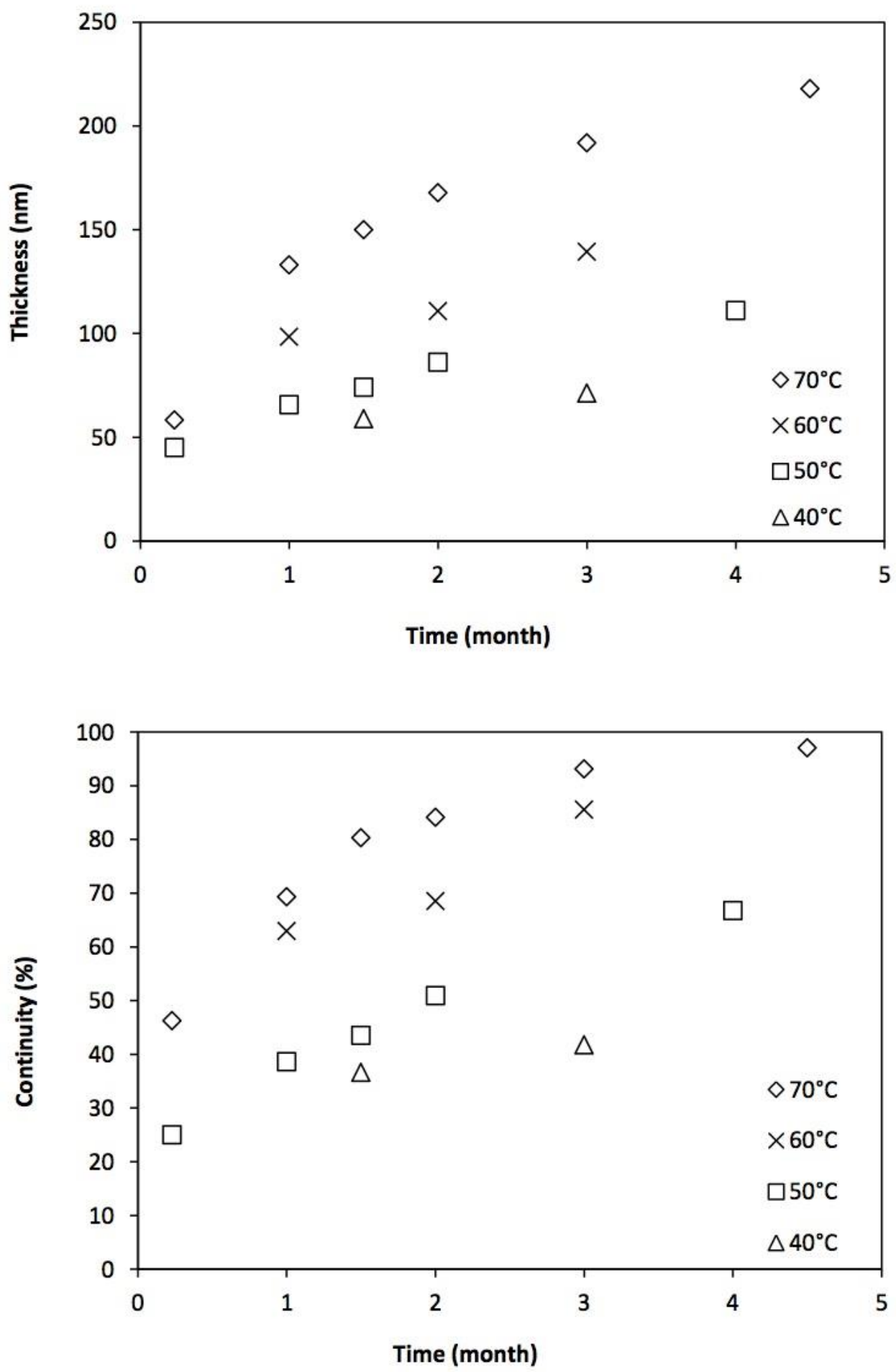

Figure 2.27 Thickness and continuity of $\beta$ along grain boundaries of 5083-H131 with sensitization at $40^{\circ} \mathrm{C}$ to $70^{\circ} \mathrm{C}$ measured with SEM analysis following diluted phosphoric acid etching by Zhu et al. [82]. 


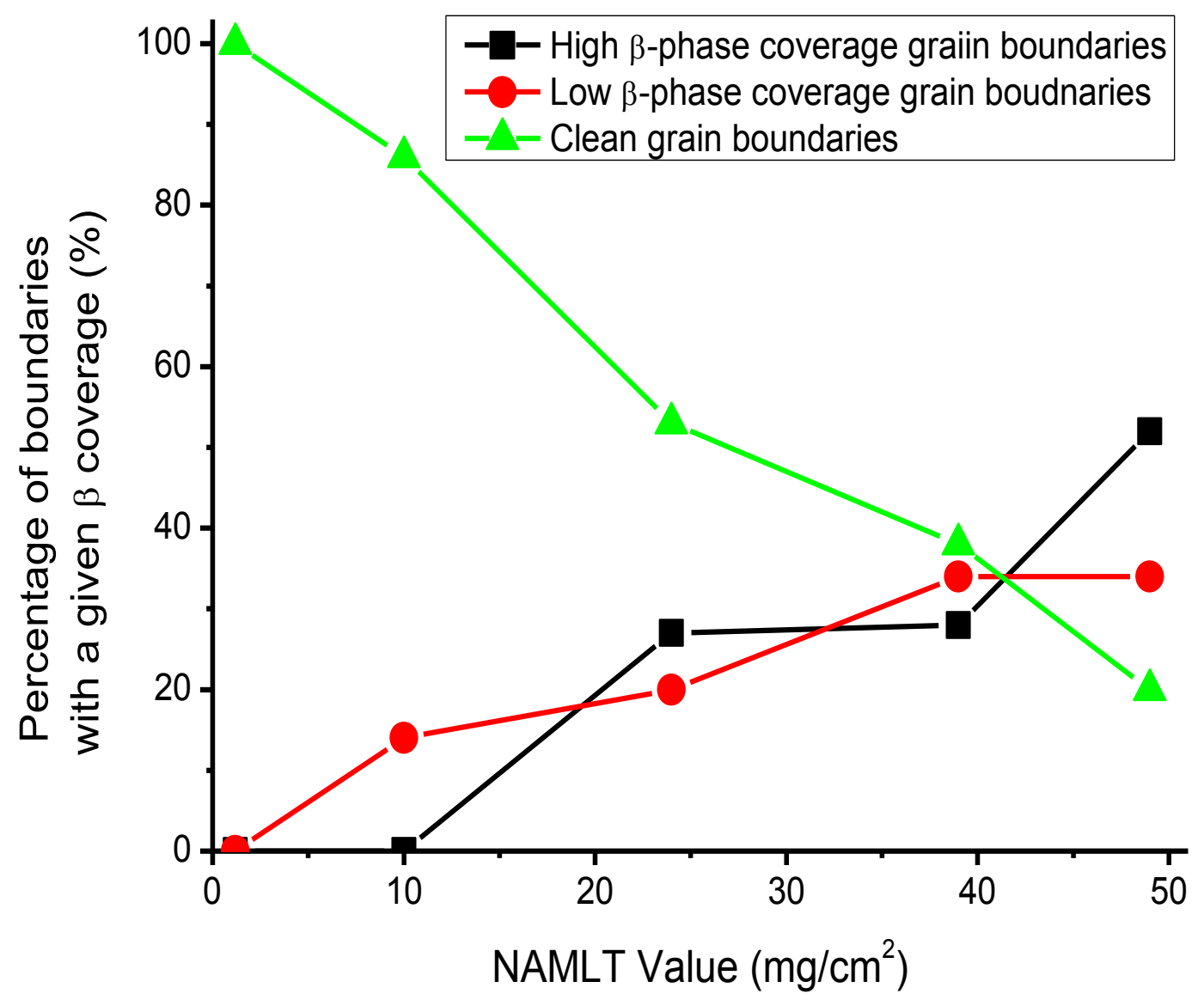

Figure 2.28 The distribution of $\beta$ along grain boundaries in SHT 5083-H131 (from a plate of the same heat used in this study) sensitized at $100^{\circ} \mathrm{C}$ by Lim et al. [6]. The grains were revealed with Barker's Etch and optical imaging, while the attack sites were exposed by a phosphorous etch and imaged by SEM [6].

Etching techniques provide a valuable method to establish the qualitative distribution of $\beta$ phase; however, there are limitations to the technique. The etched trenches do not accurately portray the thickness and spacing of $\beta$, as etching may also attack a small amount of the matrix. The results provide a reasonable representation of the grain boundary $\beta$ 
coverage, and therefore are helpful in developing a $\beta$ based mechanism for HEAC, but will not quantitatively validate the mechanism.

Transmission electron microscopy (TEM) provided a semi-quantitative representation of the change in $\beta$ morphology with sensitization. The study focused on sensitizations at three temperatures; SHT 5083-H131 sensitized at $100^{\circ} \mathrm{C}$ and non-SHT $5083-\mathrm{H} 131$ sensitized at $70^{\circ} \mathrm{C}$ and $175^{\circ} \mathrm{C}[3,8,75,83]$. The plate of $5083-\mathrm{H} 131$ studied was identical to that examined in the present IGSCC experiments. A map of these $\beta$ morphologies as a function of sensitization time and temperature is reproduced in Fig. 2.29. Discretely arrayed $\beta$ precipitated on grain boundaries for all times up to $10 \mathrm{~h}$ at $175^{\circ} \mathrm{C}\left(25 \mathrm{mg} / \mathrm{cm}^{2}\right)$, $3 \mathrm{~d}$ at $100^{\circ} \mathrm{C}\left(25 \mathrm{mg} / \mathrm{cm}^{2}\right)$, and $15 \mathrm{~d}$ at $70^{\circ} \mathrm{C}\left(12 \mathrm{mg} / \mathrm{cm}^{2}\right)[3,8,75,83]$. Close-spaced $\beta$, described as a 3-dimensional "ribbon like" morphology that did not fully cover grain boundaries, was observed for times of $10-200 \mathrm{~h}$ at $175^{\circ} \mathrm{C}, 3-42 \mathrm{~d}\left(100^{\circ} \mathrm{C}\right)$, and $15-125 \mathrm{~d}$ $\left(70^{\circ} \mathrm{C}\right)[3,8,75,83]$. Continuity of $\beta$ was observed on some grain boundaries for times in excess of $200 \mathrm{~h}$ at $175^{\circ} \mathrm{C}\left(40 \mathrm{mg} / \mathrm{cm}^{2}\right), 42 \mathrm{~d}$ at $100^{\circ} \mathrm{C}\left(50 \mathrm{mg} / \mathrm{cm}^{2}\right)$, and $125 \mathrm{~d}$ at $70^{\circ} \mathrm{C}$ $\left(40 \mathrm{mg} / \mathrm{cm}^{2}\right)[3,8,75,83]$. The presence of a close spaced, or ribbon-like morphology, for DoS levels between $12 \mathrm{mg} / \mathrm{cm}^{2}$ and $25 \mathrm{mg} / \mathrm{cm}^{2}$ is consistent with the change in $\beta$ coverage measured with etching techniques (Fig. 2.28 [6]).

The onset of a ribbon-like morphology (closely spaced $\beta$ precipitates) as seen with TEM correlates with the onset of rapid IGSCC susceptibility at a critical DoS of $10 \mathrm{mg} / \mathrm{cm}^{2}$ in the present study as shown by $(\mathrm{o}),(\square)$, and $(\diamond)$ for sensitization at $100^{\circ} \mathrm{C}, 80^{\circ} \mathrm{C}$, and $60^{\circ} \mathrm{C}$, respectively in Fig. 2.29. Given that TEM can only examine a limited number of specimens and areas of the microstructure, the time boundaries in Fig. 2.29 are approximate. Results suggest a critical $\beta$ morphology for IGSCC susceptibility; however, 
without a statistical representation of grain boundary $\beta$ morphologies, the comparison of morphology with critical DoS for IGSCC susceptibility is not precise.

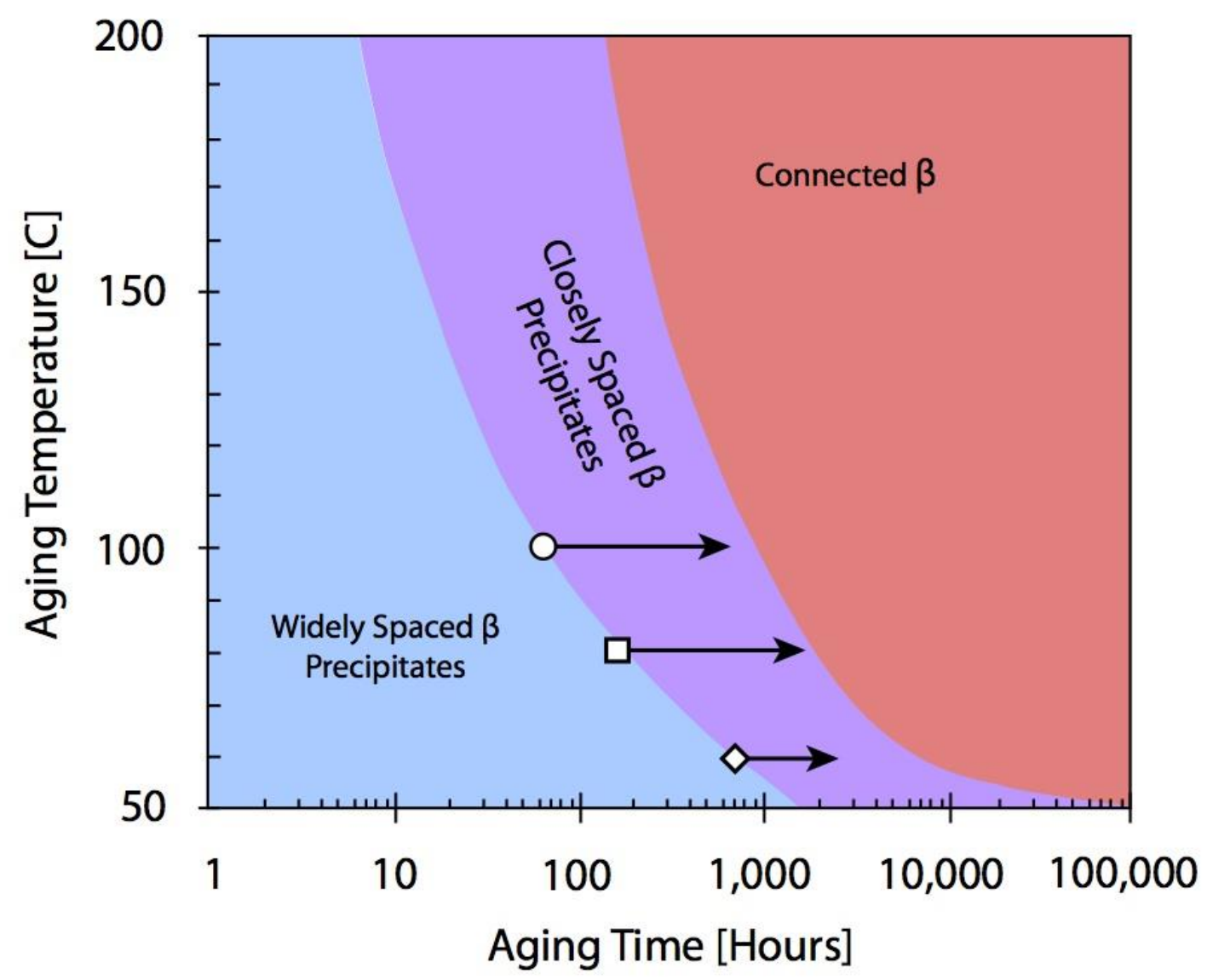

Figure 2.29 A map of $\beta$ morphology as a function of aging time and temperature. Morphology was studied with TEM on SHT 5083-H131 sensitized at $100^{\circ} \mathrm{C}$ and nonSHT 5083-H131 sensitized at $70^{\circ} \mathrm{C}$ and $175^{\circ} \mathrm{C}$ by Holtz et al. $[3,75,83]$. The 5083-H131 plate was from the same heat used in this study. The symbols and arrows indicate IGSCC susceptibility (in $0.6 \mathrm{M} \mathrm{NaCl}$ at $-0.800 \mathrm{~V}_{\mathrm{SCE}}$ in the $\mathrm{S}-\mathrm{L}$ orientation) for $5083-\mathrm{H} 131$ sensitized for times in excess of the open point at (o) $100^{\circ} \mathrm{C},(\triangle) 80^{\circ} \mathrm{C}$ and $(\diamond) 60^{\circ} \mathrm{C}$.

SEM imaging of grain boundary surfaces separated by Ga attack provided a twodimensional characterization of a large area of the grain boundary microstructure of SHT 
and sensitized 5083-H131 (using the same plate as the present study) [5]. Alloys were sensitized at $100^{\circ} \mathrm{C}$ for times between $3 \mathrm{~d}$ and $30 \mathrm{~d}$ (DoS between $10 \mathrm{mg} / \mathrm{cm}^{2}$ and $40 \mathrm{mg} / \mathrm{cm}^{2}$ ). This approach revealed discontinuous rod shaped particles, assumed to be $\beta$ phase, for all sensitization times and temperatures studied [5]. An equivalent particle diameter was defined to account for a circular shape ascribed to a rod shaped particle [5]. The nearest neighbor distance was measured as the edge to edge distance of the nearest particle, which gives a measure of the $\alpha-\alpha$ ligament between $\beta$ [5]. Results are reproduced in Fig. 2.30 [5]. At the lowest sensitization, $3 \mathrm{~d}$ at $100^{\circ} \mathrm{C}\left(10 \mathrm{mg} / \mathrm{cm}^{2}\right)$, the $\beta$ nearestneighbor spacing was reported as $300 \mathrm{~nm}$ for particles with an equivalent particle diameter of $50 \mathrm{~nm}$ [5]. The spacing to equivalent diameter ratio declined from 5 to 1 as DoS increased from $10 \mathrm{mg} / \mathrm{cm}^{2}$ to $40 \mathrm{mg} / \mathrm{cm}^{2}\left(100^{\circ} \mathrm{C}\right.$ for $3 \mathrm{~d}$ to $\left.30 \mathrm{~d}\right)$, essentially due to increasing $\beta$ size with constant spacing [5]. Results are consistent with increasing IGSCC susceptibility with increasing DoS, however, a critical change in morphology, size, or spacing was not observed at low DoS. These results provide a quantitative measurement of the assumed volume of $\beta$ on the grain boundary and are statistically meaningful with over 200 particles imaged for each sensitization [5]. Embrittlement by Ga provides direct imaging of particles, though these particles were not confirmed to be $\beta$. The small size of these particles limits EDS characterization owing to the large interaction volume size of the probe. Also, the process of opening grain boundaries may alter the morphology of each of these precipitates by changing the surface energy of each precipitate. 

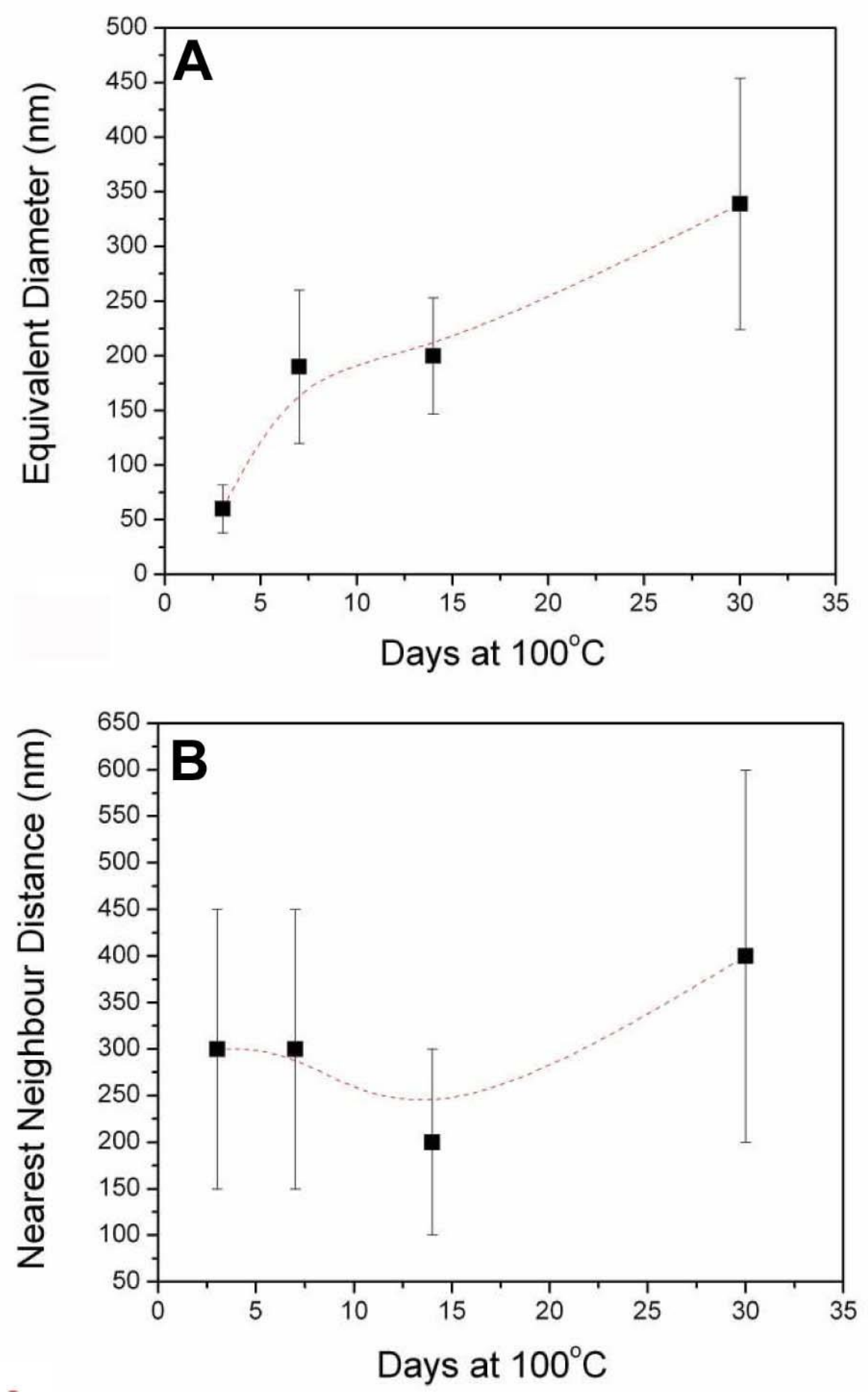

Figure 2.30 The (a) equivalent diameter and (b) nearest neighbor spacing of grain boundary $\beta$ in SHT 5083-H131 exposed by Ga attack and observed with SEM imaging as a function of sensitization time using a plate of the same heat as the present study by Birbilis et al. [5]. 
Given the complexity of $\beta$ microstructural characterization, it is challenging to draw firm conclusions on the details of the grain boundary $\beta$ microstructure that controls DoS dependent IGSCC properties, and particularly the critical DoS of about $10 \mathrm{mg} / \mathrm{cm}^{2}$. The etching technique provides a qualitative description of $\beta$ thickness and coverage, but does not provide the morphology or identification of $\beta$ required to confirm the role of $\beta$ on grain boundaries. The two dimensional TEM representation of $\beta$ provides an unaltered view of $\beta$ precipitated on the grain boundaries; however, it does not establish the statistical representation required to characterize the distribution of $\beta$ over a wide number of grain boundaries. The Ga grain boundary separation technique provides a 3-dimensional view of particles, though they are not confirmed to be exclusively $\beta$ and particle morphology may have changed as grain boundaries were separated or reacted with Ga. None-the-less, the combination of these studies confirm a change in $\beta$ morphology at low sensitization, and an increase in $\beta$ size with further sensitization, and therefore provide a qualitative basis to understand the role of $\beta$ microstructure in the IGSCC mechanism based on the mechanism in Fig. 2.22.

\subsubsection{IGSCC dependence on critical size, spacing, and morphology of $\beta$}

To better understand the results in Figs. 2.24 and 2.26, focus remains on two questions:

(1) Why is a threshold-critical amount of $\beta$ precipitation required to trigger severe IGSCC in 5083-H131?

(2) Why are the subsequent IGSCC kinetics only modestly dependent on further increases in $\beta$ volume and coverage?

The complex role of $\beta$ in IGSCC by HEAC, and particularly the impact of $\beta$ size, spacing and volume fraction, is considered here to explain the DoS dependence of $\mathrm{K}_{\mathrm{TH}}$ and 
da/dt II (Figs. 2.24 and 2.26) in the HEAC framework (Fig. 2.22). Candidate contributions of grain boundary $\beta$ include:

\section{(1) Crack Chemistry}

Grain boundary $\beta$ triggers $\alpha$ dissolution, which causes crack tip acidification and increased over-potential for H production, as detailed in Chapter 3.

(2) Crack Mechanics

Grain boundary $\beta$ causes a severe stress state typified by: (a) local stress concentration and/or (b) local constraint of the $\alpha$-boundary region.

(3) H Localization

Grain boundary $\beta$ precipitates trap $\mathrm{H}$ along the IG crack path.

(4) H Mobility

Beta distribution controls establishment of a dislocation free zone that favors rapid $\mathrm{H}$ mobility via reduced dislocation trapping proximate to the grain boundary, as detailed in Chapter 4.

In the context of the proposed $\beta$ dissolution-HEAC mechanism, one or more of these factors could enhance $\mathrm{C}_{\mathrm{H} \sigma}$ well above $\mathrm{C}_{\mathrm{H} \text {-crit }}$ to support a high da/dt $\mathrm{dI}$ through Eqn. 2.8. The size, spacing, morphology and amount of $\beta$ could impact each of these factors.

\subsection{The role of $\beta$ in developing crack tip chemistry}

First, consider the impact of $\beta$ characteristics on crack solution acidification. Specifically, grain boundary $\beta$ coverage may control the crack tip chemistry, which influences $\mathrm{C}_{\mathrm{H \sigma}}$ in Eqn. 2.8 as outlined in Chapter 3. Since $\beta$ selectively dissolves compared to $\alpha$ in neutral-to-acidic chloride solutions $[14,17,18,84-86]$, the amount of $\beta$ along the grain boundary (in 2 dimensions) is important in the context of occluded-crack cation concentration, hydrolysis, and acidification. Though the specimen is polarized to $-0.800 \mathrm{~V}_{\mathrm{SCE}}$, the crack tip potential will be slightly more cathodic due to resistance in 
the occluded crack. The Ohmic (IR) drop along the crack is predicted to be on the order of $20 \mathrm{mV}$ in Chapter 3. Since, dissolution of $\alpha$ is sluggish even with polarization to $-0.800 \mathrm{~V}_{\mathrm{SCE}}$, without $\beta$, the driving force for $\alpha$ dissolution is even lower at Ohmic drop affected crack tip potentials. Small regions along the crack mouth may initiate dissolution; however, cation diffusion out of the crack tip will stifle the acidity. The $\beta$ phase is required for rapid bursts of dissolution that sustain the low $\mathrm{pH}$ and promote further $\alpha$ dissolution. If the coverage of $\beta$ yet to dissolve and arrayed on the growing crack tip surface is not high enough to sustain the acidic environment, IGSCC may not progress at a resolvable rate because the ratio of $\mathrm{C}_{\mathrm{H} \sigma} / \mathrm{C}_{\mathrm{H}-\text { crit }}$ falls below 1 in Eqn. 2.8 .

A simplistic calculation based on the volume of $\beta$ expected at the crack tip and along the flanks shows that low sensitized 5083 will not generate the cation concentration for saturated or near saturated conditions in the crack tip. Considering the crack tip of 5083H131 sensitized to the onset of substantial IGSCC susceptibility $\left(10 \mathrm{mg} / \mathrm{cm}^{2}\right)$, grain boundary $\beta$ dissolution provides, at maximum, $0.0003 \mathrm{M} \mathrm{Al}^{3+}$ and $0.0002 \mathrm{M} \mathrm{Mg}^{2+}$ (Table 2.4) in the near-tip region, based on a calculation detailed in the Appendix. When $5083-\mathrm{H} 131$ is sensitized to $10 \mathrm{mg} / \mathrm{cm}^{2}, \beta$ is assumed to be spherical with a $50 \mathrm{~nm}$ equivalent diameter and number density of 0.8 particles per $1 \mu \mathrm{m}^{2}$ along the grain boundary [81], giving a $\beta$ volume of $2.1 \times 10^{-5} \mu \mathrm{m}^{3}$ per $\mu \mathrm{m}^{2}$ grain boundary. Assuming complete and stoichiometric dissolution of $\beta$ along the IGSCC crack length and width, $\mathrm{Al}^{3+}$ and $\mathrm{Mg}^{2+}$ concentrations are estimated in the volume of occluded crack solution. Cation depletion by diffusion out of this crack-solution volume was not accounted for, nor was corrosion product precipitation. The results of this calculation show that cation concentrations increase with DoS (Table 2.4). 
Table 2.4 Estimated cation concentrations for dissolution of occluded IGSCC crack $\beta$ at $\mathrm{K}$ of $15 \mathrm{MPa} \sqrt{\mathrm{m}}$.

\begin{tabular}{|c|c|c|}
\hline $\mathbf{D o S}\left(\mathbf{m g} / \mathbf{c m}^{\mathbf{2}}\right)$ & $\mathbf{A l}^{\mathbf{3 +}}[\mathbf{M}]$ & $\mathbf{M g}^{\mathbf{2 +}}[\mathbf{M}]$ \\
\hline 10 & 0.0003 & 0.0002 \\
\hline 22 & 0.034 & 0.022 \\
\hline 50 & 0.93 & 0.62 \\
\hline
\end{tabular}

Calculation of the $\mathrm{pH}$ or absorbed atomic $\mathrm{H}$ concentration generated by hydrolysis for a given cation concentration is beyond the scope of this dissertation, and $\mathrm{pH}$ measurements were not made with mixed $\mathrm{Al} / \mathrm{Mg}$ salt solutions at the concentrations given in Table 2.4. Measurements of solution $\mathrm{pH}$ for $2 \mathrm{M} \mathrm{AlCl}_{3}$ showed that the addition of more than $0.1 \mathrm{M}$ $\mathrm{MgCl}_{2}$ caused a severe drop in $\mathrm{pH}$ [44]. Based on the simplistic calculation described above, the volume of $\beta$ would not be sufficient to produce this concentration of $\mathrm{Mg}^{2+}$ until DoS of $50 \mathrm{mg} / \mathrm{cm}^{2}$. This suggests that $\beta$ is a trigger, and $\alpha$ dissolution is essential to develop the acidic chemistry expected in the crack tip until very high DoS.

As per Eqn. 2.8, $\mathrm{C}_{\mathrm{H \sigma}}$ has a strong influence on da/dt when the ratio $\mathrm{C}_{\mathrm{H} \sigma} / \mathrm{C}_{\mathrm{H} \text {-crit }}$ is below 6.3. A small reduction in this ratio leads to several orders of magnitude decrease in da/dt. Since, the $\mathrm{pH}$ and potential dependent $\eta_{H}$ in the crack tip governs $\mathrm{C}_{\mathrm{H} \sigma}$ (as discussed in Chapter 3), crack tip chemistry could control the significant increase in da/dt seen at $10 \mathrm{mg} / \mathrm{cm}^{2}$. In low sensitized 5083, the small regions of $\beta$ dissolution and acidification in the crack are muted by $\mathrm{H}^{+}$diffusion out of the crack, resulting in a near neutral $\mathrm{pH}$ and

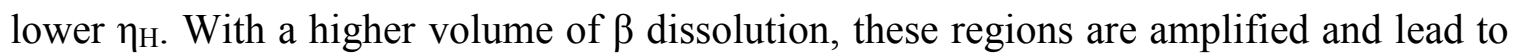
the critical acidity required for a rapidly growing occluded crack tip and high $\eta_{н}$. The continuous increase in da/dtII following $10 \mathrm{mg} / \mathrm{cm}^{2}$ may be due to an increase in $\beta$ volume 
contributing to $\mathrm{C}_{\mathrm{H} \sigma} / \mathrm{C}_{\mathrm{H}-\mathrm{crit}}>>1$, though, saturation at the crack tip may only lead to at most a 7-times increase in da/dt, owing to the squared inverse error function in Eqn. 2.8. Crack growth rate increases greater than 7-times may be attributed to additional contributions from changing $\beta$ size, spacing, and morphology on the other elements of the IGSCC-HEAC mechanism.

\subsection{The role of $\beta$ on the hydrogen diffusivity}

Next, consider the role of $\beta$ characteristics on the crack growth rate limiting $\mathrm{D}_{\mathrm{H}-\mathrm{EFF}}$ used in Eqn. 2.8. Chapter 4 proposes that rapid growth rates on the order seen in Fig. 2.24 for sensitization between $10 \mathrm{mg} / \mathrm{cm}^{2}$ and $50 \mathrm{mg} / \mathrm{cm}^{2}$ are attainable by the combined $\beta-\alpha$ dissolution and $\mathrm{H}$ embrittlement mechanism, provided that the crack surface solubility of $\mathrm{H}$ is high and $\mathrm{H}$ diffusion is enhanced. Two mechanisms are suggested in Chapter 4 for increased $\mathrm{H}$ mobility: (1) reversible-trap filling following consecutive charging of $\mathrm{Al}$ alloys, including 5083-H131, as suggested by Ai et al. [72,87], and (2) dislocation structure change in the local microstructure. Speculatively, during straining a low energy dislocation structure (LEDS) may develop ahead of a crack tip. Based on observations reported for other Al alloys, this structure would be between $0.5 \mu \mathrm{m}$ and $1 \mu \mathrm{m}$ in diameter, and is free of dislocations inside the cell [88]. The dislocation structure developed during crack tip straining is likely the prime candidate for $\mathrm{H}$ trapping that governs $\mathrm{D}_{\mathrm{H}-\mathrm{EFF}}$ in $\mathrm{Al}$ alloys with $\operatorname{Mg}$ [72] or without $\mathrm{Mg}[68,87,89]$. When spacing between $\beta$ is shorter than the size of the LEDS, the ligament of Al-Mg between $\beta$ should be dislocation free and thus H-trap free. The lack of $\mathrm{H}$ traps would result in rapid $\mathrm{H}$ diffusivity, with $\mathrm{D}_{\mathrm{H}-\mathrm{EFF}}$ approaching the level reported for pure Al by Scully et al. $[68,89]$. This significant increase in $\mathrm{D}_{\mathrm{H}-\mathrm{EFF}}$ may explain 
the rapid increase in crack growth rate at $10 \mathrm{mg} / \mathrm{cm}^{2}$. This argument is developed in Chapter 4.

\subsection{The role of $\beta$ on $X_{C R I T}$ and $\mathrm{C}_{\mathrm{H \sigma}}$}

The presence of $\beta$ precipitates on $\alpha$ grain boundaries could affect both the location of crack tip damage, $\mathrm{x}_{\mathrm{CR} I T}$, and the $\mathrm{H}$ concentration at this location, $\mathrm{C}_{\mathrm{H \sigma}}$. Equation 2.8 shows that $\mathrm{da} / \mathrm{dt}_{\mathrm{II}}$ is directly proportional to $1 / \mathrm{x}_{\mathrm{CRIT}}$, but is less sensitive to changing $\mathrm{C}_{\mathrm{H} \sigma}$ due to the form of the inverse error function when $\mathrm{C}_{\mathrm{H}-\mathrm{crit}} / \mathrm{C}_{\mathrm{H} \sigma}$ is less than about 0.15 .

The critical distance is the location ahead of the crack tip where the combination of high tensile stress and high $\mathrm{H}$ concentration is sufficient to cause decohesion. This physical basis for $\mathrm{X}_{\mathrm{CRIT}}$ is fundamental to micromechanical modeling of crack tip damage [70]. The model in Eqn. 2.8 was developed assuming that crack growth is discontinuous, where the length of the fracture event is defined as $\mathrm{X}_{\text {CRIT }}$ and the time between crack advances is defined by $\mathrm{H}$ diffusion from the crack tip surface to $\mathrm{x}_{\text {CRIT. }}$. The $\mathrm{C}_{\mathrm{H \sigma}}$ is predicted at any point ahead of the crack tip surface by the product of the H solubility on this surface (Chapter 3) and the stress sensitive function, $\exp \left[\sigma_{H} V_{H} /(R T)\right]$, where $V_{H}$ is the partial molar volume of $\mathrm{H}$ in $\mathrm{Al}, \sigma_{\mathrm{H}}$ is position-dependent crack tip hydrostatic tension, $\mathrm{R}$ is the ideal gas constant, and $\mathrm{T}$ is temperature $[28,90]$.

The XCRIT is often estimated by a fracture mechanics calculation of the location of the maximum $\sigma_{\mathrm{H}}$ ahead of the crack tip [70], as estimated by two-times the blunted crack tip opening displacement (CTOD) or approximately $\mathrm{K}^{2} / \sigma_{\mathrm{YS}} \mathrm{E}$ [43]. This maximum $\sigma_{\mathrm{H}}$ is on order of 3 to 5 times $\sigma_{Y S}$, depending on alloy work hardening [43]. The maximum hydrostatic stress is a critical part of the physical basis for $\mathrm{X}_{\mathrm{CRIT}}$. The $\mathrm{K}^{2} / \sigma_{\mathrm{YS}} \mathrm{E}$ estimate of XCRIT equals $10 \mu \mathrm{m}$ for $5083-\mathrm{H} 131$ at $\mathrm{K}$ of $15 \mathrm{MPa} \sqrt{\mathrm{m}}$. Rates of IGSCC for $\beta$-free (as- 
received, DoS $3 \mathrm{mg} / \mathrm{cm}^{2}$ ) 5083-H131 in either simulated crack solution or near-neutral $\mathrm{NaCl}$ with anodic polarization (Chapter 3) are substantially faster than $\mathrm{da} / \mathrm{dt}_{\mathrm{II}}$ modeled in Eqn. 2.8 with $\mathrm{x}_{\text {CRIT }}$ of $10 \mu \mathrm{m}$; these rates better align with an $\mathrm{x}_{\text {CRIT }}$ of $0.9 \mu \mathrm{m}$. Environmental cracking data compiled by Gangloff and interpreted in terms of Eqn. 2.8, established a single $\mathrm{x}_{\text {CRIT }}$ value of $0.9 \mu \mathrm{m}$ for a range of alloys when the squared inverse error function term is 1.0 pertinent to very small $\mathrm{C}_{\mathrm{H}-\text { crit }} / \mathrm{C}_{\mathrm{H \sigma}}[70]$. An $\mathrm{x}_{\text {CRIT }}$ on the order of $1 \mu \mathrm{m}$ aligns with the $\mathrm{K}^{2} / \sigma_{Y S} \mathrm{E}$ estimate for high strength-higher modulus alloys, particularly Fe-based alloys. This continuum estimate of location of maximum stress ahead of the crack tip (using CTOD) does not capture the complex contributions of: (a) crack tip elastic shielding and strain gradient plasticity (SGP) on the crack tip stress distribution [91], (b) microstructure-scale stresses from deformation gradients, or (c) the interaction of these effects. It is reasonable to speculate that the contributions of these highly localized stresses becomes increasingly important for lower strength microstructures such as $5083-\mathrm{H} 131$, which may contribute to lowering $\mathrm{X}_{\text {CRIT }}$ below the estimated with $\mathrm{K}^{2} / \sigma_{\mathrm{YS}} \mathrm{E}$ at $10 \mu \mathrm{m}$ to the correlated value of $0.9 \mu \mathrm{m}$. Since $\beta$ is not present in as-received 5083-H131, these crack tip work hardening and SGP speculations dictate the location of $\mathrm{H}$ cracking site, or the value of $\mathrm{x}_{\mathrm{CRIT}}$, for this single phase $\mathrm{Al}-\mathrm{Mg}$ solid solution microstructure. The stress levels and $\mathrm{C}_{\mathrm{H} \sigma}$ at this reduced $\mathrm{x}_{\mathrm{CRIT}}$ are higher than those associated with the continuum estimate of $\mathrm{x}_{\mathrm{CRIT}}=\mathrm{K}^{2} / \sigma_{\mathrm{YS}} \mathrm{E}$.

The DoS dependence of IGSCC may be explained if local crack tip stress, $\mathrm{C}_{\mathrm{H} \sigma}$, and $\mathrm{x}_{\text {CRIT }}$ are further impacted by the $\beta$-precipitate microstructure. The presence of $\beta$ must elevate the already-concentrated local tensile stress above the crack tip field operative for Al-Mg without $\beta$, which would result in shortening $\mathrm{x}_{\text {CRIT }}$ below the correlated (or 
continuum estimated) value of $0.9 \mu \mathrm{m}$. Literature on the microstructure-scale stress state of a grain boundary populated by $\beta$ particles, or constraint of inter- $\beta$ ligament plasticity, is lacking for either a uniaxial-global or crack tip deformation field; therefore, it is only possible to estimate the role of $\beta$ precipitates on $\mathrm{C}_{\mathrm{H \sigma}}$ and $\mathrm{x}_{\mathrm{CRIT}}$. A non-deforming $\beta$ particle may concentrate local tensile stress, and hydrostatic stress may be elevated through constraint of $\alpha$ deformation between $\beta$ particles. The elastic modulus of $\beta$ phase was reported to be $68 \mathrm{GPa}$ [92] or predicted to be in the range of $56 \mathrm{GPa}$ to $71 \mathrm{GPa}$ by firstprinciples calculations [93], while that for Al-Mg solid solution is $70 \mathrm{GPa}$. Since $\beta$ does not appear to be elastically stiffer than the matrix, elastic constraint of $\alpha$ by $\beta$ is not expected. However, provided that $\beta$ resists plastic deformation relative to $\mathrm{Al}-\mathrm{Mg}$, and given the high-plastic strain ( $\sim 5$ to $50 \%)$ within $\mathrm{K}^{2} / \sigma_{\mathrm{YS}} \mathrm{E}$ of the crack tip surface [43], it is reasonable to expect that the elastically deforming $\beta$ will constrain plastic flow of $\alpha$ local to the ligament between adjacent $\beta$ particles. This constraint would diminish above and below the grain boundary to a distance of about $+/$ - one particle diameter.

The complex structure of $\beta\left(\mathrm{Al}_{3} \mathrm{Mg}_{2}\right.$ : unit cell of 1168 atoms $\left.[92,94]\right)$ promotes a high yield strength due to dislocation slip limitation. Dubois reported that single phase $\mathrm{Al}_{3} \mathrm{Mg}_{2}$ exhibits a Vickers hardness of $350\left(\mathrm{H}_{\mathrm{V}}\right.$ for pure $\mathrm{Al}$ is 40$)$ and plane strain fracture toughness less than 0.5 MPa $\sqrt{\mathrm{m}}$ [92], suggesting extremely limited dislocation plasticity. The measured yield strength of single crystal $\mathrm{Al}_{3} \mathrm{Mg}_{2}$ is $280 \mathrm{MPa}$ at $325^{\circ} \mathrm{C}$ and $780 \mathrm{MPa}$ at $225^{\circ} \mathrm{C}$ [95]; linear extrapolation suggests that $\sigma_{\mathrm{Ys}}$ for $\mathrm{Al}_{3} \mathrm{Mg}_{2}$ at $25^{\circ} \mathrm{C}$ is $\sim 1500 \mathrm{MPa}$, or $\sim \mathrm{E} / 50$. This high resistance to plastic flow of $\beta$ should constrain plasticity in FPZ $\alpha$ ligaments. 
Several micromechanical models predicted the elevation of tensile and hydrostatic stresses adjacent to a non-deformable spherical particle, and within a layer of deformable phase constrained by an elastic boundary condition provided by adjacent non-deformable particles. These models are specific to global-uniaxial deformation and have not been extended to a crack tip. Lloyd suggested that a tensile stress of $600 \mathrm{MPa}$ to $750 \mathrm{MPa}$ (matrix yield strength + hydrostatic stress of $350 \mathrm{MPa}$ to $500 \mathrm{MPa}$ ) is generated at the interface of an elastic-spherical $\mathrm{SiC}$ particle in an $\mathrm{Al}$ alloy matrix under a global strain of 0.02 [96]. Modeling by Goods and Brown suggested that this stress is $500 \mathrm{MPa}$ to $600 \mathrm{MPa}$ for an elastic particle in $\mathrm{Al}$, using a relationship for particles larger than $1 \mu \mathrm{m}$ to $2 \mu \mathrm{m}$ [97]. Considering two elastic particles with height $(h)$ separated by a layer of constraineddeformable $\mathrm{Al}$ of length $(b)$, the maximum tensile stress $\left(\sigma_{\text {local }}\right)$ is midway between the particles and given by $\sigma_{\mathrm{YS}}(1+b / 2 h)$ [96]. For sensitized 5083-H131, the $\beta$ spacing is about $300 \mathrm{~nm}$ and the particle equivalent diameter is about $180 \mathrm{~nm}$ (Fig. 2.30) [5]. If $b$ equals this $\beta$ spacing and $h$ is given by either the equivalent diameter of $\beta$, or $1 / 3$ of this diameter, then the local-tensile stress is elevated to between $1.8 \sigma_{\mathrm{YS}}$ and $3.5 \sigma_{\mathrm{YS}}(450 \mathrm{MPa}$ to $875 \mathrm{MPa}$ assuming that the uniaxial yield strength of the Al-Mg solid solution is $250 \mathrm{MPa}$ ). The concept of intra-particle constraint was supported by fracture experiments [98]; however, numerical analysis using the proper matrix flow rules is required to better quantify the stress and strain fields between elastic particles and the effective height of constrained deformation.

The classic approach described above may underestimate the local stress field relevant to DoS dependent IGSCC. Two considerations are put fourth, though they are speculative and beyond the scope of this dissertation. First, the role of slip interaction with the Al-Mg 
grain boundary is not considered. Second, high stresses may result from local hardening dictated by SGP [91]. Brown and Stobbs estimated the local elastic stresses generated from dislocation tangles around non-deformable particles [99]. They argued that the dislocation density about a particle is proportional to the ratio of plastic strain-to-particle radius, thus the local strain hardening increases with decreasing particle size. This mechanism could provide a factor of 1.5 to 2 increase in local flow strength, which increases the levels of local crack tip stress noted above by a factor of 2 [97].

Collectively, this discussion supports the speculation that the local tensile stresses $\left(\sigma_{\text {local }}\right)$, acting on the grain boundary ligament between elastically deforming $\beta$ precipitates, is $\delta \sigma_{Y S}$ for the $\mathrm{Al}-\mathrm{Mg}$ solid solution, where $\delta$ is 3.6 to 7 (estimated based on Lloyd, Brown and Stobbs $[96,99])$. The associated hydrostatic tension would be $\sim(2 \delta+1) \sigma_{\mathrm{YS}} / 3$; thus, $\sigma_{\mathrm{H}}$ is $2.7 \sigma_{\mathrm{YS}}$ to $5 \sigma_{\mathrm{Ys}}$. To a first approximation, it is assumed that these microstructure scale stresses and the typical continuum stresses predicted in the SGP constrained crack tip are additive [91]. The impact of this additional level of stress elevation on $\mathrm{H}$ localization is now considered.

Following the cartoon in Fig. 2.22 and the discontinuous model of IGSCC, $\mathrm{H}$ diffuses through the Al-Mg lattice to an $\alpha$ grain boundary at $\mathrm{x}_{\text {CRIT }}$ ahead of the crack tip surface. Hydrogen trapping is expected at this grain boundary, at the dislocation structure, and along $\alpha-\beta$ interfaces; however, only the H-trap binding energy for dislocations in $\mathrm{Al}$ has been reported $(27 \mathrm{~kJ} / \mathrm{mol})$ [68]. Moreover, recent thermal desorption spectroscopy showed similar trapping states for pure $\mathrm{Al}$ and 5083-H131 at various DoS, with a broad desorption peak consistent with the $20-30 \mathrm{~kJ} / \mathrm{mol}$ binding energy $[72,87]$. Speculatively, $\mathrm{H}$ traps at $\alpha$ $\beta$ and $\alpha-\alpha$ interfaces with a similar binding energy of about $25 \mathrm{~kJ} / \mathrm{mol}\left(\mathrm{E}_{\mathrm{GB}}\right.$ for $\left.\alpha-\alpha\right)$, though 
there is no evidence to suggest that trap sensitive permeation changes with DoS [72]. As such, there is no evidence to suggest that preferential $\mathrm{H}$-trapping at $\beta$ occurs and lowers $\mathrm{x}_{\text {CRIT }}$ below a level that is dictated by crack tip and microstructure-scale $\sigma_{\mathrm{H}}$.

This microstructure-based trap binding energy of $25 \mathrm{~kJ} / \mathrm{mol}$ must be compared to that associated with microstructure-scale stresses, given by $\sigma_{H} V_{H}[28,90]$. From the previous discussion, $\sigma_{\mathrm{H}}$ in the $\alpha$ ligament is $2.7 \sigma_{\mathrm{YS}}$ to $5.0 \sigma_{\mathrm{YS}}$ of the Al-Mg solid solution. For $\sigma_{\mathrm{YS}}=250 \mathrm{MPa}, \sigma_{\mathrm{H}} \mathrm{V}_{\mathrm{H}}$ is $1.11 \mathrm{~kJ} / \mathrm{mol}$ to $2.1 \mathrm{~kJ} / \mathrm{mol} \mathrm{H}$ in Al. This $\mathrm{H}$-stress field binding energy is small compared to that for dislocation and interface trapping of $\mathrm{H}(25 \mathrm{~kJ} / \mathrm{mol})$. As such, stressing will not cause $\mathrm{H}$ to partition from microstructure trap sites to regions of highly stressed Al lattice. However, local stresses may increase the concentration of $\mathrm{H}$ trapped at stressed microstructure features. For example, as the local hydrostatic stress increases, $\mathrm{C}_{\mathrm{H \sigma}}$ trapped at a grain boundary $\left(\mathrm{C}_{\mathrm{GB} \sigma}\right)$ increases due to increased lattice concentration of $\mathrm{H}\left(\mathrm{C}_{\mathrm{L} \sigma}\right)$, which is assumed to be in equilibrium with $\mathrm{C}_{\mathrm{GB} \sigma}$. This enhancement is shown by these relationships [90]:

$$
C_{H \sigma}=C_{G B \sigma}=C_{L \sigma} \exp \left(\frac{E_{G B}}{R T}\right)=\left\{C_{L} \exp \left(\frac{\delta \sigma_{Y S} V_{H}}{R T}\right)\right\} \exp \left(\frac{E_{G B}}{R T}\right)
$$

where all terms were previously defined. For $\delta=2.7$ to 5.0 and $\sigma \mathrm{YS}=250 \mathrm{MPa}$, at $23^{\circ} \mathrm{C}$ $\mathrm{C}_{\mathrm{L} \sigma}=1.6 \mathrm{C}_{\mathrm{L}}$ to $2.3 \mathrm{C}_{\mathrm{L}}$. If SGP elevates $\delta$ to 10 , then $\sigma_{\mathrm{H}} \mathrm{V}_{\mathrm{H}}$ is $4.3 \mathrm{~kJ} / \mathrm{mol} \mathrm{H}$ in $\mathrm{Al}$ and $\mathrm{C}_{\mathrm{L} \sigma}=5.6 \mathrm{C}_{\mathrm{L}}$ at $23^{\circ} \mathrm{C}$. This analysis assumes that stress does not impact $\mathrm{E}_{\mathrm{B}}$ for $\mathrm{H}$ trapped at a grain boundary, which is reasonable for a high angle interface provided that the trap state is not altered by deformation, for example by cavity formation [68]. This enhancement in grain boundary $\mathrm{H}$ concentration may be meaningful, but the modest change is not likely to explain the dramatic rise in IGSCC susceptibility as the DoS rises through the critical level of $10 \mathrm{mg} / \mathrm{cm}^{2}$ (Figs 2.24 and 2.26). The next section considers the impact of microstructure- 


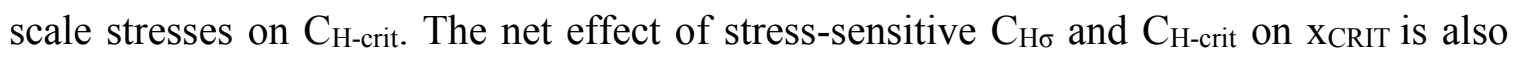
considered.

\subsection{The role of $\beta$ on the $\mathrm{C}_{\mathrm{H}-\mathrm{crit}}$}

Oriani proposed the decohesion model for the equilibrium-onset of $\mathrm{H}$ assisted damage/embrittlement when the local tensile stress acting on a $\mathrm{H}$ enriched interface just equals the maximum cohesive force per unit area, reduced by $\mathrm{H}$ [28]. This theory leads to the experimentally validated concepts of: (a) a threshold stress intensity factor $\left(\mathrm{K}_{\mathrm{TH}}\right)$ that falls as a function of increasing FPZ $\mathrm{C}_{\mathrm{H} \sigma}$ for a sharp crack [100,101], and (b) a thresholdlocal tensile stress that falls as a function of rising FPZ H concentration for a notch [102]. From these studies, and a large body of supportive research [70], it is clear that the critical concentration of $\mathrm{H}$ required to cause grain boundary decohesion, $\mathrm{C}_{\mathrm{H}-\text { crit }}$ in Eqn. 2.8, is inversely related to a function of the local tensile stress $\left(\sigma_{\text {local }}\right)$ at the decohesion site.

The challenge is to estimate the strength of the dependence of $\mathrm{C}_{\mathrm{H}-\mathrm{crit}}$ on $\sigma_{\text {local }}$, as a means to assess the importance of DoS-generated microstructural stresses on $\mathrm{C}_{\mathrm{H} \text {-crit. }}$ Oriani assumed that the cohesive strength of an interface falls linearly from the H-free intrinsic strength $\left(\sigma^{*}\right)$ due to increasing $\mathrm{H}$ concentration multiplied by a weighting factor $(\gamma$, in units as $\mathrm{MPa}$ /atom fraction $\mathrm{H}$ ) [28]; decohesion occurs when this reduced strength equals $\sigma_{\text {local }}[28]$. A more general approach is to assume that the reduction in cohesive strength is proportional to $\gamma\left(\mathrm{C}_{\mathrm{H}}\right)^{\mathrm{m}}$. As such:

$$
\sigma_{\text {local }}=\sigma_{f}=\sigma^{*}-\gamma\left(C_{H-c r i t}\right)^{m}
$$

where $\sigma_{\mathrm{f}}$ is the failure strength, and $\mathrm{m}$ is a dimensionless constant. A specific relationship between $\mathrm{C}_{\mathrm{H}-\mathrm{crit}}$ and $\sigma_{\text {local }}$ has not been reported for $\mathrm{H}$ in $\mathrm{Al}$ [68]. A role of $\beta$ presence on $\mathrm{C}_{\mathrm{H}-\text { crit }}$ in 5083-H131 is qualitatively suggested by the $\mathrm{H}$ charging experiments reported in 
Chapter 4. Three sensitizations of 5083-H131 (same heat as the present study) were charged with $\mathrm{H}$, then loaded to rupture in air. The failure strength for each sensitized specimen was lower than that of the unsensitized specimen. Since the amount and location of $\mathrm{H}$ are constant in all specimens, dictated by the constant $\mathrm{H}$-charging condition, it appears that the presence of $\beta$ in the microstructure reduced the amount of $H$ required for grain boundary decohesion, perhaps by increasing $\sigma_{\text {local }}$. This would cause embrittlement at lower applied stress in sensitized specimens.

Considering other alloys, Hall and Symons suggested that $\mathrm{C}_{\mathrm{H}-\text {-crit }}$ scales with the magnitude of the reduction in $\mathrm{K}_{\mathrm{TH}}$ below $\mathrm{K}_{\mathrm{IC}}$ [103]. Several experimental studies with high strength Fe-based and Ni-based alloys demonstrated that $\mathrm{K}_{\mathrm{TH}}$ is proportional to $\mathrm{C}_{\mathrm{H} \sigma}$ raised to a power, $\mathrm{n}$, on the order of -0.2 to $-0.5[70,104]$. Micromechanical modeling has not directly related this global $\mathrm{K}_{\mathrm{TH}}$ to a specific $\sigma_{\text {local- }} \mathrm{C}_{\mathrm{H}-\text { crit }}$ failure criterion. Studies with $\mathrm{H}$ precharged notched specimens of several high strength steels affirmed the form of Eqn. 2.10 and indicated that, at least for this alloy class, a small increase in $\sigma_{\text {local }}$ can lead to a large decrease in $\mathrm{C}_{\mathrm{H}-\text {-crit }}[102,105]$. For example, Akiyama, et al. reported extensive data which fit either of the following relationships [105]:

$$
\sigma_{\mathrm{f}}=2000\left(\mathrm{C}_{\mathrm{H}-\mathrm{crit}}\right)^{-0.21} \text { or }\left(4000-\sigma_{\mathrm{f}}\right)=1920\left(\mathrm{C}_{\mathrm{H}-\mathrm{crit}}\right)^{0.22}
$$

where $\sigma_{\mathrm{f}}$ (in $\mathrm{MPa}$ ) was established by elastic-plastic finite element analysis of the maximum stress ahead of a notch root and $\mathrm{C}_{\mathrm{H}}$ (in wppm) was equated to $\mathrm{C}_{\mathrm{H} \sigma}$ from measured-diffusible $\mathrm{H}$ concentration enhanced by $\exp \left[\sigma_{\mathrm{H}} \mathrm{V}_{\mathrm{H}} /(\mathrm{RT})\right]$ with hydrostatic stress determined from the finite element analysis. In this formulation $\mathrm{C}_{\mathrm{H \sigma}}$ is interpreted to equal $\mathrm{C}_{\mathrm{H}-\mathrm{crit}}$ in Eqn. 2.8. A similar result was obtained by Ayas et al. [102]. These relationships 
between local-critical $\mathrm{H}$ concentration and local stress at fracture are of the same form as the relationship between $\mathrm{K}_{\mathrm{TH}}$ and $\mathrm{C}_{\mathrm{H} \sigma}$.

If intergranular $\mathrm{H}$ decohesion in $\mathrm{Al}-\mathrm{Mg}$ is governed by a similar relationship between microstructure-scale stress and local $\mathrm{H}$ concentration, as given in Eqn. 2.11 for high strength steel, then a small change in $\sigma_{\text {local }}$ due to $\beta$ precipitation (sensitization) is projected to have a large impact on $\mathrm{C}_{\mathrm{H} \text {-crit, }}$ as suggested by $\mathrm{C}_{\mathrm{H} \text {-crit }}$ proportional to reciprocal $\sigma_{\text {local }}$ raised to the $5^{\text {th }}$ power as suggested by Eqn. 2.11. For example, if $\sigma_{\text {local }}$ averaged across the Al-Mg ligament between $\beta$ precipitates is increased by 4 times that typical of a $\beta$-free grain boundary (the previous analysis suggested this increase is between 3.6 to 7 times), then $\mathrm{C}_{\mathrm{H} \text {-crit }}$ is reduced 1,024-fold, showing the potential for a strong impact of $\sigma_{\text {local }}$ on $\mathrm{C}_{\mathrm{H} \text {-crit. }}$ This estimate is, at best, directionally correct, but suggests the possible impact of local stress state on $\mathrm{C}_{\mathrm{H} \text {-crit }}$ in the da/dt $\mathrm{dI}$ model (Eqn. 2.8). Additional modeling is required using a relationship between $\sigma_{\mathrm{f}}$ and $\mathrm{C}_{\mathrm{H}-\mathrm{crit}}$ specific to a high angle grain boundary in low strength Al-Mg. Moreover, the relationship between a notch-root measured $\sigma_{f}$ and the local microstructure-scale $\sigma_{\text {local }}$ versus $\mathrm{C}_{\mathrm{H}-\mathrm{crit}}$ failure criterion must be refined. None-the-less, this interaction between microstructure-scale stress and the critical $\mathrm{H}$ concentration for intergranular decohesion appears to be much stronger than the impact of $\sigma_{\text {local }}$ on $\mathrm{C}_{\mathrm{H} \sigma}$, suggesting that this former effect of $\beta$ is a significant contributor to the sharp increase in IGSCC rate with increasing DoS in the range from about $3 \mathrm{mg} / \mathrm{cm}^{2}$ to $10 \mathrm{mg} / \mathrm{cm}^{2}$ (Figs 2.14 and 2.17).

There are two implications for these analyses of the effect of $\beta$-scale stresses on $\mathrm{da} / \mathrm{dt}_{\mathrm{II}}$ through Eqn. 2.8. First, the observation that low DoS 5083-H131 (without $\beta$ ) exhibits IGSCC rates that are in line with the prediction of Eqn. 2.8 for cases where $\mathrm{C}_{\mathrm{H}-\mathrm{crit}} / \mathrm{C}_{\mathrm{H \sigma}}<<1$, 
suggests that decreased $\mathrm{C}_{\mathrm{H}-\text {-rit }}$ and increased $\mathrm{C}_{\mathrm{H} \sigma}$ due to $\beta$ precipitation have a second order effect on $\mathrm{da} / \mathrm{dt}_{\text {II. }}$. For example, the square of the inverse error function term rises only by a factor of 5 for a 1000-times decrease in $\mathrm{C}_{\mathrm{H} \text {-crit }} / \mathrm{C}_{\mathrm{H} \sigma}$ (from a factor of 1.4 when $\mathrm{C}_{\mathrm{H} \text {-crit }} / \mathrm{C}_{\mathrm{H} \sigma}=0.1$, to a factor of 7.6 when $\mathrm{C}_{\mathrm{H} \text {-crit }} / \mathrm{C}_{\mathrm{H} \sigma}=10^{-4}$ ). These changes in $\mathrm{C}_{\mathrm{H} \sigma}$ and $\mathrm{C}_{\mathrm{H} \text {-crit }}$ are not, in isolation, likely to produce the strong change in $\mathrm{da} / \mathrm{dt}_{\text {II }}$ measured for a DoS change from $3 \mathrm{mg} / \mathrm{cm}^{2}$ to $10 \mathrm{mg} / \mathrm{cm}^{2}$ (Fig. 2.24).

Second, it is reasonable to speculate that $\beta$-induced stress concentration reduces $\mathrm{x}_{\mathrm{CRIT}}$, by locating the hydrogen embrittlement FPZ through increased $\mathrm{C}_{\mathrm{H} \sigma}$ and decreased $\mathrm{C}_{\mathrm{H}-\text { crit, }}$ below the value typical of a continuum fracture mechanics model augmented by SGP. That is, while an $\mathrm{x}_{\mathrm{CRIT}}$ of $0.9 \mu \mathrm{m}$ is consistent with the global correlation of $\mathrm{da} / \mathrm{dt}_{\mathrm{II}}$ for low DoS 5083-H131 (Eqn. 2.8), stress enhancement due to $\beta$ may reduce $\mathrm{x}_{\text {CRIT. It is reasonable to }}$ speculate that $\mathrm{X}_{\mathrm{CR}}$ IT is reduced to a value intermediate between the crack tip stress field dictated value of $0.9 \mu \mathrm{m}$ and a lower limit suggested by the inter- $\beta$ spacing $(\sim 300 \mathrm{~nm}$, Figure 2.30 [5]). Ai et al. suggested that the DoS threshold of $25 \mathrm{mg} / \mathrm{cm}^{2}$ (established in the context of the occurrence of IGC in sensitized Al-Mg alloys [21]) is related to the spacing of $\beta$ and a limiting-accessible $\mathrm{H}$ diffusion distance for a continuously moving crack [72]. The focus of this dissertation is on IGSCC, where $\mathrm{H}$ embrittlement is the critical element of damage advance (see Chapter 3), and on the lower-DoS threshold of $10 \mathrm{mg} / \mathrm{cm}^{2}$ established by the IGSCC data in Figs. 2.24 and 2.26. In this context reduced $\mathrm{x}_{\text {CRIT }}$ to $300 \mathrm{~nm}$ is consistent with the expected impact of $\beta$ precipitates; not on $\mathrm{H}$ trapping, but rather on localized- $\alpha$ constraint and stress enhancement of $\mathrm{C}_{\mathrm{H} \sigma}$ and $\mathrm{C}_{\mathrm{H} \text {-crit. The role of this }}$ lower $\mathrm{x}_{\text {CRIT }}$ on the increased da/dt $\mathrm{dI}_{\text {II }}$ for $5083-\mathrm{H} 131$ sensitized to DoS levels at and above $10 \mathrm{mg} / \mathrm{cm}^{2}$ is considered in the context of $\mathrm{H}$ diffusion modeling in Chapter 4 [73]. 


\subsubsection{Sensitization dependence of intergranular corrosion}

The IGC growth rates measured with the dcPD method on fatigue cracked SENT specimens are impacted by sensitization. Initial corrosion damage measured during the low-K hold and initial rising-K periods in sensitized 5083-H131 (Fig. 2.9) were not reported in prior IGSCC studies $[1,11,12,16,34,35]$. Low $\mathrm{K}$ fatigue crack tip IGC rates correlate with stress-free IGC penetration rates over a range of mild to severe sensitizations $\left(22 \mathrm{mg} / \mathrm{cm}^{2}\right.$ to $\left.57 \mathrm{mg} / \mathrm{cm}^{2}\right)$ [6]. These measured values fall between IGC rates predicted by fissure corrosion modeling (dashed lines in Fig. 2.10) [17], suggesting that da/dt IGC is: a) intergranular "crevice" corrosion, b) essentially independent of static crack tip stress, and c) electrochemically controlled by $\beta$ dissolution. The ability to measure IGC with an SENT specimen is important for two reasons. First, slow corrosion growth, through both $\beta$ and $\alpha$ dissolution, could govern component life in a very low $\mathrm{K}$ regime that is not typically accounted for in fracture mechanics modeling. Effectively, the occurrence of IGC within an occluded crack eliminates $\mathrm{K}_{\mathrm{TH}}$ as a useful parameter in component prognosis. Second, the present experiments provide a new way of quantitatively measuring the kinetics of IGC in two dimensions and averaged across the fatigue crack front.

The impact of DoS on IGC rates is evident in Fig. 2.10. A gradual growth rate increase is recorded for increasing NAMLT DoS from $9 \mathrm{mg} / \mathrm{cm}^{2}$ to $40 \mathrm{mg} / \mathrm{cm}^{2}$, and then rapidly increases between $40 \mathrm{mg} / \mathrm{cm}^{2}$ and $60 \mathrm{mg} / \mathrm{cm}^{2}$ (Fig. 2.10). A critical DoS was observed at $25 \mathrm{mg} / \mathrm{cm}^{2}$ for unstressed IGC measurements in $\mathrm{NaCl}$ polarized to $-0.730 \mathrm{~V}_{\mathrm{SCE}}$, with fissure growth in L direction from a bold surface of SHT 5083-H131 (same heat as the present study) [6]. This DoS is consistent with initiation of high $\beta$ coverage (Fig. 2.28) measured with a combined Barkers-phosphoric acid etching technique [6], The critical DoS is likely lower than that in the present study owing to the more anodic potential, which likely 
accelerated dissolution such that a smaller volume of $\beta$ was likely required to trigger $\alpha$ dissolution.

An increase in IGC susceptibility, based on depth of penetration, was linked to $\beta$ distribution on grain boundaries [6]. The increase in amount of $\beta$ and the closer proximity of particles with increasing DoS establishes a well-connected path for IGC [6]. The propagation between particles was predicted to be due to a change in fissure environment caused by the dissolution of $\beta$, as discussed in Chapter 3 and suggested elsewhere $[6,17,18]$.

\subsection{CONCLUSIONS}

Precision monitoring of stress corrosion crack growth and SEM fractographic analysis establish the effect of degree of sensitization on the IGSCC resistance of Al-Mg alloy 5083-H131 in the susceptible S-L orientation for slow-rising stress intensity loading in $\mathrm{NaCl}$ solution. Low sensitization temperatures, below $100^{\circ} \mathrm{C}$, are emphasized.

- Elastic-plastic J-integral analysis of crack tip stress intensity, and direct current electrical potential difference measurement of crack growth, effectively characterize the kinetics of IGSCC in low strength Al-Mg alloys.

- The fracture toughness of 5083-H131 in the S-L orientation appears to rise by $25 \%$ with sensitization from $3 \mathrm{mg} / \mathrm{cm}^{2}$ to $50 \mathrm{mg} / \mathrm{cm}^{2}$, and similar primary void and microvoid sheet features were observed for both as-received and sensitized $\left(22 \mathrm{mg} / \mathrm{cm}^{2}\right)$ 5083-H131, without evidence of grain boundary participation.

- Alloy 5083-H131 without laboratory sensitization is only mildly susceptible to IGSCC in neutral $\mathrm{NaCl}$ solution at near-open circuit potential, evidenced by slow time-dependent crack growth and intergranular cracking features, albeit at high $\mathrm{K}$ above the plane strain fracture toughness.

- Alloy 5083-H131 in the S-L crack orientation is susceptible to significant IGSCC after sensitization at relatively low temperatures, below $100^{\circ} \mathrm{C}$, and for corresponding mass loss measurements of DoS as low as $10 \mathrm{mg} / \mathrm{cm}^{2}$. 
○ The apparent $\mathrm{K}_{\mathrm{TH}}$ for IGSCC depends strongly on DoS, and above $10 \mathrm{mg} / \mathrm{cm}^{2}$ correlates with a single function of ASTM G67 mass loss for sensitization at $60^{\circ} \mathrm{C}, 80^{\circ} \mathrm{C}$, and $100^{\circ} \mathrm{C}$. Below this critical DoS, $\mathrm{K}_{\mathrm{TH}}$ approaches $\mathrm{K}_{\mathrm{JIC}}$ for cracking in moist air.

- Stage II da/dt depends on a single function of mass loss for DoS levels above $10 \mathrm{mg} / \mathrm{cm}^{2}$ for sensitization at $60^{\circ} \mathrm{C}, 80^{\circ} \mathrm{C}$, and $100^{\circ} \mathrm{C}$. Below this critical DoS, crack growth rates are very slow and perhaps only occur under positive $\mathrm{dK} / \mathrm{dt}$.

- Fractographic analysis of IGSCC in 5083-H131 is complicated by crack wake corrosion.

- The occurrence of IGSCC correlates with flat grain boundary features that contain shallow dimples due to localized corrosion perhaps associated with reactive $\beta$ and cathodic Al-Mn dispersoids.

- Discrete IGSCC regions at low DoS may be representative of preferential precipitation of $\beta$.

- As the severity of IGSCC increases at higher DoS, $\beta$ coverage extends to more boundaries, which likely contributes to the increase in relative proportion of grain boundary crack features and the decrease in areas of ductile microvoid damage.

- The sensitization dependence of SCC in 5083-H131 is consistent with the combined mechanism of $\beta$ and Al-Mg matrix dissolution, coupled H production and uptake, and intra- $\beta$ ligament hydrogen embrittlement.

- Low $\mathrm{K}_{\mathrm{TH}}$ and high da/dt for DoS levels above $10 \mathrm{mg} / \mathrm{cm}^{2}$ likely correlate with the combination of a critical volume of $\beta$ for development of a high $\mathrm{H}$ concentration by the crack tip chemistry and critical spacing for increased microstructure-scale stress in the crack tip FPZ.

- A critical $\beta$ coverage is required to provide and maintain an environment suitable for matrix dissolution, $\mathrm{H}$ production and uptake. This crack tip chemistry likely influences the $\mathrm{H}$ concentration at the fracture process zone. For constant displacement rate loading in $\mathrm{NaCl}$ at near $\mathrm{OCP}$, dissolution of $\beta$ is required as a trigger for rapid dissolution to sustain 
the acidic crack tip environment. This conclusion is supported in Chapter 3.

O The stress enhanced concentration of $\mathrm{H}$ in the FPZ can potentially increase by up to 5 times due to the local stress enhancement on the grain boundary from elastic $\beta$ precipitates.

- Stress enhancement due to $\beta$ may reduce the critical fracture distance (x $\mathrm{x}$ CRT), by locating the FPZ (by increased $\mathrm{C}_{\mathrm{H \sigma}}$ and decreased $\mathrm{C}_{\mathrm{H}-\text { crit }}$ with $\beta$ precipitation) below the value typical of a continuum fracture mechanics model. The $\mathrm{X}_{\mathrm{CRIT}}$ is likely reduced to a value between the crack tip stress field dictated value of $0.9 \mu \mathrm{m}$ and a lower limit suggested by the inter- $\beta$ spacing $(\sim 300 \mathrm{~nm})$.

O The critical concentration of $\mathrm{H}$ required at the FPZ for interface decohesion may decrease by several orders of magnitude due to local stress enhancement on the grain boundary from elastic $\beta$ precipitates.

- The severe increase in crack growth rates at DoS of $10 \mathrm{mg} / \mathrm{cm}^{2}$ could be induced by rapid local $\mathrm{H}$ diffusion ahead of the crack tip when inter- $\beta$ ligaments are small enough to lie within the plasticity induced dislocation cell structures, which are free from H-dislocation interaction, or can readily fill with trapped $\mathrm{H}$, These trap free ligaments may produce a higher local $\mathrm{D}_{\mathrm{H}-\mathrm{EFF}}$, for faster crack growth rates. This conclusion is supported in Chapter 4.

- Intergranular corrosion growth is measured at the fatigue crack tip in sensitized 5083-H131 in $\mathrm{NaCl}$ at near OCP and subjected to very low $\mathrm{K}$.

- The low applied stress likely does not influence the rate of IGC, though it may contribute to faster rates in highly sensitized microstructures.

- Growth rates increase slowly with DoS above $10 \mathrm{mg} / \mathrm{cm}^{2}$, then increase substantially for DoS levels above $40 \mathrm{mg} / \mathrm{cm}^{2}$. This is likely attributed to an increase in $\beta$ connectivity at $40 \mathrm{mg} / \mathrm{cm}^{2}$. The aggressive crack tip chemistry developed with increasing volume of $\beta$ dissolution controls the dissolution rates along the grain boundary. 


\subsection{REFERENCES}

1. F.S. Bovard: "Sensitization and Environmental Cracking of 5xxx Aluminum Marine Sheet and Plate Alloys," in Corrosion Marine Saltwater Environment II, D.A. Shifler, T. Tsuru, P.M. Natishan, and S. Ito, eds., ECS, Pennington, NJ, 2005, pp. 232-43.

2. E.H. Dix, Jr., A. Anderson, and M.B. Shumaker: Corrosion, 1959, vol. 15, pp. 55-62.

3. R. Goswami, G. Spanos, P.S. Pao, and R.L. Holtz: Metall. Mater. Trans. A, 2011, vol. 42, pp. 348-55.

4. Y. Zhu, D.A. Cullen, S. Kar, M.L. Free, and L.F. Allard: Metall. Mater. Trans. A, 2012, vol. 43, pp. 4933-39.

5. N. Birbilis, M.L.C. Lim, A.K. Gupta, C.H.J. Davies, S.P. Lynch, R.G. Kelly, and J.R. Scully: Corrosion, 2013, vol. 69, pp. 396-402.

6. M.L. Lim, R.G. Kelly, and J.R. Scully: Corrosion, 2013, vol. 69, pp. 35-47.

7. A.J. Davenport, Y. Yuan, R. Ambat, B.J. Connolly, M. Strangwood, A. Afseth, and G.M. Scamans: Mater. Sci. Forum, 2010, vol. 519-521, pp. 641-46.

8. R. Goswami and R.L. Holtz: Metall. Mater. Trans. A, 2013, vol. 44, pp. 1279-89.

9. R. Goswami, G. Spanos, P.S. Pao, and R.L. Holtz: Mater. Sci. Eng. A, 2010, vol. 527, pp. 1089-95.

10. R.H. Jones: JOM, 2003, vol. 55, pp. 42-6.

11. R.H. Jones, J.S. Vetrano, and C.F. Windisch: Corrosion, 2004, vol. 60, pp. 1144-54.

12. R.H. Jones, D.R. Baer, M.S Danielson, and J.S. Vetrano: Metall. Mater. Trans. A, 2001, vol. 32, pp. 1699-1711.

13. J.L. Searles: "The Electrochemical Characteristics of Al3Mg2 and Stress Corrosion Cracking of AA5083 (Al-4.5Mg-1.0Mn)," PhD Dissertation, The Ohio State University, Columbus, OH, 2000.

14. J.L. Searles, P.I. Gouma, and R.G. Buchheit: Metall. Mater. Trans. A, 2001, vol. 32, pp. 2859-67.

15. J. Gao: "Experiments to Explore the Mechanisms of Stress Corrosion Cracking," PhD Dissertation, University of Rochester, Rochester, NY, 2011.

16. J. Gao and D.J. Quesnel: Metall. Mater. Trans. A, 2010, vol. 42, pp. 356-64.

17. E. Bumiller: "Intergranular Corrosion in AA5XXX Aluminum Alloys with Discontinuous Precipitation at the Grain Boundaries," PhD Dissertation, University of Virginia, Charlottesville, VA, 2011.

18. E. Bumiller and R.G. Kelly: "Intergranular Corrosion in AA5xxx: A Case for Continuous Attack with a Discontinuous Active Path," in Department of Defense 2011 Corrosion Conference, CorrDefense, NACE International, Houston, TX, 2011.

19. I.N.A. Oguocha, O.J. Adigun, and S. Yannacopoulos: J. Mater. Sci., 2008, vol. 43, pp. 4208-14. 
20. D.O. Sprowls and R.H. Brown: "Stress-Corrosion Mechanisms for Aluminum Alloys," in Fundamental Aspects of Stress Corrosion Cracking, R.W. Staehle, ed., NACE, Houston, TX, 1969, pp. 466-506.

21. ASTM Standard G67, 2004, "Standard Test Method for Determining the Susceptibility to Intergranular Corrosion of 5xxx Series Aluminum Alloys by Mass Loss After Exposure to Nitric Acid (NAMLT Test)," ASTM International, West Conshohocken, PA, 2004, DOI: 10.1520/G0067-04, www.astm.org.

22. D.R. Baer, C.F. Windisch, M.H. Engelhard, M.J. Danielson, R.H. Jones, and J.S. Vetrano: J. Vac. Sci. Technol. A, 2000, vol. 18, pp. 131-36.

23. D. Tanguy, B. Bayle, R. Dif, and Th. Magnin: Corros. Sci., 2002, vol. 44, pp. $1163-$ 75.

24. S.-K. Lee, P. Lv, and D.D. Macdonald: J. Solid State Electrochem., 2013, vol. 17, pp. 2319-32.

25. N.B. Ali, R. Estevez, and D. Tanguy: Eng. Fract. Mech., 2013, vol. 97, pp. 1-11.

26. E. Pouillier, A.-F. Gourgues, D. Tanguy, and E.P. Busso: Int. J. Plast., 2012, vol. 34, pp. 139-53.

27. C.N. Panagopoulos and E.P. Georgiou: Corros. Sci., 2007, vol. 49, pp. 4443-51.

28. R.A. Oriani: Corrosion, 1987, vol. 43, pp. 390-97.

29. M.-S. Han: Met. Mater. Int., 2008, vol. 14, pp. 203-11.

30. J.R. Pickens, J.R. Gordon, and J.A.S. Green: Metall. Mater. Trans. A, 1983, vol. 14, pp. 925-30.

31. E.C. Cormack: "The Effect of Sensitization on the Stress Corrosion Cracking of Aluminum Alloy 5456," MS Thesis, Naval Postgraduate School, Monterey, CA, 2012.

32. A.J.P. Haszler and D. Sampath: "Aluminum-Magnesium Plate or Extrusion," U.S. Patent No. 6342113B2, 2002.

33. K.A Unocic: "Structure-Composition-Property Relationships in 5xxx Series Aluminum Alloys," PhD Dissertation, The Ohio State University, Columbus, OH, 2008.

34. R.L. Holtz, P.S. Pao, R.A. Bayles, T. Longazel, and R. Goswami: "Corrosion Fatigue and Stress Corrosion Cracking of Sensitized Al-Mg Structural Alloys," in Symposium on Structural Materials for Aerospace and Defense, MS\&T 2011, ASM International, Materials Park, OH, 2011.

35. A.K. Vasudevan and K. Sadananda: Metall. Mater. Trans. A., 2011, vol. 42, pp. 40514.

36. F.S. Bovard: Private Communication, Alcoa Technical Center, New Kensington, PA, 2012.

37. S. Jain, M.L.C. Lim, J.L. Hudson, and J.R. Scully: Corros. Sci., 2012, vol. 59, pp. 13647. 
38. ASTM Standard E112, 2010, "Standard Test Methods for Determining Average Grain Size," ASTM International, West Conshohocken, PA, 2010, DOI: 10.1520/E0112-10, www.astm.org.

39. A.P. Newbery, B. Ahn, T.D. Topping, P.S. Pao, S.R. Nutt, and E.J. Lavernia: J. Mater. Process. Technol., 2008, vol. 203, pp. 37-45.

40. M.T Tucker: "Structure-Property Stress State Dependent Relationships Under Varying Strain Rates," PhD Dissertation, Mississippi State University, Mississippi State University, MS, 2009.

41. M.T. Tucker, M.F. Horstemeyer, W.R. Whittington, K.N. Solanki, and P.M. Gullett: Mech. Mater., 2010, vol. 42, pp. 895-907.

42. T.M. Holmes, E.S.C. Chin, P.J. Huang, and R.E. Pasternak: "Evaluation of 8090 and Weldalite-049 Aluminum-Lithium Alloys," Report No. MTL TR 92-59, US Army Materials Technology Laboratory, Watertown, MA, 1992.

43. T.L. Anderson: Fracture Mechanics: Fundamentals and Applications, 3rd ed., CRC Press, Taylor and Francis Group, Boca Raton, FL, 2005, pp. 111, 398-400, 445-46.

44. M.L. Lim, J. Scully, and R. Kelly: Private Communication, University of Virginia, Charlottesville, VA, 2013.

45. G. Scamans: "Low Temperature Sensitisation of AA5xxx Alloys," Report IR07-197, Oxon, UK, 2008.

46. H. Tada, P.C. Paris, and G.R. Irwin: The Stress Analysis of Cracks Handbook, Paris Productions Incorporated, St. Louis, MO, 1985, pp. 2.10-2.12.

47. D. Mizuno and R.G. Kelly: Corrosion, 2013, vol. 69, pp. 580-92.

48. Y. Lee and R.P. Gangloff: Metall. Mater. Trans. A., 2007, vol. 38, pp. 2174-90.

49. M.J. Haynes and R.P. Gangloff: J. Test. Eval., 1997, vol. 25, pp. 82-98.

50. J.K. Donald and J. Ruschau: "Direct Current Potential Difference Fatigue Crack Measurement Techniques," in Fatigue Crack Measurement: Techniques and Applications, K.J. Marsh, R.A. Smith, and R.O. Ritchie, eds., EMAS, West Midlands, UK, 1991, pp. 11-38.

51. R.P. Gangloff, D.C. Slavik, R.P. Piascik, and R.H. Van Stone: "Direct Current Electrical Potential Measurement of the Growth of Small Cracks," in Small Crack Test Methods, ASTM STP 1149, J.M. Larsen and J.E. Allison, eds., American Society for Testing and Materials, Philadelphia, PA, 1992, pp. 116-68.

52. H.H. Johnson: Mater. Res. Stand., 1965, vol. 5, pp. 442-45.

53. V. Kumar, M.D. German, and C.F. Shih: "An Engineering Approach for ElasticPlastic Fracture Analysis," Report P-1931, General Electric Company, Schenectady, NY, 1981.

54. S. Cravero and C. Ruggieri: Eng. Fract. Mech., 2007, vol. 74, pp. 2735-57.

55. X.-K. Zhu and J.A. Joyce: Eng. Fract. Mech., 2012, vol. 85, pp. 1-46. 
56. E. Knudsen: Private Communication, Naval Research Laboratory, Washington, DC, 2012.

57. R.P. Gangloff: "Fracture Mechanics Prediction of Component SCC Using Accelerated Laboratory Testing," in Department of Defense Corrosion 2013 Conference, CorrDefense, NACE, Houston, TX, 2013.

58. M.J. Haynes and R.P. Gangloff: Metall. Mater. Trans. A., 1998, vol. 29, p. 1599-613.

59. N. Tsangarakis: Eng. Fract. Mech., 1987, vol. 26, p. 313-21.

60. J.G. Kaufman, P.E. Schilling, and F.G. Nelson: Met. Eng. Q., 1969, vol. 9, pp. 39-47.

61. ASTM Standard E1304, 1997, "Standard Test Method for Plane-Strain (ChevronNotch) Fracture Toughness of Metallic Materials" ASTM International, West Conshohocken, PA, 1998, DOI: DOI: 10.1520/E1304-97R08E01, www.astm.org.

62. G. Pioszak and R.P. Gangloff: Private Communication, University of Virginia, Charlottesville, VA, 2012.

63. G. Bencivenni, L. Bucci, G. Finocchiaro, and C. Forti: "Creep Measurement on Aluminum - 5056 Wires,” Memo No 138, KLOE, Frascati, Italy, 1998.

64. D.S. Wilkinson and V. Vitek: Acta Mater., 1982, vol. 30, pp. 1723-32.

65. M.O. Speidel: "Hydrogen Embrittlement and Stress Corrosion Cracking of Aluminum Alloys," in Hydrogen Embrittlement and Stress Corrosion Cracking, R. Gibala and R.F. Hehemann, eds., ASM International, Materials Park, OH, 1984, pp. 271-96.

66. N.J.H. Holroyd: "Environment-Induced Cracking of High-Strength Aluminum Alloys," in Environment Induced Cracking of Metals, R.P. Gangloff and M.B. Ives, eds., NACE International, Houston, TX, 1990, pp. 311-34.

67. M.O. Speidel: Metall. Mater. Trans. A., 1975, vol. 6, p. 631-51.

68. J.R. Scully, G.A. Young, Jr., and S. Smith: "Hydrogen Embrittlement and Hydrogen Environment Embrittlement in Al Alloys," in Gaseous Hydrogen Embrittlement Metals in Energy Technologies, R.P. Gangloff and B.P. Somerday, eds., Woodhead Publishing Ltd., Cambridge, UK, 2012, pp. 707-68.

69. B.P. Somerday, Y. Leng, and R.P. Gangloff: Fatigue Fract. Eng. Mater. Struct., 1995, vol. 18, pp. 1031-50.

70. R.P. Gangloff: "Hydrogen Assisted Cracking of High Strength Alloys," in Comprehensive Structural Integrity, I. Milne, R.O. Ritchie, B. Karihaloo, J. Scott, and P. Petit, eds., Elsevier Science, New York, NY, 2003, pp. 31-101.

71. R.P. Gangloff: "Diffusion Control of Hydrogen Environment Embrittlement in High Strength Alloys," in Hydrogen Effects on Material Behavior and Corrosion Deformation Interactions, N.R. Moody, A.W. Thompson, R.E. Ricker, G.W. Was, and R.H. Jones, eds., The Minerals, Metals \& Materials Society, Warrendale, PA, 2003, pp. 477-97.

72. J. Ai, M.L. Lim, and J.R. Scully: Corrosion, 2013, DOI: http://dx.doi.org/10.5006/0987. 
73. C.B. Crane and R.P. Gangloff: "Dissolution and Hydrogen Diffusion Control of IGSCC in Sensitized Al-Mg Alloys," in Hydrogen Effects on Materials, B.P. Somerday and P. Sofronis, eds., ASME, New York, NY, 2013, In-Press.

74. K. Jafarzadeh, T. Shahrabi, S.M.M. Hadavi, and M.G. Hosseini: J. Mater. Sci. Technol., 2007, vol. 23, pp. 623-28.

75. R.L. Holtz, P.S. Pao, R.A. Bayles, and T. M.Longazel: "Corrosion Fatigue of A1 5083H131 Sensitized at 70, 100, and 175C and Relation to Microstructure and Degree of Sensitization," in Department of Defense 2011 Corrosion Conference, CorrDefense, NACE, Houston, TX, 2011.

76. M.W. Kendig and R.G. Buchheit: Corrosion, 2003, vol. 59, pp. 379-400.

77. J.S. Warner, S. Kim, and R.P. Gangloff: Int. J. Fatigue, 2009, vol. 31, pp. 1952-65.

78. Z. Gasem and R.P. Gangloff: "Rate-Limiting Processes in Environmental Fatigue Crack Propagation in 7000-Series Aluminum Alloys," in Chemistry and Electrochemistry of Corrosion and Stress Corrosion Cracking: A Symposium Honoring the Contributions of R.W. Staehle, R.H. Jones, ed., TMS-AIME, Warrendale, PA, 2001, pp. 501-21.

79. L. Chen, D.E. Brown, X. Wang, and R.G. Kelly: "Integrated Effects of Grain Boundary Characteristics on the Behavior of Intergranular Corrosion in 5xxx Alloys," in Department of Defense 2011 Corrosion Conference, CorrDefense, NACE International, Houston, TX, 2011.

80. Y.-K Yang and T.R. Allen: Mater. Charact., 2013, vol. 80, pp. 76-85.L. Chen: "Image Fusion and an Outlier Detection Framework for Hierachical Modeling with Application to Corrosion Prediction," PhD Dissertation, University of Virginia, Charlottesville, VA, 2013.

81. L. Chen: "Image Fusion and an Outlier Detection Framework for Hierachical Modeling with Application to Corrosion Prediction," PhD Disseration, University of Virginia, Charlottesville, VA, 2013.

82. Y. Zhu, S. Kar, M.L. Free, and K. Prisbrey: "Long-term Corrosion Damage Prediction Modeling of AA5083 Alloys Based on Experiment, Theory, and Molecular Dynamics Simulations," in Department of Defense 2011 Corrosion Conference, CorrDefense, NACE International, Houston, TX, 2011.

83. R.L. Holtz, P.S. Pao, R.A. Bayles, T.M. Longazel, and R. Goswami: Metall. Mater. Trans. A, 2011, vol. 43, pp. 2839-49.

84. J.A. Lyndon, R.K. Gupta, M.A. Gibson, and N. Birbilis: Corros. Sci., 2013, vol. 70, pp. 290-93.

85. N. Birbilis and R.G. Buchheit: J. Electrochem. Soc., 2005, vol. 152, pp. 140-51.

86. J. Buczynski and R.G. Kelly: "Characterization of the $\beta$-phase $\left(\mathrm{Al}_{3} \mathrm{Mg} 2\right)$ in $5 \mathrm{XXX}$ Aluminum Alloys," in Department of Defense 2011 Corrosion Conference, CorrDefense, NACE, Houston, TX, 2011.

87. J. Ai and J.R. Scully: Corrosion, 2013, vol. 69, pp. 752-67. 
88. D. Kuhlmann-Wilsdorf: Mat Res Innovat, 1998, vol. 1, pp. 265-97.

89. J.R. Scully, G.A. Young, Jr., and S.W. Smith: Mater. Sci. Forum, 2000, vol. 331-7, pp. 1583-1600.

90. J.P. Hirth: Metall. Mater. Trans. A., 1980, vol. 11, pp. 861-90

91. U. Komaragiri, S.R. Agnew, R.P. Gangloff, and M.R. Begley: J. Mech. Phys. Solids, 2008, vol. 56, pp. 3527-40.

92. J.M. Dubois: "Complex, Metallic, and So Different," in Book Series on Complex Metallic Alloys: Volume 2, Properties and Applications of Complex Intermetallics, E. Belin-Ferré, ed., World Scientific Publishing Co., Hackensack, NJ, 2009, pp. 1-91.

93. K.M. Carling and E.A. Carter: Modell. Simul. Mater. Sci. Eng., 2003, vol. 11, pp. 339 48.

94. M. Lipińska-Chwałek, S. Balanetskyy, C. Thomas, S. Roitsch, and M. Feuerbacher: Intermetallics, 2007, vol. 15, pp. 1678-85.

95. S. Roitsch, M. Heggen, M. Lipińska-Chwałek, and M. Feuerbacher: Intermetallics, 2007, vol. 15, pp. 833-37.

96. D.J. Lloyd: Acta Metall. Mater., 1991, vol. 39, pp. 59-71.

97. S.H. Goods and L.M. Brown: Acta Metall. Mater., 1979, vol. 27, pp. 1-15.

98. B.P. Somerday and R.P. Gangloff: Metall. Mater. Trans. A., 1994, vol. 25, pp. 147179.

99. L.M. Brown and W.M. Stobbs: Phil. Mag, 1976, vol. 43, pp. 351-72.

100. R.A. Oriani and P.H. Josephic, Acta Metallurgica, 1974, vol. 22, pp. 1065-74.

101. R.A. Oriani and P.H. Josephic, Acta Metallurgica, 1977, vol. 25, pp. 979-88.

102. C. Ayas, V.S. Deshpande, and N.A. Fleck: Journal of the Mechanics and Physics of Solids, 2013,. DOI: 10.1016/j.jmps.2013.10.002.

103. M.M. Hall and D.M. Symons: "Hydrogen Assisted Creep Fracture Model for Low Potential Stress Corrosion Cracking of Ni-Cr-Fe Alloys," in Chemistry and Electrochemistry of Stress Corrosion Cracking, R.H. Jones and R.W. Staehle, eds., The Minerals, Metals \& Materials Society, Warrendale, PA, 2001, pp. 447-66.

104. D.M. Symons: Eng. Fract. Mech., 2001, vol. 68, pp. 751-71.

105. E. Akiyama, M. Wang, S. Li, Z. Zhang, Y. Kimura, N. Uno, and K. Tsuzaki: Metall. Mater. Trans. A., 2012, vol. 44, pp. 1290-1300.

106. R.M. McMeeking and D.M. Parks: "On Criteria for J-Dominance of Crack-Tip Fields in Large-Scale Yielding," in Elastic-Plastic Fracture, ASTM STP 668, J.D. Landes, J.A. Begley, and G.A. Clarke, eds., ASTM, Philadelphia, PA, 1979, pp. 175-94. 
107. A. Zolriasatein, A. Shokuhfar, M. Ghadimi, S. Ebrahimi-Nnejad, R.A. Khosroshahi, and N. Nemati: "Preparation of Novel $\mathrm{Al} / \beta-\mathrm{Al}_{3} \mathrm{Mg}_{2}$ Nanocomposite by Mechanical Milling and Hot Pressing," in Physics, Chemistry and Applications of Nanostructures: Proceedings of the International Conference Nanomeeting--2011, V.E. Borisenko, S.V. Gaponenko, V.S. Gurin, and C.H. Kam, eds., World Scientific, Hackensack, NJ, 2011, pp. 396-400. 


\subsection{APPENDIX}

\subsubsection{Cation concentrations due to $\beta$ dissolution in the stress corrosion crack}

The crack tip concentration of $\mathrm{Al}^{3+}$ and $\mathrm{Mg}^{2+}$ cations from $\beta$ dissolution alone is calculated with several assumptions:

- All calculations were based on dissolution of $\beta$ only and the influence of $\alpha$ dissolution is not considered.

- The crack tip volume is calculated from the occluded IGSCC crack and does not include the fatigue precrack.

- Cation diffusion out of the crack and reaction product precipitation were not accounted for.

- All $\beta$ present on the SCC crack surfaces dissolves. While two crack surfaces are reactive, it is assumed that the total volume of $\beta$ along a grain boundary is divided between these surfaces.

The volume of $\beta$ which is available to dissolve in the IGSCC crack, $V_{\beta}$, is calculated assuming $\beta$ is a spherical particle with a diameter, $\mathrm{D}$, and number density on the grain boundary, $\mathrm{n}_{\mathrm{d}}$, given as a function of DoS by Birbilis et al. in Table 2.5 [5]. Specifically:

$$
V_{\beta}=\frac{4}{3} \pi\left(\frac{D}{2}\right)^{3} n_{d} T a
$$

where $\mathrm{T}$ is the thickness of the specimen $(6.6 \mathrm{~mm})$ and $a$ is the crack length grown during IGSCC only, not including the notch or fatigue precrack.

The volume of the crack tip solution is calculated assuming a triangle shaped crack, with the length given as $a$, the height as $\mathrm{d}$, and thickness as T (Fig. 2.31). The volume of dissolved $\beta$ is included in the crack volume, though it is negligible. This total crack volume is calculated as:

$$
V_{\text {crack }}=\frac{1}{2}(d T a)+V_{\beta}
$$


The crack mouth opening displacement (CMOD) is defined for an SENT specimen at $\mathrm{K}=15 \mathrm{MPa} \sqrt{\mathrm{m}}$ by $[106]:$

$$
d=C M O D=\frac{2\left(\frac{a}{W}\right) \sigma_{A} W}{E}\left[\frac{1.46+3.42\left(1-\cos \left(\frac{\pi a}{2 W}\right)\right)}{\left(\cos \left(\frac{\pi a}{2 W}\right)\right)^{2}}\right]
$$

Where $\mathrm{a}$ is the total crack length (not including the notch), $\mathrm{W}$ is the width of the specimen $(17.3 \mathrm{~mm}), \sigma_{\mathrm{A}}$ is the remote stress at $\mathrm{K}=15 \mathrm{MPa} \sqrt{\mathrm{m}}$, and $\mathrm{E}$ is the elastic modulus (70.3 GPa). Data from the IGSCC experiment on $5083-\mathrm{H} 131$ sensitized to $50 \mathrm{mg} / \mathrm{cm}^{2}$ were not acquired at $\mathrm{K}$ of $15 \mathrm{MPa} \sqrt{\mathrm{m}}$ because cracking rates exceeded the rate of data acquisition. All measurements are made at $\mathrm{K}$ of $5 \mathrm{MPa} \sqrt{\mathrm{m}}$ on this highly sensitized specimen.

Table 2.5 DoS dependent values used to calculate cation concentration.

\begin{tabular}{|c|c|c|c|c|c|}
\hline $\mathbf{D o S}\left(\mathbf{m g} / \mathbf{c m}^{2}\right)$ & $\mathbf{D}(\mathbf{n m})[5]$ & $\mathbf{n d}_{\mathbf{d}}\left(1 / \mu^{2}\right)[5]$ & $a(\mathbf{m m})$ & $\mathbf{d}(\boldsymbol{\mu m})$ & $\boldsymbol{\sigma}_{\mathbf{A}}(\mathbf{M P a})$ \\
\hline 3 & 0 & - & 0.86 & 3.0 & 83.3 \\
\hline 10 & 50 & 0.8 & 0.30 & 1.2 & 94.28 \\
\hline 22 & 180 & 3 & 3.58 & 10 & 55.6 \\
\hline $50^{*}$ & 350 & 3 & 2.35 & 2.3 & 21.1 \\
\hline$* *$ calculated at K of $5 \mathrm{MPa} \sqrt{\mathrm{m}}$ & \multicolumn{5}{l}{} \\
\hline
\end{tabular}

Table 2.6 The molecular weight and density of $\mathrm{Al}, \mathrm{Mg}, \beta$ and $\alpha$.

\begin{tabular}{|l|c|c|}
\hline & $\begin{array}{c}\text { Molecular Weight } \\
(\mathbf{g} / \mathbf{m o l})\end{array}$ & $\begin{array}{c}\text { Density } \\
\left(\mathbf{g} / \mathbf{c m}^{\mathbf{3}}\right)\end{array}$ \\
\hline $\mathrm{Al}$ & 26.98 & 2.70 \\
\hline $\mathrm{Mg}$ & 24.30 & 1.74 \\
\hline$\beta$ & 129.6 & $2.25[107]$ \\
\hline
\end{tabular}




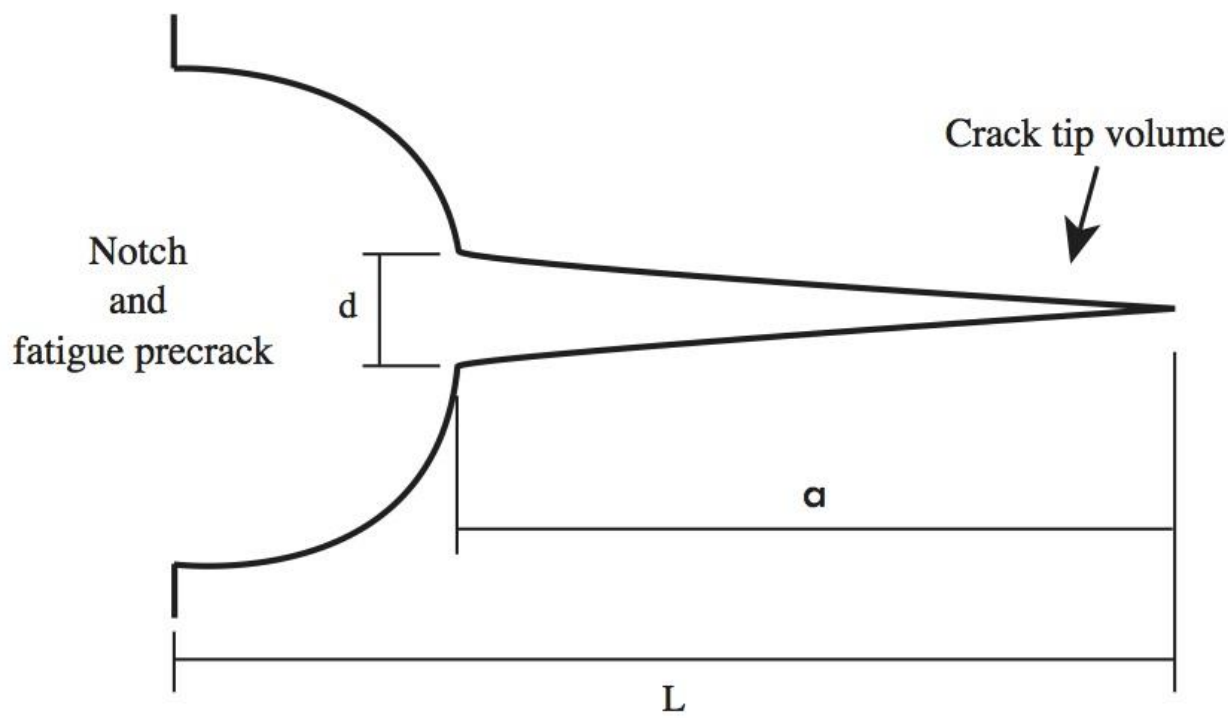

Figure 2.31 Crack geometry used in cation concentration calculation.

The $\mathrm{V}_{\text {crack }}$ is converted to $\mathrm{L}$, assuming $10^{-3} \mathrm{~m}^{3}$ of crack tip solution is $1 \mathrm{~L}$ of crack tip solution. The $\mathrm{V}_{\beta}$ is converted to moles of $\beta$ with $\mathrm{MW}_{\beta}$ and $\rho_{\beta}$ [107] provided in Table 2.6, giving a molar volume $(\mathrm{mol} / \mathrm{L})$ of $\beta$. The concentration as a function of DoS is given in Table 2.4. 


\section{CHAPTER 3}

CRACK TIP CHEMISTRY CONTROL OF INTERGRANULAR STRESS CORROSION CRACKING

IN 5083-H131 


\subsection{ABSTRACT}

The proposed mechanism for intergranular stress corrosion cracking (IGSCC) in sensitized Al-Mg alloys is validated; crack growth between $\beta$ is driven by $\mathrm{H}$ embrittlement, which relies on dissolution controlled crack tip chemistry. Applied-anodic potential $\left(-0.730 \mathrm{~V}_{\mathrm{SCE}}\right)$ increases corrosion and crack growth rates consistent with enhanced $\beta$ dissolution for crack acidification and $\mathrm{H}$ uptake. Cathodic polarization below the relevant $\beta$ breakdown potential of $-1.015 \mathrm{~V}_{\mathrm{SCE}}$ essentially eliminates IGSCC by limiting $\beta$ dissolution and crack acidification. Without sensitization, 5083-H131 is susceptible to IGSCC in anodically polarized $\left(-0.730 \mathrm{~V}_{\mathrm{SCE}}\right)$ neutral $\mathrm{NaCl}$ and in mildly cathodically polarized (-1.000 V $\left.\mathrm{V}_{\mathrm{SCE}}\right)$ acidic simulated crack tip solution. In contrast, unsensitized 5083$\mathrm{H} 131$ is highly resistant to corrosion and IGSCC in neutral $\mathrm{NaCl}$ at near open circuit potential $\left(-0.800 \mathrm{~V}_{\mathrm{SCE}}\right)$ and in $\mathrm{H}$-producing $\mathrm{NaOH}$ with high cathodic polarization. Quantitative predictions of the fissure and crack tip chemistry, $\mathrm{pH}$, potential, and overpotential for $\mathrm{H}$ production were developed using passive current densities and the environment sensitive measured dissolution rates at the fissure tip. Using a hydrogen diffusion-limited crack growth rate model, the $\mathrm{H}$ concentration at the fracture process zone that caused measured crack growth rates increases exponentially with increasing magnitude of predicted $\mathrm{H}$ overpotential. For a given overpotential, $\mathrm{H}$ uptake could decrease with increasing alkalinity, providing an additional cause of the reduced severity of IGSCC by $\mathrm{H}$ embrittlement as pertinent to cathodic polarization in chloride and hydroxide solutions. A highly acidic, $\mathrm{Cl}^{-}$concentrated crack tip chemistry promotes significant $\mathrm{H}$ production and uptake for IGSCC, even in $\beta$-free 5083-H131 representative of the ligaments between $\beta$ in sensitized $\mathrm{Al}-\mathrm{Mg}$. 


\subsection{NOMENCLATURE}

$a$ - crack length

$\alpha-\mathrm{Al}-4 \% \mathrm{Mg}$ (wt. pct.) solid solution matrix phase

$\alpha$-dimensionless constant in Ramberg-Osgood equation

$\beta-\mathrm{Al}_{3} \mathrm{Mg}_{2}$ intergranular precipitate in $\mathrm{Al}-\mathrm{Mg}$ alloys

$\mathrm{CEFM}$ - coupled environmental fracture model

$\mathrm{C}_{\mathrm{H} \text {-crit }}$ - critical concentration of $\mathrm{H}$ at the FPZ necessary to nucleate damage

$\mathrm{C}_{\mathrm{H} \text {-Diff }}$ - amount of diffusible $\mathrm{H}$ in the microstructure

$\mathrm{C}_{\mathrm{H} \sigma}$ - concentration of $\mathrm{H}$ in the FPZ

$\mathrm{C}_{\mathrm{s}}$ - concentration of $\mathrm{H}$ at the surface of the crack tip

CMOD - crack mouth opening displacement

CTOD - crack tip opening displacement

$\mathrm{D}_{\mathrm{H}-\mathrm{EFF}}$ - trap-sensitive diffusivity of $\mathrm{H}$

DoS - degree of sensitization quantified by NAMLT

$\mathrm{d}$ - maximum crack tip ionic species diffusion distance

$\mathrm{d}_{\mathrm{o}}$ - crack tip ionic species diffusion distance

$\mathrm{da} / \mathrm{dt}$ - crack growth rate

$\mathrm{da} / \mathrm{dt}_{\mathrm{II}}$ - Stage II crack growth rate

$\mathrm{da} / \mathrm{dt}_{\mathrm{IGC}}$ - intergranular corrosion growth rate

$\mathrm{da} / \mathrm{dt}_{\mathrm{K} 15}$ - crack growth rate at $15 \mathrm{MPa} \sqrt{\mathrm{m}}_{\mathrm{m}}$

dcPD - direct current potential difference

$\mathrm{dK} / \mathrm{dt}$ - loading rate

$\mathrm{dn}$ - dimensionless constant used to calculate CTOD

E - elastic modulus

$\mathrm{E}_{\text {app }}$ - bulk applied potential

$\mathrm{E}_{\mathrm{B}}-\mathrm{H}$ binding energy

$\mathrm{E}_{\mathrm{Br}-\alpha}-$ breakdown potential of $\alpha$

$\mathrm{E}_{\mathrm{Br}-\beta}-$ breakdown potential of $\beta$

$\mathrm{E}_{\text {tip }}$ - potential at the crack tip by Ohmic drop

$\mathrm{FPZ}$ - fracture process zone

$f$ - fraction of crack/fissure tip current density contributing to potential difference

$\mathrm{H}$ - atomic hydrogen

HEAC - hydrogen environment assisted cracking

HER - hydrogen reduction reaction

$\mathrm{h}$ - height of slot or fissure

$\eta_{\mathrm{H}}-$ overpotential for $\mathrm{H}$ production by proton or water reduction

IGC - intergranular corrosion

IGSCC - intergranular stress corrosion cracking

$\mathrm{IR}_{\text {tip }}$ - voltage difference due to dissolution at the crack/fissure tip 
$\mathrm{IR}_{\text {wall }}$ - voltage difference due to dissolution on the crack/fissure flanks

$i$ - dissolution current density at the localized corrosion site

$\mathrm{i}_{\text {tip }}$ - current density at the tip (calculated from IGC rates)

$\mathrm{i}_{\text {wall }}$ - passive current density on the walls $\left(17 \mu \mathrm{A} / \mathrm{cm}^{2}\right)$

$\mathrm{K}$ - linear elastic stress intensity

$\mathrm{K}_{\mathrm{IC}}$ - plane strain fracture toughness

$\mathrm{K}_{\mathrm{J}}$ - elastic-plastic stress intensity

$\mathrm{K}_{\mathrm{JIC}}$ - elastic-plastic fracture toughness

$\mathrm{K}_{\mathrm{TH}}$ - threshold stress intensity

$\kappa$ - solution conductivity

$\mathrm{L}$ - longitudinal (plate rolling) direction

NAMLT - nitric acid mass loss test per ASTM G67

$\mathrm{n}$ - strain hardening exponent

OCP - open circuit potential

$\mathrm{R}$ - ideal gas constant

$\mathrm{S}$ - short-transverse direction (plate thickness)

SCE - saturated calomel electrode

SENT - single edge notched tensile specimen

SEM - scanning electron microscopy

SHT - solution heat-treated

$\mathrm{S}-\mathrm{L}$ - crack orientation, loading in $\mathrm{S}$ and crack growth in $\mathrm{L}$ directions

$\sigma_{\mathrm{A}}-$ remote applied stress

$\sigma_{\mathrm{H}}-$ local hydrostatic stress

$\sigma_{i}$ - hydrostatic stress as a function of the distance ahead of the crack tip

$\sigma_{\mathrm{o}}$ - Ramberg-Osgood reference stress, defined as true $2 \%$-offset yield strength

бUTS - ultimate tensile strength

бYs $-0.2 \%$-offset yield strength

$\sigma_{Y S-c}-0.2 \%$-offset yield strength in compression

$\mathrm{T}-$ absolute temperature

$\mathrm{T}-$ transverse (plate width) direction

$t$ - time

$\mathrm{V}_{\mathrm{H}}-$ partial molar volume of $\mathrm{H}$

$v$ - Poisson's ratio

$\mathrm{W}$ - width of SENT specimen

$x$ - distance ahead of the crack tip surface

$\mathrm{X}_{\text {CRIT }}$ - critical distance ahead of the crack tip where $\mathrm{H}$ damage nucleates 


\subsection{INTRODUCTION}

Non-heat treatable wrought Al-Mg alloys applied in ship structures are exposed to aggressive marine atmospheric environments and require light weight, moderate strength, formability, weldability, and general corrosion resistance. When the solid solution strengthening Mg content exceeds about 3 wt. pct., the alloy can become "sensitized" to intergranular corrosion (IGC) and/or intergranular stress corrosion cracking (IGSCC) due to prolonged thermal exposure [1-3]. An anodically reactive phase $\left(\beta, \mathrm{Al}_{3} \mathrm{Mg}_{2}\right)$ precipitates on grain boundaries at temperatures between $40^{\circ} \mathrm{C}$ and $180^{\circ} \mathrm{C}$ [2,4-8]. The grain boundary $\beta$ amount, morphology and distribution control the degree of sensitization (DoS) $[4-6,9]$ and the kinetics of IGC and IGSCC $[2,8,10-19]$ when exposed to chloride solution. At low to moderate sensitization, $\beta$ forms as discrete particles along grain boundaries $[4,6-$ $9,15,16,19,20]$; though, the precise size and morphology based on thermal exposure is not fully developed. Rather, electrochemical nitric acid mass loss measurements (NAMLT) governed by ASTM G67 quantify DoS in Al-Mg alloys [21].

Chapter 2 shows that sensitized 5083-H131, with a mass loss greater than $10 \mathrm{mg} / \mathrm{cm}^{2}$ (following extended exposure at a temperature between $60^{\circ} \mathrm{C}$ and $100^{\circ} \mathrm{C}$ ), is susceptible to severe IGSCC in $\mathrm{NaCl}$ polarized to $-0.800 \mathrm{~V}$ versus the saturated calomel electrode (SCE), which is near open circuit potential, (OCP) for the bounding S-L crack orientation (loading in the short direction, $\mathrm{S}$, and crack propagation in the rolling direction, $\mathrm{L}$ ). The slow-rising displacement threshold stress intensity for IGSCC $\left(\mathrm{K}_{\mathrm{TH}}\right)$ decreases from $\sim 20 \mathrm{MPa} \sqrt{\mathrm{m}}$ to $\sim 7 \mathrm{MPa} \sqrt{\mathrm{m}}$, and Stage II subcritical crack growth rate (da/dt II) increases from $5 \mathrm{~nm} / \mathrm{s}$ to $10,000 \mathrm{~nm} / \mathrm{s}$, as DoS rises from $10 \mathrm{mg} / \mathrm{cm}^{2}$ to $54 \mathrm{mg} / \mathrm{cm}^{2}$. 
The hypothesized mechanism for IGSCC is coupled grain boundary $\beta$-matrix dissolution and hydrogen embrittlement at the occluded crack tip, as first proposed by Jones et al. [13]. Crack growth begins with limited dissolution of the Al-4\% Mg matrix $\left(\alpha: \mathrm{Al} \rightarrow \mathrm{Al}^{3+}+3 \mathrm{e}^{-}\right)$leading to a modest degree of hydrolytic acidification $\left(\mathrm{Al}^{3+}+\mathrm{H}_{2} \mathrm{O} \rightarrow\right.$ $\left.\mathrm{H}^{+}+\mathrm{Al}(\mathrm{OH})\right)$ at near open circuit potential (OCP) [22,23]. In parallel grain boundary $\beta$ rapidly dissolves to promote $\mathrm{Al}^{+3}$ and $\mathrm{Mg}^{+2}$ concentration for hydrolysis in the crack tip solution and further reduce the local $\mathrm{pH}$. In this solution the $\alpha$ passive film breaks down causing further $\alpha$ dissolution for near-equilibrium acidification ( $\mathrm{pH}$ 2-3). This intensifies cathodic hydrogen production and uptake at the crack tip. With the unstable passive film in the acidic solution, a high concentration of atomic hydrogen $(\mathrm{H})$ adsorbs into the microstructure and diffuses to the fracture process zone (FPZ) proximate to the crack tip. In combination with the locally concentrated tensile stress, $\mathrm{H}$ promotes inter- $\beta$ ligament $\mathrm{H}$ embrittlement along the Al grain boundary [24-26]. The fundamental hypothesis is that dissolution of grain boundary $\beta$ is the primary trigger of crack electrochemistry change leading to substantial hydrogen environment assisted crack (HEAC) in sensitized Al-Mg alloys.

Chapter 2 demonstrated the requirement of $\beta$ presence by establishing a critical DoS of about $10 \mathrm{mg} / \mathrm{cm}^{2}$ for IGSCC susceptibility. The reason for this susceptibility was correlated with a size, spacing, and morphology of $\beta$. In addition, as-received 5083 was highly resistant to IGSCC, though not immune as demonstrated with fractography. The electrochemical role of $\beta$ in crack chemistry development needs to be investigated, so as to determine if the active phase is required for IGSCC in 5083-H131. 


\subsubsection{Objective}

The objective of the present work is to test this proposed mechanism of IGSCC by manipulation of crack tip chemistry and electrochemistry. First, the requirement of $\beta$ is probed with stress corrosion cracking experiments that expose unsensitized 5083-H131 with minimal grain boundary $\beta$ to near neutral $\mathrm{NaCl}$, simulated-acidic crack tip solution, and alkaline $\mathrm{NaOH}$ producing various levels of crack tip $\mathrm{H}$ overpotential and $\mathrm{H}$ uptake into the FPZ. Second, the role of crack tip environment is investigated for sensitized Al-Mg in near-neutral $\mathrm{NaCl}$, with a range of applied potentials to promote or preclude $\beta$ and $\alpha$ breakdown. The essential questions that will be answered are: (a) Is IGSCC possible in $\beta$ free, unsensitized 5083-H131? (b) Can IGSCC, in susceptible 5083, be stifled by cathodic polarization? and (c) Is the hypothesized mechanism validated?

\subsection{EXPERIMENTAL}

Investigation focused on a partially recrystallized $5.7 \mathrm{~cm}$ thick plate of 5083-H131 with the heat-specific chemical composition given in Table 3.1 [27]. The reported tensile yield strength ( $\left.\sigma_{Y S}\right)$ of $335 \mathrm{MPa}$ and ultimate tensile strength ( $\left.\sigma_{\mathrm{UTS}}\right)$ of $353 \mathrm{MPa}$ were measured in the $\mathrm{L}$ direction [27]. Compression testing was conducted on both as-received and sensitized $\left(100^{\circ} \mathrm{C}\right.$ for $175 \mathrm{~h}$ ) $5083-\mathrm{H} 131$ (DoS of $3 \mathrm{mg} / \mathrm{cm}^{2}$ and $22 \mathrm{mg} / \mathrm{cm}^{2}$, respectively $[21,28])$. For the as-received case, a $0.2 \%$ offset yield strength $\left(\sigma_{Y S-c}\right)$ of $259 \mathrm{MPa}$ and elastic modulus (E) of $70.3 \mathrm{GPa}$ were measured, and Ramberg-Osgood flow rule parameters of $\mathrm{n}=11.5$ and $\alpha=0.52$ were calculated assuming $\sigma_{\mathrm{o}}=\sigma_{\mathrm{YS}}$ [29]. For the sensitized condition, $\sigma_{Y S-c}=263 \mathrm{MPa}, \mathrm{E}=72.4 \mathrm{GPa}, \mathrm{n}=12.1$, and $\alpha=0.48$. J-integral based measurements of plane strain fracture toughness $\left(\mathrm{K}_{\text {IIC }}\right) 21.7 \mathrm{MPa} \sqrt{\mathrm{m}}\left(3 \mathrm{mg} / \mathrm{cm}^{2}\right)$, and 23.2 MPa $\sqrt{\mathrm{m}}\left(22 \mathrm{mg} / \mathrm{cm}^{2}\right)$ for the S-L orientation were measured in Chapter 2. 
Table 3.1 Chemical composition of 5083-H131 in wt. pct. [27].

\begin{tabular}{lllllllllllll}
\hline $\mathrm{Mg}$ & $\mathrm{Mn}$ & $\mathrm{Fe}$ & $\mathrm{Si}$ & $\mathrm{Cr}$ & $\mathrm{Zn}$ & $\mathrm{Ti}$ & $\mathrm{Ga}$ & $\mathrm{Pb}$ & $\mathrm{Ni}$ & $\mathrm{Cu}$ & $\mathrm{Na}$ & $\mathrm{Al}$ \\
\hline $\mathbf{4 . 4}$ & $\mathbf{0 . 7}$ & $\mathbf{0 . 2 2}$ & $\mathbf{0 . 1}$ & $\mathbf{0 . 0 8}$ & $\mathbf{0 . 0 2}$ & $\mathbf{0 . 0 2}$ & $\mathbf{0 . 0 1}$ & $\mathbf{0 . 0 0 1}$ & $\mathbf{0 . 0 0 4}$ & $\mathbf{0 . 0 5}$ & $\mathbf{0 . 0 0 0 1}$ & Bal. \\
\hline
\end{tabular}

For IGSCC testing, single edge notch tensile (SENT) specimens were machined in the S-L orientation, with a notch length of $1.5 \mathrm{~mm}$, specimen width of $17.3 \mathrm{~mm}$, and thickness of $6.6 \mathrm{~mm}$. The specimens were fatigue precracked to $3.3 \mathrm{~mm}$ in moist air, with a final maximum stress intensity $(\mathrm{K})$ of $3.5 \mathrm{MPa} \sqrt{ } \mathrm{m}$. A $185 \mathrm{~mL}$ Plexiglas cell housed the SENT specimen under full immersion in three non-deaerated aqueous solutions: 1) $0.6 \mathrm{M} \mathrm{NaCl}$ $(\mathrm{pH} \sim 7.3), 2) 0.01 \mathrm{M} \mathrm{NaOH}(\mathrm{pH} 12)$, and 3) $80 \%$ saturated $\mathrm{Al}-4 \% \mathrm{Mg}$ simulated crack tip solution $\left(\mathrm{AlCl}_{3} / \mathrm{MgCl}_{2}: 2.5 \mathrm{M} \mathrm{Al}^{3+}, 1.1 \mathrm{M} \mathrm{Mg}^{2+}, 7.7 \mathrm{M} \mathrm{Cl}^{-}, \mathrm{pH}\right.$-0.4) [17]. Solution was circulated at $30 \mathrm{~mL} / \mathrm{min}$ from a $2 \mathrm{~L}$ reservoir at ambient temperature. Open circuit potential and $\mathrm{pH}$ were monitored before and after each experiment, with the exception of $\mathrm{NaOH}$, which was adjusted throughout the test to preserve $\mathrm{pH}$ of 12 . Polarization of the grounded SENT specimen was maintained constant during loading by a potentiostat with a floating ground. The specimen was loaded under grip displacement rate control $(0.0002 \mathrm{~mm} / \mathrm{min})$ to $\mathrm{K}$ of $4 \mathrm{MPa} \sqrt{\mathrm{m}}$ and held at constant load for $10 \mathrm{~h}$. Immediately following this hold, the specimen was loaded at an initial rate $(\mathrm{dK} / \mathrm{dt})$ of $0.25 \mathrm{MPa} \sqrt{\mathrm{m}} / \mathrm{h}$ until final fracture.

Crack length $(a)$ was continuously monitored as a function of time $(t)$ using a computerautomated direct current potential difference (dcPD) method [30-33]. Reference probes were used on all experiments to eliminate false crack growth due to current supply variation as well as temperature and uniform-strain-based resistance and resistivity changes [32,33]. Experiments in air, or with IGSCC resistant microstructures, were analyzed with stress intensity $\left(\mathrm{K}_{\mathrm{J}}\right)$ determined by the elastic-plastic J-integral analysis described in Chapter 2. 
Crack growth rate (da/dt) was calculated at a given time $(t)$ with an incrementally stepped second-order polynomial fit to $a$ versus $t$ over $t \pm 3$ or $t \pm 10$ data points.

\subsection{RESULTS}

Chapter 2 demonstrated that DoS dependent "crevice" IGC occurs within the fatigue precrack of 5083-H131 (S-L) at low K, followed by classic IGSCC with $\mathrm{K}_{\mathrm{TH}}$ and subcritical crack growth rates (da/dt) under full immersion in near-neutral $\mathrm{NaCl}$ at a single potential of $-0.800 \mathrm{~V}_{\mathrm{SCE}}$, which is near the initial bulk OCP $\left(-0.760 \mathrm{~V}_{\mathrm{SCE}}\right)$. The dcPD measurement system was optimized to accurately resolve the kinetics for each stage of subcritical damage progression, as recorded in Chapter 2. The work reported in this chapter further optimized this measurement method to yield the results of experiments designed to test the hypothesized mechanism for IGSCC.

\subsubsection{Crack growth detection resolution}

Experiments conducted in moist air establish the crack growth measurement resolution governed by: (a) dc potential drift with time at low $\mathrm{K}$, and (b) crack tip plasticity which rises with increasing $\mathrm{K}$, as developed in Fig. 3.1.

For quasi-static loading at a $\mathrm{K}$ of $4 \mathrm{MPa} \sqrt{\mathrm{m}}$ for $20 \mathrm{~h}$ in air, regression analysis of unsensitized $\left(3 \mathrm{mg} / \mathrm{cm}^{2}\right)$ and sensitized $\left(22 \mathrm{mg} / \mathrm{cm}^{2}\right)$ SENT specimen data yielded an average-apparent crack growth rate of $-0.001 \mathrm{~nm} / \mathrm{s}$ (growth versus time for sensitized 5083H131 is illustrated in Fig. 3.1). Over shorter time (5 h), this apparent growth rate is up to $0.004 \mathrm{~nm} / \mathrm{s}$. This latter value is used as the resolution of the dcPD measurement technique for quasi-static $\mathrm{K}$ below $5 \mathrm{MPa} \sqrt{\mathrm{m}}$. Growth measured above this limit is considered to be real precrack extension, as illustrated in Fig. 3.1 for sensitized 5083-H131 stressed at low $\mathrm{K}(4 \mathrm{MPa} \sqrt{\mathrm{m}}$ to $6 \mathrm{MPa} \sqrt{\mathrm{m}})$ in $\mathrm{NaCl}$. 


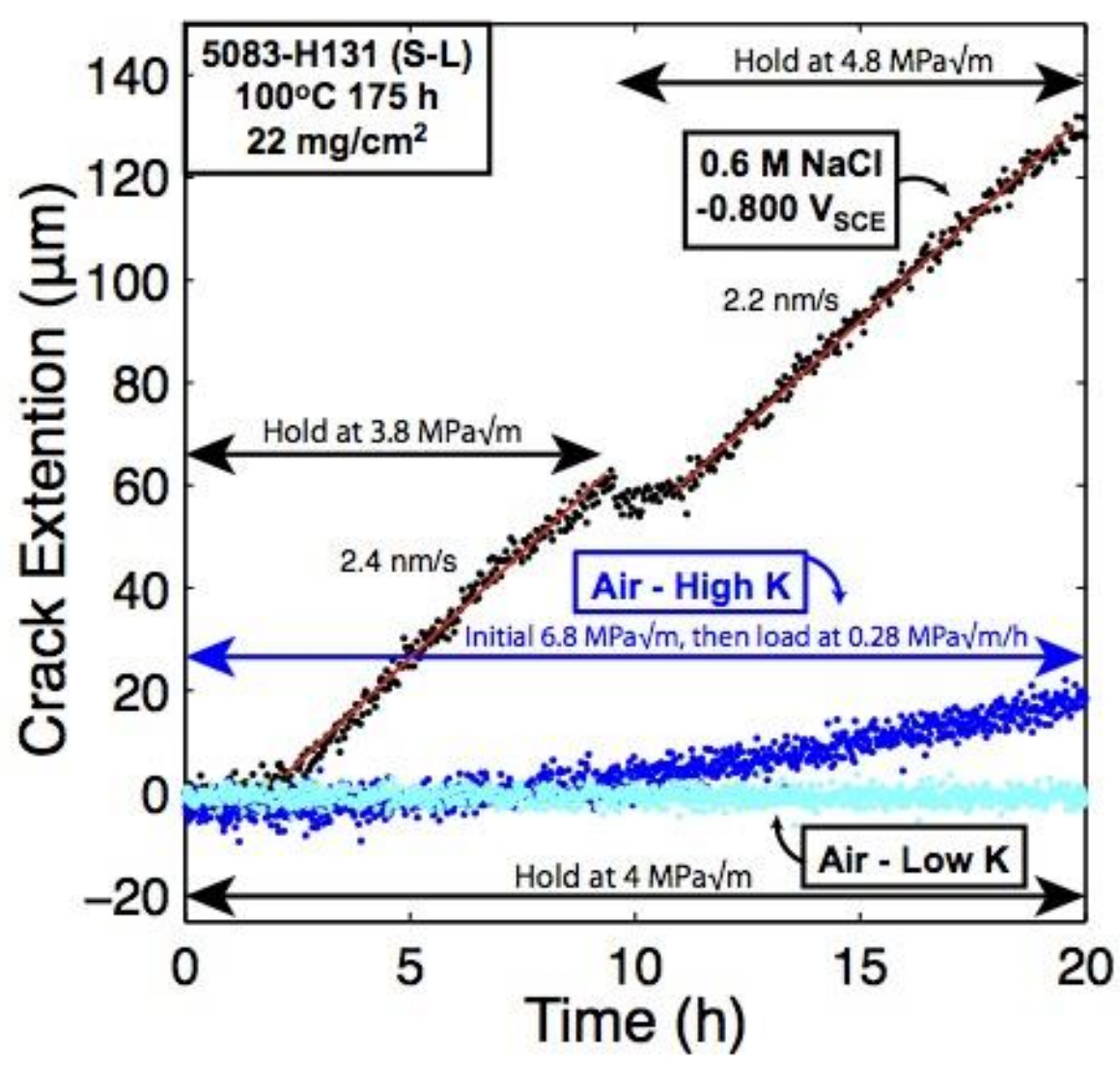

Figure 3.1 Crack extension versus time for three SENT 5083-H131 specimens sensitized at $100^{\circ} \mathrm{C}$ for $175 \mathrm{~h}\left(22 \mathrm{mg} / \mathrm{cm}^{2}\right)$, then stressed to low $\mathrm{K}$ in moist air (bottom), to high $\mathrm{K}$ in moist air (middle) or immersed in $0.6 \mathrm{M} \mathrm{NaCl}$ polarized to $-0.800 \mathrm{~V}_{\mathrm{SCE}}$ while loaded to low K (top).

Following the hold at $4 \mathrm{MPa} \sqrt{\mathrm{m}}$, the dcPD signal increased with slow-rate loading at $\mathrm{dK} / \mathrm{dt}$ of $0.25 \mathrm{MPa} \sqrt{\mathrm{m}} / \mathrm{h}$, creating an apparent crack growth rate that increased with rising $\mathrm{K}$ even with linear reference probe correction. For unsensitized 5083-H131 stressed in moist air, Fig. 3.2 shows that the average apparent da/dt increased from $0.7 \mathrm{~nm} / \mathrm{s}$ to $1.3 \mathrm{~nm} / \mathrm{s}$ for slow-rising $\mathrm{K}$ between $8 \mathrm{MPa} \sqrt{\mathrm{m}}$ and $20 \mathrm{MPa} \sqrt{\mathrm{m}}$, and up to $2.5 \mathrm{~nm} / \mathrm{s}$ as $\mathrm{K}$ approached the initiation fracture toughness. For the modestly sensitized specimen $\left(22 \mathrm{mg} / \mathrm{cm}^{2}\right)$, the apparent da/dt rose from below $0.1 \mathrm{~nm} / \mathrm{s}$ at $8 \mathrm{MPa} \sqrt{\mathrm{m}}$ to $2.0 \mathrm{~nm} / \mathrm{s}$ at $20 \mathrm{MPa} \sqrt{ }$, and then increased to higher levels as $\mathrm{K}$ approached $\mathrm{K}_{\mathrm{IC}}$ of $23.2 \mathrm{MPa} \sqrt{\mathrm{m}}$. A 
heavily sensitized specimen $\left(45 \mathrm{mg} / \mathrm{cm}^{2}\right)$ was loaded at a rapid rate $(31 \mathrm{MPa} \sqrt{\mathrm{m}} / \mathrm{h})$ to high $\mathrm{K}$. The measured da/dt, reduced by 100-times for proper comparison to the slow loading rate data, rose from $0.1 \mathrm{~nm} / \mathrm{s}$ at $8 \mathrm{MPa} \sqrt{\mathrm{m}}$ to $2.2 \mathrm{~nm} / \mathrm{s}$ at $20 \mathrm{MPa} \sqrt{\mathrm{m}}$, then rose as $\mathrm{K}$ approached $\mathrm{K}_{\mathrm{JIC}}$ of $27.5 \mathrm{MPa} \sqrt{\mathrm{m}}$; rates essentially identical to those measured during slow loading. The moist air crack growth rates in Fig. 3.2 may be caused by several mechanisms that are difficult to isolate (see Section 3.6.1), yet provide a reference basis for interpreting IGSCC data. The dashed line provides a specific upper bound resolution limit on da/dt for $\mathrm{K}$ up to $21 \mathrm{MPa} \sqrt{\mathrm{m}}$.

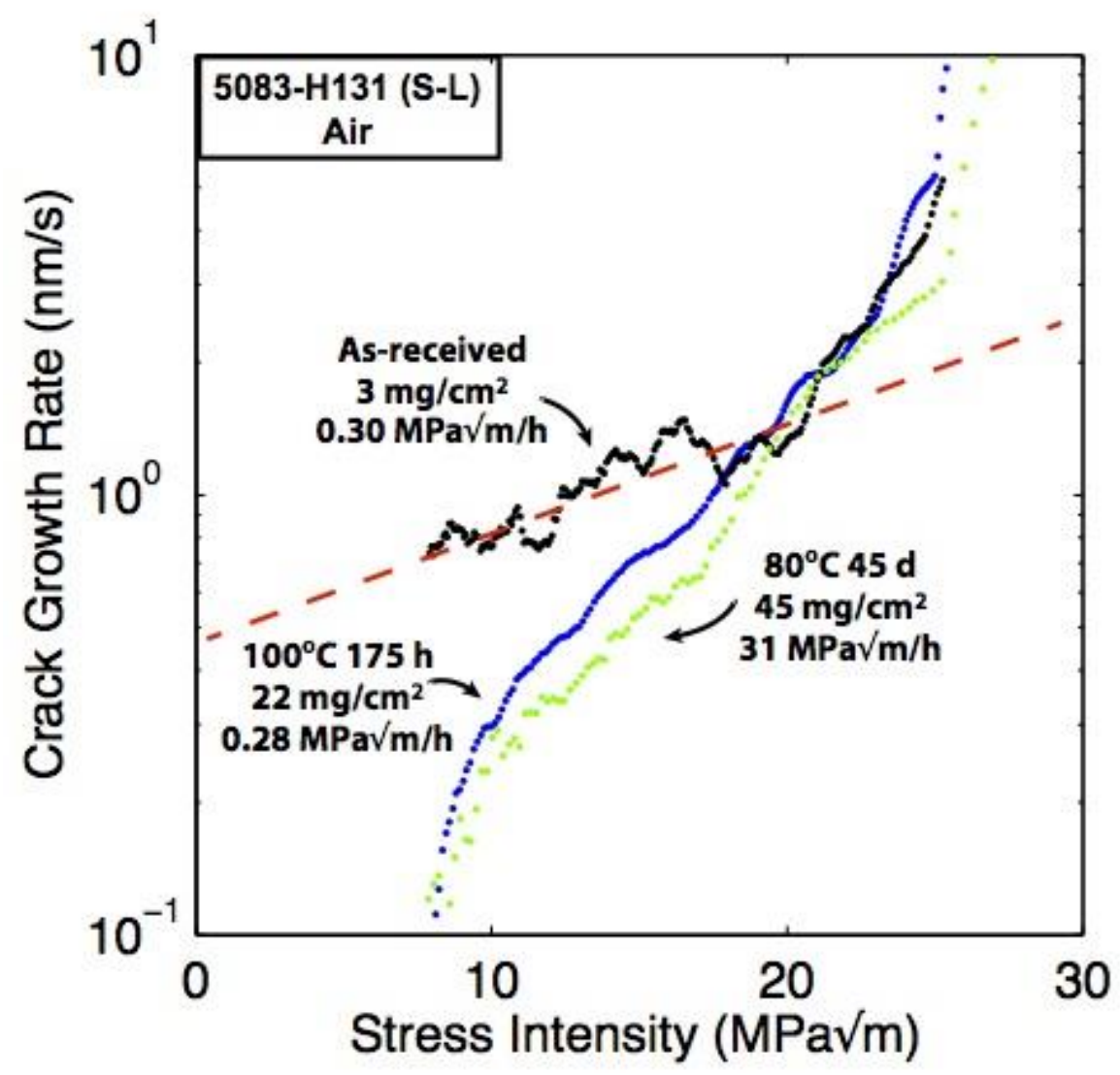

Figure 3.2 The crack growth rate measured in moist air for 5083-H131 (S-L) with different sensitization and loading rates. 


\subsubsection{Effect of applied polarization of sensitized 5083-H131}

Applied potential significantly affects the IGC and IGSCC susceptibilities of sensitized $\left(22 \mathrm{mg} / \mathrm{cm}^{2}\right)$ 5083-H131 stressed in the S-L orientation during immersion in $0.6 \mathrm{M}$ near neutral $\mathrm{NaCl}$.

\subsubsection{Intergranular corrosion growth}

Figure 3.3 presents results for localized corrosion growth in sensitized 5083-H131 $\left(22 \mathrm{mg} / \mathrm{cm}^{2}\right)$ during $10 \mathrm{~h}$ of constant low $\mathrm{K}$ loading ( $4 \mathrm{MPa} \sqrt{\mathrm{m}}$ ), followed by slow rising displacement to $6 \mathrm{MPa} \sqrt{ }$ for a range of applied potentials in $0.6 \mathrm{M} \mathrm{NaCl}$. Rates were determined with regression analysis over the first $10 \mathrm{~h}$ of the static-K hold and are plotted as function of potential in Fig. 3.4 on: (a) logarithmic, and (b) linear scales. The range of $\mathrm{pH}$-sensitive breakdown potentials for $\alpha$ and $\beta$ are indicated in Fig. 3.4, and defined in Section 3.6.2.1.1. Rapid IGC $(8.4 \mathrm{~nm} / \mathrm{s})$ was measured for sensitized 5083-H131 during the $10 \mathrm{~h}$ hold at $4 \mathrm{MPa} \sqrt{\mathrm{m}}$ when anodically polarized to $-0.730 \mathrm{~V}_{\mathrm{SCE}}$; this growth rate decreased to about $1.4 \mathrm{~nm} / \mathrm{s}$ when polarized to $-0.800 \mathrm{~V}_{\mathrm{SCE}}$. In Chapter 2 seven replicate experiments on sensitized specimens $\left(22 \mathrm{mg} / \mathrm{cm}^{2}\right)$ polarized to $-0.800 \mathrm{~V}_{\text {SCE }}$ yielded IGC rates that varied between $0.80 \mathrm{~nm} / \mathrm{s}$ and $2.6 \mathrm{~nm} / \mathrm{s}$. Growth rates when polarized to $-0.900 \mathrm{~V}_{\mathrm{SCE}}$ decreased to $0.9 \mathrm{~nm} / \mathrm{s}$, but were at the lower bound variability of the specimens polarized to $-0.800 \mathrm{~V}_{\mathrm{SCE}}$. Intergranular corrosion rates were slow and similar for polarizations to $-0.975 \mathrm{~V}_{\mathrm{SCE}}$ and $-1.300 \mathrm{~V}_{\mathrm{SCE}}(0.35 \mathrm{~nm} / \mathrm{s}$ and $0.31 \mathrm{~nm} / \mathrm{s}$, respectively), yet faster than the dcPD signal drift measured during slow loading in air $(0.004 \mathrm{~nm} / \mathrm{s})$. Polarizations to $-1.020 \mathrm{~V}_{\mathrm{SCE}}$ and $-1.100 \mathrm{~V}_{\mathrm{SCE}}$ each yielded much slower growth rates, $(0.03 \mathrm{~nm} / \mathrm{s}$ and $0.05 \mathrm{~nm} / \mathrm{s}$, respectively), which were close to that measured in air at $4 \mathrm{MPa} \sqrt{\mathrm{m}}$ (shown in Fig. 3.3). Growth rates at $-0.900 \mathrm{~V}_{\mathrm{SCE}},-1.020 \mathrm{~V}_{\mathrm{SCE}},-1.100 \mathrm{~V}_{\mathrm{SCE}}$, 
and $-1.300 \mathrm{~V}_{\mathrm{SCE}}$ began to increase at $10 \mathrm{~h}$ upon active loading at $0.25 \mathrm{MPa} \sqrt{\mathrm{m}} / \mathrm{h}$ to $6 \mathrm{MPa} \sqrt{\mathrm{m}}$ (Fig. 3.3). Growth at $-0.975 \mathrm{~V}_{\mathrm{SCE}}$ decreased slightly with active loading to $6 \mathrm{MPa} \sqrt{\mathrm{m}}$.

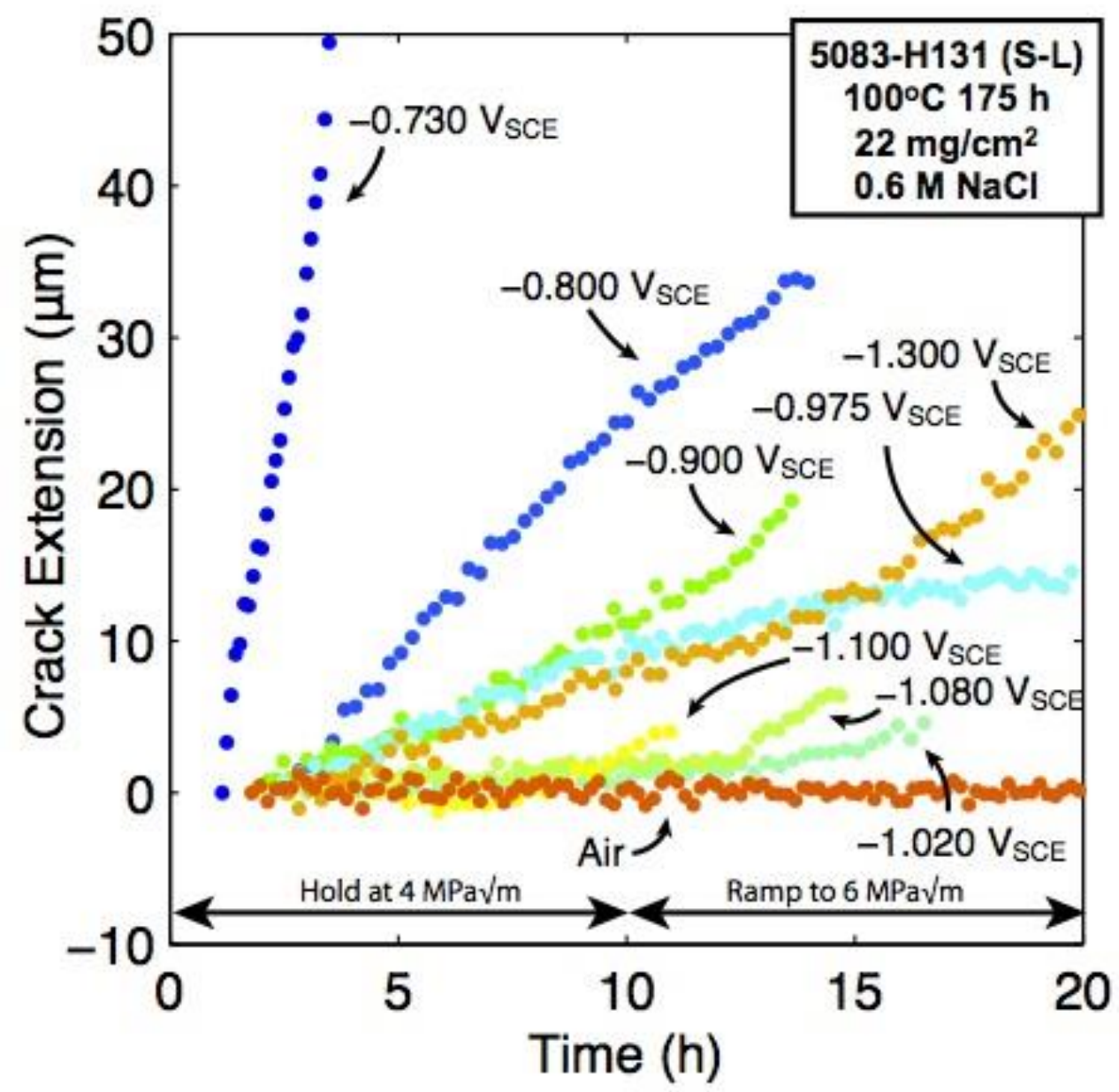

Figure 3.3 Crack extension versus time for $5083-\mathrm{H} 131$ (S-L) sensitized at $100^{\circ} \mathrm{C}$ for $175 \mathrm{~h}\left(22 \mathrm{mg} / \mathrm{cm}^{2}\right)$, immersed in $0.6 \mathrm{M} \mathrm{NaCl}$ and held at $4 \mathrm{MPa} \sqrt{\mathrm{m}}$, then loaded at $0.25 \mathrm{MPa} \sqrt{\mathrm{m}} / \mathrm{h}$ to $6 \mathrm{MPa} \sqrt{\mathrm{m}}$ for various constant-applied potentials. As-received 5083$\mathrm{H} 131$ (S-L, $3 \mathrm{mg} / \mathrm{cm}^{2}$ ) loaded to $4 \mathrm{MPa} \sqrt{\mathrm{m}}$ in $\operatorname{air}(\bullet)$ for $20 \mathrm{~h}$ is shown for reference. 
a)

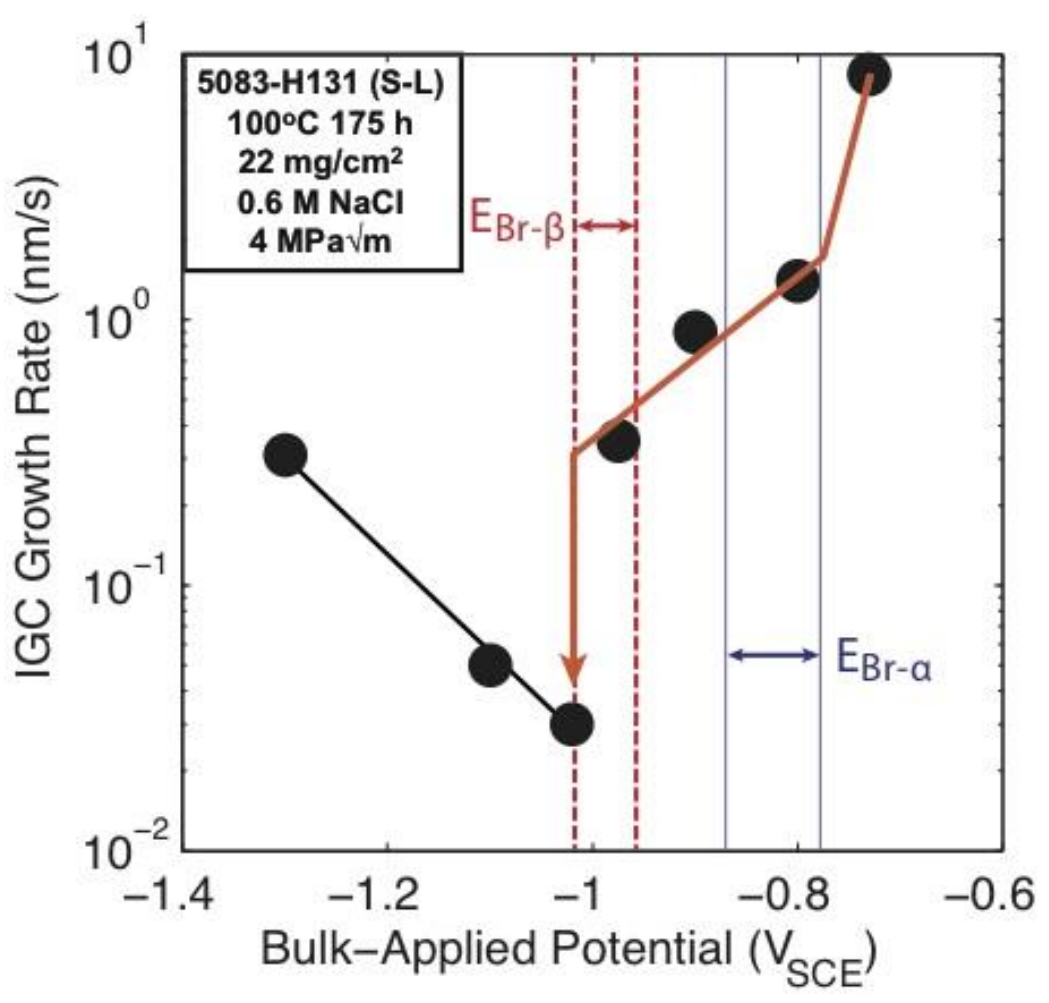

b)

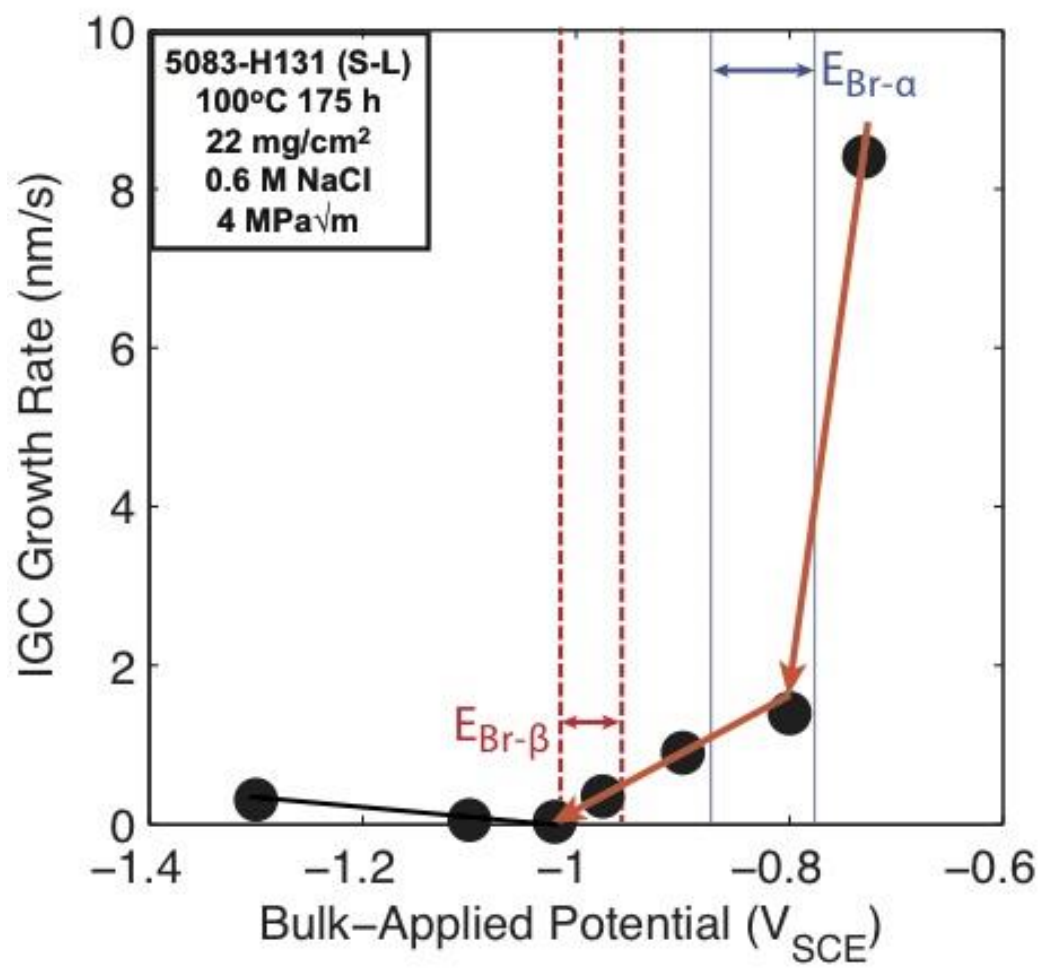

Figure 3.4 Rates of fatigue crack IGC on: a) logarithmic and b) linear scales for sensitized 5083-H131 (S-L, $\left.22 \mathrm{mg} / \mathrm{cm}^{2}\right)$ during a hold at $4 \mathrm{MPa} \sqrt{\mathrm{m}}$. The range of $\mathrm{pH}-$ sensitive breakdown potentials for $\alpha$ is shown with the thin vertical lines, and the range of $\mathrm{pH}$-sensitive $\beta$ breakdown potentials is shown by the thick vertical dashed lines. 


\subsubsection{Intergranular stress corrosion cracking}

The crack growth rates versus slow-rising $\mathrm{K}$ (beginning at $\mathrm{K}$ of $4 \mathrm{MPa} \sqrt{\mathrm{m}}$ ) for sensitized $5083-\mathrm{H} 131\left(22 \mathrm{mg} / \mathrm{cm}^{2}\right)$ in $\mathrm{NaCl}$ at various remote polarization levels are plotted in Fig. 3.5. Elastic-plastic fracture toughness ( $\mathrm{K}_{\mathrm{JIC}}: 23.2 \mathrm{MPa} \sqrt{\mathrm{m}}$ calculated in Chapter 2$)$ is noted.

Typical two stage SCC characteristics are observed in sensitized 5083-H131 polarized at $-0.730 \mathrm{~V}_{\mathrm{SCE}}$ and $-0.800 \mathrm{~V}_{\mathrm{SCE}}$ in $0.6 \mathrm{NaCl}$. At $-0.730 \mathrm{~V}_{\mathrm{SCE}}, \mathrm{K}_{\mathrm{TH}}$ (defined as the transition from slow corrosion growth to rapid IGSCC in Stage I) was 7.9 MPa $\sqrt{\mathrm{m}}$ and Stage II da/dt $/$ II

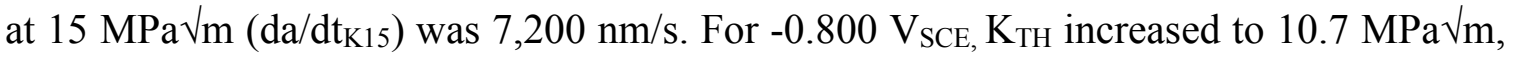
and da/dt 15 decreased to $3,000 \mathrm{~nm} / \mathrm{s}$. Seven replicate experiments established that $\mathrm{K}_{\mathrm{TH}}$ varied from $8 \mathrm{MPa} \sqrt{\mathrm{m}}$ to $14 \mathrm{MPa} \sqrt{\mathrm{m}}$, and da/dt $/ \mathrm{d}_{\mathrm{K}}$ varied from $800 \mathrm{~nm} / \mathrm{s}$ to $10,000 \mathrm{~nm} / \mathrm{s}$ for this polarization and DoS, as detailed in Chapter 2 and Fig. 2.8. The threshold stress intensities for these experiments are much less than $\mathrm{K}_{\mathrm{JIC}}$ for moist air, establishing subcritical IGSCC susceptibility. J-integral analysis accounted for plasticity at high stress intensities in sensitized 5083-H131 during polarization from $-0.900 \mathrm{~V}_{\mathrm{SCE}}$ to $-1.300 \mathrm{~V}_{\mathrm{SCE}}$ in 0.6 M NaCl. At $-0.900 \mathrm{~V}_{\mathrm{SCE}}$, Stage I exhibits a more shallow slope, obscuring threshold definition, but $\mathrm{K}_{\mathrm{TH}}$ is likely between $10 \mathrm{MPa} \sqrt{\mathrm{m}}$ and $15 \mathrm{MPa} \sqrt{\mathrm{m}}$; da/dt 15 is $10 \mathrm{~nm} / \mathrm{s}$. Similar behavior is observed for $-0.975 \mathrm{~V}_{\mathrm{SCE}}$ and $-1.020 \mathrm{~V}_{\mathrm{SCE}}$. For $-0.975 \mathrm{~V}_{\mathrm{SCE}}, \mathrm{K}_{\mathrm{TH}}$ is between $10 \mathrm{MPa} \sqrt{\mathrm{m}}$ and $18 \mathrm{MPa} \sqrt{\mathrm{m}}$, and da/dtt 15 is $5 \mathrm{~nm} / \mathrm{s}$. For $-1.020 \mathrm{~V}_{\mathrm{SCE}}, \mathrm{K}_{\mathrm{TH}}$ is $11 \mathrm{MPa} \sqrt{\mathrm{m}}$ to $13 \mathrm{MPa} \sqrt{\mathrm{m}}$, and da/dt $/ 515$ is $8 \mathrm{~nm} / \mathrm{s}$. 


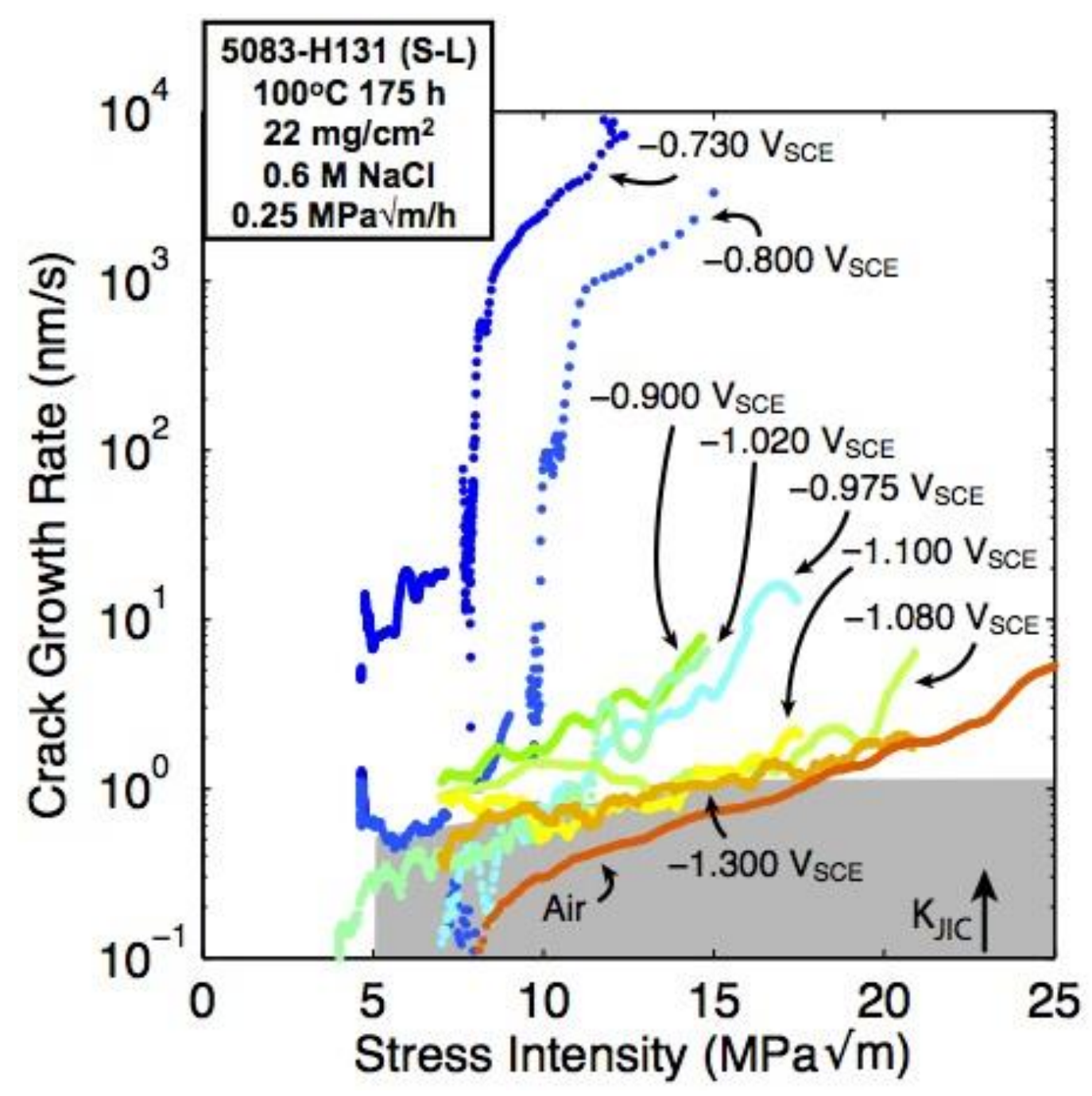

Figure 3.5 The stress intensity dependence of da/dt for sensitized $\left(100^{\circ} \mathrm{C}\right.$ for $175 \mathrm{~h}$, $22 \mathrm{mg} / \mathrm{cm}^{2}$ ) 5083-H131 (S-L) stressed with the constant then rising displacement protocol while immersed in $0.6 \mathrm{M} \mathrm{NaCl}$ solution with different constant applied potentials. Specimens polarized between $-1.300 \mathrm{~V}_{\mathrm{SCE}}$ and $-0.900 \mathrm{~V}_{\mathrm{SCE}}$ and in air were analyzed with elastic-plastic analysis. Sensitized 5083-H131 $\left(22 \mathrm{mg} / \mathrm{cm}^{2}\right)$, loaded with the same protocol in air is plotted for reference. The grey box represents growth rate resolution from Fig. 3.2.

Crack growth rates measured for sensitized 5083-H131 $\left(22 \mathrm{mg} / \mathrm{cm}^{2}\right)$ polarized to $-1.100 \mathrm{~V}_{\mathrm{SCE}}$ and $-1.300 \mathrm{~V}_{\mathrm{SCE}}$ essentially equal the apparent da/dt measured during loading in air. Fractographic analysis was not performed to assess the extent of IGSCC, if any, for the $-1.100 \mathrm{~V}_{\mathrm{SCE}}$ or $-1.300 \mathrm{~V}_{\mathrm{SCE}}$ cases. The important relationship between da/dtK15 
and bulk-applied potential is presented in Fig. 3.6. The ranges of $\mathrm{pH}$-sensitive breakdown potentials for $\alpha$ and $\beta$ are indicated and defined in Section 3.6.2.1.1.

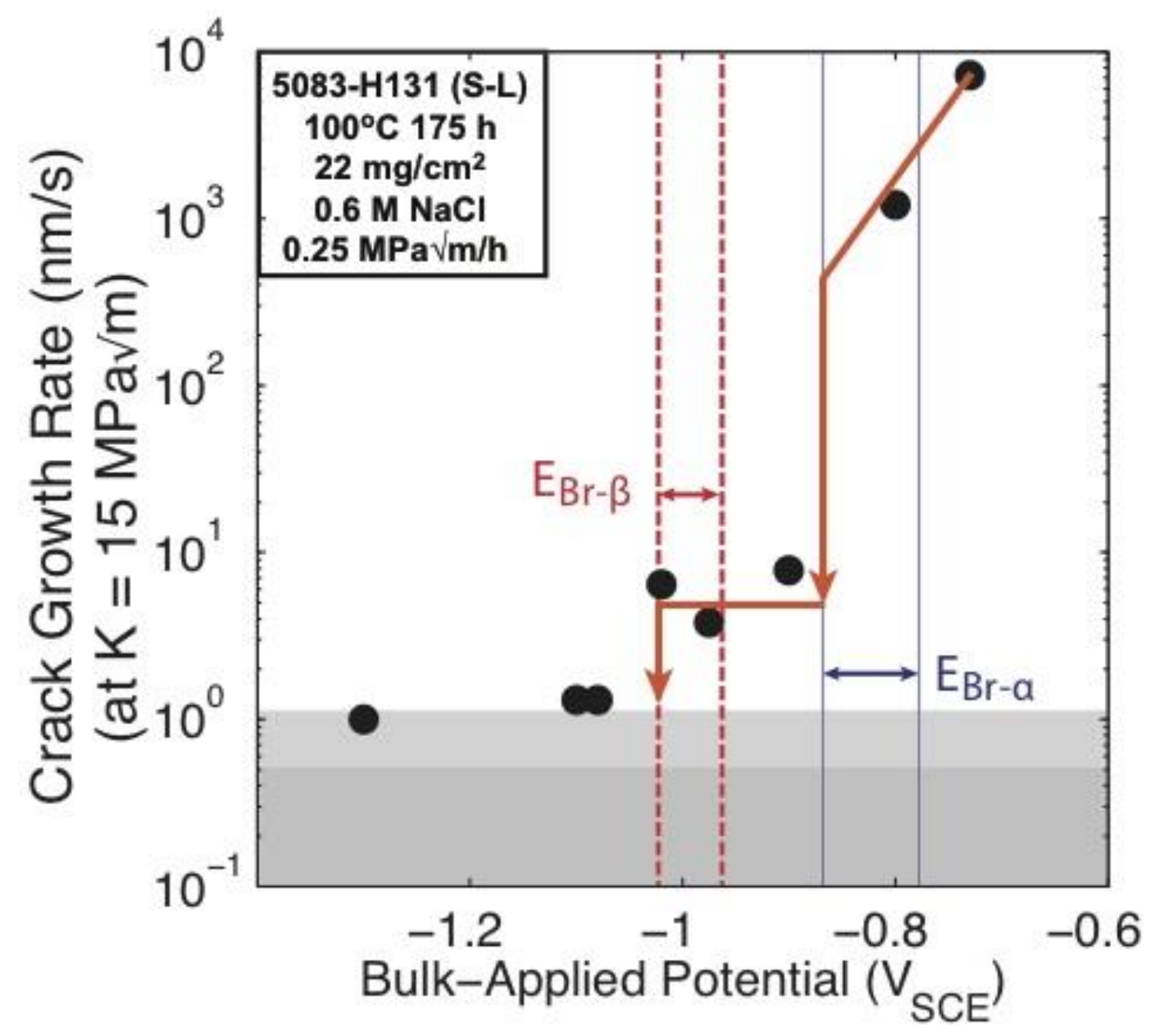

Figure 3.6 The crack growth rate of sensitized (DoS $\left.22 \mathrm{mg} / \mathrm{cm}^{2}\right) 5083-\mathrm{H} 131$ (S-L) at constant $\mathrm{K}$ of $15 \mathrm{MPa} \sqrt{\mathrm{m}}$ plotted as a function of applied potential. The range of $\mathrm{pH}$ sensitive breakdown potentials for $\alpha$ is shown with the thin vertical lines, and the range of $\mathrm{pH}$-sensitive $\beta$ breakdown potentials is shown by the dashed vertical lines. The resolution limit of the dcPD measurement is shown with grey boxes (lower for $22 \mathrm{mg} / \mathrm{cm}^{2}$ in air and upper for as-received in air at $\mathrm{K}=15 \mathrm{MPa} \sqrt{\mathrm{m}}$ ).

\subsubsection{Effect of solution composition for unsensitized 5083-H131}

Intergranular corrosion and SCC experiments were performed on as-received 5083H131 (3 mg/ $\left.\mathrm{cm}^{2}\right)$ SENT specimens (S-L) fully immersed in various solutions. 


\subsubsection{Intergranular corrosion}

Figure 3.7 presents results for localized corrosion growth in unsensitized 5083-H131 ( $3 \mathrm{mg} / \mathrm{cm}^{2}$ ) during the low $\mathrm{K}(4 \mathrm{MPa} \sqrt{\mathrm{m}})$ hold followed by slow rising displacement to $6 \mathrm{MPa} \sqrt{\mathrm{m}}$ in: (a) $0.6 \mathrm{M} \mathrm{NaCl}(\mathrm{pH} \sim 7.3)$ polarized to $-0.730 \mathrm{~V}_{\mathrm{SCE}},-0.800 \mathrm{~V}_{\mathrm{SCE}}$, and $-1.020 \mathrm{~V}_{\mathrm{SCE}}$, (b) $0.01 \mathrm{M} \mathrm{NaOH}(\mathrm{pH} 12)$ at $\mathrm{OCP}\left(\sim-1.37 \mathrm{~V}_{\mathrm{SCE}}\right)$ and polarized to $-1.800 \mathrm{~V}_{\mathrm{SCE}}$, and (c) two replicate specimens in $\mathrm{AlCl}_{3} / \mathrm{MgCl}_{2}(\mathrm{pH}-0.4)$ polarized to $-1.000 \mathrm{~V}_{\mathrm{SCE}}$. An experiment conducted with the $\mathrm{AlCl}_{3} / \mathrm{MgCl}_{2}$ solution at $-0.800 \mathrm{~V}_{\mathrm{SCE}}$ resulted in extensive general corrosion of the SENT specimen, which compromised dcPD interpretation, consistent with anodic polarization above the measured OCP of $-0.880 \mathrm{~V}_{\mathrm{SCE}}$ for $5083-\mathrm{H} 131$ in this solution. The average rate of crack advance by corrosion in asreceived 5083-H131 (3 mg/ $\left.\mathrm{cm}^{2}\right)$ during constant loading at $4 \mathrm{MPa} \sqrt{\mathrm{m}}$ were determined with linear regression analysis of the data in Fig. 3.7 over the first $10 \mathrm{~h}$, and plotted as a function of potential in Fig. 3.8 with results from sensitized 5083-H131 in $0.6 \mathrm{M} \mathrm{NaCl}$. The ranges of $\mathrm{pH}$-sensitive breakdown potentials for $\alpha$ and $\beta$ are indicated in Fig. 3.8 and defined in the Section 3.6.2.1.1.

Slow IGC propagation was recorded for unsensitized $5083-\mathrm{H} 131\left(3 \mathrm{mg} / \mathrm{cm}^{2}\right)$ in $\mathrm{NaCl}$ at both $-0.800 \mathrm{~V}_{\mathrm{SCE}}$ and $-1.020 \mathrm{~V}_{\mathrm{SCE}}(0.03 \mathrm{~nm} / \mathrm{s}$ and $0.06 \mathrm{~nm} / \mathrm{s}$, respectively, Fig. 3.7); rates are marginally faster than growth measured in air $(0.004 \mathrm{~nm} / \mathrm{s})$ at $4 \mathrm{MPa} \vee \mathrm{m}$. The corrosion growth rate increased rapidly with anodic polarization at $-0.730 \mathrm{~V}_{\mathrm{SCE}}$ in $\mathrm{NaCl}(3.6 \mathrm{~nm} / \mathrm{s})$. The potentiostat used for the $-0.730 \mathrm{~V}_{\mathrm{SCE}}$ experiment reported suspect values of applied current during this initial $16 \mathrm{~h}$ of low K loading; applied potentials could have been as high as $-0.450 \mathrm{~V}_{\mathrm{SCE}}$ during this period. None-the-less, rapid growth was measured for unsensitized 5083-H131 in NaCl. Scanning electron microscopy (SEM) of the anodically 
polarized sample (shown in Section 3.5.3.2) suggests that corrosion initiated on the bold surface causing significantly longer crack extension on the edges of the crack front compared to the center. This corrosion growth likely contributed to dcPD increase during the low K hold. This type of growth was not observed in other electrolytes, though severe corrosion compromised fatigue crack surfaces for specimens in the $\mathrm{NaOH}$ and acidic solutions (shown in Section 3.5.3.2).

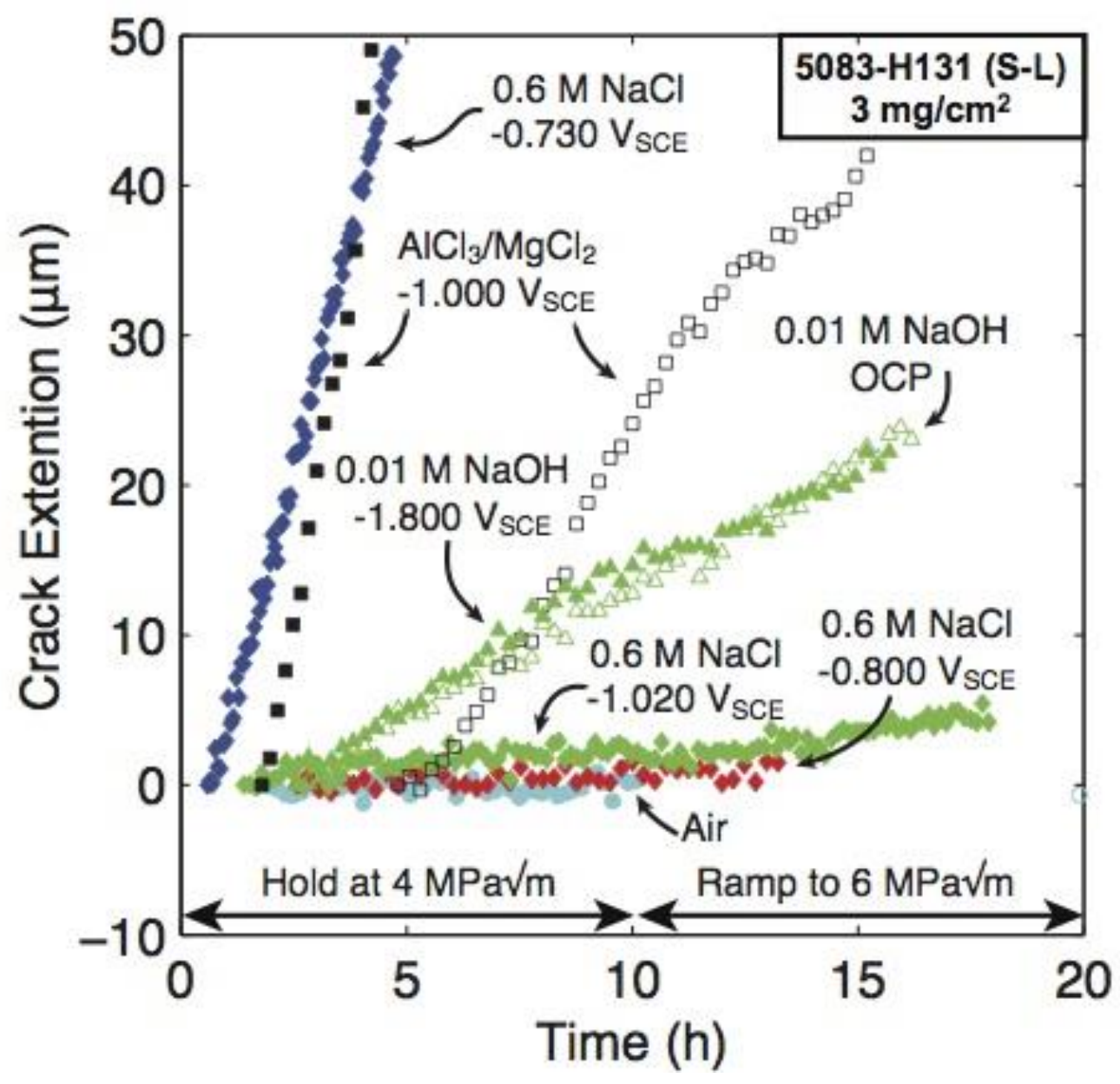

Figure 3.7 Crack extension versus time for as-received 5083-H131 SENT (S-L, $\left.3 \mathrm{mg} / \mathrm{cm}^{2}\right)$ specimens fully immersed in $\mathrm{NaOH}(\Delta), \mathrm{NaCl}(\diamond)$, and $\mathrm{AlCl}_{3} / \mathrm{MgCl}_{2}$ solutions ( $\square$ ); held at $4 \mathrm{MPa} \sqrt{\mathrm{m}}$ for $10 \mathrm{~h}$, then loaded at $0.25 \mathrm{MPa} \sqrt{\mathrm{m}} / \mathrm{h}$ to $6 \mathrm{MPa} \sqrt{\mathrm{m}}$. As-received 5083-H131 (S-L, $\left.3 \mathrm{mg} / \mathrm{cm}^{2}\right)$ loaded to $4 \mathrm{MPa} \sqrt{\mathrm{m}}$ in air $(\bullet)$ for $20 \mathrm{~h}$ is shown for reference. 


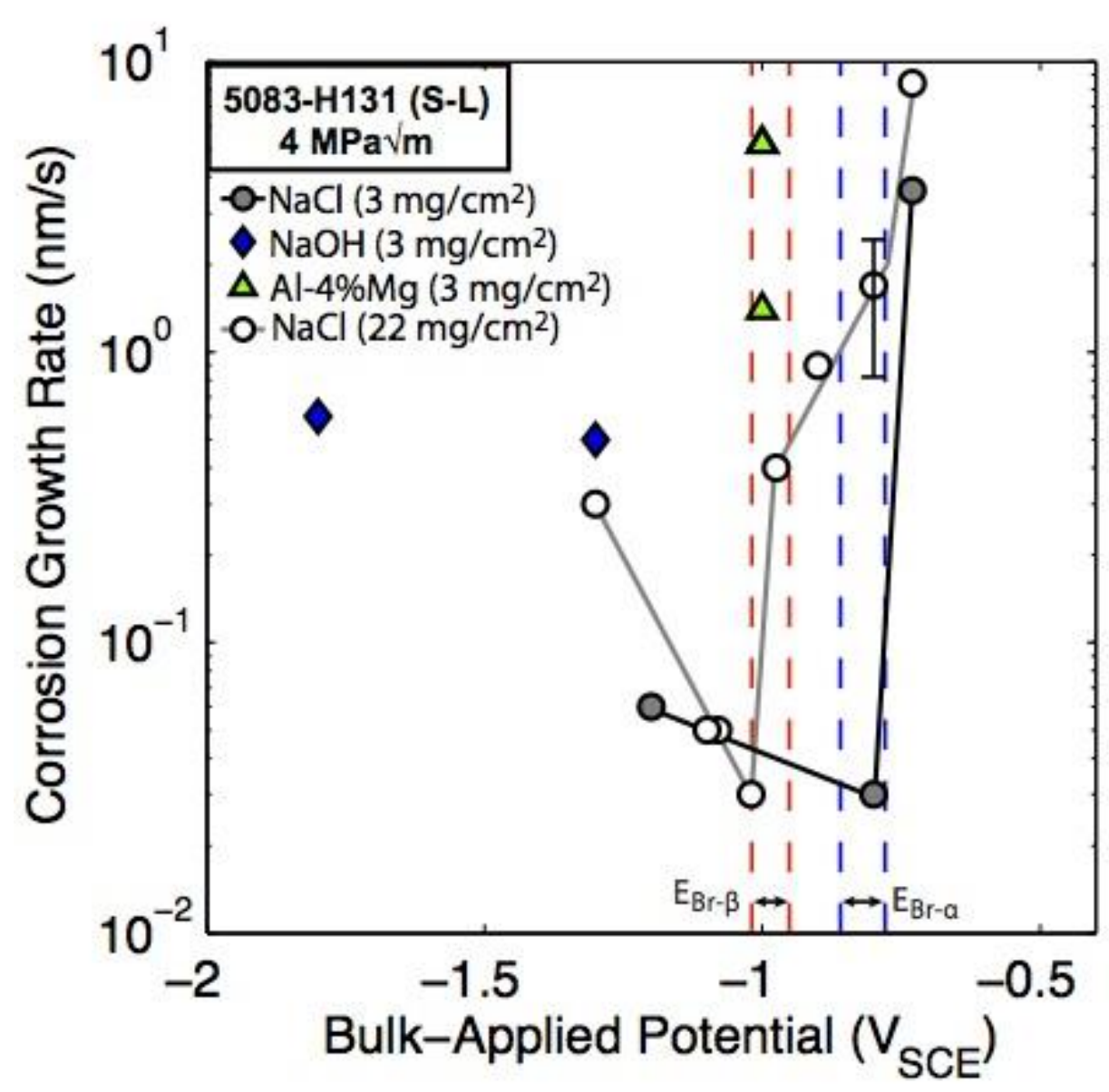

Figure 3.8 Rates of fatigue crack IGC for 5083-H131 (S-L) as-received and sensitized microstructures in various environments, stressed at constant $\mathrm{K}$ of $4 \mathrm{MPa} \sqrt{\mathrm{m}}$. The bar at $-0.800 \mathrm{~V}_{\mathrm{SCE}}$ represents maximum and minimum rates measured in replicate experiments. The $\mathrm{NaOH}$ specimen at $-1.370 \mathrm{~V}_{\mathrm{SCE}}$ remained at OCP (with no applied potential). The range of environmental sensitive breakdown potentials of both $\alpha$ and $\beta$ are shown with vertical dashed lines. The dcPD resolution limit is $4 \times 10^{-3} \mathrm{~nm} / \mathrm{s}$ for static loading at $\mathrm{K}$ of $4 \mathrm{MPa} \vee \mathrm{m}$.

The average rate of crack advance by corrosion in as-received 5083-H131 during constant loading at $4 \mathrm{MPa} \sqrt{ } \mathrm{m}$ in simulated crack tip solution $\left(\mathrm{AlCl}_{3} / \mathrm{MgCl}_{2}\right.$ at $\left.-1.000 \mathrm{~V} \mathrm{SCE}\right)$ for duplicate experiments ranged from $1.4 \mathrm{~nm} / \mathrm{s}$ to $5.2 \mathrm{~nm} / \mathrm{s}$, both of which were much faster than that measured for the other environments at similar and lower potentials (Fig. 3.8). Significant corrosion damage on both the bold surface and the fatigue flanks 
was observed, which may have contributed to dcPD increase not representative of IGC, but rather uniform corrosion (Fractography is shown in Section 3.5.3.2).

For as-received 5083-H131 loaded in $\mathrm{NaOH}$, hold period growth rates are similar when either highly cathodically polarized $\left(-1.8 \mathrm{~V}_{\mathrm{SCE}}, 0.6 \mathrm{~nm} / \mathrm{s}\right)$ or held at OCP $\left(\sim-1.37 \mathrm{~V}_{\mathrm{SCE}}\right.$, $0.5 \mathrm{~nm} / \mathrm{s}$ ). Rates are significantly higher than those measured for as-received 5083-H131 in both air and cathodically polarized $\mathrm{NaCl}$, yet much lower than rates measured in anodically polarized $\mathrm{NaCl}$ and acidic solution (Fig. 3.8).

\subsubsection{Intergranular stress corrosion cracking}

Figure 3.9 illustrates IGSCC kinetics plotted as a function of rising $\mathrm{K}$ for as-received 5083-H131. The fracture toughness, $\mathrm{K}_{\mathrm{JIC}}$ of $21.7 \mathrm{MPa} \vee_{\mathrm{m}}$ (measured in Chapter 2), is marked to approximate the initiation of ductile crack growth. J-integral analysis accounted for plasticity at high $\mathrm{K}$ for IGSCC-resistant cases (air, $\mathrm{NaCl}$ at $-0.800 \mathrm{~V}_{\mathrm{SCE}}$ and $-1.020 \mathrm{~V}_{\mathrm{SCE}}$, and each $\mathrm{NaOH}$ experiment). The da/dt $\mathrm{K} 15_{5}$ values for as-received 5083-H131 and sensitized 5083-H131 are plotted as a function of applied polarization in Fig. 3.10.

During slow-rising $\mathrm{K}$ loading of as-received $5083-\mathrm{H} 131\left(3 \mathrm{mg} / \mathrm{cm}^{2}\right)$ in acidic $\mathrm{AlCl}_{3} / \mathrm{MgCl}_{2}$ crack tip solution, multi-stage IGSCC behavior is clearly resolved in replicate experiments (Fig. 3.9). Threshold stress intensities are 4.0 MPa $\sqrt{\mathrm{m}}$ and $7.5 \mathrm{MPa} \sqrt{\mathrm{m}}$, and $\mathrm{da} / \mathrm{dt}_{\mathrm{K} 15}$ are $50 \mathrm{~nm} / \mathrm{s}$ and $200 \mathrm{~nm} / \mathrm{s}$, followed by ductile fracture between $17 \mathrm{MPa} \sqrt{\mathrm{m}}$ and $26 \mathrm{MPa} \sqrt{\mathrm{m}}$. The threshold stress intensities for both experiments are much less than $\mathrm{K}_{\mathrm{JIC}}$ for as-received 5083-H131 (S-L: 21.7 MPa $\sqrt{\mathrm{m}}$, Chapter 2), establishing subcritical IGSCC susceptibility without sensitization. Two differences were noted for these replicate experiments. The faster cracking experiment was exposed to an aged solution ( $\mathrm{pH}-0.2)$ and exhibited uniform corrosion on the boldly exposed SENT surfaces, similar to, but less 
severe than that seen in the $\mathrm{AlCl}_{3} / \mathrm{MgCl}_{2}$ solution polarized to $-0.800 \mathrm{~V}$ SCE. The slower growth rate experiment was carried out in freshly prepared $\mathrm{AlCl}_{3} / \mathrm{MgCl}_{2}$ solution ( $\left.\mathrm{pH}-0.4\right)$ and exhibited severe corrosion damage on the flank of the crack, just ahead of the notch. Such corrosion likely affected the accuracy of crack lengths calculated from measured dcPD. Intergranular cracking was not confirmed, nor refuted, with SEM analysis (shown in Fig 3.11).

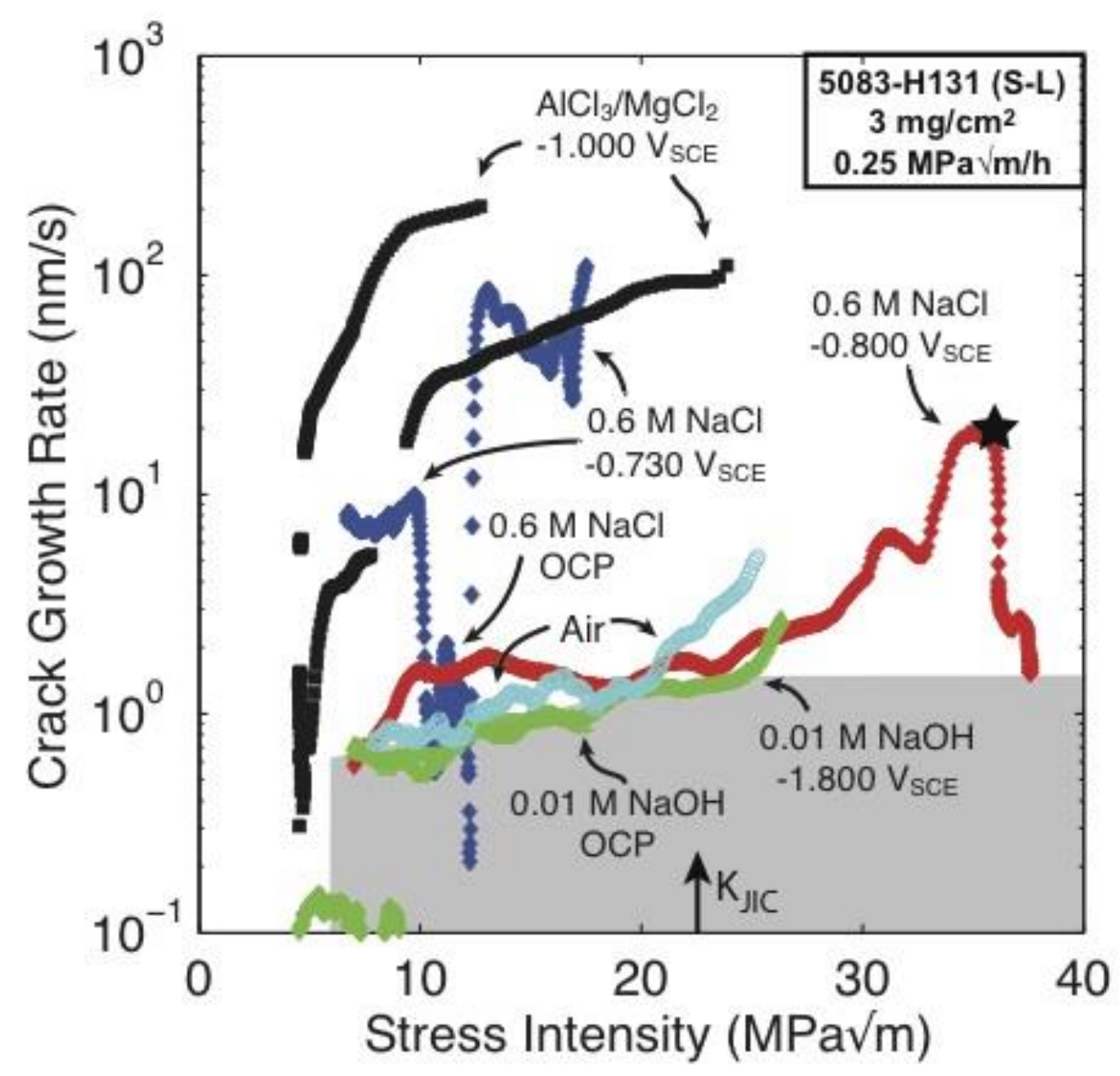

Figure 3.9 The $\mathrm{K}_{\mathrm{J}}$ dependence of da/dt for as-received $\left(3 \mathrm{mg} / \mathrm{cm}^{2}\right) 5083-\mathrm{H} 131$ (S-L) stressed with the constant then rising displacement protocol while immersed in $\mathrm{NaOH}$ $(\Delta), \mathrm{NaCl}(\diamond)$, and $\mathrm{AlCl}_{3} / \mathrm{MgCl}_{2}$ solutions $(\square)$. All experiments were analyzed with elastic-plastic $\mathrm{K}_{\mathrm{J}}$, with the exception of the specimens immersed in $\mathrm{AlCl}_{3} / \mathrm{MgCl}_{2}$ and polarized to $-0.730 \mathrm{~V}_{\mathrm{SCE}}$ in $\mathrm{NaCl}$. As-received $5083-\mathrm{H} 131\left(3 \mathrm{mg} / \mathrm{cm}^{2}\right)$ loaded with the same protocol in air is plotted for reference. The grey box represents growth rate resolution from Fig. 3.2. 


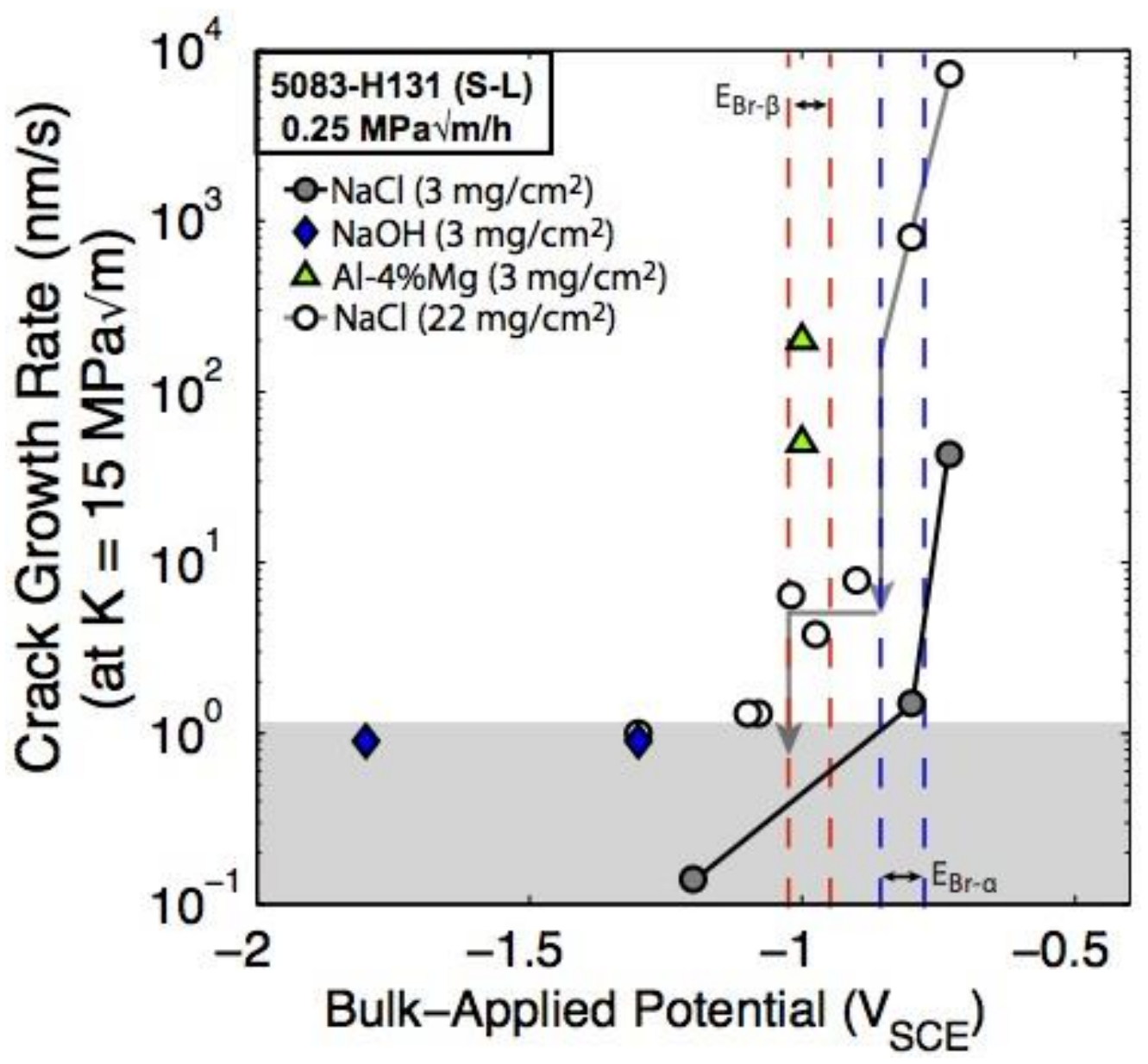

Figure 3.10 Rates of IGSCC for 5083-H131 (S-L) as-received and sensitized microstructures in various environments, stressed at constant $\mathrm{dK} / \mathrm{dt}$ of $0.25 \mathrm{MPa} \sqrt{\mathrm{m}} / \mathrm{h}$. The $\mathrm{pH}$ sensitive range of environmental sensitive breakdown potentials of both $\alpha$ and $\beta$ are shown with vertical dashed lines. The resolution at $\mathrm{K}$ of $15 \mathrm{MPa} \sqrt{\mathrm{m}}$ is shown by the grey box.

During active loading of as-received 5083-H131 (3 mg/ $\left.\mathrm{cm}^{2}\right)$, both specimens loaded in $\mathrm{NaOH}$ exhibit similar low IGSCC rates $(\sim 1.3 \mathrm{~nm} / \mathrm{s}$ at $15 \mathrm{MPa} \sqrt{\mathrm{m}})$ within the resolution limit defined by moist air (Figs. 3.9 and 3.10). Fracture surfaces were compromised by corrosion product (shown in Fig. 3.12); therefore, SEM analysis could neither confirm nor refute occurrence of IGSCC. At $25 \mathrm{MPa} \sqrt{\mathrm{m}}$, da/dt in cathodically polarized $\mathrm{NaOH}$ (Fig. 3.9, $\mathbf{\Delta}$ ) accelerated likely due to stable-ductile crack growth. 


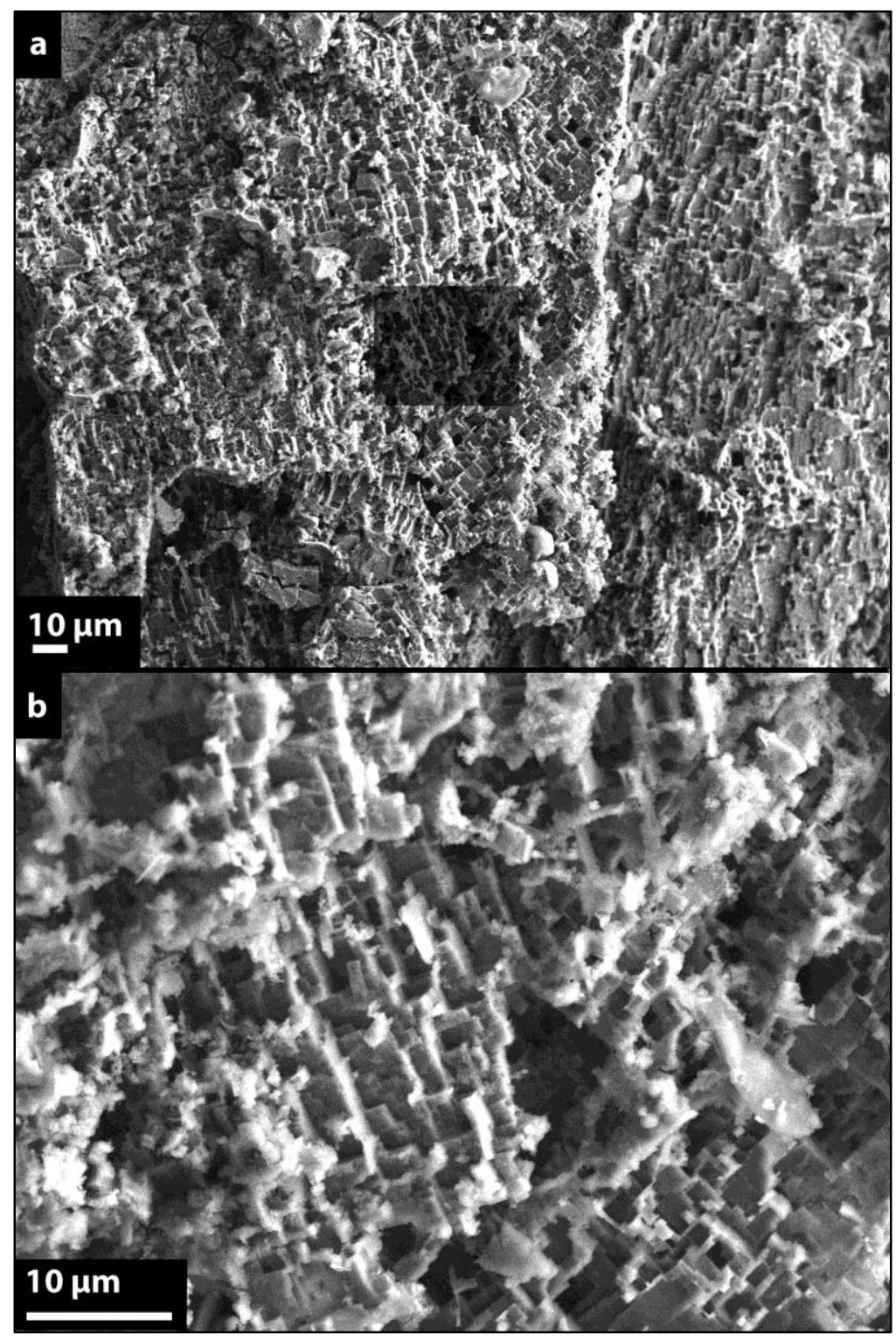

Figure 3.11 SEM fractographs of corrosion product covered/damaged regions in unsensitized 5083-H131 after $2.1 \mathrm{~mm}$ of crack extension during loading in acidic $\mathrm{AlCl}_{3} / \mathrm{MgCl}_{2}$ at $-1.000 \mathrm{~V}_{\mathrm{SCE}}$. The resulting corrosion damage at the shaded rectangle in (a) is enlarged in (b). Crack growth is down in the L direction, with $\mathrm{T}$ in the horizontal direction.

Crack growth kinetics for as-received 5083-H131 in neutral $\mathrm{NaCl}$ demonstrated the important role of applied polarization. Kinetics for an as-received specimen polarized to $-0.730 \mathrm{~V}_{\mathrm{SCE}}$ are shown in Fig. 3.9 (at $\mathrm{K}$ of $6 \mathrm{MPa} \sqrt{\mathrm{m}}$ and above, polarization 
at $-0.730 \mathrm{~V}_{\mathrm{SCE}}$ was sustained following a faulty potential hold period due to a malfunctioning potentiostat). During this polarization at $-0.730 \mathrm{~V}_{\mathrm{SCE}}$, growth rates were constant near $9 \mathrm{~nm} / \mathrm{s}$ while $\mathrm{K}$ increased from $7 \mathrm{MPa} \sqrt{\mathrm{m}}$ to $10 \mathrm{MPa} \sqrt{\mathrm{m}}$. At this point

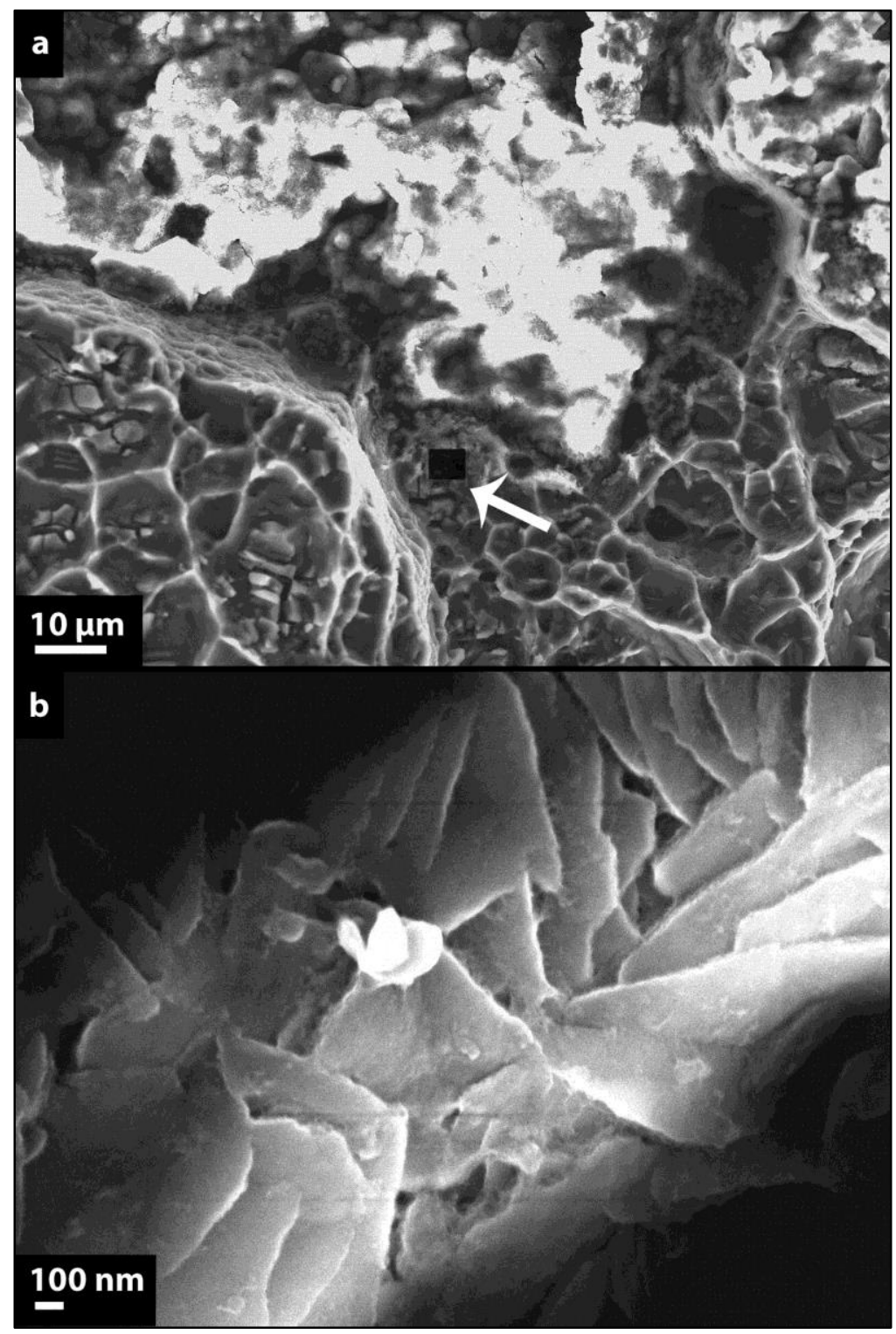

2Figure 3.12 SEM fractographs of corrosion covered regions in unsensitized 5083$\mathrm{H} 131$ loaded in alkaline $\mathrm{NaOH}$ at $\mathrm{OCP}$. The resulting corrosion damage at the shaded rectangle in (a) is enlarged in (b). Crack growth is down in the L direction, with $\mathrm{T}$ in the horizontal direction. 
polarization ceased, the specimen was left at $\mathrm{OCP}$, and the crack growth rate dropped to near the resolution limit $(1 \mathrm{~nm} / \mathrm{s})$ while $\mathrm{K}$ increased to $12 \mathrm{MPa} \sqrt{\mathrm{m}}$. At this $\mathrm{K}$ level, a potential of $-0.730 \mathrm{~V}_{\mathrm{SCE}}$ was reapplied for the remainder of the experiment and the crack growth accelerated to near $90 \mathrm{~nm} / \mathrm{s}$. During further loading, the crack growth rate stabilized to $\mathrm{da} / \mathrm{dt}_{\mathrm{K} 15}$ of $43 \mathrm{~nm} / \mathrm{s}$. The $\mathrm{K}_{\mathrm{TH}}$ is between $10 \mathrm{MPa} \sqrt{\mathrm{m}}$ and $12 \mathrm{MPa} \sqrt{\mathrm{m}}$. Fractography revealed significant corrosion product coverage, yet regions resembling IGSCC were identified and illustrated in Fig. 3.13a. The suspected IGSCC region during polarization to $-0.730 \mathrm{~V}_{\mathrm{SCE}}$ is compared to isolated IGSCC regions (produced at very high $\mathrm{K}$ ) in asreceived 5083-H131 during polarization to $-0.800 \mathrm{~V}_{\mathrm{SCE}}$ in Fig. 3.13b. Similar localized corrosion is observed in both specimens. Small pits in both specimens are likely due to localized corrosion on the matrix due to a local chemistry gradient. Though there are facets that resemble grain boundaries, a region that contained several grains was not identified in Fig. 3.13a due to the significant corrosion product coverage. The specimen had a nonuniform crack front with significantly longer growth near the edge of the specimen, than near the center of the crack front.

Cracking kinetics for as-received 5083-H131 $\left(3 \mathrm{mg} / \mathrm{cm}^{2}\right)$ polarized to $-0.800 \mathrm{VSCE}$ (applied for the entire experiment) are shown in Fig. 3.9 (this condition was investigated in detail in Chapter 2). While da/dt during rising $\mathrm{K}$ somewhat exceeded the moist air values, IGSCC did not likely occur in this neutral $\mathrm{NaCl}$ case until well above $\mathrm{K}_{\text {JIC. }}$. When $\mathrm{K}_{\mathrm{J}}$ exceeded $\mathrm{K}_{\text {IIC }}$, crack growth in $\mathrm{NaCl}$ demonstrates R-curve characteristics, which include stable ductile rupture until an elastic-plastic $\mathrm{KJ}_{\mathrm{J}}$ of $36 \mathrm{MPa} \sqrt{\mathrm{m}}$ ( $\star$ in Fig. 3.9) where the displacement is held constant. Crack growth continues at a decreasing rate, characteristic 
of IGSCC. Fractography revealed isolated regions of intergranular corrosion surrounded by ductile microvoids, as shown in Fig. 3.13b and expanded in Chapter 2.

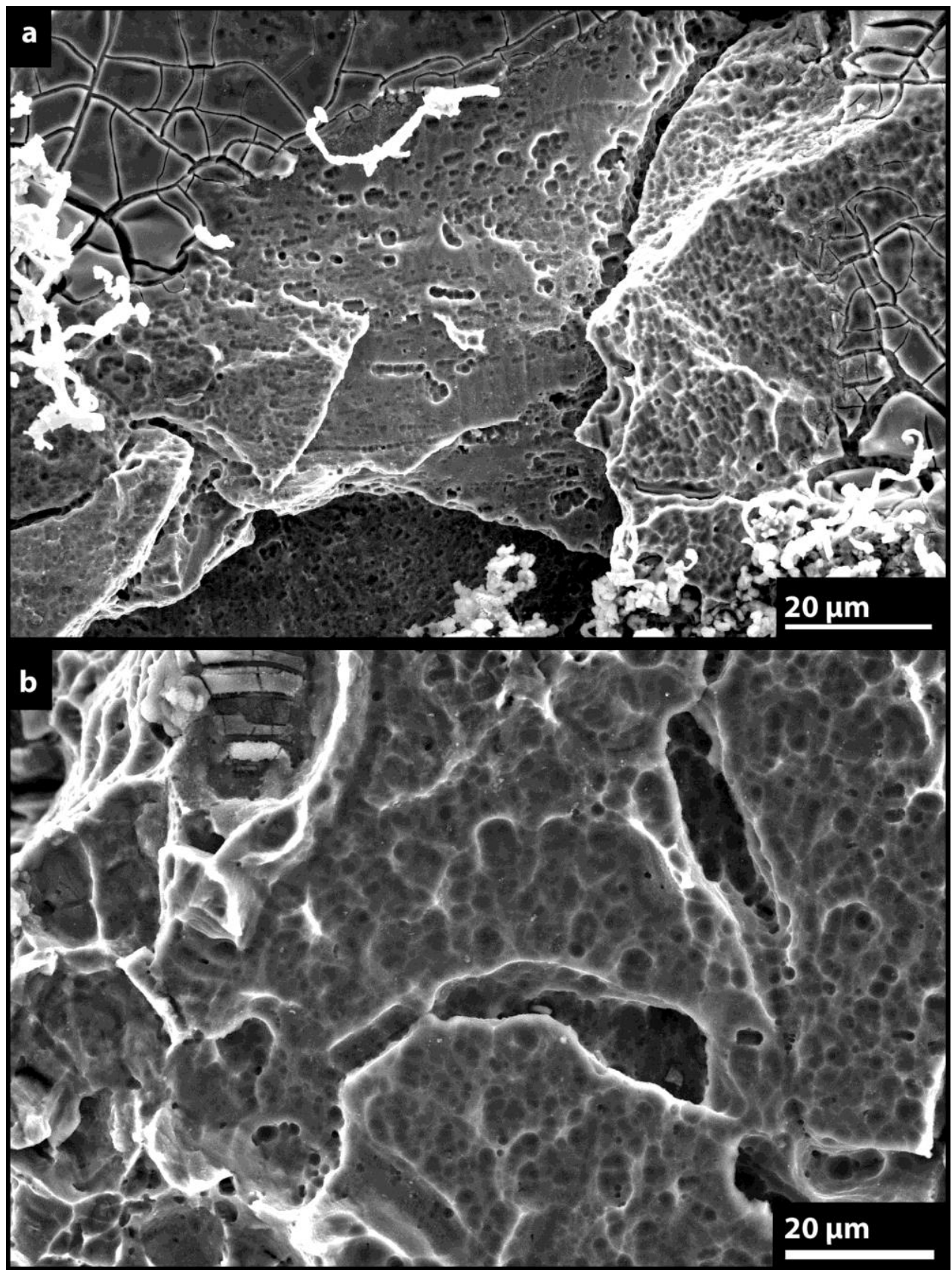

Figure 3.13 Fractographs of possible IGSCC regions in unsensitized 5083-H131 loaded in neutral $\mathrm{NaCl}$ at a) $-0.730 \mathrm{~V}_{\mathrm{SCE}}$ and b) $-0.800 \mathrm{~V}_{\text {SCE}}$. Crack growth is down in the $\mathrm{L}$ direction, with $\mathrm{T}$ in the horizontal dirction. 
Stress corrosion growth was likely nil for as-received 5083-H131 polarized to $-1.020 \mathrm{~V}_{\mathrm{SCE}}$ in $\mathrm{NaCl}$. The specimen was loaded from $6 \mathrm{MPa} \sqrt{\mathrm{m}}$ to $10 \mathrm{MPa} \vee \mathrm{m}$, and the average da/dt of $0.1 \mathrm{~nm} / \mathrm{s}$ was an order of magnitude lower than all other experiments for these loading conditions.

\subsection{DISCUSSION}

Results establish that IGSCC in Al-Mg alloys such as 5083 is dominated by an acidic crack tip environment with a high concentration of chloride, which produces measureable subcritical crack growth in both as-received and sensitized microstructures. Grain boundary $\beta$ dissolution generates cations for hydrolysis, which lowers the $\mathrm{pH}$ of the crack tip solution and triggers $\alpha$ dissolution. This crack chemistry generates high crack tip $\mathrm{H}$ production and uptake for grain boundary embrittlement. The HEAC scenario is affirmed. Evidence for these conclusions is discussed in the following sections, which focus on occluded crack electrochemistry.

\subsubsection{Crack growth rate resolution and water vapor HEAC}

Does slow-subcritical crack growth due to hydrogen embrittlement occur in 5083 H131 during slow rate loading in moist air?

Three experiments in moist air (Fig. 3.2) provide insight regarding this question. Sensitized $\left(22 \mathrm{mg} / \mathrm{cm}^{2}\right)$ and unsensitized $\left(3 \mathrm{mg} / \mathrm{cm}^{2}\right)$ 5083-H131 was stressed under slow loading $(0.25 \mathrm{MPa} \sqrt{\mathrm{m}} / \mathrm{h}$ to $0.30 \mathrm{MPa} \sqrt{\mathrm{m}} / \mathrm{h})$ to fracture at high $\mathrm{K}$, and highly sensitized 5083-H131 (45 mg/cm²) was rapidly loaded at $31 \mathrm{MPa} \sqrt{\mathrm{m}} / \mathrm{h}$. Linear reference probe normalization minimized temperature and global strain effects on specimen resistance, and hence this component of false dcPD for each experiment. 
The continuous rise in $\mathrm{dcPD}$ and $\mathrm{da} / \mathrm{dt}$ with rising $\mathrm{K}$, given by the dashed line in Fig. 3.2, is likely due to crack tip plasticity due to rising $\mathrm{K}$ loading (but not physical crack growth and thus an apparent da/dt component), plus real subcritical HEAC by H uptake due to water vapor reaction at the crack tip, plus possible creep crack growth. The level of plasticity and/or creep-based crack growth is estimated by the da/dt response of the specimen loaded at very high $\mathrm{dK} / \mathrm{dt}$ where creep and HEAC are unlikely to have sufficient time to occur. Prior research using the dcPD technique with several ultra-high strength steels showed a similar rise in da/dt with $\mathrm{K}$ in moist air, where the absence of growth by subcritical HEAC was confirmed by SEM analysis [34]. Creep is not expected in this ultrahigh strength steel at room temperature. Assuming that crack tip dcPD change is directly proportional to plastic strain, given by $\mathrm{K}^{2} /\left(\sigma_{Y S E}\right)$ at any position ahead of the tip and applied $\mathrm{dK} / \mathrm{dt}$ [29], then the steel behavior is numerically similar to the measured $\mathrm{da} / \mathrm{dt}$ versus $\mathrm{K}$ response of the two sensitized 5083-H131 specimens shown in Fig. 3.2 with a projected da/dt of $0.5 \mathrm{~nm} / \mathrm{s}$ to $0.7 \mathrm{~nm} / \mathrm{s}$ at a $\mathrm{K}$ of $15 \mathrm{MPa} \sqrt{ } .^{2}$ This comparison indicates a small to nil role for water vapor HEAC and creep crack growth in aluminum under slow loading conditions; however, the somewhat faster da/dt observed for slow loading of asreceived 5083-H131 in moist air (compared to da/dt observed during slow loading of sensitized 5083-H131 in moist air) suggests either experimental variability, creep growth, or a contribution of water vapor HEAC to da/dt.

Creep in aluminum at ambient temperature is reported in the literature; for example, in 5056 wires under constant load for 1.5 y [35]. Hypothetical creep controlled crack growth

${ }^{2}$ The simple equation for plastic strain (crack tip opening displacement) does not take into account the effect of work hardening. 
rates $\left(5 \times 10^{-4} \mathrm{~nm} / \mathrm{s}\right)$, which are much lower than the dcPD measurement resolution, were measured and modeled for very low sensitized and recrystallized 5083 when cathodically polarized below a threshold potential at $\mathrm{K}$ of $25 \mathrm{MPa} \sqrt{\mathrm{m}}_{\mathrm{m}}[13,36]$. Slow loading in $\mathrm{SENT}$ specimens could cause creep growth; however, the small influence on crack growth rates is likely neither resolved, nor important for the present study.

Rates of HEAC for 5083 stressed in water vapor at $25^{\circ} \mathrm{C}$ have not been broadly reported; limited data suggest that $\mathrm{da} / \mathrm{dt}_{\mathrm{II}}$ is $1.3 \mathrm{~nm} / \mathrm{s}$ for $5456-\mathrm{H} 321(\mathrm{~S}-\mathrm{L})$ stressed at $\mathrm{K}$ of $28 \mathrm{MPa} \sqrt{\mathrm{m}}_{\mathrm{m}}$ in $100 \%$ relative humidity $(\mathrm{RH})$ at $25^{\circ} \mathrm{C}$ [37]. Extensive data for $7075-\mathrm{T} 651$ (S-L) show that da/dt $/ \mathrm{dI}_{\text {iI }} 5 \mathrm{~nm} / \mathrm{s}$ for $100 \% \mathrm{RH}$ and $\mathrm{K}$ above $12 \mathrm{MPa} \sqrt{\mathrm{m}}$ (with $\mathrm{K}_{\mathrm{TH}}$ of $8 \mathrm{MPa} \sqrt{\mathrm{m}})[23,37,38]$. This rate declines to $2 \mathrm{~nm} / \mathrm{s}$ for $40 \% \mathrm{RH}$ typical of a laboratory environment $[23,37]$. Assuming this same water vapor pressure dependence for Al-Mg alloys [37], the range of $\mathrm{da} / \mathrm{dt}_{\mathrm{II}}$ possible for water vapor driven $\mathrm{HEAC}$ at high $\mathrm{K}$ is $\sim 0.5 \mathrm{~nm} / \mathrm{s}$ to $1.3 \mathrm{~nm} / \mathrm{s}$. This level of subcritical crack growth is just above the apparent plasticity-based resolution limit shown in Fig. 3.2, and is in the range of the measured da/dt values for as-received 5083-H131 stressed at slow-rising K in air.

The analysis associated with the moist air da/dt data in Fig. 3.2 is not sufficient to either prove or preclude water vapor driven HEAC for 5083 stressed at low $\mathrm{dK} / \mathrm{dt}$ or low temperature creep. Two points are notable. First, because there is no reason to expect that sensitization decreases da/dt for water vapor HEAC, additional moist air experiments and careful SEM fractographic characterizations are required to understand the growth rate variability in Fig. 3.2. Second, the dcPD method resolves crack growth rates in the range of $0.1 \mathrm{~nm} / \mathrm{s}$ and higher, relevant to subcritical cracking in low-H concentration environments such as moist air and several of the electrochemical conditions discussed in 
the ensuing sections. This intrinsic resolution limit is likely set by crack tip plasticity, which increases local dcPD during rising $\mathrm{K}$.

\subsubsection{Fissure tip electrochemistry as a function of potential and solution}

What factors govern the effects of electrolyte composition and applied potential on rates of IGC at the tip of the fatigue crack during low-K static loading?

For both sensitized and unsensitized specimens, the environment developed in the occluded fatigue crack at low K controls IGC, and similarly IGSCC, at higher K based on local $\mathrm{pH}$, IR affected potential, and $\mathrm{Cl}^{-}$concentration [16-18,22,23,39-43]. This experimental approach provides the first reported measurement of low K IGC rates ahead of an occluded fatigue crack tip in sensitized Al-Mg. The results presented in Figs. 3.3 and 3.4 can be compared to rates of IGC, which are measured by metallographic sections of localized corrosion growth from a boldly exposed (unstressed) surface. Collectively, these measurements of IGC provide the kinetics for corrosion growth modeling in components and for assessment of electrochemical understanding of localized corrosion along sensitized grain boundaries in Al-Mg [16-18,44-46]. Such electrochemical considerations pertinent to IGC provide a basis for understanding the effect of applied potential on occluded fissure chemistry, which in turn controls rates of IGSCC, as considered in the following sections.

\subsubsection{Effect of applied potential}

The potential dependent rates of IGC at the fatigue crack tip in sensitized 5083-H131 (S-L, $22 \mathrm{mg} / \mathrm{cm}^{2}$; Fig. 3.4) are: (a) confirmed by comparisons in the literature, and (b) interpreted based on understanding of fissure electrochemistry for Al alloys, and particularly fissure tip potential and $\mathrm{pH}$ as influenced by applied polarization. Determining 
fissure tip potential is complicated by IR-based potential difference within the occluded geometry $[22,23,41-43]$. Quantitative calculations of fissure tip potential and associated $\mathrm{pH}$ are made based on geometry, expected current density, and solution conductivity.

\subsection{Polarization dependence of IGC in sensitized 5083}

Bumiller and Kelly modeled unstressed IGC penetration rates for high purity Al-Mg in bulk $0.6 \mathrm{M} \mathrm{NaCl}$ as a function of potential and grain boundary $\beta$ coverage (DoS). The model was based on Faraday's Law $^{3}$ using current densities measured from potentiodynamic scans of $\alpha$ and $\beta$ phases in quiescent simulated fissure/crack tip $\mathrm{AlCl}_{3} / \mathrm{MgCl}_{2}$ solution (derivation of this simulated fissure tip solution is explained in Section 3.6.2.1.2) $[17,18]$. Potentiodynamic scans for $\alpha$ and $\beta$ phases in the $\mathrm{AlCl}_{3} / \mathrm{MgCl}_{2}$ are reproduced in Fig. 3.14, with potentiodynamic scans for $\alpha$ and $\beta$ in $\mathrm{NaCl}$. The bars represent the range of $\mathrm{pH}$ sensitive breakdown potential $\left(\mathrm{E}_{\mathrm{Br}}\right)$ for each phase-solution combination (breakdown potential was defined at the potential where the current density increases by more than a magnitude without significant potential increase). Specific values are given in Table 3.2. Table 3.3 compares the model predicted IGC growth rates with measured IGC rates of sensitized 5083-H131 in the fatigue crack stressed at low-static K in the indicated-bulk chloride environment. Growth rates were also measured from a metallographic sectioning study of IGC propagating in the L direction from an unstressed boldly exposed surface of the same lot of 5083-H131 and sensitization condition $\left(22 \mathrm{mg} / \mathrm{cm}^{2}\right)$ used in the present study [28]. These rates decreased from $3.5 \mathrm{~nm} / \mathrm{s}$ to $0.7 \mathrm{~nm} / \mathrm{s}$

${ }^{3}$ Faraday's Law is da/dt $=i_{a} M /(z F \rho)$ where $i_{a}$ is the fissure tip current, $M$ is the atomic weight $(26.98 \mathrm{~g} / \mathrm{mol}$ for $\mathrm{Al}), \mathrm{z}$ is the valence ( 3 eq. for $\mathrm{Al}), \mathrm{F}$ is Faraday's constant (96,487 C/eq.), and $\rho$ is density (2.7 $\mathrm{g} / \mathrm{cm}^{2}$ for $\left.\mathrm{Al}\right)[52]$. 
with applied potential $\left(\mathrm{E}_{\text {app }}\right)$ from $-0.730 \mathrm{~V}_{\mathrm{SCE}}$ to $-0.800 \mathrm{~V}_{\mathrm{SCE}}$ [28], which is on the order measured for fatigue cracked specimens (Fig. 3.8). This metallographic rate includes both initiation and propagation stages of IGC, and therefore is expected to be somewhat slower than fatigue precrack corrosion propagation rate from continuous dcPD measurement of corrosion growth.

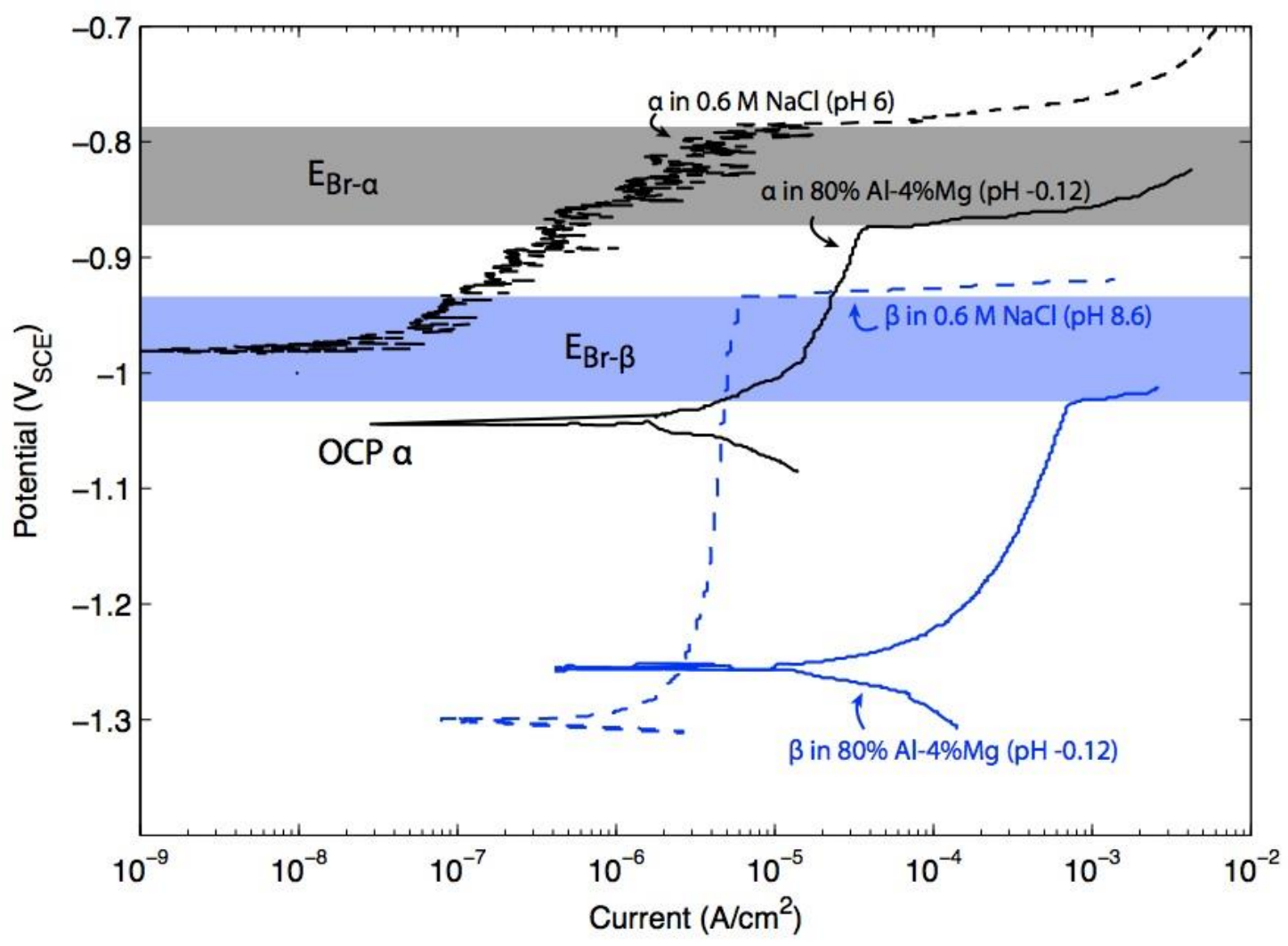

Figure 3.14 Potentiodynamic scans of $\alpha$ in $0.6 \mathrm{M} \mathrm{NaCl}(\mathrm{pH} 6)$, and $\beta$ in $0.6 \mathrm{M} \mathrm{NaCl}$ (pH 8.6) [15], and $\alpha$ and $\beta$ in $80 \%$ saturated $\mathrm{Al}-4 \% \mathrm{Mg}$ acidic solution ( $\mathrm{pH}-0.12)[17,18]$. The range of $\mathrm{pH}$-sensitive breakdown potential for each phase is shown with a horizontal bar.

Table 3.2 Breakdown potentials of $\beta$ and $\alpha$ phase in neutral and acidic environments from Fig. 3.14.

\begin{tabular}{cccc}
\hline Solution & $\mathrm{pH}$ & $\mathrm{E}_{\text {Br }-\beta}\left(\mathrm{V}_{\text {SCE }}\right)$ & $\mathrm{E}_{\text {Br- } \alpha}\left(\mathrm{V}_{\text {SCE }}\right)$ \\
\hline $80 \%$ Saturated Al-4\%Mg & -0.8 & $-1.015[17,18]$ & $-0.870[17,18]$ \\
$0.6 \mathrm{M} \mathrm{NaCl}$ & $6.0-8.6$ & $-0.960[15]$ & -0.790 \\
\hline
\end{tabular}


Table 3.3 Predicted bold surface [17,18] and measured fatigue crack (K of $5 \mathrm{MPa} \sqrt{\mathrm{m}}$ ) IGC growth rates for sensitized $\left(22 \mathrm{mg} / \mathrm{cm}^{2}\right) 5083-\mathrm{H} 131$ in $0.6 \mathrm{M} \mathrm{NaCl}$.

\begin{tabular}{|l|l|l|}
\hline$E_{\text {app }}\left(\mathrm{V}_{\mathrm{SCE}}\right)$ & $\begin{array}{l}\text { Fatigue Crack IGC Rates } \\
\text { Fig. 3.8 }(\mathrm{nm} / \mathrm{s})\end{array}$ & $\begin{array}{l}\text { Predicted Rates } \\
(\mathrm{nm} / \mathrm{s})\end{array}$ \\
\hline-0.73 & 8.4 & 2.5 \\
\hline-0.8 & $0.8-2.6^{\dagger}$ & 0.9 \\
\hline-0.9 & 0.9 & 0.008 \\
\hline-0.975 & 0.4 & 0.001 \\
\hline-1.02 & 0.03 & $<0.00008$ \\
\hline-1.08 & 0.05 & $<0.00008$ \\
\hline-1.1 & 0.05 & $<0.00008$ \\
\hline-1.3 & 0.3 & $<0.00008$ \\
\hline
\end{tabular}

${ }^{\%}$ Growth rates modeled by $[17,18]$.

'Replicate experiments in Chapter 2.

Both measured and modeled growth rates in sensitized 5083 in $\mathrm{NaCl}$ decrease with

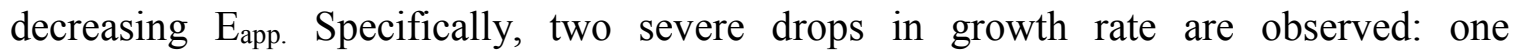
between $-0.730 \mathrm{~V}_{\mathrm{SCE}}$ and $-0.800 \mathrm{~V}_{\mathrm{SCE}}$ and the other between $-0.975 \mathrm{~V}_{\mathrm{SCE}}$ and $-1.020 \mathrm{~V}_{\mathrm{SCE}}$. The criteria used to develop the bold surface modeled rates assumed that IGC is rate controlled by the slowest corrosion kinetics in the system, which are those of $\alpha$ dissolution (Fig. 3.14). Growth rates measured from the fatigue crack also seem to follow this trend at $E_{\text {app }}$ above $-0.900 \mathrm{~V}_{\mathrm{SCE}}$. For example, from $\mathrm{E}_{\text {app }}$ of $-0.730 \mathrm{~V}_{\mathrm{SCE}}$ to $-0.800 \mathrm{~V}_{\mathrm{SCE}}$, the fatigue crack IGC growth rate falls 4-fold, suggesting that $\alpha$ dissolution is limited, possibly because the applied potential is below the relevant rate controlling breakdown potential of $\alpha\left(\mathrm{E}_{\mathrm{Br}-\alpha}:-0.870 \mathrm{~V}_{\mathrm{SCE}}\right.$ in acidic $\mathrm{AlCl}_{3} / \mathrm{MgCl}_{2}$ from Table $\left.3.2[17,18]\right)$. Though $\beta$ dissolution is still active, the acidic environment required for severe corrosion may not be developed with limited $\alpha$ dissolution. With further cathodic polarization in the range $-0.975 \mathrm{~V}_{\mathrm{SCE}}$ to $-1.020 \mathrm{~V}_{\mathrm{SCE}}$, modeled corrosion growth slowed significantly, reflecting a Tafel-type decline in the dissolution rate at the OCP of $\alpha\left(-1.050 \mathrm{VSCE}\right.$ in acidic $\mathrm{AlCl}_{3} / \mathrm{MgCl}_{2}$, Table. $3.2[17,18])$. Fatigue crack corrosion growth is effectively eliminated at $-1.020 \mathrm{VSCE}$, 
which corresponds with the breakdown potential of $\beta$ in acidic solution $\left(\mathrm{E}_{\mathrm{Br}-\beta}\right.$, Table 3.2) $[17,18]$. The elimination of fatigue crack IGC could be due to limited $\beta$ dissolution, and/or the elimination of $\alpha$ dissolution; the rate controlling potential (the fissure tip potential, $\mathrm{E}_{\text {tip }}$ ) likely falls to $-1.050 \mathrm{~V}_{\mathrm{SCE}}$ due to Ohmic resistance in the fissure. Both explanations indicate the important role of $\beta$ dissolution to trigger $\alpha$ dissolution in IGC. The finite fatigue crack IGC rates measured for cathodically polarized specimens $\left(-1.020 \mathrm{~V}_{\mathrm{SCE}}\right.$ to $\left.-1.300 \mathrm{~V}_{\mathrm{SCE}}\right)$ are likely caused by Al-Mg corrosion in the increasingly alkaline fissure tip and wake due to cathodic polarization, a phenomenon not considered in the IGC model.

Corrosion growth rates suggest that, even though the presence and dissolution of $\beta$ are critical to enable and sustain fissure tip acidification, rapid corrosion growth relies on both $\alpha$ and $\beta$ dissolution. Above both $\mathrm{E}_{\mathrm{Br}-\beta}$ and $\mathrm{E}_{\mathrm{Br}-\alpha}, \beta$ dissolution likely triggers the critical acidic chemistry required to sustain $\alpha$ dissolution. Development of an acidic fissure tip

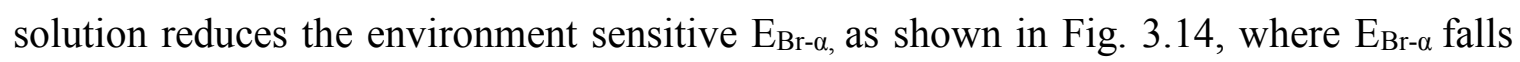
from $-0.790 \mathrm{~V}_{\mathrm{SCE}}$, in near neutral $\mathrm{NaCl}$, to $-0.870 \mathrm{~V}_{\mathrm{SCE}}$ in acidic solution. The combination of $\alpha$ and $\beta$ dissolution produces rapid corrosion growth.

When $\mathrm{E}_{\text {app }}$ is below $\mathrm{E}_{\mathrm{Br}-\alpha}$, but above $\mathrm{E}_{\mathrm{Br}-\beta}\left(-0.900 \mathrm{~V}_{\mathrm{SCE}}\right.$ to $\left.-1.020 \mathrm{~V}_{\mathrm{SCE}}\right)$, IGC growth decreases significantly. This corrosion decrease may be due to the limited development of an acidic fissure tip chemistry with $\beta$ dissolution alone. The volume fraction of $\beta$ at the fissure tip of $5083-\mathrm{H} 131$ sensitized to $22 \mathrm{mg} / \mathrm{cm}^{2}$ may not be sufficient to produce the critical acidic chemistry developed by $\alpha$ and $\beta$ dissolution at $\mathrm{E}_{\mathrm{app}}>\mathrm{E}_{\mathrm{Br}-\alpha}$. Fatigue crack IGC is eliminated below both $\mathrm{E}_{\mathrm{Br}-\beta}$ and $\mathrm{E}_{\mathrm{Br}-\alpha}$ because only passive dissolution of both phases is expected, though growth could occur by cathodic corrosion. 


\subsection{Fissure tip chemistry and IGC growth stability}

To test the proposed IGC dependence on fissure tip potential, quantitative predictions of the fissure chemistry are made based on geometry, critical chemistry, and electrochemical kinetics of the relevant material as a function of applied potential. The crack/fissure tip chemical and electrochemical conditions are highly dependent on both the presence of grain boundary $\beta$ and mass transport. Quantitative considerations of these environments will enhance crack tip chemistry based understanding of IGSCC (discussed in Section 3.6.4).

Though the occluded chemistry inside Al-Mg fissures has not been directly measured, Bumiller predicted the conditions relevant to IGC $[17,18]$. The solution chemistry needed for IGC propagation to occur without continuous $\beta$ in AA5083 was bounded by stoichiometric dissolution of synthesized $\alpha(\mathrm{Al}-4 \% \mathrm{Mg}$ solid solution $)$ and $\beta\left(\mathrm{Al}_{3} \mathrm{Mg}_{2}\right)$ in an array of diluted saturated solutions. Bumiller demonstrated that the fissure tip chemistry must be approximately $80 \%$ saturated $\mathrm{Al}-4 \% \mathrm{Mg}$ chloride solution $\left(2.5 \mathrm{M} \mathrm{Al}^{3+}\right.$, 1.1 $\mathrm{M} \mathrm{Mg}^{2+}, 7.7 \mathrm{M} \mathrm{Cl}^{-}, \mathrm{pH} 0.1$, solution conductivity $\mathrm{\kappa}=93 \mathrm{mS} / \mathrm{cm}$ ) in order for both: (a) the tip to corrode at the experimentally measured corrosion rate, and (b) the flanks of the fissure to be passive at the local potential $[17,18]$. This level of saturation is consistent with analyses of localized stability in other systems [47-51].

The kinetics of active localized corrosion can be characterized by the repassivation potential $[28,44]$ and by the active dissolution kinetics obtained from measurements in simulated occluded environments $[17,18]$. The repassivation potential represents the minimum potential at which localized corrosion can propagate stably, whereas the dissolution kinetics provide input data to calculate the chemical conditions within an 
occluded region. Reported repassivation potentials for 5083-H131 (of the same lot used in the present study) were between $-0.900 \mathrm{~V}_{\mathrm{SCE}}$ and $-0.950 \mathrm{~V}_{\mathrm{SCE}}$ in a bulk $0.6 \mathrm{M} \mathrm{NaCl}$ solution $[28,44]$. Electrochemical kinetics are also provided for $\alpha$ in a range of occluded solution analogs (e.g. $\alpha$ in $80 \%$ saturated Al-4\%Mg is reproduced in Fig. 3.14) $[17,18]$. In all solutions studied, from $50 \%$ saturation to $100 \%$ saturation of stoichiometric solutions, both phases were spontaneously passive until the breakdown potential, where the active current densities increased rapidly. The passive current density of $\alpha$ is approximately $17 \mu \mathrm{A} / \mathrm{cm}^{2}$ (Fig. 3.14), assuming the fissure tip chemistry is $80 \%$ saturated $\mathrm{Al}-4 \% \mathrm{Mg}[17,18]$.

The electrochemical criteria for localized corrosion stability is known as the pit stability product, (id) $)_{\text {crit }}$ in which $\mathrm{i}$ is the dissolution current density at the localized corrosion site, and $\mathrm{d}$ is the depth of the localized corrosion site, which characterizes the diffusion length. When local (id) is below the critical value, the pit will cease to grow because, either the current is not sufficient to maintain dissolution, or the diffusion distance is too short to sustain a critical environment chemistry. The pit stability product was first developed by Galvele [48-50], and has been widely used to estimate the dissolution rate required to maintain a critical chemistry for a given diffusion length [45,52]. Lucente and Scully and Cook et al. used the artificial pit method for pure Al to calculate the critical pit stability product as a function of potential (Fig. 3.15) [47,51]. Measurements are not currently available for the pit stability product in 5083 . 


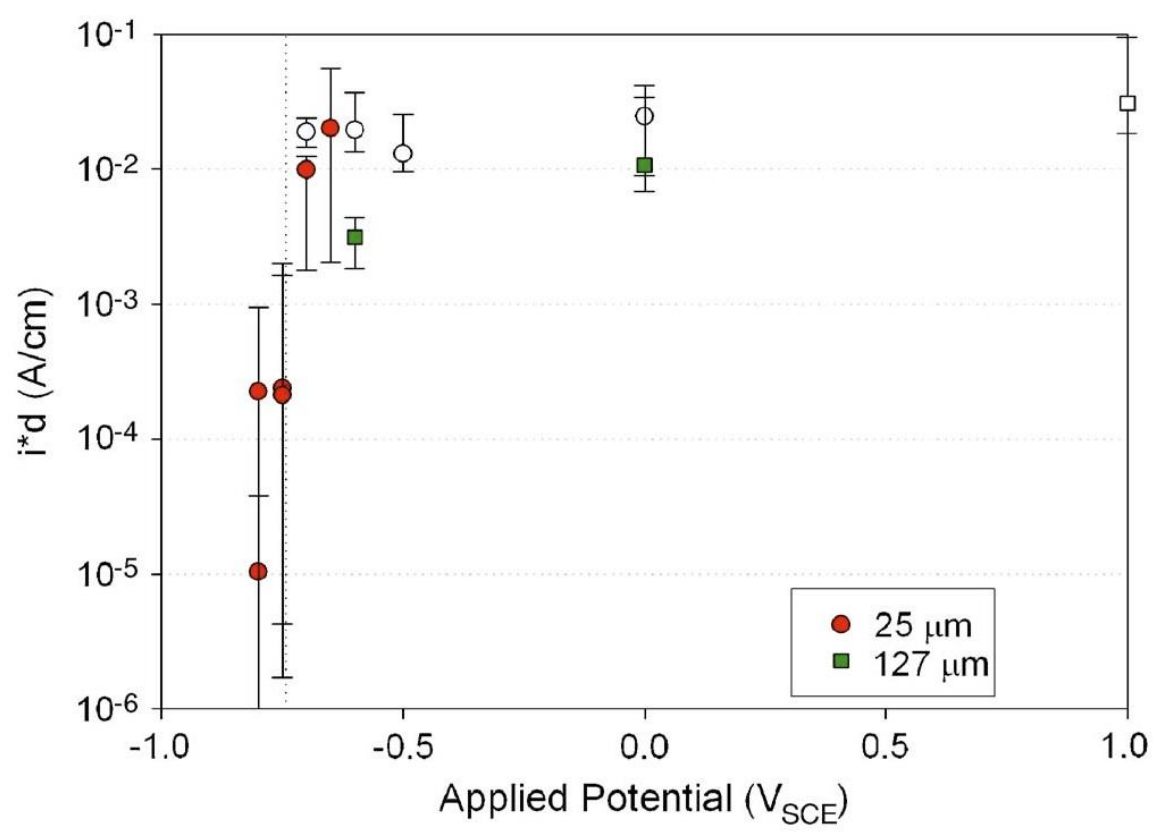

Figure 3.15 The average pit stability product calculated for artificial pits in $25 \mu \mathrm{m}$ and $127 \mu \mathrm{m}$ diameter $\mathrm{Al}$ wires after $200 \mathrm{~s}$ at the given applied potential [47].

\subsection{Quantitative predictions of fissure tip potential}

To predict the potential at the fissure tip, first consider the ability to maintain the critical chemistry at a given location within the fissure. Occlusion is expected to occur during IGC in the fatigue crack at $\mathrm{K}$ of $5 \mathrm{MPa} \sqrt{\mathrm{m}}$. Based on full immersion of the SENT specimen, three orientations and diffusion distances are considered: (A) transport in the L direction down the crack including the precrack and IGC fissure tip, (B) transport across the specimen thickness, in the transverse $(\mathrm{T})$ direction, from the bold surface to the center of the fissure front, and $(\mathrm{C})$ transport in the T direction, from the bold surface to a quarter of the away across the front. The three orientations are illustrated in Fig. 3.16. The latter two conditions are examined with the assumption that the easiest path for current flow, as well as ion diffusion, is out the sides of the sample rather than down the length of the fatigue 
crack and fissure. Though the maximum diffusion distance is the same for these cases $(d=3.3 \mathrm{~mm})$, the diffusion distance of interest $\left(\mathrm{d}_{\mathrm{o}}\right)$ is different $(3.3 \mathrm{~mm}$ in $(B)$ and $1.65 \mathrm{~mm}$ in (C)). Based on the stability criterion (a critical product of $0.01 \mathrm{~A} / \mathrm{cm}$ at $\mathrm{E}_{\text {app }}$ of $-0.800 \mathrm{~V}_{\mathrm{SCE}}$ from Fig. 3.15), if $\mathrm{d}_{\mathrm{o}}$ is $3.3 \mathrm{~mm}$, a current density of $30 \mathrm{~mA} / \mathrm{cm}^{2}$ is required to maintain solution saturated in $\mathrm{AlCl}_{3}$. This current density corresponds to an IGC rate of $11 \mathrm{~nm} / \mathrm{s}$ by Faraday's Law. Only $24 \mathrm{~mA} / \mathrm{cm}^{2}$ is required to maintain $80 \%$ saturation, leading to an IGC rate of $8.6 \mathrm{~nm} / \mathrm{s}$; which is on the order of IGC measured in the fatigue crack with applied potential of $-0.730 \mathrm{VSCE}$.

Though the stability criterion is reasonable for the mid-crack-front diffusion distance, $\mathrm{d}_{\mathrm{o}}$, of $3.3 \mathrm{~mm}$, the stability criterion for pure Al may be inconsistent with IGC and IGSCC measurements made for 5083 with shorter diffusion distances [47]. If $0.01 \mathrm{~A} / \mathrm{cm}$ is the assumed pit stability product, then the current density at the quarter location $\left(\mathrm{d}_{\mathrm{o}}=1.65 \mathrm{~mm}\right)$ would have to be at least $60 \mathrm{~mA} / \mathrm{cm}^{2}$ to overcome diffusional loss and maintain a critical solution chemistry. Using Faraday's law, this current corresponds to a minimum IGC rate of $20 \mathrm{~nm} / \mathrm{s}$, which is more than 2-times faster than the highest rate measured in this study and others $[16,44]$. The stability criterion for 5083 is currently being investigated, and will help clarify this inconsistency [28].

Given that maintenance of the critical chemistry is feasible at the center of the crack $\left(\mathrm{d}_{\mathrm{o}}=3.3 \mathrm{~mm}\right)$, attention can be focused on the Ohmic drop associated with the electrochemistry developing within the fissure. Stewart developed an analytical solution for such a geometry if the walls of the slot are passive, and the tip is active [53]. The Ohmic drop at the center of the crack tip is as follows for the slot shown in Fig. 3.16: 


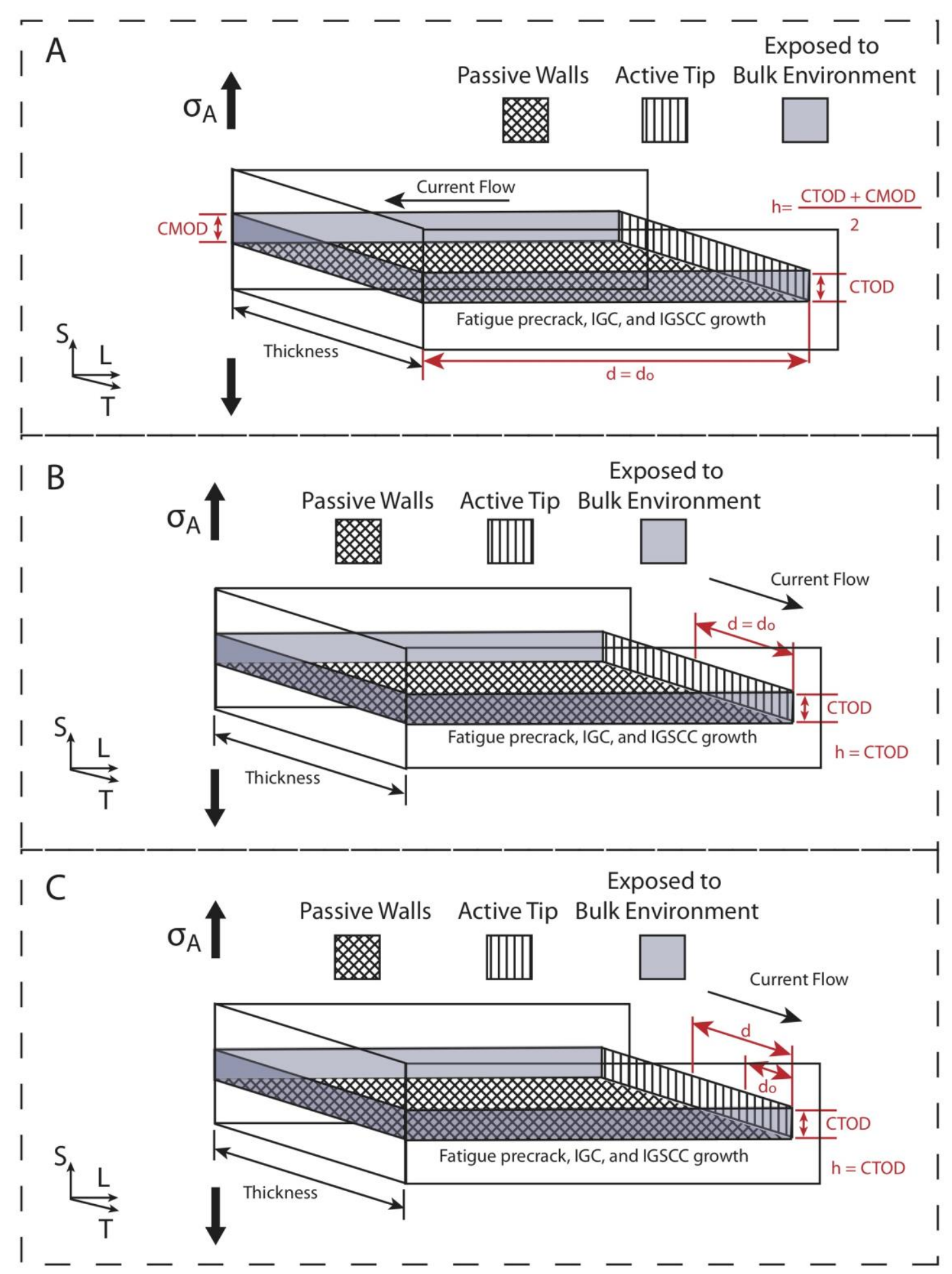

Figure 3.16 Three orientations of the occluded fissure (crack) used to calculate Ohmic drop adapted from Stewart [53]. 


$$
I R=\frac{f i_{\text {wall }}}{\kappa h} d d_{o}-\frac{f i_{\text {wall }}}{2 \kappa h} d_{o}^{2}-\frac{i_{\text {tip }}}{\kappa} d
$$

Where: $\mathrm{i}_{\text {wall }}=$ passive current density on the walls $\left(17 \mu \mathrm{A} / \mathrm{cm}^{2}\right)^{4}[17,18]$

$$
\begin{aligned}
& \mathrm{i}_{\text {tip }}=\text { current density at the tip (calculated from IGC rates) } \\
& \kappa=\text { solution conductivity } \\
& \mathrm{h}=\text { height of slot or fissure } \\
& \mathrm{d}=\text { maximum diffusion distance } \\
& \mathrm{d}_{\mathrm{o}}=\text { diffusion distance of interest }
\end{aligned}
$$

The height of the fissure is illustrated for each of the three orientations in Fig. 3.16. For orientation A (parallel to crack growth direction) the fissure opening is estimated by the average of the crack tip opening displacement (CTOD) [54] and the crack mouth opening displacement (CMOD) [55]. The calculations for each are detailed in the appendix. In sensitized 5083-H131, the CTOD is $0.5 \mu \mathrm{m}$ at $\mathrm{K}$ of $5 \mathrm{MPa} \sqrt{\mathrm{m}}$, and the CMOD is about $8 \mu \mathrm{m}$; h in orientation $\mathrm{A}$ is $4.5 \mu \mathrm{m}$. For orientations $\mathrm{B}$ and $\mathrm{C}$ (perpendicular to the crack growth direction), $\mathrm{h}$ is estimated by the CTOD alone.

For the environment-microstructure condition under consideration, the only unknown parameters are $\kappa$ and $i_{\text {tip. }}$ The conductivity is bounded by results from Bumiller $[17,18]$ : the average of $93 \mathrm{mS} / \mathrm{cm}$ and $45 \mathrm{mS} / \mathrm{cm}$, for $80 \%$ saturated and $100 \%$ saturated $\mathrm{Al}-4 \% \mathrm{Mg}$ chloride solution, respectively. The fissure tip current density can be estimated as that associated with the IGC rate measured at a given $\mathrm{E}_{\mathrm{app}}$. The maximum Ohmic drop over the

4 Note that due to local water reduction, $15 \%$ of the anodic current is balanced by local cathodic reactions [22]; therefore $85 \%$ of the passive current density was used in the calculation of ohmic drop. 
fissure is limited by the OCP at the fissure tip, which is assumed to be OCP of $\alpha$ in the predicted fissure tip chemistry $\left(-1.050 \mathrm{~V}_{\mathrm{SCE}}\right.$ in acidic $\left.\mathrm{AlCl}_{3} / \mathrm{MgCl}_{2}[17,18]\right)$.

Following Eqn. 3.1, the calculated fissure tip potentials for the three cases in Fig. 3.16 are given in Table 3.4 as a function of applied potential, and plotted in Fig. 3.17. The magnitude of the Ohmic drop is represented by the difference between the black line (the applied voltage equals the tip potential) and estimated crack tip potential. For orientation A, the fissure tip potentials (Etip) are very close to Eapp, showing that a small Ohmic drop is expected down the fissure in the $\mathrm{L}$ direction, due to the large slot opening. For orientations B and C, Etip is independent of Eapp until anodic potentials; the Ohmic drop is extremely high due to the very narrow CTOD, which increases fissure tip resistance.

Table 3.4 Predicted $\mathrm{pH}$ and potential at the fatigue crack-IGC fissure tip in sensitized $\left(22 \mathrm{mg} / \mathrm{cm}^{2}\right) 5083-\mathrm{H} 131$ in $0.6 \mathrm{M} \mathrm{NaCl}$ at $\mathrm{K}$ of $5 \mathrm{MPa} \sqrt{\mathrm{m}}$ for the three orientations represented in Fig. 3.16.

\begin{tabular}{|l|l|l|l|l|}
\hline \multirow{2}{*}{$E_{\text {app }}\left(\mathrm{V}_{\mathrm{SCE}}\right)$} & Orientation A & Orientation B & Orientation C & Orientation A \\
\cline { 2 - 5 } & $\mathrm{E}_{\text {tip }}\left(\mathrm{V}_{\mathrm{SCE}}\right)$ & $\mathrm{E}_{\text {tip }}\left(\mathrm{V}_{\mathrm{SCE}}\right)$ & $\mathrm{E}_{\text {tip }}\left(\mathrm{V}_{\mathrm{SCE}}\right)$ & Tip $\mathrm{pH}$ \\
\hline-0.73 & -0.76 & -1.04 & -0.95 & 1.6 \\
\hline-0.80 & -0.81 & -1.05 & -1.00 & 2.9 \\
\hline-0.90 & -0.91 & -1.05 & -1.05 & 5.1 \\
\hline-0.98 & -0.98 & -1.05 & -1.05 & 6.8 \\
\hline-1.02 & -1.03 & -1.05 & -1.05 & 7.7 \\
\hline-1.08 & -1.05 & -1.05 & -1.05 & 8.2 \\
\hline-1.10 & -1.05 & -1.05 & -1.05 & 8.2 \\
\hline-1.30 & -1.05 & -1.05 & -1.05 & 8.2 \\
\hline
\end{tabular}




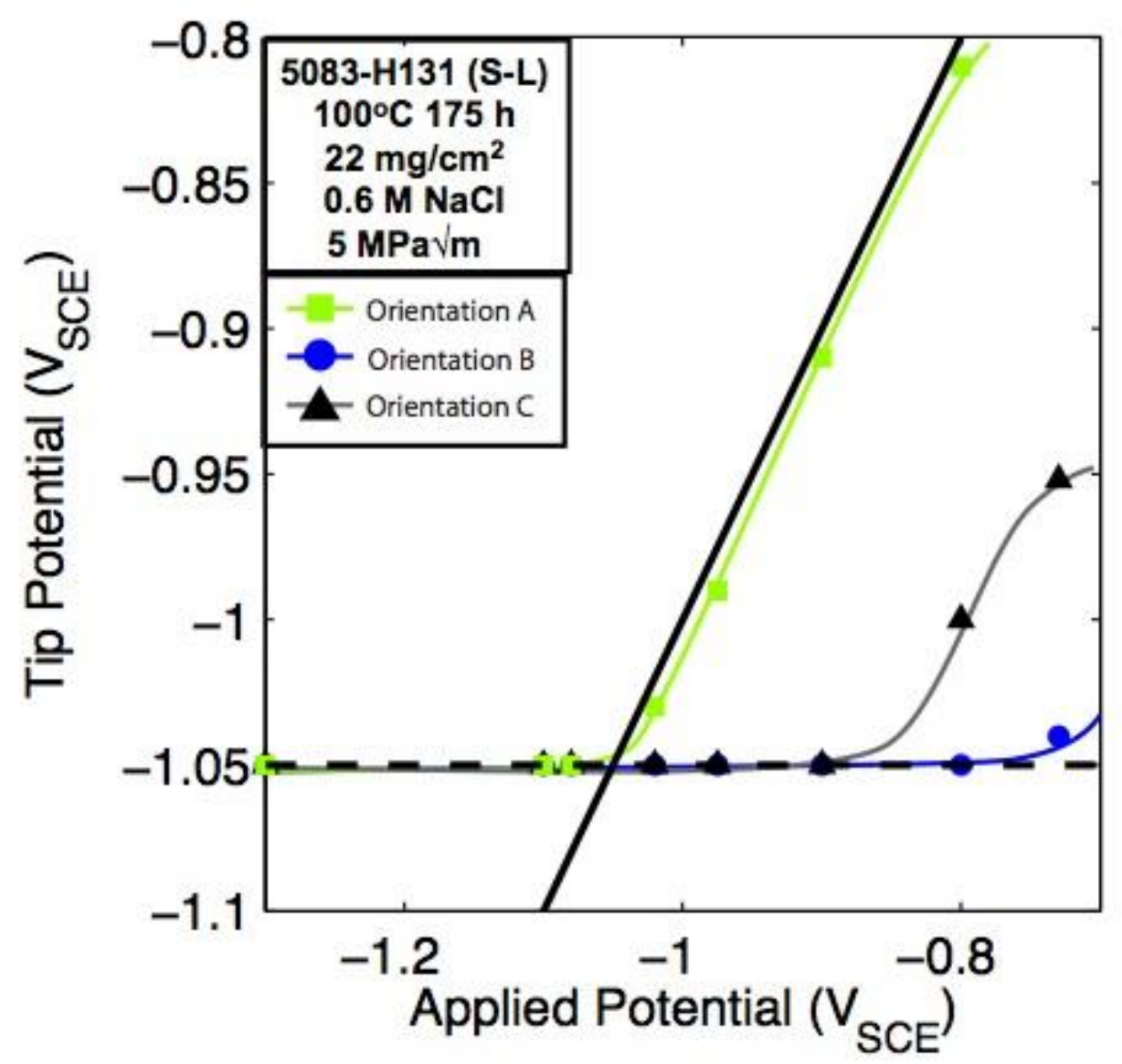

Figure 3.17 Predicted fatigue crack tip corrosion fissure potential at $\mathrm{K}=5 \mathrm{MPa} \sqrt{\mathrm{m}}$ as a function of applied potential for sensitized 5083-H131 (S-L, $22 \mathrm{mg} / \mathrm{cm}^{2}$ ) and the three orientations represented in Fig. 3.16. The black line is the applied potential equal to crack tip potential. The dashed line represents the lower bound of the fissure tip potential (OCP of $\alpha$ in simulated crack tip solution $[17,18]$ ).

The predicted fissure tip potentials for all three orientations are shown with the Ohmic drop magnitude and direction in Fig. 3.18. The $\mathrm{E}_{\text {tip }}$ values predicted for orientation $\mathrm{A}$ confirm the explanation given in Section 3.6.2.1.1 for the potential dependence observed

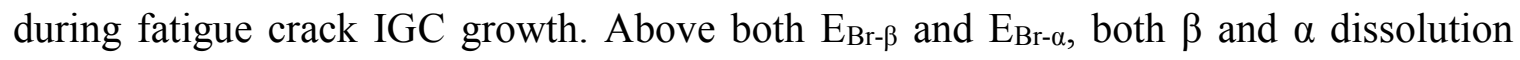
promotes development of an acidic fissure tip solution, causing rapid IGC. When $\mathrm{E}_{\text {tip }}$ is below $\mathrm{E}_{\mathrm{Br}-\alpha}$, but above $\mathrm{E}_{\mathrm{Br}-\beta}\left(-0.900 \mathrm{~V}_{\mathrm{SCE}}\right.$ to $\left.-1.020 \mathrm{~V}_{\mathrm{SCE}}\right)$, IGC growth decreases significantly in the absence of $\alpha$ dissolution. Fatigue crack tip IGC is essentially eliminated 
when $E_{\text {tip }}$ is below both $E_{\mathrm{Br}-\beta}$ and $\mathrm{E}_{\mathrm{Br}-\alpha}$ because dissolution of both phases is limited. The Ohmic drop calculated with orientations B and C indicate a severe drop in potential across the crack tip. Since IGC growth was measured at these applied potentials, these crack tip potential predictions must be flawed. Fortunately the potential drop at the fissure tip during IGC is not essential for this Dissertation. Crack tip potential calculations during IGSCC are more consistent with cracking results, as discussed in Section 3.6.4.2.

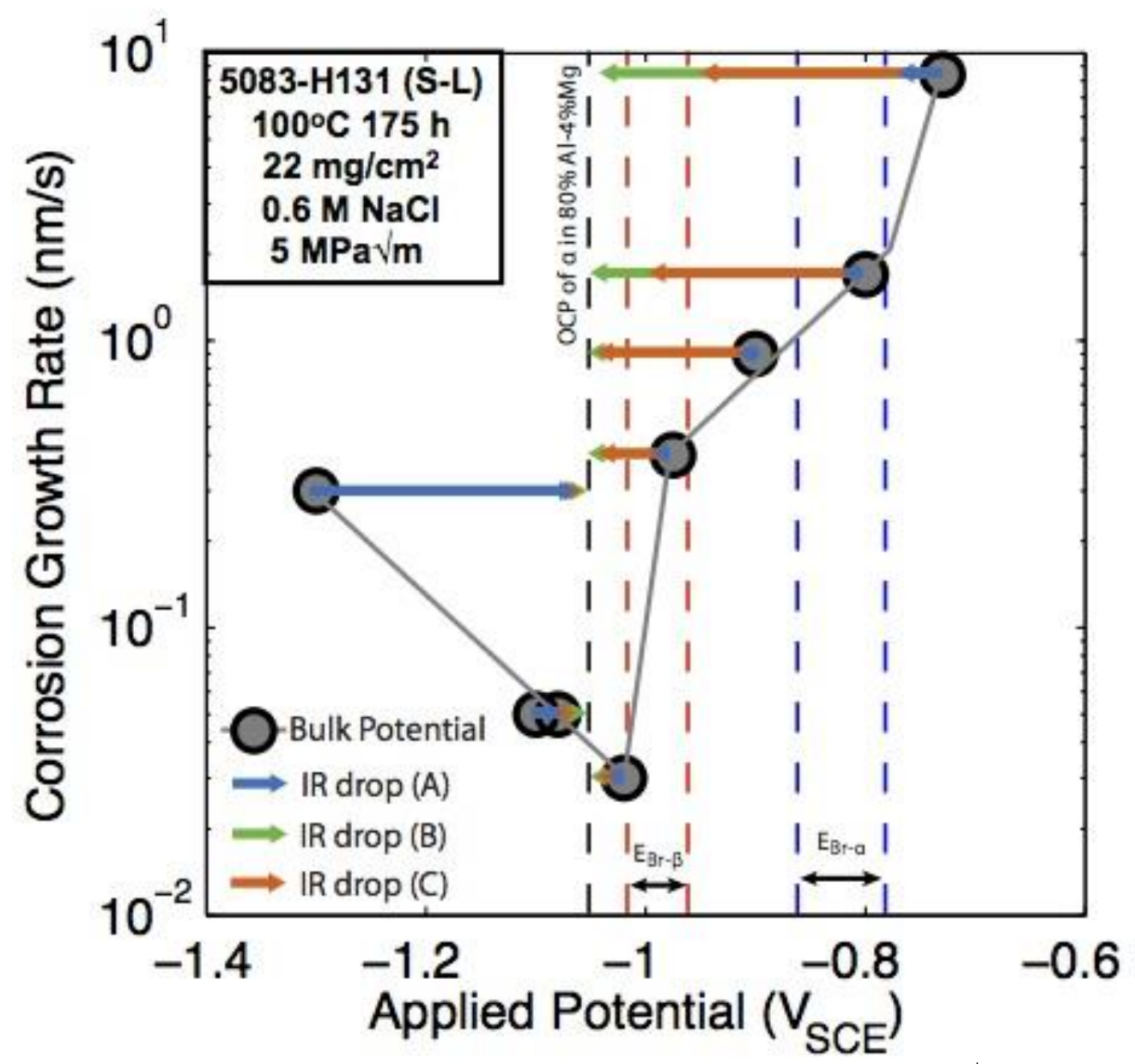

Figure 3.18 The fatigue crack tip corrosion growth rate at $5 \mathrm{MPa} \sqrt{\mathrm{m}}$ in sensitized $\left(22 \mathrm{mg} / \mathrm{cm}^{2}\right)$ 5083-H131 (S-L) in NaCl plotted as a function of applied potential. Arrows represent the Ohmic (IR) drop predicted in the crack tip for the three orientations represented in Fig. 3.16. The $\mathrm{pH}$ sensitive breakdown potentials of $\beta$ and $\alpha$ are shown with dashed lines $[17,18]$. The black dashed line represents the lower limit for fissure tip potential (OCP of $\alpha$ in simulated crack tip solution $[17,18]$ ). 


\subsubsection{4 pH predictions}

The local fissure tip $\mathrm{pH}$ was not measured in 5083, though values can be estimated as a function of tip potential based on the combination of occluded geometry $\mathrm{pH}$ measured at the tip of 7xxx alloys in chloride solution (Fig. 3.19 [22]) scaled with $\mathrm{pH}$ measurements made for bulk $\mathrm{AlCl}_{3} / \mathrm{MgCl}_{2}$ solutions (Fig. 3.20 [28]).

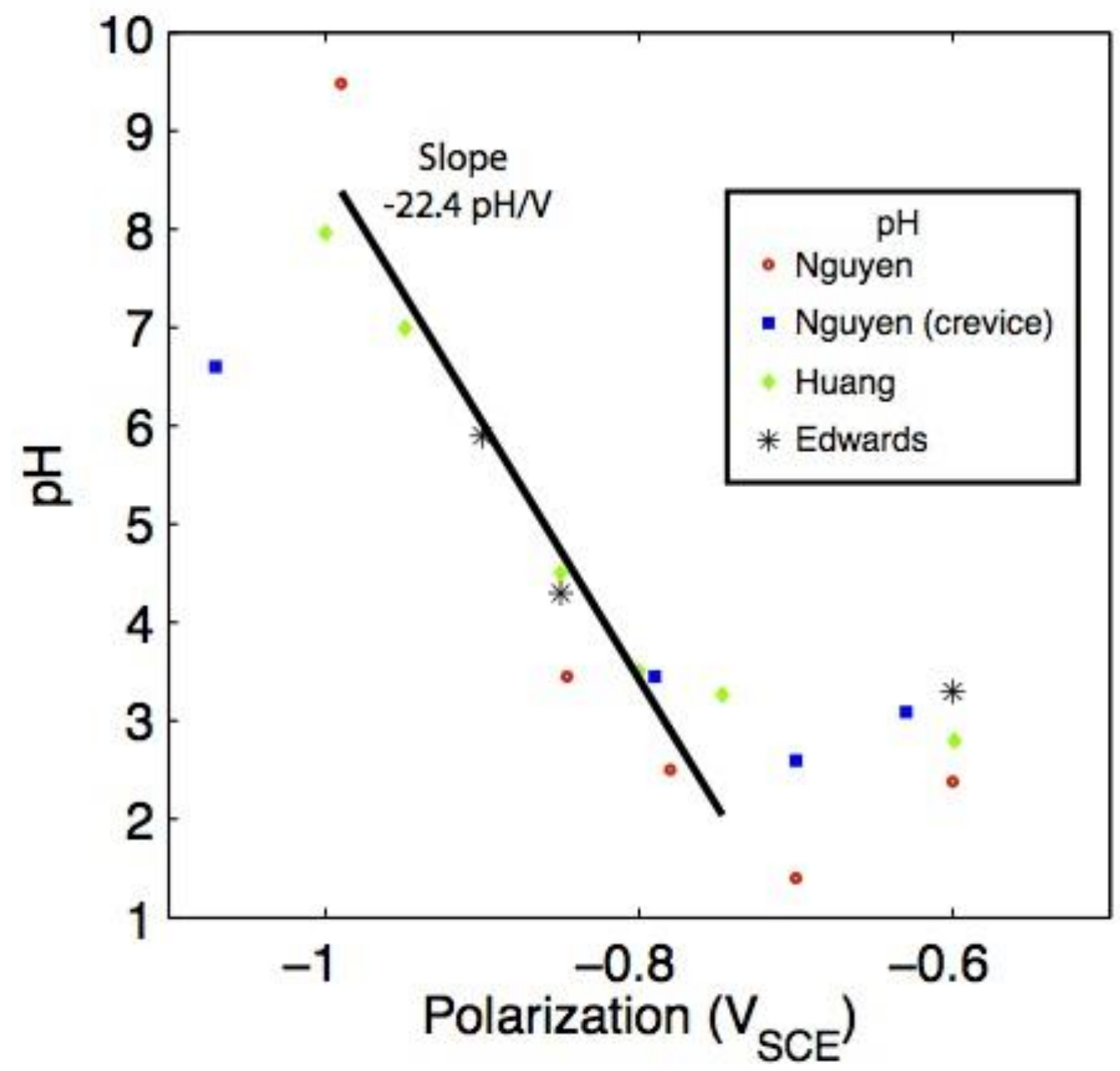

Figure 3.19 Reported potential dependent $\mathrm{pH}$ from literature used to estimate crack tip $\mathrm{pH}$ in this study over the potential range $-1.000 \mathrm{~V}_{\mathrm{SCE}}$ to $-0.730 \mathrm{~V}_{\mathrm{SCE}}$ [22]. The right axis provides the crack growth rate measured in this study as a function of applied potential for reference. 
The localized tip $\mathrm{pH}$ was measured as a function of crack tip potential in several 7xxx alloys exposed to $\mathrm{Cl}^{-}$solution [22]. Specifically in Fig. 3.19, Nguyen showed that when the crack tip was polarized to $-0.700 \mathrm{~V}_{\mathrm{SCE}}$, the 7075 crack tip $\mathrm{pH}$ was 1.5 [22]. When polarized to $-1.000 \mathrm{~V}_{\mathrm{SCE}}, \mathrm{pH}$ increased to 9.4 [22]. These measurements were confirmed by similar results by Huang and Edwards for this potential range [22]. Overall, the rate of fissure tip $\mathrm{pH}$ decrease with potential is estimated using the slope of the trend line in Fig. 3.19 $\left(-22.4 \mathrm{pH} / \mathrm{V}_{\mathrm{SCE}}\right)$ specifically relevant to the potential range of $-0.700 \mathrm{~V}_{\mathrm{SCE}}$ to $-1.000 \mathrm{~V}_{\mathrm{SCE}}[22]$.

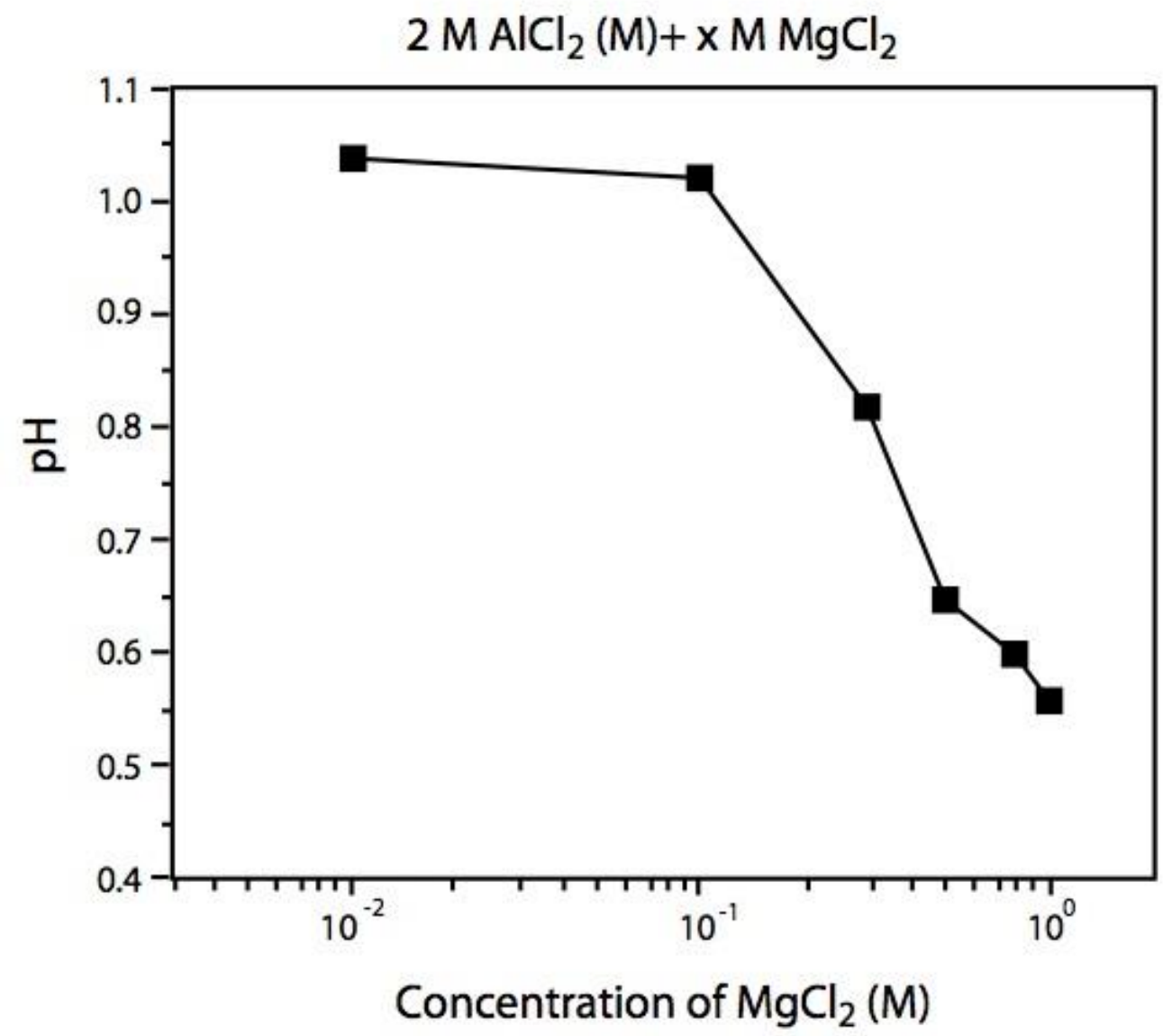

Figure 3.20 The $\mathrm{pH}$ measured in $2 \mathrm{M} \mathrm{AlCl}_{3}$ as a function of $\mathrm{MgCl}_{2}$ addition [28]. 
Measurements of $\mathrm{pH}$ were made for a bulk $2 \mathrm{M} \mathrm{AlCl}_{3}$ solution, with increasing concentration of $\mathrm{MgCl}_{2}$ (Fig. 3.20) [28]. There is a steady-sharp drop in the $\mathrm{pH}$ of $\mathrm{AlCl}_{3}$ solution for $\mathrm{Mg}$ concentrations above $0.1 \mathrm{M}$. These measurements suggest that $\beta$ dissolution, which produces $\mathrm{Mg}^{2+}$ cations, contributes to a substantial decrease in $\mathrm{pH}$ at the fissure tip for 5083. For saturated solutions, stoichiometric dissolution of $\beta\left(\mathrm{Al}_{3} \mathrm{Mg}_{2}\right)$ would result in a $\mathrm{Mg}^{2+}$ concentration of $1.3 \mathrm{M}$, whereas stoichiometric dissolution of the solid solution $\alpha(\mathrm{Al}-4 \% \mathrm{Mg})$ phase would lead to a $\mathrm{Mg}^{2+}$ concentration of $0.14 \mathrm{M}[17,18]$. The fissure solution in sensitized $\left(22 \mathrm{mg} / \mathrm{cm}^{2}\right) 5083-\mathrm{H} 131$ at $-0.730 \mathrm{~V}_{\mathrm{SCE}}$ is expected to be somewhere between these two values, likely near $2 \mathrm{M} \mathrm{AlCl}_{3}$ with additional $\mathrm{Mg}$ concentration due to $\beta$ dissolution (likely about $0.3 \mathrm{M} \mathrm{MgCl}_{2}$ ) [28]. Based on $\mathrm{pH}$ measurements in Fig. 3.20, the $\mathrm{pH}$ at $-0.730 \mathrm{~V}_{\mathrm{SCE}}$ is assumed to be 0.8 units in a sensitized 5083-H131 fissure. With this calibration point, the slope from Fig. 3.19 is used to predict the $\mathrm{pH}$ at each fissure tip potential (using orientation A), results are presented in Table 3.4.

The calculated potential dependent $\mathrm{pH}$ is consistent with the explanation for potential dependent IGC rates. At anodic potentials where both $\alpha$ and $\beta$ dissolution are active, rapid corrosion growth was observed and an acidic fissure is developed $(\mathrm{pH} 1-3)$. The $\mathrm{pH}$ increases to $5-7$, when only $\beta$ dissolution is active, resulting in a drop in IGC growth rates. When passive dissolution of both $\alpha$ and $\beta$ are controlling (potentials below $-1.020 \mathrm{~V}_{\mathrm{SCE}}$ ) the $\mathrm{pH}$ reaches a maximum of 8.2 , resulting in slow to nil IGC growth.

\subsubsection{Effect of fissure tip chemistry on IGC in unsensitized 5083}

The interaction of aluminum corrosion, passivation, occluded-fissure chemistry, and Ohmic difference govern fissure tip environments and rates of IGC in $\mathrm{Al}-\mathrm{Mg}$ without sensitization. Without $\beta$, the chemistry developed relies on $\alpha$ dissolution alone. Three 
questions follow: a) Why is IGC absent at -0.800 VSCE and lower potentials, but measurable at and above $-0.730 V_{S C E}$ ? b) Why is IGC promoted at $-1.000 V_{S C E}$ in acidic $\mathrm{AlCl}_{3} / \mathrm{MgCl}_{2}$ solution? and c) Why is IGC not promoted in alkaline $\mathrm{NaOH}$ solution?

\subsection{The effect of anodic polarization on unsensitized 5083}

Literature has demonstrated the importance of high-rate $\beta$ dissolution to IGC of Al-Mg alloys $[16,44,45]$. Mizuno and Kelly showed that unsensitized 5083-H131 $\left(3 \mathrm{mg} / \mathrm{cm}^{2}\right.$, the same heat as in the present study) did not undergo IGC at bold surface potentials as high as $-0.760 \mathrm{~V}_{\mathrm{SCE}}$ in $0.6 \mathrm{M} \mathrm{NaCl}$, whereas sensitized $5083-\mathrm{H} 131\left(22 \mathrm{mg} / \mathrm{cm}^{2}\right)$ exhibited rapid IGC under the same conditions [44]. Jain showed that the breakdown potential for sensitized 5083 in $0.6 \mathrm{M} \mathrm{NaCl}$ is approximately $-0.7 \mathrm{~V}_{\mathrm{SCE}}$, meaning that stable localized corrosion cannot occur below this potential, although metastable pitting occurs, primarily at constituent particles [56]. It is speculated that the cause of stable IGC in sensitized 5083H131 is derived from the high $\mathrm{Mg}^{2+}$ concentrations (from $\beta$ dissolution). This speculation is supported by the significant drop in $\mathrm{pH}$ with $\mathrm{Mg}$ additions to $2 \mathrm{M} \mathrm{AlCl}_{2}$ solution in Fig. 3.20 [28]. Dissolution of $\beta$ may provide a local burst of low $\mathrm{pH}$ solution, leading to a more aggressive condition within the fissure and thus stabilizing IGC.

For as-received $5083-\mathrm{H} 131\left(3 \mathrm{mg} / \mathrm{cm}^{2}\right)$ in neutral $\mathrm{NaCl}$ solution polarized to $-0.800 \mathrm{~V}_{\mathrm{SCE}}$ and lower, a highly acidic fissure tip environment is likely not developed due to the absence of $\beta$ dissolution and Mg cation hydrolysis; the breakdown potential of $\alpha$ in near-neutral $\mathrm{NaCl}$ is $-0.760 \mathrm{~V}_{\mathrm{SCE}}$ (Table 3.2), meaning passive $\alpha$ dissolution is expected at lower potentials. Low-rate passive $\alpha$ dissolution may mildly acidify the fissure tip, governed by $\mathrm{Al}^{3+}$ production and hydrolysis; however, without $\beta$ dissolution to trigger 
high cation concentration and hydrolysis, the critical acidic level to promote $\alpha$ dissolution is likely neither achieved nor sustained.

Unsensitized $5083-\mathrm{H} 131\left(3 \mathrm{mg} / \mathrm{cm}^{2}\right)$ is resistant to IGC in $\mathrm{NaCl}$ at $-0.800 \mathrm{VSCE}$, as verified by the very slow growth measured for an (S-L) fatigue crack tip (Figs. 3.7 and 3.8). The modeled rate for IGC in $\mathrm{NaCl}$ at $-0.800 \mathrm{~V}_{\mathrm{SCE}}(0.6 \mathrm{~nm} / \mathrm{s}[17,18])$ is 20-times higher than that measured $(0.03 \mathrm{~nm} / \mathrm{s})$ in a fatigue crack (Table 3.5). The model prediction likely over estimates the fatigue crack IGC rate because it assumes a highly acidic occluded tip $[17,18]$, which may not be established in this environment-microstructure condition. For as-received 5083-H131 at $-1.020 \mathrm{~V}_{\mathrm{SCE}}$, modeled rates are much slower than that measured from a fatigue crack at the same potential. Modeled rates are also significantly lower than the fatigue crack corrosion rates for cathodically polarized, sensitized 5083H131 (Table 3.5). During cathodic polarization, the fissure tip tends to become alkaline, due to cathodic hydroxyl production (Fig. 3.19 [22]). At high $\mathrm{pH}$, low rates of cathodic corrosion, rather than IGC, may occur increasing the measured rate above that predicted. The measured rates for $-0.800 \mathrm{~V}_{\mathrm{SCE}}$ and $-1.020 \mathrm{~V}_{\mathrm{SCE}}$ are above the resolution limit $(0.004 \mathrm{~nm} / \mathrm{s})$, but the exact level of measured da/dt for IGC/corrosion is challenging to quantify with the dcPD method.

For potentials at and above $-0.730 \mathrm{~V}_{\mathrm{SCE}}{ }^{5}$, IGC was measured as fast as $3.6 \mathrm{~nm} / \mathrm{s}$ in the fatigue crack of $\beta$-free 5083, which is only 2 times lower than growth rates measured for sensitized 5083-H131 (22 mg/cm²) at the same potential. Rates modeled by Bumiller are within the same range, suggesting IGC measured at the fatigue crack is real

5 The malfunctioning potentiostat may not have held the potential at $-0.730 \mathrm{~V}_{\text {SCE }}$. Very small anodic applied currents were recorded, yet the exact applied potential is not known. 
(Table $3.5[17,18]$ ). Since growth in $\beta$-free 5083 is due to $\alpha$ dissolution, the solution developed at the fissure tip could be close to the $\mathrm{Al}-4 \% \mathrm{Mg}$ solution from stoichiometric dissolution of $\alpha$, predicted in a sensitized 5083-H116 fissure tip [17], though a lower $\mathrm{Mg}$ concentration is expected in the $\beta$-free case. Two conclusions can be made: (a) a role of $\beta$ is evident since corrosion growth rates are faster in sensitized 5083-H131 at the same potential, and (b) significant growth in $\beta$-free 5083-H131 is possible with anodic polarization, likely due to the development of a highly acidic $\mathrm{AlCl}_{3} / \mathrm{MgCl}_{2}$ simulated crack tip solution.

Table 3.5 Measured and modeled IGC rates in unsensitized 5083-H131.

\begin{tabular}{|c|c|c|c|}
\hline Electrolyte & $\mathrm{E}_{\mathrm{app}}\left(\mathrm{V}_{\mathrm{SCE}}\right)$ & $\begin{array}{l}\text { Fatigue Crack IGC Rates } \\
\text { Fig. } 3.4(\mathrm{~nm} / \mathrm{s})\end{array}$ & $\begin{array}{c}\text { Predicted Rates } \% \\
(\mathrm{~nm} / \mathrm{s})\end{array}$ \\
\hline $0.6 \mathrm{M} \mathrm{NaCl}$ & -0.730 & 3.6 & 2.0 \\
\hline $0.6 \mathrm{M} \mathrm{NaCl}$ & -0.800 & 0.03 & 0.6 \\
\hline $0.6 \mathrm{M} \mathrm{NaCl}$ & -1.020 & 0.06 & $<0.00008$ \\
\hline $\mathrm{Al}-4 \% \mathrm{Mg}$ & -1.000 & $1.4,5.2^{*}$ & $<0.00008$ \\
\hline $0.01 \mathrm{M} \mathrm{NaOH}$ & -1.800 & 0.6 & -- \\
\hline $0.01 \mathrm{M} \mathrm{NaOH}$ & $\mathrm{OCP}^{* *}$ & 0.5 & -- \\
\hline \multicolumn{4}{|c|}{$\begin{array}{l}{ }^{*} \text { Duplicate experiments } \\
\text { \% Modeled growth rates reported by }[17,18] \\
{ }^{* *} \text { OCP is near }-1.37 \mathrm{~V}_{\mathrm{SCE}}\end{array}$} \\
\hline
\end{tabular}

The predicted fissure tip potentials and associated $\mathrm{pH}$ for unsensitized 5083-H131 calculated with Eqn. 3.1 are given in Table 3.6. The $\mathrm{pH}$ was calibrated with measured $\mathrm{pH}$ in $\mathrm{AlCl}_{3}$ without $\mathrm{MgCl}_{2}$ addition (Fig. 3.20). When the fissure tip potential is $-0.730 \mathrm{~V}_{\mathrm{SCE}}$ the $\mathrm{pH}$ is expected to be 1.1 units. These values confirm potential dependence of IGC in 
unsensitized 5083-H131 discussed above, and will be used in the following sections to explain the role of solution composition on IGC rates.

Table 3.6 The predicted fissure $\mathrm{pH}$ and tip potentials for unsensitized 5083-H131 at K of $5 \mathrm{MPa} \sqrt{\mathrm{m}}$ with the three orientations provided in Fig. 3.16.

\begin{tabular}{|c|c|c|c|c|c|}
\hline \multirow[t]{2}{*}{ Solution } & \multirow{2}{*}{$\begin{array}{l}\mathrm{E}_{\mathrm{app}} \\
\left(\mathrm{V}_{\mathrm{SCE}}\right)\end{array}$} & $\begin{array}{l}\text { Orientation } \\
\text { A }\end{array}$ & $\begin{array}{l}\text { Orientation } \\
\mathrm{B}\end{array}$ & $\begin{array}{l}\text { Orientation } \\
\mathrm{C}\end{array}$ & $\begin{array}{l}\text { Orientation } \\
\text { A }\end{array}$ \\
\hline & & $E_{\text {tip }}\left(V_{\mathrm{SCE}}\right)$ & $\mathrm{E}_{\text {tip }}\left(\mathrm{V}_{\mathrm{SCE}}\right)$ & $\mathrm{E}_{\text {tip }}\left(\mathrm{V}_{\mathrm{SCE}}\right)$ & Tip $\mathrm{pH}$ \\
\hline $0.6 \mathrm{M} \mathrm{NaCl}$ & -0.730 & -0.750 & -0.940 & -1.013 & 1.65 \\
\hline $0.6 \mathrm{M} \mathrm{NaCl}$ & -0.800 & -0.810 & -0.990 & -1.050 & 2.93 \\
\hline $0.6 \mathrm{M} \mathrm{NaCl}$ & -1.020 & -1.030 & -1.050 & -1.050 & 7.86 \\
\hline $\mathrm{Al}-4 \% \mathrm{Mg}$ & -1.000 & -1.020 & -1.050 & -1.050 & 4.00 \\
\hline $0.01 \mathrm{M} \mathrm{NaOH}^{\%}$ & -1.800 & -1.200 & -- & -- & 10.0 \\
\hline $0.01 \mathrm{M} \mathrm{NaOH}^{\%}$ & $\mathrm{OCP}^{* *}$ & -1.200 & -- & -- & 10.0 \\
\hline
\end{tabular}

\subsection{Rapid IGC growth in unsensitized 5083 in acidic $\mathrm{AICl}_{3} / \mathrm{MgCl}_{2}$}

To experimentally recreate a highly acidic $\mathrm{pH}$ fissure tip environment in the absence of $\beta$ at the grain boundaries, unsensitized 5083-H131 $\left(3 \mathrm{mg} / \mathrm{cm}^{2}\right)$ was exposed to a solution that mimics the fissure tip solution expected in sensitized 5083-H131 [17,18]. Even with cathodic polarization $\left(-1.000 \mathrm{~V}_{\mathrm{SCE}}\right)$, the fissure tip $\mathrm{pH}$ remained low with a high concentration of $\mathrm{Cl}^{-}$, leading to IGC in $\beta$-free $5083-\mathrm{H} 131$. Cathodic polarization tends to promote an alkaline fissure environment due to the strong over-potential for water reduction and hydroxyl production. At about $\mathrm{pH} 4$, corrosion products such as $\mathrm{Al}(\mathrm{OH})_{3}$ and $\mathrm{Al}(\mathrm{OH})_{2} \mathrm{Cl}$ are least soluble and precipitate on crack flanks $[23,57]$. The fissure tip solution will tend toward an equilibrium $\mathrm{pH}$ 4-5 set by solubility considerations independent of the applied potential [57]. For the predicted $\mathrm{E}_{\text {tip }}\left(-1.020 \mathrm{~V}_{\mathrm{SCE}}\right)$ at $\mathrm{pH}$ of 4 , 
$\mathrm{Al}$ is thermodynamically passive in water [48]; though high $\mathrm{Cl}^{-}(9 \mathrm{M}$ to $10 \mathrm{M})$ at the tip may compromise the $\mathrm{Al}$ passive film $\left(\mathrm{Al}_{2} \mathrm{O}_{3}\right)$ promoting $\mathrm{Al}$ dissolution $[17,18,57]$. The unstressed IGC model prediction under the same conditions (as-received 5083-H131 in $\mathrm{AlCl}_{3} / \mathrm{MgCl}_{2}$ cathodically polarized to $\left.-1.000 \mathrm{~V}_{\mathrm{SCE}}[17,18]\right)$ is at odds with the measuredsignificant IGC rate (Table 3.5). The model predicts slow IGC penetration because the applied potential is below $\mathrm{E}_{\mathrm{Br}-\alpha}$ in acidic fissure solution $\left(-0.870 \mathrm{~V}_{\mathrm{SCE}}\right.$ from Table 3.2 $)^{6}[17,18]$. The occluded nature of the fissure that develops at the fatigue crack tip likely differs significantly from the highly acidic $(\mathrm{pH}-0.4)$ model predicted environment. Analysis with SEM showed extensive corrosion of the crack flanks, perpendicular to the direction of crack growth for one specimen (growth rate of $1.4 \mathrm{~nm} / \mathrm{s}$ in Fig. 3.7), and extensive corrosion of the specimen surface at the notch mouth for a second specimen (growth rate of $5.2 \mathrm{~nm} / \mathrm{s}$ in Fig. 3.7). This corrosion is likely associated with high $\mathrm{pH}(10-12)$ on areas of the bold surface and near-mouth flanks where cathodic polarization produced very high $\mathrm{OH}^{-}$concentration promoting cathodic corrosion. As such, the measured dcPD rate during the hold period for unsensitized 5083- $\mathrm{H} 131$ in $\mathrm{AlCl}_{3} / \mathrm{MgCl}_{2}$ at $-1.000 \mathrm{~V}_{\mathrm{SCE}}$ (Fig. 3.8 and Table 3.5) is likely due to flank/mouth corrosion rather than fatigue crack tip IGC. This extensive cathodic corrosion, and associated false indication of IGC, were not observed for 5083-H131 exposed to either neutral $\mathrm{NaCl}$ or alkaline $\mathrm{NaOH}$

6 The open circuit potential of unsensitized $5083-\mathrm{H} 131$ in $80 \%$ saturated $\mathrm{Al}-4 \mathrm{wt} \% \mathrm{Mg}$ simulated fissure tip solution is very close to $-0.870 \mathrm{~V}_{\mathrm{SCE}}$ (the breakdown potential of $\alpha$ in saturated $\mathrm{Al}-4 \% \mathrm{Mg}$ simulated fissure tip solution). Polarization scans were concluded before the breakdown potential of unsensitized 5083-H131. The anodic polarization curve follows that of $\alpha$ (Fig. 3.14) above $-0.870 \mathrm{~V}_{\mathrm{SCE}}$ in saturated Al- $4 \mathrm{wt} \% \mathrm{Mg}$ simulated crack tip solution $[17,18]$. 
solutions with cathodic polarization, suggesting that such corrosion is exacerbated by the high $\mathrm{Cl}^{-}$content associated with the simulated fissure solution.

\subsection{Intergranular corrosion resistance in alkaline environments}

The expected fissure chemistry developed during exposure of as-received 5083-H131 to highly alkaline $\mathrm{NaOH}$ solution at either OCP $\left(-1.370 \mathrm{~V}_{\mathrm{SCE}}\right)$ or polarized to $-1.800 \mathrm{~V}_{\mathrm{SCE}}$ qualitatively explains the measured rates of IGC plotted in Fig. $3.8(0.5 \mathrm{~nm} / \mathrm{s}$ and $0.6 \mathrm{~nm} / \mathrm{s}$, respectively). Though speculative, the predicted fissure chemistry developed during exposure of as-received 5083-H131 to highly alkaline $\mathrm{NaOH}$ solution qualitatively explains the measured rates of IGC. The fissure tip chemistry developed at both OCP $\left(-1.37 \mathrm{~V}_{\mathrm{SCE}}\right)$ and polarized to $-1.800 \mathrm{~V}_{\mathrm{SCE}}$ in $\mathrm{NaOH}$ may be isolated from the bulk solution due to occluding corrosion product precipitation along the flanks of the fatigue crack. Precipitation of aluminum hydroxide gel $\left(\mathrm{Al}(\mathrm{OH})_{3}\right)$ in the crack may constrain all cathodic and anodic reactions to the tip. The isolated fissure solution $\mathrm{pH}$ would tend toward 10-10.5 based on the equilibrium hydrolysis reactions [28]. The OCP of unsensitized 5083-H131 in $\mathrm{NaOH}$ at this $\mathrm{pH}$ increases to $-1.200 \mathrm{~V}_{\mathrm{SCE}}$ [28]. Considering cathodic polarization to $-1.800 \mathrm{~V}_{\mathrm{SCE}}$, a similar-isolated fissure tip $\mathrm{pH}$ of $10-10.5$ is likely, though the tip potential may be polarized below the OCP of $-1.200 \mathrm{~V}_{\text {SCE }}$. If $\mathrm{H}_{2}$ bubbles are present in the crack under these conditions (which would be reasonable given the expected high overpotential for $\mathrm{H}$ production at this $\mathrm{pH}$ ), then the Ohmic resistance within the crack may increase and the fissure tip potential could tend toward the OCP of $-1.200 \mathrm{~V}_{\mathrm{SCE}}$.

Corrosion growth rates in $\mathrm{NaOH}$ are low, though they are on the order measured during cathodic polarization in $\mathrm{NaCl}$; therefore, growth rates may be due to cathodic corrosion, 
rather than IGC. Unfortunately, fracture surfaces were covered with corrosion product debris, which precluded characterization of the corrosion process (Fig. 3.12).

\subsubsection{Fracture process zone hydrogen embrittlement controlled IGSCC}

In contrast to IGC, IGSCC propagation in a discontinuous $\beta$ microstructure relies on $\mathrm{H}$ embrittlement of $\alpha$ grain boundaries. Crack tip dissolution kinetics are important for setting local $\mathrm{pH}$ and potential, but crack advance requires an additional damage mechanism: $\mathrm{H}$ embrittlement. The connection between crack electrochemistry and IGSCC kinetics is based on the view that da/dt is controlled by the stress enhanced concentration of $\mathrm{H}$ introduced to the fracture process zone (FPZ), $\mathrm{C}_{\mathrm{H} \sigma}$. This concentration is supplied by the localized $\mathrm{H}$ concentration $\left(\mathrm{C}_{\mathrm{s}}\right)$ produced at the crack tip surface, which is in equilibrium with the potential and $\mathrm{pH}$ controlled overpotential for $\mathrm{H}$ production $\left(\eta_{\mathrm{H}}\right)^{7}$. A negative $\eta_{\mathrm{H}}$ indicates net $\mathrm{H}$ production. As the magnitude of $\eta_{\mathrm{H}}$ increases, the associated solubility of $\mathrm{H}$ will tend to increase, leading to a higher concentration of diffusible $\mathrm{H}$ at the FPZ ahead of the crack tip surface $[52,58]$ (The precise solubility will vary with solution $\mathrm{pH}$ and perhaps ionic composition [52]). Grain boundary decohesion initiates at a critical distance ahead of the crack tip ( $\mathrm{x}_{\mathrm{CRIT}}$ ), where the maximum hydrostatic stress exceeds the grain boundary decohesive strength, which is lowered by a critical concentration of $\mathrm{H}$ ( $\mathrm{C}_{\mathrm{H}-\mathrm{crit}}$ ) [59]. The combination of high $\mathrm{H}$ concentration and stress ahead of the crack tip provides the driving force for $\mathrm{H}$ embrittlement of the $\alpha$ grain boundary. A variety of solutions to the crack tip diffusion problem show that $\mathrm{H}$-diffusion rate limited $\mathrm{da} / \mathrm{dt}$ is related to the ratio of $\mathrm{C}_{\mathrm{H \sigma}}$ and $\mathrm{C}_{\mathrm{H}-\text { crit, }}$ as given by this relationship [60]:

${ }^{7}$ Hydrogen overpotential is defined as $\eta_{\mathrm{H}}=\mathrm{E}-\mathrm{E}_{\mathrm{H} / \mathrm{H}^{+}}<0$. 


$$
\frac{d a}{d t_{I I}}=\frac{4 D_{H-E F F}}{x_{c r i t}}\left[\operatorname{erf}^{-1}\left(1-\frac{C_{H-c r i t}}{C_{H \sigma}}\right)\right]^{2}
$$

In this formulation, $\mathrm{D}_{\mathrm{H}-\mathrm{EFF}}$ is the trap-sensitive $\mathrm{H}$ diffusivity and $\mathrm{C}_{\mathrm{H} \sigma}$ is given as a function of $\mathrm{C}_{\mathrm{s}}$ below. The formulation of Eqn. 3.2 is based on discontinuous cracking, where the fracture distance is described by $\mathrm{x}_{\mathrm{CRIT}}$, and the fracture time is dependent on the time for $\mathrm{H}$ to diffuse to XCRIT. The relevant trap-affected $\mathrm{D}_{\mathrm{H}-\mathrm{EFF}}$ measured on the same heat of 5083$\mathrm{H} 131$ used in the present study is $1.3 \times 10^{-10} \mathrm{~cm}^{2} / \mathrm{s}$ at $23^{\circ} \mathrm{C}$, independent of DoS and sample thickness [46]. Faster values of $\mathrm{H}$ diffusivity, tending toward $10^{-8} \mathrm{~cm}^{2} / \mathrm{s}$ or $10^{-7} \mathrm{~cm}^{2} / \mathrm{s}$. are possible, as discussed in Chapter $4[38,46]$. Extensive results establish that $\mathrm{x}_{\mathrm{CRIT}}$ is $0.9 \mu \mathrm{m}$ for HEAC in a wide variety of alloys. Applied stress intensity, alloy flow properties, and microstructure establish the local-tensile stress that inversely affects $\mathrm{C}_{\mathrm{H} \text {-crit, }}$ as detailed in Chapter 2 for $\beta$-populated Al-Mg grain boundaries.

Hydrogen uptake occurs following electrochemical $\mathrm{H}$ production by water and proton reduction on the Al surface [38]. Uptake into the microstructure can be limited by: (a) species diffusion to the $\mathrm{Al}$ surface, (b) surface reaction rates to produce atomic $\mathrm{H}$ from water or $\mathrm{H}^{+}$, or (c) diffusion through the surface oxide and into the metal [38]. In Al-Mg alloys both an $\mathrm{Al}_{2} \mathrm{O}_{3}$ and $\mathrm{MgO}$ film may be developed at the crack tip. The protective $\mathrm{Al}_{2} \mathrm{O}_{3}$ passive film offers $\mathrm{H}$ uptake resistance, as it limits the water reaction with $\mathrm{Al}$, yet a $\mathrm{MgO}$ film, may not provide the same protection [38]. In this work, where high $\mathrm{Cl}^{-}$concentrations likely compromise both passive films, crack growth rates in Al-Mg are assumed to be $\mathrm{H}$ diffusion limited rather than surface reaction rate limited.

The other limitation to $\mathrm{H}$ uptake involves $\mathrm{H}$ solubility in Al. Although $\mathrm{Al}$ has a much smaller perfect lattice solubility than other FCC alloys, the "apparent" solubility is often much higher owing to $\mathrm{H}$ localization at trap sites such as grain boundaries, precipitate 
interfaces and dislocations. Alloying additions also may increase the solubility of $\mathrm{H}$. Magnesium, in particular, may increase $\mathrm{H}$ solubility over pure $\mathrm{Al}$ due to (a) high affinity for $\mathrm{H}$, and (b) trapping at $\mathrm{Mg}$-rich precipitates [38]. For a Ni alloy (Monel K-500) in $\mathrm{NaCl}$ at $\mathrm{pH} 7$ the concentration of diffusible $\mathrm{H}\left(\mathrm{C}_{\mathrm{H}-\mathrm{Diff}}\right)$ increases as the magnitude of $\eta_{\mathrm{H}}$ increases (Fig. 3.21a) [61]. Environment $\mathrm{pH}$ also influences $\mathrm{C}_{\mathrm{H}-\mathrm{Diff}}$, as illustrated by a study of an ultra-high strength martensitic stainless steel (AerMet 100) immersed in a borate buffered electrolyte (Fig. 3.21b) [52]; the relationship between $\mathrm{C}_{\mathrm{H}-\mathrm{Diff}}$ and $\eta_{\mathrm{H}}$ is highly dependent

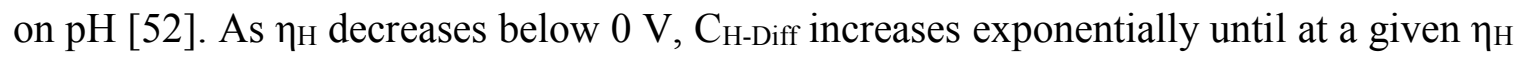
$(-0.3 \mathrm{~V}$ to $-0.4 \mathrm{~V})$ where $\mathrm{C}_{\mathrm{H}-\mathrm{Diff}}$ plateaus for high $\eta_{\mathrm{H}}$ [52]. Figure $3.21 \mathrm{~b}$ shows that for any $\eta_{\mathrm{H}}$ below $0 \mathrm{~V}, \mathrm{H}$ solubility is relatively low and similar for $\mathrm{pH}$ between 6 and 10, though the rising and plateau regions are still observed [52]. As $\mathrm{pH}$ falls from 6 to 2, a dramatic increase in $\mathrm{H}$ solubility is observed for all $\eta_{\mathrm{H}}$ below $0 \mathrm{~V}$ [52]. Results of this study indicated that $\mathrm{Cl}^{-}$did not have a significant effect on $\mathrm{H}$ uptake [52]. The relationship between $\eta_{\mathrm{H}}$ and $\mathrm{H}$ solubility $\left(\mathrm{C}_{\mathrm{s}}\right.$ or $\left.\mathrm{C}_{\mathrm{H}-\mathrm{Diff}}\right)$ in $\mathrm{Al}$ or $\mathrm{Al}$ alloys is not reported in the literature.

The following discussion focuses on explaining IGSCC in 5083-H131 (S-L) for: (a) a sensitized condition $\left(22 \mathrm{mg} / \mathrm{cm}^{2}\right)$ as a function of applied polarization, and (b) the asreceived condition $\left(3 \mathrm{mg} / \mathrm{cm}^{2}\right)$ as a function of bulk-solution environment, using the $\mathrm{H}$ diffusion limited model in Eqn. 3.2, with an emphasis on how crack tip chemistry influences $\mathrm{C}_{\mathrm{H} \sigma}$. The flow chart in Fig. 3.22 demonstrates the $\mathrm{C}_{\mathrm{H} \sigma}$ dependence on crack tip chemistry. The $\mathrm{E}_{\mathrm{app}}$ influences both the Ohmic drop controlled $\mathrm{E}_{\text {tip }}$ and crack tip $\mathrm{pH}$, as developed for IGC fissures in Section 3.6.2.1. Next, using $E_{t i p}$ and tip $\mathrm{pH}, \eta_{\mathrm{H}}$ is calculated in Section 3.6.4.2. The $\eta_{\mathrm{H}}$ and $\mathrm{pH}$ are assumed to control the concentration of soluble $\mathrm{H}$ 
a)

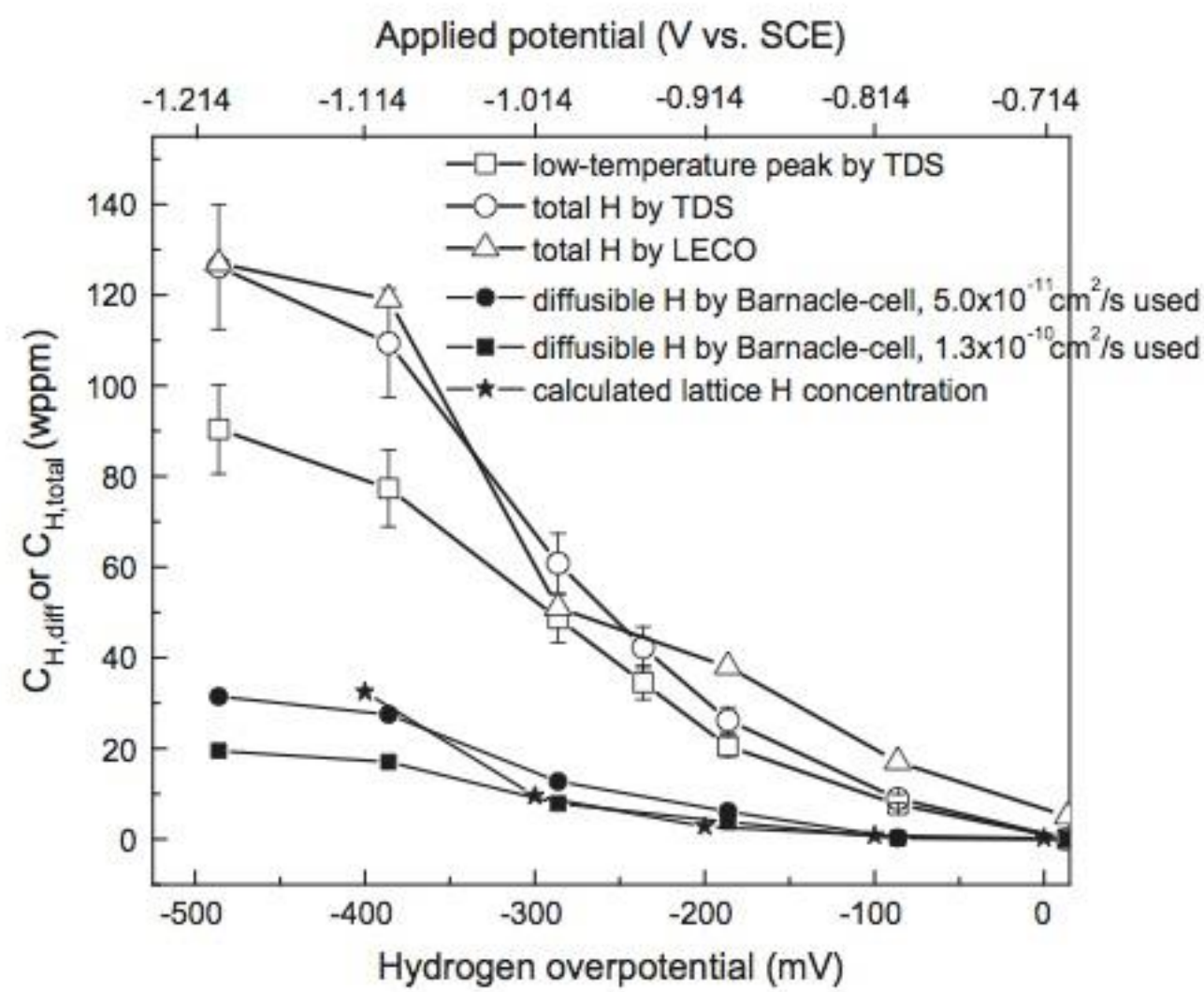

b)

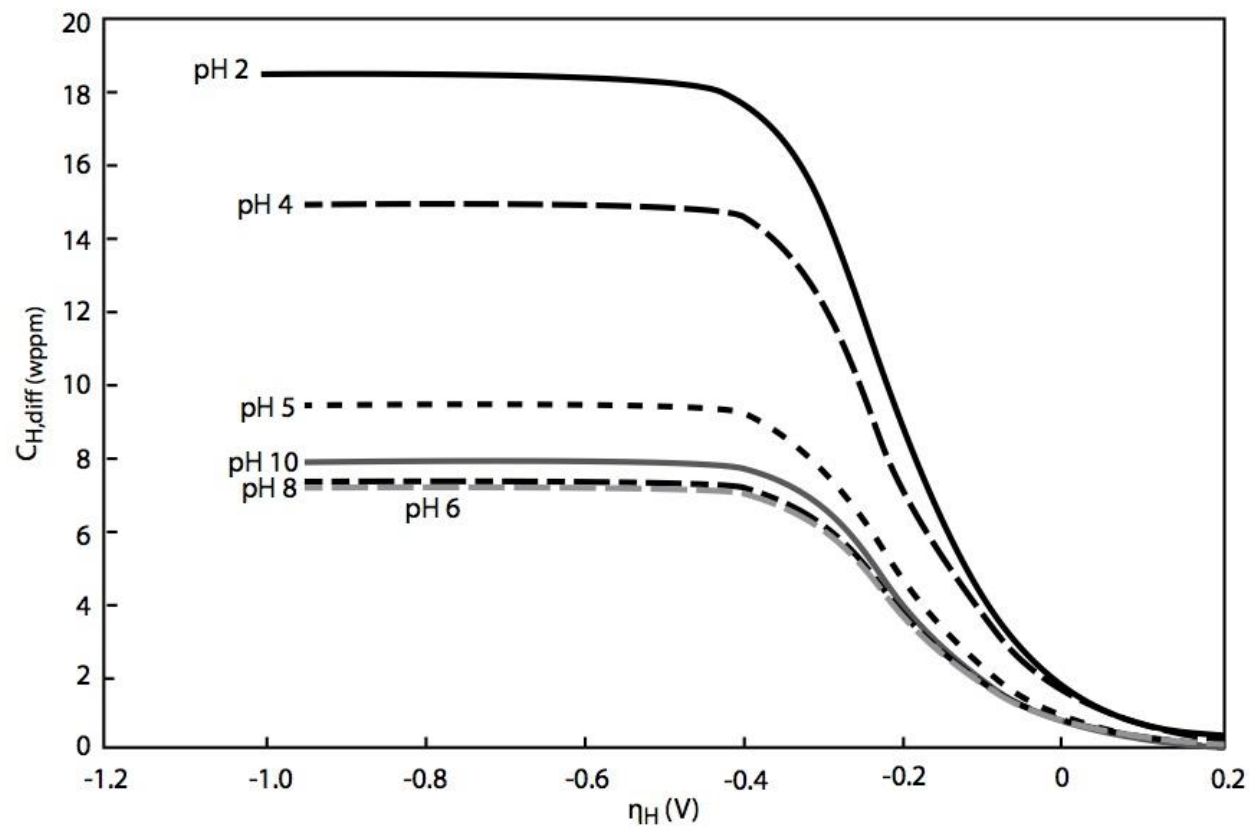

Figure 3.21 $\mathrm{C}_{\mathrm{H}-\mathrm{Diff}}$ as a function of $\eta_{\mathrm{H}}$ for a: a) $\mathrm{Ni}$ alloy (Monel K-500) in $\mathrm{NaCl}$ at $\mathrm{pH}$

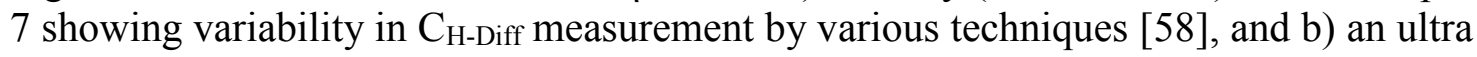
high strength martensitic steel AerMet 100 immersed in borate buffered chloride-free electrolyte, showing how $\mathrm{H}$ solubility differs with $\mathrm{pH}$ [52]. 

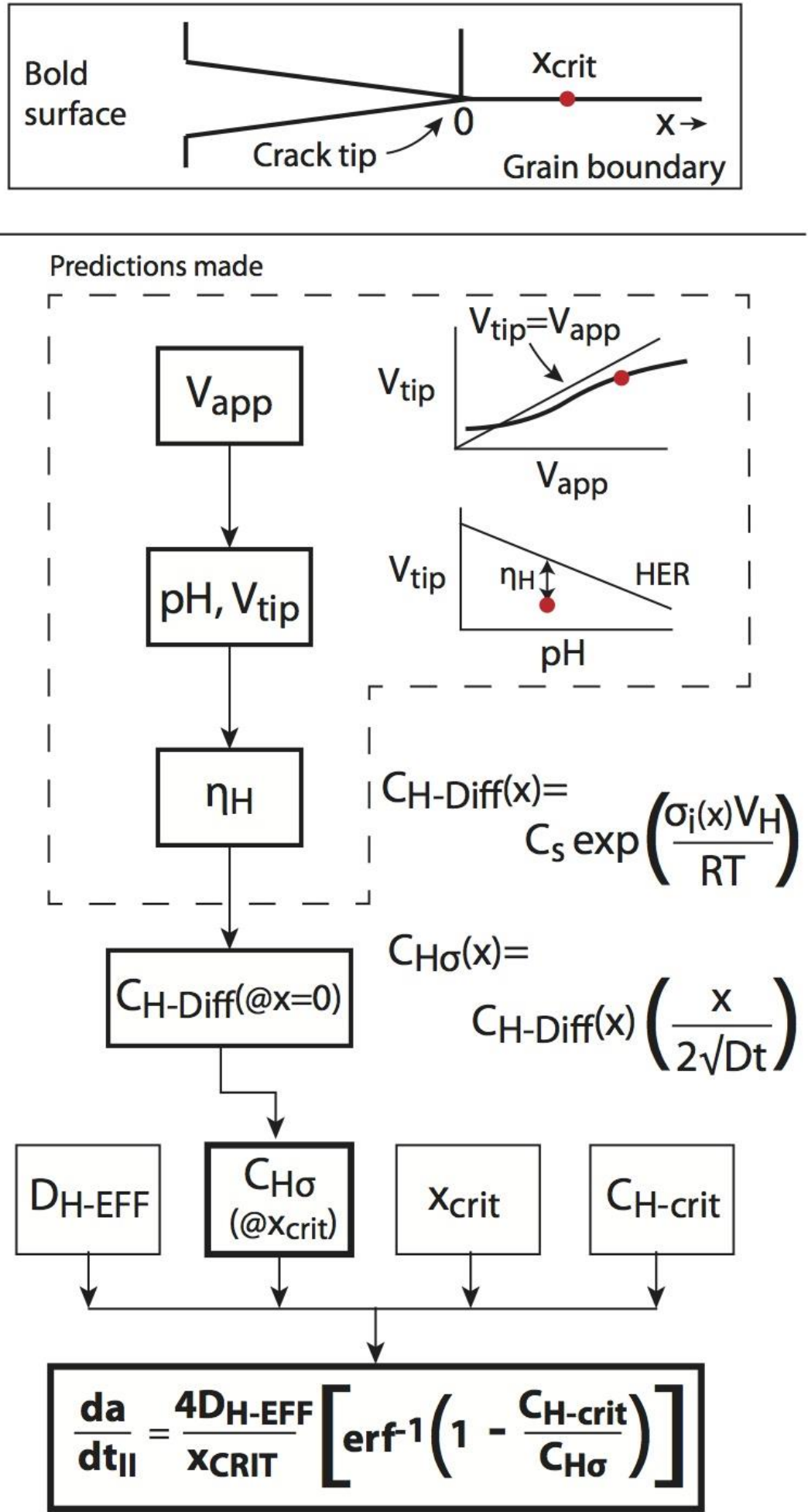

Figure 3.22 Flow chart demonstrating how applied potential-dependent crack tip chemistry influences crack growth rate. 
that enters the lattice, $\mathrm{C}_{\mathrm{s}}$, at the crack tip surface $(\mathrm{x}=0)$. The $\mathrm{H}$ diffusion profile into the FPZ $\left(\mathrm{C}_{\mathrm{H \sigma}}(\mathrm{x})\right)$ is controlled by gradients in the crack tip $\mathrm{H}$ concentration and the crack tip hydrostatic stress profile by [30]:

$$
C_{H \sigma}(x)=C_{H-D i f f}(x)\left[1-\operatorname{erf}\left(\frac{x}{\sqrt{4 D_{H-E F F} t}}\right)\right]
$$

where $\mathrm{x}$ is distance ahead of the crack tip, $\mathrm{t}$ is the time for diffusion, and $\mathrm{C}_{\mathrm{H} \text {-Diff }}$ is defined at a position $\mathrm{x}$ ahead of the crack tip by [62]:

$$
C_{H-D i f f}(x)=C_{L} \exp \left(\frac{\sigma_{i}(x) V_{H}}{R T}\right)
$$

where $\sigma_{\mathrm{i}}$ is the crack tip hydrostatic stress at $\mathrm{x}, \mathrm{V}_{\mathrm{H}}$ is the partial molar volume of $\mathrm{H}$ in $\mathrm{Al}$, $\mathrm{R}$ is the ideal gas constant, and $\mathrm{T}$ is the absolute temperature. At $\mathrm{x}_{\mathrm{CRIT}}$, when $\mathrm{C}_{\mathrm{H \sigma}}$ equals $\mathrm{C}_{\mathrm{H} \text {-crit }}$ the crack will extend a distance $\left(\mathrm{x}=\mathrm{x}_{\mathrm{CRIT}}\right)$ after $\mathrm{t}=\Delta \mathrm{t}$. Section 3.6 .4 focuses on the crack tip chemistry control of da/dt $\mathrm{dI}_{\text {II }}$, based on estimated values of tip $\mathrm{pH}, \mathrm{E}_{\mathrm{tip}}$, and $\eta_{\mathrm{H}}$.

\subsubsection{Intergranular SCC as a function of applied potential in sensitized 5083}

Present results show that highly IGSCC susceptible sensitized 5083-H131 becomes resistant to IGSCC when $\beta$ dissolution is limited by applied cathodic polarization. Measured Stage II crack growth rates for sensitized 5083-H131 (S-L, DoS of $22 \mathrm{mg} / \mathrm{cm}^{2}$ at $\mathrm{K}$ of $15 \mathrm{MPa} \sqrt{\mathrm{m}}$ ) in near neutral $\mathrm{NaCl}$ are reduced by four orders of magnitude or more with decreasing applied potential from $-0.730 \mathrm{~V}_{\mathrm{SCE}}$ to $-1.300 \mathrm{~V}_{\mathrm{SCE}}$ as shown in Fig. 3.6. The essential roles of $\alpha$ and $\beta$ dissolution in rapid IGSCC are suggested by crack growth rates, which: a) slowed rapidly once $\alpha$ dissolution was limited with polarization below $\mathrm{E}_{\mathrm{Br}-\alpha}$, and $\mathrm{b}$ ) dropped to the da/dt resolution limit once $\beta$ dissolution was limited with polarization below $\mathrm{E}_{\mathrm{Br}-\beta}$. This qualitatively validates the proposed-central role of $\alpha$ and $\beta$ 
dissolution as necessary for crack tip acidification and IGSCC by severe hydrogen embrittlement. These cracking kinetics are likely quantitatively controlled by crack tip $\mathrm{pH}$ and potential which is limited by Ohmic drop in the occluded crack. Section 3.6.4.1 will review literature on potential dependent IGSCC in Al-Mg alloys [13]. Then, using the Ohmic drop calculation developed in Eqn. 3.1 and the discussion on IGC rates, a quantitative calculation of crack tip potential and associated $\mathrm{pH}$ is suggested based on geometry, crack tip current density, and solution conductivity (Section 3.6.4.2). Crack tip chemistry predictions may provide a semi-qualitative means to validate the $\mathrm{H}$ diffusion limited HEAC model for Al-Mg alloys, as discussed in Section 3.6.4.3.

\subsubsection{Applied potential dependent IGSCC in the literature}

Previous work established the importance of applied polarization in controlling crack growth rate in highly IGSCC resistant recrystallized 5083-H321, either unsensitized or sensitized $\left(1 \mathrm{~h}\right.$ at $\left.175^{\circ} \mathrm{C}, 6 \mathrm{mg} / \mathrm{cm}^{2}\right)$ and stressed in neutral $\mathrm{NaCl}[13,36]$. Rates were substantially faster in anodically polarized $5083-\mathrm{H} 321(4 \mathrm{~nm} / \mathrm{s}$ and $3 \mathrm{~nm} / \mathrm{s}$ at $25 \mathrm{MPa} \sqrt{\mathrm{m}}$ in unsensitized and sensitized microstructures, respectively) compared to rates measured at $\mathrm{OCP}(0.1 \mathrm{~nm} / \mathrm{s}$ and $0.25 \mathrm{~nm} / \mathrm{s}$ at $25 \mathrm{MPa} \sqrt{\mathrm{m}}$ for the unsensitized and sensitized cases, respectively) [13]. The rate increase was attributed to a higher electrochemical driving force for crack growth [13]. Cathodic polarization slowed and eventually eliminated crack growth, due to restriction of matrix dissolution [13]. The role of $\beta$ was not established because: (a) growth rates were comparable in both sensitized and unsensitized 5083-H321 when anodically polarized, and (b) $1 \mathrm{~h}$ at $175^{\circ} \mathrm{C}$ produced minimal $\beta$ precipitation at grain boundary triple points only. 
Crack growth rates measured in 5083-H321 are much slower than expected based on the results of the current study; the reason for this difference is not understood. The isotropic recrystallized grain microstructure presumably promoted a somewhat more tortuous crack path that reduced crack growth rates, though the isotropic-small grain size (10 $\mu \mathrm{m}$ to $30 \mu \mathrm{m})$ suggests that this effect should not be large. Also, since growth rates were measured at high $\mathrm{K}(25 \mathrm{MPa} \sqrt{\mathrm{m}})$, creep may have contributed to these growth rates, but this contribution should only exacerbate $\mathrm{da} / \mathrm{dt}$. These experimental data were used to confirm a coupled environmental fracture model (CEFM) for IGSCC in AA5083-H321 in $\mathrm{NaCl}$ [36]. Both results show that IGSCC in relatively $\beta$-free 5083 is potential dependent, but neither investigated the role of $\beta$ or sensitization on IGSCC with potential control.

\subsubsection{Predicting crack tip chemistry during IGSCC in sensitized 5083}

The crack tip chemistry developed during IGSCC can be predicted using the approach developed in Section 3.6.3 (and detailed in the Appendix) to predict fissure tip chemistry during IGC. Assuming that the stability product criterion is met at the tip of a growing IGSCC crack [47], the crack tip potential and associated pH can be calculated with Eqn. 3.1 for the 3 different orientations illustrated in Fig. 3.16. At an elastic $\mathrm{K}$ of $15 \mathrm{MPa} \sqrt{\mathrm{m}}$, sensitized 5083-H131 (22 mg/cm²) polarized near OCP typically exhibits IGSCC extension of about $2.3 \mathrm{~mm}$ from the fatigue precrack. For this total crack length $(4.1 \mathrm{~mm})$, tip blunting at $\mathrm{K}$ of $15 \mathrm{MPa} \sqrt{\mathrm{m}}$ produces a calculated CTOD of $4 \mu \mathrm{m}$ [54] and a CMOD of $22 \mu \mathrm{m}$ [55], resulting in an average slot height, $\mathrm{h}$, of $13 \mu \mathrm{m}$ for orientation A. The CTOD is taken as the $\mathrm{h}$ for orientations $\mathrm{B}$ and $\mathrm{C}$. The diffusion distances for each orientation are: A: $d_{o}=d=4.1 \mathrm{~mm}, B: d_{o}=d=3.3 \mathrm{~mm}$, and C: $d_{o}=1.65 \mathrm{~mm}$ with $\mathrm{d}=3.3 \mathrm{~mm}$. The $i_{\text {wall }}$ is the passive current density of $\alpha\left(17 \mu \mathrm{A} / \mathrm{cm}^{2}\right.$ from Fig. 3.14). Due to local water reduction, 
$15 \%$ of this anodic current is balanced locally [22]; therefore only $85 \%$ of the passive current density was used in the calculation of Ohmic drop. During cracking, the only current that emits from the crack tip is due to IGC; $i_{\text {tip }}$ is calculated from IGC rates (Table 3.3). Crack electrolyte conductivity $(\kappa)$ is assumed to equal the average of $93 \mathrm{mS} / \mathrm{cm}$ in $80 \%$ saturated $\mathrm{Al}-4 \% \mathrm{Mg}$ and $45 \mathrm{mS} / \mathrm{cm}$ in $100 \%$ saturated $\mathrm{Al}-4 \% \mathrm{Mg}$. The results of the calculations using these input parameters are presented in Table 3.7.

Table 3.7 Predicted crack tip $\mathrm{pH}$ and potential during IGSCC in sensitized 5083-H131 $\left(22 \mathrm{mg} / \mathrm{cm}^{2}\right)$ in $0.6 \mathrm{M} \mathrm{NaCl}$ at $\mathrm{K}$ of $15 \mathrm{MPa} \sqrt{\mathrm{m}}$ for three different orientations (Fig. 3.16)

\begin{tabular}{|l|l|l|l|l|l|l|}
\hline \multirow{2}{*}{$\begin{array}{l}\mathrm{da} / \mathrm{dt}_{\mathrm{K} 15} \\
(\mathrm{~nm} / \mathrm{s})\end{array}$} & $\begin{array}{l}\mathrm{E}_{\text {app }} \\
\left(\mathrm{V}_{\mathrm{SCE}}\right)\end{array}$ & $\begin{array}{l}\text { Orientation } \\
\mathrm{A}\end{array}$ & $\begin{array}{l}\text { Orientation } \\
\mathrm{B}\end{array}$ & $\begin{array}{l}\text { Orientation } \\
\mathrm{C}\end{array}$ & $\begin{array}{l}\text { Orientation } \\
\mathrm{A}\end{array}$ & $\begin{array}{l}\text { Orientation } \\
\mathrm{A}\end{array}$ \\
\hline 7200 & -0.730 & -0.80 & -0.82 & -0.78 & 2.4 & -0.42 \\
\hline $\left.540 \mathrm{~V}_{\mathrm{SCE}}\right)$ & $\mathrm{E}_{\text {tip }}\left(\mathrm{V}_{\mathrm{SCE}}\right)$ & $\mathrm{E}_{\text {tip }}\left(\mathrm{V}_{\mathrm{SCE}}\right)$ & $\mathrm{Tip} \mathrm{pH}$ & $\eta_{\mathrm{H}}(\mathrm{V})$ \\
\hline 7.8 & -0.800 & -0.83 & -0.84 & -0.83 & 3.2 & -0.39 \\
\hline 3.8 & -0.900 & -0.92 & -0.94 & -0.93 & 5.3 & -0.36 \\
\hline 6.4 & -0.975 & -0.99 & -1.01 & -1.00 & 6.9 & -0.34 \\
\hline 1.3 & -1.020 & -1.03 & -1.05 & -1.04 & 7.9 & -0.33 \\
\hline 1.3 & -1.080 & -1.05 & -1.05 & -1.05 & 8.2 & -0.32 \\
\hline 1.0 & -1.100 & -1.05 & -1.05 & -1.05 & 8.2 & -0.32 \\
\hline \multicolumn{7}{|}{ 'Average value of replicate experiments from Chapter 2.} \\
\hline
\end{tabular}

The relationship between $E_{\text {tip }}$ and $E_{\text {app }}$ is shown in Fig. 3.23. The magnitude of the Ohmic drop is represented by the difference between the black line $\left(E_{\text {tip }}=E_{\text {app }}\right)$ and $E_{\text {tip. }}$. The magnitude of the predicted Ohmic drop is similar for each orientation, between $20 \mathrm{mV}$ and $40 \mathrm{mV}$, for all applied potentials between $-0.800 \mathrm{~V}_{\mathrm{SCE}}$ and $-1.020 \mathrm{~V}_{\mathrm{SCE}}$. The results for orientation A will be used for the remainder of this discussion. 


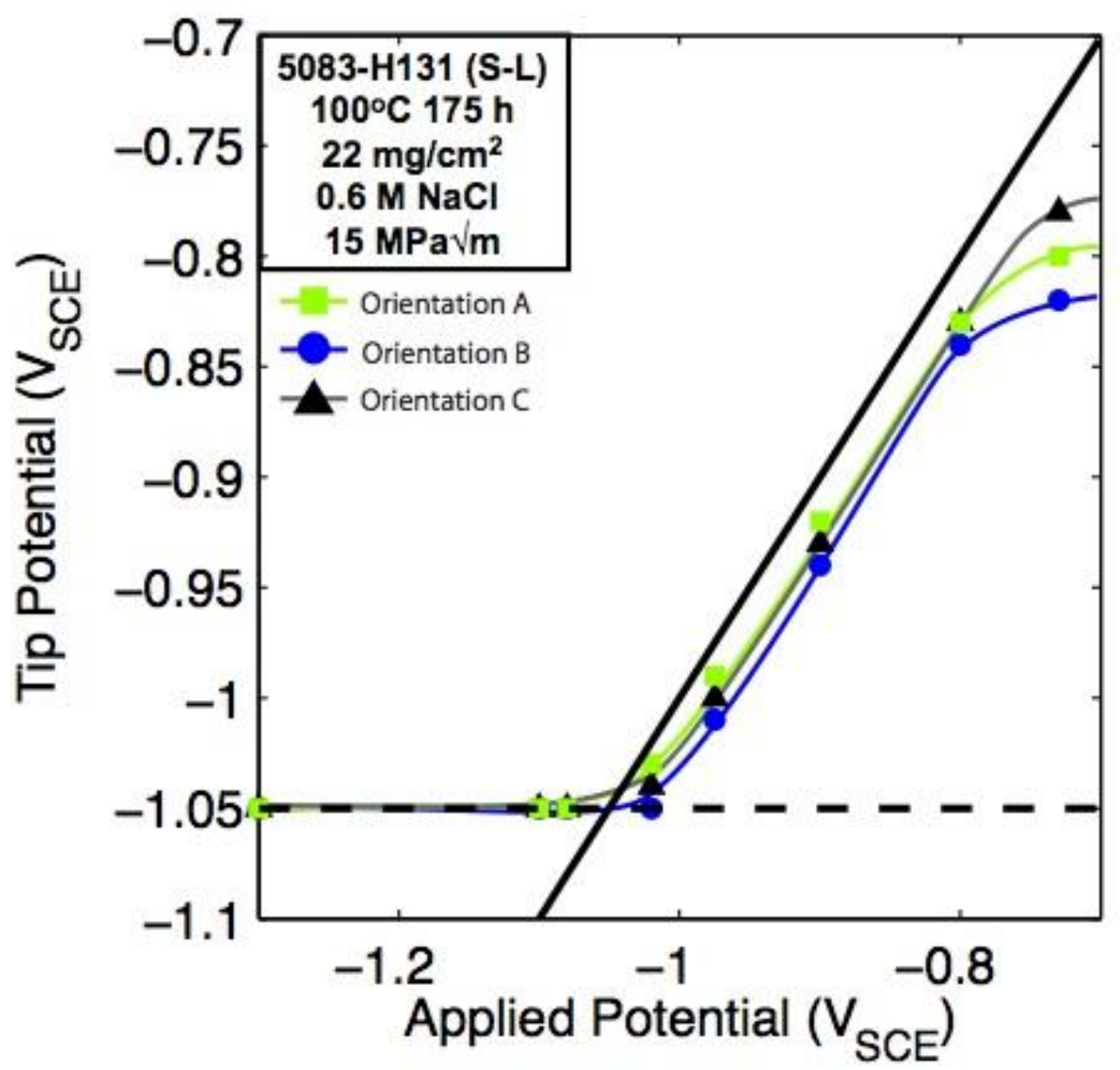

Figure 3.23 Predicted crack tip potential at $\mathrm{K}=15 \mathrm{MPa} \sqrt{\mathrm{m}}$ as a function of applied potential for sensitized 5083-H131 (S-L, $22 \mathrm{mg} / \mathrm{cm}^{2}$ ). The black line is the applied potential equal to the tip potential. The dashed line represents the lower bound of the crack tip potential (OCP of $\alpha$ in simulated crack tip solution $[17,18]$ ).

The resulting crack tip $\mathrm{pH}$ is calculated as a function of predicted $\mathrm{E}_{\text {tip }}$ (Table 3.7). The $\mathrm{pH}$ dependence on crack tip potential was generated from the slope of the trend line in Fig. 3.19, calibrated with the approach used for an IGC fissure in sensitized 5083-H131. The crack tip solution in sensitized 5083-H131 $\left(22 \mathrm{mg} / \mathrm{cm}^{2}\right)$ at $-0.730 \mathrm{~V}_{\mathrm{SCE}}$ is expected to be near $2 \mathrm{M} \mathrm{AlCl}_{3}$ with additional $\mathrm{Mg}$ concentration due to $\beta$ dissolution (likely at least 
$0.3 \mathrm{M} \mathrm{MgCl}_{2}$ ) [28]; therefore, the $\mathrm{pH}$ at $-0.730 \mathrm{~V}_{\mathrm{SCE}}$ is expected to be 0.8 units in the sensitized condition (Fig. 3.20).

The overpotential for $\mathrm{H}$ production $\left(\eta_{\mathrm{H}}\right)$ is calculated with both $\mathrm{E}_{\text {tip }}$ and $\mathrm{pH}$ at the crack tip given in Table 3.7 .

\subsubsection{Tip electrochemistry control and hypothesized IGSCC mechanism}

Do the electrochemical-potential-controlled rates of IGSCC during slow-rising $K$ loading validate the hypothesized mechanism for IGSCC?

The measured effect of applied potential, and predicted crack tip potential, on IGSCC rates confirms the hypothesis that grain boundary $\beta$ dissolution is a prerequisite for severe IGSCC of 5083-H131. Beta dissolution is required to activate sufficient grain boundary $\alpha$ dissolution. Collectively, $\alpha$ and $\beta$ dissolution lead to crack tip acidification, $\mathrm{H}$ production, and uptake. The crack electrochemistry considerations in Table 3.7 are relevant to testing this hypothesis and provide a semi-quantitative approach to understand da/dt based on the flow chart in Fig. 3. 22.

\subsection{Crack tip potential control of IGSCC rates}

The measured applied potential dependence of IGSCC rates, shown with Ohmic drop estimates in Fig. 3.24, confirms the proposed mechanism that both $\alpha$ and $\beta$ dissolution are critical for rapid IGSCC growth rates. The Ohmic drop is calculated for three different orientations shown in Fig. 3.16, with the magnitude and direction shown by arrows.

Considering the most rapid IGSCC growth rates at $\mathrm{E}_{\text {app }}$ of $-0.730 \mathrm{~V}_{\mathrm{SCE}}$ and $-0.800 \mathrm{~V}_{\mathrm{SCE}}$, the corresponding predicted tip potentials for orientation A (between $-0.780 \mathrm{~V}_{\mathrm{SCE}}$ and $\left.-0.840 \mathrm{~V}_{\mathrm{SCE}}\right)$ are above both $\mathrm{E}_{\mathrm{Br}-\alpha}$ and $\mathrm{E}_{\mathrm{Br}-\beta}$ in an acidic chloride solution. As in IGC, 
reactive dissolution of $\beta$ on grain boundaries stimulates crack acidification and dissolution of $\alpha$, leading to a highly concentrated $\mathrm{Al}^{3+}$ and $\mathrm{Mg}^{2+}$ solution with an expected crack $\mathrm{pH}$ in the range of 2-3 (Table 3.7). This acidic crack tip environment not only provides high $\mathrm{H}^{+}$ through hydrolysis, but also destabilizes the passive film to allow $\mathrm{H}$ uptake into the FPZ. The low $\mathrm{pH}$ and high magnitude of $\eta_{\mathrm{H}}(-0.42)$ in this microstructure-environment could provide a high $\mathrm{C}_{\mathrm{H} \sigma}$ for rapid da/dt $(800 \mathrm{~nm} / \mathrm{s}$ to $7200 \mathrm{~nm} / \mathrm{s})$, by the flow chart in Fig. 3.22, Eqn. 3.2. The contribution of acidic $\mathrm{pH}$ to $\mathrm{H}$ uptake, above that associated with larger $\eta_{\mathrm{H}}$, is suggested by $\mathrm{C}_{\mathrm{H} \text {-diff }}$ behavior measured for steel (Fig. 3.21b) [52]. Without measurement of the $\mathrm{pH}$ and $\eta_{\mathrm{H}}$ dependence of $\mathrm{C}_{\mathrm{H}-\text { diff }}$ for $\mathrm{Al}$ alloys, this hypothesis cannot be confirmed.

A severe drop in IGSCC rate occurs below $E_{\text {app }}$ of $-0.800 V_{S C E}$, but above $E_{\text {app }}$ of $-0.900 \mathrm{~V}_{\mathrm{SCE}}$, resulting in $\mathrm{E}_{\text {tip }}$ between $-0.830 \mathrm{~V}_{\mathrm{SCE}}$ and $-0.920 \mathrm{~V}_{\mathrm{SCE}}$. The crack growth rate likely decreases because the crack tip potential falls below $E_{B r-\alpha}$ for the acidic electrolyte expected in an actively corroding crack tip $\left(-0.870 \mathrm{~V}_{\mathrm{SCE}}\right)[17,18]$. Below $\mathrm{E}_{\mathrm{Br}-\alpha}$, $\alpha$ dissolution rate is reduced to passive-Al dissolution only and development of the acidic environment relies on the small volume of crack tip $\beta$ dissolution. The predicted crack tip $\mathrm{pH}$ increases to as high as 5 , resulting in a low magnitude of $\eta_{\mathrm{H}}(-0.36 \mathrm{~V})$.

Crack growth rate is low but relatively constant (near $6 \mathrm{~nm} / \mathrm{s}$ ) for $\mathrm{E}_{\mathrm{app}}$ of $-0.900 \mathrm{~V}_{\mathrm{SCE}}$ to $-1.020 \mathrm{~V}_{\mathrm{SCE}}$, ( $\mathrm{E}_{\text {tip }}-0.92 \mathrm{~V}_{\mathrm{SCE}}$ to $\left.-1.03 \mathrm{~V}_{\mathrm{SCE}}\right)$. This lower applied potential aligns with $\mathrm{E}_{\mathrm{Br}-\beta}$ for acidic solution and is somewhat below $\mathrm{E}_{\mathrm{Br}-\beta}$ for neutral chloride (-0.960 $\mathrm{V}_{\mathrm{SCE}}$ from Table $3.2[15])$. In this potential range, the crack tip would be acidified by $\beta$ dissolution only, as the passive $\alpha$ dissolution rate would continue to fall by Tafel kinetics (Fig. 3.14). 


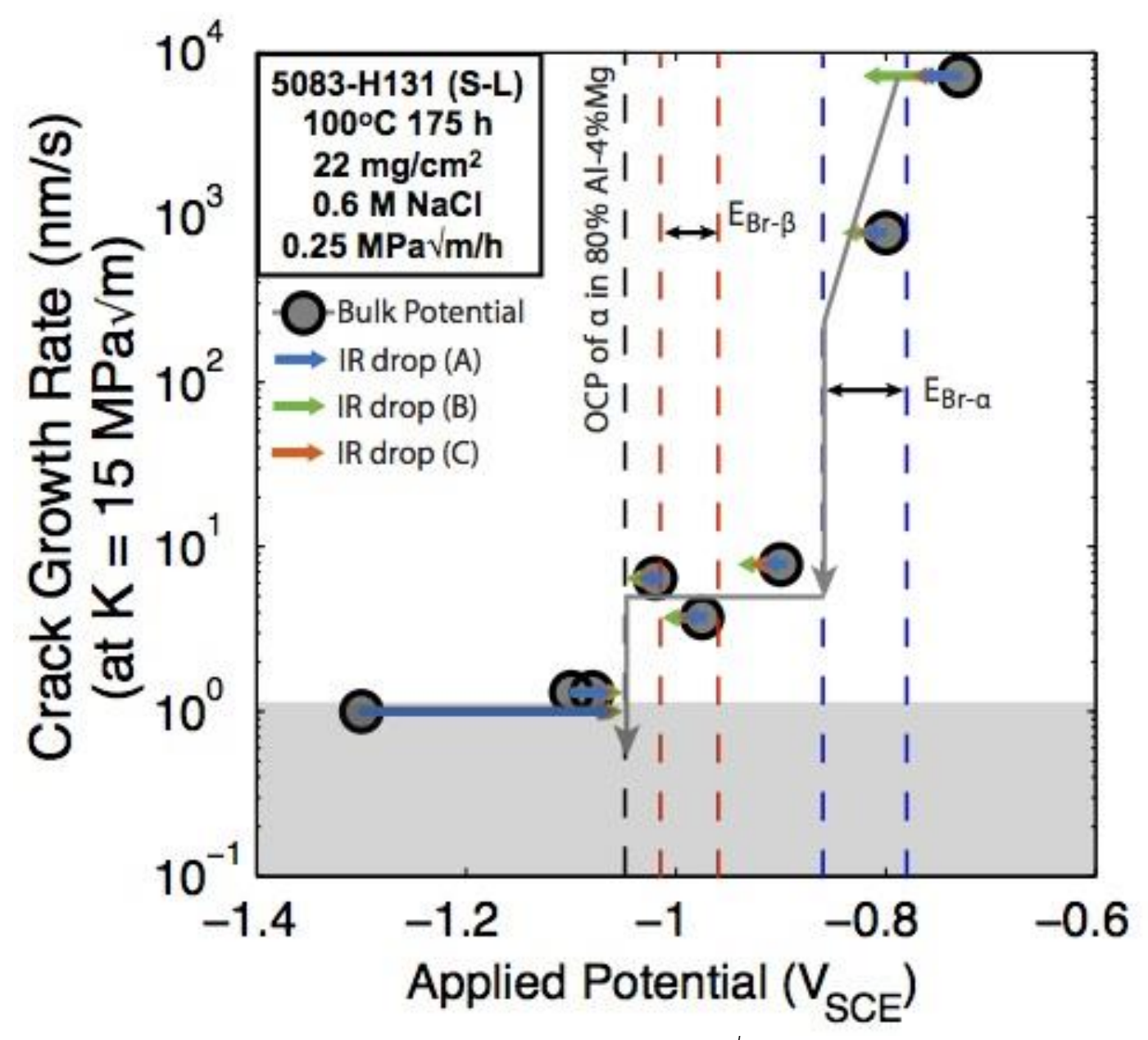

Figure 3.24 The crack growth rate at $15 \mathrm{MPa} \sqrt{\mathrm{m}}$ in sensitized5083-H131 (S-L, $22 \mathrm{mg} / \mathrm{cm}^{2}$ ) in $\mathrm{NaCl}$ as a function of polarization. Arrows represent the Ohmic drop predicted at the crack tip for three orientations illustrated in Fig. 3.16. The $\mathrm{pH}$ sensitive breakdown potentials of $\beta$ and $\alpha$ are shown with dashed lines [17,18]. The vertical black dashed line represents the lower limit for crack tip potential (OCP of $\alpha$ in simulated crack tip solution $[17,18])$. The resolution limit for the dcPD measurement technique is shown with the grey box.

With bulk-applied potentials lower than $-1.020 \mathrm{~V}_{\mathrm{SCE}}$, the corresponding crack tip potential approaches the lower bound at OCP typical of $\alpha$ in acidic chloride $\left(-1.050 \mathrm{~V}_{\mathrm{SCE}}\right)[17,18]$. The rate of IGSCC is below the resolution limit of the dcPD

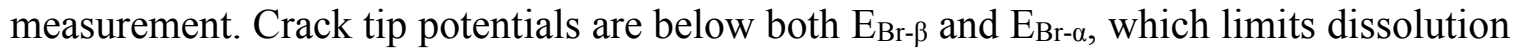


of both $\alpha$ and $\beta$; therefore, a critical crack tip chemistry is likely not developed, and $\eta_{\mathrm{H}}$ is insufficient to support da/dt $\left(\mathrm{C}_{\mathrm{H \sigma}}\right.$ is less then or equal to $\left.\mathrm{C}_{\mathrm{H} \text {-crit }}\right)$ in Eqn. 3.2. If crack acidification is eliminated by cathodic polarization, then polarization below $\mathrm{E}_{\mathrm{Br}-\beta}$ of $-1.020 \mathrm{~V}_{\mathrm{SCE}}$ is the pertinent applied potential for very low da/dt, as the $\mathrm{E}_{\text {tip }}$ reaches a minimum of $-1.050 \mathrm{~V}_{\mathrm{SCE}}$ below this $\mathrm{E}_{\text {app }}$.

\subsubsection{2 $\mathrm{pH}$ dependence of IGSCC rates}

The role of crack tip $\mathrm{pH}$ is essential to IGSCC. The $\mathrm{da} / \mathrm{dt}_{\mathrm{K} 15}$ as a function of predicted $\mathrm{pH}$ is illustrated in Fig. 3.25 for each orientation in Fig. 3.16. The thermodynamic passive region of $\mathrm{Al}$ in water is shown by the shaded region between $\mathrm{pH} 2$ and 8.6, while the thermodynamic passive region of $\mathrm{Mg}$ in water (without $\mathrm{Cl}^{-}$) is shown by the shaded region from 8.4 and above [57].

For all orientations, crack growth is rapid in sensitized 5083-H131 when $\mathrm{pH}$ is low (between 2.8 and 3.3). Measured crack growth rates decrease as the crack tip pH increases to 5.5 , then plateau until the maximum $\mathrm{pH}$ of 8 , where crack growth rates fall to the dcPD resolution limit. This potential controlled $\mathrm{pH}$ is limited by the minimum predicted crack tip potential (-1.05 $\mathrm{V}_{\mathrm{SCE}}$ the OCP of $\alpha$ in acidic solution). This range of predicted crack tip $\mathrm{pH}$ has a strong impact on crack growth rates, even though the crack tip passive film is thermodynamically stable over the full range. The crack tip chloride concentration is directly related to $\mathrm{pH}$ due to charge neutrality [64]. At low $\mathrm{pH}$, a high concentration of $\mathrm{Cl}^{-}$ is present and the passive film likely becomes unstable. 


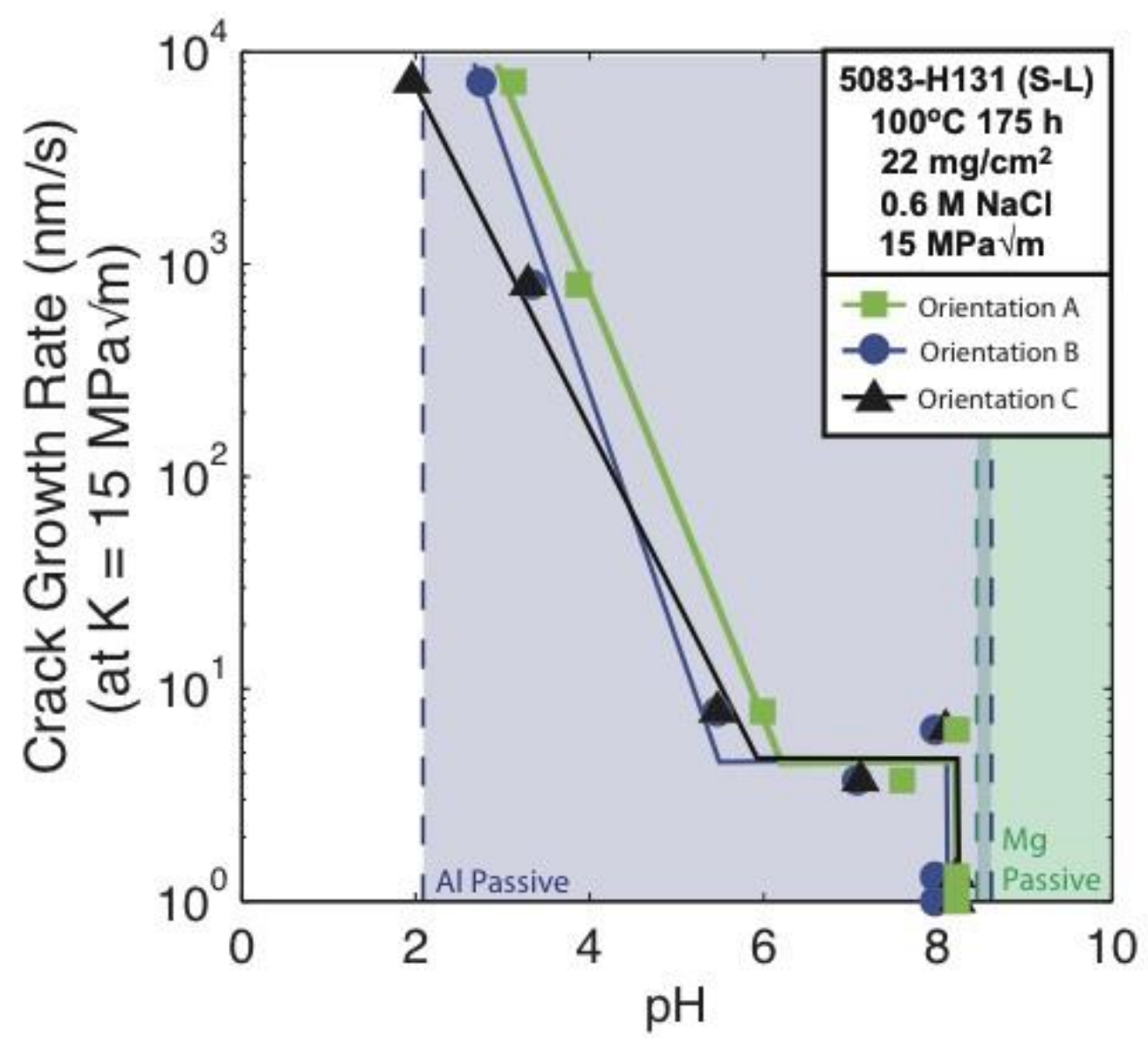

Figure 3.25 The da/dt 15 for sensitized (S-L) $5083-\mathrm{H} 131\left(22 \mathrm{mg} / \mathrm{cm}^{2}\right)$ as a function of predicted crack tip $\mathrm{pH}$.

\subsection{H overpotential dependence of IGSCC rates}

A quantitative representation of the IGSCC tip pH-potential combination is shown as $(\bullet)$ in Fig. 3.26 for sensitized 5083-H131 at several applied potentials. The $\mathrm{pH}$ dependence of the reversible potential for water reduction to form $\mathrm{H}$ by the hydrogen evolution reaction (HER) is given by the solid line and the $\mathrm{pH}$ dependence of the overpotential for $\mathrm{H}$ production $\left(\eta_{H}\right)$ is shown with arrows for several applied potentials discussed below. 


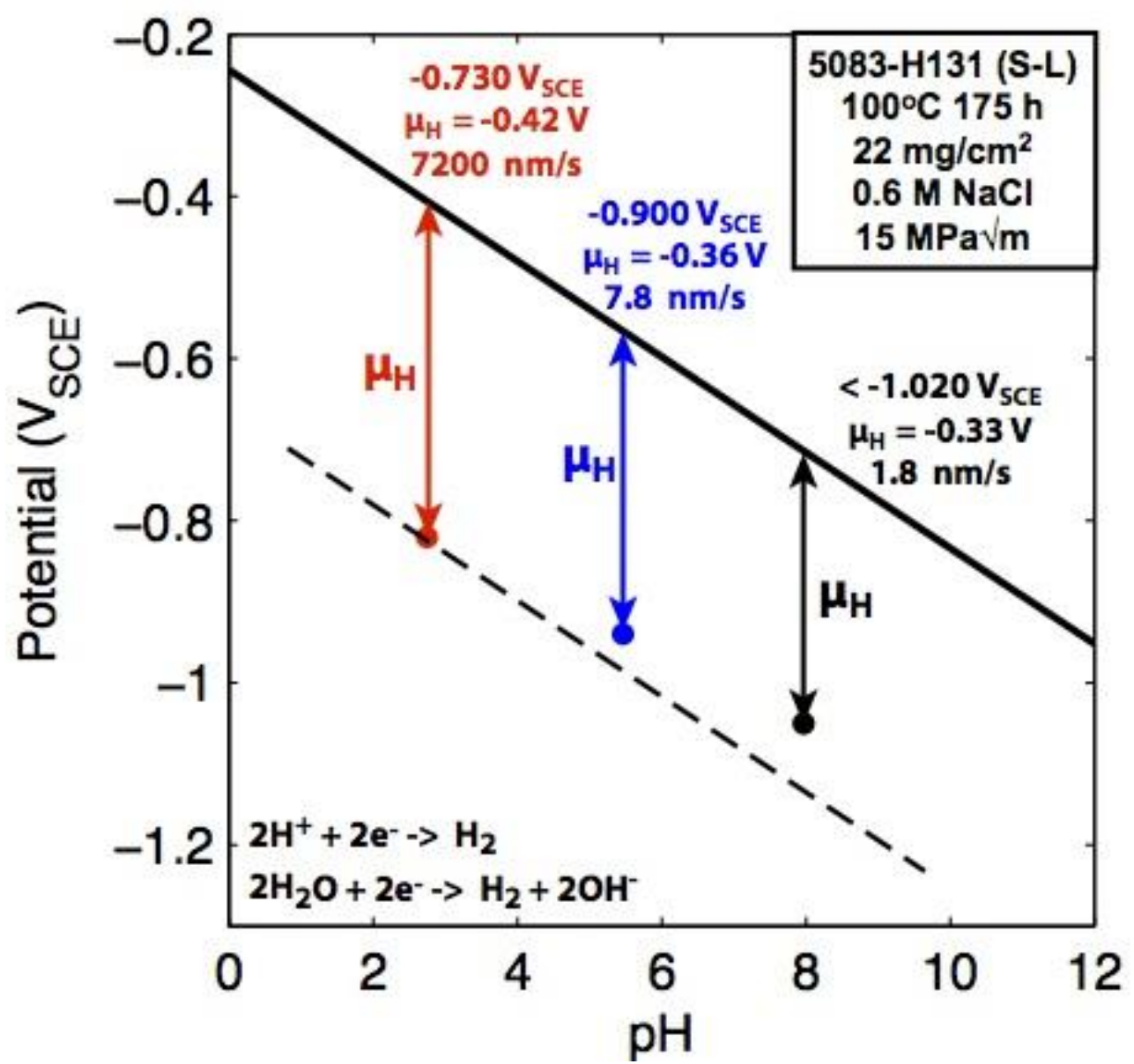

Figure 3.26 Crack tip potential as a function of crack tip $\mathrm{pH}$, showing the predicted overpotential for $\mathrm{H}$ production at the crack tip of sensitized $5083-\mathrm{H} 131\left(22 \mathrm{mg} / \mathrm{cm}^{2}\right)$ stressed in $\mathrm{NaCl}$ at three applied potentials. The lower dashed line is parallel to the $\mathrm{pH}$ dependent reversible potential for water and proton reduction and is drawn for reference. Applied potential, crack tip overpotential, and crack growth rate from Fig. 3.24 are given for each experiment.

Considering IGSCC of sensitized 5083- $\mathrm{H} 131$ in $\mathrm{NaCl}$ anodically polarized to $-0.730 \mathrm{~V}_{\mathrm{SCE}}, \mathrm{H}$ production is favored at the crack tip $\left(\eta_{\mathrm{H}}<0\right)$. The high magnitude of $\eta_{\mathrm{H}}$ and low pH (see Fig. 3.21b [52]) likely supports $\mathrm{C}_{\mathrm{H \sigma}} \gg \mathrm{C}_{\mathrm{H}-\mathrm{crit}}$ in Eqn. 3.2 for the extremely rapid Stage II HEAC $(7200 \mathrm{~nm} / \mathrm{s})$ in this sensitized 5083-H131 microstructure. When the applied polarization falls to $-0.900 \mathrm{~V}_{\mathrm{SCE}}, \eta_{\mathrm{H}}$ falls to $-0.36 \mathrm{~V}$, owing to the more alkaline crack tip ( $\mathrm{pH} \mathrm{5-6).} \mathrm{Crack} \mathrm{growth} \mathrm{is} \mathrm{still} \mathrm{resolved,} \mathrm{though} \mathrm{slow}(7.8 \mathrm{~nm} / \mathrm{s})$, 
suggesting that $\eta_{\mathrm{H}}$ and $\mathrm{pH}$ promote $\mathrm{C}_{\mathrm{H} \sigma}>\mathrm{C}_{\mathrm{H} \text {-crit }}$ for slow HEAC. Below $-1.020 \mathrm{~V}_{\mathrm{SCE}}, \eta_{\mathrm{H}}$ magnitude drops to $-0.33 \mathrm{~V}$, and the $\mathrm{pH}$ rises to 8 . At the slow to nil crack growth rate measured in sensitized 5083-H131 $(1.8 \mathrm{~nm} / \mathrm{s}), \mathrm{C}_{\mathrm{H \sigma}}$ likely equal to or less than $\mathrm{C}_{\mathrm{H}-\text { crit. }}$ Even at this cathodic potential, the overpotential for $\mathrm{H}$ production does not supply a sufficient $\mathrm{H}$ concentration to the FPZ, perhaps due to the reduction in $\mathrm{H}$ solubility with increasing $\mathrm{pH}$ reported for steel (Fig. 3.21b) [52].

The strong influence of predicted $\eta_{H}$ on measured crack growth rate is demonstrated in Fig. 3.27, including $\eta_{H}$ values predicted for all three orientations illustrated in Fig. 3.16. A linear trend in $\log \mathrm{da} / \mathrm{dt}$ with $\eta_{\mathrm{H}}$ is observed from $-0.42 \mathrm{~V}$ to $-0.35 \mathrm{~V}$ for all three orientations. The minimum $\eta_{\mathrm{H}}$ at $-0.33 \mathrm{~V}$ is due to the minimum predicted crack tip potential (-1.05 $\mathrm{V}_{\mathrm{SCE}}$, the OCP of $\alpha$ in acidic solution). A 3 order of magnitude drop in $\mathrm{da} / \mathrm{dt}_{\mathrm{II}}$ is observed over the relatively small change in $\eta_{\mathrm{H}}($ from $-0.42 \mathrm{~V}$ to $-0.36 \mathrm{~V}$ ). Either $\mathrm{pH}$ (and perhaps cation concentration) affect a more significant change in $\mathrm{C}_{\mathrm{H \sigma}}$ than expected based on $\mathrm{H}$ overpotential alone, or the squared inverse error function in Eqn. 3.2 contributes to this significant drop in crack growth rate over a small change in $\mathrm{C}_{\mathrm{H \sigma}}$.

Collectively, the IGSCC crack tip potential dependence and semi-quantitative crack tip chemistry considerations demonstrate that IGSCC in sensitized Al-Mg alloys requires $\beta$ dissolution to generate a critical acidic chemistry, and significant $\eta_{\mathrm{H}}$, for $\mathrm{H}$ embrittlement. Results are summarized as:

- Beta dissolution stimulates rapid $\alpha$ dissolution for $\mathrm{C}_{\mathrm{H \sigma}}>>\mathrm{C}_{\mathrm{H}-\mathrm{crit}}$ and rapid da/dt when: (a) $\mathrm{E}_{\text {tip }}$ is above $\mathrm{E}_{\mathrm{Br}-\alpha}\left(-0.870 \mathrm{~V}_{\mathrm{SCE}}\right)$, (b) crack tip $\mathrm{pH}$ is between 2 and 3, and (c) crack tip $\eta_{H}$ is near or more negative than $-0.41 \mathrm{~V}$. 
- Beta dissolution alone sustains $\mathrm{C}_{\mathrm{H} \sigma}>\mathrm{C}_{\mathrm{H}-\text { crit }}$ and sluggish da/dt when: (a) $\mathrm{E}_{\text {tip }}$ is above $\mathrm{E}_{\mathrm{Br}-\beta}\left(-1.015 \mathrm{~V}_{\mathrm{SCE}}\right)$, but below $\mathrm{E}_{\mathrm{Br}-\alpha}\left(-0.870 \mathrm{~V}_{\mathrm{SCE}}\right)$, (b) crack tip $\mathrm{pH}$ is between 5 and 8 , and (c) crack tip $\eta_{\mathrm{H}}$ is between $-0.33 \mathrm{~V}$ and $-0.37 \mathrm{~V}$.

- Both $\beta$ and $\alpha$ dissolution are limited resulting in $\mathrm{C}_{\mathrm{H} \sigma} \leq \mathrm{C}_{\mathrm{H}-\text {-rit, }}$, which causes da/dt to fall to the resolution limit when: (a) $\mathrm{E}_{\text {tip }}$ is below $\mathrm{E}_{\mathrm{Br}-\beta}\left(-1.015 \mathrm{~V}_{\mathrm{SCE}}\right)$, (b) crack tip pH is at 8 or above, and (c) crack tip $\eta_{\mathrm{H}}$ is at or below $-0.33 \mathrm{~V}$.

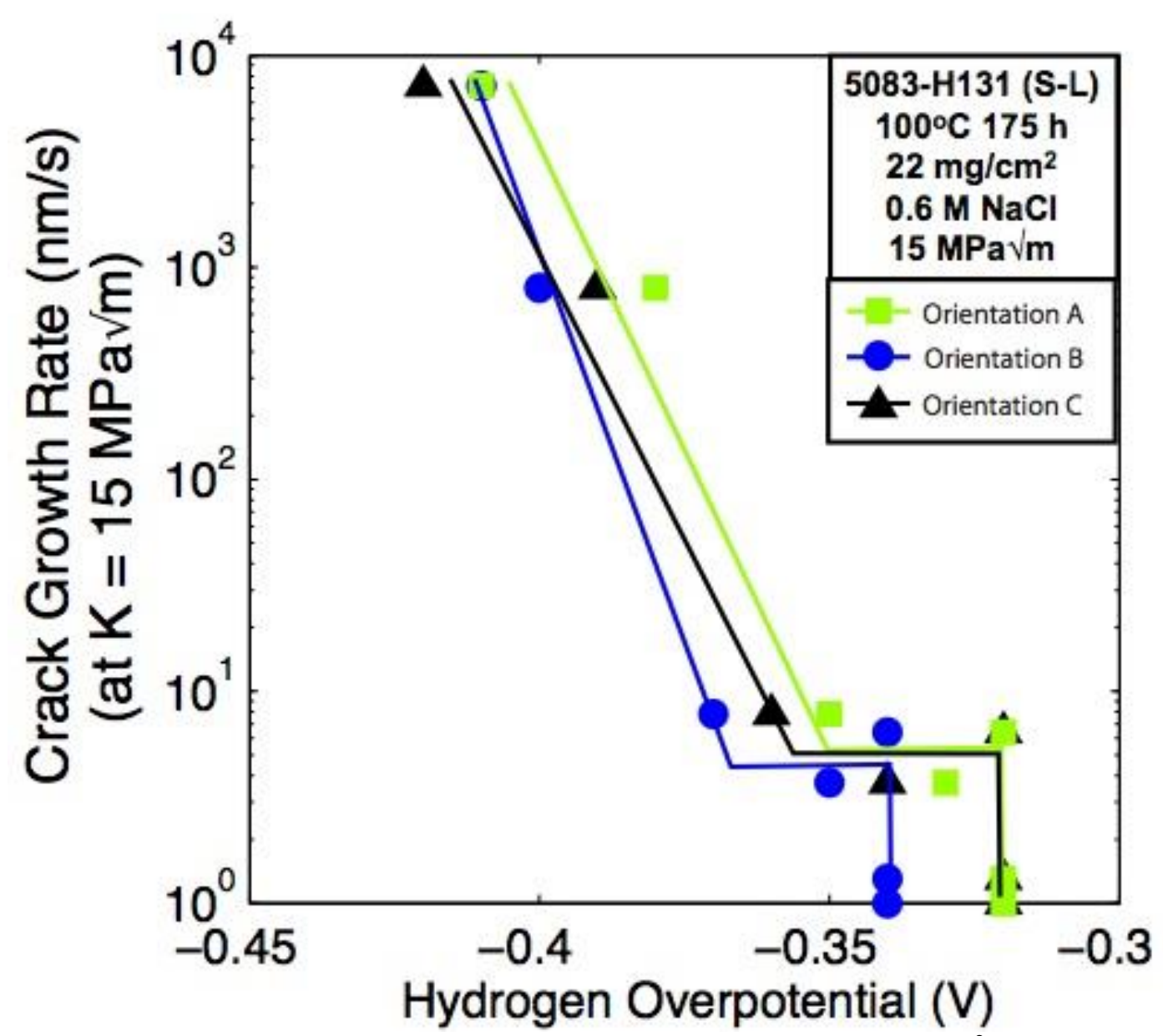

Figure 3.27 The da/dt $\mathrm{K}_{15}$ for sensitized 5083-H131 (S-L, $\left.22 \mathrm{mg} / \mathrm{cm}^{2}\right)$ as a function of predicted overpotential for $\mathrm{H}$ production for the three crack tip orientations illustrated in Fig. 3.16. 
The key conclusion from the HEAC results presented in Fig. 3.24 and this crack chemistry interpretation is that it is possible to essentially prevent IGSCC for the upper bound-susceptible S-L orientation of sensitized 5083-H131. If potentials in the IGSCC resistant range (near $-1.050 \mathrm{~V}_{\mathrm{SCE}}$ ) can be maintained at a fissure or crack tip with a coating or impressed current cathodic protection system, then modest cathodic polarization could provide a means to minimize IGSCC in 5083 components. Even with excess cathodic applied polarization $\left(-1.300 \mathrm{~V}_{\mathrm{SCE}}\right)$, Ohmic-drop-controlled crack tip potential limits the development of an acidic crack tip and a high magnitude of $\eta_{\mathrm{H}}$ for insufficient $\mathrm{H}$ production and H uptake.

As a final point, crack tip $\mathrm{H}$ production may persist, and even increase, due to water or proton reduction at the low potentials that eliminate $\beta$ dissolution and the associated-high crack tip acidification. Persistent but modest $\mathrm{H}$ production (such that $\mathrm{C}_{\mathrm{H} \sigma}>\mathrm{C}_{\mathrm{H} \text {-crit }}$ in Eqn. 3.2) and HEAC could explain the finite crack growth rates (1 nm/s to $1.5 \mathrm{~nm} / \mathrm{s})$ measured at $\mathrm{E}_{\text {tip }}$ below $-1.050 \mathrm{~V}_{\mathrm{SCE}}$, as represented in Fig. 3.24. This consideration is further assessed in Section 3.6.5 by experiments conducted with as-received 5083 stressed in a variety of neutral and alkaline electrolytes with highly cathodic polarization. These experiments also assess the practical extent to which cathodic polarization can promote HEAC without strong crack acidification. Hydrogen induced crack growth models developed in the literature [36], describe a possible mechanism of crack growth in 5083 with very low grain boundary $\beta$ coverage as discussed in Section 3.6.6.2.

\subsubsection{Crack tip chemistry controlled non-uniform crack front}

For sensitized $5083-\mathrm{H} 131\left(15 \mathrm{mg} / \mathrm{cm}^{2}\right.$ to $\left.40 \mathrm{mg} / \mathrm{cm}^{2}\right)$ polarized to $-0.800 \mathrm{~V}$ SCE in $\mathrm{NaCl}$, a non-uniform crack front was typically observed (illustrated in Chapter 2, Fig. 2.20). 
Crack extension is: a) highest at a location approximately $25 \%$ of the specimen thickness $(1.65 \mathrm{~mm}), \mathrm{b})$ slightly lower at the midpoint of the thickness $(3.3 \mathrm{~mm})$, and c) the lowest at the bold surface. This crack front is unique, because the stress gradient across the specimen thickness often causes more rapid crack growth at the midpoint.

This shape may be explained by the local gradient in potential across the crack front. The potential and $\mathrm{pH}$ are fixed at the bold surface $\left(\mathrm{pH} 7.3\right.$ and $\mathrm{E}_{\mathrm{app}}$ of $\left.-0.800 \mathrm{~V}_{\mathrm{SCE}}\right)$; cation diffusion out of the crack, the neutral $\mathrm{pH}$, and lower stress gradient all contribute to low crack growth at the bold surface. The potential and $\mathrm{pH}$ will each decrease with distance into the crack due to Ohmic drop [43]. The crack tip potential and $\mathrm{pH}$ was predicted at both of these distances in Table 3.7, using orientations B and C in Fig. 3.16. With the applied potential at $-0.800 \mathrm{~V}_{\mathrm{SCE}}$, the average potential at the center of the specimen (orientation $\mathrm{B}$ ) is about $-0.840 \mathrm{~V}_{\mathrm{SCE}}$ and $\mathrm{pH}$ is 3.3 , giving an $\eta_{\mathrm{H}}$ of $-0.40 \mathrm{~V}$. At $1.65 \mathrm{~mm}$ (orientation $\mathrm{C}$ ), the average potential is about $-0.830 \mathrm{~V}_{\mathrm{SCE}}, \mathrm{pH}$ is 3.3 , resulting in $\eta_{\mathrm{H}}$ of $-0.39 \mathrm{~V}$. Though the environments within the crack tip are very similar, the more anodic potential at the intermediate region could promote more dissolution, $\mathrm{H}$ production and uptake, though the $\eta_{\mathrm{H}}$ is lower owing to the small change in $\mathrm{pH}$ with increase in potential. This discrepancy may point to errors in assumptions made in the Ohmic drop calculations.

This crack front is typical for DoS in the range of $15 \mathrm{mg} / \mathrm{cm}^{2}$ to $40 \mathrm{mg} / \mathrm{cm}^{2}$ polarized to $-0.800 \mathrm{~V}_{\mathrm{SCE}}$ in $\mathrm{NaCl}$, though the extent of crack penetration in the center, illustrated in Fig. 2.20, varied for the replicate experiments. These variations could reflect either crack tip polarization due to factors such as $\mathrm{H}_{2}$ bubbles or microstructural variation. Significantly different fracture surface shapes were observed at DoS outside of this range. 


\subsubsection{Intergranular SCC in $\beta$-free Al-Mg}

Is IGSCC possible in Al-Mg without $\beta$ particles for dissolution?

The role of $\beta$ was established in Chapter 2; crack growth rates increased and $\mathrm{K}_{\mathrm{TH}}$ decreased with increasing sensitization. Section 3.6.4 established that $\beta$ dissolution is the critical factor necessary to establish an acidic crack tip required for $\mathrm{H}$ production and uptake; when $\beta$ dissolution was limited crack growth rates were not resolved. The question remains: How does IGSCC propagate between $\beta$; that is, is $\beta$ necessary for IGSCC apart from crack chemistry alteration? Crack growth rates in Fig. 3.10 suggest that as-received 5083-H131 (S-L) is highly susceptible to IGSCC when stressed under slow-rising K in: (a) acidic simulated crack tip solution polarized cathodically, and (b) near neutral $\mathrm{NaCl}$ polarized anodically. These results show that grain boundary $\beta$ presence is not uniquely required for stress concentration, local constraint, or novel H trapping during IGSCC in 5083-H131. The literature also confirmed that Al-Mg alloys are susceptible to HEAC without $\beta$ when stressed in several environments $[13,26]$. This section investigates the role of crack tip electrochemical environment on IGSCC in $\beta$-free Al-Mg in an attempt to understand how IGSCC propagates between discontinuous arrayed $\beta$ precipitates at $\alpha$ grain boundaries.

\subsubsection{The literature regarding $\mathrm{H}$ embrittlement in anodic-particle free alloys}

Results presented in Chapter 4 establish that 5083-H131 is embrittled in moist air when the microstructure contains $\mathrm{H}$ from prior precharging. Notched specimens of unsensitized and sensitized 5083-H131 were charged for $16 \mathrm{~d}$ and $21 \mathrm{~d}$ at $\mathrm{OCP}$ in $\mathrm{NaOH}$, then loaded in air. Both conditions were embrittled by $\mathrm{H}$ compared to uncharged specimens, though the sensitized specimen fractured at a lower stress. In addition intergranular features were 
observed in the sensitized specimens, located up to $350 \mu \mathrm{m}$ from the notch root surface, but intergranular features were not resolved in the unsensitized 5083-H131 case. Results confirm that: (a) FPZ H can embrittle unsensitized Al-Mg, and (b) the presence of $\beta$ enhances intergranular $\mathrm{H}$ embrittlement.

Anodic polarization enhanced crack growth in unsensitized 5083, as demonstrated in two studies by Jones et al. and Elboujdaini et al. [13,65]. As discussed in Section 3.6.4.1, Jones et al. demonstrated that anodic dissolution in $\mathrm{NaCl}$ enhanced relatively low crack growth rates in unsensitized and low sensitized $5083\left(6 \mathrm{mg} / \mathrm{cm}^{2}\right)$ [13]. Elboujdaini et al. confirmed that anodic dissolution promoted IGSCC during slow strain rate loading of unnotched unsensitized 5083-H321 [65]. Fractography indicated that anodic polarization promoted significant pitting, which transitioned to IGSCC growth during polarization to $-0.540 \mathrm{~V}_{\mathrm{SCE}}$ in $0.6 \mathrm{M} \mathrm{NaCl}$ [65]. Mixed ductile and intergranular cracking was observed when polarized to $-0.690 \mathrm{~V}_{\mathrm{SCE}}$ (the breakdown potential of the alloy), and ductile failure only was observed at $\mathrm{OCP}\left(-0.900 \mathrm{~V}_{\mathrm{SCE}}\right)$. Though these results focus on IGSCC initiation, rather than propagation, the critical role of anodic polarization in IGSCC is established. If the potential is lower than a critical value, shallow pits or cracks will not form, and therefore, a critical acidic crack tip chemistry will not be established. If shallow pits or cracks are present, they will remain inactive. Above this potential, pitting will occur and the rate of dissolution in pits and cracks will be enhanced to trigger the critical production and uptake of intergranular $\mathrm{H}$ for embrittlement.

Tanguy et al. studied IGSCC in a thin notched specimen of unsensitized Al-5Mg subjected to slow strain rate loading in either acidic $\mathrm{NaCl}(\mathrm{pH} 4.2)$ or an acidic simulated crack solution of $\mathrm{AlCl}_{3}(\mathrm{pH} 2.4)$ [26]. Intergranular SCC failure occurred after $2 \mathrm{~d}$ and was 
hypothesized to occur following IGC penetration contributing to the loss of passivity at the notch root, which generated a highly acidic, $\mathrm{Cl}^{-}$concentrated fissure chemistry that transitioned to IGSCC with the ensuing H production and uptake [26]. To validate this hypothesis, the experiment was repeated with a deaerated solution expected in the crack tip. Intergranular SCC also occurred, though with a much longer failure time [26]. By removing the $\mathrm{O}_{2}$ reduction reaction, Tanguy et al. assumed global depassivation; though anodic dissolution and pitting were likely reduced because the only acting cathodic reaction was $\mathrm{H}$ reduction [26]. Results establish that intergranular failure occurred in $\beta$-free 5083 if a highly acidic chemistry is developed in an occluded fissure to provide sufficient $\mathrm{H}$ to the FPZ. Specifically, notched $\mathrm{Al}-5 \mathrm{Mg}$ is susceptible to IGSCC in acidic $\mathrm{NaCl}$ because a $\mathrm{Cl}^{-}$ concentrated acidic environment developed due to corrosion near the notch tip [26]. Tanguy et al. proposed that dissolution alone is not the driving force for IGSCC [26].

Each of these studies indicated that IGSCC propagates in $\beta$-free Al-Mg alloys, as long as an acidic-high $\mathrm{Cl}^{-}$concentrated environment is developed in a stressed occluded fissure or crack. Crack growth between $\beta$ is likely due to HEAC from this critical chemistry. The literature has not reported chemistry controlled crack growth rates to test the $\mathrm{H}$ diffusion limited HEAC model for $\beta$-free Al-Mg.

\subsubsection{Predicted crack tip chemistry during IGSCC in $\beta$-free 5083}

The chemistry at an IGSCC tip was predicted using the criterion developed in Eqn. 3.1. Results are summarized in Tables 3.8 and 3.9. The parameters are assumed for unsensitized $5083-\mathrm{H} 131$ in $\mathrm{NaCl}$ at $\mathrm{K}$ of $15 \mathrm{MPa} \sqrt{\mathrm{m}}$ where only $0.3 \mathrm{~mm}$ of IGSCC crack extension occurs. For orientation A in Fig. 3.16, $\mathrm{d}_{\mathrm{o}}=\mathrm{d}$ is $2.1 \mathrm{~mm}$ (in the $\mathrm{L}$ direction), CTOD is $4 \mu \mathrm{m}$, CMOD is $18 \mu \mathrm{m}$, and average $\mathrm{h}$ is $11 \mu \mathrm{m}$. Orientations $\mathrm{B}$ and $\mathrm{C}$ have the same parameters 
as that for sensitized 5083-H131 in Section 3.6.4.2, with h equated to CTOD. For all orientations, $i_{\text {wall }}$ is the passive current density of $\alpha\left(17 \mu \mathrm{A} / \mathrm{cm}^{2}\right.$ from Fig. 3.14), and $i_{\text {tip }}$ is calculated from the IGC rates in Table 3.5. The crack solution conductivity $(\kappa)$ is the average of $93 \mathrm{mS} / \mathrm{cm}$ in $80 \%$ saturated $\mathrm{Al}-4 \% \mathrm{Mg}$ and $45 \mathrm{mS} / \mathrm{cm}$ in $100 \%$ saturated Al$4 \% \mathrm{Mg}$, and is used for all calculations. The $\mathrm{pH}$ is predicted using the slope on the literature data in Fig. 3.19, and assuming that the crack tip $\mathrm{pH}$ is 1.1 at $-0.73 \mathrm{~V}_{\mathrm{SCE}}$, which is that measured in $2 \mathrm{M} \mathrm{Al}_{3} \mathrm{Cl}$ (Fig. 3.20) [28].

Table 3.8 Predicted potential at the IGSCC tip in unsensitized $5083-\mathrm{H} 131\left(3 \mathrm{mg} / \mathrm{cm}^{2}\right)$ at $\mathrm{K}$ of $15 \mathrm{MPa} \sqrt{\mathrm{m}}$ for the three orientations illustrated in Fig. 3.16.

\begin{tabular}{|c|c|c|c|c|c|}
\hline \multirow{2}{*}{$\begin{array}{c}\mathrm{da} / \mathrm{dt}_{\mathrm{K} 15} \\
(\mathrm{~nm} / \mathrm{s})\end{array}$} & \multirow{2}{*}{ Electrolyte } & \multirow{2}{*}{$\begin{array}{c}E_{\text {app }} \\
\left(V_{\mathrm{SCE}}\right)\end{array}$} & Orientation A & Orientation B & Orientation $\mathrm{C}$ \\
\hline & & & $\mathrm{E}_{\text {tip }}\left(\mathrm{V}_{\mathrm{SCE}}\right)$ & $\mathrm{E}_{\text {tip }}\left(\mathrm{V}_{\mathrm{SCE}}\right)$ & $\mathrm{E}_{\text {tip }}\left(\mathrm{V}_{\mathrm{SCE}}\right)$ \\
\hline 43 & $0.6 \mathrm{M} \mathrm{NaCl}$ & -0.730 & -0.75 & -0.79 & -0.77 \\
\hline 1.5 & $0.6 \mathrm{M} \mathrm{NaCl}$ & -0.800 & -0.80 & -0.83 & -0.82 \\
\hline 0.14 & $0.6 \mathrm{M} \mathrm{NaCl}$ & -1.020 & -1.02 & -1.05 & -1.04 \\
\hline $50,200^{*}$ & $\mathrm{Al}-4 \% \mathrm{Mg}$ & -1.000 & -1.02 & -1.05 & -1.04 \\
\hline 0.9 & $0.01 \mathrm{M} \mathrm{NaOH}^{\%}$ & -1.800 & -1.20 & -- & -- \\
\hline 0.9 & $0.01 \mathrm{M} \mathrm{NaOH} \%$ & $\mathrm{OCP}^{* *}$ & -1.20 & -- & -- \\
\hline
\end{tabular}

Table 3.9 Predicted $\mathrm{pH}$ and $\eta_{\mathrm{H}}$ at the IGSCC tip in unsensitized 5083-H131 $\left(3 \mathrm{mg} / \mathrm{cm}^{2}\right)$ at $\mathrm{K}$ of $15 \mathrm{MPa} \sqrt{\mathrm{m}}$ for the three orientations illustrated in Fig. 3.16.

\begin{tabular}{|c|c|c|c|c|}
\hline \multirow{2}{*}{$\mathrm{da} / \mathrm{dt}_{\mathrm{K} 15}(\mathrm{~nm} / \mathrm{s})$} & \multirow{2}{*}{ Electrolyte } & \multirow{2}{*}{$\mathrm{E}_{\mathrm{app}}\left(\mathrm{V}_{\mathrm{SCE}}\right)$} & Orientation $\mathrm{A}$ & Orientation A \\
\hline & & & Tip $p H$ & $\eta_{\mathrm{H}}(\mathrm{V})$ \\
\hline 43 & $0.6 \mathrm{M} \mathrm{NaCl}$ & -0.730 & 1.5 & -0.42 \\
\hline 1.5 & $0.6 \mathrm{M} \mathrm{NaCl}$ & -0.800 & 2.8 & -0.40 \\
\hline 0.14 & $0.6 \mathrm{M} \mathrm{NaCl}$ & -1.020 & 7.7 & -0.33 \\
\hline $50,200^{*}$ & $\mathrm{Al}-4 \% \mathrm{Mg}$ & -1.000 & 4.0 & -0.54 \\
\hline 0.9 & $0.01 \mathrm{M} \mathrm{NaOH}^{\%}$ & -1.800 & 10.0 & -0.37 \\
\hline 0.9 & $0.01 \mathrm{M} \mathrm{NaOH}^{\%}$ & $\mathrm{OCP}^{* *}$ & 10.0 & -0.37 \\
\hline
\end{tabular}




\subsection{Intergranular SCC susceptibility in unsensitized 5083-H131}

Crack growth rates in Fig. 3.10 demonstrate that generally resistant $\beta$-free 5083-H131 (3 $\mathrm{mg} / \mathrm{cm}^{2}$ ) becomes highly susceptible to IGSCC when stressed: (a) under anodic polarization near-neutral $\mathrm{NaCl}$, or (b) in acidic simulated crack tip solution. This behavior is examined in light of subtle crack tip chemistry differences among: (a) unsensitized 5083H131 in simulated crack solution with modest cathodic polarization $\left(-1.000 \mathrm{~V}_{\mathrm{SCE}}\right)$, (b) unsensitized 5083-H131 in neutral $\mathrm{NaCl}$ with significant anodic polarization $\left(-0.730 \mathrm{~V}_{\mathrm{SCE}}\right)$, and (c) the sensitized microstructure in neutral $\mathrm{NaCl}$ at $-0.730 \mathrm{~V}_{\mathrm{SCE}}$. Figure $3.28(\bullet)$ illustrates the crack tip $\mathrm{pH}$ and potential for each of these experiments. The reversible potential for water $\left(\right.$ and $\mathrm{H}^{+}$) reduction to form $\mathrm{H}$ is shown by the solid line, and the magnitude of $\eta_{H}$ is shown by the arrows for each experiment. The correlation between $\mathrm{da} / \mathrm{dt}_{\mathrm{II}}$ and estimated $\eta_{\mathrm{H}}$ for each microstructure-environment is considered below.

Considering unsensitized 5083-H131 (S-L) in near-neutral $\mathrm{NaCl}$ at $-0.730 \mathrm{~V}_{\mathrm{SCE}}$, the predicted crack tip $\mathrm{pH}$ is $1-2, \mathrm{E}_{\mathrm{tip}}$ is $-0.750 \mathrm{~V}_{\mathrm{SCE}}$, and the resulting crack tip $\eta_{\mathrm{H}}$ is $-0.42 \mathrm{~V}$. This high overpotential and low $\mathrm{pH}$ produces a relatively rapid crack growth rate $(43 \mathrm{~nm} / \mathrm{s})$. The highly acidic crack tip chemistry was likely developed by $\alpha$ dissolution alone. Since the predicted $\mathrm{E}_{\mathrm{tip}}$ is well above the $\mathrm{pH}$ sensitive $\mathrm{E}_{\mathrm{Br}-\alpha}, \alpha$ dissolution was promoted by anodic dissolution. As the crack tip became more acidic with hydrolysis, EBr- likely fell to that measured in a simulated crack tip solution (Fig. 3.14), which would cause the driving force for $\alpha$ dissolution to increase further. 


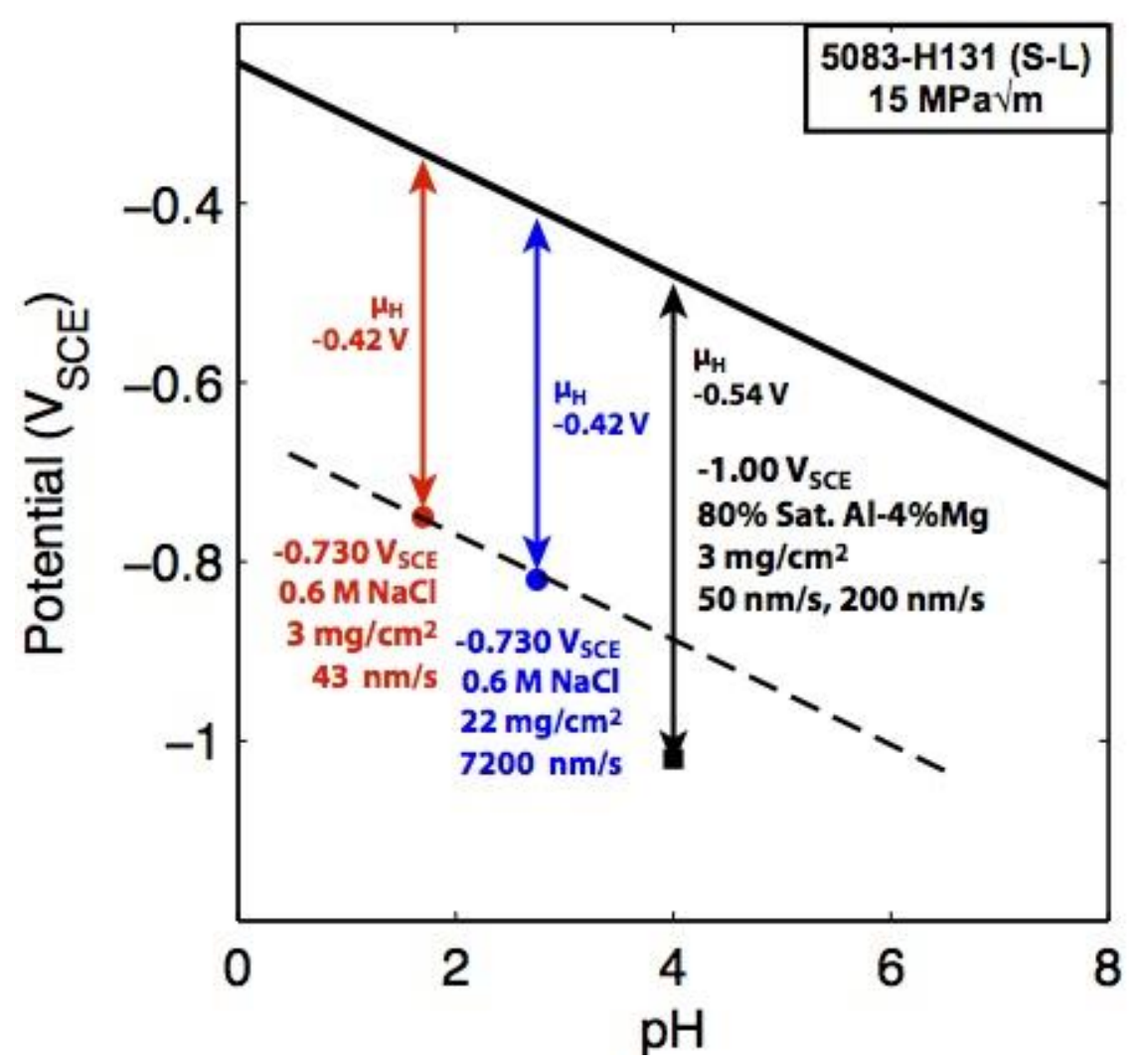

Figure 3.28 Crack tip potential as a function of crack tip pH (Tables 3.7-3.9), showing the predicted overpotential for $\mathrm{H}$ production in a crack tip of 5083-H131 at three different microstructure-environment combinations. The lower dashed line is parallel to the $\mathrm{pH}$ dependent reversible potential for water and proton reduction and is drawn for reference. Applied potential, bulk solution, DoS and measured crack growth rate from Fig. 3.10 are listed for each experiment.

A discrepancy in the crack tip chemistry $-\mathrm{da} / \mathrm{dt}_{\text {II }}$ relationship is observed when the crack growth rates for sensitized and unsensitized 5083-H131 (S-L) are compared in the same environment. For sensitized 5083-H131 (S-L) in near-neutral $\mathrm{NaCl}$ at $-0.730 \mathrm{~V}_{\mathrm{SCE}}$, the predicted crack tip $\mathrm{pH}$ is $2-3, \mathrm{E}_{\mathrm{tip}}$ is $-0.800 \mathrm{~V}_{\mathrm{SCE}}$, and the resulting crack tip $\eta_{\mathrm{H}}$ is also $-0.42 \mathrm{~V}$, yet the crack growth rate is $7200 \mathrm{~nm} / \mathrm{s}$, which is almost 200 times faster than that in unsensitized 5083 for the same $\mathrm{H}$ overpotential. The $\mathrm{H}$ diffusion HEAC model described in Eqn. 3.2 can explain this significant crack growth difference. The trap 
sensitive $\mathrm{H}$ diffusivity may increase due to $\beta$ presence, as developed in Chapter 4 . A more rapid $\mathrm{H}$ diffusivity linearly increases the $\mathrm{H}$ diffusion limited crack growth rate for a given ( $\eta_{\mathrm{H}}$ influenced) $\mathrm{C}_{\mathrm{H \sigma}} / \mathrm{C}_{\mathrm{H}-\mathrm{crit}}$ relationship, as seen in Eqn. 3.2. Additionally, though the same $\eta_{\mathrm{H}}(-0.42 \mathrm{~V})$ is produced in both environment-microstructure conditions, the resulting $\mathrm{C}_{\mathrm{H}-\mathrm{Diff}}$ in as-received 5083-H131 may be much lower than that in sensitized 5083-H131; for example due to an effect of $\mathrm{Mg}^{2+}$, or $\mathrm{OH}^{-}$on $\mathrm{H}$ uptake, as suggested by the trends in Fig. $21 \mathrm{~b}$ reported for steel [52].

Considering IGSCC of as-received 5083-H131 $\left(3 \mathrm{mg} / \mathrm{cm}^{2}\right)$ in acidic simulated crack solution at $-1.000 \mathrm{~V}_{\mathrm{SCE}}, \mathrm{H}$ production is favored at an acidic crack tip with an extremely high crack tip $\eta_{H}(-0.54 \mathrm{~V})$, resulting in relatively rapid crack growth rates $(50 \mathrm{~nm} / \mathrm{s}$ and $200 \mathrm{~nm} / \mathrm{s}$ in Fig. 3.10). The high $\eta_{\mathrm{H}}$ may be developed by the combination of a cathodic tip potential (-1.05 $\left.\mathrm{V}_{\mathrm{SCE}}\right)$ and relatively low $\mathrm{pH}$ to near 4, as predicted in Section 3.6.2.2. Cathodic corrosion product solubility in the occluded crack tip may counteract cathodic hydroxyl production, which often causes alkaline environments during cathodic polarization.

The crack growth rates for as-received 5083-131 in: (a) simulated crack tip solution, and (b) anodically polarized $\mathrm{NaCl}$ are on the same order yet the difference in $\eta_{\mathrm{H}}$ is $100 \mathrm{mV}$. Reported solubility of $\mathrm{H}$ as a function of $\eta_{H}$ in ultra-high strength steels shows that the solubility of $\mathrm{H}$ may become independent of $\eta_{\mathrm{H}}$ at high magnitudes (Fig. 3.21b) [52]. In unsensitized 5083-H131, the $\mathrm{C}_{\mathrm{H}-\mathrm{Diff}}$ produced from $\eta_{\mathrm{H}}$ of $-0.42 \mathrm{~V}$ in $\mathrm{NaCl}$ may be similar to that produced at $-0.54 \mathrm{~V}$ in acidic simulated crack tip solution. To further this point, when the ratio of $\mathrm{C}_{\mathrm{H} \sigma} / \mathrm{C}_{\mathrm{H}-\mathrm{crit}}$ exceeds 6.3 (as it likely does for these high $\eta_{\mathrm{H}}$ and low $\mathrm{pH}$ environments), a significant increase in $\mathrm{H}$ concentration will at most contribute to a crack 
growth rate increase of 7 times, owing to the squared inverse error term in Eqn. 3.2. Even though there may be a large difference in $\mathrm{C}_{\mathrm{H} \sigma}$, the resulting $\mathrm{da} / \mathrm{dt}$ may not be as significant. This explanation is quantitatively assessed in Section 3.6.6.1.

Collectively, these results demonstrate that: (a) crack acidification (known to be produced by $\beta$ dissolution) is necessary for $\mathrm{H}$ production and uptake in IGSCC of 5083$\mathrm{H} 131$, and (b) $\beta$-free $5083-\mathrm{H} 131$ (representative of $\alpha$ ligaments between $\beta$ ) is susceptible to IGSCC by $\mathrm{H}$ embrittlement. The former result points to the dominant role of crack chemistry, while the latter result shows that $\beta$ is not uniquely required for stress concentration, local constraint, or novel $\mathrm{H}$ trapping during IGSCC. Growth between $\beta$ is likely driven by $\mathrm{H}$ embrittlement and controlled by the crack tip chemistry. The local stress state of this grain boundary microstructure was detailed in Chapter 2.

\subsection{Intergranular SCC resistance in unsensitized 5083-H131}

Though unsensitized 5083-H131 is generally highly resistant to IGSCC in near neutral $\mathrm{pH}$ chloride solutions, the previous discussion showed that unsensitized 5083-H131 is susceptible to IGSCC when the crack tip chemistry provides a high enough concentration of diffusible $\mathrm{H}$ for $\mathrm{H}$ embrittlement. It is not surprising that this crack tip chemistry is not produced in unsensitized 5083-H131 at near OCP and cathodic potentials in $\mathrm{NaCl}$, where there is little to no driving force for $\alpha$ dissolution, crack solution hydrolysis, and $\mathrm{H}$ production. What is surprising is that unsensitized 5083-H131 is highly resistant to IGSCC in high $\mathrm{H}$ producing alkaline environments, as shown by the growth rate data in Fig. 3.10. The crack tip chemistry developed and the influence on da/dt II is discussed for these resistant environment-microstructure conditions. 
Considering unsensitized $5083-\mathrm{H} 131\left(3 \mathrm{mg} / \mathrm{cm}^{2}\right)$ in neutral $\mathrm{NaCl}$ polarized to $-0.800 \mathrm{~V}_{\mathrm{SCE}}, \mathrm{da} / \mathrm{dt}$ is $1.5 \mathrm{~nm} / \mathrm{s}$ and the predicted crack tip potential-pH condition $\left(-0.800 \mathrm{~V}_{\mathrm{SCE}}\right.$ and $\mathrm{pH}$ of $\left.2-3\right)$ during IGSCC yields an $\eta_{\mathrm{H}}$ of $-0.40 \mathrm{~V}$. The crack growth rate is much slower compared to unsensitized $5083-\mathrm{H} 131$ in $\mathrm{NaCl}$ polarized to $-0.730 \mathrm{~V}_{\mathrm{SCE}}$, which is $43 \mathrm{~nm} / \mathrm{s}$ with a predicted crack tip potential of $-0.750 V_{\mathrm{SCE}}, \mathrm{pH}$ of 1.5 , and $\eta_{\mathrm{H}}$ of $-0.42 \mathrm{~V}$. This comparison, in addition to the relationship between $\eta_{\mathrm{H}}, \mathrm{pH}$, and $\mathrm{C}_{\mathrm{H}-\mathrm{Diff}}$ measured in AerMet 100 in Fig. 21b [52], suggests that $\mathrm{pH}$ may influence the $\mathrm{H}$ solubility (and therefore HEAC) in 5083-H131 more than $\eta_{\mathrm{H}}$. Since the $\mathrm{C}_{\mathrm{H}-\mathrm{Diff}}$ dependence on $\eta_{\mathrm{H}}$ and $\mathrm{pH}$ has not been established for $\mathrm{Al}-\mathrm{Mg}$, the relationship for $5083-\mathrm{H} 131$ is assumed from AerMet 100 measurements shown in Fig. 21b [52]. A small change in $\mathrm{pH}$ (when below pH 6) can contribute to a significant change in $\mathrm{C}_{\mathrm{H}-\mathrm{Diff}}$, though a small change in $\eta_{\mathrm{H}}$ may not contribute to this change when $\eta_{\mathrm{H}}$ is below a critical value $(-0.4 \mathrm{~V}$ for AerMet 100). Alternatively, when above this critical $\eta_{\mathrm{H}}$, the $\mathrm{C}_{\mathrm{H}-\mathrm{Diff}}$ may increase significantly with a small decrease in $\eta_{H}$ on the order predicted for these two experiments. The change in magnitude of da/dtII between unsensitized $5083-\mathrm{H} 131$ polarized to $-0.730 \mathrm{~V}_{\mathrm{SCE}}$ and -0.800 $\mathrm{V}_{\mathrm{SCE}}$ is plausible based on Eqn. 3.2 due to the character of the squared inverse error function term; the $\mathrm{pH}$ or $\eta_{\mathrm{H}}$ controlled decrease in $\mathrm{C}_{\mathrm{H}-\mathrm{DEFF}}$ likely contributes to $\mathrm{C}_{\mathrm{H} \sigma}$ falling to near $\mathrm{C}_{\mathrm{H}-\text {-crit, }}$ which would cause a several order-of-magnitude decrease in $\mathrm{da} / \mathrm{dt}$ II. In addition, a highly aggressive crack tip chemistry is not expected for this environmentmicrostructure condition (unsensitized 5083- $\mathrm{H} 131$ in neutral $\mathrm{NaCl}$ at $\mathrm{E}_{\text {app }}-0.800 \mathrm{~V}_{\mathrm{SCE}}$ ). The crack tip potential, $-0.830 \mathrm{~V}_{\mathrm{SCE}}\left(\right.$ Table 3.7 ), lies within the range of $\mathrm{pH}$ sensitive $\mathrm{E}_{\mathrm{Br}-\alpha}$ (Table 3.2); therefore, the driving force for $\alpha$ dissolution is not as large as it is in the $-0.730 \mathrm{~V}_{\mathrm{SCE}}$ case, which is polarized above the $\mathrm{pH}$ sensitive $\mathrm{E}_{\mathrm{Br}-\alpha}$ range. 
Unsensitized 5083-H131 (3 mg/ $\left.\mathrm{cm}^{2}\right)$ polarized to $-1.020 \mathrm{~V}$ SCE in $\mathrm{NaCl}$ has a low magnitude of predicted $\eta_{\mathrm{H}}(-0.33 \mathrm{~V})$ and relatively high $\mathrm{pH}(7.7)$. Very low-level da/dt measured in this microstructure-environment is consistent with low crack tip H solubility due to high $\mathrm{pH}$ and low $\eta_{\mathrm{H}}$, leading to the expectation of very low to nil HEAC in this environment.

Even with strong cathodic polarization for $\mathrm{H}$ production, $\mathrm{HEAC}$ is minimal for asreceived 5083-H131 $\left(3 \mathrm{mg} / \mathrm{cm}^{2}\right)$ in $\mathrm{NaOH}$ solution. Alkaline $\mathrm{NaOH}$ at $\mathrm{OCP}-1.37 \mathrm{VSCE}$ and pH 12 produced $\mathrm{H}$ uptake on bold surfaces of $5083-\mathrm{H} 131$ based on permeation measurements [46]. However, the similar potential- $\mathrm{pH}$ range $\left(-1.200 \mathrm{~V}_{\mathrm{SCE}}\right.$ at $\left.\mathrm{pH} 10\right)$ expected at an isolated crack tip is different from that at the bold surface for SENT specimens in $\mathrm{NaOH}$ at either OCP, or polarized to $-1.800 \mathrm{~V}_{\mathrm{SCE}}$. The occluded nature of the crack tip drives an alternate chemistry, as discussed in Section 3.6.2.2. Each of these crack tip potential-pH combinations produces a mid-level $\eta_{H}$ of $-0.37 \mathrm{~V}$. The absence of film destabilizing $\mathrm{Cl}^{-}$reduces uptake, which is consistent with low measured crack growth rates (0.9 nm/s in Fig. 3.10). Moreover, this low magnitude of $\eta_{\mathrm{H}}$ and high $\mathrm{pH}$ suggest a low $\mathrm{H}$ solubility at the crack tip of this microstructure-environment, with the assumed relationship shown in Fig. $21 \mathrm{~b}$ [52]. It is important to note that the change in $\mathrm{Cl}^{-}, \mathrm{Mg}^{2+}$, and $\mathrm{OH}^{-}$ concentrations in these environments may negate the $\mathrm{C}_{\mathrm{H} \text {-Diff }}$ comparison between environment-microstructure conditions. Without $\mathrm{H}$ solubility measurements specific to 5083-H131, these suggestions cannot be confirmed. Nonetheless, the lack of measured HEAC in chloride free alkaline environments establishes the importance of $\beta$ dissolution in promoting an acidic crack tip chemistry for high $\mathrm{H}$ production and uptake required for IGSCC. 
In the absence of a highly acidic crack tip electrolyte, limited $\mathrm{H}$ production and uptake may at best support low rate HEAC $(\sim 0.1 \mathrm{~nm} / \mathrm{s}$ to $1.3 \mathrm{~nm} / \mathrm{s})$ in as-received $5083-\mathrm{H} 131$ at high K. Low crack growth rates in these resistant material-environment scenarios are the same order as the maximum possible level of water vapor HEAC, which is consistent with limited $\mathrm{H}$ uptake. In contrast, highly acidic, chloride-rich crack tip environments (developed artificially or by $\beta$ dissolution) contribute to significant $\mathrm{H}$ production and yield the H uptake required for IGSCC by the proposed mechanism.

\subsubsection{Modeling potential controlled IGSCC}

Can the daldt measured for sensitized and unsensitized 5083 in various environments be quantitatively predicted based on H concentration at the crack tip FPZ?

Two cracking models, one crack tip $\mathrm{H}$ diffusion controlled and the other film rupture based, have been put forth to predict IGSCC kinetics in 5083. The validity of each model in predicting IGSCC in unsensitized and sensitized 5083 is explored. The $\beta$ dissolution$\mathrm{H}$ diffusion model (Eqn. 3.2) is used to predict crack growth rates based on predicted crack tip chemistries from the present study. The coupled environmental fracture model (CEFM), originally developed for film rupture-based IGSCC in sensitized stainless steel [66], was recently modified to include a $\mathrm{H}$ embrittlement element and predict the effect of applied potential on IGSCC in Al-Mg [36]. This latter model has not been adapted for sensitized microstructures; therefore, it is not applicable to the broad results developed in this study.

\subsubsection{Hydrogen diffusion limited crack growth in $\mathbf{5 0 8 3}$}

Crack growth rates of 5083-H131 (S-L) are compared in Fig. 3.29 with the fastest rates of environmental crack growth by $\mathrm{H}$ embrittlement reported for a wide range of high strength alloy classes as a function of the best estimate of trap-sensitive diffusivity of $\mathrm{H}$ in 
the alloy $\left(\mathrm{D}_{\mathrm{H}-\mathrm{EFF}}\right)$ from permeation experiments. The trend line depicts the direct proportionality of the crack growth rate to $\mathrm{D}_{\mathrm{H}-\mathrm{EFF}}$, illustrating the rate-limiting role of $\mathrm{H}$ diffusivity in HEAC in these alloys as fit to Eqn. 3.2.

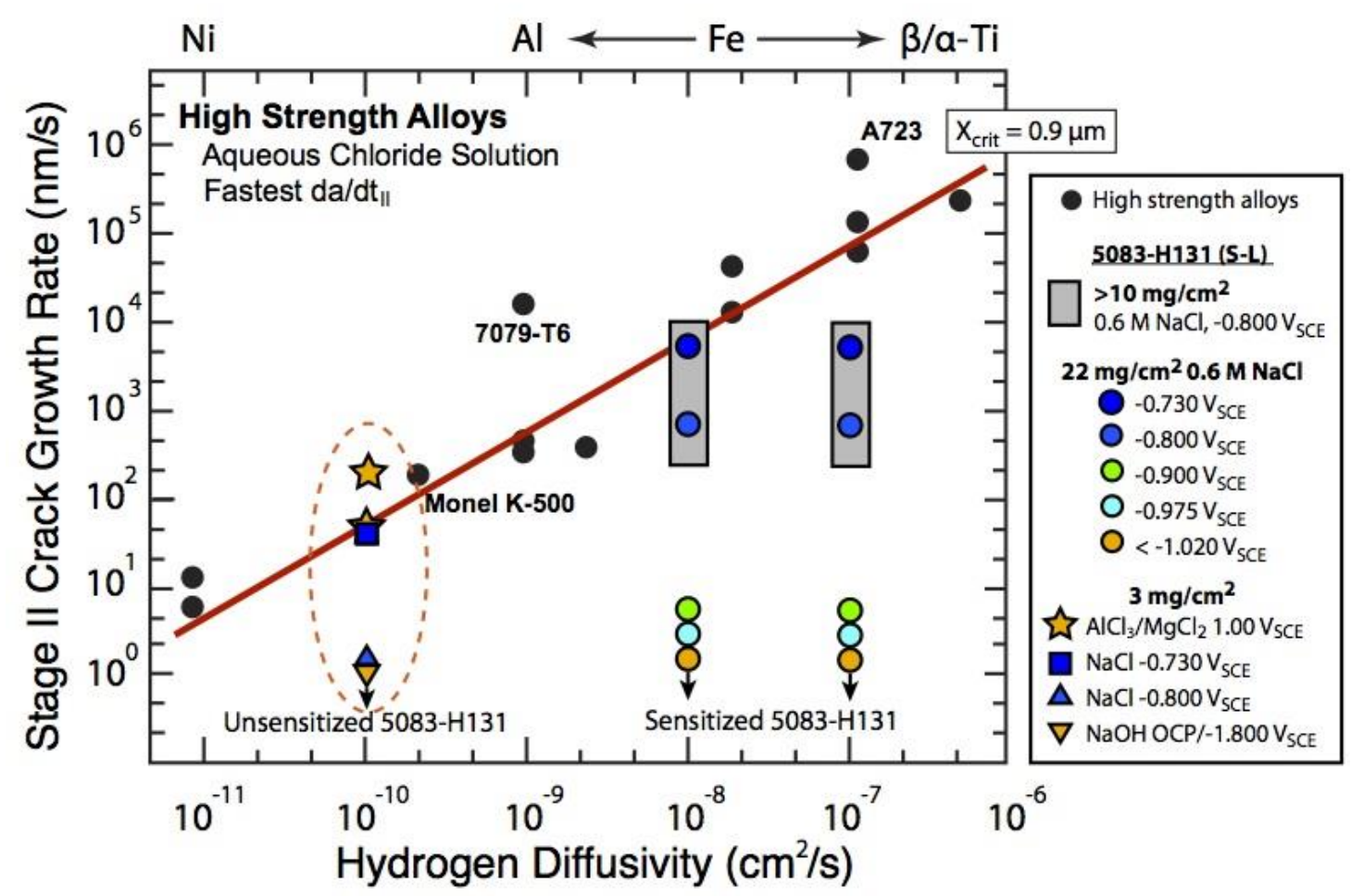

Figure 3.29 Stage II crack growth rate plotted as a function of trap sensitive $\mathrm{H}$ diffusivity. The solid trend line and filled symbols $(\bullet[61,68])$ represent maximum $\mathrm{da} / \mathrm{dt}_{\mathrm{II}}$ reported for $\mathrm{H}$ diffusion controlled HEAC in high strength alloys. All other data represent $\mathrm{da} / \mathrm{dt}_{\mathrm{K} 15}$ in $5083-\mathrm{H} 131$ (S-L): (a) the 2 grey rectangles are sensitized (from $10 \mathrm{mg} / \mathrm{cm}^{2}$ to $49 \mathrm{mg} / \mathrm{cm}^{2}$ ) in $0.6 \mathrm{M} \mathrm{NaCl}$ polarized to $-0.800 \mathrm{~V}_{\mathrm{SCE}}$, (b) (O) are sensitized $\left(22 \mathrm{mg} / \mathrm{cm}^{2}\right)$ in $0.6 \mathrm{M} \mathrm{NaCl}$ at given applied potentials, $(\dot{\omega})$ as-received $\left(3 \mathrm{mg} / \mathrm{cm}^{2}\right)$ in $\mathrm{AlCl}_{3} / \mathrm{MgCl}_{2}$ at $-1.000 \mathrm{~V}_{\mathrm{SCE}},(\square)$ as-received $\left(3 \mathrm{mg} / \mathrm{cm}^{2}\right)$ in $\mathrm{NaCl}$ at $-0.730 \mathrm{~V}_{\mathrm{SCE}},(\Delta)$ asreceived $\left(3 \mathrm{mg} / \mathrm{cm}^{2}\right)$ in $\mathrm{NaCl}$ at $-0.800 \mathrm{~V}_{\mathrm{SCE}}$ and $(\nabla)$ as-received in $\mathrm{NaOH}$ at both $\mathrm{OCP}$ and $-1.800 \mathrm{~V}_{\text {SCE }}$.

Stage II crack growth rates for 5083-H131 (S-L) can be interpreted in the context of H

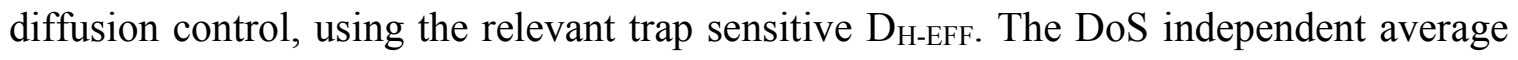
diffusivity measured by a first rise transient permeation analysis for the present lot of 5083- 
$\mathrm{H} 131$ is $1.3 \times 10^{-10} \mathrm{~cm}^{2} / \mathrm{s}$ in the relevant $\mathrm{L}$ direction [46]. After three rising permeation transients, each followed by H egress, this DH-EFF increased to an average of $5.8 \times 10^{-9} \mathrm{~cm}^{2} / \mathrm{s}$ for DoS between $2 \mathrm{mg} / \mathrm{cm}^{2}$ and $39 \mathrm{mg} / \mathrm{cm}^{2}$ in the $\mathrm{L}$ direction (assumed to be $10^{-8} \mathrm{~cm}^{2} / \mathrm{s}$ for simplicity) [46]. In pure $\mathrm{Al}$, a similar increase in $\mathrm{D}_{\mathrm{H}-\mathrm{EFF}}$ to $10^{-8} \mathrm{~cm}^{2} / \mathrm{s}$ was observed following two charging repetitions [67]. This increase was attributed to $H$ trap filling, however the identity of these $H$ traps was not confirmed [46,67]. Without $H$ trapping, $\mathrm{D}_{\mathrm{H}-\mathrm{EFF}}$ was reported to increase to a maximum of $10^{-7} \mathrm{~cm}^{2} / \mathrm{s}$ in pure $\mathrm{Al}$ [38]. Chapter 4 suggests that the first rise transient $\mathrm{D}_{\mathrm{H}-\mathrm{EFF}}$ is accurate for $5083-\mathrm{H} 131\left(10^{-10} \mathrm{~cm}^{2} / \mathrm{s}\right.$ is used for simplicity), though the $D_{\text {H-EFF }}$ local to the crack tip could increase to between $10^{-8} \mathrm{~cm}^{2} / \mathrm{s}$ and $10^{-7} \mathrm{~cm}^{2} / \mathrm{s}$ depending on the $\mathrm{H}$ trapping characteristics at the crack tip. Crack growth rates from Fig. 3.10 are plotted at the relevant $\mathrm{D}_{\mathrm{H}-\mathrm{EFF}}$ in Fig. 3.27 (rates from Figs. 2.17 and 3.24 are plotted at two $D_{\text {H-EFF }}$ demonstrating that either $10^{-8} \mathrm{~cm}^{2} / \mathrm{s}$ or $10^{-7} \mathrm{~cm}^{2} / \mathrm{s}$ is relevant for these environment-microstructure conditions).

Crack growth rates for a range of sensitized 5083-H131 in near neutral $\mathrm{NaCl}$ polarized to $-0.800 \mathrm{~V}_{\mathrm{SCE}}$ ( 2 shaded boxes in Fig. 3.29 showing data from Fig. 2.17), are close to but below the fastest predicted $\mathrm{H}$ diffusion rate limited da/dt at $\mathrm{D}_{\mathrm{H}-\mathrm{EFF}}$ of $10^{-7} \mathrm{~cm}^{2} / \mathrm{s}$, yet lie on the fastest predicted rates at $\mathrm{D}_{\mathrm{H}-\mathrm{EFF}}$ of $10^{-8} \mathrm{~cm}^{2} / \mathrm{s}$. (The issue of which $\mathrm{D}_{\mathrm{H}-\mathrm{EFF}}$ is pertinent to the crack tip FPZ is discussed in Chapter 4). The filled-large circles at $10^{-7} \mathrm{~cm}^{2} / \mathrm{s}$ and $10^{-8} \mathrm{~cm}^{2} / \mathrm{s}$ show the potential dependence of crack growth rates for a single condition of sensitized 5083-H131 $\left(22 \mathrm{mg} / \mathrm{cm}^{2}\right)$ in near neutral $\mathrm{NaCl}$. Crack growth rates measured in unsensitized $5083-\mathrm{H} 131\left(3 \mathrm{mg} / \mathrm{cm}^{2}\right)$ in various solutions are plotted at $\mathrm{D}_{\mathrm{H}-\mathrm{EFF}}$ of $10^{-10} \mathrm{~cm}^{2} / \mathrm{s}$. 
Using the various crack growth rates measured for as-received 5083-H131, the Stage II $\mathrm{da} / \mathrm{dt}$ model in Eqn. 3.2, $\mathrm{x}_{\text {CRIT }}$ of $0.9 \mu \mathrm{m}$, and assigned $\mathrm{D}_{\mathrm{H}-\mathrm{EFF}}$ values; the ratio of $\mathrm{C}_{\mathrm{H} \sigma}$ to $\mathrm{C}_{\mathrm{H}-\mathrm{crit}}$ can be predicted for each experiment represented in Fig. 3.29. For example, with $D_{\text {H-EFF }}$ of $10^{-10} \mathrm{~cm}^{2} / \mathrm{s}$ and $\mathrm{x}_{\text {CRIT }}$ of $0.9 \mu \mathrm{m}$, the crack growth rate expected when the inverse error function goes to $1\left(\mathrm{C}_{\mathrm{H \sigma}} / \mathrm{C}_{\mathrm{H}-\text { crit }}\right.$ is 6.3$)$ is $44 \mathrm{~nm} / \mathrm{s}$, as shown by the unity-slope trend line in Fig. 3.29. By comparing measured crack growth rates with this standard set of conditions, the relationship, $\mathrm{C}_{\mathrm{Ho}} / \mathrm{C}_{\mathrm{H}-\text { crit, }}$, was predicted for each relevant $\mathrm{da} / \mathrm{dt}$ in unsensitized 5083-H131 $\left(3 \mathrm{mg} / \mathrm{cm}^{2}\right)$. The same ratios were calculated for sensitized 5083H131: with $\mathrm{X}_{\text {CRIT }}$ of $0.9 \mu \mathrm{m}$, the crack growth rate expected when the inverse error function goes to 1 is $44,400 \mathrm{~nm} / \mathrm{s}$ for $D_{\text {H-EFF }}$ of $10^{-7} \mathrm{~cm}^{2} / \mathrm{s}$ and $4,400 \mathrm{~nm} / \mathrm{s}$ for $D_{\text {H-EFF }}$ of $10^{-8} \mathrm{~cm}^{2} / \mathrm{s}$. Using this approach, the ratio $\mathrm{C}_{\mathrm{H \sigma}} / \mathrm{C}_{\mathrm{H}-\text { crit }}$ was calculated for each measured $\mathrm{da} / \mathrm{dt}$ in asreceived $\left(3 \mathrm{mg} / \mathrm{cm}^{2}\right)$ and sensitized $5083-\mathrm{H} 131\left(22 \mathrm{mg} / \mathrm{cm}^{2}\right)$; results are presented in Table 3.10.

When as-received $5083-\mathrm{H} 131$ is exposed to $\mathrm{AlCl}_{3} / \mathrm{MgCl}_{2}$ simulated crack tip solution polarized to $-1.000 \mathrm{~V}_{\mathrm{SCE}}$, the cathodically polarized, highly acidic crack tip environment promotes significant $\mathrm{H}$ production and uptake $\left(\eta_{\mathrm{H}}-0.54 \mathrm{~V}\right.$, Table 3.9). The replicate values of measured da/dtk15 ( $\vec{s}$ in Fig. 3.29; $50 \mathrm{~nm} / \mathrm{s}$ and $200 \mathrm{~nm} / \mathrm{s}$ ) in 5083-H131 are just above the unity-slope trend line for the fastest predicted $\mathrm{da} / \mathrm{dt}_{\mathrm{II}}$ for diffusion-controlled $\mathrm{H}$ embrittlement with $\mathrm{D}_{\text {H-EFF }}$ of $10^{-10} \mathrm{~cm}^{2} / \mathrm{s}$. The 2.5 -times increase in average-measured crack growth rate, above the trend line can be explained by a $\mathrm{C}_{\mathrm{H} \sigma}$ increase to $333 \mathrm{C}_{\mathrm{H}-\mathrm{crit}}$ (Table 3.10). The combination of low $\mathrm{pH}$, high magnitude $\eta_{\mathrm{H}}$, and film destabilization by $\mathrm{Cl}^{-}$could produce this high $\mathrm{H}$ concentration at the FPZ. 
Table 3.10 Crack growth rate in 5083-H131 (S-L), measured for various environments, and corresponding $\mathrm{C}_{\mathrm{H \sigma}} / \mathrm{C}_{\mathrm{H} \text {-crit }}$ predicted by Eqn. 3.2 and assuming $\mathrm{x}_{\mathrm{CRIT}}=0.9 \mu \mathrm{m}$.

\begin{tabular}{|c|c|c|c|c|}
\hline $\begin{array}{c}\mathrm{da} / \mathrm{dt}_{\mathrm{K} 15} \\
(\mathrm{~nm} / \mathrm{s})\end{array}$ & Electrolyte & $\mathrm{E}_{\mathrm{app}}\left(\mathrm{V}_{\mathrm{SCE}}\right)$ & $\mathrm{C}_{\mathrm{H \sigma}} / \mathrm{C}_{\mathrm{H}-\mathrm{crit}}$ & $\begin{array}{c}\eta_{\mathrm{H}}(\mathrm{V}) \\
\text { Orientation A }\end{array}$ \\
\hline \multicolumn{5}{|c|}{ AS-RECEIVED $3 \mathrm{mg} / \mathrm{cm}^{2}-D_{\text {H-EFF }}=10^{-10} \mathrm{~cm}^{2} / \mathrm{s}$} \\
\hline 44 & \multicolumn{2}{|c|}{ Master Line Fig. 3.29} & 6.3 & -- \\
\hline 200 & $\mathrm{Al}-4 \% \mathrm{Mg}$ & -1.000 & 333 & -0.57 \\
\hline 50 & $\mathrm{Al}-4 \% \mathrm{Mg}$ & -1.000 & 7.5 & -0.57 \\
\hline 43 & $0.6 \mathrm{M} \mathrm{NaCl}$ & -0.730 & 6.1 & -0.40 \\
\hline 1.5 & $0.6 \mathrm{M} \mathrm{NaCl}$ & -0.800 & 1.3 & -0.39 \\
\hline 0.14 & $0.6 \mathrm{M} \mathrm{NaCl}$ & -1.020 & 1.1 & -0.32 \\
\hline 0.9 & $0.01 \mathrm{M} \mathrm{NaOH}$ & -1.800 & 1.2 & -0.37 \\
\hline 0.9 & $0.01 \mathrm{M} \mathrm{NaOH}$ & $\mathrm{OCP}$ & 1.2 & -0.37 \\
\hline \multicolumn{5}{|c|}{ SENSITIZED $22 \mathrm{mg} / \mathrm{cm}^{2}-D_{\text {H-EFF }}=10^{-8} \mathrm{~cm}^{2} / \mathrm{s}$} \\
\hline 4440 & \multicolumn{2}{|c|}{ Master Line Fig. 3.29} & 6.3 & -- \\
\hline 7200 & $0.6 \mathrm{M} \mathrm{NaCl}$ & -0.730 & 13.89 & -0.41 \\
\hline 800 & $0.6 \mathrm{M} \mathrm{NaCl}$ & -0.800 & 1.82 & -0.40 \\
\hline 7.8 & $0.6 \mathrm{M} \mathrm{NaCl}$ & -0.900 & 1.05 & -0.37 \\
\hline 3.8 & $0.6 \mathrm{M} \mathrm{NaCl}$ & -0.975 & 1.03 & -0.35 \\
\hline 6.4 & $0.6 \mathrm{M} \mathrm{NaCl}$ & -1.020 & 1.04 & -0.34 \\
\hline 1.3 & $0.6 \mathrm{M} \mathrm{NaCl}$ & -1.080 & 1.02 & -0.34 \\
\hline 1.3 & $0.6 \mathrm{M} \mathrm{NaCl}$ & -1.100 & 1.02 & -0.34 \\
\hline 1.0 & $0.6 \mathrm{M} \mathrm{NaCl}$ & -1.300 & 1.02 & -0.34 \\
\hline \multicolumn{5}{|c|}{ SENSITIZED $22 \mathrm{mg} / \mathrm{cm}^{2}-D_{\text {H-EFF }}=10^{-7} \mathrm{~cm}^{2} / \mathrm{s}$} \\
\hline 44400 & \multicolumn{2}{|c|}{ Master Line Fig. 3.29} & 6.3 & -- \\
\hline 7200 & $0.6 \mathrm{M} \mathrm{NaCl}$ & -0.730 & 1.8 & -0.41 \\
\hline 800 & $0.6 \mathrm{M} \mathrm{NaCl}$ & -0.800 & 1.2 & -0.40 \\
\hline 7.8 & $0.6 \mathrm{M} \mathrm{NaCl}$ & -0.900 & 1.02 & -0.37 \\
\hline 3.8 & $0.6 \mathrm{M} \mathrm{NaCl}$ & -0.975 & 1.01 & -0.35 \\
\hline 6.4 & $0.6 \mathrm{M} \mathrm{NaCl}$ & -1.020 & 1.01 & -0.34 \\
\hline 1.3 & $0.6 \mathrm{M} \mathrm{NaCl}$ & -1.080 & 1.01 & -0.34 \\
\hline 1.3 & $0.6 \mathrm{M} \mathrm{NaCl}$ & -1.100 & 1.01 & -0.34 \\
\hline 1.0 & $0.6 \mathrm{M} \mathrm{NaCl}$ & -1.300 & 1.01 & -0.34 \\
\hline
\end{tabular}

A da/dt similar to that measured for unsensitized 5083-H131 in $\mathrm{AlCl}_{2} / \mathrm{MgCl}_{2}$, was measured for unsensitized 5083-H131 polarized to $-0.730 \mathrm{~V}_{\mathrm{SCE}}$ ( $\square$ in Fig. 3.29; $43 \mathrm{~nm} / \mathrm{s}$ ). 
This crack growth rate lies just below the line for the fastest rates predicted for diffusion controlled HEAC with $\mathrm{D}_{\mathrm{H}-\mathrm{EFF}}$ of $10^{-10} \mathrm{~cm}^{2} / \mathrm{s}$. Rates are explained by a $\mathrm{C}_{\mathrm{H} \sigma}$ decrease to 6.1 $\mathrm{C}_{\mathrm{H}-\mathrm{crit}}$ and are consistent with a decrease in magnitude of $\eta_{\mathrm{H}}(-0.42 \mathrm{~V}$, Table 3.9). Growth rates in $\mathrm{NaOH}\left(\mathrm{OCP}\right.$ and $\left.-1.800 \mathrm{~V}_{\mathrm{SCE}}\right)$ and $\mathrm{NaCl}\left(-0.800 \mathrm{~V}_{\mathrm{SCE}}\right)$ fall to and below the resolution limit, and are represented by $(\nabla)$ and $(\Delta)$, respectively in Fig. 3.29. Crack growth rates in unsensitized 5083-H131 at $-0.800 \mathrm{~V}_{\mathrm{SCE}}$ have a relatively high magnitude $\eta_{\mathrm{H}}(-0.40 \mathrm{~V})$, though the growth-rate estimated value of $\mathrm{C}_{\mathrm{H \sigma}} / \mathrm{C}_{\mathrm{H}-\mathrm{crit}}$ is only 1.3 .

The relationship between chemistry predicted $\eta_{\mathrm{H}}$ and crack growth rate model predicted $\mathrm{C}_{\mathrm{H \sigma}} / \mathrm{C}_{\mathrm{H}-\text { crit }}$ is shown in Fig. 3.30 for as-received 5083-H131 using both linear and logarithmic relationships. The exponential trend is expected based on the character of the squared inverse error function term in Eqn. 3.2; however, the values predicted for asreceived 5083-H131 in acidic simulated crack tip $\left(\eta_{\mathrm{H}}\right.$ at $\left.-0.54 \mathrm{~V}\right)$ do not fit well with the other predicted values. The variability between the two replicate experiments for the most negative $\eta_{\mathrm{H}}$ is large, but the average value of $\mathrm{C}_{\mathrm{H \sigma}} / \mathrm{C}_{\mathrm{H}-\text { crit }}$ reasonably aligns with this trend line. Additional crack growth experiments are needed with as-received 5083-H131. Moreover, the range of $\mathrm{pH}, \mathrm{Mg}^{2+}$ concentration, and $\mathrm{Cl}^{-}$concentration among these different experiments may compromise this $\eta_{\mathrm{H}-\mathrm{only}}$ based comparison (for example, see Fig. 3.21b [52]). The validity of this type of relationship will be enhanced with knowledge of the $\mathrm{C}_{\mathrm{H}-\mathrm{Diff}}$ in 5083-H131 as a function of potential and solution composition. 

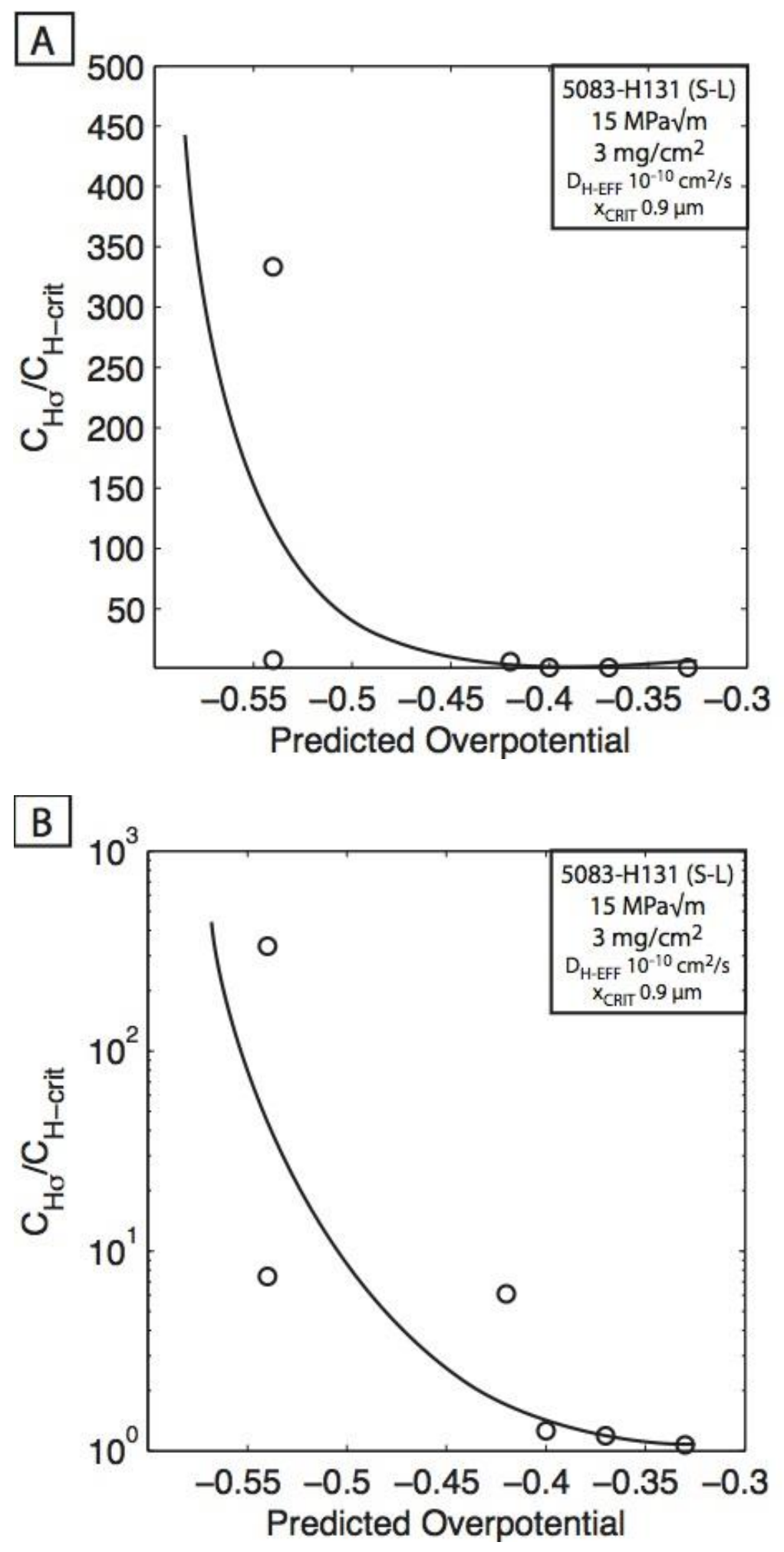

Figure 3.30 The (A) linear and (B) logarithmic relationship between $\mathrm{C}_{\mathrm{H} \sigma} / \mathrm{C}_{\mathrm{H} \text {-crit }}$ (calculated from measured crack growth rates using Eqn. 3.2 with $D_{H-E F F}$ of $10^{-10} \mathrm{~cm}^{2} / \mathrm{s}$ and $\mathrm{x}_{\text {CRIT }}$ of $\left.0.9 \mu \mathrm{m}\right)$ for as-received $5083-\mathrm{H} 131\left(3 \mathrm{mg} / \mathrm{cm}^{2}\right)$ as a function of electrochemically predicted crack tip $\eta_{\mathrm{H}}$ at $\mathrm{K}$ of $15 \mathrm{MPa} \sqrt{\mathrm{m}}$. 

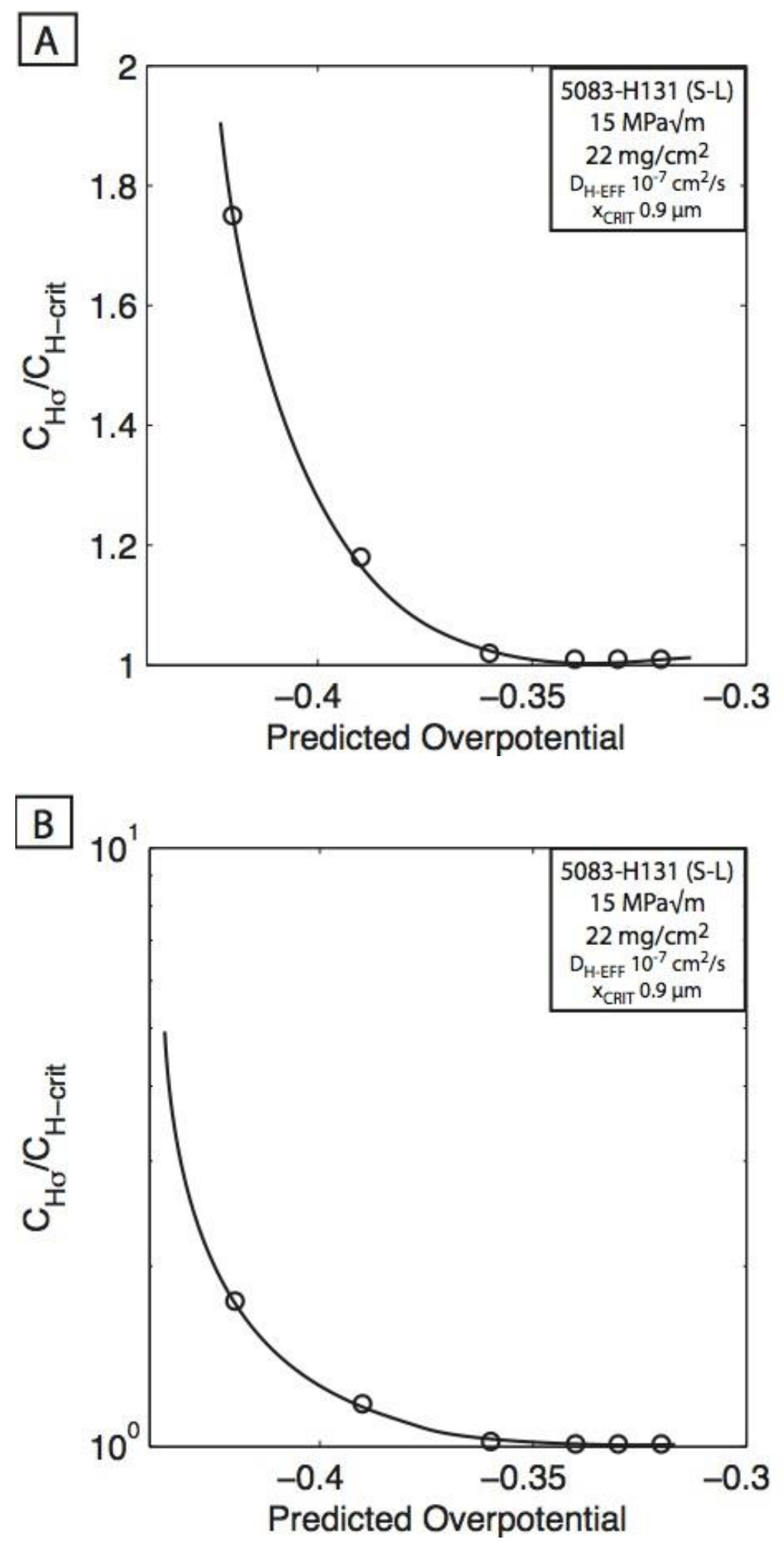

Figure 3.31 The (A) linear and (B) logarithmic relationship between $\mathrm{C}_{\mathrm{H} \sigma} / \mathrm{C}_{\mathrm{H} \text {-crit }}$ (calculated from measured crack growth rates using Eqn. 3.2 with $D_{H-E F F}$ of $10^{-7} \mathrm{~cm}^{2} / \mathrm{s}$ and $\mathrm{X}_{\text {CRIT }}$ of $\left.0.9 \mu \mathrm{m}\right)$ for sensitized $5083-\mathrm{H} 131\left(22 \mathrm{mg} / \mathrm{cm}^{2}\right)$ as a function of electrochemically predicted $\eta_{\mathrm{H}}$ at $\mathrm{K}$ of $15 \mathrm{MPa} \sqrt{\mathrm{m}}$. 

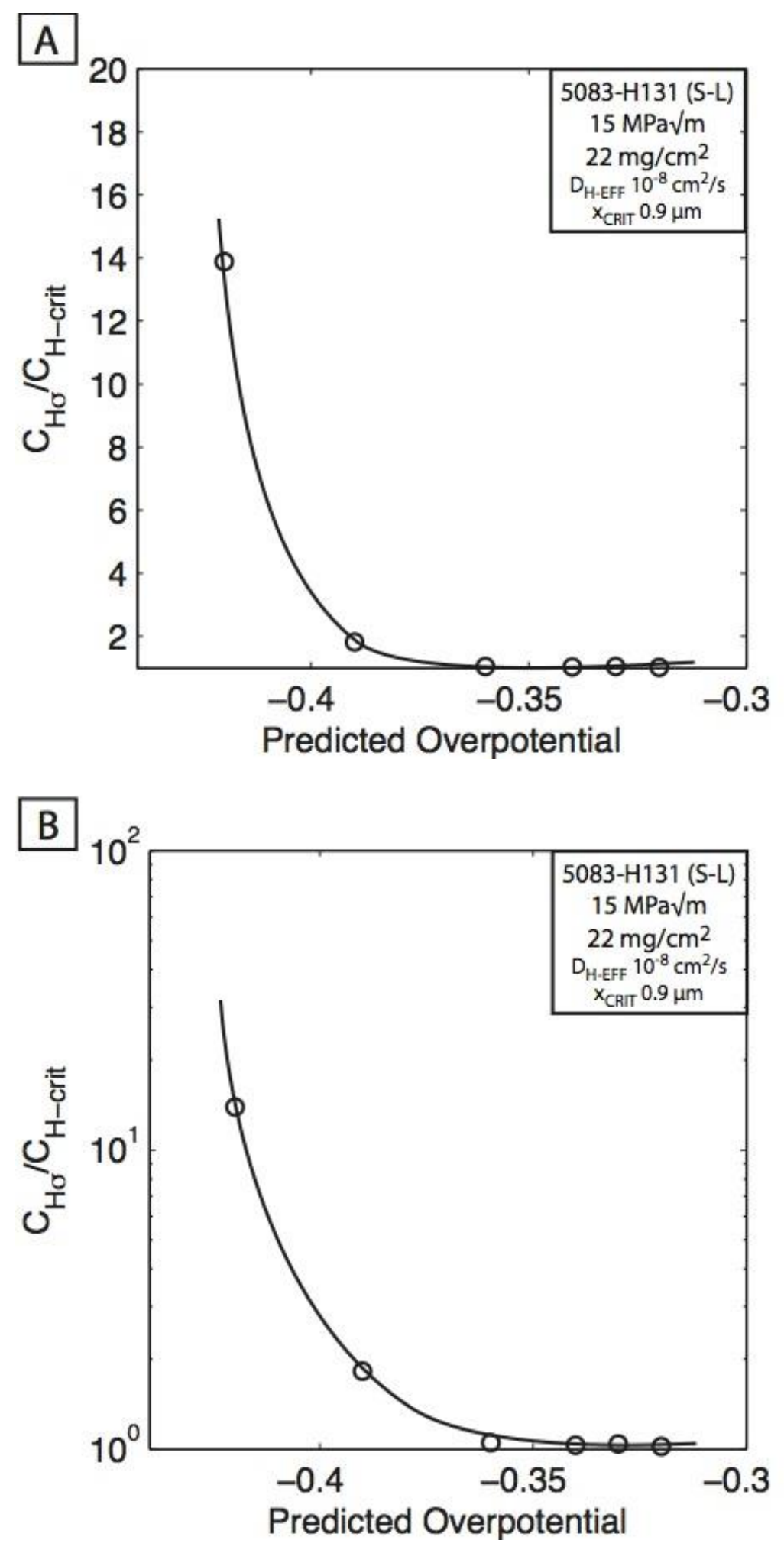

Figure 3.32 The (A) linear and (B) logarithmic relationship between the $\mathrm{C}_{\mathrm{H} \sigma} / \mathrm{C}_{\mathrm{H} \text {-crit }}$ (calculated from measured crack growth rates using Eqn. 3.2 with $D_{H-E F F}$ of $10^{-8} \mathrm{~cm}^{2} / \mathrm{s}$ and $\mathrm{X}_{\text {CRIT }}$ of $\left.0.9 \mu \mathrm{m}\right)$ for sensitized $5083-\mathrm{H} 131\left(22 \mathrm{mg} / \mathrm{cm}^{2}\right)$ as a function of electrochemically predicted $\eta_{\mathrm{H}}$ at $\mathrm{K}$ of $15 \mathrm{MPa} \sqrt{\mathrm{m}}$. 
This comparison may be more accurate for sensitized 5083-H131 in $\mathrm{NaCl}$ with different applied polarization. The decrease in $\mathrm{da} / \mathrm{dt}_{\mathrm{K} 15}$ with increasing cathodic polarization in sensitized $5083-\mathrm{H} 131\left(22 \mathrm{mg} / \mathrm{cm}^{2}\right)$ is explained by a decrease in $\mathrm{C}_{\mathrm{H \sigma}} / \mathrm{C}_{\mathrm{H}-\mathrm{crit}}$ (Table 3.10). The exponential relationship between $\mathrm{C}_{\mathrm{H \sigma}} / \mathrm{C}_{\mathrm{H}-\text { crit }}$ and $\eta_{\mathrm{H}}$ is different than that predicted for as-received 5083-H131 when using the upper bound $D_{\mathrm{H}-\mathrm{EFF}}$ of $10^{-7} \mathrm{~cm}^{2} / \mathrm{s}$ (Fig. 3.31). Even for very rapid da/dt $\mathrm{K}_{15}, \mathrm{C}_{\mathrm{H \sigma}}$ is not greater than $2 \mathrm{C}_{\mathrm{H}-\text { crit. }}$ This may be evidence that this upper bound $D_{\mathrm{H}-\mathrm{EFF}}\left(10^{-7} \mathrm{~cm}^{2} / \mathrm{s}\right)$, expected for pure $\mathrm{Al}$ without $\mathrm{H}$ traps, over estimates this more complex-deformed 5083-H131 microstructure. A lower $\mathrm{D}_{\mathrm{H}-\mathrm{EFF}}$ $\left(10^{-8} \mathrm{~cm}^{2} / \mathrm{s}\right)$, measured with multiple rise permeation experiments in 5083-H131 [46], produces a $\mathrm{C}_{\mathrm{H \sigma}} / \mathrm{C}_{\mathrm{H}-\mathrm{crit}}-\eta_{\mathrm{H}}$ relationship (Fig. 3.32) similar to that for unsensitized 5083-H131 in Fig. 3.30. These two $\mathrm{D}_{\mathrm{H}-\mathrm{EFF}}$ values bound the $\mathrm{C}_{\mathrm{H \sigma}} / \mathrm{C}_{\mathrm{H}-\mathrm{crit}}-\eta_{\mathrm{H}}$ relationship for sensitized 5083-H131. The issues associated with the correct diffusivity for $\mathrm{H}$ transport in a crack tip FPZ microstructure and deformation field are discussed in Chapters 2 and 4.

These relationships and experiments support the proposed mechanism that an aggressive crack tip solution (equilibrium-acidic $\mathrm{pH}$ of 2-3 and concentrated in $\mathrm{Cl}^{-}$) developed by $\beta$ dissolution, is required to promote a high magnitude of $\eta_{H}$ for the fastest possible rates of $\mathrm{H}$ embrittlement of $\mathrm{Al}-\mathrm{Mg}$ solid solution grain boundaries. This modeling provides a strong framework to couple the various contributing factors, but is speculative as the $\mathrm{H}$ trap behavior, $\mathrm{H}$ solubility, and effect of $\beta$ on $\mathrm{C}_{\mathrm{H} \text {-crit }}$ have not been established for 5083-H131. Hydrogen charging experiments in Chapter 4 suggested that $\beta$ will enhance $\mathrm{H}$ damage; $\mathrm{H}$ charged sensitized 5083-H131 promoted more severe embrittlement than in unsensitized 5083-H131, demonstrating that $\beta$ may raise the concentration of $\mathrm{C}_{\mathrm{H \sigma}}$ due to $\mathrm{H}$ trapping, and lower $\mathrm{C}_{\mathrm{H}-\text {-crit }}$ by increasing the local FPZ tensile strength through $\beta$ stress 
concentration and/or inter- $\beta$ ligament constraint. These microstructure-based stress effects are considered in Chapter 2.

\subsubsection{Coupled environmental fracture model}

The coupled environmental fracture model (CEFM), developed for film rupture-based IGSCC in sensitized stainless steel [66]; and amplified to center on crack growth due to interactive crack tip dissolution, film rupture and $\mathrm{H}$ damage [69]; was recently applied to predict the effect of bold-surface electrochemical potential on IGSCC in Al-Mg [36]. The CEFM model couples bold-surface net-cathodic currents with the net-positive current flowing through the crack mouth and originated by dissolution after crack tip passive film rupture, which is local strain rate and hence $\mathrm{K}$ sensitive [70]. Crack tip hydrogen production is qualitatively linked to crack tip dissolution which favors acidification and IR difference $[36,66]$. Lacking a specific crack tip fracture criterion and associated distance, the CEFM crack growth rate was equated to the product of microfracture event dimension squared and event frequency normalized by crack front length (e.g., SENT specimen thickness). Threshold $\mathrm{K}_{\mathrm{TH}}$ is interpreted as the $\mathrm{K}$ level below which film rupture does not occur, due to insufficient crack tip strain, and the crack net-anodic current tends to a very low value. This approach aligns with the hypothesized mechanism for IGSCC in sensitized Al-Mg [13,26]; specifically, crack tip corrosion leads to acidification which couples with IR-lowered crack tip potential to enhance $\mathrm{H}$ production and uptake key to HEAC.

The CEFM requires calibration with measured crack growth rate data for a specific environmental condition, which was accomplished for the near-neutral $0.6 \mathrm{M} \mathrm{NaCl}$ environment using $\mathrm{da} / \mathrm{dt}$ measurements reported for a resistant crack orientation in AA5083-H321 with a lightly sensitized (DoS of $6 \mathrm{mg} / \mathrm{cm}^{2}$ ) equiaxed grain 
structure $[13,36]$. For this condition, the CEFM predicted the beneficial effect of decreasing bold surface potential on da/dt; specifically, da/dt at high $\mathrm{K}(25 \mathrm{MPa} \sqrt{ } \mathrm{m})$ declined from $3 \mathrm{~nm} / \mathrm{s}$ at $-0.540 \mathrm{~V}_{\mathrm{SCE}}$ to $0.1 \mathrm{~nm} / \mathrm{s}$ at $-0.800 \mathrm{~V}_{\mathrm{SCE}}$ and lower [36]. The rate of IGSCC was predicted to equal 0 below $-0.800 \mathrm{~V}_{\mathrm{SCE}}$, with the $0.1 \mathrm{~nm} / \mathrm{s}$ growth rate modeled as due to creep crack growth apart from $\mathrm{H}$ embrittlement. This predicted trend qualitatively parallels the results for AA5083-H131 shown in Fig. 3.10; however, the CEFM predictions for IGSCC rate in AA5083 are specific to crack tip passive dissolution reaction of Al, without corrosion current due to reactive $\beta$ and $\alpha$ dissolution above $\mathrm{E}_{\mathrm{Br}-\beta}$ and $\mathrm{E}_{\mathrm{Br}-\alpha}$ [36]. As such, this calibration of the CEFM predictions is not relevant to the present investigation of IGSCC in sensitized AA5083-H131. At best for sensitized Al-Mg, mechanical rupture of a likely passivated Al surface in the potential range of $-0.900 \mathrm{~V}_{\mathrm{SCE}}$ and lower (Fig. 3.10), could be modeled by the CEFM approach.

Substantial uncertainties are associated with application of the CEFM to predict rates of IGSCC by HEAC in sensitized Al-Mg alloys. Clearly, $\mathrm{K}_{\mathrm{TH}}$ and da/dt versus $\mathrm{K}$ are fundamentally based on the concentration of $\mathrm{H}$ trapped at highly stressed sites within the crack tip FPZ $\left(\mathrm{C}_{\mathrm{H \sigma}}\right)[60]$. The challenge is to predict this concentration and relate it through a physically based failure criterion to predict $\mathrm{K}_{\mathrm{TH}}$ or da/dt versus $\mathrm{K}$. The CEFM provides one approach to modeling crack electrochemistry and $\eta_{\mathrm{H}}$, but controversy exists [71-73]. Moreover, no evidence was presented that validates the capability of the CEFM to predict crack tip anodic current density, overpotential for $\mathrm{H}$ production, and $\mathrm{H}$ uptake in an actively dissolving $\alpha$ grain boundary with discontinuously arrayed reactive $\beta$ precipitates.

As a second concern, the present analysis and CEFM approach each center on crack tip $\mathrm{H}$ embrittlement; however, there are important differences. For CEFM, the microfracture 
event frequency was modeled as the ratio of crack tip strain rate to passive film fracture strain [36]. Both quantities are uncertain in spite of decades of research. As such, microfracture frequency was extracted from analysis of the noise transients associated with the measured coupling current [69], but these measurements were not reported for AA5083 [36]. The microscale crack advance distance for AA5083 was apparently calibrated to equal $58 \mu \mathrm{m}$, using a measured da/dt and an event frequency estimated from crack tip strain rate given as a function of $\mathrm{K}$ following analysis by Shoji [74]. Predicted microfracture dimensions for other da/dt (and K) levels were between $2000 \mu \mathrm{m}(\mathrm{K}=$ $12 \mathrm{MPa} \sqrt{\mathrm{m}})$ and $45 \mu \mathrm{m}(\mathrm{K}=30-45 \mathrm{MPa} \sqrt{\mathrm{m}})$. For Stage II K levels, this distance was sensibly constant at $40-60 \mu \mathrm{m}$ [36]. This fracture length was similarly predicted to equal $49 \mu \mathrm{m}$ for an ultra-high strength martensitic steel subjected to HEAC in $\mathrm{NaOH}$ solution $[36,69]$. These distances were ascribed to the location of crack tip hydrostatic stress controlled $\mathrm{H}$ damage sites, and were also associated with a microstructural characteristic such as precipitate spacing or grain size [69], and/or $\mathrm{H}$ diffusion distance [36]. Crack tip $\mathrm{H}$ diffusion and mechanics analyses were not reported, and the reason for a microstructure-based critical distance was not put forth.

These CEFM-based microscale distances for discontinuous $\mathrm{H}$ crack advance are 40 to 500 times larger than the $\mathrm{x}_{\mathrm{CRIT}}$ of $0.9 \mu \mathrm{m}$ (Eqn. 3.2), which was established by analysis of HEAC growth rate and threshold stress intensity data for a wide range of high strength alloys, coupled with considerations of various solutions to the crack tip $\mathrm{H}$ diffusion problem $[60,68]$. Stated alternately, HEAC in a wide variety of alloys progresses at rates that cannot be sustained by $\mathrm{H}$ diffusion over a distance of order 50-100 $\mu \mathrm{m}$ based on measured trap sensitive $\mathrm{H}$ diffusivities [46]. The CEFM formulation implicitly assumes 
that such $\mathrm{H}$ diffusion occurs and moreover does not limit da/dt relative to the frequency of crack tip film rupture [36]. A distance of order $1 \mu \mathrm{m}$ is consistent with modern predictions of the location of the maximum crack tip hydrostatic tension, ahead of a either a blunted [75] or sharp-shielded crack tip [76]. A classic upper bound of this distance is provided by $\mathrm{K}^{2} / \sigma_{\mathrm{YS}} \mathrm{E}$, which is $10 \mu \mathrm{m}$ for the flow properties of AA5083 and $0.7 \mu \mathrm{m}$ for a high strength steel such as $4340\left(\sigma_{Y S}=1600 \mathrm{MPa}\right)$, each stressed at $\mathrm{K}$ of $15 \mathrm{MPa} \sqrt{\mathrm{m}}$. While this upper bound is $100 \mu \mathrm{m}$ for AA5083 loaded to $\mathrm{K}$ of $45 \mathrm{MPa} \sqrt{\mathrm{m}}$, this high $\mathrm{K}$ is not physically realistic, and microscale stress concentration associated with $\beta$ and strain gradient plasticity are likely to substantially reduce this value toward $1 \mu \mathrm{m}$ and lower, as affirmed for other Al alloys [68]. This latter point is amplified by consideration of microstructure scale stresses in Chapter 2.

Interaction of $\mathrm{H}$ with trap sites in the corroding $\alpha-\beta$ microstructure must also be considered with regard to the critical distance, but this geometry does not change the conclusion that $\mathrm{X}_{\mathrm{CRIT}}$ (Eqn. 3.2) for IGSCC/HEAC in sensitized AA5083 is $1 \mu \mathrm{m}$ or smaller dictated by interaction of the crack tip stress gradient, stress enhanced $\mathrm{H}$ localization, and the grain boundary $\beta$ spacing of about $300 \mathrm{~nm}$ [9]. A critical distance, in the range of $100 \mathrm{~nm}$ to $1 \mu \mathrm{m}$, is likely to be similar for sensitized Al-Mg alloys with discontinuous $\beta$ precipitation on grain boundaries (see Chapter 2). The very large microfracture distances predicted by the CEFM (for example $2,000 \mu \mathrm{m}$ at $\mathrm{K}$ of $12 \mathrm{MPa} \sqrt{\mathrm{m}}$ [36]) are particularly unreasonable. The large microfracture dimension in the CEFM formulation may be associated with selection of the larger and less frequent current transients for the steel case [69], and with the assumed crack tip strain rate versus $\mathrm{K}$ dependence when coupling current noise is not measured [36]. As the microfracture frequency increases, the crack 
advance distance falls, with the limiting case being near-continuous HEAC and a very short microfracture distance.

IGSCC in sensitized Al-Mg alloys is reasonably explained by a coupled crack tip $\alpha-\beta$ dissolution plus $\mathrm{H}$ embrittlement mechanism. The crack tip mechanics framework exists to predict $\mathrm{K}_{\mathrm{TH}}$ and da/dt versus bold-surface electrochemical potential; however, challenges remain in quantifying occluded-crack electrochemistry and the associated concentration of $\mathrm{H}$ produced in the crack tip FPZ, as well as a fundamental association of such trapped H with cracking properties.

\subsection{CONCLUSIONS}

The rate of intergranular "crevice" corrosion (IGC) ahead of an occluded fatigue precrack is measured by the dcPD method during static-low stress intensity exposure in various bulk environments. Such IGC rates are explained based on occluded-fatigue crack $\mathrm{pH}$ and potential changes in response to varying external polarization and solution composition. Specific conclusions are as follows.

- In fatigue precracked 5083-H131 without laboratory sensitization (3 mg/ $\left.\mathrm{cm}^{2}\right)$, IGC is possible when solution exposure develops a highly acidic chloride concentrated electrochemistry in the fissure:

- Intergranular corrosion is not measureable in $\mathrm{NaCl}$ when applied potential is near or below $\mathrm{OCP}\left(-0.800 \mathrm{~V}_{\mathrm{SCE}}\right.$ and below $)$, but is measurable and rapid at and above $-0.730 \mathrm{~V}_{\mathrm{SCE}}$ where matrix dissolution is promoted.

O Corrosion is promoted at $-1.000 \mathrm{~V}_{\mathrm{SCE}}$ in an acidic $\mathrm{AlCl}_{3} / \mathrm{MgCl}_{2}$ due to the highly acidic, chloride concentrated nature of the fissure tip chemistry. 
- In fatigue precracked sensitized 5083-H131 (22 mg/cm²), exposed in near-neutral $\mathrm{NaCl}$ solution, IGC is promoted for polarization above the breakdown potentials of both the matrix and $\beta$ phases. Intergranular corrosion is essentially eliminated when the specimen is polarized below the $\beta$ breakdown potential.

- Intergranular corrosion growth at the occluded fatigue crack tip in sensitized 5083$\mathrm{H} 131\left(22 \mathrm{mg} / \mathrm{cm}^{2}\right)$ in $\mathrm{NaCl}$ at $-0.730 \mathrm{~V}$ SCE was more than 2 times the rates measured in unsensitized 5083-H131 at the same potential; a role of $\beta$ is confirmed.

- The electrochemistry developed at the fatigue crack fissure tip depends on applied potential, the geometry of the fissure, the passive current density on the fissure flanks, and the environment sensitive dissolution rate at the fissure tip as observed with applied potential dependent corrosion rates and Ohmic drop calculations.

- The calculated Ohmic drop down the fatigue crack is small owing to low resistance attributed to the relatively wide crack mouth opening displacement.

○ Model predicted crack tip potentials confirm the role of $\beta$ dissolution and $\alpha$ dissolution in promoting corrosion growth: corrosion is accelerated at crack tip potentials above the matrix breakdown potential, and stifled when the potential is cathodic to the breakdown potential of $\alpha$.

Experimental evidence and occluded crack electrochemistry considerations validate the proposed mechanism for IGSCC of sensitized Al-Mg alloys: $\beta$ dissolution is required for crack solution acidification, coupled $\mathrm{H}$ production, and uptake stimulated by chloride enhancement. When $\beta$ dissolution is mitigated by either low DoS or bulk cathodic polarization, IGSCC is essentially eliminated during slow rising $\mathrm{K}$ loading for exposure in 
neutral $\mathrm{NaCl}$ solution. The presence of $\beta$ triggers rapid generation of a critical-acidic crack tip environment, which increases crack growth rates. Growth between $\beta$ in sensitized alloys is likely driven by $\mathrm{H}$ embrittlement and controlled by the crack tip chemistry. Specific conclusions are as follows:

- Upper bound (S-L) rates of IGSCC in fatigue precracked sensitized 5083-H131 (DoS $22 \mathrm{mg} / \mathrm{cm}^{2}$ ) are nearly eliminated by applied cathodic polarization below $-1.020 \mathrm{~V}_{\mathrm{SCE}}$, which forces the crack tip potential below the $\beta$-breakdown potential (-1.015 $\mathrm{V}_{\mathrm{SCE}}$ for acidic $\left.\mathrm{NaCl}\right)$.

- Fatigue precracked 5083-H131 (S-L) without laboratory sensitization $\left(3 \mathrm{mg} / \mathrm{cm}^{2}\right)$ :

- Resists IGSCC while stressed in $\mathrm{NaCl}$ polarized to $-0.800 \mathrm{~V}_{\mathrm{SCE}}$ and below, because $\alpha$ dissolution is not promoted and the crack tip is only mildly acidic.

O Is highly susceptible to IGSCC while stressed in $\mathrm{NaCl}$ polarized to $-0.730 \mathrm{~V}_{\mathrm{SCE}}$, because $\alpha$ dissolution is promoted resulting in a highly acidic crack tip chemistry for $\mathrm{H}$ embrittlement propagation.

- Develops a $\mathrm{Cl}^{-}$saturated crack tip, with a $\mathrm{pH}$ near 4 and high magnitude overpotential for $\mathrm{H}$ production, while stressed in simulated-acidic crack tip chloride solution $\left(\mathrm{AlCl}_{3}+\mathrm{MgCl}_{2}\right)$ polarized at $-1.000 \mathrm{~V}$ SCE. The low $\mathrm{pH}$ and high magnitude of $\mathrm{H}$ overpotential likely promote crack growth rates similar to or just above the fastest $\mathrm{H}$ diffusion limited IGSCC rate predicted for 5083-H131 with $D_{\mathrm{H}-\mathrm{EFF}}$ of $10^{-10} \mathrm{~cm}^{2} / \mathrm{s}$.

- Develops an isolated alkaline crack tip due to extensive corrosion product precipitation when stressed in $\mathrm{H}$ producing $\mathrm{NaOH}$ polarized to either $-1.800 \mathrm{~V}_{\mathrm{SCE}}$ or at OCP. 
- Using a hydrogen diffusion-limited crack growth rate model, the $\mathrm{H}$ concentration at the fracture process zone available to generate measured crack growth rates increases exponentially with decreasing predicted crack tip overpotential for $\mathrm{H}$ production. The ratio of $\mathrm{H}$ concentration to critical $\mathrm{H}$ concentration in the FPZ was predicted from measured crack growth rates for each experiment, and overpotentials for $\mathrm{H}$ production were predicted from crack tip potential and $\mathrm{pH}$, in each experiment.

○ The $\mathrm{pH}, \mathrm{Mg}^{2+}$ concentration, and $\mathrm{Cl}^{-}$concentration may each influence the relationship between $\eta_{H}$ and $H$ solubility. A single relationship between crack tip $\eta_{\mathrm{H}}$ and either $\mathrm{da} / \mathrm{dt}$ or $\mathrm{FPZ} \mathrm{C}_{\mathrm{H} \sigma} / \mathrm{C}_{\mathrm{H}-\text { crit }}$ may not be applicable to all 5083-H131 environment-microstructure conditions.

- Results support the proposed mechanism for IGSCC in sensitized AlMg alloys; specifically, crack tip electrochemistry developed from $\beta$ dissolution promotes $\mathrm{H}$ production, uptake and rapid, $\mathrm{H}$ diffusion limited crack growth rates. 


\subsection{REFERENCES}

1. M.O. Speidel: "Hydrogen Embrittlement and Stress Corrosion Cracking of Aluminum Alloys," in Hydrogen Embrittlement and Stress Corrosion Cracking, R. Gibala and R.F. Hehemann, eds., ASM International, Materials Park, OH, 1984, pp. 271-96.

2. E.H. Dix, Jr., A. Anderson, and M.B. Shumaker: Corrosion, 1959, vol. 15, pp. 55-62.

3. R.K. Gupta, R. Zhang, and N. Birbilis: Corrosion, 2013, DOI: http://dx.doi.org/10.5006/0948.

4. R. Goswami and R.L. Holtz: Metall. Trans. A, 2013, vol. 44, pp. 1279-89.

5. R. Goswami, G. Spanos, P.S. Pao, and R.L. Holtz: Mat. Sci. Eng. A, 2010, vol. 527, pp. 1089-95.

6. R. Goswami, G. Spanos, P.S. Pao, and R.L. Holtz: Metall. Mater. Trans. A, 2011, vol. 42 , pp. $348-55$

7. Y. Zhu, D.A. Cullen, S. Kar, M.L. Free, and L.F. Allard: Metall. Mater. Trans. A, 2012, vol. 43, pp. 4933-9.

8. D.O. Sprowls and R.H. Brown: "Stress-Corrosion Mechanisms for Aluminum Alloys," in Fundamental Aspects of Stress Corrosion Cracking, R.W. Staehle, ed., NACE, Houston, TX, 1969, pp. 466-506.

9. N. Birbilis, M.L.C. Lim, R.K. Gupta, C.H.J. Davies, S.P. Lynch, R.G. Kelly and J.R. Scully: Corrosion, 2013, vol. 69, pp. 396-402.

10. F.S. Bovard: "Sensitization and Environmental Cracking of 5xxx Aluminum Marine Sheet and Plate Alloys," in Corrosion Marine Saltwater Environment II, D.A. Shifler, T. Tsuru, P.M. Natishan, and S. Ito, eds., ECS, Pennington, NJ, 2005, pp. 232-43.

11. R.L. Holtz, P.S. Pao, R.A. Bayles, T. Longazel, and R. Goswami: "Corrosion Fatigue and Stress Corrosion Cracking of Sensitized Al-Mg Structural Alloys," in Symposium on Structural Materials for Aerospace and Defense, MS\&T, Columbus, OH, 2011.

12. J. Gao and D.J. Quesnel: Metall. Mater. Trans. A, 2010, vol. 42, pp. 356-64.

13. R.H. Jones, D.R. Baer, M.S Danielson, and J.S. Vetrano: Metall. Mater. Trans. A, 2001, vol. 32, pp. 1699-1711.

14. R.H. Jones: J. Miner. Met. Mater. Soc., 2003, vol. 55, pp. 42-6.

15. J.L. Searles, P.I. Gouma, and R.G. Buchheit: Metall. Mater. Trans. A, 2001, vol. 32, pp. 2859-67.

16. M.L. Lim, S. Jain, R.G. Kelly, J.R. Scully: Corrosion, 2013, vol. 69, pp. 35-47.

17. E. Bumiller: "Intergranular Corrosion in AA5XXX Aluminum Alloys with Discontinuous Precipitation at the Grain Boundaries," PhD Dissertation, University of Virginia, Charlottesville, VA, 2011.

18. E. Bumiller and R.G. Kelly: "Intergranular Corrosion in AA5xxx: A Case for Continuous Attack with a Discontinuous Active Path," in Department of Defense 2011 Corrosion Conference, CorrDefense, NACE International, Houston, TX, 2011. 
19. A.J. Davenport, Y. Yuan, R. Ambat, B.J. Connolly, M. Strangwood, A. Afseth, and G.M. Scamans: Mater. Sci. Forum, 2010, vol. 519-521, pp. 641-6.

20. L. Chen, D.E. Brown, X. Wang, and R.G. Kelly: "Integrated Effects of Grain Boundary Characteristics on the Behavior of Intergranular Corrosion in 5xxx Alloys," in Department of Defense 2011 Corrosion Conference, CorrDefense, NACE International, Houston, TX, 2011.

21. ASTM Standard G67, 2004, "Standard Test Method for Determining the Susceptibility to Intergranular Corrosion of 5xxx Series Aluminum Alloys by Mass Loss After Exposure to Nitric Acid (NAMLT Test)," ASTM International, West Conshohocken, PA, 2004, DOI: 10.1520/G0067-04, www.astm.org.

22. K. Cooper: "Chemistry and Electrochemistry of Environment-Assisted Cracking of an Al-Zn-Mg-Cu Alloy," PhD Dissertation, University of Virginia, Charlottesville, VA, 2001 .

23. N.J.H. Holroyd: "Environment-Induced Cracking of High-Strength Aluminum Alloys," in Environment Induced Cracking of Metals, R.P. Gangloff and M.B. Ives, eds., NACE International, Houston, TX, 1990, pp. 311-34.

24. E. Pouillier, A.-F. Gourgues, D. Tanguy, and E.P. Busso: Int. J. Plast., 2012, vol. 34, pp. 139-53.

25. N.B. Ali, R. Estevez, and D. Tanguy: Eng. Fract. Mech., 2013, vol. 97, pp. 1-11.

26. D. Tanguy, B. Bayle, R. Dif, Th. Magnin: Corros. Sci., 2002, vol. 44, pp. 1163-75.

27. F. Bovard: Private Communication, Alcoa Technical Center, New Kensington, PA, 2012.

28. M.L. Lim, R.G. Kelly, J.R. Scully: Private Communication, University of Virginia, Charlottesville, VA, 2011.

29. T.L. Anderson: Fracture Mechanics: Fundamentals and Applications, 3rd ed., CRC Press, Taylor and Francis Group, Boca Raton, FL, 2005, pp. 398-400,445-6.

30. Y. Lee and R.P. Gangloff. Metall. Mater. Trans., 2007, vol. 38, pp. 2174-90.

31. M.J. Haynes and R.P. Gangloff: J. Test. Eval., 1997, vol. 25, pp. 82-98.

32. J.K. Donald and J. Ruschau: "Direct Current Potential Difference Fatigue Crack Measurement Techniques," in Fatigue Crack Measurement: Techniques and Applications, K.J. Marsh, R.A. Smith, and R.O. Ritchie, eds., EMAS, West Midlands, UK, 1991, pp. 11-38.

33. R.P. Gangloff, D.C. Slavik, R.S. Piascik, and R.H. Van Stone: "Direct Current Electrical Potential Measurements of Growth of Small Cracks," in Small-Crack Test Methods, ASTM STP 1149, J.M. Larsen and J.E. Allison, eds., American Society for Testing and Materials, Philadelphia, 1992, pp. 116-68.

34. G. Pioszak and R.P. Gangloff: Private Communication, University of Virginia, Charlottesville, VA, 2012.

35. G. Bencivenni, L. Bucci, G. Finocchiaro, and C. Forti: "Creep Measurement on Aluminum - 5056 Wires,” KLOE Report, Frascati, Italy, 1998, pp. 1-13. 
36. S.-K. Lee, P. Lv, and D.D. Macdonald: J. Solid State Electrochem., 2013, vol. 17, pp. 2319-32.

37. M.O. Speidel: "Hydrogen Embrittlement and Stress Corrosion Cracking of Aluminum Alloys," in Hydrogen Embrittlement and Stress Corrosion Cracking, R. Gibala and R.F. Hehemann, eds., ASM International, Materials Park, OH, 1984, pp. 271-96.

38. J.R. Scully, G.A. Young, Jr., and S.W. Smith: "Hydrogen Embrittlement and Hydrogen Environment Embrittlement in Al Alloys," in Gaseous Hydrogen Embrittlement of Metals in Energy Technologies, vol. 1, R.P. Gangloff and B.P. Somerday, eds., Woodhead Publishing Ltd., Cambridge, UK, 2012, pp. 707-68.

39. N. Birbilis and R.G. Buchheit: J. Electrochem. Soc., 2005, vol. 152, pp. 140-51.

40. R.H. Jones, D.R. Baer, M.J. Danielson, J.S. Vetrano, and C.F. Windisch: "Crack-tip Interactions with Electrochemically Active Particles," in Chemistry and Electrochemistry of Corrosion and Stress Corrosion Cracking, R.H. Jones, ed., TMS, Warrendale, PA, 2001, pp. 583-94.

41. R.A.H. Edwards: "The Electrochemical Conditions Inside Stress Corrosion and Corrosion Fatigue Cracks," PhD Dissertation, Delft University of Technology, Delft, Netherlands, 1986.

42. R.A.H. Edwards: "The Relation Between Potential Drop and Local Changes in Solution Chemistry in Localized Corrosion," Predictive Capabilities in Environmentally Assisted Cracking, R. Rungta, ed., ASME, New York, NY, 1985, pp. 153-75.

43. K. Cooper and R.G. Kelly: Corros. Sci., 2007, vol. 49, pp. 2636-62.

44. D Mizuno and R G Kelly: Corrosion, 2013, vol. 69, pp. 580-92.

45. S. Jain, M.L. Lim, J.L. Hudson, and J.R. Scully: Corros. Sci., 2012, vol. 59, pp. 13647.

46. J. Ai, M.L. Lim, and J.R. Scully: Corrosion, 2013, DOI: http://dx.doi.org/10.5006/0987.

47. A.M. Lucente and J.R. Scully: J. Electrochem. Soc., 2008, vol. 155, pp. 234-43.

48. J.R. Galvele: J. Electrochem. Soc., 1976, vol. 123, pp. 464-74.

49. S.M. Gravano and J.R. Galvele: Corros. Sci., 1984, vol. 24, pp. 517-34.

50. J.R. Galvele: Corros. Sci., 1981, vol. 21, pp. 551-79.

51. A.B. Cook, D.L. Engelberg, N.P.C. Stevens, N. Laycock, S. White, M. Ghahari, M. Monir, N.J.H. Holroyd, and R.C. Newman: ECS Transactions, 2012, vol. 41, pp. 12132.

52. B. Kehler: "Modeling and Experiments to Explain the Potential Dependency of an UHSS to Hydrogen Environment Assisted Cracking," PhD Dissertation, University of Virginia, Charlottesville, VA, 2008.

53. K.C. Stewart: "Intermediate Attack in Crevice Corrosion by Cathodic Focusing," $\mathrm{PhD}$ Dissertation, University of Virginia, Charlottesville, VA, 1999. 
54. K.R. Cooper, L.M. Young, R.P. Gangloff, and R.G. Kelly: Mater. Sci. Forum, 2000, vol. 331-337, pp. 1625-34.

55. R. Yuan: "The Relationships between Weight Functions, Geometric Functions, and Compliance Functions in Linear Elastic Fracture Mechanics," PhD Dissertation, University of California, Berkeley, CA, 2004.

56. S. Jain: "Microstructural-Scale Model for Surface Spreading of Intergranular Corrosion in Sensitized Stainless Steels and Al-Mg (AA5XXX) Alloys," PhD Dissertation, University of Virginia, Charlottesville, VA, 2011.

57. M. Pourbaix: Atlas of Electrochemical Equilibria in Aqueous Solutions, NACE International, Houston, TX, 1974, pp. 168-176.

58. J. Ai, H.M. Ha, R.P. Gangloff, and J.R. Scully: Acta Mater., 2013, vol. 61, pp. 318699.

59. R.A. Oriani: Corrosion, 1987, vol. 43, pp. 390-7.

60. R.P. Gangloff: "Hydrogen Assisted Cracking of High Strength Alloys," in Comprehensive Structural Integrity, I. Milne, R.O. Ritchie, B. Karihaloo, J. Scott, and P. Petit, eds., Elsevier Science, New York, NY, 2003, pp. 31-101.

61. R.P. Gangloff, H.M. Ha, J.T. Burns, and J.R. Scully: Metall. Mater. Trans. A, in review, 2013.

62. P. Doig and G.T. Jones: Metall. Mater. Trans. A, 1977, vol. 8, pp. 1993-8.

63. N. Birbilis and R.G. Buchheit: J. Electrochem. Soc., 2005, vol. 152, pp. 140-51.

64. S. Jain, J.L. Hudson, and J.R. Scully: Electrochim. Acta, 2013, vol. 108, pp. 253-64.

65. M. Elboujdaini, M.T. Shehata, and E. Ghali: Microstruct. Sci., 1997, vol. 25, pp. 419.

66. D.D. Macdonald and M. Urquidi-Macdonald: Corros. Sci., 1991, vol. 32, pp. 51-81.

67. J. Ai and J.R. Scully: Corrosion, 2013, vol. 69, pp. 752-67.

68. R.P. Gangloff: "Diffusion Control of Hydrogen Environment Embrittlement in High Strength Alloys," in Hydrogen Effects on Material Behavior and Corrosion Deformation Interactions, N.R. Moody, A.W. Thompson, R.E. Ricker, G.W. Was, and R.H. Jones, eds., The Minerals, Metals \& Materials Society, Warrendale, PA, 2003, pp. 477-97.

69. S. Lui and D.D. Macdonald: Corrosion, 2002, vol. 58, pp. 835-45.

70. F.P. Ford: "The Crack-Tip System and its Relevance to the Prediction of Cracking in Aqueous Environments," in Environment-Induced Cracking of Metals, R.P. Gangloff and M.B. Ives, eds., NACE, Houston, TX, 1990, pp. 139-165.

71. P.L Andresen: Corros. Sci., 1995, vol. 37, pp. 2087-9.

72. P.L. Andresen and F.P. Ford: Corros. Sci., 1996, vol. 38, pp. 1011-6.

73. D.D. Macdonald: Corros. Sci., 1997, vol. 39, pp. 1487-90.

74. T. Shoji, Z. Lu, and H. Murakami: Corros. Sci., 2010, vol. 52, pp. 769-79. 
75. R.M. McMeeking: J. Mech. Phys. Solids, 1977, vol. 25, pp. 357-81.

76. U. Komaragiri, S.R. Agnew, R.P. Gangloff, and M.R. Begley: J. Mech. Phys. Solids, 2008, vol. 56, pp. 3527-40. 


\subsection{APPENDIX}

\subsubsection{Formulation of Ohmic drop predictions}

Ohmic drop predictions were considered for both IGC fissures and IGSCC cracks based on work by Stewart [53] and adapted to 5083-H131 using measured IGC rates. Calculations were made assuming the fissure/crack is a slot filled with $0.6 \mathrm{M} \mathrm{NaCl}$ with a diffusion length (d), and height (h) defined below. The voltage difference is defined as:

$$
I R=I R_{\text {wall }}-I R_{\text {tip }}
$$

where $\mathrm{IR}_{\text {wall }}$ is the voltage difference due to dissolution on the flanks of the slot, and $\mathrm{IR}_{\text {tip }}$ is the voltage difference due to dissolution at the tip of the slot. Transport in the slot is defined in 3 orientations (Fig. 3.16): (A) down the length of the fissure/crack, (B) from the side of the sample to the center, and (C) from the side of the sample to a quarter of the way to the center.

Stewart developed an analytical solution for such a geometry if the mouth and bold surface is held potentiostatically constant at the given applied potential, the walls of the slot are passive, and the tip is active [53]. To calculate the Ohmic difference due to the active tip only, the current at the tip and the conductivity of the solution must be determined for the relationship:

$$
I R_{t i p}=\frac{i_{t i p}\left({\frac{d a}{d t_{I G C}}}\right)}{2 \kappa} d_{o}
$$

where $i_{\text {tip }}$ is current density calculated with Faraday's Law ${ }^{8}$ assuming $1 \mathrm{~nm} / \mathrm{s}$ IGC growth $\left(0.0024 \mathrm{~A} / \mathrm{cm}^{2}\right), \mathrm{da} / \mathrm{dt}_{\mathrm{IGC}}$ is the IGC growth rates from Tables 3.3 and $3.5, \mathrm{~d}_{\mathrm{o}}$ is the diffusion

${ }^{8}$ Faraday's Law is da/dt $=i_{a} M /(z F \rho)$ where $i_{a}$ is the fissure tip current, $M$ is the atomic weight ( $26.98 \mathrm{~g} / \mathrm{mol}$ for $\mathrm{Al}$ ), $\mathrm{z}$ is the valence (3 eq. mole for $\mathrm{Al}$ ), $\mathrm{F}$ is Faraday's constant (96487 C/eq.), and $\rho$ is density $\left(2.7 \mathrm{~g} / \mathrm{cm}^{2}\right.$ for $\left.\mathrm{Al}\right)[52]$. 
distance of interest, $\mathrm{d}$ is the maximum diffusion distance, and $\kappa$ is the solution conductivity $(69 \mathrm{mS} / \mathrm{cm})$. The diffusion distances for each orientation are shown in Fig. 3.16, and given in Table 3.11. The conductivity is the average of conductivity results from Bumiller: $93 \mathrm{mS} / \mathrm{cm}$ and $45 \mathrm{mS} / \mathrm{cm}$, for $80 \%$ saturated and $100 \%$ saturated $\mathrm{Al}-4 \% \mathrm{Mg}$ chloride solution, respectively $[17,18]$.

Table 3.11 Diffusion distances and slot height used to calculate the Ohmic difference due to the active tip and passive wall for $5083-\mathrm{H} 131$ sensitized at $10 \mathrm{mg} / \mathrm{cm}^{2}$ and $22 \mathrm{mg} / \mathrm{cm}^{2}$.

\begin{tabular}{|c|c|c|c|}
\hline & $\begin{array}{c}\mathrm{d}_{\mathrm{o}} \\
\mathrm{mm}\end{array}$ & $\begin{array}{c}\mathrm{d} \\
\mathrm{mm}\end{array}$ & $\begin{array}{c}\mathrm{h} \\
\mu \mathrm{m}\end{array}$ \\
\hline \multicolumn{4}{|c|}{$\mathrm{IGC}, \mathrm{K}=5 \mathrm{MPa} \sqrt{\mathrm{m}}$} \\
\hline Orientation A (DoS $\left.10 \mathrm{mg} / \mathrm{cm}^{2}\right)$ & 1.8 & 1.8 & 3.9 \\
\hline Orientation A (DoS $\left.22 \mathrm{mg} / \mathrm{cm}^{2}\right)$ & 1.9 & 1.9 & 4.5 \\
\hline Orientation B (any DoS) & 3.3 & 3.3 & 0.5 \\
\hline Orientation C (any DoS) & 1.65 & 3.3 & 0.5 \\
\hline $\mathrm{IGSCC}, \mathrm{K}=15 \mathrm{MPa} \sqrt{\mathrm{m}}$ & 10.9 \\
\hline Orientation A (DoS $\left.10 \mathrm{mg} / \mathrm{cm}^{2}\right)$ & 2.1 & 2.1 & 12.9 \\
\hline Orientation A (DoS 22 $\left.\mathrm{mg} / \mathrm{cm}^{2}\right)$ & 4.1 & 4.1 & 4 \\
\hline Orientation B (any DoS) & 3.3 & 3.3 & 4 \\
\hline Orientation C (any DoS) & 1.65 & 3.3 & \\
\hline
\end{tabular}

The height of the slot does not matter for the voltage difference due to dissolution at the crack tip because the current will drop proportionally with a decrease in height. The voltage difference due to dissolution of passive walls, however, is dependent on the height of the slot. The height of the slot for orientation $\mathrm{A}$ is estimated to equal the average of the CTOD and CMOD. The CTOD is defined by [54]:

$$
C T O D=\frac{d n(1-v) K^{2}}{E \sigma_{Y S}}
$$


where, $\mathrm{dn} \sim 0.65, v$ is Poisson's ratio (0.33), E is the elastic modulus (70 GPa), $\sigma$ Ys is the yield strength ( $335 \mathrm{MPa}$ ), and $\mathrm{K}$ is the stress intensity. The CMOD of a SENT specimen is given by [55]:

$$
C M O D=\frac{2\left(\frac{a}{W}\right) \sigma_{A} W}{E}\left[\frac{1.46+3.42\left(1-\cos \left(\frac{\pi a}{2 W}\right)\right)}{\left(\cos \left(\frac{\pi a}{2 W}\right)\right)^{2}}\right]
$$

where $a$ is the crack length, $\mathrm{W}$ is the width of the specimen $(17.3 \mathrm{~mm})$, and $\sigma_{\mathrm{A}}$ is the applied stress. Values used to calculate $\mathrm{h}$ in Table 3.11 for each orientation are given in Table 3.12. The height for orientations $\mathrm{B}$ and $\mathrm{C}$ is the CTOD.

Table 3.12 Values used to calculate the height of the slot for IGC and IGSCC crack tips.

\begin{tabular}{|c|c|c|c|c|}
\hline $\begin{array}{c}\text { DoS } \\
\left(\mathrm{mg} / \mathrm{cm}^{2}\right)\end{array}$ & $a(\mathrm{~mm})$ & CMOD $(\mu \mathrm{m})$ & CTOD $(\mu \mathrm{m})$ & $\sigma_{\mathrm{A}}(\mathrm{MPa})$ \\
\hline \multicolumn{5}{|c|}{ IGC, $\mathrm{K}=5 \mathrm{MPa} \sqrt{\mathrm{m}}$} \\
\hline 10 & 3.3 & 7.3 & 0.5 & 43.8 \\
\hline 22 & 3.4 & 8.4 & 0.5 & 48.0 \\
\hline \multicolumn{5}{|c|}{ IGSCC, $\mathrm{K}=15 \mathrm{MPa} \sqrt{\mathrm{m}}$} \\
\hline 10 & 3.6 & 17.8 & 4 & 94.4 \\
\hline 22 & 5.3 & 21.9 & 4 & 55.1 \\
\hline
\end{tabular}

The voltage difference due to dissolution of passive walls is calculated with the passive current density of $\alpha$ in simulated crack tip solution ( $i_{\text {wall }}: 17 \mu \mathrm{A} / \mathrm{cm}^{2}$ ) [17,18], and the estimated conductivity of the solution, with the relationship:

$$
I R_{\text {wall }}=\frac{f i_{\text {wall }}}{\kappa h} d d_{o}-\frac{f i_{\text {wall }}}{2 \kappa h} d_{o}{ }^{2}
$$


Where $f$ is the fraction of passive current expected to contribute to Ohmic drop, and all other variables are defined earlier and given in Table 3.11. Due to local water reduction, some of the anodic current is balanced by local cathodic reactions [22]. The calculations in this dissertation assumed that $f=85 \%$ of the passive current density which contributes to Ohmic drop. 


\section{CHAPTER 4}

\section{DISSOLUTION AND HYDROGEN DIFFUSION CONTROL OF IGSCC IN SENSITIZED 5083-H131}




\subsection{ABSTRACT}

Prior research affirmed that the mechanism for IGSCC in sensitized 5083-H131 in chloride solution requires dissolution of grain boundary $\beta$ to promote severe crack tip acidification, hydrogen production and uptake, and process zone embrittlement. This study establishes two new findings that strengthen this interactive dissolution and hydrogen embrittlement mechanism. First, H precharged-notched specimens of sensitized 5083H131 exhibit grain boundary embrittlement. Without $\beta$, specimens are embrittled, though intergranular failure was not observed. The interaction between $\mathrm{H}$ and $\beta$ could be due to either $H$ trapping at $\beta$, or non-deformable $\beta$ particles enhancing the local tensile stress at the grain boundaries. This $\mathrm{H}$ charging technique may provide a method to reveal grain boundary $\beta$ size, spacing, and morphology, though $\beta$ phase confirmation limits this approach. Second, the interactive $\beta-\mathrm{H}$ mechanism was confirmed with $\mathrm{H}$ diffusion crack growth rate modeling. The extra-ordinarily high rates of IGSCC are supported by $\mathrm{H}$ diffusion over a micrometer-scale distance ahead of the crack tip, provided that diffusivity is on the order of $10^{-8} \mathrm{~cm}^{2} / \mathrm{s}$ to $10^{-7} \mathrm{~cm}^{2} / \mathrm{s}$, as is possible due to reduced reversible $\mathrm{H}$ trapping. 


\subsection{NOMENCLATURE}

$\alpha-\mathrm{Al}-4 \% \mathrm{Mg}$ (wt. pct.) solid solution matrix phase

$\beta-\mathrm{Al}_{3} \mathrm{Mg}_{2}$ intergranular precipitate in Al-Mg alloys

$\mathrm{C}_{\mathrm{H} \text {-crit }}$ - critical concentration of $\mathrm{H}$ at the FPZ necessary to nucleate damage

$\mathrm{C}_{\mathrm{H} \sigma}$ - concentration of $\mathrm{H}$ trapped in the FPZ

$\mathrm{C}_{\mathrm{s}}$ - concentration of absorbed $\mathrm{H}$ at the crack tip surface

$\mathrm{da} / \mathrm{dt}$ - crack growth rate

$\mathrm{da} / \mathrm{dt}_{\text {II }}$ - Stage II crack growth rate

dadt $_{\mathrm{K} 15}$ - crack growth rate at $15 \mathrm{MPa} \sqrt{\mathrm{m}}$

$\mathrm{D}_{\mathrm{H}-\mathrm{EFF}}$ - trap-sensitive diffusivity of $\mathrm{H}$

DoS - degree of sensitization quantified by NAMLT

EDX - energy dispersive X-ray spectroscopy

FIB - focused ion beam

$\mathrm{FPZ}$ - crack tip fracture process zone

HEAC - hydrogen environment assisted cracking

$\eta-\mathrm{MgZn}_{2}$ intergranular precipitate in 7xxx alloys

IGC - intergranular corrosion

IGSCC - intergranular stress corrosion cracking

$\mathrm{K}$ - linear elastic stress intensity

$\mathrm{K}_{\mathrm{J}}$ - elastic-plastic stress intensity

$\mathrm{K}_{\mathrm{TH}}$ - threshold stress intensity

$\mathrm{L}$ - longitudinal (plate rolling) direction

NAMLT - nitric acid mass loss test per ASTM G67

OCP - open circuit potential

$\mathrm{R}$ - ideal gas constant

$\mathrm{S}$ - short-transverse (plate thickness) direction

SCE - saturated calomel electrode

SEM - scanning electron microscopy

SENT - single edge notched tensile specimen

SHT - solution heat-treated

$\mathrm{S}-\mathrm{L}$ - crack orientation, loading in $\mathrm{S}$ and crack growth in $\mathrm{L}$ directions

$\sigma_{i}-$ hydrostatic stress as a function of the distance ahead of the crack tip

$\mathrm{T}$ - transverse (plate width) direction

$\mathrm{T}$ - absolute temperature

TEM - transmission electron microscopy

$\mathrm{t}$ - time (for diffusion)

$\mathrm{V}_{\mathrm{H}}$ - partial molar volume of $\mathrm{H}$

$\mathrm{V}$ - velocity of a moving line source for diffusion

$\mathrm{x}$ - distance ahead of the crack tip

$\mathrm{X}_{\text {CRIT }}$ - critical distance ahead of the crack tip where $\mathrm{H}$ damage nucleates 


\subsection{INTRODUCTION}

Non-heat treatable wrought Al-Mg alloys used in ship structures are prone to rapid intergranular stress corrosion crack (IGSCC) growth during exposure to marine environments [1-7]. The susceptibility to IGSCC increases with grain boundary $\beta$ precipitation which causes "sensitization"; $\beta$ morphology and distribution highly influence the degree of sensitization (DoS) [8-11] and the kinetics of IGSCC when stressed in chloride solution. The hypothesized mechanism is coupled $\beta$ dissolution and $\mathrm{H}$ embrittlement causing hydrogen environment assisted cracking (HEAC) [2]. Crack growth begins with passive dissolution of the $\mathrm{Al}-4 \% \mathrm{Mg}$ matrix $\left(\alpha: \mathrm{Al} \rightarrow \mathrm{Al}^{3+}+3 \mathrm{e}^{-}\right)$leading to hydrolytic acidification $\left(\mathrm{Al}^{3+}+\mathrm{H}_{2} \mathrm{O}+3 \mathrm{Cl}^{-} \rightarrow \mathrm{H}^{+}+\mathrm{AlCl}_{3}+\mathrm{OH}^{-}\right)$at near open circuit potential (OCP) $[12,13]$. In parallel, grain boundary $\beta$ dissolution promotes rapid $\mathrm{Al}^{3+}$ and $\mathrm{Mg}^{2+}$ saturation in the crack tip [12,13], which promotes further $\alpha$ dissolution and acidification ( $\mathrm{pH} 2-3)$. This chemistry increases the rate of cathodic $\mathrm{H}$ production and concentration of absorbed $\mathrm{H}$ uptake available for diffusion into the fracture process zone (FPZ). In combination with locally concentrated tensile stress, $\mathrm{H}$ at the FPZ promotes inter$\beta$ ligament $\mathrm{H}$ embrittlement along the $\mathrm{Al}$ grain boundary [14-16]. IGSCC in 5083-H131 was fully characterized, and the $\beta$ dissolution-H embrittlement mechanism for IGSCC was validated with slow subcritical crack growth experiments as a function of DoS (quantified by the electrochemical nitric acid mass loss measurement governed by ASTM G67 [17]), as detailed in Chapter 2. This mechanism was amplified and validated by experiments using applied polarization and environment control in Chapter 3. This work is summarized as follows. 


\subsubsection{IGSCC dependence on sensitization}

As documented in Chapter 2, severe IGSCC in Al-Mg alloy 5083-H131 begins at a critical DoS value of about $10 \mathrm{mg} / \mathrm{cm}^{2}$ and susceptibility increases with exposure time at sensitization temperatures between $60^{\circ} \mathrm{C}$ to $100^{\circ} \mathrm{C}$. The threshold stress intensity for IGSCC $\left(\mathrm{K}_{\mathrm{TH}}\right)$ decreases from $\sim 20 \mathrm{MPa} \sqrt{\mathrm{m}}$ to $\sim 7 \mathrm{MPa} \sqrt{\mathrm{m}}$, and Stage II subcritical crack growth rate at $15 \mathrm{MPa} \sqrt{\mathrm{m}}\left(\mathrm{da}_{\mathrm{dt}} \mathrm{dt}_{\mathrm{K} 15}\right)$ increases from $500 \mathrm{~nm} / \mathrm{s}$ to $10,000 \mathrm{~nm} / \mathrm{s}$ as DoS rises from $10 \mathrm{mg} / \mathrm{cm}^{2}$ to $54 \mathrm{mg} / \mathrm{cm}^{2}$; below $10 \mathrm{mg} / \mathrm{cm}^{2}$, the material resists IGSCC. Typical results are reproduced in Fig. 4.1.

The critical DoS, $10 \mathrm{mg} / \mathrm{cm}^{2}$, likely correlates with a transition in $\beta$ size, morphology and grain boundary coverage based on characterization results reported in the literature and detailed in Chapter 2. Severe IGSCC corresponds to the combination of a critical volume of grain boundary $\beta$ for development of acidic crack tip chemistry, interacting with intensification of the microstructure-scale tensile and hydrostatic stresses acting on $\mathrm{Al}-\mathrm{Mg}$ solid solution grain boundaries between non-deformable $\beta$ precipitates. This effect of stress state can act to reduce the critical distance necessary for $\mathrm{H}$ diffusion, compared to that given by a continuum crack tip mechanics model, and decrease the critical amount of $\mathrm{H}$ needed for FPZ damage. These factors can interact to increase crack growth rate. These findings affirmatively answer the important question: Is the hypothesized interaction of $\beta$ dissolution and crack tip $H$ embrittlement validated by crack tip H diffusion modeling? Specifically, are the kinetics of $\beta$ dissolution and H diffusion in the FPZ capable of supporting the very high rates of IGSCC shown in Fig. 4.1? Recent high precision measurements of $\mathrm{H}$ diffusion in pure $\mathrm{Al}$ and the plate of 5083-H131 used in the current study provide important input to this analysis [18,19]. 


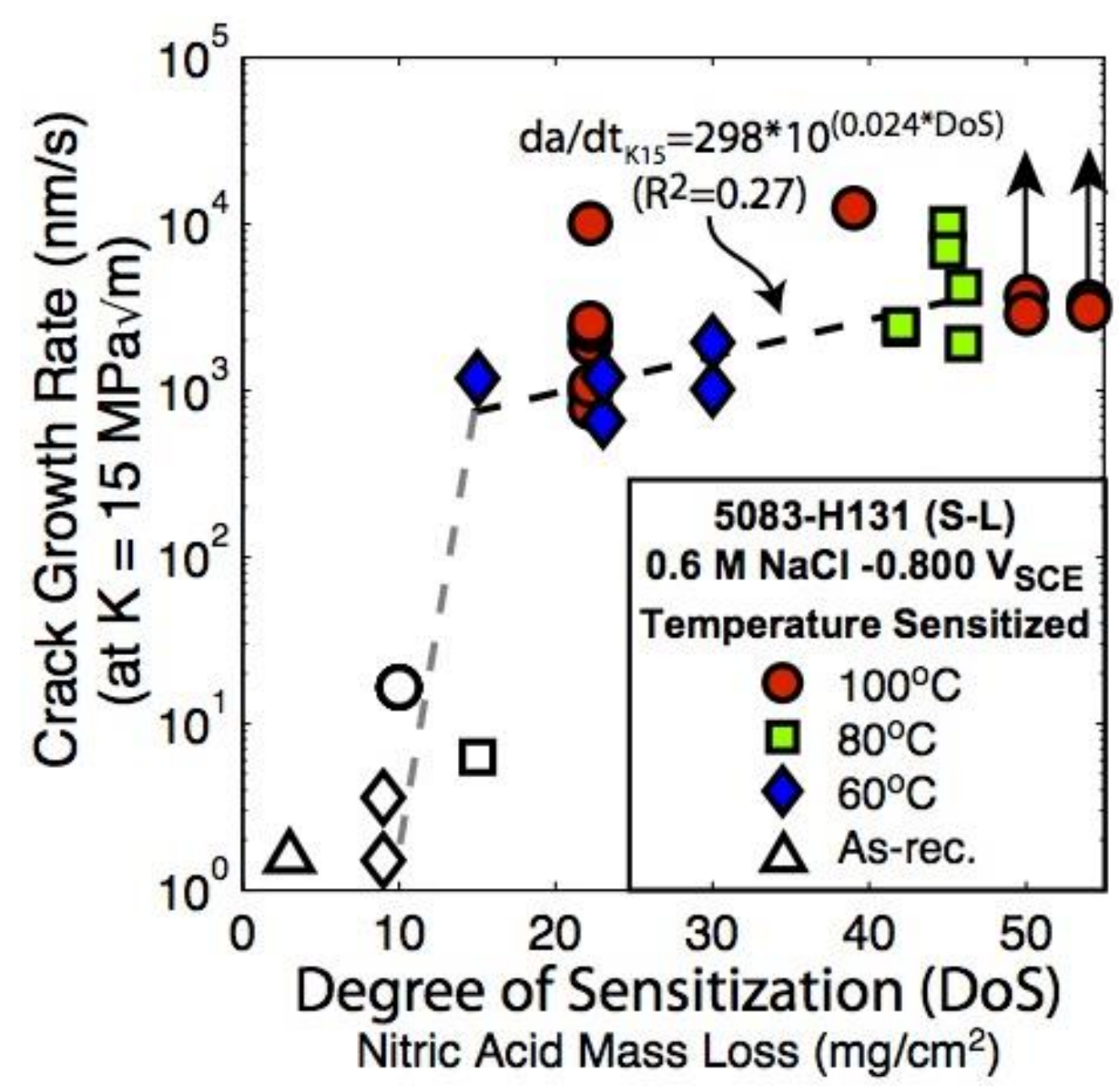

Figure 4.1 Stage II crack growth rate (at an elastic stress intensity, K, of $15 \mathrm{MPa} \sqrt{\mathrm{m}}$ ) as a function of DoS from ASTM International Standard G67-04 for Al-Mg alloy 5083$\mathrm{H} 131$ stressed in $0.6 \mathrm{M} \mathrm{NaCl}$ polarized to $-0.800 \mathrm{~V}_{\mathrm{SCE}}$ which is near the open-circuit potential (OCP). The Mode I crack was stressed in the plate-thickness (S) direction and grew in the plate rolling $(\mathrm{L})$ direction.

It is well known that a characterization of the distribution of $\beta$ size, shape and spacing on $\alpha$ grain boundaries is critical to understanding the micromechanics and $\mathrm{H}$ diffusion in the FPZ [11]. Uncertainties associated with $\beta$ characterization in the literature point to the importance of revealing grain boundary $\beta$ particles by a statistically meaningful method without changing precipitate characteristics. Precharged $\mathrm{H}$ cracking of $\mathrm{Al}-\mathrm{Mg}$ grain 
boundaries may provide a means to achieve this goal. Such experiments also provide input to understanding the interaction between tensile stress and $\mathrm{H}$ concentration, necessary for formulation of a quantitative model of da/dt for IGSCC by H embrittlement.

\subsubsection{Crack tip electrochemical control of IGSCC in Al-Mg}

The hypothesized role of $\beta$ dissolution in IGSCC by HEAC in sensitized Al-Mg alloys was clarified based on consideration of occluded-crack electrochemistry and validated experimentally in Chapter 3. Applied polarization was used to either promote or preclude crack tip $\beta$ breakdown in subcritical cracking experiments with sensitized 5083-H131 $\left(100^{\circ} \mathrm{C}\right.$ for $175 \mathrm{~h}, 22 \mathrm{mg} / \mathrm{cm}^{2}$, S-L orientation) stressed under slow-rising $\mathrm{K}$ in $\mathrm{NaCl}$ (Fig. 4.2). Results confirmed that grain boundary $\beta$ dissolution is the critical trigger that promotes $\mathrm{Mg}^{2+}$ and $\mathrm{Al}^{3+}$ hydrolytic acidification for further $\alpha$ dissolution to establish an equilibrium $\mathrm{pH}$ of 2-3, which in turn leads to significant $\mathrm{H}$ production, uptake, and then H embrittlement.

The role of crack tip chemistry was also investigated with as-received 5083-H131 $\left(3 \mathrm{mg} / \mathrm{cm}^{2}\right.$ ) immersed in a variety of electrolytes designed to control crack tip electrochemistry. Crack growth rate for each experiment is plotted in Fig. 4.2 as a function of applied potential. Unsensitized 5083-H131 (without grain boundary $\beta$ ) is embrittled in simulated-acidic crack tip chloride solution $\left(\mathrm{AlCl}_{3} / \mathrm{MgCl}_{2}\right.$ at $\left.\mathrm{pH}-0.4\right)$ polarized at $-1.000 \mathrm{~V}_{\mathrm{SCE}}$ and stressed in $\mathrm{NaCl}$ polarized to $-0.730 \mathrm{~V}_{\mathrm{SCE}}$. In both environments, $\alpha$ dissolution is promoted causing significant $\mathrm{H}$ production and uptake for $\mathrm{HEAC}$, attributed to increased magnitude of the crack tip overpotential for $\mathrm{H}$ production and possibly acidification for increased $\mathrm{H}$ solubility. In contrast, the $\beta$-free microstructure resists IGSCC in neutral $\mathrm{NaCl}$ polarized to $-0.800 \mathrm{~V}_{\mathrm{SCE}}$. High resistance to IGSCC is also observed for $\beta$ - 
free $5083-\mathrm{H} 131$ in $\mathrm{Cl}^{-}$free $\mathrm{NaOH}$ at $\mathrm{OCP}(\sim-1.037 \mathrm{VSCE})$ as well as when polarized to $-1.800 \mathrm{~V}_{\mathrm{SCE}}$. The high-pH alkaline environment, increased crack tip potential, and absence of destabilizing $\mathrm{Cl}^{-}$at the crack tip results in IGSCC resistance in $\mathrm{NaOH}$.

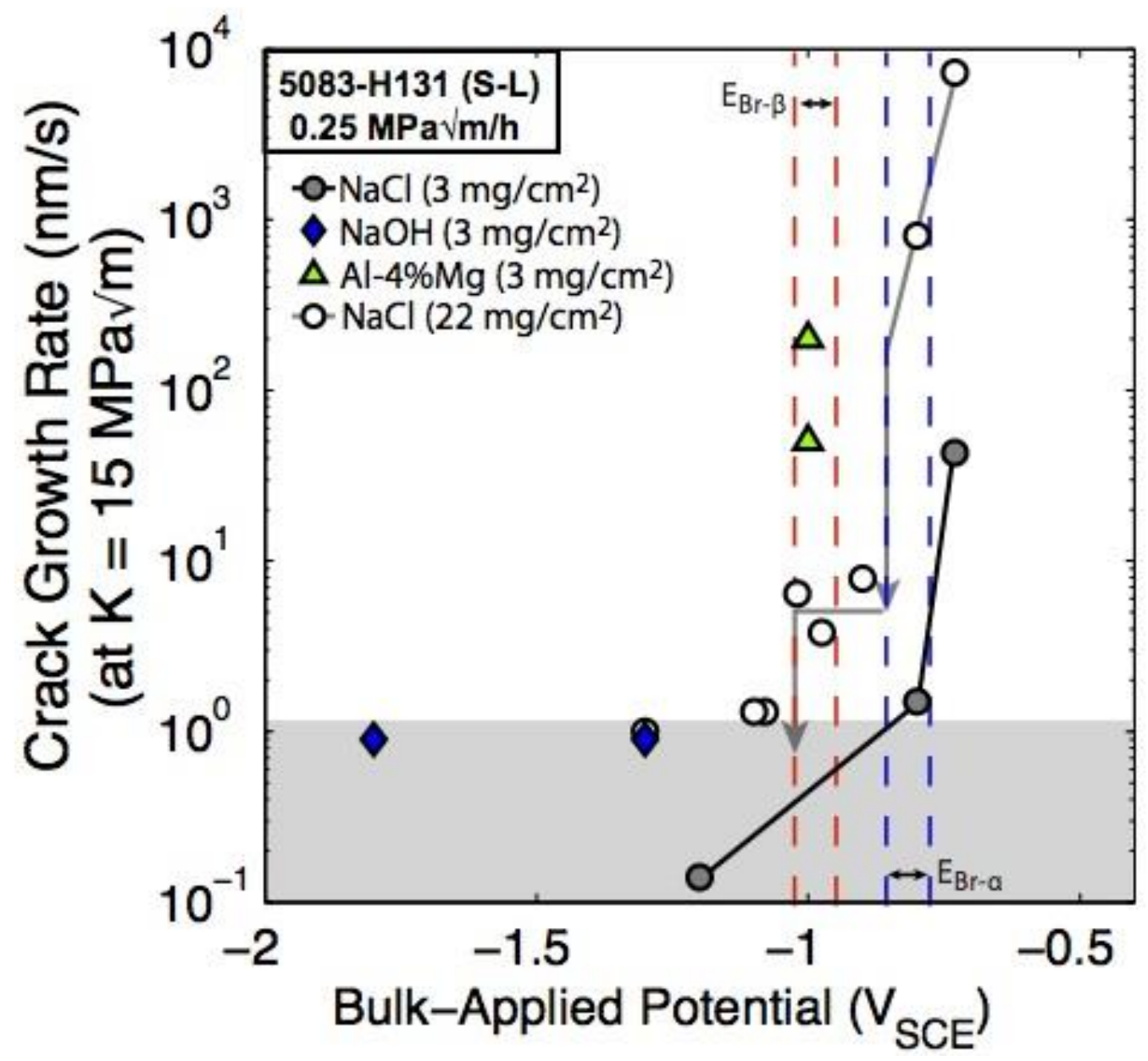

Figure 4.2 Rates of IGSCC for as-received and sensitized microstructures of 5083-H131 (S-L) stressed in various environments at constant $\mathrm{dK} / \mathrm{dt}$ of $0.25 \mathrm{MPa} \sqrt{\mathrm{m}} / \mathrm{h}$. The ranges of $\mathrm{pH}$ sensitive breakdown potentials of both $\alpha$ and $\beta$ are shown with vertical dashed lines. The crack growth rate resolution at $\mathrm{K}$ of $15 \mathrm{MPa} \sqrt{\mathrm{m}}$ is shown by the grey box.

Results from Chapter 3 affirmatively answer two fundamental question: Can IGSCC susceptibility in sensitized 5083-H131 be eliminated with polarization? And Is $\beta$ dissolution required for H production and uptake? 
The question remains: How does H interact with the grain boundary microstructure at and between $\beta$, and how does this interaction control IGSCC kinetics through the HEAC mechanism?

\subsubsection{Objective}

The coupled $\beta$ dissolution- $\mathrm{H}$ embrittlement mechanism for IGSCC in sensitized Al-Mg alloys, originally put forth by Jones et al. [2], is validated by the above results. However, very fast crack growth rates call into question how the kinetics of $\beta$ dissolution, $\mathrm{H}$ uptake, and $\mathrm{H}$ diffusion in the crack tip FPZ can sustain such rapid cracking. Though highly informative, uncertainties associated with $\beta$ characterization using etching techniques, TEM and Ga- $\beta$ interaction (see Chapter 2) point to the need to better reveal grain boundary $\beta$ particles by a statistically meaningful method and without altering precipitate characteristics. Precharged $\mathrm{H}$ cracking of $\mathrm{Al}-\mathrm{Mg}$ grain boundaries could provide a means to achieve this goal. Moreover, the intrinsic $\mathrm{H}$ embrittlement resistance of Al-Mg grain boundaries as a function of grain boundary $\beta$ is not fully understood, in part because highly reactive $\beta$ dissolves during stressing in electrolytes, limiting fractographic study.

The objective of this chapter is to assess how rapid da/dtII is sustained by $\beta$ dissolution and $\mathrm{H}$ embrittlement. The contributions of greatly enhanced crack tip $\mathrm{H}$ concentration from $\beta$ dissolution, and the characteristics of $\mathrm{H}$ diffusion in the crack tip FPZ with small-size intra- $\beta$ ligaments, are considered in the context of film rupture-dissolution and $\mathrm{H}$ diffusion limited Stage II crack propagation. Hydrogen charging experiments illustrate the role of sensitization on $\mathrm{H}$ embrittlement decoupled from $\beta$ dissolution, and provide a grain boundary surface for $\beta$ precipitate characterization. 


\subsection{EXPERIMENTAL}

Crack growth rate data in Figs. 4.1 and 4.2 provide the basis for the analysis presented in this chapter. Experimental procedures and characterization of the 5083-H131 plate used are presented in Chapter 2. Four sensitized conditions were studied: (a) as-received, with DoS of $3 \mathrm{mg} / \mathrm{cm}^{2}$, (b) sensitized at $100^{\circ} \mathrm{C}$ for $175 \mathrm{~h}, 22 \mathrm{mg} / \mathrm{cm}^{2}$, (c) sensitized at $100^{\circ} \mathrm{C}$ for $30 \mathrm{~d}, 50 \mathrm{mg} / \mathrm{cm}^{2}$, and (d) sensitized at $60^{\circ} \mathrm{C}$ for $90 \mathrm{~d}, 23 \mathrm{mg} / \mathrm{cm}^{2}$.

Round circumferentially double-notched tensile specimens (S-L orientation, $26.7 \mathrm{~mm}$ long and $4.0 \mathrm{~mm}$ diameter containing two $0.9 \mathrm{~mm}$ deep notches, with a radius of $70 \mu \mathrm{m}+/-6 \mu \mathrm{m}$, and $9.9 \mathrm{~mm}$ apart equidistant from the center line) were precharged by immersion in $550 \mathrm{~mL}$ of continuously stirred $0.01 \mathrm{M} \mathrm{NaOH}$ solution at $\mathrm{pH} 12$ and $\mathrm{OCP}$ $\left(\sim-1.375 \mathrm{~V}_{\mathrm{SCE}}\right)$. Charging time of $16 \mathrm{~d}\left(21 \mathrm{~d}\right.$ for the $60^{\circ} \mathrm{C}$ sensitized specimen) assured that $\mathrm{H}$ concentration was at least $60 \%$ of the $\mathrm{H}$ concentration fixed at the surface, over 100 $\mu \mathrm{m}$ inward by assuming: (a) one dimensional Fickian diffusion in an infinite plate of thickness $2.2 \mathrm{~mm}$, (b) a constant non-depleting source of $\mathrm{H}$ at each surface, and (c) $\mathrm{H}$ diffusivity, $\mathrm{D}_{\mathrm{H}-\mathrm{EFF}}$, of $10^{-10} \mathrm{~cm}^{2} / \mathrm{s}$ [19]. This charging condition produced $\mathrm{H}$ uptake and transport in 5083 foils (taken from the plate used in this study) based on DevananthanStachurski permeation measurements [19]. Specimens were coated with a stop-off lacquer, exposing only the notched region to $\mathrm{H}$ charging solution. Immediately following charging, specimens were stored in liquid nitrogen until 15 min prior to loading in a servo-electric feedback-controlled tensile machine operating in grip displacement control at a rate of $0.00045 \mathrm{~mm} / \mathrm{min}$, which corresponded to an applied stress rate of $23 \mathrm{MPa} / \mathrm{h}$ to $29 \mathrm{MPa} / \mathrm{h}$. All specimens fractured within $20 \mathrm{~h}$. Fractured specimens were cleaned in acetone and stored in vacuum prior to scanning electron microscopy (SEM) analysis. As-received and 
sensitized $\left(100^{\circ} \mathrm{C}\right.$ for $\left.30 \mathrm{~d}\right) 5083-\mathrm{H} 131$ specimens were loaded in air at the same rate, but without $\mathrm{H}$ precharging.

\subsection{RESULTS}

Hydrogen precharging embrittled 5083-H131 in the S-L notch orientation. The nominal net-section stress versus displacement trend for each sensitization is shown in Fig. 4.3 (the notch root elastic stress concentration factor of 4.0 with regard to gross section stress was not used in these calculations [20]). Each charged specimen fractured at a nominal netsection stress lower than that for the uncharged as-received specimen. Hydrogen precharged as-received 5083-H131 fractured at a net-section stress of $347 \mathrm{MPa}$, which is reduced compared to the uncharged specimen $(433 \mathrm{MPa})$, but higher than the values characteristic of the three sensitized and $\mathrm{H}$ charged specimens (255 MPa to $289 \mathrm{MPa}$ ). Netsection stresses at fracture of the sensitized specimens did not correlate with DoS; sensitization at $100^{\circ} \mathrm{C}$ for $175 \mathrm{~h}\left(22 \mathrm{mg} / \mathrm{cm}^{2}\right)$ and for $30 \mathrm{~d}\left(50 \mathrm{mg} / \mathrm{cm}^{2}\right)$ resulted in fracture at $275 \mathrm{MPa}$ and $289 \mathrm{MPa}$, respectively, while sensitization at $60^{\circ} \mathrm{C}$ for $90 \mathrm{~d}\left(23 \mathrm{mg} / \mathrm{cm}^{2}\right)$ resulted in a maximum net-section stress of $255 \mathrm{MPa}$.

Fractographic analysis revealed small distinct areas of intergranular fracture restricted to the notch root and surrounded by ductile microvoiding for all sensitized and $\mathrm{H}$ charged specimens. In contrast unsensitized 5083-H131 $\left(3 \mathrm{mg} / \mathrm{cm}^{2}\right)$, with and without precharged $\mathrm{H}$, exhibited only ductile microvoiding. The largest intergranular region was found in sensitized 5083-H131 $\left(22 \mathrm{mg} / \mathrm{cm}^{2}\right)$ and extended inward from the notch tip by a distance of $350 \mu \mathrm{m}$, covering over 3 grains; Fig. 4.4 (the grain size of 5083-H131 is $70 \mu \mathrm{m}$ in $\mathrm{L}$ and $65 \mu \mathrm{m}$ in T; Chapter 2). The intergranular H embrittled surfaces in sensitized 5083-H131 were populated by particles ranging in size from $50 \mathrm{~nm}$ to $800 \mathrm{~nm}$ (Fig. 4.5a). Uncharged 
as-received and sensitized $\left(50 \mathrm{mg} / \mathrm{cm}^{2}\right) 5083-\mathrm{H} 131$ failed by microvoid coalescence at particles with $5 \mu \mathrm{m}$ to $10 \mu \mathrm{m}$ diameters, without evidence of intergranular regions.

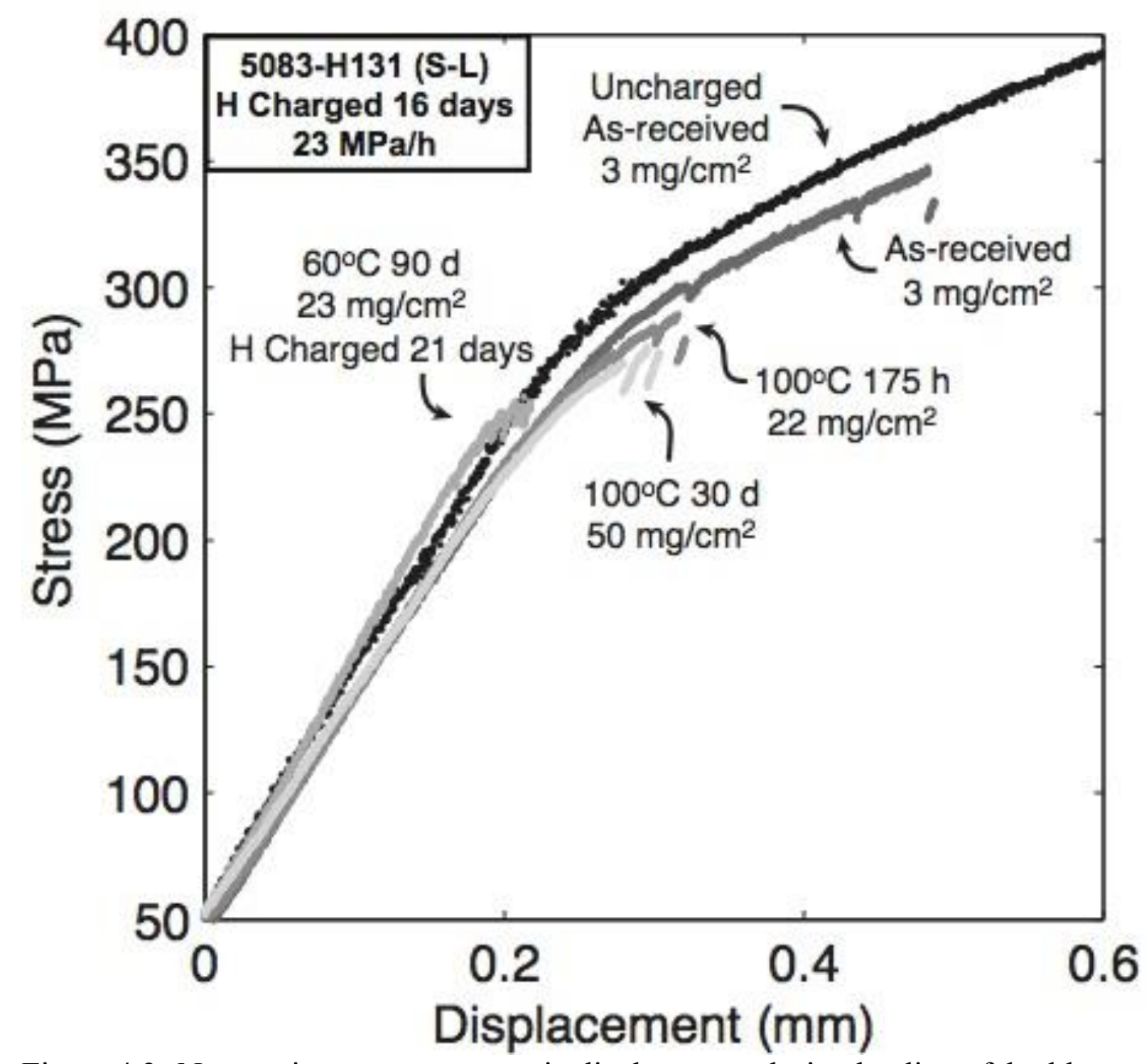

Figure 4.3 Net-section stress versus grip displacement during loading of double notched specimens in moist air at $0.00045 \mathrm{~mm} / \mathrm{min}(23 \mathrm{MPa} / \mathrm{h}$ to $29 \mathrm{MPa} / \mathrm{h})$ for $\mathrm{H}$ precharged S$\mathrm{L}$ oriented 5083-H131 at different sensitization conditions.

Three particle types were observed for the H-precharged $100^{\circ} \mathrm{C}$ sensitizations of 5083H131: (1) coarse square particles, $500 \mathrm{~nm}$ long or larger (lower arrows in Figs. 4.5a), are likely Fe-Si rich constituent particles (e.g., $\mathrm{Al}_{13} \mathrm{Fe}_{4}$ ) [9,21], (2) rod shaped particles, $500 \mathrm{~nm}$ to $1000 \mathrm{~nm}$ long (upper white arrows in Figs. 4.5a), are likely $\mathrm{AlMn}_{3}, \mathrm{Al}_{6} \mathrm{Mn}$ or 
(Al-Mn-Fe-Cr) dispersoids [9,21], and (3) tiny spherical particles, $50 \mathrm{~nm}$ to $200 \mathrm{~nm}$ in diameter and about $500 \mathrm{~nm}$ to $800 \mathrm{~nm}$ apart (white arrows in Fig. 4.5b), which may be $\beta$ $\left(\mathrm{Al}_{3} \mathrm{Mg}\right)$ precipitates. These small particles are on the same order and size seen by Birbilis et al. [11]; however, the number density of $\beta$ sized particles on grain boundaries exposed with $\mathrm{H}$ charging is much smaller than that observed by Birbilis during Ga metal embrittlement [11]. Some areas exhibited no resolvable particles, while other grains

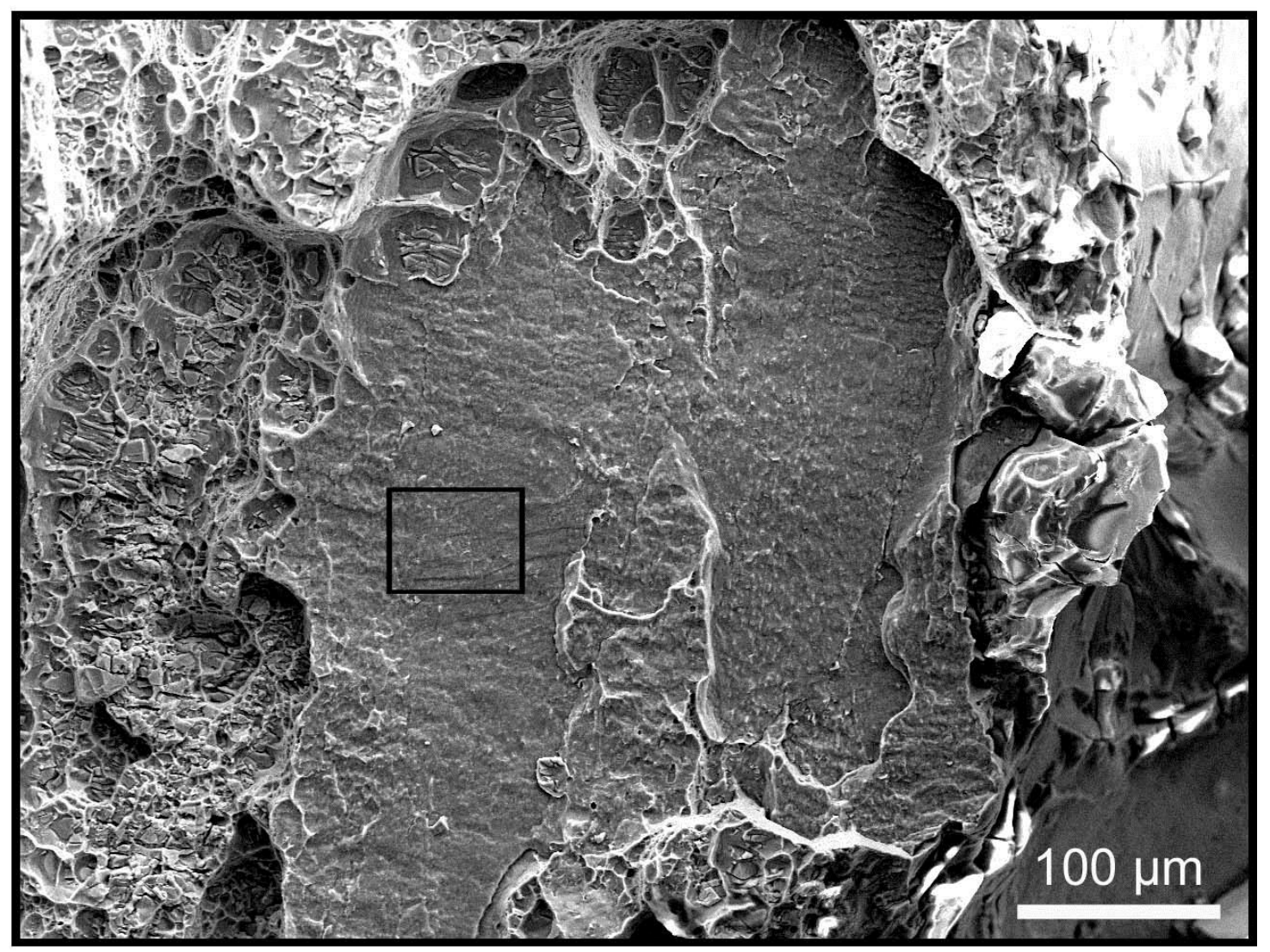

Figure 4.4 Scanning electron fractograph of 5083-H131 sensitized at $100^{\circ} \mathrm{C}$ for $175 \mathrm{~h}$ $\left(22 \mathrm{mg} / \mathrm{cm}^{2}\right)$ and $\mathrm{H}$ charged for $16 \mathrm{~d}$ prior to slow-rate loading in moist air. 

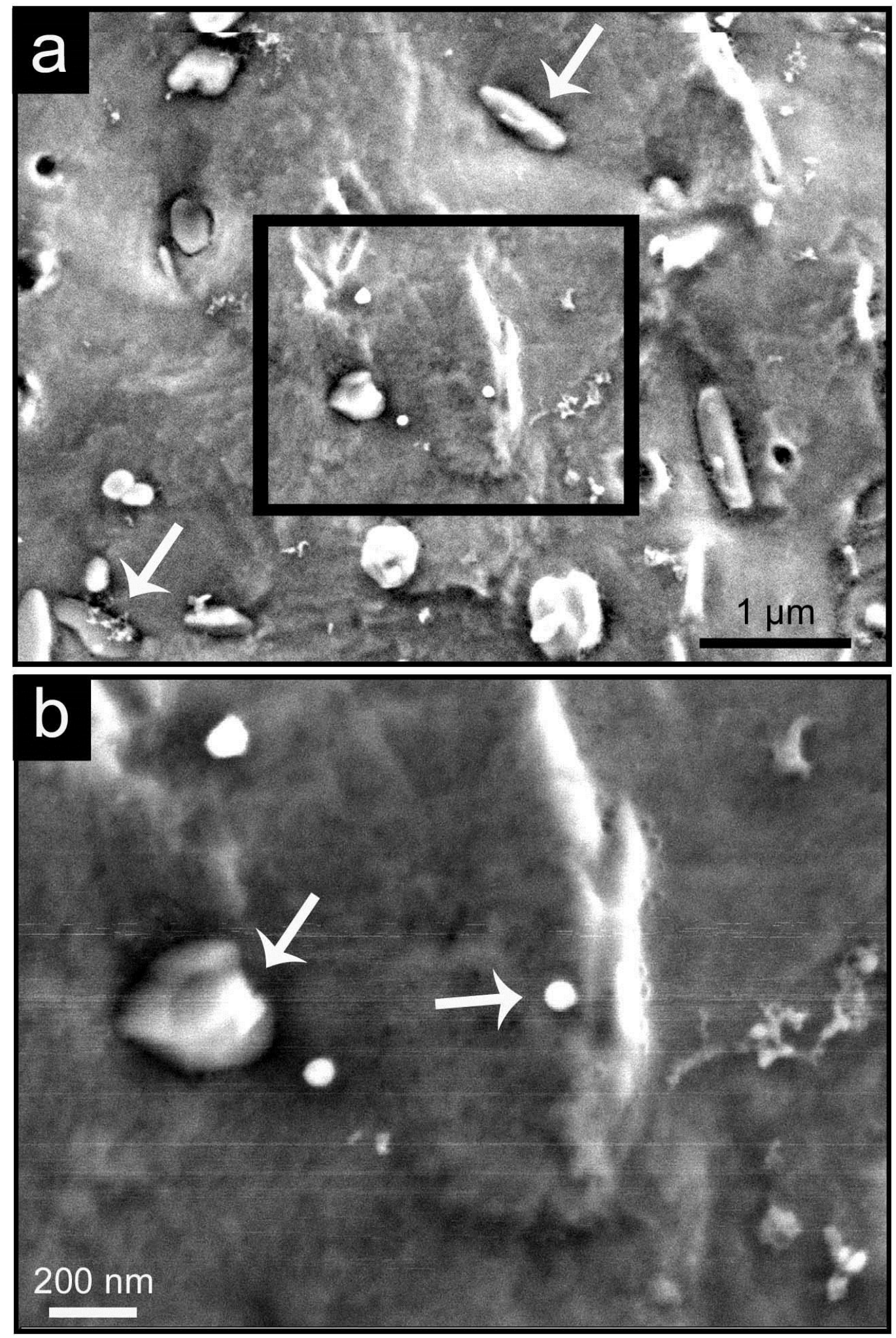

Figure 4.5 Scanning electron fractographs of 5083-H131 sensitized at $100^{\circ} \mathrm{C}$ for $175 \mathrm{~h}$ and $\mathrm{H}$ charged for $16 \mathrm{~d}$ prior to slow-rate loading in moist air illustrating particles on the grain surface. The boxed area in Fig. 4.4 is detailed in (a), the area noted in (a) is detailed in (b). 
showed subtle-bright features that may reflect either particles or plasticity. A mottled texture was observed on some grains (e.g. Fig. 4.5b) that could reflect unresolved particles at the $100 \mathrm{~nm}$ length scale. Compositional profiling by energy dispersive X-ray spectroscopy (EDX) was not informative for the small particles due to the large electron interaction volume compared to particle size. Fractographic analyses of grain boundary features produced by $\mathrm{H}$ embrittlement are compared to $\mathrm{Ga}$ attacked boundaries for several levels of sensitization in Appendix 1.

\subsection{DISCUSSION}

\subsubsection{Hydrogen charging literature}

As-received Al-Mg alloy 5083-H131 is modestly embrittled by H charging compared to the $\mathrm{H}$-free case, which confirms the possibility for $\mathrm{H}$ embrittlement of $\beta$-free grain boundaries (Fig. 4.3). The literature reported the role of $\mathrm{H}$ embrittlement in $\beta$-free 5083 for situations with various loading modes and $\mathrm{H}$ recombination poisons in full immersion [4,22], as well as with $\mathrm{H}$ precharging followed by stressing in moist air [14,23]. Intergranular initiation was identified for $\mathrm{H}$ precharged recrystallized 5083 using surface strain fields measured by in-situ SEM of notched specimens [14]. These brittle cracks initiated only on grain boundaries normal to the tensile direction, and measurements indicated that intergranular initiation was related to both average strain level and grain boundary orientation [14]. Intergranular embrittlement susceptibility was also reported for as-received 5083 and increased with increasing H-charging time; however, such embrittlement was not clear in the fractographs provided [23]. Surface hardening due to dislocation pinning by $\mathrm{H}$ was cited as the source of embrittlement in these alloys [23]. The role of increasing $\beta$ was not explored. 


\subsubsection{Embrittlement by $\mathrm{H}$ charging in 5083-H131}

In the present study, $\beta$ appears to exacerbate $\mathrm{H}$ embrittlement of sensitized 5083-H131, as the maximum net-section stress at failure decreases with sensitization for $\mathrm{H}$ charged specimens (Fig. 4.3). The yield strength measured in compression for this plate of $\mathrm{H}$-free 5083-H131 does not vary with sensitization (Chapter 2) and the ultimate tensile strength of 5083-H116 was reported to be relatively constant (355 MPa to $375 \mathrm{MPa}$ ) for sensitizations at $80^{\circ} \mathrm{C}$ to $175^{\circ} \mathrm{C}$ [24]. Moreover, the plane strain fracture toughness of 5083 increases with sensitization as reported in Chapter 2 and elsewhere [5]. Since the fracture toughness of uncharged 5083-H131 is independent of (or increases with) sensitization [5], the deleterious effect of sensitization on the fracture resistance of H-charged 5083-H131 (Fig. 4.3) is assumed to be due to an interaction of $\mathrm{H}$ and grain boundary $\beta$ rather than an effect of sensitization on grain boundary ductile fracture.

Results are not sufficiently replicated to define the effect of DoS on $\mathrm{H}$ embrittlement (Fig. 4.3). The difference in maximum failure stress for $60^{\circ} \mathrm{C}$ versus $100^{\circ} \mathrm{C}$ sensitizations at fixed DoS (the DoS of $22 \mathrm{mg} / \mathrm{cm}^{2}$ to $23 \mathrm{mg} / \mathrm{cm}^{2}$ ) could be due to the longer charging time for the $60^{\circ} \mathrm{C}$ specimen $\left(23 \mathrm{mg} / \mathrm{cm}^{2}\right)$, local microstructural variability, or a difference in $\beta$ morphology not reflected in mass loss measurements. Small drops in load prior to fracture may be due to distinct regions of embrittlement before microvoid coalescence takes over. The location of embrittlement is assumed to be at the grain boundary; however, it is uncertain whether cracking occurs at the matrix- $\beta$ interface or within the boundaryadjacent matrix. Speculatively, interaction between grain boundary $\beta$ and $\mathrm{H}$ could be based on either: (a) $\mathrm{H}$ trapping at grain boundary $\beta$, which provides a source for $\mathrm{H}$ partition to the adjacent Al boundary, or (b) enhanced microstructure scale tensile stress concentration and/or constraint acting on the grain boundary causing boundary decohesion. Recent 
results show that $\mathrm{H}$ is trapped in both pure $\mathrm{Al}$ and 5083-H131 microstructures $[18,19]$; similar thermal desorption spectra were reported for each alloy. This similarity suggests that either $\beta$ is not a $\mathrm{H}$ trap site, or that $\beta$ traps $\mathrm{H}$ with a binding energy and trap site concentration similar to other traps such as dislocations and high angle grain boundaries [25].

\subsubsection{Fractography indicating intergranular failure in 5083-H131}

Discrete locations of intergranular embrittlement (Fig. 4.4) were observed near the notch tip in sensitized and $\mathrm{H}$ precharged specimens of 5083-H131, suggesting a high $\mathrm{H}$ concentration in these regions. Since these regions were not observed in the $\mathrm{H}$ charged asreceived specimens, $\beta$ likely influences the increased concentration of $\mathrm{H}$ in these areas, or the critical $\mathrm{H}$ content required for local interface cracking. Calculations in Chapter 2 demonstrate how increased local stress can develop between $\beta$ due to constraint and could increase the $\mathrm{H}$ concentration in these regions, and also decrease the critical $\mathrm{H}$ concentration necessary for local fracture nucleation. Hydrogen diffuses to a region of high stress triaxiality, such as that present ahead of a notch [26], as well as at a non-deformable particle, and in response to the constraint that occurs between $\beta$. Here, such $\mathrm{H}$ could cause discontinuous cracking within this region, as discussed in Chapter 2.

Assuming that finite element analysis of a single-edge U notched plate [27] is relevant to the double-notched round specimen, the maximum opening direction stress (766 MPa) occurs at $65 \mu \mathrm{m}$ ahead of the notch root for embrittlement of $\mathrm{H}$ charged as-received 5083H131, based on measured load at fracture. This tensile stress ranges from $625 \mathrm{MPa}$ to $667 \mathrm{MPa}$ and moves closer to the notch root $(30 \mu \mathrm{m}$ to $50 \mu \mathrm{m})$, for $\mathrm{H}$ charged sensitized 5083-H131. Based on diffusion analysis, $\mathrm{H}$ penetration during the prolonged charging time 
is substantial over these distances. As such, these local stresses provide a reasonable estimate of the H-sensitive fracture strength for each sensitization condition. The SEM fractographic results correlate with these estimates in that discrete regions of intergranular fracture were observed within $100 \mu \mathrm{m}$ to $350 \mu \mathrm{m}$ of the notch tip. Since a relatively slow loading rate was employed, $\mathrm{H}$ cracking may have nucleated anywhere between the notch tip and the estimated locations of maximum stress triaxiality, then grew inward to form the $100 \mu \mathrm{m}$ to $350 \mu \mathrm{m}$ deep zones of intergranular cracking (Fig. 4.4).

A second objective of $\mathrm{H}$ charging of $\mathrm{Al}-\mathrm{Mg}$ was to reveal $\beta$-decorated grain boundaries for quantitative SEM, as employed for Al-Zn-Mg [28]. Such results would complement use of Ga attack to reveal grain boundaries in alloys such as 5083, allowing $\beta$ size and spacing quantification [11]. Initial results of H-charging of 5083-H131 revealed grain boundary particles with a range of sizes, but did not provide definitive results specific to $\beta$. Sensitized 5083-H131 revealed three distinct types of particle within the embrittled regions of the H-fracture surface. The smaller of these particles were roughly spherical, $50 \mathrm{~nm}$ to $200 \mathrm{~nm}$ in diameter, and about $500 \mathrm{~nm}$ to $800 \mathrm{~nm}$ apart (Fig 4.5b), which is the morphology expected for $\beta$ precipitates in $100^{\circ} \mathrm{C}$ sensitized 5083 based on TEM and SEM analyses $[2,9,11]$. Based on TEM, after only $3 \mathrm{~d}$ at $100^{\circ} \mathrm{C}, \beta$ precipitated as a ribbon morphology that was less than $50 \mathrm{~nm}$ thick on grain boundaries [9], and was also seen for both 5182 sensitized at $150^{\circ} \mathrm{C}$ for $10 \mathrm{~h}$ [29] and solution heat treated (SHT) 5083-H131 sensitized for $175^{\circ} \mathrm{C}$ for $50 \mathrm{~h}$ [8]. A continuous film of $\beta$ with thickness $25 \mathrm{~nm}$ to $30 \mathrm{~nm}$ was detected on grain boundaries after SHT and aging at $100^{\circ} \mathrm{C}$ for more than $45 \mathrm{~d}$ [9]. This film was not observed on fracture surfaces produced by $\mathrm{H}$ charging, but it is not clear how such a feature would be revealed by SEM. Gallium attack and SEM analysis revealed 
$\beta$ decorated grain boundaries with elongated particles of equivalent diameter $250 \mathrm{~nm}$ and $300 \mathrm{~nm}$ apart for SHT $5083-\mathrm{H} 131$ sensitized at $100^{\circ} \mathrm{C}$ for $7 \mathrm{~d}$ with SEM [11]. Equivalent

diameter increased with sensitization and nearest neighbor distance remained relatively equal with large variability [11].

Several problems hinder use of hydrogen embrittlement and SEM fractography to reveal the size, shape and spacing of grain boundary $\beta$ for quantitative correlation with rates of IGSCC versus DoS (Fig. 4.1 and Chapter 2). First, composition measurement by EDX was inconclusive for the various small particles shown in Fig. $4.5 \mathrm{~b}$ due to the large electron interaction volume compared to particle size. Second, backscattered electron imaging is not useful due to the similar atomic masses of the various-possible particles and the Al matrix. Finally, the usefulness of $\mathrm{H}$ cracking to image $\beta$ depends on the extent to which embrittlement separates the interface between $\beta$ and the $\mathrm{Al}-\mathrm{Mg}$ solid solution matrix. In principle intergranular cracking can progress near but not precisely along such interfaces; if $\mathrm{H}$ decohesion does not occur at these interfaces it is possible that the complete distribution of grain boundary $\beta$ precipitates is not revealed by SEM analysis. Additional experiments are required to address these issues and refine the use of internal hydrogen embrittlement as a method to complement $\mathrm{Ga}$ attack of $\mathrm{Al}-\mathrm{Mg}$ grain boundaries.

\subsubsection{Hydrogen diffusion controlled HEAC and IGSCC}

The fastest Stage II rates of HEAC reported for a wide range of high strength alloy classes stressed in aqueous environments are plotted in Fig. 4.6 as a function of the best estimate of trap-sensitive diffusivity of $\mathrm{H}$ in the alloy $\left(\mathrm{D}_{\mathrm{H}-\mathrm{EFF}}\right)$, typically from permeation experiments that analyzed the first rise transient [30]. The solid line depicts the direct proportionality of fastest da/dtII to $\mathrm{D}_{\mathrm{H}-\mathrm{EFF}}$, supporting the rate-limiting role of $\mathrm{H}$ diffusion. 


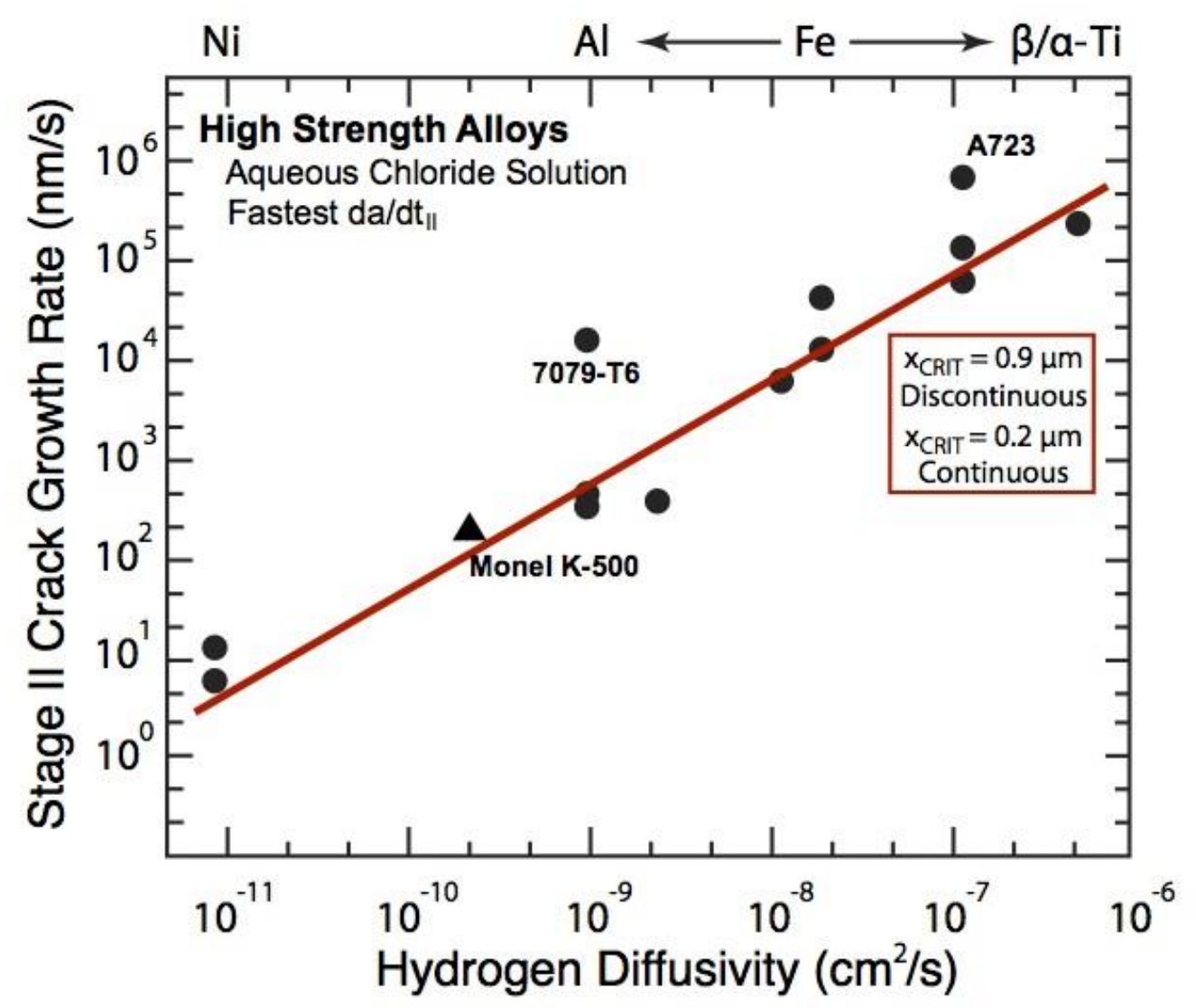

Figure 4.6: Maximum da/dtII reported for $\mathrm{H}$ diffusion controlled HEAC in high strength alloys ( [30], $\boldsymbol{\Delta}$ [33]). Trend line is plotted with the discontinuous model (Eqn. 4.1) and the continuous model (Eqn. 4.6), defining $\mathrm{x}_{\mathrm{CRIT}}$ as $0.9 \mu \mathrm{m}$ and $0.2 \mu \mathrm{m}$, respectively.

Crack tip FPZ based models of $\mathrm{H}$ diffusion rate limited crack growth depend on four parameters: $\mathrm{D}_{\mathrm{H}-\mathrm{EFF}}$, the critical distance ahead of the crack tip where $\mathrm{H}$ damage nucleates ( $\left.\mathrm{x}_{\mathrm{CRIT}}\right)$, the stress-enhanced concentration of $\mathrm{H}$ trapped in the FPZ $\left(\mathrm{C}_{\mathrm{H \sigma}}\right)$ at $\mathrm{x}=\mathrm{x}_{\mathrm{CRIT}}$, and the critical concentration of $\mathrm{H}$ necessary to nucleate damage in the context of the crack tip stress field $\left(\mathrm{C}_{\mathrm{H}-\text { crit }}\right)[31]$ :

$$
\left(\frac{\mathrm{da}}{\mathrm{dt}}\right)_{\mathrm{II}}=\frac{4 \mathrm{D}_{\mathrm{H}-\mathrm{EFF}}}{\mathrm{x}_{\mathrm{CRIT}}}\left[\operatorname{erf}^{-1}\left(1-\frac{\mathrm{C}_{\mathrm{H}-\mathrm{crit}}}{\mathrm{C}_{\mathrm{H} \sigma}}\right)\right]^{2}
$$


This model is based on the assumption of discontinuous $\mathrm{H}$ crack growth over a distance $\mathrm{X}_{\text {CRIT }}$ [31-35]. This approach is based on the observed location of $\mathrm{H}$ cracking, ahead of a notch root [26], as well as the well accepted principle that the notch or crack tip stress field dictates the location of $\mathrm{H}$ cracking $[31,34]$. In this scenario da/dt $\mathrm{dI}_{\text {II }}$ equals the ratio of cracking distance given by $\mathrm{x}_{\text {CRIT }}$ to the time $(\Delta \mathrm{t})$ required for $\mathrm{H}$ to diffuse from the crack tip surface $\left(\mathrm{C}_{\mathrm{s}}=\mathrm{C}_{\mathrm{H} \sigma(\mathrm{x}=0)}\right)$ to $\mathrm{x}_{\mathrm{CRIT}}$ and establishing $\mathrm{C}_{\mathrm{H} \sigma(\mathrm{x}=\mathrm{xCRIT})}=\mathrm{C}_{\mathrm{H} \text {-crit. }}$. The absorbed $\mathrm{H}$ concentration at the crack tip surface $\left(\mathrm{C}_{\mathrm{s}}\right)$ is assumed to be in rapid equilibrium with the local environment $\mathrm{pH}$ and potential (or $\mathrm{H}_{2}$ pressure for gaseous environments). When $\mathrm{C}_{\mathrm{H \sigma}(\mathrm{x}=\mathrm{xCRIT})}=6.3 \mathrm{C}_{\mathrm{H}-\mathrm{crit}}$, the squared inverse error function in Eqn. 4.2 is 0.99 and $\mathrm{da} / \mathrm{dt}_{\mathrm{II}}$ is directly proportional to $\mathrm{D}_{\mathrm{H}-\mathrm{EFF}}$, yielding the curve-fit value for $\mathrm{x}_{\mathrm{CRIT}}$ of $0.9 \mu \mathrm{m}$ in Fig. 4.6 . As the concentration of $\mathrm{H}$ at the FPZ $\left(\mathrm{x}=\mathrm{x}_{\mathrm{CRIT}}\right)$ decreases toward $\mathrm{C}_{\mathrm{H}-\mathrm{crit}}$, the squared inverse error function tends towards 0 and da/dt ${ }_{\text {II }}$ sharply decreases below the trend line.

It is reasonable to assume that, at any time ( $\mathrm{t}$ ) and distance (x) ahead of the crack tip, the $\mathrm{H}$ concentration $(\mathrm{C})$ is controlled by diffusion from a stationary planar source $[32,34,35]$ :

$$
C(x, t)=C_{s}\left(1-\operatorname{erf}\left[\frac{x}{2 \sqrt{D_{H-E F F} t}}\right]\right)
$$

The $\mathrm{H}$ concentration is elevated at each position, $\mathrm{x}$ and including $\mathrm{x}_{\mathrm{CRIT}}$, by the crack tip position dependent hydrostatic stress $\left(\sigma_{\mathrm{i}}(\mathrm{x})\right)$ according to [34]:

$$
C(x, t)=C_{s} \exp \left(\frac{\sigma_{i}(x) V_{H}}{R T}\right)\left[1-\operatorname{erf}\left(\frac{x}{\sqrt{4 D_{H-E F F} t}}\right)\right]
$$


where $\sigma_{\mathrm{i}}$ is the hydrostatic stress at any $\mathrm{x}, \mathrm{V}_{\mathrm{H}}$ is the partial molar volume of hydrogen in $\mathrm{Al}, \mathrm{R}$ is the ideal gas constant, and $\mathrm{T}$ is the absolute temperature. In the context of Eqn. 4.1, the stress enhanced mobile concentration of $\mathrm{H}\left(\mathrm{C}_{\mathrm{H \sigma}}\right)$ is:

$$
\mathrm{C}_{\mathrm{H} \sigma}(\mathrm{x})=\mathrm{C}_{\mathrm{s}} \exp \left(\frac{\sigma_{\mathrm{i}}(\mathrm{x}) \mathrm{V}_{\mathrm{H}}}{\mathrm{RT}}\right)
$$

with the failure criterion $\mathrm{C}_{\mathrm{H} \sigma}=\mathrm{C}_{\mathrm{H}-\text { crit }}$ at $\Delta \mathrm{x}=\mathrm{x}_{\mathrm{CRIT}}$, and time $\Delta \mathrm{t}$, the crack growth rate (da/dtII) can be predicted by $\Delta \mathrm{x} / \Delta \mathrm{t}$ giving Eqn. 4.1 [32].

A model of $\mathrm{H}$ diffusion limited crack growth rate can also be derived based on a continuous crack growth scenario as first proposed by Johnson [36] and favored by Scully and coworkers $[19,25]$. While a micromechanics-based analysis has not been published, given the focus on microscopically discontinuous cracking [31], it is possible to couple a moving crack tip solution for $\mathrm{H}$ diffusion with a failure criterion to derive $\mathrm{da} / \mathrm{dt}_{\mathrm{II}}$. The following steady state solution for $\mathrm{H}$ diffusion in the $\mathrm{x}$ direction (along $\mathrm{y}=0$ ), ahead of a planar $\mathrm{H}$ source moving at a velocity, $\mathrm{v}$, is similar to the fixed source solution in Eqn. 4.2 [37]:

$$
C(x, t)=C_{s}\left(1-\operatorname{erf}\left[\sqrt{\frac{v}{2 D_{H-E F F}}} \sqrt{2 x}\right]\right)
$$

While not reported in prior work $[19,25,36]$, a reasonable-postulated failure criterion is that steady state da/dt $/ \mathrm{II}=\mathrm{v}$ in Eqn. 4.5 when the $\mathrm{H}$ distribution ahead of the crack tip exceeds the critical amount required for $\mathrm{H}$ embrittlement $\left(\mathrm{C}_{\mathrm{H}-\mathrm{crit}}\right)$ at all locations between $\mathrm{x}=0$ and $\mathrm{x}=\mathrm{x}_{\text {CRIT }}$. Essentially, over this interval, $\mathrm{C}(\mathrm{x}, \mathrm{t}) \geq \mathrm{C}_{\mathrm{H}-\text { crit }}$ to equal $\mathrm{C}_{\mathrm{H} \text {-crit }}$ at $\mathrm{x}_{\text {CRIT. }}$. Following Eqns. 4.4 and 4.5 , the resulting model for continuous $\mathrm{H}$ diffusion limited $\mathrm{da} / \mathrm{dt}_{\mathrm{II}}$ now includes a required stress-based critical distance and can be formulated analogous to that 
in Eqn. 4.1, the only difference being a decrease in the coefficient from 4 to 1 . It follows that the critical diffusion distance ( $\mathrm{x}_{\mathrm{CRIT}}$ ) to correlate crack growth rates reported in Fig. 4.6 is $0.23 \mu \mathrm{m}$ for this continuous model (represented by the trend line). The diffusion field in Eqn. 4.5 is used here to demonstrate the order of the difference in predictions between the discontinuous and continuous crack growth rate models [31]. An alternate approach is to use the diffusion solution for a moving crack tip "line" source [36]; this Bessel-function based solution must deal with a concentration singularity at $\mathrm{x}=0$, which is similar to analyzing Eqn. 4.2 for the crack plane only $(y=0)$.

The uncertainties associated with determination of $\mathrm{H}$ diffusivity, specific to the crack tip surface condition, FPZ microstructure and plastic strain field, are larger than the detail of this diffusion analysis [30]. Precise and experimentally validated determination of XCRIT remains a cutting edge problem in crack tip $\mathrm{H}$ embrittlement, as illustrated by the discussion in Chapter 2 and the broad literature pertinent to this issue [31]. This challenge is clearly answered for a notch [26], but is exacerbated for a crack tip when high strain continuum deformation, as well as microstructure-scale stress considerations render the $\mathrm{X}_{\text {CRIT }}$ into the sub-micrometer regime (see Chapter 2) [31]. Equation 4.1, based on discontinuous $\mathrm{H}$ cracking in the FPZ, is used in the analysis that follows.

\subsubsection{Hydrogen diffusion controlled crack growth rates in 5083-H131}

Crack growth rates for as-received 5083-H131 fall at and below the maximum da/dtII predicted from the HEAC trend line using the DoS independent $\mathrm{D}_{\mathrm{H}-\mathrm{EFF}}$ measured in this alloy (average $D_{H}=1.3 \times 10^{-10} \mathrm{~cm}^{2} / \mathrm{s}$ in the relevant $\mathrm{L}$ direction from the first-rise permeation transient; $D_{\mathrm{H}-\mathrm{EFF}}$ is plotted as $10^{-10} \mathrm{~cm}^{2} / \mathrm{s}$ for simplicity [19]), as shown in Fig. 4.7. This $\mathrm{H}$ diffusivity is taken as a starting point for discussion since the values used 
in this broad correlation were almost exclusively based on first-rise transient permeation analysis [30]. This broad agreement validates the use of the crack tip H-diffusion model to further test the hypothesized interaction of grain boundary $\beta$ dissolution and crack tip $\mathrm{H}$ embrittlement, beyond the occluded crack electrochemical considerations in Chapter 3.

Crack growth rates for as-received 5083-H131 stressed in either an acidic-simulated crack tip solution or anodically polarized in near-neutral $\mathrm{NaCl}$ solution, correlate with the fastest predicted $\mathrm{da} / \mathrm{dt}_{\mathrm{II}}$ for diffusion controlled $\mathrm{H}$ embrittlement in 5083-H131 with $\mathrm{D}_{\mathrm{H}-\mathrm{EFF}}$ of $10^{-10} \mathrm{~cm}^{2} / \mathrm{s}$ and $\mathrm{X}_{\text {CRIT }}$ of $0.9 \mu \mathrm{m}$ (as calculated for discontinuous $\mathrm{H}$ embrittlement modeling, Eqn. 4.1). Chapter 3 demonstrates the strong influence of crack tip chemistry and $\mathrm{C}_{\mathrm{H \sigma}}$ (from $\mathrm{Cs}_{\mathrm{s}}$ through Eqn. 4.4) on da/dt II. The low $\mathrm{pH}$ and high magnitude of overpotential for crack tip $\mathrm{H}$ production expected in these alloys likely causes the ratio $\mathrm{C}_{\mathrm{H \sigma}} / \mathrm{C}_{\mathrm{H}-\mathrm{crit}}$ to be near or above 6.3 . For resistant microstructure-environment conditions, crack growth rates fall significantly below this line, yet the model can also explain this decrease in crack growth rate. Crack growth rates up to 40-times slower than the fastest predicted $\mathrm{da} / \mathrm{dt}_{\mathrm{II}}$ for diffusion controlled $\mathrm{H}$ embrittlement in 5083-H131 ( $\mathrm{D}_{\mathrm{H}-\mathrm{EFF}}$ of $10^{-10} \mathrm{~cm}^{2} / \mathrm{s}$ and $\mathrm{X}_{\text {CRIT }}$ at $\left.0.9 \mu \mathrm{m}\right)$, are predicted to have a $\mathrm{C}_{\mathrm{H \sigma}} / \mathrm{C}_{\mathrm{H}-\text { crit }}$ of 1.2 . These rates are consistent with the view developed in Chapter 3 and demonstrated in Fig. 3.30. Lower overpotential for crack tip $\mathrm{H}$ production could reduce the $\mathrm{H}$ concentration accumulated at the FPZ, (which may also be influenced by various combinations of crack tip $\mathrm{pH}$, potential, $\mathrm{Mg}^{3+}$ concentration and chloride content) and thus lower the squared inverse error function term in Eq. 4.1. 


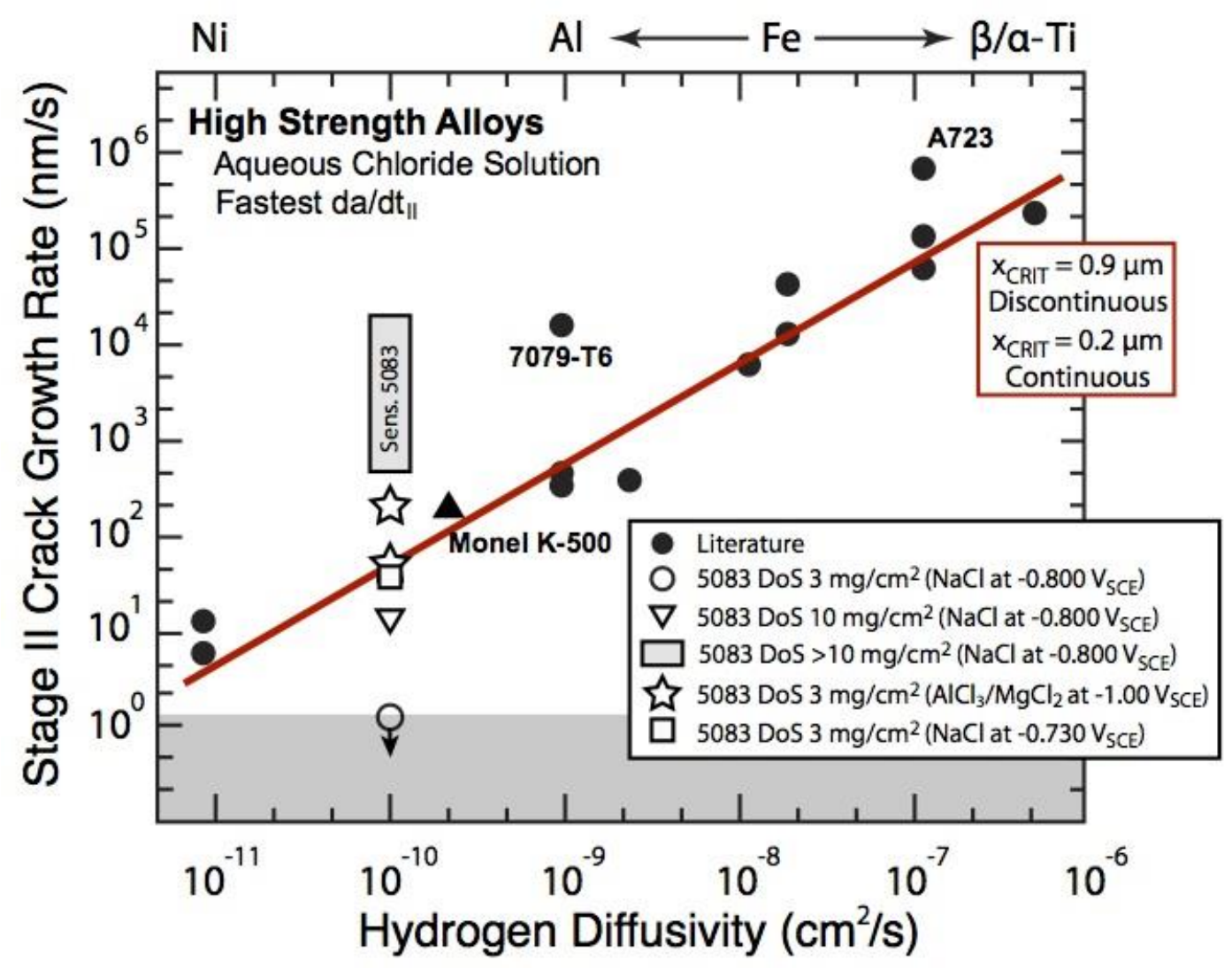

Figure 4.7: Stage II crack growth rate as a function of trap sensitive effective $\mathrm{H}$ diffusivity. The solid trend line and filled symbols ( $\bullet$ [30], $\boldsymbol{\Delta}$ [33]) represent maximum $\mathrm{da} / \mathrm{dt}_{\mathrm{II}}$ reported for $\mathrm{H}$ diffusion controlled HEAC in high strength alloys. Open symbols are for 5083-H131 (S-L): ( $\vec{*}$ ) as-received in $\mathrm{AlCl}_{3} / \mathrm{MgCl}_{2}$ at $-1.000 \mathrm{~V}$ SCE (Fig. 4.2), ( $\square$ ) as-received in $\mathrm{NaCl}$ at $-0.730 \mathrm{~V}_{\mathrm{SCE}}$ (Fig. 4.2$),(\nabla)$ sensitized $\left(10 \mathrm{mg} / \mathrm{cm}^{2}\right)$ in $\mathrm{NaCl}$ at $-0.800 \mathrm{~V}_{\mathrm{SCE}}$ (Fig. 4.1), (O) as-received in $\mathrm{NaCl}$ at $-0.800 \mathrm{~V}_{\mathrm{SCE}}$ (Fig. 4.1). The light

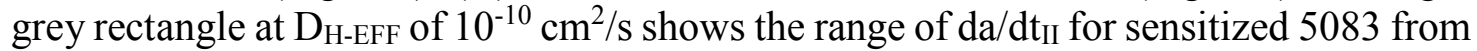
Fig. 4.1.

\subsubsection{High da/dt by the HEAC Mechanism}

Rates of IGSCC measured for sensitized $\left(10 \mathrm{mg} / \mathrm{cm}^{2}\right.$ to $\left.54 \mathrm{mg} / \mathrm{cm}^{2}\right) 5083-\mathrm{H} 131$ (S-L) in $\mathrm{NaCl}$ polarized at near $\mathrm{OCP}\left(-0.800 \mathrm{~V}_{\mathrm{SCE}}\right)$, are higher than the fastest $\mathrm{H}$ diffusion limited crack growth rates predicted from the correlation at a $D_{\mathrm{H}-\mathrm{EFF}}$ of $10^{-10} \mathrm{~cm}^{2} / \mathrm{s}$, as shown by the light grey rectangle in Fig. 4.7. It is necessary to understand the fundamental basis for 
such high rates of HEAC in order to validate the proposed crack tip $\beta$ dissolution- $\mathrm{H}$ embrittlement mechanism.

Based on the discontinuous $\mathrm{H}$ diffusion rate limited crack growth rate model (Eqn. 4.1) increased crack growth rates may in principle be explained by enhanced $\mathrm{H}$ production and uptake, stimulated by dissolution of reactive $\beta$ and acidification from $\mathrm{Mg}$ and $\mathrm{Al}$ cation hydrolysis. However, higher FPZ H concentration $\left(\mathrm{C}_{\mathrm{H \sigma}}\right)$ cannot alone explain this 400-times (or higher) increase in da/dtII above the Fig. 4.7 trend line. From the squared inverse error function term in Eqn. 4.1, an extraordinary high level of $\mathrm{H}$ uptake (e.g., $\mathrm{C}_{\mathrm{H \sigma}}=10,000 \mathrm{C}_{\mathrm{H} \text {-crit) }}$ produces, at most, a factor of 7 increase in $\mathrm{da} / \mathrm{dt}_{\mathrm{II}}$ above the trend line. Other model parameters in Eqn. 4.1 must be modified to contribute to the large da/dtII increase and are demonstrated in Fig. 4.8. For crack growth rates on the order of $10^{4} \mathrm{~nm} / \mathrm{s}$ in 5083-H131, using the discontinuous model (Eqn. 4.1) with $D_{\mathrm{H}-\mathrm{EFF}}=10^{-10} \mathrm{~cm}^{2} / \mathrm{s}$ and $\mathrm{C}_{\mathrm{H \sigma}}=6.3 \mathrm{C}_{\mathrm{H}-\text {-crit, }}$, the $\mathrm{x}_{\mathrm{CRIT}}$ would have to be $2 \mathrm{~nm}$ (thin dashed line in Fig. 4.8 ) in order for $\mathrm{H}$ diffusion to support this level of HEAC. This very small $\mathrm{x}_{\mathrm{CR}}$ h has not been required for the majority of alloys represented in Fig. 4.8; there is no justification that such a small distance is uniquely occurring in sensitized 5083-H131. Ai et al. suggested that XCRIT is on the order of $\beta$ particle spacing (200 nm to $300 \mathrm{~nm}$ ) [19]; this value (plotted as the thick dashed line in Fig. 4.8) could explain the somewhat higher crack growth rates for asreceived 5083-H131 (z ), but not the rapid rates for sensitized 5083-H131.

\subsection{Electrochemical contributions to rapid da/dt}

Electrochemical contributions from $\beta$ dissolution alone cannot accelerate crack growth rates to those measured in sensitized 5083-H131. Ford modeled a maximum theoretical crack propagation rate supported by slip-dissolution in $\mathrm{Al}-7 \% \mathrm{Mg}$ and as a function of crack 
tip electrode potential $[38,39]$. Bare-surface dissolution rate was on the order of $0.15 \mathrm{~A} / \mathrm{cm}^{2}$, as measured from the transient-anodic current density of a scratched rotating disk electrode in aerated $\mathrm{NaCl}(\mathrm{pH} 5.5)$ polarized to $-0.800 \mathrm{~V}_{\text {SCE}}$. This rate correlated with a da/dt of $80 \mathrm{~nm} / \mathrm{s}$ measured for $\mathrm{Al}-7 \% \mathrm{Mg}$, consistent with slip dissolution-based stress corrosion crack growth in a wide variety of alloys [38] but much less than the band of very fast rates measured for sensitized 5083-H131 (Fig. 4.8).

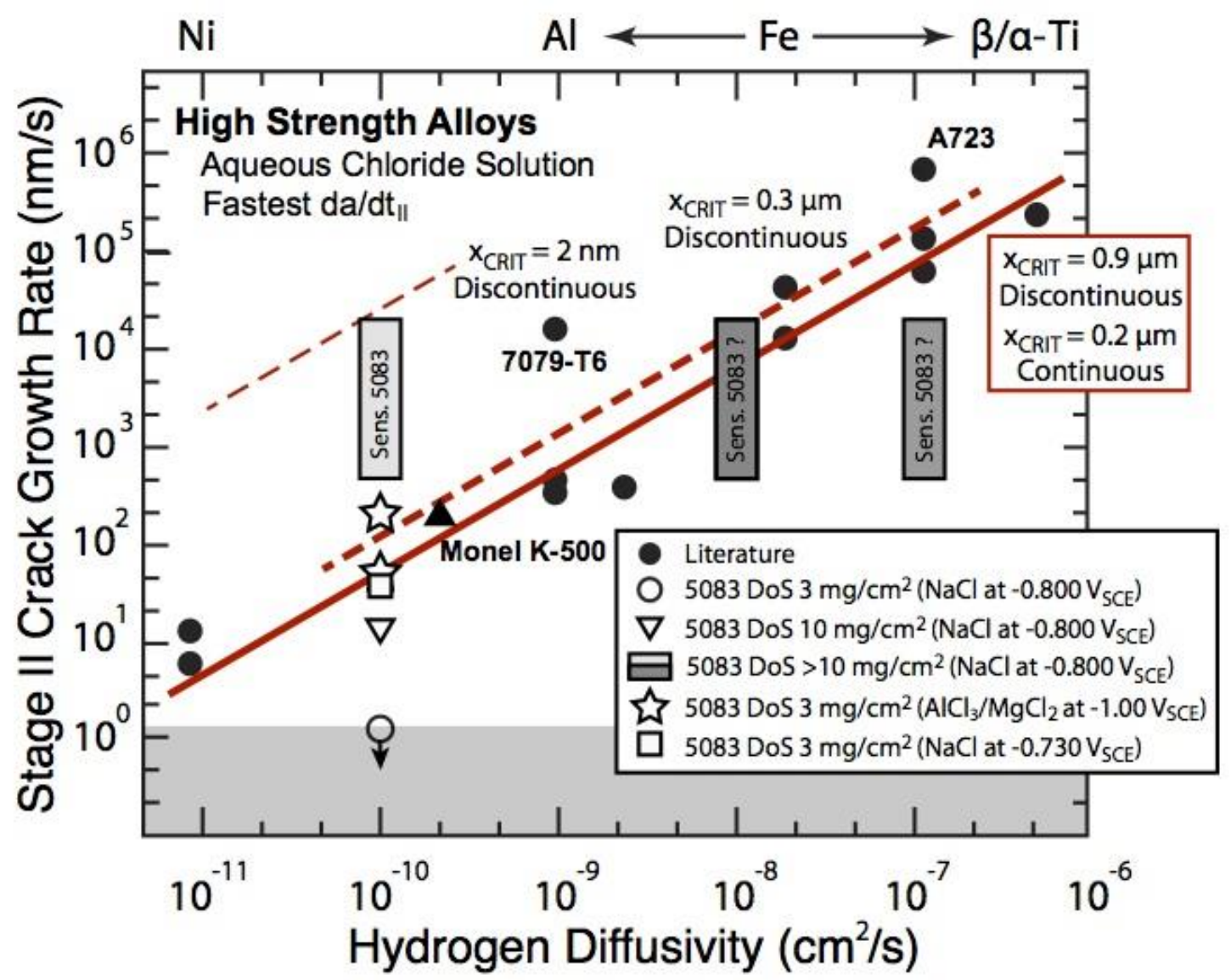

Figure 4.8 Modification of Fig. 4.7, demonstrating that a decrease in XCRIT cannot explain the high crack growth rates in sensitized 5083-H131, though an increase in DH-EFF can do so. 
The maximum-possible da/dt due to dissolution of a continually bare crack tip of Al$\mathrm{Mg}$ is $20,000 \mathrm{~nm} / \mathrm{s}$, and only limited by mass-transport of $\mathrm{H}_{2} \mathrm{O}$ to the tip [39]. This da/dt aligns with the fastest rates measured for sensitized 5083-H131 (S-L) in $\mathrm{NaCl}$ at $-0.800 \mathrm{~V}_{\mathrm{SCE}}$ (Fig. 4.8), but is physically unrealistic. Based on the Ford correlation, a current density of $20 \mathrm{~A} / \mathrm{cm}^{2}$ is required for this level of da/dt [38]. Since crack tip potential is limited by the open circuit potential of $\alpha$ in simulated-acidic crack tip solution $\left(-1.050 \mathrm{~V}_{\mathrm{SCE}}\right)$, and since solution resistance is finite, such a high current density cannot be sustained by the associated voltage drop between the occluded crack tip and mouth [40,41]. With this Ohmic limitation in the crack tip electrolyte, current densities necessary to support rates of IGSCC on the order of $10^{3}$ to $10^{4} \mathrm{~nm} / \mathrm{s}$ are not possible.

\subsection{Mechanical contribution to rapid da/dt}

Elevated da/dt II above the H-diffusion controlled trend line in Fig. 4.7 is not likely due to a mechanical contribution from fracture of brittle $\beta$ particles in the FPZ ahead of the corroded crack tip. When sensitized for $7 \mathrm{~d}$ at $100^{\circ} \mathrm{C}\left(22 \mathrm{mg} / \mathrm{cm}^{2}\right), \beta$ particles are $100 \mathrm{~nm}$ to $1000 \mathrm{~nm}$ in length $[9,11]$, with a number density on the grain boundary of $\sim 2 \mu \mathrm{m}^{-2}[11]$. This small size and low coverage suggests that such particles do not degrade grain boundary mechanical cohesion. Experiments conducted with sensitized $\left(45 \mathrm{mg} / \mathrm{cm}^{2}\right) 5083-$ H131 loaded in moist air revealed extremely low measurable rates of subcritical crack growth (below $2 \mathrm{~nm} / \mathrm{s}$ for $\mathrm{K}$ up to $20 \mathrm{MPa} \sqrt{\mathrm{m}}$ and loading rates as fast as $31 \mathrm{MPa} \sqrt{\mathrm{m}} / \mathrm{h}$ ). Moreover, plane strain fracture toughness is constant or increases as DoS increases to a very high level ( $\left.\sim 60 \mathrm{mg} / \mathrm{cm}^{2}\right)$ [5], suggesting that even an extensive coverage of boundary $\beta$ does not promote intergranular fracture. 


\subsection{Enhanced $\mathrm{H}$ diffusion rate contribution to rapid da/dt}

Rapid crack growth rates in Fig. 4.8 can be explained based on enhanced H diffusion within the crack tip FPZ, tied to the $\beta$-dissolution mechanism, which was affirmed by the controlled environment and polarization experiments in Chapter 3. Assuming a $\beta$ precipitate number density reported in the literature for SHT 5083-H131 (from the lot used in this work), the intra- $\beta$ distance on sensitized Al-Mg grain boundaries is about $300 \mathrm{~nm}$ for sensitizations between $10 \mathrm{mg} / \mathrm{cm}^{2}$ and $50 \mathrm{mg} / \mathrm{cm}^{2}$ [8,9,11]. Hydrogen transport over this distance could control da/dtII by the proposed mechanism [19]; however, this reduced diffusion distance is not sufficient to explain the $\mathrm{da} / \mathrm{dt}_{\mathrm{II}}$ enhancement by either the continuous model (thick solid line in Fig. 4.8) or the discontinuous model (thick dashed line in Fig. 4.8).

The measured-fast crack growth rates for IGSCC in sensitized 5083-H131 are best rationalized based on increased $D_{H-E F F}$ in Eqn. 4.1. The maximum diffusivity of lattice $\mathrm{H}$ in pure $\mathrm{Al}$ was reported as high as $10^{-7} \mathrm{~cm}^{2} / \mathrm{s}$ at $25^{\circ} \mathrm{C}$, provided that $\mathrm{H}$ does not interact with trap sites such as precipitates, dislocations and solute [25]. This large increase in $D_{\text {H-EFF }}$ rationalizes how very rapid rates of IGSCC by $\mathrm{H}$ embrittlement can be sustained by both the discontinuous and continuous $\mathrm{H}$ diffusion limited crack growth rate models with XCRIT between $200 \mathrm{~nm}$ and $900 \mathrm{~nm}$ as illustrated by the dark grey rectangle at $D_{\text {H-EFF }}=10^{-7} \mathrm{~cm}^{2} / \mathrm{s}$ in Fig. 4.8). If $\mathrm{H}$ mobility is at this upper bound, growth rates as high as $100,000 \mathrm{~nm} / \mathrm{s}$ could be supported; such rates have not been reported for HEAC in any Al alloy, including sensitized Al-Mg in the highly susceptible S-L crack orientation.

The issue is the mechanism by which $\mathrm{H}$ diffusion is not trap impacted in the crack tip FPZ. Analysis of multiple-rise $\mathrm{H}$ permeation experiments on 5083-H131 evidenced that 
DoS independent (between $2 \mathrm{mg} / \mathrm{cm}^{2}$ and $39 \mathrm{mg} / \mathrm{cm}^{2}$ ) $\mathrm{D}_{\mathrm{H}-\mathrm{EFF}}$ at $23^{\circ} \mathrm{C}$ increases from an average of $1.3 \times 10^{-10} \mathrm{~cm}^{2} / \mathrm{s}$ to an average of $5.8 \times 10^{-9} \mathrm{~cm}^{2} / \mathrm{s}$ in the L direction after trap filling expected for multiple-rise transients in the $H$ permeation experiment [19]. This increase in $\mathrm{D}_{\mathrm{H}-\mathrm{EFF}}$ could explain the fastest $\mathrm{da} / \mathrm{dt}_{\mathrm{II}}$ in the context of both the discontinuous and continuous $\mathrm{H}$ diffusion models (Eqn. 4.1 and Fig. 4.8) with $\mathrm{x}_{\text {CRIT }}$ bounded by $200 \mathrm{~nm}$ and $300 \mathrm{~nm}$ [19] and justified to an extent in Chapter 2. This bounded increase in $\mathrm{D}_{\mathrm{H}-\mathrm{EFF}}$ (simplified to be between $10^{-8} \mathrm{~cm}^{2} / \mathrm{s}$ and $10^{-7} \mathrm{~cm}^{2} / \mathrm{s}$ ) suggests the presence of reversible $\mathrm{H}$ traps in the permeation foil, which hinder $\mathrm{H}$ diffusion typical of low to moderate trap binding energies, with $\mathrm{D}_{\mathrm{H}-\mathrm{EFF}}$ dependent on diffusible H concentration [42]. Note that the same increase in $\mathrm{D}_{\mathrm{H}-\mathrm{EFF}}$ was reported for multiple permeation rises in both pure $\mathrm{Al}$ [18] and 5083-H131 [19], and the dominant trap was not identified; this increase in $\mathrm{D}_{\mathrm{H}-\mathrm{EFF}}$ is not unique to sensitized 5083. Moreover, foil thickness independence of the faster $\mathrm{D}_{\mathrm{H}-\mathrm{EFF}}$ was not demonstrated for the multiple exposure permeation experiments with either $\mathrm{Al}$ or $5083[19,43]$. The notion that trap filling results in increased $\mathrm{D}_{\mathrm{H}-\mathrm{EFF}}$ is sound based on trapping theory [43], but is not verified to the same level of rigor which characterizes the first-rise $D_{H-E F F}$ values around $10^{-10} \mathrm{~cm}^{2} / \mathrm{s}[18,19]$. Of course, the mapping of $H$ transport in a permeation foil, to a plastically deforming crack tip, is a cutting edge challenge [25].

The H-trap sites present within intra- $\beta$ ligaments in the crack tip FPZ are likely limited to dislocations and possibly vacancies on the reacting crack tip surface. The high plastic strain within the first 1-2 $\mu \mathrm{m}$ of the crack tip FPZ could create a high dislocation density in as-received 5083, but speculatively a low-dislocation density between $\beta$ precipitates in a sensitized microstructure. This difference could be due to dislocation arrangement into a low energy dislocation structure (LEDS). Such recovery processes could be favored by 
the unusually slow crack tip strain rates typical of IGSCC in the present work. Generally, LEDS in aluminum is typically $\sim 0.5 \mu \mathrm{m}$ to $1 \mu \mathrm{m}$ diameter $[44,45,46]$, which is just larger than the ligament size between $\beta$ for the sensitization temperatures and times examined in Chapters 2 and 3 [11]. If the intra- $\beta$-ligament dislocation density is low, then an increased value of $D_{\mathrm{H}-\mathrm{EFF}} \sim 10^{-8} \mathrm{~cm}^{2} / \mathrm{s}$ (and as high as $10^{-7} \mathrm{~cm}^{2} / \mathrm{s}$ ) is reasonable. Growth rates from experiments conducted with $\beta$-free 5083-H131 stressed slowly in acidic and alkaline environments (Fig. 4.8) suggest that high- $\mathrm{D}_{\mathrm{H}-\mathrm{EFF}}$ transport did not occur. Either the $\beta$ ligament geometry unique to the sensitized case is necessary for a dislocation free zone, or trap-free $\mathrm{H}$ transport did occur such that the open data points in Fig. 4.8 should be plotted at a higher $\mathrm{D}_{\mathrm{H}-\mathrm{EFF}}$. This latter possibility is somewhat inconsistent with the semiquantitative consideration of crack tip overpotential for $\mathrm{H}$ production in an acidic crack solution (Chapter 3). Growth rates below the upper bound H-diffusion correlation do not detract from validation of the proposed hypothesis since Eqn. 4.1 predicts a strong effect of $\mathrm{C}_{\mathrm{H \sigma}}$ and $\mathrm{da} / \mathrm{dt}_{\mathrm{II}}$. None-the-less, the $\mathrm{Mg}$ content of the intra- $\beta$ ligament, undissolved $\beta$, and crack tip strain/strain rate may affect the morphology and size of dislocation structures [46], and hence the extent of $\mathrm{H}$ trapping.

In sensitized 5083-H131, $\beta$ may be considered a $H$ trap site inside the LEDS, which could hinder this increase in local DH-EFF. Though Ai et al. indicated that $\mathrm{D}_{\mathrm{H}-\mathrm{EFF}}$ is independent of sensitization in 5083-H131, they did not confirm nor deny the possibility of $\mathrm{H}$ trapping at $\beta$ with a trap binding energy similar to dislocation structure [19]. If $\beta$ has a modest trap energy, the trap sites at $\beta$ interfaces inside or proximate to the LEDS may saturate, and in the case of high $\mathrm{C}_{\mathrm{H \sigma}}$, contribute to rapid $\mathrm{D}_{\mathrm{H}-\mathrm{EFF}}$ in this local region. It is also possible that LEDS do not form ahead of the crack tip. Without LEDS, the strain- 
induced dislocations could collect at the $\beta$ interfaces, containing all the local trap sites in one location. This would cause a trap free region in the ligaments between $\beta$, where a rapid $\mathrm{D}_{\text {H-EFF }}$ could explain the high da/dtII illustrated in Fig. 4.8. These hypothesis are highly speculative. A combined focused ion beam, TEM analysis is required to assess the appearance and size of dislocation substructures in the $\beta$-free ligaments proximate to grain boundaries at the crack tip. Such studies in other alloys support the existence of recovered dislocation structures with cell sizes of several hundred of $\mathrm{nm}[47,48]$.

\subsubsection{Mechanism confirmation with other Al alloys}

Analogous to $\beta$ in 5083, grain boundary $\eta\left(\mathrm{MgZn}_{2}\right)$ dissolution in $\mathrm{Al}-\mathrm{Zn}-\mathrm{Mg}-(\mathrm{Cu})$ alloys should be critical to an embrittling crack chemistry development through acidification, leading to IGSCC by the HEAC mechanism. Growth rates of the high level measured for sensitized 5083-H131 were not reported for S-L oriented 7075, the fastest of which $(\bullet)$ comply with the bold trend line in Fig. $4.6[30,31]$. This result can be explained. Alloy 7075-T651 contains GB $\eta$ and very finely spaced intragranular $\eta$ ' precipitates which are effective $\mathrm{H}$ traps in $\mathrm{Al}$ [25]. If sufficiently wide (60 nm to $80 \mathrm{~nm}$ [49]) and of low dislocation density, the $\eta$ ' precipitate free zone at GBs in 7075-T651 may not trap H at ligaments between undissolved grain boundary $\eta$ precipitates, resulting in enhanced $D_{\text {H-EFF }}$ (up to $10^{-7} \mathrm{~cm}^{2} / \mathrm{s}$ ) and expected fast da/dtII. However, $\mathrm{Cu}$ enriches GB $\eta$ to cause a more noble breakdown potential in $\mathrm{NaCl}[50,51]$, and will not acidify the crack tip to the low level provided by $\mathrm{Cu}$-free $\eta$ or $\beta$, resulting in reduced $\mathrm{C}_{\mathrm{H \sigma}}$ and low $\mathrm{da} / \mathrm{dt}_{\mathrm{II}}$ relative to sensitized 5083-H131. Figure 4.6 shows that IGSCC in $\mathrm{Cu}$-free and $\eta$ ' precipitation hardened 7079-T6 (S-L in $\mathrm{NaCl}$ at $\mathrm{OCP}$ ) propagates much more rapidly than predicted by the H-diffusion model [31]. Dissolution of reactive $\eta$ precipitates (without $\mathrm{Cu}$ in 7079-T6) 
promotes crack acidification, $\mathrm{H}$ production, and uptake. Crack tip $\mathrm{H}$ will not trap in the $\eta$ 'free zone within ligaments. Both active phase dissolution and a small volume of $\mathrm{H}$ trapfree $\mathrm{Al}$ are necessary for extraordinarily rapid IGSCC, consistent with $\mathrm{H}$ diffusion rate limited HEAC.

\subsection{CONCLUSIONS}

Considerations of crack growth rate limitation by FPZ $\mathrm{H}$ diffusion validates the hypothesized mechanism for IGSCC of sensitized Al-Mg alloys in aqueous chloride solution. Specifically, crack tip $\beta$ dissolution and resulting hydrolytic acidification are a necessary precursor for severe hydrogen environment assisted cracking, which is rate limited by $\mathrm{H}$ diffusion in the crack tip fracture process zone.

- Very fast rates of intergranular stress corrosion cracking are supported by crack tip $\mathrm{H}$ diffusion, but only if $\mathrm{H}$ transport occurs with a diffusivity which is characteristic of substantially reduced reversible-H-trap interaction (between $10^{-8} \mathrm{~cm}^{2} / \mathrm{s}$ and $10^{-7} \mathrm{~cm}^{2} / \mathrm{s}$ ). Such rapid transport is possible if either reversible $\mathrm{H}$ traps fill or if a crack tip dislocation cell structure size exceeds that of precipitate-free inter- $\beta$ ligaments. Identification of the $\mathrm{D}_{\mathrm{H}-\mathrm{EFF}}$ relevant to a micrometer scale crack tip fracture process zone is uncertain and at the cutting edge of environmental cracking and H-metal interaction research.

- Grain boundaries of 5083-H131 are embrittled by H precharging, with intergranular cracking severity increasing with $\beta$ precipitation during sensitization.

- Though H charged as-received 5083-H131 was embrittled compared to noncharged 5083-H131, intergranular fracture was only observed on $\mathrm{H}$ charged- 
sensitized $5083-\mathrm{H} 131\left(22 \mathrm{mg} / \mathrm{cm}^{2}\right.$ to $\left.50 \mathrm{mg} / \mathrm{cm}^{2}\right)$. This suggests that H- $\beta$ interaction influences intergranular fracture.

- Internal H assisted cracking may provide a means to reveal the size, shape and spacing of reactive grain boundary $\beta$, but this approach is hindered by phase analysis limitation. 


\subsection{REFERENCES}

1. F.S. Bovard: "Sensitization and Environmental Cracking of 5xxx Aluminum Marine Sheet and Plate Alloys," in Corrosion Marine Saltwater Environment II, D.A. Shifler, T. Tsuru, P.M. Natishan, and S. Ito, eds., ECS, Pennington, NJ, 2005, pp. 232-43.

2. R.H. Jones, D.R. Baer, M.S Danielson, and J.S. Vetrano: Metall. Mater. Trans. A, 2001, vol. 32, pp. 1699-1711.

3. R.H. Jones, J.S. Vetrano, and C.F. Windisch: Corrosion, 2004, vol. 60, pp. 1144-54.

4. R.H. Jones: JOM, 2003, vol. 55, pp. 42-6.

5. J. Gao and D.J. Quesnel: Metall. Mater. Trans. A, 2010, vol. 42, pp. 356-64.

6. R.L. Holtz, P.S. Pao, R.A. Bayles, and T.M. Longazel: "Corrosion Fatigue of Al 5083$\mathrm{H} 131$ Sensitized at 70,100 , and $175^{\circ} \mathrm{C}$ and Relation to Microstructure and Degree of Sensitization," in Department of Defense 2011 Corrosion Conference, CorrDefense, NACE, Houston, TX, 2011.

7. R.L. Holtz, P.S. Pao, R.A. Bayles, T.M. Longazel, and R. Goswami: Metall. Mater. Trans. A, 2011, vol. 43, pp. 2839-49.

8. R. Goswami, G. Spanos, P.S. Pao, and R.L. Holtz: Metall. Mater. Trans. A, 2011, vol. 42, pp. 348-55.

9. R. Goswami and R.L. Holtz: Metall. Mater. Trans. A, 2013, vol. 44, pp. 1279-89.

10. Y. Zhu, D.A. Cullen, S. Kar, M.L. Free, and L.F. Allard: Metall. Mater. Trans. A, 2012, vol. 43, pp. 4933-9.

11. N. Birbilis, M.L.C. Lim, A.K. Gupta, C.H.J. Davies, S.P. Lynch, R.G. Kelly, and J.R. Scully: Corrosion, 2013, vol. 69, pp. 396-402.

12. E. Bumiller: "Intergranular Corrosion in AA5XXX Aluminum Alloys with Discontinuous Precipitation at the Grain Boundaries," PhD Dissertation, University of Virginia, Charlottesville, VA, 2011.

13. E. Bumiller and R.G. Kelly: "Intergranular Corrosion in AA5xxx: A Case for Continuous Attack with a Discontinuous Active Path," in Department of Defense 2011 Corrosion Conference, CorrDefense, NACE International, Houston, TX, 2011.

14. E. Pouillier, A.-F. Gourgues, D. Tanguy, and E.P. Busso: Int. J. Plast., 2012, vol. 34, pp. 139-53.

15. N.B. Ali, R. Estevez, and D. Tanguy: Eng. Fract. Mech., 2013, vol. 97, pp. 1-11.

16. D. Tanguy, B. Bayle, R. Dif, and Th. Magnin: Corros. Sci., 2002, vol. 44, pp. $1163-$ 75.

17. ASTM Standard G67, 2004, "Standard Test Method for Determining the Susceptibility to Intergranular Corrosion of 5xxx Series Aluminum Alloys by Mass Loss After Exposure to Nitric Acid (NAMLT Test)," ASTM International, West Conshohocken, PA, 2004, DOI: 10.1520/G0067-04, www.astm.org.

18. J. Ai and J.R. Scully: Corrosion, 2013, vol. 69, pp. 752-67. 
19. J. Ai, M.L. Lim, and J.R. Scully: Corrosion, 2013, DOI: http://dx.doi.org/10.5006/0987.

20. W.D. Pilkey and D.F. Pilkey, 2008, Peterson's Stress Concentration Factors, $3^{\text {rd }}$ ed., John Wiley and Sons, Inc., New York, NY, pp. 74, 100.

21. L. Tan and T.R. Allen: Corros. Sci., 2010, vol. 52, pp. 548-54.

22. J.R. Pickens, J.R. Gordon, and J.A.S. Green: Metall. Mater. Trans. A, 1983, vol. 14, pp. 925-30.

23. C.N. Panagopoulos and E.P. Georgious: Corros. Sci., 2007, vol. 49, pp. 4443-51.

24. J.K. Brosi: "Mechanical Property Evolution of Al-Mg Alloys Following Intermediate Temperature Thermal Exposure," PhD Dissertation, Case Western Reserve University, Cleveland, OH, 2010.

25. J.R. Scully, G.A. Young, Jr., and S.W. Smith: Mat. Sci. Forum, 2000, vol. 331-337, pp. 1583-1600.

26. R. Page and W.W. Gerberich: Metall. Mater. Trans A, 1982, vol. 13, pp. 305-11.

27. W. Guo, C.H. Wang, L.R.F. Rose: "Elastoplastic Analysis of Notch-Tip Fields in Strain Hardening Materials," Technical Report DSTI-RR-0137, DSTO Aeronautical and Maritime Research Lab, Melbourne, Victoria, Australia, 1998.

28. N.B. Ali, D. Tanguy, and R. Estevez: Scr. Mater., 2011, vol. 65, pp. 210-3.

29. A.J. Davenport, Y. Yuan, R. Ambat, B.J. Connolly, M. Strangwood, A. Afseth, and G. Scamans: Mater. Sci. Forum, 2006, vol. 519-521, pp. 641-6.

30. R.P. Gangloff: "Diffusion Control of Hydrogen Environment Embrittlement in High Strength Alloys," in Hydrogen Effects on Material Behavior and Corrosion Deformation Interactions, N.R. Moody, A.W. Thompson, R.E. Ricker, G.W. Was, and R.H. Jones, eds., The Minerals, Metals \& Materials Society, Warrendale, PA, 2003, pp. 477-97.

31. R.P. Gangloff: "Hydrogen Assisted Cracking of High Strength Alloys," in Comprehensive Structural Integrity, I. Milne, R. Ritchie, B. Karihaloo, J. Scott, P. Petit, eds., Elsevier Science, New York, NY, 2003, pp. 31-101.

32. Y. Lee and R.P. Gangloff: Metall. Mater. Trans. A., 2007, vol. 38, pp. 2174-90.

33. Gangloff, H. Ha, J.T. Burns, and J.R. Scully: "Measurement and Modeling of Hydrogen Environment Assisted Cracking in Monel K-500", Metall. Mater. Trans. A, in review, 2013.

34. P. Doig and G.T. Jones: Metall. Mater. Trans. A, 1977, vol. 8, pp. 1993-8.

35. M.M. Hall and D.M. Symons: "Hydrogen Assisted Creep Fracture Model for Low Potential Stress Corrosion Cracking of Ni-Cr-Fe Alloys," in Chemistry and Electrochemistry of Stress Corrosion Cracking, R.H. Jones and R.W. Staehle, eds., The Minerals, Metals \& Materials Society, Warrendale, PA, 2001, pp. 447-66. 
36. H.H. Johnson: "Hydrogen Gas Embrittlement," in: Hydrogen in Metals, I.M. Bernstein and A.W. Thompson, eds., ASM International, Materials Park, OH, 1974, pp. 35-49.

37. C. Atkinson: J of App. Phys., 1971, vol. 42, pp. 1994-7.

38. F.P. Ford: "The Crack-Tip System and its Relevance to the Prediction of Cracking in Aqueous Environments," in Environment Induced Cracking of Metals, R.P. Gangloff and M.B. Ives, eds., NACE, Houston, TX, 1990, pp. 139-66.

39. F.P. Ford: Mater. Sci. Eng., 1978, vol. 12, pp. 326-34.

40. R.A.H. Edwards: "The Relation Between Potential Drop and Local Changes in Solution Chemistry in Localized Corrosion," in Predictive Capabilities in Environmentally Assisted Cracking, R. Rungta, ed., ASME, New York, NY, 1985, pp. 153-75.

41. R.A.H. Edwards: "The Electrochemical Conditions Inside Stress Corrosion and Corrosion Fatigue Cracks," PhD Dissertation, Deft University of Technology, Deft, Netherlands, 1986.

42. J.R. Scully, G.A. Young, Jr. and S. Smith: "Hydrogen Embrittlement and Hydrogen Environment Embrittlement in Al Alloys," in Gaseous Hydrogen Embrittlement of Metals in Energy Technologies, R.P. Gangloff and B.P. Somerday, eds., Vol. 1, Woodhead Publishing Ltd., Cambridge, UK, 2012, pp. 707-68.

43. R.A. Oriani: Corrosion, 1987, vol. 43, pp. 390-97.

44. H. Fujita and T. Tabata: Acta Mater., 1973, vol. 21, pp. 355-65.

45. J. Gan, J.S. Vetrano, and M.A. Khaleel: J. Eng. Mater. Technol., 2002, vol. 124, pp. 297-301.

46. D.A. Hughes, M.E. Kassner, M.G. Stout, and J.S. Vetrano: JOM, 1998, vol. 50, pp. 16-21.

47. Y. Ro, S.R. Agnew, and R.P. Gangloff: Metall. Mater. Trans. A., 2012, vol. 43, pp. 2275-92.

48. M.L. Martin, B.P. Somerday, R.O. Ritchie, P. Sofronis, and I.M. Robertson: Acta Mater., 2012, vol. 60, pp. 2739-45.

49. S.P. Knight, N. Birbilis, B.C. Muddle, A.R. Trueman, and S.P. Lynch: Corros. Sci., 2010, vol. 52, pp. 4073-80.

50. R. Goswami, S. Lynch, N.J.H. Holroyd, S.P. Knight, and R.L. Holtz: Metall. Mater. Trans. A., 2012, vol. 44, pp. 1268-78.

51. M.O. Speidel: "Hydrogen Embrittlement and Stress Corrosion Cracking of Aluminum Alloys," in Hydrogen Embrittlement and Stress Corrosion Cracking, R. Gibala and R.F. Hehemann, eds., ASM International, Materials Park, OH, 1984, pp. 271-96. 


\subsection{APPENDIX}

The distribution of $\beta$ in sensitized 5083-H131 was investigated through comparison of two grain boundary separation techniques, one using $\mathrm{Ga}$ attack and the other using $\mathrm{H}$ precharging. Though both methods are capable of exposing grain boundaries for particle observation, a statistically relevant analysis proved challenging. In addition, identification of the various particle compositions was not successful.

\subsubsection{Gallium embrittlement}

Since $\beta$ characterization was reported to be successful for SHT and sensitized 5083H131 using liquid Ga attack [11], the same method was applied to non-SHT 5083-H131 for 4 DoS levels: as-received $\left(3 \mathrm{mg} / \mathrm{cm}^{2}\right), 100^{\circ} \mathrm{C}$ for $7 \mathrm{~d}\left(22 \mathrm{mg} / \mathrm{cm}^{2}\right), 60^{\circ} \mathrm{C}$ for $90 \mathrm{~d}$ $\left(23 \mathrm{mg} / \mathrm{cm}^{2}\right)$, and $100^{\circ} \mathrm{C}$ for $30 \mathrm{~d}\left(50 \mathrm{mg} / \mathrm{cm}^{2}\right)$. Unfortunately, quantification of $\beta$ was not possible on a large number of grain boundaries due to Ga contamination.

Specimens were embrittled using $7.9 \mathrm{~mm}$ diameter round unnotched specimens of 5083-H131. After sensitization, specimens were cleaned in acetone and methanol, then rolled in liquid $\mathrm{Ga}$ at $40^{\circ} \mathrm{C}$. Gallium was left on the specimen for $30 \mathrm{~min}$ at $40^{\circ} \mathrm{C}$, excess Ga was wiped off and the specimen was easily broken by hand. The fracture surface was observed in the SEM as soon as possible (without surface cleaning).

Gallium diffuses rapidly along grain boundaries, and on separated surfaces, resulting in Ga film coverage over a majority of the fracture surface, as seen on an unsensitized specimen in Fig. 4.9a. Small regions near the center had "clean" grain boundaries, yet unidentified features may be Ga contamination, as seen on the same specimen in Fig. 4.9b. 

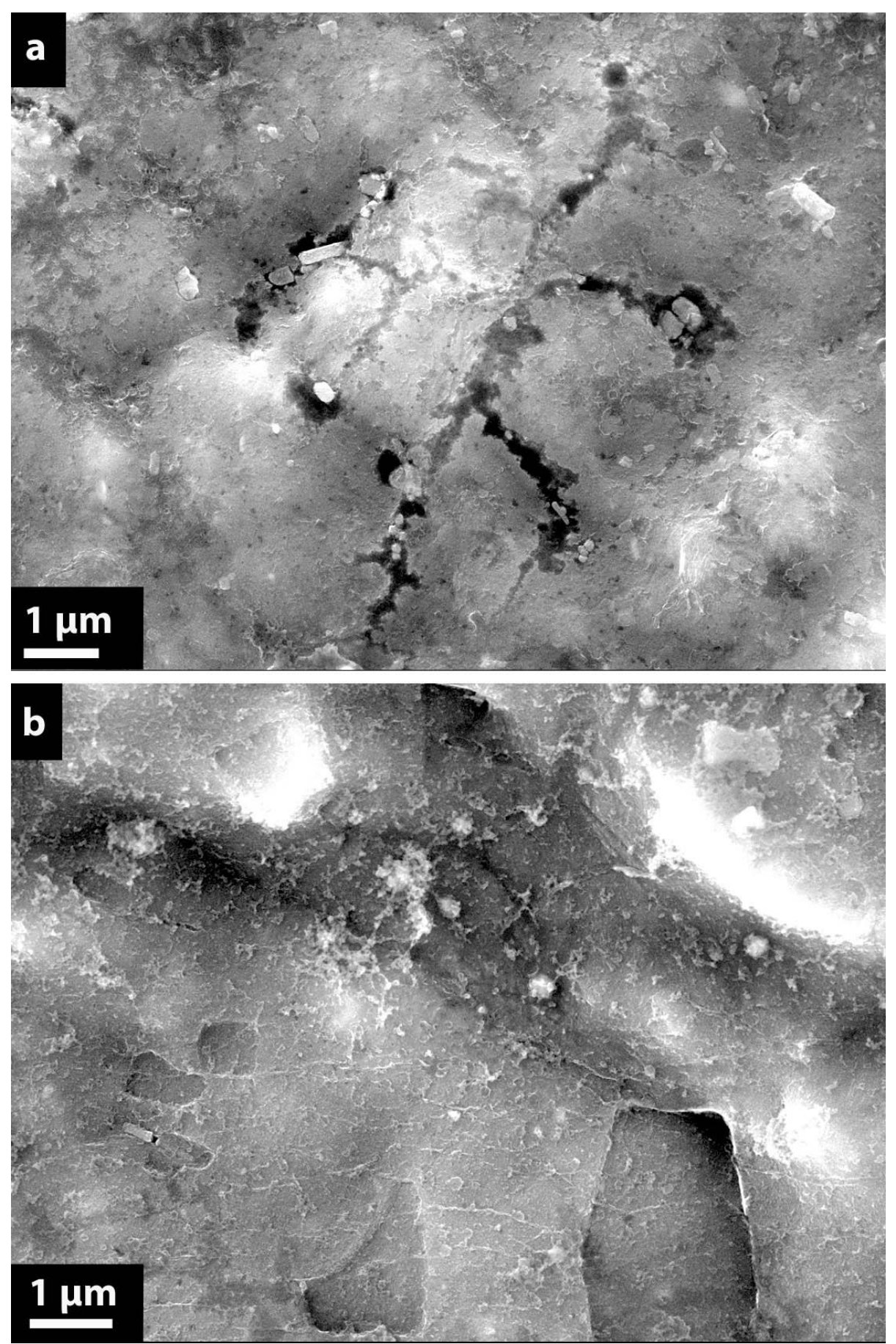

Figure 4.9 SEM fractographs of grain boundaries (LT surface) of unsensitized 5083H131 (3 mg/ $\mathrm{cm}^{2}$ ) separated with Ga: (a) shows boundaries covered with Ga contamination, and (b) shows a relatively clean grain surface with some Ga debris.

The morphologies of particles on exposed grain boundaries are compared in Fig. 4.10 for: (a) unsensitized $\left(3 \mathrm{mg} / \mathrm{cm}^{2}\right)$ and (b) sensitized $\left(60^{\circ} \mathrm{C}\right.$ for $\left.90 \mathrm{~d} ; 23 \mathrm{mg} / \mathrm{cm}^{2}\right) 5083-\mathrm{H} 131$. 
Small $100 \mathrm{~nm}$ sized particles are distributed on the grain boundaries in the sensitization case, while particles are absent in the as-received case. These particles were not confirmed to be $\beta$, as the energy dispersive $\mathrm{X}$-ray spectroscopy (EDS) probe volume is much larger than the particles and characterized the combination of the matrix and particle, rather than the particle alone. Elevated $\mathrm{Mg}$ content was not observed.

This type of uniform particle distribution was not found for grain boundaries sensitized at $100^{\circ} \mathrm{C}$, as seen in Fig. 4.11 for: (a) $100^{\circ} \mathrm{C}$ for $7 \mathrm{~d}\left(22 \mathrm{mg} / \mathrm{cm}^{2}\right)$ and (b) $100^{\circ} \mathrm{C}$ for $30 \mathrm{~d}$ $\left(50 \mathrm{mg} / \mathrm{cm}^{2}\right)$. In the specimen sensitized $100^{\circ} \mathrm{C}$ for $7 \mathrm{~d}\left(22 \mathrm{mg} / \mathrm{cm}^{2}\right)$, particles are larger and had a wider spacing than those observed for $60^{\circ} \mathrm{C}$ for $30 \mathrm{~d}\left(23 \mathrm{mg} / \mathrm{cm}^{2}\right)$. The particles in Fig. $4.11 \mathrm{~b}$ are much larger, and have a significantly different morphology than those at lower sensitization temperature. It is not clear whether this is a change in morphology or Ga contamination; EDS analysis was not performed to confirm or deny either possibility.

Particles observed on Ga revealed grain boundaries are not statistically representative of the fracture surface. To make a statistical analysis, many more Ga free regions would need to be investigated. It is also possible that Ga attacks only specific grain boundaries. The literature has shown that $\beta$ may precipitate preferentially on grain boundaries due to grain misorientation angles [52]; if embrittlement by $\mathrm{Ga}$ is also preferential to grain orientation, then the distribution of $\beta$ observed from this technique may be biased. Though, the fact that a wide range of precipitation distributions and sizes was observed on the analyzed grain boundaries (some grain boundaries were precipitate free even in the sensitized conditions studies), suggests that Ga embrittlement is unbiased. 

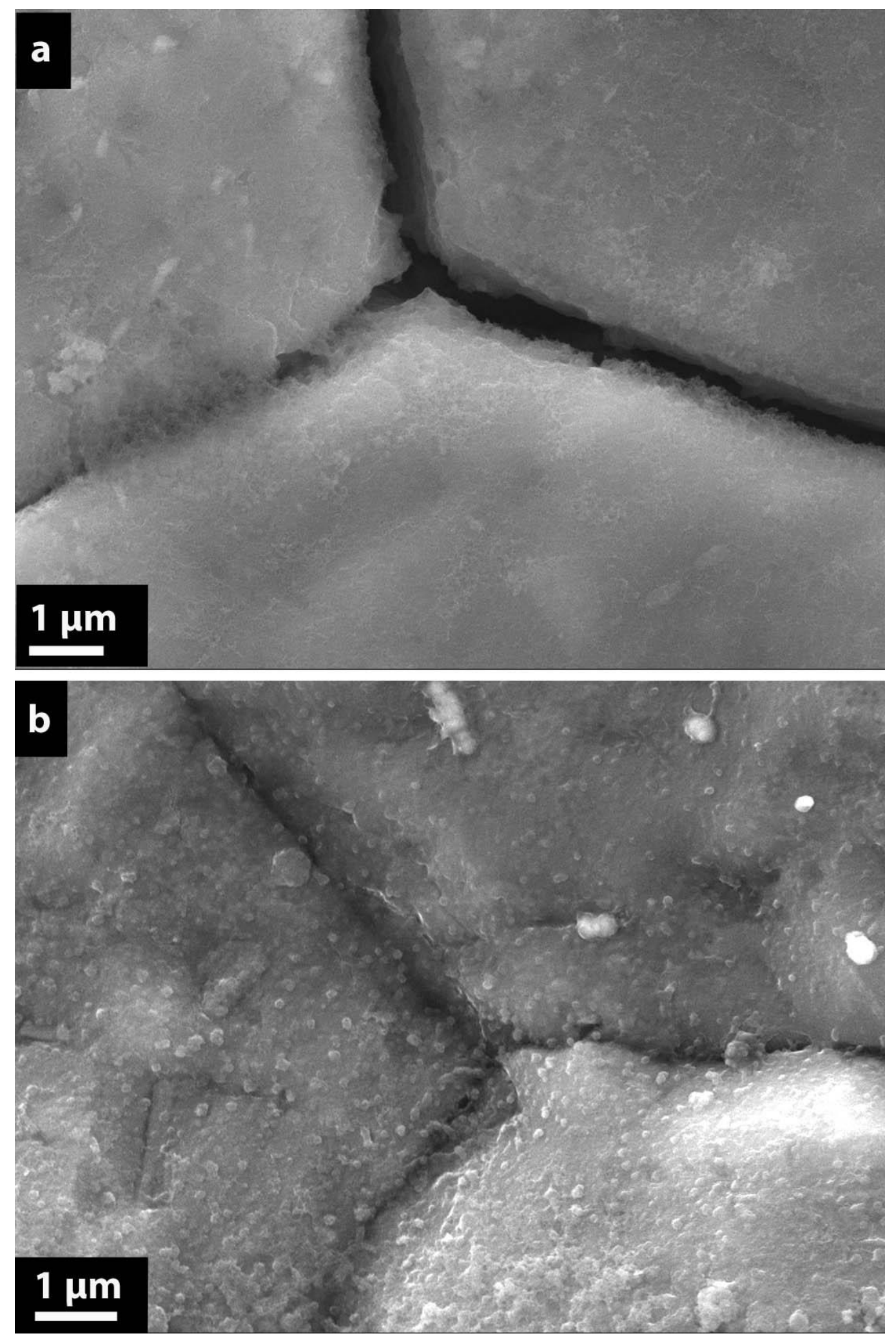

Figure 4.10 Grain boundary surfaces (LT surface) of 5083-H131 separated with Ga attack: (a) unsensitized $\left(3 \mathrm{mg} / \mathrm{cm}^{2}\right)$, and (b) sensitized at $60^{\circ} \mathrm{C}$ for $30 \mathrm{~d}\left(23 \mathrm{mg} / \mathrm{cm}^{2}\right)$. 

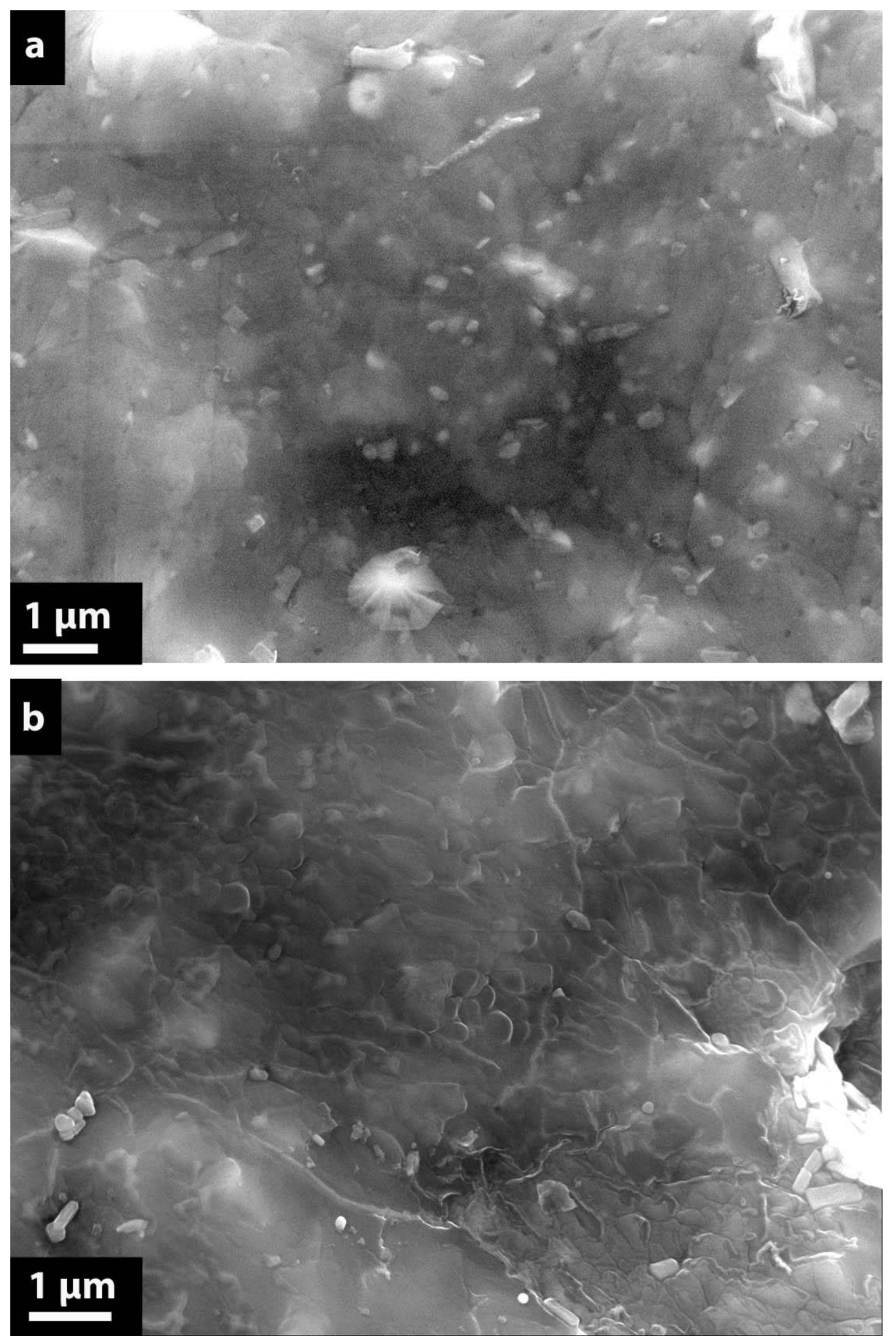

Figure 4.11 Grain boundary surfaces of 5083-H131 separated with Ga attack following sensitization at: (a) $100^{\circ} \mathrm{C}$ for $7 \mathrm{~d}\left(22 \mathrm{mg} / \mathrm{cm}^{2}\right)$, and (b) $100^{\circ} \mathrm{C}$ for $30 \mathrm{~d}\left(50 \mathrm{mg} / \mathrm{cm}^{2}\right)$. 
This study illustrates that the technique is applicable to non-SHT 5083-H131, though challenging, particularly in the sense that particle composition cannot be determined by SEM-EDX analysis.

\subsubsection{H Embrittlement}

Grain boundary separation was successful after $\mathrm{H}$ charging of round double notched specimens. Experimental procedures, fracture characteristics, and notch root strengths were discussed in the body of Chapter 4. Though all specimens were embrittled following $\mathrm{H}$ charging, only sensitized specimens exhibited grain boundary sized regions of intergranular failure. The small area of intergranular fracture limited a statistical quantification of grain boundaries for each sensitization.

Though a region of intergranular fracture was not identified on the fracture surface of $\mathrm{H}$ embrittled as-received 5083-H131, a smooth, particle free region (where initiation likely occurred) is observed (Fig. 4.12); the remainder of the specimen is ductile microvoid failure.

The $\mathrm{H}$ embrittled fracture surfaces of $5083-\mathrm{H} 131$, sensitized at $100^{\circ} \mathrm{C}$ for $175 \mathrm{~h}$, $22 \mathrm{mg} / \mathrm{cm}^{2}$, consisted of several isolated and relatively flat regions surrounded by ductile microvoiding. These regions were the typical size of grains ( $200 \mu \mathrm{m}$ by $100 \mu \mathrm{m})$, as seen in Fig. 4.4. The particles in this region were not uniformly distributed (also seen with Ga separation) and several particle morphologies were observed (Fig. 4.13).

A different region is shown in Fig. 4.14 at a higher magnification. Evidence of plasticity between particles is not confirmed nor denied with these images; therefore the nature of the fracture between $\beta$ is not identified with fractography. 


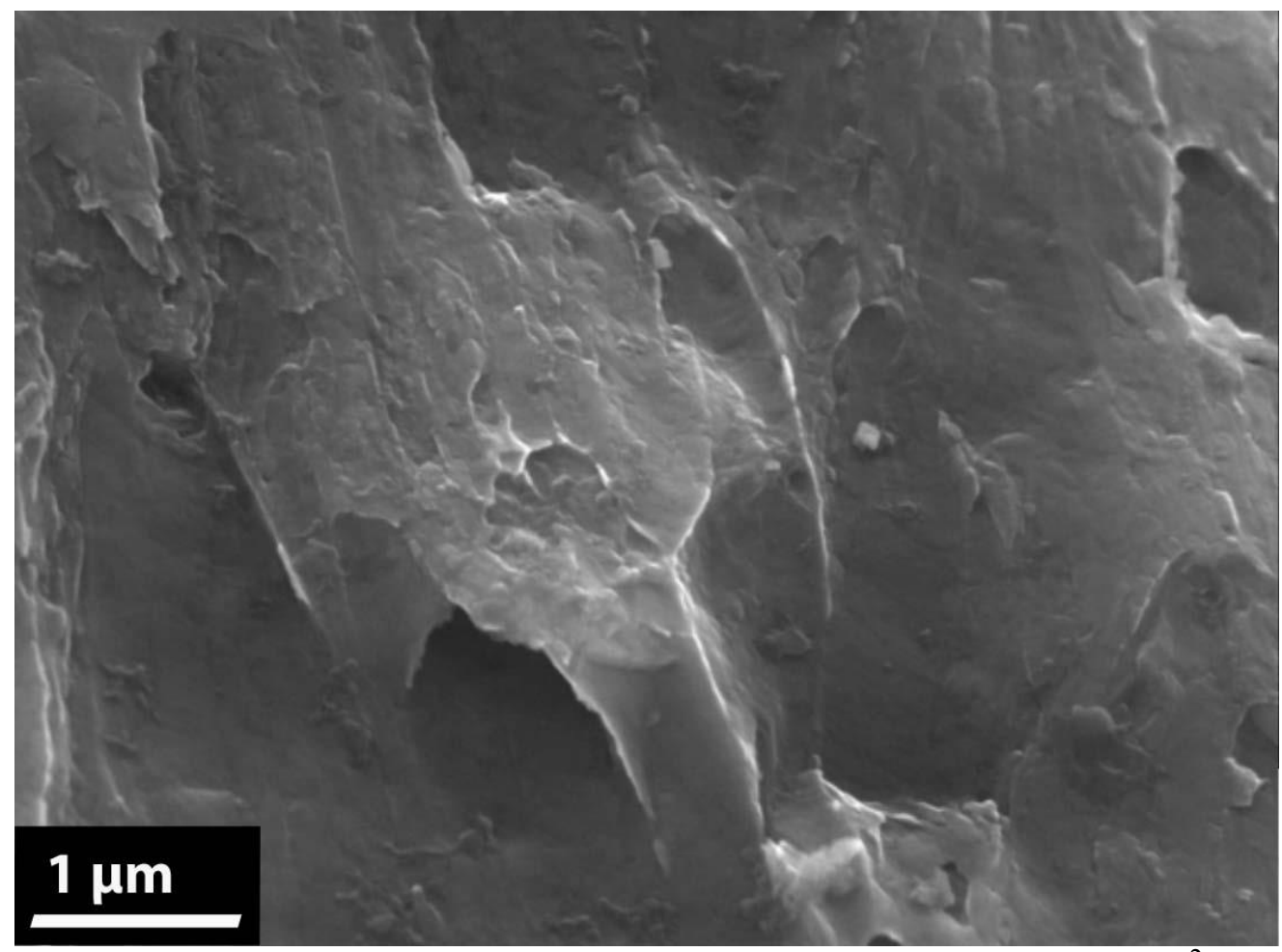

Figure 4.12 Fracture surface of $\mathrm{H}$ charged as-received 5083-H131 (3 mg/cm $\left.{ }^{2}\right)$.

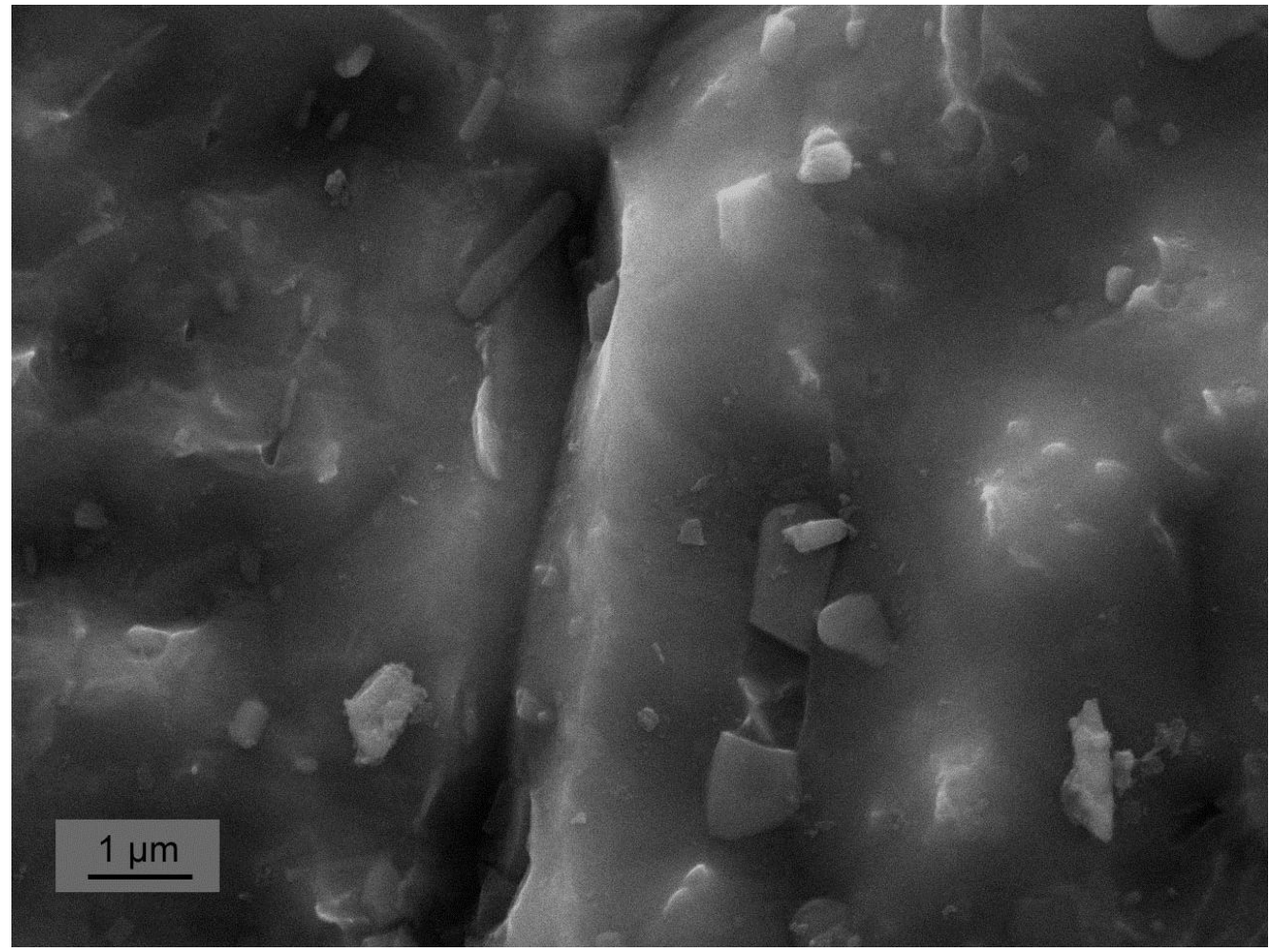

Figure 4.13 Fracture surface of $\mathrm{H}$ charged $5083-\mathrm{H} 131$, sensitized at $100^{\circ} \mathrm{C}$ for $175 \mathrm{~h}$ $\left(22 \mathrm{mg} / \mathrm{cm}^{2}\right)$. 


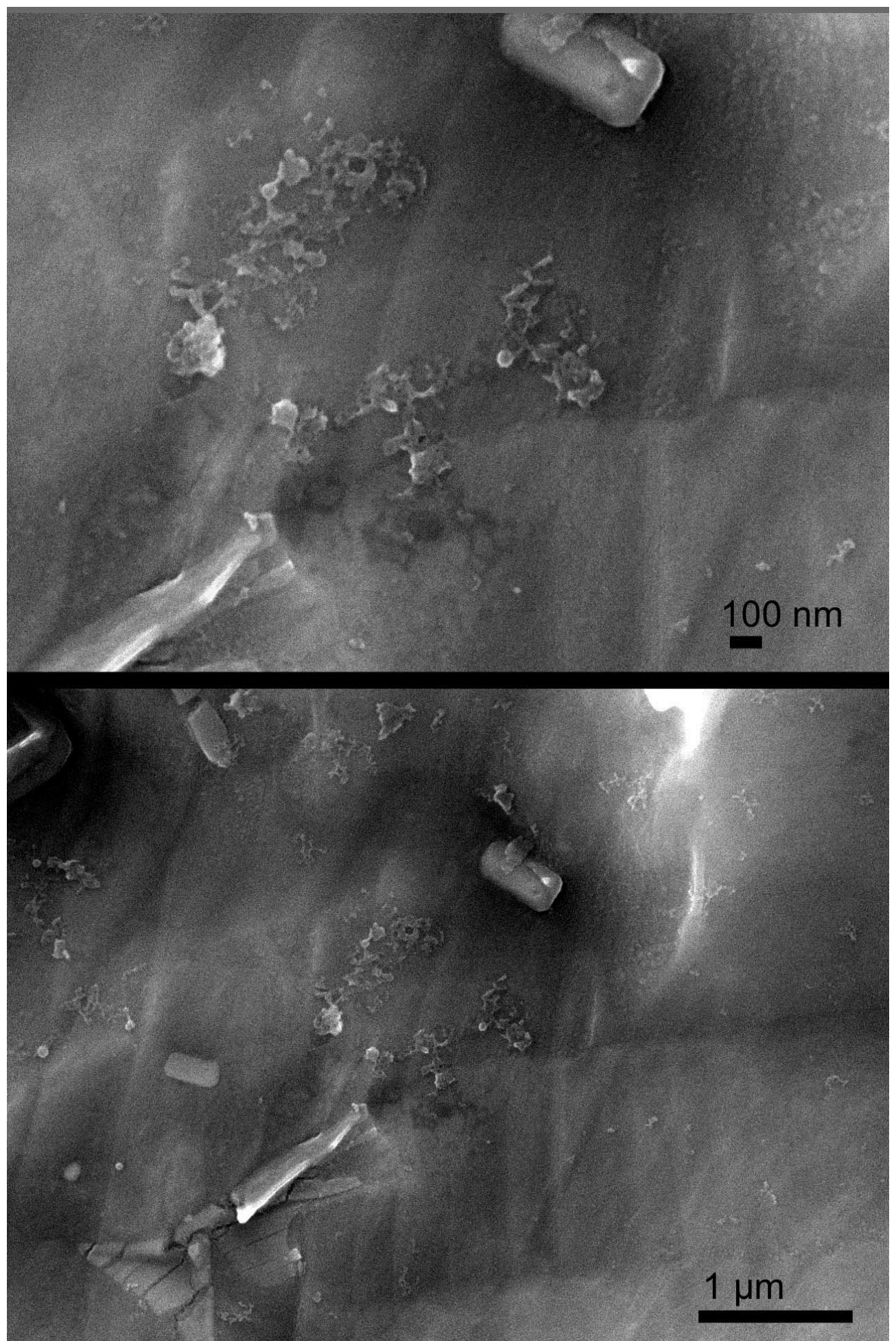

Figure 4.14 Fracture surface of $\mathrm{H}$ charged sensitized $5083-\mathrm{H} 131100^{\circ} \mathrm{C}$ for $175 \mathrm{~h}$ $\left(22 \mathrm{mg} / \mathrm{cm}^{2}\right)$. 
Similar isolated intergranular regions were observed after fracture of 5083-H131 sensitized at $100^{\circ} \mathrm{C}$ for $30 \mathrm{~d}\left(50 \mathrm{mg} / \mathrm{cm}^{2}\right)$, and were located as far as $200 \mu \mathrm{m}$ from the notch tip (Fig. 4.15a). A higher number of isolated regions was observed compared to 5083-H131 sensitized at $22 \mathrm{mg} / \mathrm{cm}^{2}$, though grain boundary precipitation was generally similar for both conditions. The same three particle morphologies seen in Fig. 4.13 were evident on some intergranular regions (Fig. 4.15b), while no particles were observed on some other grains studied. The region between particles on several grain boundaries contained thin bright features (Fig. 4.16). These features may indicate either plasticity between particles, or are unidentified particles on the grain surface.

Though the specimen sensitized at $60^{\circ} \mathrm{C}$ had the lowest fracture strain, grain sized intergranular regions similar to those found in Fig. 4.4 were not observed. The location of expected fracture initiation is shown in Fig. 4.17. The region is grain sized, yet much smoother than intergranular regions in the other sensitized specimens. The fracture as a whole was significantly more ductile than the other fracture surfaces, though the fracture strength is much lower (see Chapter 4). The particles are similar in size to those observed following Ga separation at the same sensitization, though these particles had a much wider spacing. Particles almost resemble debris that is not part of the grain boundary microstructure. To utilize this characterization technique, significantly more specimens must be embrittled for a statistical number of observable grain boundaries. 


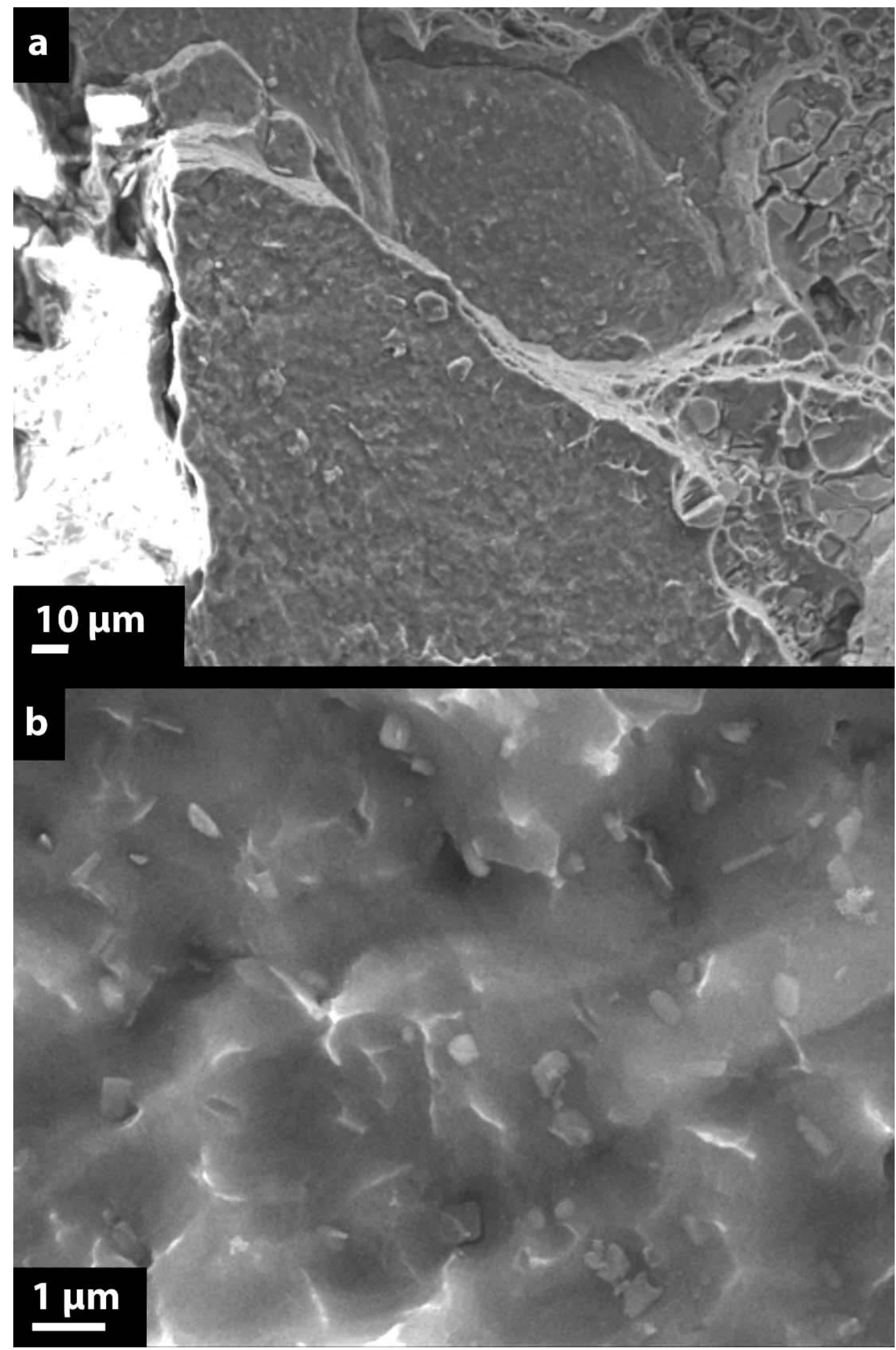

Figure 4.15 Fracture surface of $\mathrm{H}$ charged $5083-\mathrm{H} 131$ sensitized at $100^{\circ} \mathrm{C}$ for $30 \mathrm{~d}$ $\left(50 \mathrm{mg} / \mathrm{cm}^{2}\right)$. Intergranular features are surrounded by ductile features in (a), and evidence of several particles is provided in (b). 


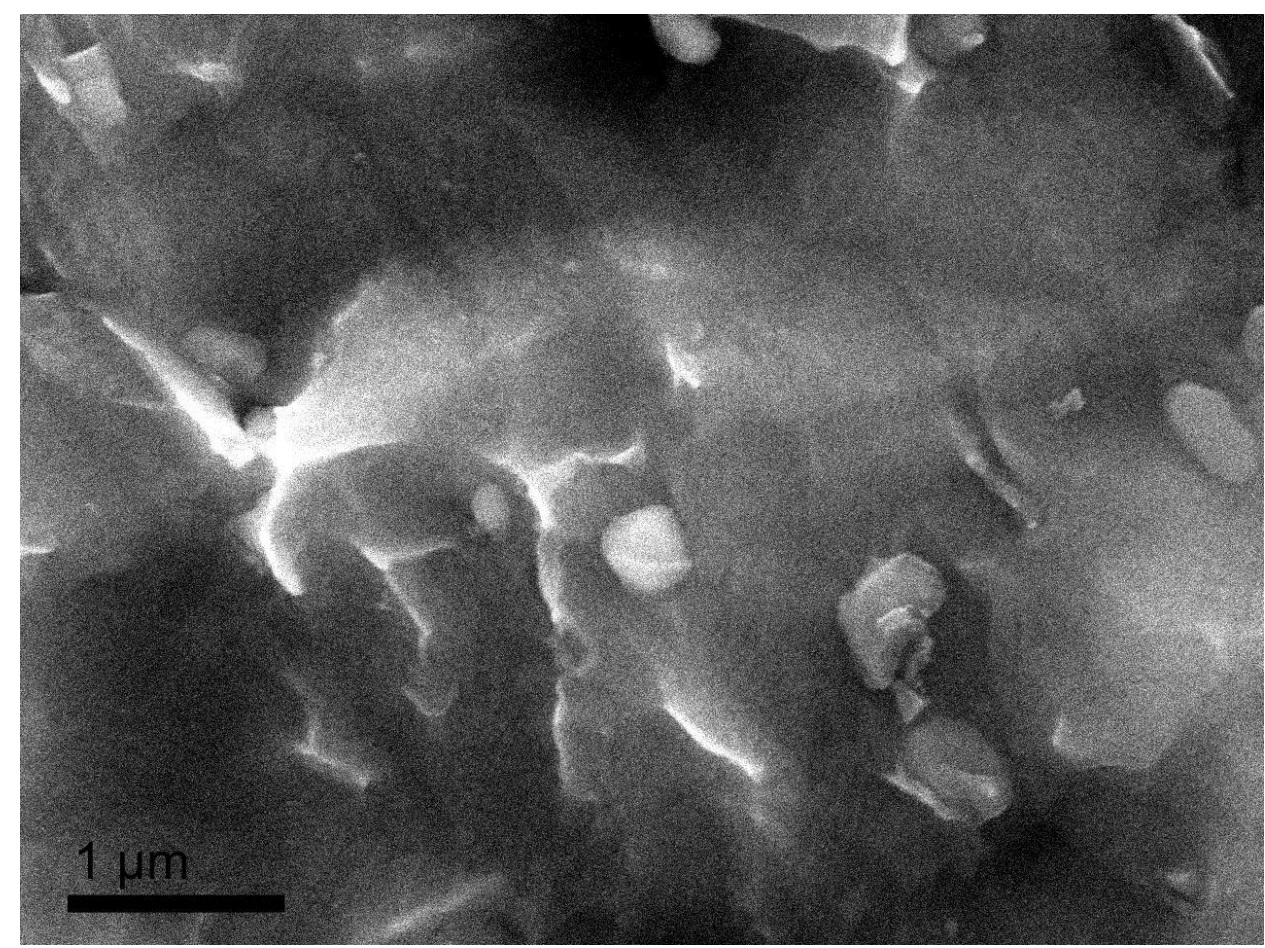

Figure 4.16 Fracture surface of $\mathrm{H}$ charged $5083-\mathrm{H} 131$ sensitized at $100^{\circ} \mathrm{C}$ for $30 \mathrm{~d}$ $\left(50 \mathrm{mg} / \mathrm{cm}^{2}\right)$.

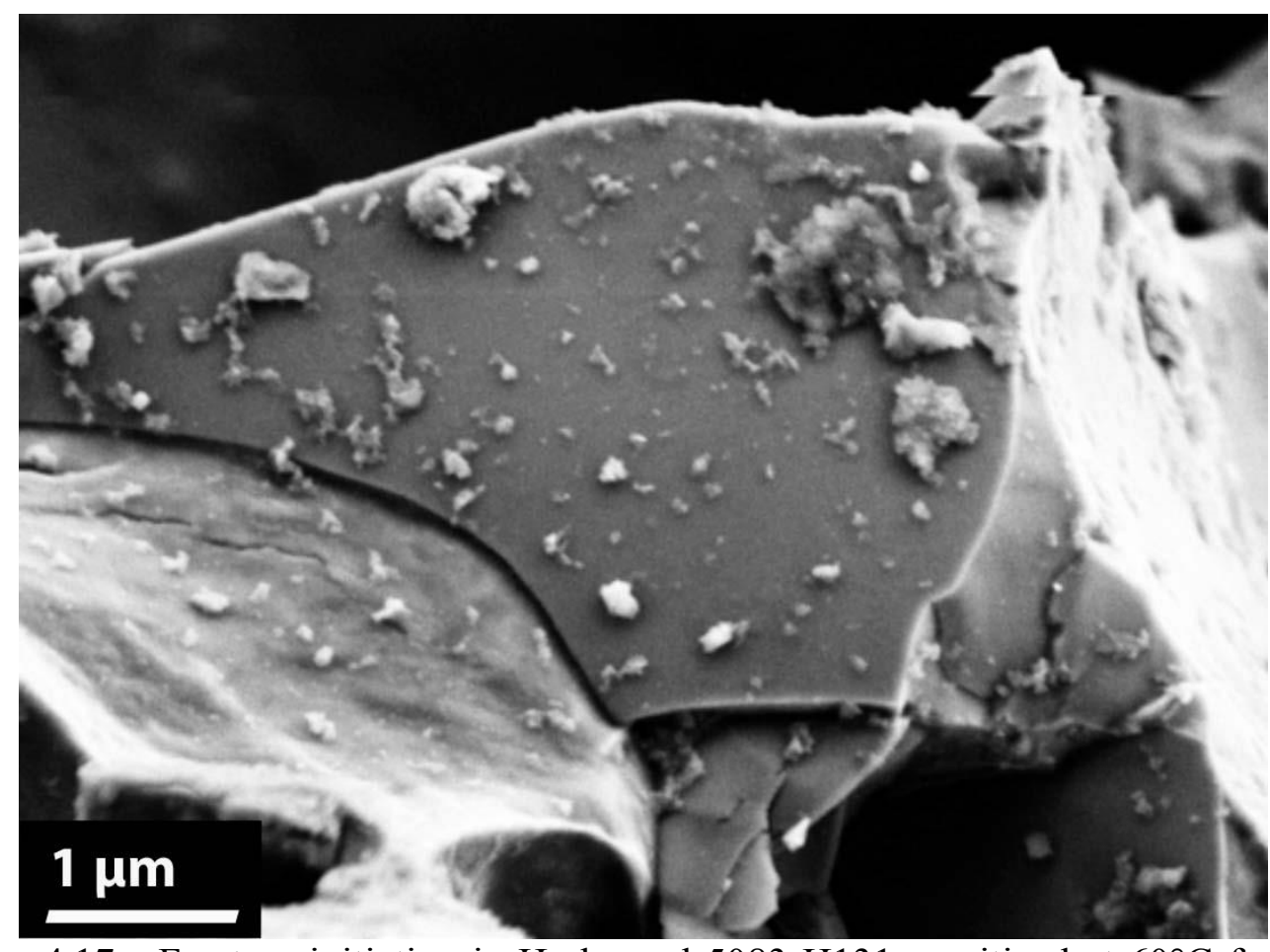

Figure 4.17 Fracture initiation in $\mathrm{H}$ charged $5083-\mathrm{H} 131$ sensitized at $60^{\circ} \mathrm{C}$ for $90 \mathrm{~d}$ $\left(23 \mathrm{mg} / \mathrm{cm}^{2}\right)$. 
CHAPTER 5

CONCLUSIONS 


\subsection{CHAPTER 2}

Precision monitoring of stress corrosion crack growth and SEM fractographic analysis establish the effect of degree of sensitization on the IGSCC resistance of Al-Mg alloy 5083-H131 in the susceptible S-L orientation for slow-rising stress intensity loading in $\mathrm{NaCl}$ solution. Low sensitization temperatures, below $100^{\circ} \mathrm{C}$, are emphasized.

- Elastic-plastic J-integral analysis of crack tip stress intensity, and direct current electrical potential difference measurement of crack growth, effectively characterize the kinetics of IGSCC in low strength Al-Mg alloys.

- The fracture toughness of 5083-H131 in the S-L orientation appears to rise by $25 \%$ with sensitization from $3 \mathrm{mg} / \mathrm{cm}^{2}$ to $50 \mathrm{mg} / \mathrm{cm}^{2}$, and similar primary void and microvoid sheet features were observed for both as-received and sensitized $\left(22 \mathrm{mg} / \mathrm{cm}^{2}\right)$ 5083-H131, without evidence of grain boundary participation.

- Alloy 5083-H131 without laboratory sensitization is only mildly susceptible to IGSCC in neutral $\mathrm{NaCl}$ solution at near-open circuit potential, evidenced by slow time-dependent crack growth and intergranular cracking features, albeit at high $\mathrm{K}$ above the plane strain fracture toughness.

- Alloy 5083-H131 in the S-L crack orientation is susceptible to significant IGSCC after sensitization at relatively low temperatures, below $100^{\circ} \mathrm{C}$, and for corresponding mass loss measurements of DoS as low as $10 \mathrm{mg} / \mathrm{cm}^{2}$.

- The apparent $\mathrm{K}_{\mathrm{TH}}$ for IGSCC depends strongly on DoS, and above $10 \mathrm{mg} / \mathrm{cm}^{2}$ correlates with a single function of ASTM G67 mass loss for sensitization at $60^{\circ} \mathrm{C}, 80^{\circ} \mathrm{C}$, and $100^{\circ} \mathrm{C}$. Below this critical DoS, $\mathrm{K}_{\mathrm{TH}}$ approaches $\mathrm{K}_{\text {IIC }}$ for cracking in moist air.

- Stage II da/dt depends on a single function of mass loss for DoS levels above $10 \mathrm{mg} / \mathrm{cm}^{2}$ for sensitization at $60^{\circ} \mathrm{C}, 80^{\circ} \mathrm{C}$, and $100^{\circ} \mathrm{C}$. Below this critical DoS, crack growth rates are very slow and perhaps only occur under positive $\mathrm{dK} / \mathrm{dt}$.

- Fractographic analysis of IGSCC in 5083-H131 is complicated by crack wake corrosion. 
- The occurrence of IGSCC correlates with flat grain boundary features that contain shallow dimples due to localized corrosion perhaps associated with reactive $\beta$ and cathodic Al-Mn dispersoids.

- Discrete IGSCC regions at low DoS may be representative of preferential precipitation of $\beta$.

- As the severity of IGSCC increases at higher DoS, $\beta$ coverage extends to more boundaries, which likely contributes to the increase in relative proportion of grain boundary crack features and the decrease in areas of ductile microvoid damage.

- The sensitization dependence of SCC in 5083-H131 is consistent with the combined mechanism of $\beta$ and $\mathrm{Al}-\mathrm{Mg}$ matrix dissolution, coupled $\mathrm{H}$ production and uptake, and intra- $\beta$ ligament hydrogen embrittlement.

- Low $\mathrm{K}_{\mathrm{TH}}$ and high da/dt $/ \mathrm{dI}_{\text {f }}$ for DoS levels above $10 \mathrm{mg} / \mathrm{cm}^{2}$ likely correlate with the combination of a critical volume of $\beta$ for development of a high $\mathrm{H}$ concentration by the crack tip chemistry and critical spacing for increased microstructure-scale stress in the crack tip FPZ.

- A critical $\beta$ coverage is required to provide and maintain an environment suitable for matrix dissolution, $\mathrm{H}$ production and uptake. This crack tip chemistry likely influences the $\mathrm{H}$ concentration at the fracture process zone. For constant displacement rate loading in $\mathrm{NaCl}$ at near OCP, dissolution of $\beta$ is required as a trigger for rapid dissolution to sustain the acidic crack tip environment. This conclusion is supported in Chapter 3.

- The stress enhanced concentration of $\mathrm{H}$ in the FPZ can potentially increase by up to 5 times due to the local stress enhancement on the grain boundary from elastic $\beta$ precipitates.

- Stress enhancement due to $\beta$ may reduce the critical fracture distance ( $\mathrm{x}_{\mathrm{CRIT}}$ ), by locating the FPZ (by increased $\mathrm{C}_{\mathrm{H} \sigma}$ and decreased $\mathrm{C}_{\mathrm{H}-\text { crit }}$ with $\beta$ precipitation) below the value typical of a continuum fracture mechanics model. The XCRIT is likely reduced to a value between the 
crack tip stress field dictated value of $0.9 \mu \mathrm{m}$ and a lower limit suggested by the inter- $\beta$ spacing $(\sim 300 \mathrm{~nm})$.

- The critical concentration of $\mathrm{H}$ required at the FPZ for interface decohesion may decrease by several orders of magnitude due to local stress enhancement on the grain boundary from elastic $\beta$ precipitates.

- The severe increase in crack growth rates at DoS of $10 \mathrm{mg} / \mathrm{cm}^{2}$ could be induced by rapid local $\mathrm{H}$ diffusion ahead of the crack tip when inter- $\beta$ ligaments are small enough to lie within the plasticity induced dislocation cell structures, which are free from H-dislocation interaction, or can readily fill with trapped $\mathrm{H}$, These trap free ligaments may produce a higher local $\mathrm{D}_{\mathrm{H}-\mathrm{EFF}}$, for faster crack growth rates. This conclusion is supported in Chapter 4.

- Intergranular corrosion growth is measured at the fatigue crack tip in sensitized 5083- $\mathrm{H} 131$ in $\mathrm{NaCl}$ at near OCP and subjected to very low $\mathrm{K}$.

- The low applied stress likely does not influence the rate of IGC, though it may contribute to faster rates in highly sensitized microstructures.

- Growth rates increase slowly with DoS above $10 \mathrm{mg} / \mathrm{cm}^{2}$, then increase substantially for DoS levels above $40 \mathrm{mg} / \mathrm{cm}^{2}$. This is likely attributed to an increase in $\beta$ connectivity at $40 \mathrm{mg} / \mathrm{cm}^{2}$. The aggressive crack tip chemistry developed with increasing volume of $\beta$ dissolution controls the dissolution rates along the grain boundary.

\subsection{CHAPTER 3}

The rate of intergranular "crevice" corrosion (IGC) ahead of an occluded fatigue precrack is measured by the dcPD method during static-low stress intensity exposure in various bulk environments. Such IGC rates are explained based on occluded-fatigue crack $\mathrm{pH}$ and potential changes in response to varying external polarization and solution composition. Specific conclusions are as follows. 
- In fatigue precracked 5083-H131 without laboratory sensitization (3 mg/ $\left.\mathrm{cm}^{2}\right)$, IGC is possible when solution exposure develops a highly acidic chloride concentrated electrochemistry in the fissure:

- Intergranular corrosion is not measureable in $\mathrm{NaCl}$ when applied potential is near or below $\mathrm{OCP}\left(-0.800 \mathrm{~V}_{\mathrm{SCE}}\right.$ and below), but is measurable and rapid at and above $-0.730 \mathrm{~V}_{\mathrm{SCE}}$ where matrix dissolution is promoted.

○ Corrosion is promoted at $-1.000 \mathrm{~V} \mathrm{SCE}$ in an acidic $\mathrm{AlCl}_{3} / \mathrm{MgCl}_{2}$ due to the highly acidic, chloride concentrated nature of the fissure tip chemistry.

- In fatigue precracked sensitized 5083-H131 (22 mg/ $\left.\mathrm{cm}^{2}\right)$, exposed in near-neutral $\mathrm{NaCl}$ solution, IGC is promoted for polarization above the breakdown potentials of both the matrix and $\beta$ phases. Intergranular corrosion is essentially eliminated when the specimen is polarized below the $\beta$ breakdown potential.

- Intergranular corrosion growth at the occluded fatigue crack tip in sensitized 5083$\mathrm{H} 131\left(22 \mathrm{mg} / \mathrm{cm}^{2}\right)$ in $\mathrm{NaCl}$ at $-0.730 \mathrm{~V}$ SCE was more than 2 times the rates measured in unsensitized 5083-H131 at the same potential; a role of $\beta$ is confirmed.

- The electrochemistry developed at the fatigue crack fissure tip depends on applied potential, the geometry of the fissure, the passive current density on the fissure flanks, and the environment sensitive dissolution rate at the fissure tip as observed with applied potential dependent corrosion rates and Ohmic drop calculations.

- The calculated Ohmic drop down the fatigue crack is small owing to low resistance attributed to the relatively wide crack mouth opening displacement. 
- Model predicted crack tip potentials confirm the role of $\beta$ dissolution and $\alpha$ dissolution in promoting corrosion growth: corrosion is accelerated at crack tip potentials above the matrix breakdown potential, and stifled when the potential is cathodic to the breakdown potential of $\alpha$.

Experimental evidence and occluded crack electrochemistry considerations validate the proposed mechanism for IGSCC of sensitized Al-Mg alloys: $\beta$ dissolution is required for crack solution acidification, coupled $\mathrm{H}$ production, and uptake stimulated by chloride enhancement. When $\beta$ dissolution is mitigated by either low DoS or bulk cathodic polarization, IGSCC is essentially eliminated during slow rising K loading for exposure in neutral $\mathrm{NaCl}$ solution. The presence of $\beta$ triggers rapid generation of a critical-acidic crack tip environment, which increases crack growth rates. Growth between $\beta$ in sensitized alloys is likely driven by $\mathrm{H}$ embrittlement and controlled by the crack tip chemistry. Specific conclusions are as follows:

- Upper bound (S-L) rates of IGSCC in fatigue precracked sensitized 5083-H131 (DoS $22 \mathrm{mg} / \mathrm{cm}^{2}$ ) are nearly eliminated by applied cathodic polarization below $-1.020 \mathrm{~V}_{\mathrm{SCE}}$, which forces the crack tip potential below the $\beta$-breakdown potential $\left(-1.015 \mathrm{~V}_{\mathrm{SCE}}\right.$ for acidic $\left.\mathrm{NaCl}\right)$.

- Fatigue precracked 5083-H131 (S-L) without laboratory sensitization $\left(3 \mathrm{mg} / \mathrm{cm}^{2}\right)$ :

- Resists IGSCC while stressed in $\mathrm{NaCl}$ polarized to $-0.800 \mathrm{~V}_{\mathrm{SCE}}$ and below, because $\alpha$ dissolution is not promoted and the crack tip is only mildly acidic.

- Is highly susceptible to IGSCC while stressed in $\mathrm{NaCl}$ polarized to $-0.730 \mathrm{~V}_{\mathrm{SCE}}$, because $\alpha$ dissolution is promoted resulting in a highly acidic crack tip chemistry for $\mathrm{H}$ embrittlement propagation. 
○ Develops a $\mathrm{Cl}^{-}$saturated crack tip, with a $\mathrm{pH}$ near 4 and high magnitude overpotential for $\mathrm{H}$ production, while stressed in simulated-acidic crack tip chloride solution $\left(\mathrm{AlCl}_{3}+\mathrm{MgCl}_{2}\right)$ polarized at $-1.000 \mathrm{~V}_{\mathrm{SCE}}$. The low $\mathrm{pH}$ and high magnitude of $\mathrm{H}$ overpotential likely promote crack growth rates similar to or just above the fastest $\mathrm{H}$ diffusion limited IGSCC rate predicted for 5083-H131 with $D_{\mathrm{H}-\mathrm{EFF}}$ of $10^{-10} \mathrm{~cm}^{2} / \mathrm{s}$.

- Develops an isolated alkaline crack tip due to extensive corrosion product precipitation when stressed in $\mathrm{H}$ producing $\mathrm{NaOH}$ polarized to either $-1.800 \mathrm{~V}_{\mathrm{SCE}}$ or at $\mathrm{OCP}$.

- Using a hydrogen diffusion-limited crack growth rate model, the $\mathrm{H}$ concentration at the fracture process zone available to generate measured crack growth rates increases exponentially with decreasing predicted crack tip overpotential for $\mathrm{H}$ production. The ratio of $\mathrm{H}$ concentration to critical H concentration in the FPZ was predicted from measured crack growth rates for each experiment, and overpotentials for $\mathrm{H}$ production were predicted from crack tip potential and $\mathrm{pH}$, in each experiment.

○ The $\mathrm{pH}, \mathrm{Mg}^{2+}$ concentration, and $\mathrm{Cl}^{-}$concentration may each influence the relationship between $\eta_{H}$ and $H$ solubility. A single relationship between crack tip $\eta_{\mathrm{H}}$ and either $\mathrm{da} / \mathrm{dt}$ or $\mathrm{FPZ} \mathrm{C}_{\mathrm{H} \sigma} / \mathrm{C}_{\mathrm{H}-\text { crit }}$ may not be applicable to all 5083-H131 environment-microstructure conditions.

- Results support the proposed mechanism for IGSCC in sensitized AlMg alloys; specifically, crack tip electrochemistry developed from $\beta$ 
dissolution promotes $\mathrm{H}$ production, uptake and rapid, $\mathrm{H}$ diffusion limited crack growth rates.

\subsection{CHAPTER 4}

Considerations of crack growth rate limitation by FPZ $\mathrm{H}$ diffusion validates the hypothesized mechanism for IGSCC of sensitized Al-Mg alloys in aqueous chloride solution. Specifically, crack tip $\beta$ dissolution and resulting hydrolytic acidification are a necessary precursor for severe hydrogen environment assisted cracking, which is rate limited by $\mathrm{H}$ diffusion in the crack tip fracture process zone.

- Very fast rates of intergranular stress corrosion cracking are supported by crack tip $\mathrm{H}$ diffusion, but only if $\mathrm{H}$ transport occurs with a diffusivity which is characteristic of substantially reduced reversible-H-trap interaction (between $10^{-8} \mathrm{~cm}^{2} / \mathrm{s}$ and $10^{-7} \mathrm{~cm}^{2} / \mathrm{s}$ ). Such rapid transport is possible if either reversible $\mathrm{H}$ traps fill or if a crack tip dislocation cell structure size exceeds that of precipitate-free inter- $\beta$ ligaments. Identification of the $\mathrm{D}_{\mathrm{H}-\mathrm{EFF}}$ relevant to a micrometer scale crack tip fracture process zone is uncertain and at the cutting edge of environmental cracking and H-metal interaction research.

- Grain boundaries of 5083-H131 are embrittled by H precharging, with intergranular cracking severity increasing with $\beta$ precipitation during sensitization.

- Though H charged as-received 5083-H131 was embrittled compared to noncharged 5083-H131, intergranular fracture was only observed on $\mathrm{H}$ chargedsensitized $5083-\mathrm{H} 131\left(22 \mathrm{mg} / \mathrm{cm}^{2}\right.$ to $\left.50 \mathrm{mg} / \mathrm{cm}^{2}\right)$. This suggests that $\mathrm{H}-\beta$ interaction influences intergranular fracture. 
- Internal $\mathrm{H}$ assisted cracking may provide a means to reveal the size, shape and spacing of reactive grain boundary $\beta$, but this approach is hindered by phase analysis limitation. 